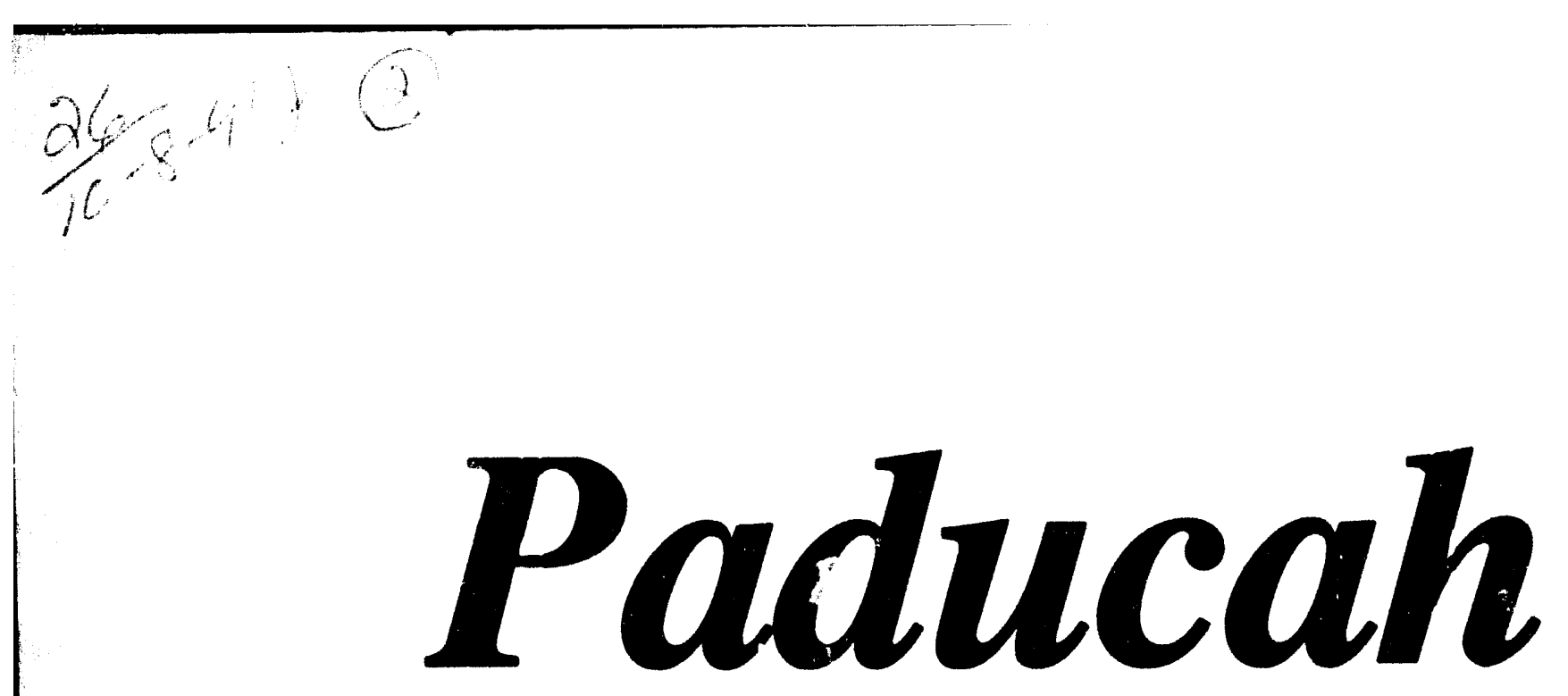


This report has been reproduced directly from the best available copy.

Available to DOE and DOE contractors from the Office of Scientific and Technical Information, P.O. Box 62, Oak Ridge, TN 37831; prices available from (615) 576-8401, FTS 626-8401.

Available to the public from the National Technical Information Service, U.S. Department of Commerce, 5285 Port Royal Rd., Springfield, VA 22161.

This report was prepared as an account of work sponsored by an agency of the United States Government. Neither the Uniced States Government nor any agency thereof, nor any of their employses, makes any warranty, express or implied, or assumes any legal liability or responsibility for the accuracy, completeness, or usefuiness of any information, apparatus, product, or process disclosed, or represents that its use would not infringe privately owned rights. Reference herein to any specific commercial product, process, or service by trade name, trademark, manufacturer, or otherwise, does not necessarily constitute or imply its endorsement, recommendation, or favoring by the United States Government or any agency thereof. The views and opinions of authors expressed herein do not necessarily state or reflect those of the United States Government or any agency thereof. 


\title{
PADUCAH GASEOUS DIFFUSION PLANT ENVIRONMENTAL REPORT FOR 1990
}

\author{
Project director \\ F. C. Kornegay \\ Project coordinator \\ D. C. West \\ Technical coordinator \\ T. G. Jett \\ Coordinating editor \\ Deborah Counce-Brown
}

Date published: September 1991

Prepared by

Environmental, Safety, and Health Compliance

and Environm: $n$ tal Management Staff

MARTIN MARIETTA ENERGY SYSTEMS, INC.

P.O. Box 2008

Oak Ridge, Tennessee 37831

and the

Environmental Compliance Department

Paducah Gaseous Diffusion Plant

MARTIN MARIETTA ENERGY SYSTEMS, INC.

P.O. Box 1410

Paducah, Kentucky 42001

for the

U.S. DEPARTMENT OF ENERGY

under contract DE-AC05-76OR00001 


\section{EXECUTIVE SUMMARY}

\section{SCOPE AND PURPOSE}

This two-part report, Paducah Gaseous Diffusion Plant Site Environmental Report for 1990, is published annually. It reflects the results of a comprehensive, year-round program to monitor the impact of operations at Paducah Gaseous Diffusion Plant (PGDP) on the area's groundwater and surface waters, soil, air quality, vegetation, and wildlife. In addition, an assessment of the effect of PGDP effluents on the resident human population is made.

PGDP's overall goal for environmental management is to protect the environment and PGDP's neighbors and to maintain full compliance with all current regulations. The current environmental strategy is to identify any deficiencies and to develop a system to resolve them. The long-range goal of environmental management is to minimize the source of pollutants, to reduce the formation of waste, and to minimize hazardous waste by substitution of materials.

\section{MONITORING NETWORKS}

Environmental-monitoring systems at PGDP include emission-monitoring networks for airborne and aqueous discharges, groundwater monitoring, solid waste characterization, and ambient-sampling networks for air, surface water, vegetation, food crops, fish, wildlife, soil, and surface stream sediments.

Effluent and waste monitoring includes:

- regular laboratory analysis of delivered coal and an $\mathrm{SO}_{2}$ monitor on steam plant stacks;

- a network of 16 sampling locations for monitoring plant wastewater prior to discharge;

- a sampling program for identification and characterization of solid waste streams generated by plant operations:
- an ongoing sampling program of stored wastes and sludges to characterize these materials in support of Resource Conservation and Recovery Act (RCRA) and Comprehensive Environmental Response, Compensation, and Liability Act activities;

- PGDP groundwater-monitoring wells; and

- stack sampling for radionuclide and fluoride emissions.

Ambient sampling networks include:

- 12 air-sampling stations (4 fence-line and 8 off-site),

- 6 surface water-sampling locations,

- 18 vegetation-sampling locations (4 fence-line and 14 off-site),

- fish samples from 1 on-site location,

- 10 soil-sampling locations [4 fence-line, 4 that are $8 \mathrm{~km}$ (5 miles) from PGDP, and 2 that are 13 to $15 \mathrm{~km}$ (8 to 9 miles) from PGDP],

- 26 stream-sediment-sampling locations,

- 15 gamma-radiation-monitoring locations (4 fence-line and 11 off-site),

- a Biological Monitoring Program with several monitoring locations, and

- several groundwater-monitoring wells.

The results of analyses and investigations are presented in this report, and the major findings are summarized in the following subsections.

\section{WATERBORNE DISCHARGES AND SURFACE WATER MONITORING}

The Clean Water Act is administered for PGDP by the Kentucky Division of Water (KDOW) through the Kentucky Pollutant Discharge Elimination System (KPDES) permitting program. A KPDES permit and Agreed Order allow PGDP to discharge effluents into Big and Little Bayou creeks. During 1990, PGDP experienced a compliance rate of $99.31 \%$ with the 
KPDES Agreed Order limits. The 1989 compliance rate was $98.27 \%$. The number of noncompliances dropped from 82 in 1989 in 33 in 1990. Parameters intermittently out of compliance were total residual chlorine, $\mathrm{pH}$, temperature, total suspended solids, and fecal coliform.

Sodium thiosulfate feed stations have caused the number of total residual chlorine noncompliances to drop from 64 in 1989 to 12 in 1990. Erosion control devices, such as silt fences, hay bales, and filter fabric, have been installed at construction sites. Improved oversight and erosion control devices have caused the number of total suspended solids noncompliances to drop from five in 1989 to three in 1990. Biological monitoring studies have indicated that slightly elevated $\mathrm{pH}$ in PGDP effluents is not causing $\mathrm{pH}$ in the receiving streams to be elevated above water quality criteria.

Biological monitoring, a requirement of the Agreed Order, is being conducted by the University of Kentucky in collaboration with Oak Ridge National Laboratory (ORNL), Planned and implemented by the University of Kentucky, the monitoring program was patterned after the Biological Monitoring and Abatement Program developed by ORNL for the three Department of Energy (DOE) facilities in Oak Ridge, Tennessee. The purpose of the Biological Monitoring Program is to determine the effects of plant effluents on aquatic life in the receiving streams. The findings of the program have been consolidated into a three-year report and submitted to KDOW. ORNL is conducting an evaluation of the findings and will present its evaluation to KDOW in 1991.

Radiological effluent monitoring as required by DOE Order 5400.5 also was performed during 1990. Uranium releases are expressed as a percentage of the Derived Concentration Guide (DCG), the recommended screening level for treatment of effluents. The average concentrations of uranium in all PGDP effuents are well below the DCG guideline (Fig. 1). Technetium releases from PGDP continued to decrease in 1990 . Only $5.12 \mathrm{~g}$ of ${ }^{99} \mathrm{Tc}$ were released to surface waters during that period (Fig. 2). The highest average concentration from any outfall corresponds to only $0.035 \%$ of the DCG for technetium.

\section{AIRBORNE DISCHARGES AND METEOROLOCICAL MONITORING}

PGDP currently has 27 air pollution emission sources that are listed on the Kentucky Division for Air Quality (KDAQ) operating permit. Air pollution control equipment used at PGDP includes venturi scrubbers, water sprays, electrostatic precipitators, filters, and chemical traps (i.e., $\mathrm{NaF}$ and $\mathrm{Al}_{2} \mathrm{O}_{3}$ ).

The C-600 steam plant is the primary source of conventional pollutants. Emissions are controlled through the use of electrostatic precipitators on units 2 and 3 operating with a collection efficiency of greater than $99 \%$. Testing and experience show compliance with state regulations. Unit 1 may be operated with natural gas or fuel oil. Fugitive emissions from coal and ash handling are controlled with water sprays.

PGDP monitors the C -310 stack that emits minute quantities of radionuclides that are air contaminants regulated under the National Emission Standards for Hazardous Air Poliutants (NESHA ${ }^{\circ}$ ). During $1990,31.8 \mathrm{~g}$ of uranium was released to the atmosphere. Trend data are shown in Fig. 3. Also, $0.4 \mathrm{mCi}$ of technetium was released; trend data are shown in Fig. 4. No new introduction of ${ }^{99} \mathrm{Tc}$ into the cascade has occurred.

Regulations for airborne radionuclide emissions under NESHAP limit total plant off-site radiological dosages to the public. The maximum off-site radiological dose attributable to 1990 PGDP emissions is a 50-year committed effective dose equivalent of $1.8 \times 10^{-4} \mathrm{mrem}$. This dose is a small fraction of the limit imposed by the regulations.

Air dispersion modeling is the accepted way of predicting the impact on air quality from a source. To provide accurate meteorological data, a meteorological tower was installed at PGDP during 1987 with automated data collection and solid state telemetry data transfer to a computer. Wind and other meteorological parameters were monitored to provide data for dose calculations for the 1990 report.

PGDP operates 12 ambient air monitors surrounding the plant to monitor concentrations of fluorides and radioactive particulates. Fluoride concentrations in the ambient air ranged from a low of 0.037 parts per billion (ppb) to a high of 0.333 ppb. All fluoride concentrations measured in 1990 were well below Kentucky air quality standards. 


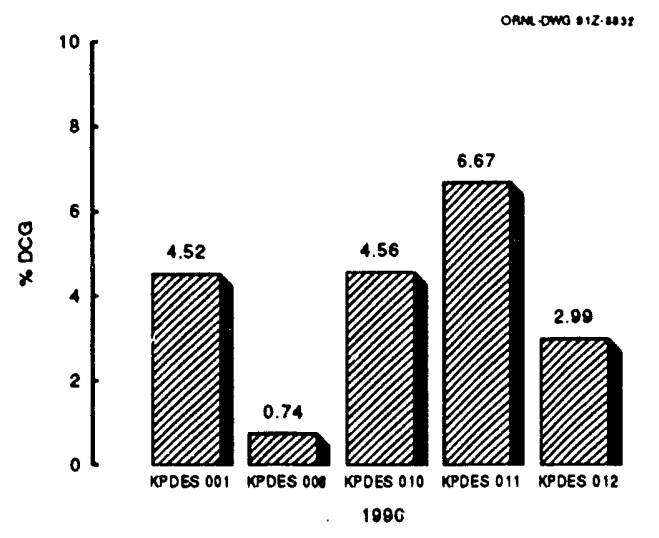

Fig. 1. Uranium concentrations in PGDP liquid effluents in 1990 (percentage of derived concentration guide).

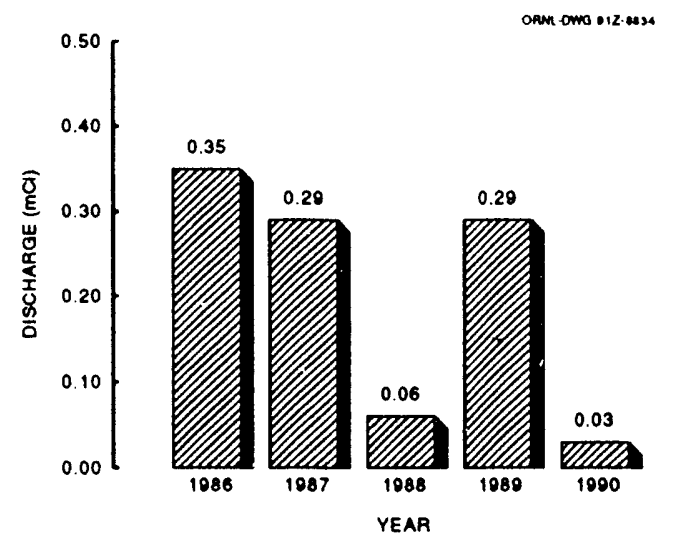

Fig. 3. Millicuries of uranium released to the atmosphere from PGDP operations, 1986-1990.

\section{EXTERNAL GAMMA RADIATION}

Ambient gamma radiation levels are monitored with thermoluminescent dosimeters (TLDs) at 15 locations surrounding PGDP. The mean exposure rate, as measured by the TLDs, for indicator locations at or beyond the reservation boundary is approximately $67 \mathrm{mrem} / \mathrm{year}$. The average background exposure in Kentucky is

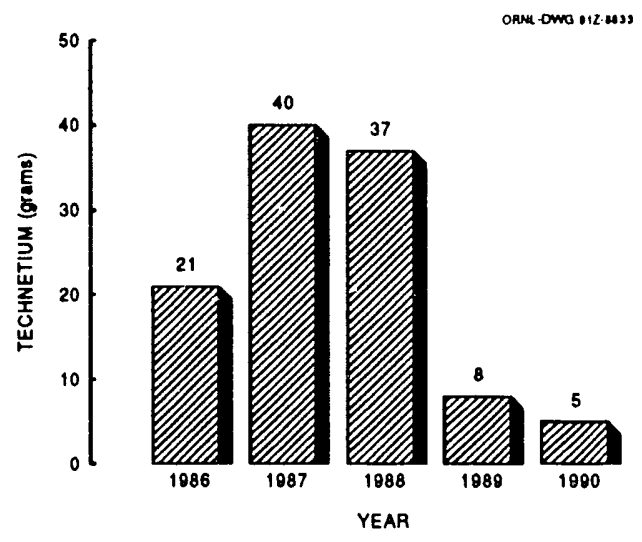

Fig. 2. Technetium discharges to surface water, 1986-1990.

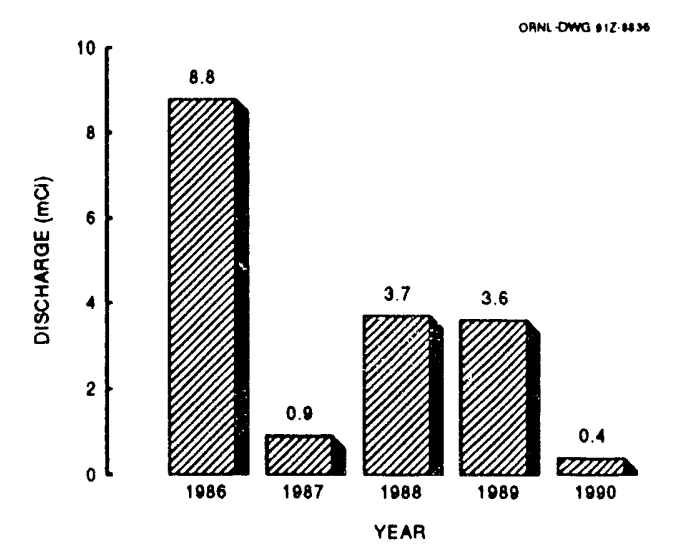

Fig. 4. Millicuries of technetium released to the atmosphere from PGDP operations, 1986-1990.

60-70 mrem/year. There is no significant difference observed between indicator and background exposure rates at the $95 \%$ confidence level. Because the levels of gamma radiation cannot be distinguished from background, quantifiable measurements using TLDs are difficult to obtain.

Several walkover surveys were performed during 1990 to verify TLD results and map the gamma fields 
surrounding PGDP. An acrial radiological survey also was performed to map the spatial distribution of man-made radionuclides at PGDP. All surveys indicate that levels of gamma radiation have not increased significantly over time. Figure 5 illustrates the trend over a three-year period at each location. The higher exposure rates at locations on the perimeter were attributed to direct radiation from the uranium cylinder storage and handling areas.

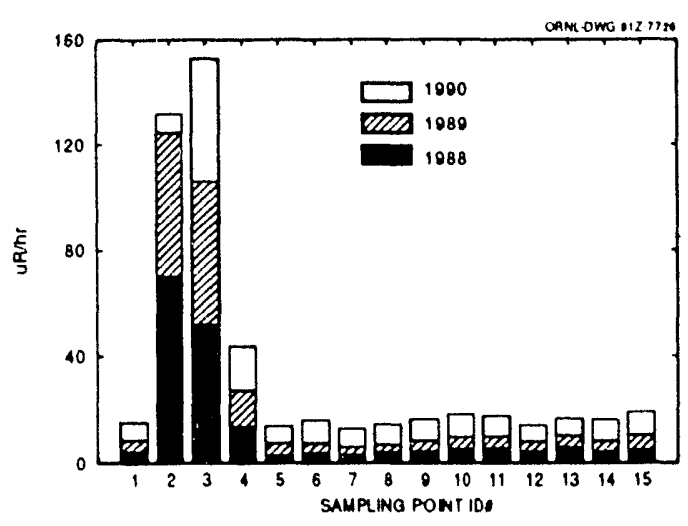

Fig. 5. PGDP external gamma radiation, 1988-1990.

\section{BIOLOGICAL MONITORING}

Vegetation samples are collected at 18 locations surrounding the plant and analyzed for fluorides. The primary objective of vegetation sampling is to determine the total fluorides in the vegetation for comparison with the fluoride-in-foliage section of the Kentucky air pollution control regulations. All samples taken in 1990 were well below the $60 \mu \mathrm{g} / \mathrm{g}$ standard. Samples taken from outside the fence area range from less than $5 \%$ to $7 \%$ of the standard.

During 1990, food crops and animal tissue from the PGDF vicinity were sampled to monitor the plant's effects on the ecology of the surrounding area. The doses from each type of crop were significantly below $1 \mathrm{mrem} /$ year. The calculated worst-case dose from ingestion of all types of foodcrops over a one-year period was significantly less than the DOE dose limit of $10 \mathrm{mrem} /$ year. In addition, eight deer were harvested in the West Kentucky Wildlife Management Area and two deer from the Land
Between the Lakes area for background comparison. Both the radionuclide and metals data indicated no significant difference ( $95 \%$ confidence) between the concentrations in the reservation and the background deer.

\section{SOIL AND SEDIMENT SAMPLING}

Soil sampled during 1990 from ten locations surrounding the plant ranged from $2.2 \mu \mathrm{g} / \mathrm{g}$ of uranium at a background location $15 \mathrm{~km}$ ( 9 miles) south of the plant to $7.1 \mu \mathrm{g} / \mathrm{g}$ of uranium at the southern boundary of the plant. Since 1985, levels of uranium from areas between 8 and $15 \mathrm{~km} \mathrm{(5} \mathrm{and}$ 9 miles) from PGDP have ranged from 0.7 to $4.3 \mu \mathrm{g} / \mathrm{g}$. These levels of uranium are typical of soils in western Kentucky.

Table 6.4 gives 1990 radionuclide and polychlorinated biphenyl (PCB) data. Both radionuclides and $\mathrm{PCBS}$ are elevated at $\mathrm{SS7}$, the C-615 sewage treatment plant. The sewage sludge is drummed annually for storage. Sediments in the north/south diversion ditch, an on-site ditch, contain elevated levels of radionuclides and PCBs. Effluents from this ditch flow into the C-616 full-flow lagoon before discharge through KPDES outfall 001. Big

Bayou Creek sediments, SS1, show levels of radionuclides above the upstream Big Bayou Creek station, SS20. In addition, Little Bayou Creek sediments (SS2) indicate radionuclide levels above those at the upstream Little Bayou Creek station (SS21). During 1990, a public advisory was issued for the Little Bayou Creek area and signs were posted to make the public aware that prolonged exposure to the sediments could result in a dose above background (see Sect. 2.4.2, Environmental Radiation Surveys). Many of the KPDES outfall sediments contain levels of radionuclides and PCBs above background. Cesium was present in all sediment samples and is present throughout the world from weapons testing.

A variety of metals is analyzeci in each sediment sample. Metals analyses in each 1990 sediment sample were distinctly elevated above the 1989 metals data. However, the 1989 samples were not analyzed by PGDP, but the 1990 samples were. Archived 1989 samples were reanalyzed along with selected 1990 samples by PGDP. Analytical results were in good agreement, indicating the elevated 1990 
metals levels are due to variability between the two laboratories.

\section{UNUSUAL OCCURRENCES}

During 1990, 536 spills or releases of various types of materials occurred. Approximately 261 of the incidents involved leaking PCB gaskets. The new DOE Order 5000.3A, "Occurrence Reporting and Processing of Operations Information," was issued in 1990. It governs the categorization, investigation, and reporting of all releases. Highlights of the incidents are given in Subsects. 9.1 through 9.1.11.

\section{RCRA}

PGDP maintains its interim status for the ten RCRA-regulated units (i.e., four storage units and six treatment units). Part B Permit applications have been submitted for seven of these units, and three have be I designated as fermit-by-rule. Notices of violations (NOV) or, the permit applications have been addressed and : orrected. Highlights of the year include an Energy Systems co-operator agreement with DOE to operate PGDP; the toxicity characteristic leaching procedure rule, which greatly expanded the scope of material regulated as hazardous waste. NOVs were issued by the Kentucky Division of Waste Management (KDWM) and corrective actions were implemented by Energy Systems. Phase I of the RCRA Air Emission Standards applicable to hazardous waste management units and the semiannual assessment fee issued by KDWM to parties that either generate hazardous waste in or transport it into the state of Kentucky were issued in 1990. 


\section{COMPLIANCE SUMMARY ENVIRONMENTAL COMPLIANCE ACTIVITY U.S. DEPARTMENT OF ENERGY}

\section{PADUCAH GASEOUS DIFFUSION PLANT}

\section{BACKGROUND AND OVERVIEW}

The Paducah Gaseous Diffusion Plant (PGDP) operates in conformance with requirements established by a number of federal and state statutes and regulations, Executive Orders, Department of Energy (DOE) Orders, and Compliance and Settlement Agreements. Compliance status with regard to major environmental statutes is summarized below.

The DOE Order 5400.1, "General Environmental Protection Program," defines the mandatory environmental standards in effect at DOE operations. These environmental standards fall into three categories: (1) those imposed by federal statutes, regulations, and requirements;

(2) those imposed by state and local statutes, regulations, and requirements applicable to DOE; and (3) those imposed by DOE directives. This compliance summary section addresses the standards that are significant for PGDP environmental compliance.

Several federal, state, and local agencies are responsible for enforcing environmental regulations at PGDP. DOE itself, through directives to field offices and compliance audits, is the initiating organization. Principal among other regulating agencies are EPA Region IV and the Kentucky Department for Environmental Protection (KDEP). These agencies issue permits, review compliance reports, participate in joint monitoring programs, inspect facilities and operations, and oversee compliance with applicable regulations.

EPA develops, promulgates, and enforces environmental tection regulations and technology-bascu standards as directed by statutes passed by the U.S. Congress. In some instances, EPA has delegated regulatory authority to KDEP when the Kentucky program meets or exceeds EPA's requirements. Where regulatory authority is not delegated, EPA Region IV is responsible for reviewing and evaluating compliance with the EPA regulations as they pertain to PGDP.

Although progress has been made toward achieving full regulatory compliance at PGDP, much remains to be done. Ongoing self assessments of compliance status and implementation of corrective actions continue to identify environmental issues. These issues are discussed openly with the regulatory agencies to ensure that compliance with all environmental regulations will be attained.

\section{COMPLIANCE STATUS}

\section{Clean Air Act (CAA) and National Emission Standards for Hazardous Air Pollutants (NESHAP)}

PGDP has an ongoing program to maintain compliance with all regulations resulting from the CAA. A Notice of Violation (NOV) received from the Kentucky Division of Air Quality (KDAQ) during 1989 regarding the refurbishing of two cooling towers was successfully resolved in 1990 with no fines or penalties. The proposed Agreed Order resulting from the NOV was canceled, and the NOV was withdrawn. The major difficulty in complying with regulations resulting from the CAA is documenting compliance. Some sources are limited by throughput or operating rates, and documentation of compliance with permit limits is not always available. Fluoride emissions above permitted limits from the C-310 purge vent stack were documented in 
1990. However, no exceedance of the ambient air standard for gaseous fluorides occurred due to these emissions. Emissions from the C- 600 boilers due to malfunctions, startups, and shutdowns that temporarily exceeded the standards were reported in accordance with KDAQ regulations. PGDP did not receive an NOV from any air regulatory agency in 1990.

\section{Clean Water Act (CWA)}

The Clean Water Act applies to all nonradiological discharges to navigable surface waters. At PGDP, the regulations are applied through a Kentucky Pollutant Discharge Elimination system (KPDES) permit for effluent discharges to Big and Little Bayou creeks. KPDES Permit No. KY0004049 is enforced by the Kentucky Division of Water (KDOW). Effluent discharges occur via 16 outfalls. Approximately 4,752 analyses were performed in 1990 , with a compliance rate of $99.31 \%$.

Noncompliances were due to total residual chlorine, $\mathrm{pH}$, total suspended solids, temperature, and fecal coliform. (See Sect. 3 for a discussion of noncompliances and associated corrective actions.)

Four noncompliances with KPDES Agreed Order limits occurred in March 1991. Three of the noncompliances were total suspended solids at rainfall runoff locations. The other noncompliance was due to an iron exceedance.

\section{Resource Conservation and Recovery Act (RCRA)}

Hazardous waste facilities at PGDP are currently operated under interim status granted by the state of Kentucky (facility ID Number KY8890008982). The Part A application was revised to include waste streams listed under the new toxic characteristic leaching procedure and to request interim status for the C-746-A storage facility. Part B applications have been submitted for the eight storage and treatment units located on the plant site. A postclosure plan has been submitted for the $\mathrm{C}-404$ low-level radioactive waste burial ground, and closure of the C-746-B waste chemical storage area is awaiting approval by the Kentucky Division of Waste Management (KDWM). At present, those units are still operating under interim status following the requirements of 401 Kentucky Administrative Regulations Chapter 35.

In CY 1990, the Annual Hazardous Waste Report and the Federal Facilities Biennial Hazardous Waste
Activities Report were completed for CY 1989 and submitted to KDWM. In the first quarter of CY 1991, the CY 1990 Annual Hazardous Waste Report was submitted to KDWM. The annual report identifies waste generated and shipped off-site and waste generated and remaining on-site. The biennial report, completed in odd ye us, includes information on programs such as environmental monitoring, environmental contamination, response actions, and permit status.

The closure of the C-746-B waste chemical storage area was completed on September 14, 1990, according to the closure plan approved by KDWM. DOE and an independent professional engineer registered in Kentucky certified that the unit was closed according to the closure plan. KDWM must perform a closure inspection of this facility.

\section{Toxic Substances Control Act (TSCA)}

Polychlorinated biphenyls (PCBs) are used at PGDP and are regulated under TSCA, Title 40 Code of Federal Regulations (CFR) 761. Authorized uses of PCBs under TSCA at PGDP include use in dielectric fluid in electrical equipment and in lube oil/hydraulic oil systems in concentrations of less than 50 parts per million (PPM). The compliance issues associated with TSCA regulations include use of PCBs in ventilation duct gaskets, historic PCB oil spills on process building floors, storage of uranium-contaminated wastes beyond the TSCA one-year limit, use of unauthorized containers for storage of 2 containers of PCB solid waste, the presence of $\mathrm{PCBs}$ above regulatory limits in two hydraulic systems, and leaking PCB capacitors inside switchyard potential devices. These issues are being addressed through a Federal Facilities Compliance Agreement (FFCA) being negotiated between DOE and EPA and through corrective actions taken by PGDP.

\section{Comprehensive Environmental Response, Compensation, and Liability Act (CERCLA)}

An Administrative Consent Order ( $\mathrm{ACO}$ ) under Sections 104 and 106 of CERCLA was produced in 1988 between EPA and DOE. The ACO was produced in response to the discovery of off-site groundwater contamination in residential wells north of PGDP. The contaminants in the wells are trichloroethylene (TCE), a degreasing solvent used at 
PGDP, and technetium-99 $\left({ }^{99} \mathrm{Tc}\right)$, a man-made radionuclide developed during the fission of uranium. The source of ${ }^{99} \mathrm{Tc}$ at PGDP was the enrichment of reprocessed uranium from government reactors at other DOE facilities. The major requirements of the ACO include monitoring of residential wells potentially affected by the contamination, provision of alternative drinking water supplies to residents with contaminated wells, and investigation of the nature, extent, and source of the contamination to develop a plan for remediation.

\section{National Environmental Policy Act (NEPA)}

NEPA Compliance personnel review all Engineering Service Orders and submit appropriate NEPA documentation to DOE for project approval. Activities that do not require engineering involvement are handled via a Work Order system. Compliance with NEPA is maintained by following the guidelines set forth by CEQ, DOE, and Martin Marietta Energy Systems, Inc.

\section{Federal Insecticide, Fungicide, and Rodenticide Act (FIFRA)}

No restricted-use pesticides are used by PGDP personnel. If application of a restricted-use pesticide at the plant is necessary, a certified contractor will be used to make the application. General-use pesticides used at the plant by plant personnel are used in a manner consistent with the product labeling. All product warnings and cautions are strictly adhered to. Applications of pesticides by $\mathrm{pl}$ ant and contractor personnel must be approved by the Plant Pesticide Coordinator. The Waste Management Department at PGDP currently is seeking a vendor that will dispose of the Napchlor-G fungicide being held on-site.

\section{Safe Drinking Water Act (SDWA)}

PGDP operates a "nontransient, noncommunity" public water system subject to regulation by KDOW. The PGDP water treatment facility is a Class II facility. There are ten operators on-site with the Class II certification or above. Monthly operational reports are provided to the state describing operational activity for the farility. The ongoing training required to maintain certification is provided by a program developed in-house. The s!ate of Kentucky has approved the program as meeting state requirements.
Surveys of the sanitary water supply system indicate that the plant's drinking water meets all state and federal regulations for maximum contaminant levels. In $1989 \mathrm{KDOW}$ completed a quarterly survey of PGDP's sanitary water system for 8 regulated and 51 unregulated volatile organic compounds (VOCs). None of the regulated VOCs was detected in the system, but 3 of the unregulated VOCs were detected. Because of the detection of the three unregulated VOCs, PGDP will monitor for all 59 VOCs annually, starting in 1991.

\section{CURRENT ISSUES AND ACTIONS}

\section{NESHAP Compliance}

The NESHAP regulation, promulgated in December 1989, pertains to DOE facilities emitting radionuclides other than radon. It requires documentation of cumpliance by March 15, 1990. It requires extensive evaluation of each potential radionuclide air emission point and either continuous measurements of each emission point (stack sampling), or documentation that emissions from each point are below a level that would cause the most affected individual to receive an annual effective dose equivalent of $0.1 \mathrm{mrem}$.

PGDP, in conjunction with DOE/ORO and the three Oak Ridge facilities, submitted a compliance plan to EPA Region IV in March 1990. Due to the enormous number of potential radiological air emission points (albeit small ones) and the difficulty of initially evaluating each point and periodically confirming the insignificant emissions, the plan requested approval to use ambient air samplers to collect data and demonstrate compliance with the 10-mrem standard established in the regulation. On February 8, 1991, DOE/ORO received correspondence from EPA stating that ambient air sampling could not be used to demonstrate compliance with any portion of the regulation except computation of dose. Therefore, PGDP and the Oak Ridge facilities will still be required to perform the stack sampling on each emission point or submit evidence that the emissions from each stack result in a dose less than $0.1 \mathrm{mrem}$. A revised compliance plan is scheduled for submittal to EPA Region IV by May 1. It is anticipated that an FFCA based on the compliance plan will be negotiated. 
Currently, PGDP continuously samples only one stack, the C- -310 purge vent. The sampling and analysis methods are not those specified in the regulation. PGDP has submitted information to Energy Systems Environment, Safety, and Health Organization (ES\&H) to be sent to DOE and EPA in a request for approval of the present methods.

DOE Headquarters and EPA Headquarters are negotiating a Memorandum of Understanding (MOU) that would establish a schedule and responsibilities for complying with NESHAP. Sections of the document are substantially different from the NESHAP provisions. Also, information presented in a meeting between representatives from DOE/ORO, EPA Region IV, Energy Systems ES\&H, the Oak Ridge facilities, and PGDP indicated that a Federal Facility Comfliance Agreement could be the avenue of compliancr; with NESHAP for PGDP.

As of April 1991, PGDP intends to comply with all provisions of NESHAP to the extent possible by evaluating and documenting as many potential radiological emission points as possible until direct guidance from EPA and DOE are available. The information generated from the source evaluations will be included on the PGDP 1990 NESHAP report due to EPA by June 30, 1991.

Documentation of compliance, i.e., implementation of throughput/usage logbooks, is increasing throughout the piant. Some permitted usage rate exceedances have occurred (such as at the paint shop). Documentation of compliance with all regulations and permit conditions continues to be an unfulfilled goal.

\section{Clean Water Act}

PGDP effluents do not always meet discharge limits. Therefore, several corrective actions have been implemented. Total residual chlorine noncompliances have been reduced through the use of temporary sodium thiosulfate feed stations at several outfalls. The plant effluent chlorine and temperature control project now under construction will eliminate the remaining total residual chlorine noncompliances and temperature excursions. That project is $90 \%$ complete. Fecal coliform noncompliances have been alleviated through the use of additional chlorine for disinfecting the C-615 Sewage Treatment Plant effluent. The water is subsequently dechlorinated. Total suspended solids (TSS) noncompliances have been dealt with by using silt fences, seeding outfall ditch areas, and covering dirt piles at construction sites. To alleviate $\mathrm{pH}$ noncompliances, alternate $\mathrm{pH}$ limits will be discussed with KDOW during the KPDES permit renewal process. (The current permit expires on October 21 , 1991.)

During 1990, KDOW issued an NOV to PGDP for the discharge of PCBs into Big and Little Bayou creeks. Subsequent monitoring of the effluent waters indicated that PCBs may be intermittently present in some of the KPDES outfalls. It was decided that a new Agreed Order would be negotiated with KDOW to resolve the NOV.

During January 1991, KDOW issued PGDP a draft KPDES Agreed Order that will supersede the 1987 Agreed Order. Included in the draft document are requirements for a Best Management Practices Plan for TSS control. The plan will documeni TSS control measures and remove numerical TSS limits established by the 1987 Agreed Order. Toxicity testing and bioaccumulation studies will continue, with KDOW approving sampling and testing methods and locations. A toxicity identification/reduction plan will be prepared for KDOW approval that will discuss actions to be undertaken if toxicity is found. In addition, the Oak Ridge National Laboratory Environmental Sciences Division will conduct a critical evaluation of biological monitoring data gathered to date. The new Agreed Order also will increase the frequency of PCB analyses of effluents, and it may establish new discharge limits. A PCB Source Identification Project also will be conducted. It will involve simultaneous $\mathrm{PCB}$ analyses of creeks, outfalls, and sewers to determine whether PCBs are discharged during wet or dry periods and, if so, their sources.

\section{Land Disposal Restrictions}

Land disposal restricted (LDR) waste such as pentachlorophenol and mixed LDR waste have been stored in some areas at PGDP for longer than 1 year. These wastes are currently subject to LDR storage prohibitions that permit storage only for accumulation of sufficient quantities to facilitate proper treatment, recycling, or disposal. The waste is being stored because of the nationwide shortage of treatment and disposal facilities for such waste. PGDP is actively seeking treatment or disposal for the pentachlorophenol waste. DOE and EPA will continue to discuss the mixed LDR waste issue 
during FY 1991 and FY 1992. DOE's Oak Ridge Operations Office expects to negotiate an FFCA that would detail the steps needed to attain compliance with regulations. A draft FFCA that addresses spent solvent and California-list mixed waste streams is under preparation.

In October 1991, PGDP Environmental Ccmpliance and Waste Management Jepartment personnel mit with Energy Systerıs Central Waste Managemen', and Hazardous Waste Remedial Action Programs personnel to discuss and update information regarding land disposal restrictions (LDR) on radioactive mixed waste (RMW). Data that had previously been submitted in the National LDR Report and in the Waste Management Information System (WMIS) Third Report were verified. LDR RMW inventories were updated, and planning activities with regard to RMW management systems were identified. Formal data input for the National Report on LDR RMW was provided to Central Waste Management in October 1990.

\section{Unauthorized Mixed TSCA Waste Storage}

Uranium-contaminated PCB wastes (mixed wastes) are being stored in excess of the one-year limit imposed by TSCA, due to the lack of treatment and mixed-waste disposal capabilities. EPA issued a complaint to Energy Systems about this issue on October 3, 1990. In addition, negotiation of an FFCA is continuing between DOE and EPA on compliance with TSCA and the PCB Regulations found at 40 CFR 761. The unauthorized storage of uranium-contaminated PCB wastes is being addressed in the negotiations. Negotiations between MMES and EPA over the fine are continuing. This issue will be included in the FFCA.

\section{Unauthorized Storage Containers}

All Energy Systems Environmental Compliance Reviev, conducted in December 1990 found PCB solid wastes being stored in unauthorized containers. PCB-and uranium-contaminated wood pallets were found in C-746-A wrapped in plastic and placed in an undersized wooden box with no lid. Correspondence was submitted to the EPA Regional TSCA

Coordinator in March 1991 to seek concurrence for using alternate packaging methods for storage of large PCB solid wastes.

\section{DOE Tiger Team Assessment of PGDP}

Secretary of Energy James D. Watkins' ten-point initiative to strengthen safety, environmental protection. and waste management activities at DOE's production, research, and testing facilities resulted in the Tiger Team Assessmei. of the PGDP June 18 through June 29 and July 9 through July 20.

During its compliance assessment, the Tiger Team reported no noncompliance issues of a magnitude that would necessitate curtailing overall operations at the plant. The Tiger Team identified a tutal of 199 findings and 4 noteworthy practices. Of the 199 findings, 62 pertained to environmental issues, 123 involved safety and health issues, and 14 were related to management issues, 3 of which addressed DOE matters.

One hundred and fifty of the 199 findings (46 environmental, 94 safety and health, and 10 management) had been identified previously either by Energy Systems, or by prior external audits or reviews.

Key environmental findings were (1) environmental monitoring and evaluation lack some necessary elements for accurate monitoring and characterization; (2) a general lack of formal procedures exists; and (3) environmental programs are not supported by a fully effective quality assurance program. The Tiger Team noted that several of the more significant environmental compliance findings are beyond the ability of PGDP to address alone.

Key concerns identifieo by the safety and health subteam were (1) compliance with DOE orders and mandatory standards is deficient in a wide variety of activities; (2) the system of preparing or revising, reviewing, and approving administrative control documents has serious deficiencies; (3) training and certification programs and practices do not fulfill site needs; (4) instrument calibration practices in some areas do not meet minimum standards; (5) there is no long-range plan for safe storage of depleted uranium; and (6) no integrated site-wide management system is available to track and correct identified deficiencies. A total of 241 Occupational Safety and Health Administration violations were identified and included with the safety and health issues. Immediate abatement of these violations was started and a correction-traching system was initiated. 
Key management findings included (1) DOE's failure to provide effective oversight of PGDP Environmental, Safety, and Health (ES\&H) activities; (2) Energy Systems' lack of a strategic plan to define, guide, and accomplish ES\&H objectives; and (3) Energy Systems'/PGDP's inadequate development of fundamental management control systems.

An action plan was written to address formally all $199 \mathrm{fi}$ Jings and fifteen root causes issues cited by the Tiger Team Assessment. The action plan includes descriptions of the actions to be taken by the site to satisfy the findings, action schedules and milestones, and associated costs. Collectively, the action plans represent an integrated network of actions necessary to resolve ES\&H deficiencies and the commitment by uranium enrichment management to pursue performance excellence diligently.

\section{Comprehensive Environmental Response, Compensation, and Liabilizy Act}

Routine monitoring of residential wells near the area of known groundwater contamination continued. No additional residential wells were found to be contamirtated with TCE or ${ }^{99} \mathrm{Tc}$ above action levels in 1990. Provision of water supplies continued to residents whose wells are contaminated.

The fieldwork for the Phase I Site Investigation was completed in 1990. The Draft Phase I Site Investigation Report was submitted to EPA and the state and made available to the public for comment on December 21, 1990. Regulatory agency comments on the report were received early in 1991. EPA and state comments were addressed and the report resubmitted for approval within the 30-day time frame required by the ACO.

TCE was discovered in two Phase I well clusters outside the plant security area. As a result, residents who live near those well clusters were contacted to identify additional well users and to collect samples from their well:s. Seventy-seven contacts were made with residents, and 21 wells were identified and sampled. No TCE or ${ }^{99} \mathrm{Tc}$ was detected in any of the 21 wells. Routine monitoring was modified to include some of these wells, based upon their use and their proximity to contaminated monitoring wells.

A survey of plant discharges to the environment was conducted in the final quarter of 1990 to determine whether CERCLA reporting requirements peitain to any of these continuous or routine releases. Releases to the atmosphere of chromium, trichloroethylene, and fluorine were found to exceed reportable quantities on a continuous or routine basis. They must be reported according to CERCLA reporting rules for continuous releases. Federal, state, and local authorities were initially notified by telephone, and written follow-up was sent to them 30 days after the telephone contact. The sources of the chromium, TCE, and fluorine emissions were the cooling tower drift, C-400 vapor degreaser, and cascade process vent, respectively.

The Phase II Site Investigation Work Plan was submitted to EPA and the state in July 1990. After comments from the regulatory agencies were incorporated, the work plan was conditionally approved in October 1990, and implementation began in November 1990. The Phase II investigation will focus on characterizing the sources of TCE and ${ }^{99} \mathrm{Tc}$ contamination on-site and on providing additional off-site data to better define the nature and extent of contamination off the DOE property.

The first Phase II groundwater sampling series was completed in early 1991, including residential wells, plant monitoring wells, wells installed as part of Phase I, wells at the Tennessee Valley Authority Shawnee Steam Plant, and the 35 on-site Phase II wells. Deep soil borings and sediment and surface water sampling have been completed on-site. Plans and schedules have been developed and are being implemented for another groundwater sampling series; off-site soil, sediment, and surface water sampling; and on-site sampling of PCB sources.

\section{Resource Conservation and Recovery Act}

On March 29, 1990, EPA promulgated the toxicity characteristic (TC) rule, the requirements of which went into effect on September 25, 1990. According to the toxicity characteristic leaching procedure, all waste streams must undergo a full characterization of components either by the new analytical method or by knowledge of the waste stream. PGDP has initiated reevaluation of waste streams under the TC rule and is coordinating this effort with other off-site laboratories to expedite the testing to comply with the new standard.

Six NOVs were received from the Kentucky Division of Waste Management (KDWM) regarding training, manifests, waste management, and spills. Manifests were not completely filled out; i.e., handling codes and other information were not available. Drums were stored past the allowable time 
limit for accumulation, and sample evaluations were not performed for three drums in storage. A large number of spills were recorded, and the facility was not being operated to prevent releases. All these violations have been addressed and corrective actions taken to ensure compliance.

EPA Region IV issued a formal request to PGDP to submit the information specified in 40 CFR 270.24 and 270.25 . This information specifies the equipment and facilities that are regulated and the inspections (visual or emission monitoring) that must be performed. A leak detection and repair plan has been developed to comply with Phase I of the RCRA Air Emission Standards. This plan will implement all tecord-keeping requirements, inspections, and emissions monitoring necessary for all applicable hazardous waste units.

On September 25, 1990, Energy Systems and DOE entered into a "co-operator" agreement to operate PGDP. This agreement is the result of the KDWM decision to regulate government-owned, contractor-operated facilities as one entity. DOE will be listed as the owner/operator and Energy Systems as co-operator of PGDP. It is hoped this move will streamline policies and decisions.

Notices of Deficiency have been received from KDWM regarding the RCRA part B permit. Most of the deficiencies were minor and were corrected and submitted to KDWM. Following submission of the corrections, a fourth revision of the permit application was completed. A letter from KDWM indicated that no deficiencies exist and that the permit application has been forwarded for public review and comment. After this procedure, the comments, if any, will be addressed and the final permit issued. PGDP will then be a permitted facility and must comply with regulations governing such operations.

The Annual Hazardous Waste Report was completed and submitted to KDWM before March 1, 1991. It contains a listing of all hazardous waste generated during CY 1990 that either was shipped off-site or still remains on-site.

\section{Unauthorized Use of PCBs in Ventilation Duct Gaskets}

Buildings at PGDP contain ventilation duct systems for heating and cooling both personnel space and process equipment. The gaskets in a number of these systems contain varying levels of PCBs. As a result, the gaskets constitute non-totally enclosed
PCB systems, which are prohibited by 40 CFR 761.20 (a). Certain systems (notably the motor exhaust duct systems) have come in contact with leaching media (chiefly oil), resulting in migration or drips of PCBs to the floors of the process buildings. These drips of PCB-contaminated oil are considered PCB spills.

TSCA requires documentation, cleanup action, and verification of cleanup after discovery of $\mathrm{PCB}$ spills. All new drips from the ventilation duct gaskets are cleaned in accordance with the EPA Spill Cleanup Policy. This includes daily inspections to identify leaks, initiation of cleanup within 24 hours, and sampling to verify cleanup results. In addition, immediate installation of spill containment/collection systems is carried out when drips are discovered.

Negotiations of an FFCA are continuing between DOE and EPA on compliance with TSCA and the $P C B$ regulations found at $40 \mathrm{CFR} 761$. The unauthorized use of PCBs in ventilation duct gaskets is being addressed in those negotiations.

\section{Historic PCB Oil Spills}

PCB-contaminated oil drips from ventilation duct gaskets leaked onto the concrete floors of the process buildings and associated equipment under the ducts in the past before it was discovered that the leaks were PCB contaminated. Negotiations of an FFCA are continuing between DOE and EPA concerning compliance with TSCA and the $\mathrm{PCB}$ regulations found at 40 CFR 761. Historic PCB spills onto the floors of the process building are being addressed as part of the negotiations.

\section{Unauthorized Use of Leaking PCB Capacitors in Potential Devices}

The electrical switchyards at PGDP are designed to use up to 128 potential devices (PDs). The devices contain inaccessible small capacitors, a small transformer, and various other electrical components. Currently 122 PDs are in service. The capacitors in 92 of them are suspected to contain PCBs in concentrations greater than $500 \mathrm{ppm}$. About 60 of these small PCB capactiors were observed to have leaked and seeped onto the surfaces of the PDs in September 1990. Sample results from leaks of this type of capacitor contained 677 to $2500 \mathrm{ppm}$ PCBs. Use of PCBs in leaking capacitors is unauthorized under TSCA regulations. 
Negotiations of an FFCA are continuing between DOE and EPA concerning compliance with TSCA and $P C B$ regulations found at 40 CFR 761. DOE proposed in February 1991 that PDs at PGDP be included in this agreement and that their continued use be allowed until their scheduled replacement by May 1993. In the interim, PGDP will continue to (1) conduct daily documented inspections to check for seepage of oil to the external surfaces; (2) initiate immediatc documented cleanup of external surfaces if oil is found; (3) contain recurring seepage in clear plastic with daily change of the plastic and cleanup of the external surfaces; and (4) restrict access to PDs showing seepage by the use of flags and caution signs. Final compliance will be achieved by replacing all potential devices that are unauthorized for use.

\section{Unauthorized Use of PCBs in Hydraulic Systems}

Two hydraulic systems with PCB labels affixed were found in C-340 during an inspection conducted by PGDP personnel during February 1991. Due to lack of documentation that these systems were below $50 \mathrm{ppm}$ PCBs, samples were taken of residual oil in the systems reservoir. After the inspection, documentation was found indicating that the systems had been drained and placed on standby status in 1982. Results of samples taken in February 1991 showed PCB concentrations in excess of $50 \mathrm{ppm}$, which is an unauthorized use of PCBs under TSCA and in non-compliance with 40 CFR 761.30 (e).

TSCA regulations require that within six months of a test that indicates that a hydraulic system contains more than $50 \mathrm{ppm}$ PCBs, the system must be drained and refilled with a fluid that contains less than $50 \mathrm{ppm}$ PCBs. However, EPA Region IV indicated in a phone conversation on March 11, 1991, that if data are not available to document that the systems were previously flushed to less than $50 \mathrm{ppm}$ PCBs, then the system should be drained, flushed, and refilled within 30 days of discovery at $50 \mathrm{ppm}$ or greater. Also, a documented decision could be made to remove these systems for disposal. Disposal would have to be completed within one year by TSCA. A compliance strategy for these systems will be developed and included in the FFCA being negotiated.

\section{Underground Storage Tanks}

A site inspection by KDWM was performed on March 18, 1991. The piping of the UST system was exposed for this inspection. An NOV was issued by KDWM for an unauthorized disposal (leak) from the storage tanks. A response will be prepared for KDWM. The tanks were removed from the ground in April and the disposition of the potentially contaminated soil is dependent upon analytical results.

\section{National Environmental Policy Act}

The NEPA process establishes general guidelines and responsibilities for addressing environmental considerations during project planning, design, and construction. PGDP will as much as possible use all practical means, consistent with the requirements of the act and other essential considerations of national policy, to restore and enhance the quality of the human environment and avoid or minimize any adverse effects of its actions on the quality of the human environment.

A number of options are available to project: depending on their scope. When evaluating a project, NEPA Compliance personnel initially complete a checklist to help determine the level of documentation the project may require. The checklist may lead to a request for a categorical exclusion, an environmental assessment, or an environmental impact statement. DOE will determine the type of document required.

A number of DOE Executive Orders and federal environmental protection statutes are integrated into the NEPA programs to ensure that the resources they are concerned with are protected against any adverse environmental impacts that might result from a plant activity or project. They include DOE Executive Order 11988, Floodplain Management; DOE Executive Order 11990, Protection of Wetlands; the Endangered Species Act; the Fish and Wildlife Coordination Act; the Farmland Protection Policy Act; the National Historic Preservation Act, which protects national historic landmarks; the American Indian Religious Freedom Act, which protects the freedoms of American Indians; and the Wild and Scenic Rivers Act. 


\section{CONTENTS}

Page

EXECUTIVE SUMMARY $\ldots \ldots \ldots \ldots \ldots \ldots \ldots \ldots \ldots \ldots \ldots$

COMPLIANCE SUMMARY $\ldots \ldots \ldots \ldots \ldots \ldots \ldots \ldots \ldots \ldots \ldots$

ABBREVIATIONS, ACRONYMS, AND INITIALISMS $\ldots \ldots \ldots \ldots \ldots \ldots \ldots$

PART 1. NARRATIVE, SUMMARIES, AND CONCLUSIONS $\ldots \ldots \ldots \ldots \ldots$

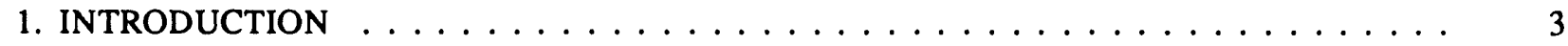

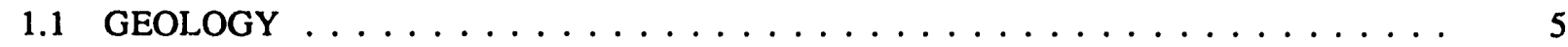

1.2 SURFACE WATER SYSTEM $\ldots \ldots \ldots \ldots \ldots \ldots \ldots \ldots \ldots \ldots$

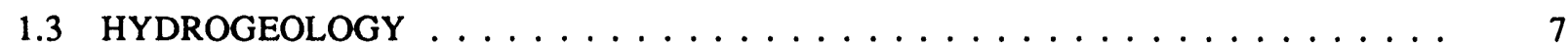

1.4 REGIONAL DEMOGRAPHY $\ldots \ldots \ldots \ldots \ldots \ldots \ldots \ldots \ldots \ldots$

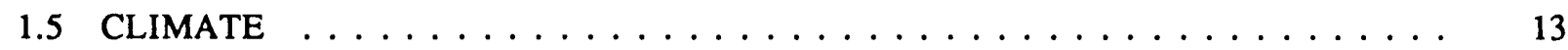

1.6 APPLICABLE ENVIRONMENTAL REQUIREMENTS $\ldots \ldots \ldots \ldots \ldots \ldots$

1.7 ENVIRONMENTAL PROGRAM INFORMATION $\ldots \ldots \ldots \ldots \ldots \ldots$

2. AIRBORNE DISCHARGES, AMBIENT AIR MONITORING, METEOROLOGICAL MONITORING, AND EXTERNAL GAMMA RADIATION $\quad 17$

2.1 AIRBORNE DISCHARGES $\ldots \ldots \ldots \ldots \ldots \ldots \ldots \ldots \ldots \ldots \ldots$

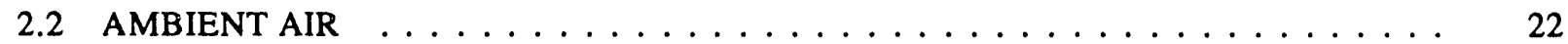

2.3 METEOROLOGICAL MONITORING $\ldots \ldots \ldots \ldots \ldots \ldots \ldots \ldots$

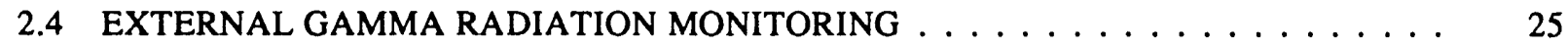

2.4.1 Thermoluminescent Dosimeter Sampling Program . . . . . . . . . . . . 25

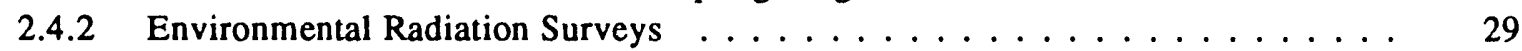

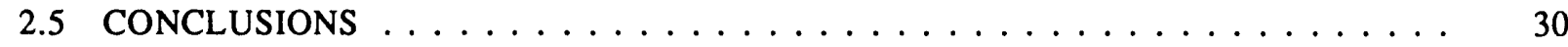

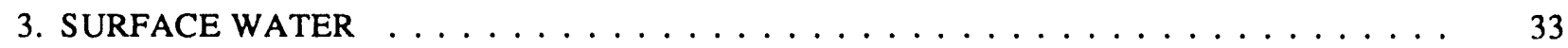

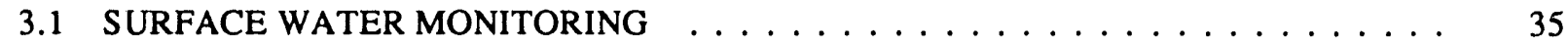

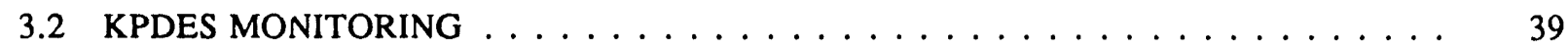

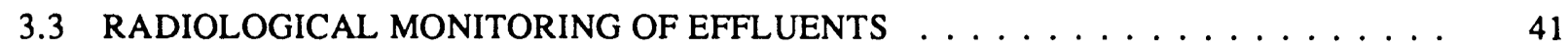

3.4 BIOLOGICAL MONITORING OF EFFLUENTS AND RECEIVING WATERS $\ldots \ldots$

3.5 CONCLUSIONS $\ldots \ldots \ldots \ldots \ldots \ldots \ldots \ldots \ldots \ldots \ldots \ldots$

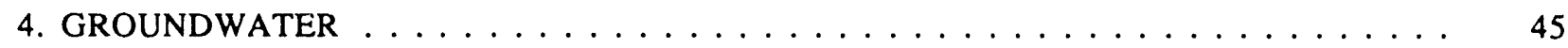

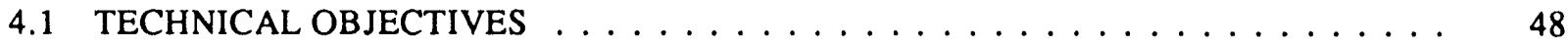

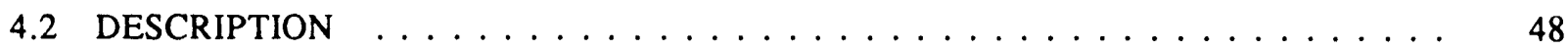


4.2 .1 Effluent Monitoring . . . . . . . . . . . . . . . . . . . 49

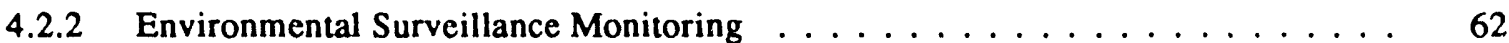

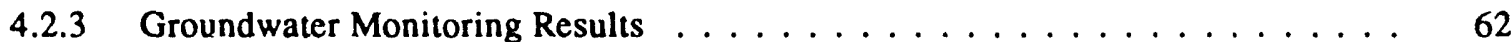

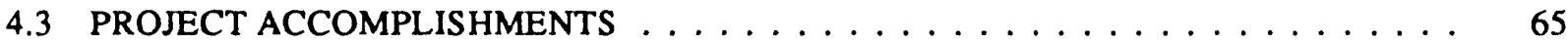

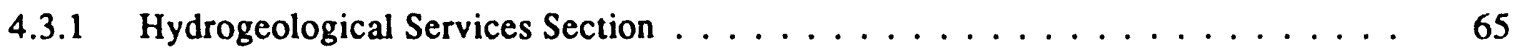

4.3.2 Related Activities . . . . . . . . . . . . . . . . . . 67

5. BIOLOGICAL SAMPLING $\ldots \ldots \ldots \ldots \ldots \ldots \ldots$

5.1 FOOD CROP AND TISSUE SAMPLING $\ldots \ldots \ldots \ldots \ldots \ldots \ldots \ldots \ldots$

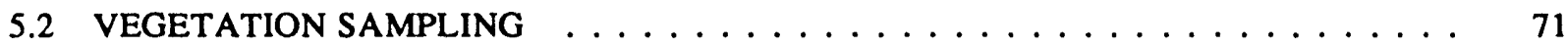

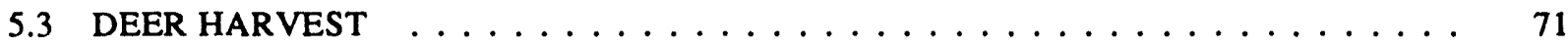

6. SOIL AND SEDIMENT MONITORING $\ldots \ldots \ldots \ldots \ldots \ldots \ldots \ldots \ldots \ldots$

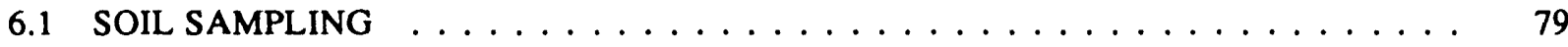

6.2 SEDIMENT SAMPLING $\ldots \ldots \ldots \ldots \ldots \ldots \ldots \ldots \ldots \ldots \ldots \ldots$

7. POTENTIAL RADIATION DOSE TO THE PUBLIC $\ldots \ldots \ldots \ldots \ldots \ldots \ldots$

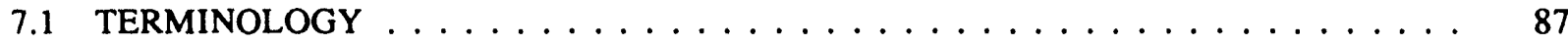

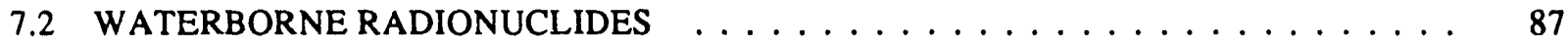

7.3 DIRECT RADIATION $\ldots \ldots \ldots \ldots \ldots \ldots \ldots \ldots \ldots \ldots \ldots \ldots \ldots$

7.4 CONTAMINATED SEDIMENT IN LITTLE BAYOU CREEK $\ldots \ldots \ldots \ldots \ldots$

7.5 INGESTION OF TERRESTRIAL FOODSTUFFS $\ldots \ldots \ldots \ldots \ldots \ldots \ldots \ldots$

7.6 AIRBORNE RADIONUCLIDES $\ldots \ldots \ldots \ldots \ldots \ldots \ldots \ldots \ldots \ldots \ldots$

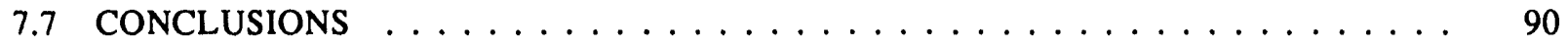

8. SOLID WASTE MANAGEMENT PROGRAM $\ldots \ldots \ldots \ldots \ldots \ldots \ldots \ldots \ldots$

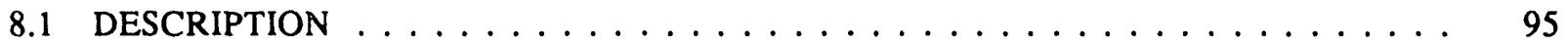

$8.1 .1 \quad$ Purpose . . . . . . . . . . . . . . . . . . . 95

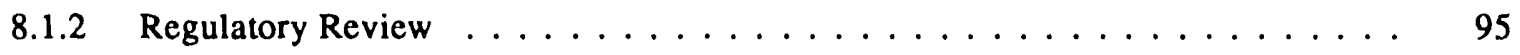

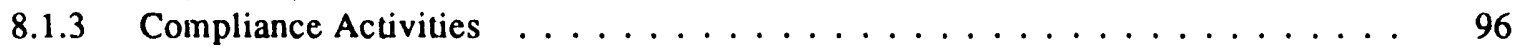

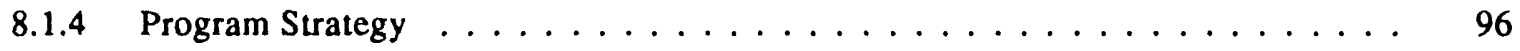

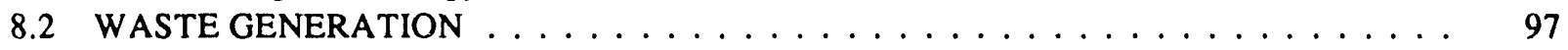

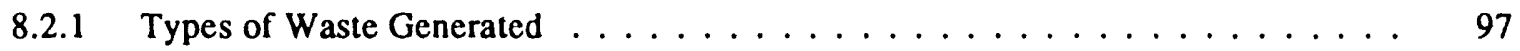

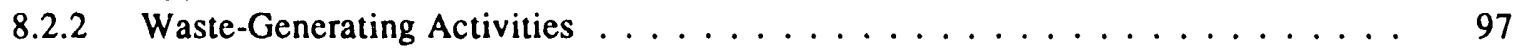

8.2 .3 Waste Generation Summary $\ldots \ldots \ldots \ldots \ldots \ldots \ldots \ldots$

8.3 WASTE MANAGEMENT ACTIVITIES $\ldots \ldots \ldots \ldots \ldots \ldots \ldots$

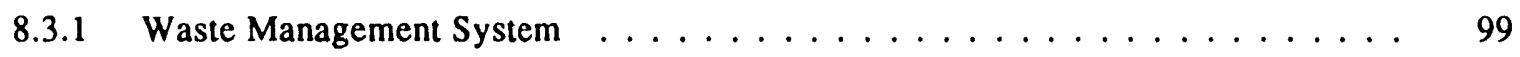

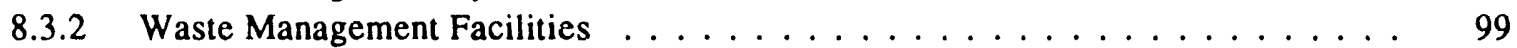

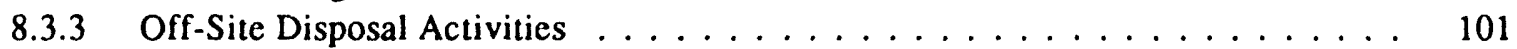

8.3 .4 Waste Placed in Storage $\ldots \ldots \ldots \ldots \ldots \ldots \ldots \ldots$

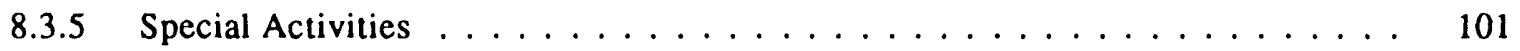

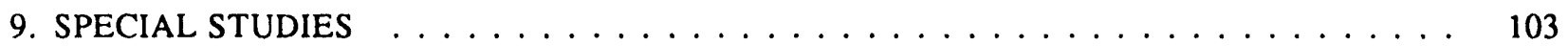

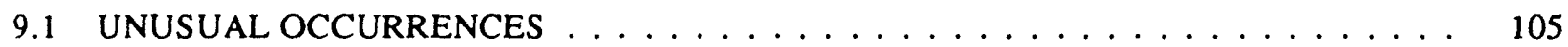

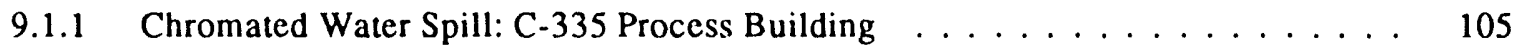

9.1.2 PCB Capacitor Failure: C-533 Switchyard . . . . . . . . . . . . . . 105

9.1.3 Diesel Fuel Spill: C-611 Diesel Generator . . . . . . . . . . . . . . . . 105

9.1 .4 Chromated Water Leak: C-337 Truck Alley . . . . . . . . . . . . . . . 105

9.1.5 Sprinkler Water Spill: C-333 Filter Room $2 \ldots \ldots \ldots \ldots$ 
9.1.6 Chromated Water Spill: C-633 Cooling Tower . . . . . . . . . . . . 106

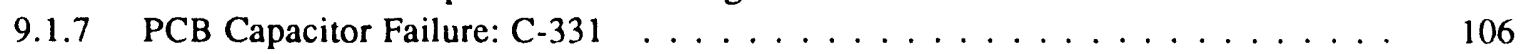

9.1.8 Potential Devices Leaking PCBs: Plant Switchyards . . . . . . . . . . . . 106

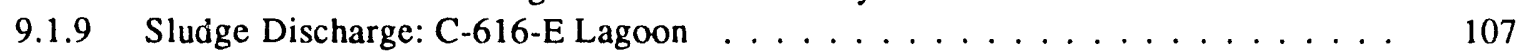

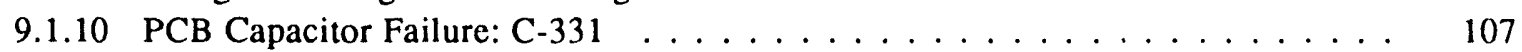

9.1.11 Current Transformer Failure: C-533 Switchyard . . . . . . . . . . . . . 107

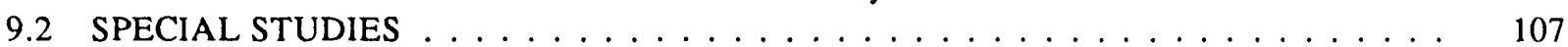

9.2.1 Uranium Release Study . . . . . . . . . . . . . . . . . . . . . . . 107

9.2.2 National Environmental Policy Act _. . . . . . . . . . . . . . . . . . 108

9.2.3 Environmental Advisory Committee . . . . . . . . . . . . . . . . 108

9.2.4 PCB-Contaminated Ventilation Duct Gaskets . . . . . . . . . . . . . . . . 109

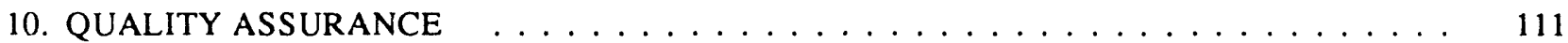

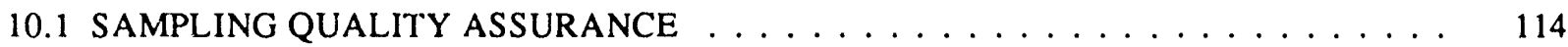

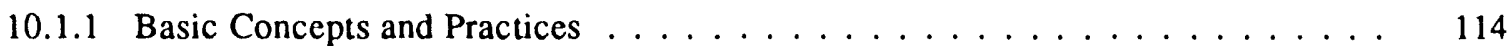

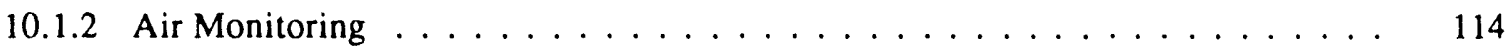

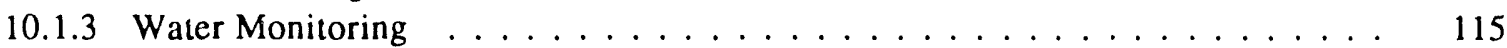

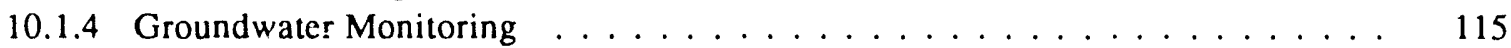

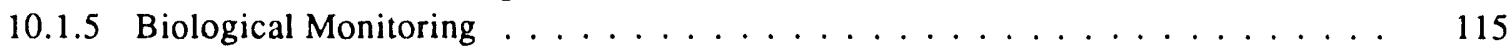

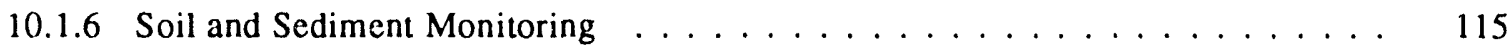

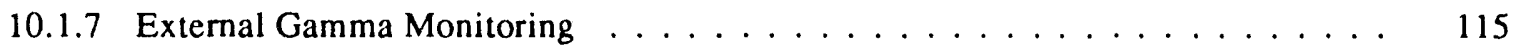

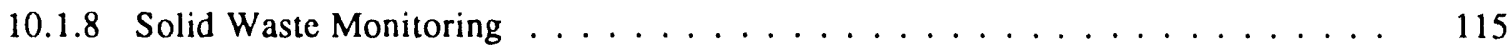

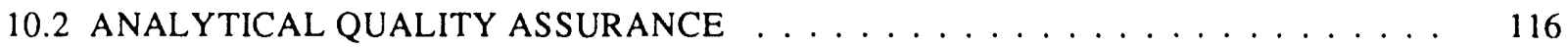

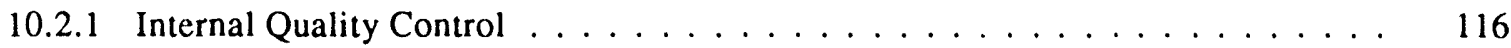

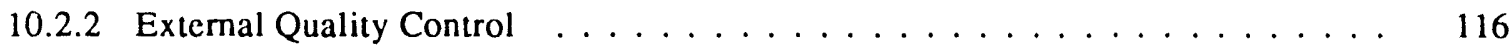

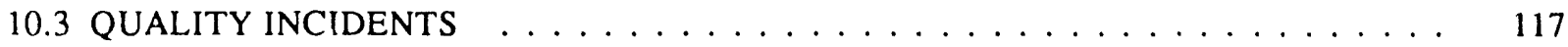

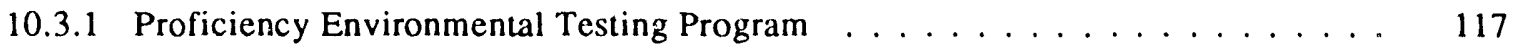

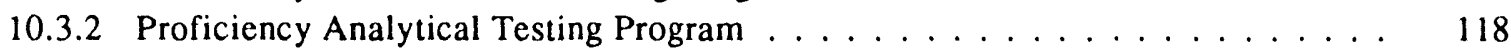

10.3.3 Internal Quality Incidents . . . . . . . . . . . . . . . . . . . . 118

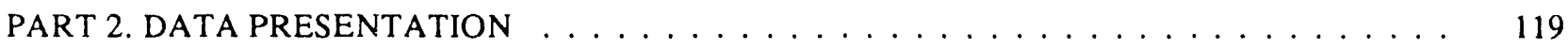

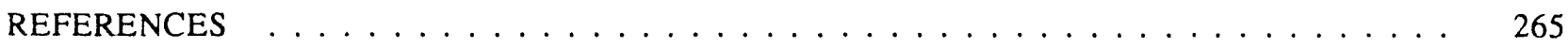

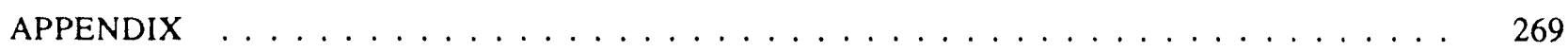




\title{
ABBREVIATIONS, ACRONYMS, AND INITIALISMS
}

ACO
ALARA
$\mathrm{Al}_{2} \mathrm{O}_{3}$
ANSI
APG
BMP
BOD
BTEX
${ }^{\circ} \mathrm{C}$
CAA
CEDE
CERCLA
CFR
Ci
cm
cm
COD
C. ${ }^{6+}$
${ }_{137}$ Cs
CWA
d
DCG
DMR-QA
DOE
DOT
EML
EPA
ERP
ESP
${ }^{\circ} F$
FDA
ft
g
gal
GC
GMP
GWPP
GWPP-MP
h
ha
ha
HCl
HF
HSS
HSWA
I31 I

\author{
Administrative Consent Order \\ as low as reasonably achievable \\ Aluminum oxide \\ American National Standards Institute \\ Analytical Products Group, Inc. \\ Biological Monitoring Program \\ biochemical oxygen demand \\ benzene, toluene, ethylbenzene, xylene \\ degrees Celsius \\ Clean Air Act \\ committed effective dose equivalent \\ Comprehensive Environmental Response, \\ Compensation, and Liability Act \\ Code of Federal Regulations \\ curies \\ centimeter \\ square centimeter \\ chemical oxygen demand \\ hexavalent chromium \\ cesium-137 \\ Clean Water Act \\ day \\ derived concentration guide \\ Discharge Monitoring Report-Quality Assurance \\ U.S. Department of Energy \\ U.S. Department of Transportation \\ Environmental Measurements Laboratory \\ Environmental Protection Agency \\ Environmental Restoration Program \\ electrostatic precipitator \\ degrees Fahrenheit \\ Food and Drug Administration \\ foot \\ gram \\ gallon \\ gas chromatograph \\ groundwater monitoring plan \\ groundwater protection plan \\ groundwater protection plan-management plan \\ hour \\ hectare \\ hydrochloric acid \\ hydrofluoric acid \\ hydrogeologic services section \\ Hazardous and Solid Waste Amendments \\ iodine-131 \\ International Commission on Radiological Protection \\ inch \\ Integrated Risk Information System \\ potassium -40
}




\begin{tabular}{|c|c|}
\hline $\begin{array}{l}\text { KAR } \\
\text { KDAO }\end{array}$ & Kentucky Administrative Regulations \\
\hline $\begin{array}{l}\text { KDAQ } \\
\text { KDOW }\end{array}$ & Kentucky Division for Air Quality \\
\hline KDOW & Kentucky Division of Water \\
\hline $\mathrm{km}$ & $\begin{array}{l}\text { kilogram } \\
\text { kilometer }\end{array}$ \\
\hline KPDES & $\begin{array}{l}\text { kilometer } \\
\text { Kentucky Pollutant Discharge Elimination System }\end{array}$ \\
\hline KDWM & Kentucky Division of Waste Management \\
\hline L & liter \\
\hline lb & pound \\
\hline LCR & lowest concentration reported \\
\hline LLW & low-level waste \\
\hline m & meter \\
\hline $\mathrm{m}^{2}$ & square meter \\
\hline $\mathrm{m}^{3}$ & cubic meter \\
\hline$\mu \mathrm{Ci}$ & microcurie \\
\hline$\mu \mathrm{g}$ & microgram \\
\hline$\mu \mathrm{mho}$ & micro mlio \\
\hline $\mathrm{mCi}$ & millicurie \\
\hline mg & milligram \\
\hline Mgd & million gallons per day \\
\hline $\min$ & minute \\
\hline $\mathrm{mL}$ & milliliter \\
\hline mum & millimeter \\
\hline mrem & millirem \\
\hline NA & not applicable \\
\hline $\mathrm{NaF}$ & sodium fluoride \\
\hline NEPA & National Environmental Policy Act \\
\hline NESHAP & National Emission Standards for Hazardous Air Pollutants \\
\hline NIOSH & National Institute for Occupational Safety and Health \\
\hline NIST & National Institute of Standards and Technology \\
\hline $\mathrm{NO}_{3}-\mathrm{N}$ & nitrate as nitrogen \\
\hline $\mathrm{NO}_{x}$ & nitrogen oxides \\
\hline NOV & Notice of Violation \\
\hline${ }^{237} \mathrm{~Np}$ & neptunium-237 \\
\hline NPDES & National Pollutant Discharge Elimination System \\
\hline OCB & oil circuit breaker \\
\hline ORNL & Oak Ridge National Laboratory \\
\hline ORO & Oak Ridge Operations \\
\hline PAT & Proficiency Analytical Testing \\
\hline PCB & polychlorinated biphenyl \\
\hline $\mathrm{pCi}$ & picocurie \\
\hline PD & potential device \\
\hline PET & Proficiency Environmental Testing Program \\
\hline PGDP & Paducah Gaseous Diffusion Plant \\
\hline $\mathrm{pH}$ & hydrogen ion concentration \\
\hline $\mathrm{PO}_{4}$ & phosphate \\
\hline $\mathrm{ppb}$ & parts per billion \\
\hline ppm & parts per million \\
\hline${ }^{239} \mathrm{Pu}$ & plutonium-239 \\
\hline PVC & polyvinylchjoride \\
\hline QA & quality assurance \\
\hline QC & quality control \\
\hline RCRA & Resource Conservation and Recovery Act \\
\hline RCW & recirculating cooling water \\
\hline RFI & RCRA Facility Investigation \\
\hline RGA & Regional groundwater aquifer \\
\hline RI/FS & Remedial Investigation/Feasibility Study \\
\hline SARA & Superfund Amendments and Reauthorization Act \\
\hline SCS & Spill Containment System \\
\hline SDWA & Safe Drinking Water Act \\
\hline SGS & shallow ground system \\
\hline $\mathrm{SO}_{2}$ & sulfur dioxide \\
\hline $\mathrm{SO}_{4}$ & sulfate \\
\hline
\end{tabular}




${ }^{90} \mathrm{Sr}$
SWMU
${ }_{99} \mathrm{Tc}$
TCA
TCE
TCL
TDS
${ }^{230} \mathrm{Th}$
TLD
TOC
TPH
TRC
TSCA
TSP
TSS
TVA
U
UK
USGS
UST
WKWMA
yd
VOC

strontium -90

solid waste management unit

technetium-99

tetrachloroethane

trichloroethylene

Target Compound List

total dissolved solids

thorium-230

thermoluminescent dosimeter

total organic carbon

total petroleum hydrocarbons

total residual chlorine

Toxic Substances Control Act

total suspended particulates

total suspended solids

Tennessee Valley Authority

uranium

University of Kentucky

United States Geological Survey

underground storage tank

West Kentucky Wildlife Management Area

yard

volatile organic compound 
 


\section{INTRODUCTION}

This report presents environmental data and supporting narratives for the U.S. Department of Energy's (DOE's) Paducah Reservation Environmental Monitoring Program during 1990. Part 1 includes all narrative descriptions, summaries, and conclusions and is intended to be a "stand-alone" report for the reader who does not want to review in detail all of the 1990 data. Part 2 includes the detailed data summarized in a format designed to ensure that all environmental data are represented in the tables. Narratives are generally not included in Part 2.

Paducah Gaseous Diffusion Plant (PGDP) is an active uranium enrichment facility consisting of a diffusion cascade and extensive support facilities. Construction of PGDP began in 1951. The plant began operating in 1952 and was fully operational by 1955, supplying enriched uranium for commercial reactors and military defense reactors. Enriched uranium is uranium in which the concentration of the fissionable ${ }^{235} \mathrm{U}$ has been increased. Natural uranium is mostly ${ }^{238} \mathrm{U}$ with about $0.72 \%{ }^{235} \mathrm{U}$ and $0.0051 \%$ ${ }^{234} \mathrm{U}$. Uranium mills process the ores to produce a concentrated uranium oxide, $\mathrm{U}_{3} \mathrm{O}_{8}$, which is then commercially converted to gaseous uranium hexafluoride $\left(\mathrm{UF}_{6}\right)$ for enrichment at a gaseous diffusion plant. The enrichment mechanism is based on the fact that a $U_{6}$ molecule containing ${ }^{235} \mathrm{U}$ is slightly lighter than a $U_{6}$ molecule containing ${ }^{238} \mathrm{U}$. As the $\mathrm{UF}_{6}$ molecules move through the miles of tubing in a cascade system, slightly more ${ }^{235} U$ than ${ }^{238} \mathrm{U}$ escapes through the small holes in the tubing. As the process is repeated (cascading), the ${ }^{235} \mathrm{U}$ concentration increases. About two-thirds of the ${ }^{235} \mathrm{U}$ in the natural ore is removed during enrichment, so there are two product streams: enriched uranium and depleted uranium tailings.

Currently, uranium enriched at PGDP is further enriched at another DOE gaseous diffusion plant managed by Martin Marietta Energy Systems in Portsmouth, Ohio. Most of the uranium from PGDP is ultimately designated for the commercial sector as fuel for nuclear power reactors in the United States and abroad. The fuel in commercial power reactors is about $3 \%{ }^{235} \mathrm{U}$, fuel for the production reactor at the Savannah River site is typically $60 \%{ }^{235} \mathrm{U}$, and naval reactor fuel is $97.3 \%{ }^{235} \mathrm{U}$. Depleted uranium is used for components in both nuclear and conventional weapons.

Extensive support facilities are required to maintain the diffusion process. These include a steam plant, four electrical switchyards, four sets of cooling towers, a chemical cleaning and decontamination facility, water and wastewater treatment plants, a chromium reduction facility, maintenance and laboratory facilities, and two active landfills. Several inactive facilities also are located on the plant site.

The area surrounding PGDP is predominantly rural. Residences and farms surround the plant. Immediately adjacent to PGDP is the West Kentucky Wildlife Management Area (WKWMA), which is used by a considerable number of hunters and fishermen each year. About 20 of the 35 ponds in the wildlife management area support fishing.

Approximately 200 deer are harvested from the area eack year through hunting. Figures 1.1 and 1.2 show the geographic location of PGDP.

\subsection{GEOLOGY}

PGDP is located in the Jackson Purchase region of western Kentucky and lies in the northern margin of the Mississippi Embayment. The Mississippi Embayment was a large sedimentary trough oriented nearly north-south that existed during Cretaceous and Tertiary time. The sedimentary sequence overlying Mississippian age bedrock in the vicinity of PGDP consists mainly of fine- to medium-grained clastic materials including (from oldest to youngest) a basal gravel (i.e., Tuscaloosa Formation), the McNairy Formation, the Porters Creek Clay, and 


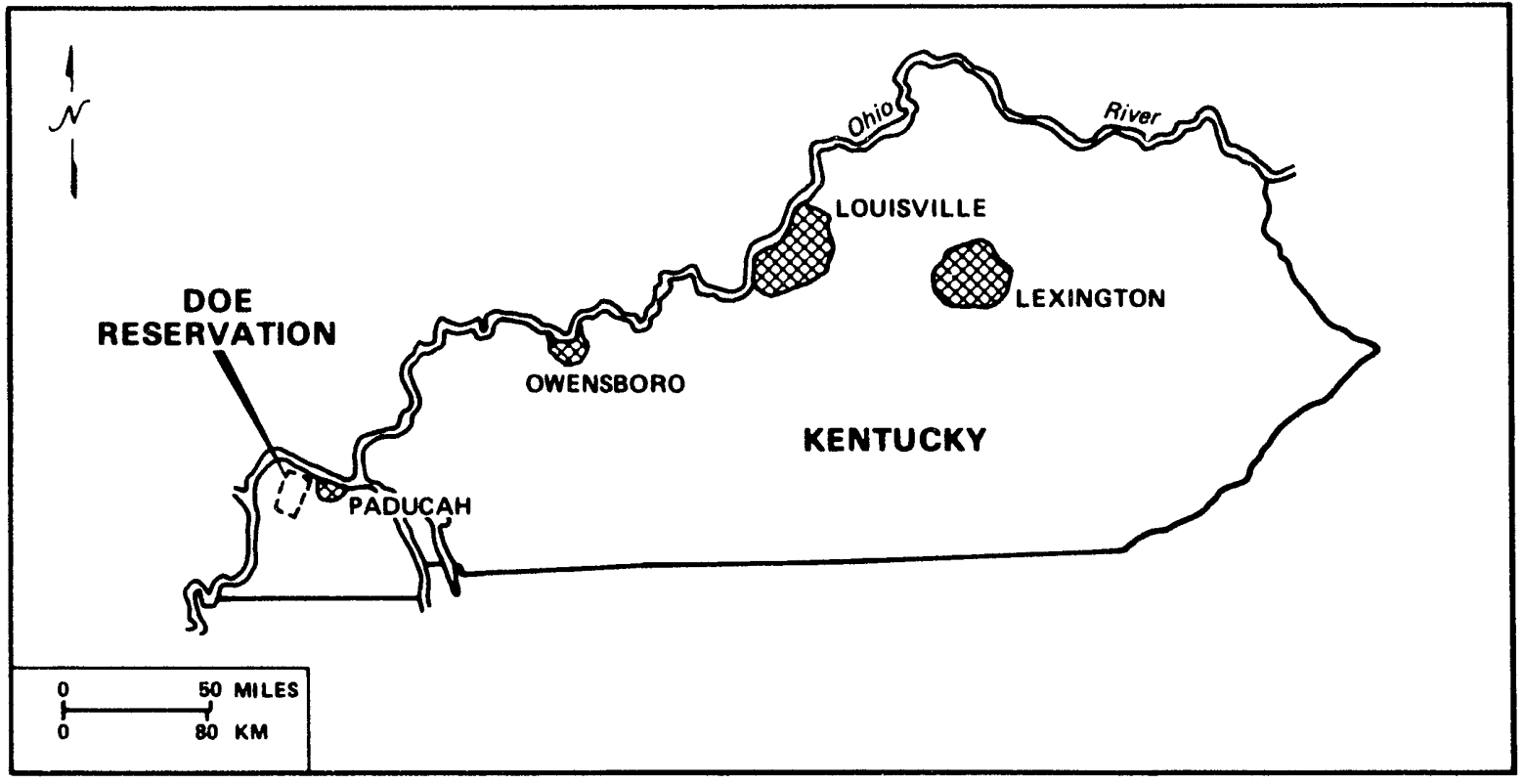

Fig. 1.1. Map showing the location of the Department of Energy's Paducah Reservation in Kentucky.

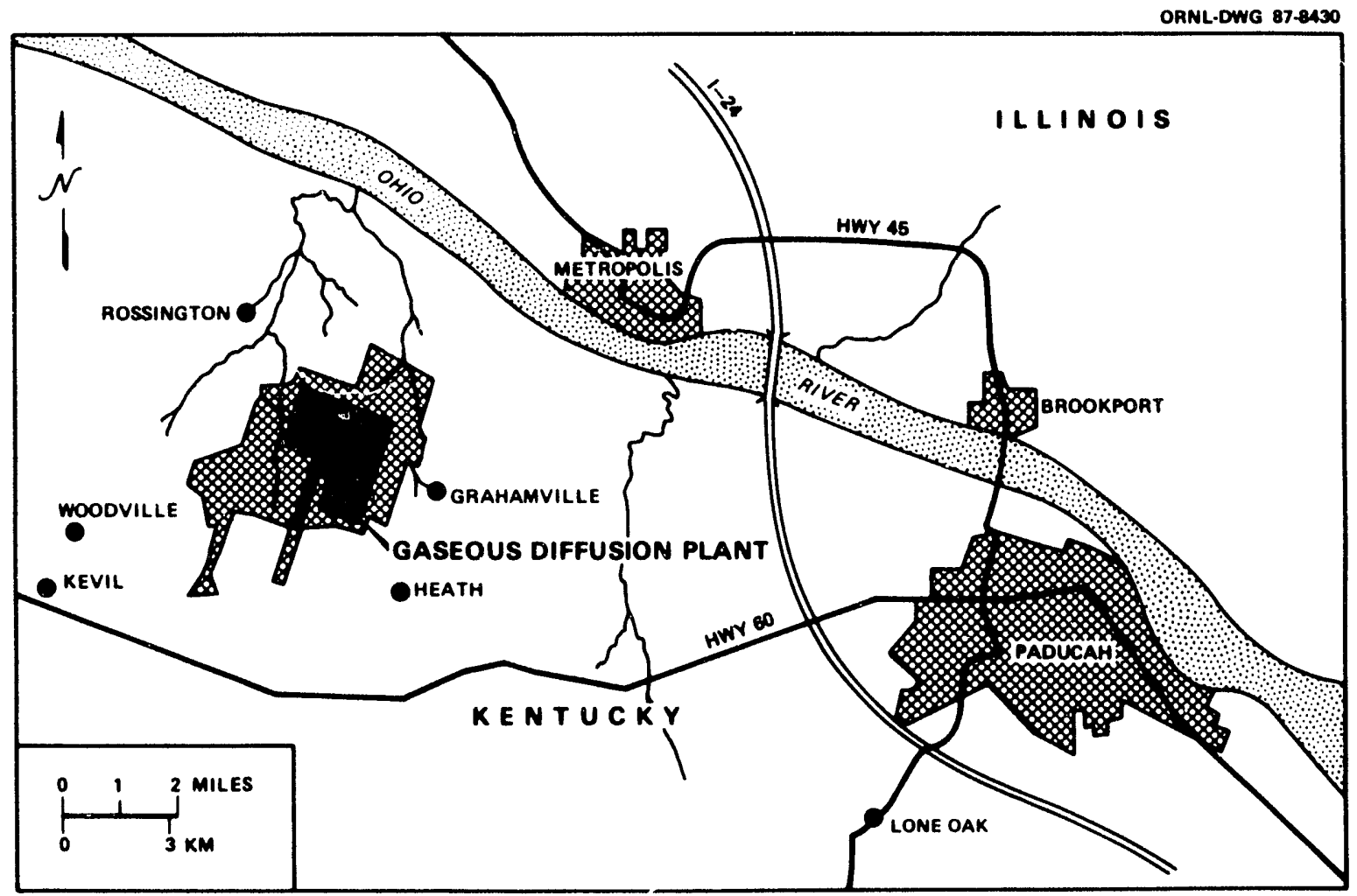

Fig. 1.2. Map showing the location of PGDP in relationship to the geographic region. 
undifferentiated Eocene sands. These strata dip gently to the south-southwest toward the axis of the embayment.

Following deposition of the embayment sediments, the embayment was upliifted and/or sea level was lowered, resulting in the development of an erosional surface that truncated the sediments.

Subsequently, during the late Tertiary and Quaternary' time, a formational unit designated as the Continental Deposits was laid down in the region, creating an angular unconformity with the uriderlying sediments. As a result of changes in base level during Pleistocene time, terraces were formed by streams that eroded a:ld laier alluviated their valleys, reworking the Continental Deposits at different elevations. Immediately overlying the Continental Deposits, Pieistocene loess (originating as wind-blown material generated by glacial activity to the north) was deposited in a layer of variable thickness. Figure 1.3 is a geologic map of the PGDP site.

The Continental Deposits can be subdivided into two stratigraphic components: a lower gravel or sandy gravel unit (i.e., gravel facies) that reportedly varies in thickness from 0 to $32 \mathrm{~m}(105 \mathrm{ft})$ and an upper clay-sand unit (i.e., clay facies) with a comparable range in thickness. The top of the gravel facies unit occurs at a depth of approximately 13 to $20 \mathrm{~m} \mathrm{(43} \mathrm{to} 66 \mathrm{ft}$ ) in the vicinity of PGDP. Based on data from numerous auger holes drilled by the U.S. Geological Survey (USGS) throughout the region and by DOE at PGDP, the gravel appears to be continuous within the vicinity of the plant and to extend northward to the Ohio Rivar. Near the southern boundary of PGDP, the gravel exists as a thin $[<3 \mathrm{~m}$ (10 ft)] veneer where it is draped over an escarpment or terrace slope that was carved in the underlying sediments by an ancient river system. The gravel thickens immediately north of this terrace and thins once again near the Ohio River. Figure 1.4 depicts the erosional surface beneath the Continental Deposits. Figures 1.5 and 1.6 shcw the thickness of the gravel facies and the elevation of the upper surface of the gravel facies, respectively. The clay facies of the Continental Deposits is thought to consist of discontinuous, fine, sand lenses enclosed by clay. Figure 1.7 is a geologic cross section that illustrates some of the stratigraphic relationships at the PGDP site. This interpretation is based on limited data, and the degree of interconnectedness of the interbedded sand lenses cannot be verified definitely at present.

\subsection{SURFACE WATER SYSTEM}

PGDP is located in the western part of the Ohio River basin. The confluence of the Ohio River and the Tennessee River is approximately 15 miles upstream of the site, and the confluence with the Mississippi River is approximately 56 miles downstream. PGDP is located within the drainage areas of Big and Little Bayou creeks, which meet about 3 miles north of the site and discharge into the Ohio River. (See Figs. 1.8 and 1.9).

PGDP is located on a local drainage divide; surface flow is to the east and northeast toward Little Bayou Creek and to the west and northwest toward Big Bayou Creek. Big Bayou Creek is a perennial stream whose drainage extends from approximately 2.5 miles south of PGDP to the Ohio River. It flows toward the river along a 9-mile course that passes along the western boundary of the plant. Little Bayou Creek originates in the wildlife management area and flows north toward the Ohio River along a 6.5-mile course that includes parts of the eastern boundary of the plant. Big Bayou Creek has an 11,910-acre drainage basin, and the watershed for Little Bayou Creek consists of about 6,000 acres.

During dry weather, much of the flow in both creeks is due to liquic releases from PGDP. Effluents from PGDP operations constitute about $85 \%$ of the normal flow in Big Bayou Creek and $: 00 \%$ of the normal flow in Little Bayou Creek.

\subsection{HYDROGEOLOGY}

The recognized importance of the gravel facies of the Continental Deposits dominates current understanding of local groundwater hydrology in the vicinity of PGDP. This unit is termed the regional gravel aquifer (RGA) and is the primary source of groundwater in this area. This seztion discusses the current level of understanding of the hydraulic properties of the local groundwater flow system.

The hydrology of the RGA was first investigated by the USGS in the mid-1960s. Results of these studies indicate that the gravel is saturated over most of its ar al extent in the region of the plant, and wells completed within it are reportedly capable of producing yiclds of up to $3790 \mathrm{~L} / \mathrm{min}(985 \mathrm{gal} / \mathrm{min}$, 
ORNL-DWG 87.8686

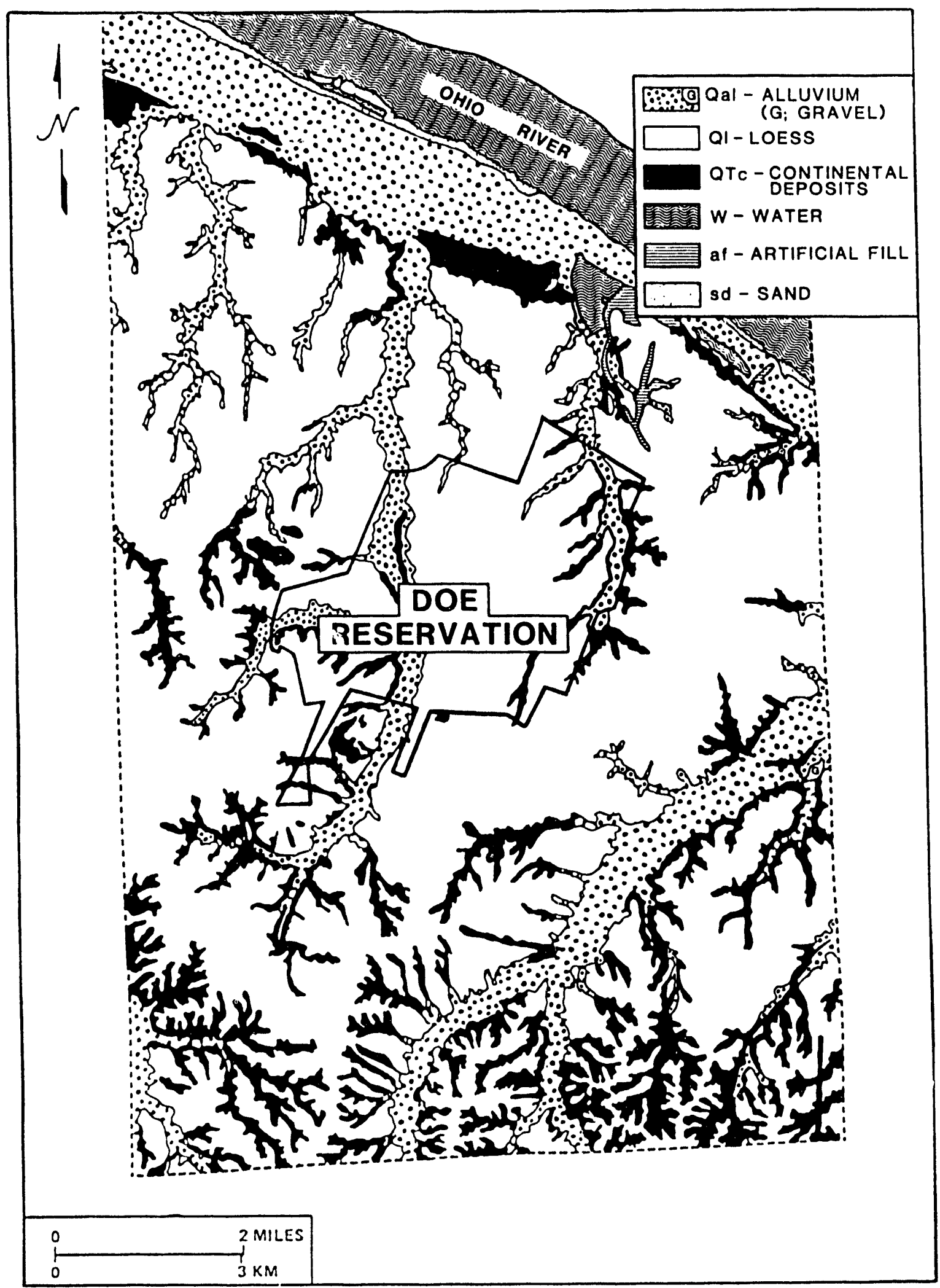

Fig. 1.3. Geologic map of the PGDP site. 


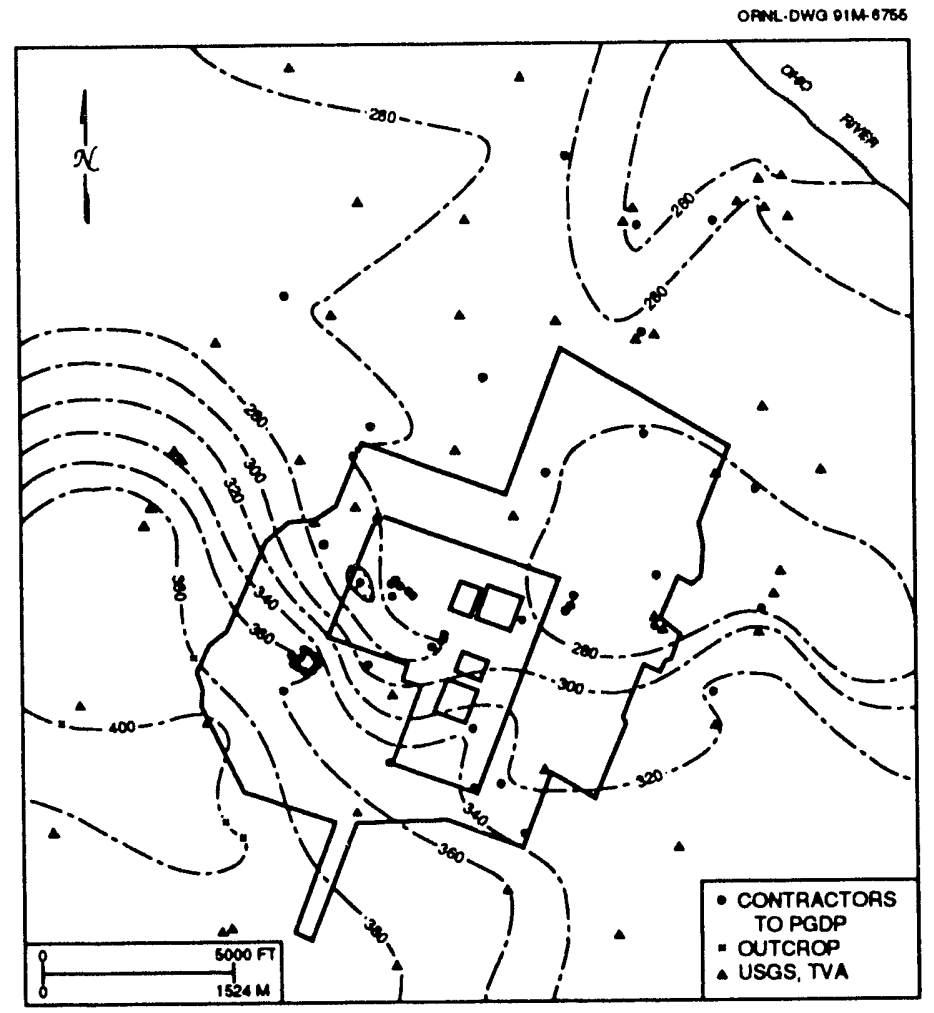

Fig. 1.4. Elevation of erosienal surface cut on sediments of Eocene, Paleocene, and late Cretaceous Age in the vicinity of PGDP (contours are in feet above MSL).

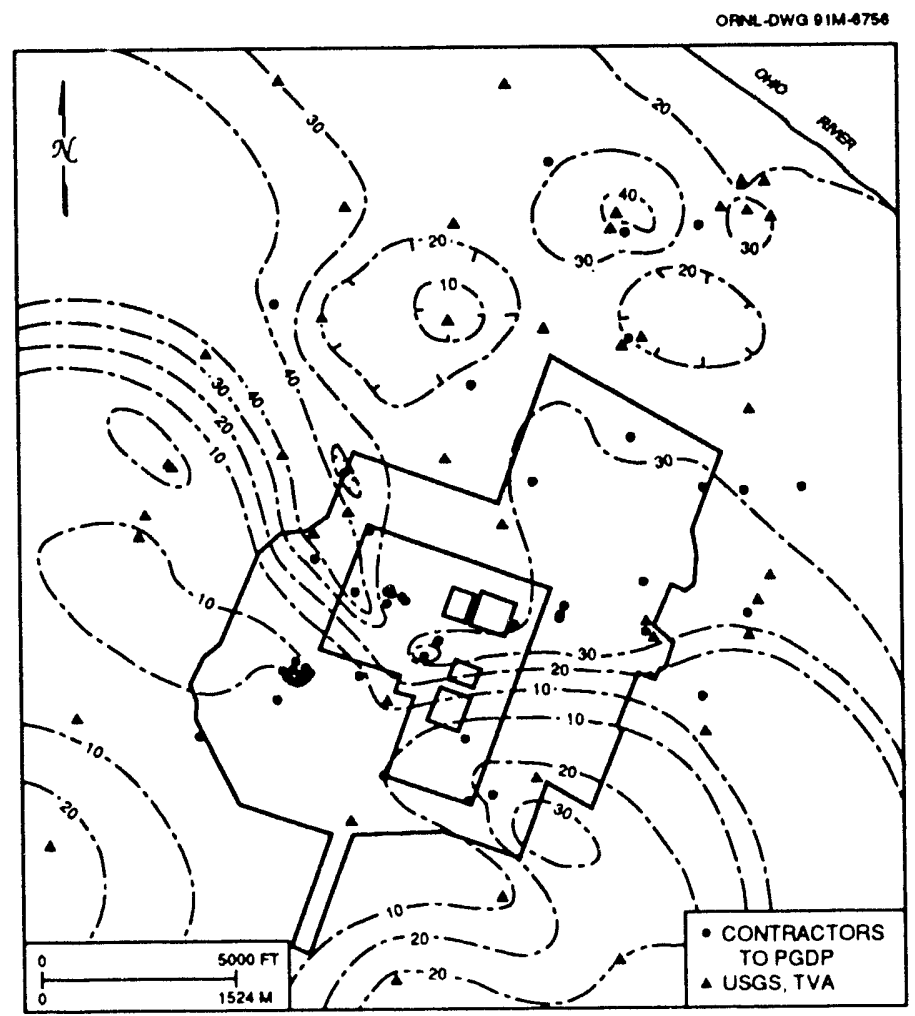

Fig. 1.5. Isopach map of the lower Continental Deposits (gravel facies) in the vicinity of PGDP (thicknesses are in feet). 


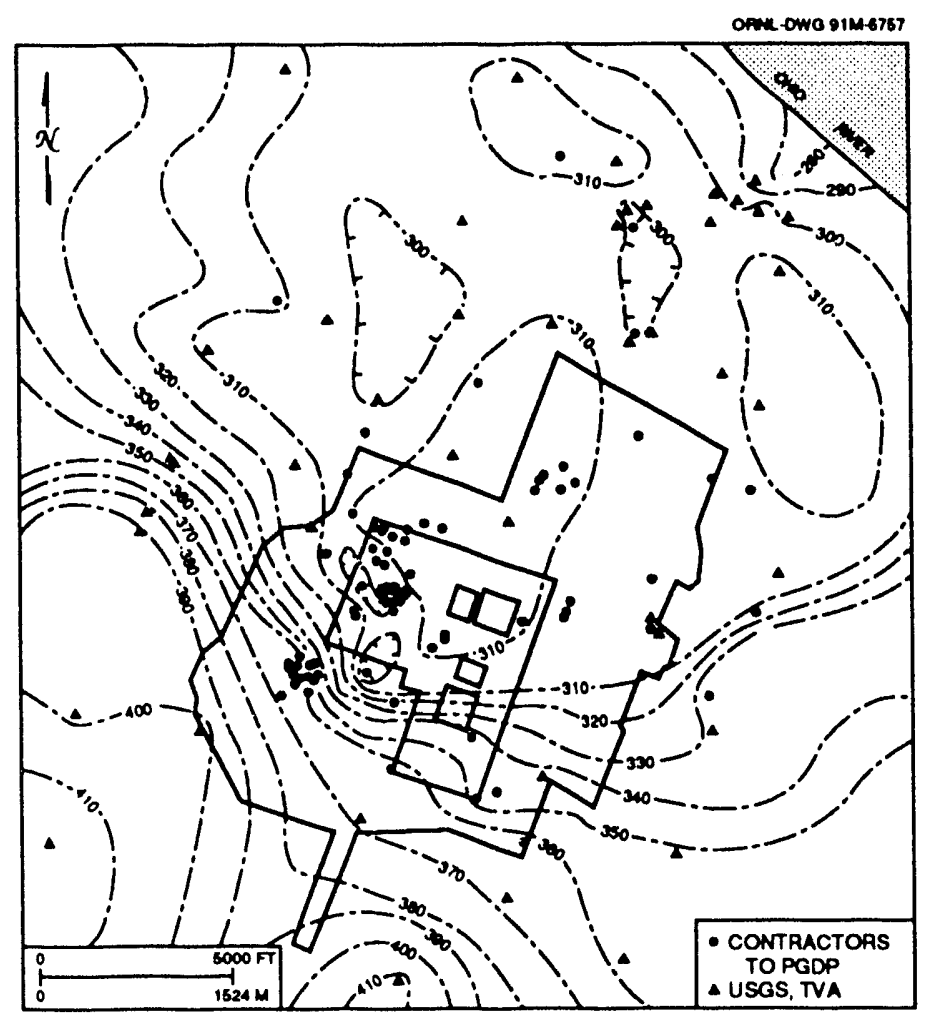

Fig. 1.6. Elevation of the top of the lower Continental Deposits (gravel facies) in the vicinity of PGDP (contours are in feet above MSL).

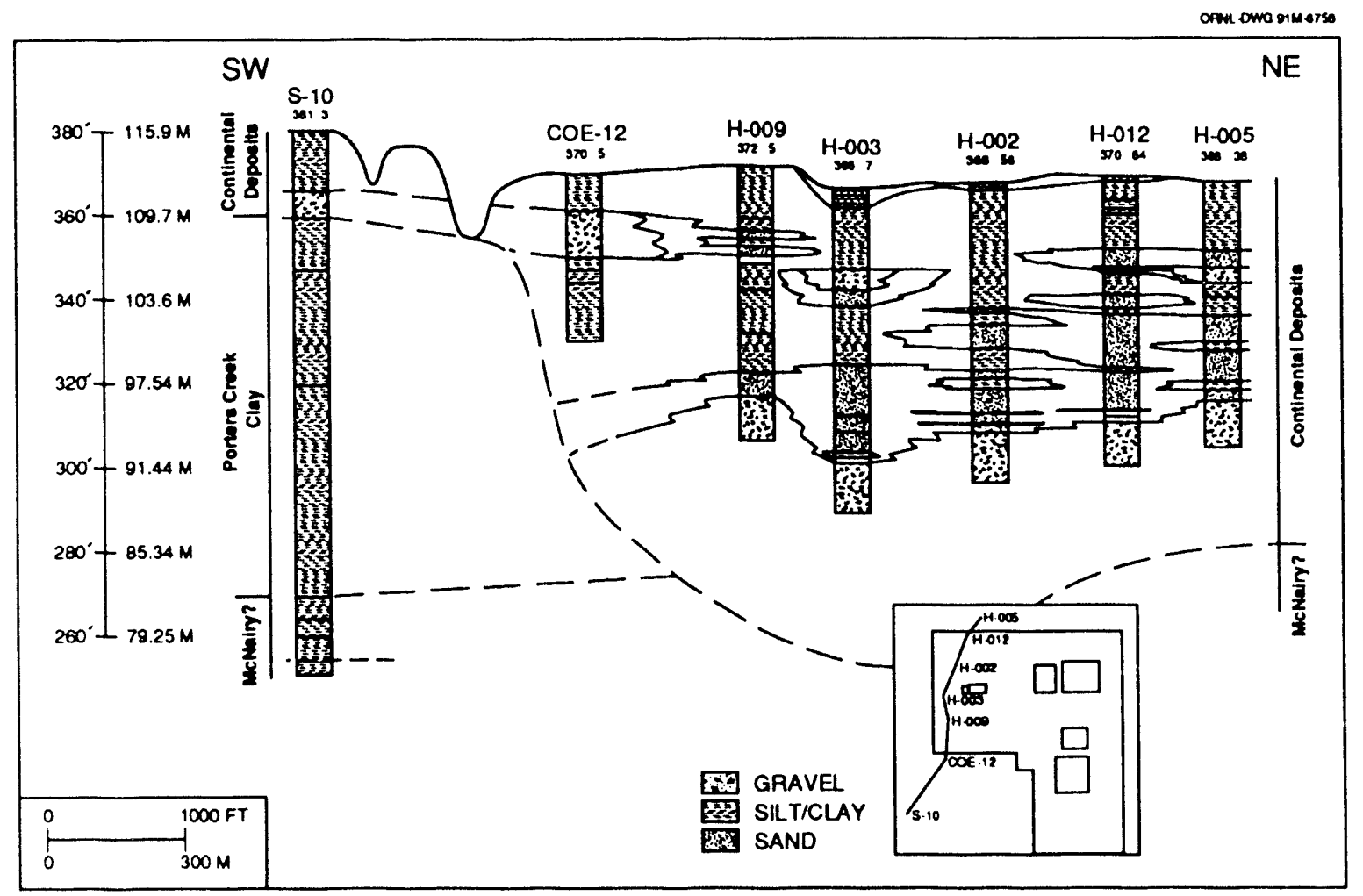

Fig. 1.7. Geologic cross section. 


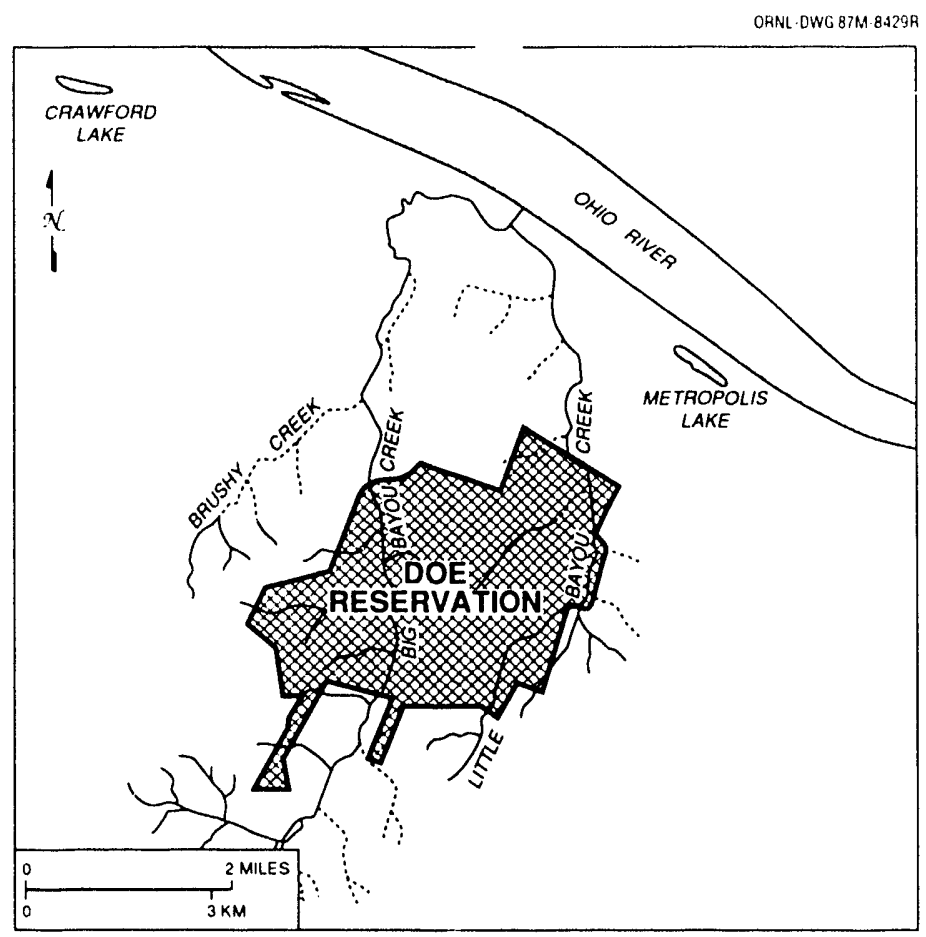

Fig. 1.8. Local PGDP surface hydrology systems.

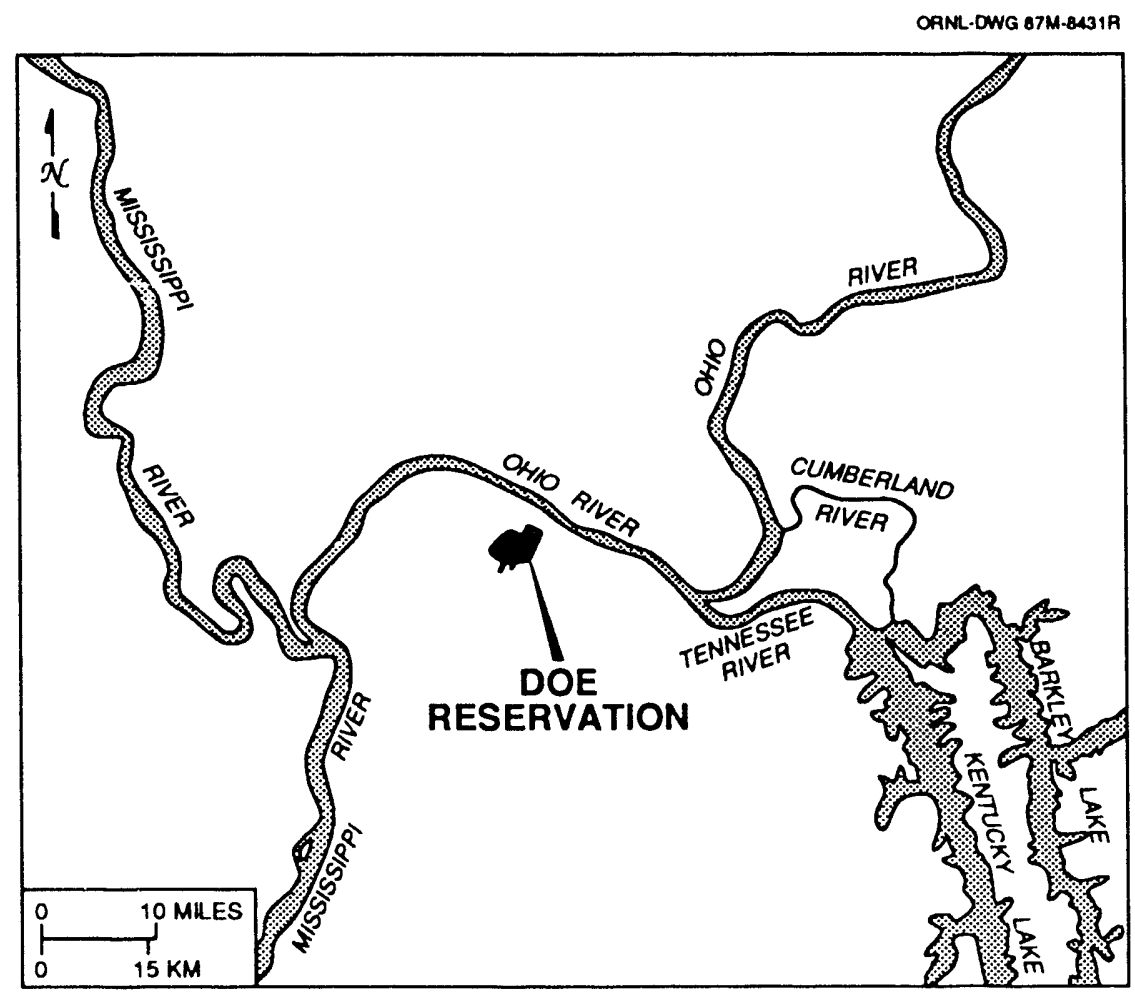

Fig. 1.9. The regional area primary surface hydrology system. 
Yields of between 189.5 and $1516 \mathrm{~L} / \mathrm{min}(50$ and $395 \mathrm{gal} / \mathrm{min}$ ) have been observed.

In general, the potentiometric surface for the RGA slopes toward the Ohio River, suggesting that groundwater flow within the aquifer trends northward toward the Ohio River. Until recently, no attempts had been made to reevaluate potentiometric conditions in the RGA since the studies by the USGS over two decades ago. Hydraulic head data gathered during 1990 (CH2M Hill 1990) from a series of PGDP and Tennessee Valley Authority (TVA) wells yielded a more refined picture of the potentiometric surface of the RGA, but they appear to substantiate earlier investigations. Systematic potentiometric data collection has recently been initiated, and subsequent analyses of this data are expected to lead to a refined model of groundwater flow in the vicinity of PGDP.

Based on measurements (both field and laboratory) and on estimations of grain size analysis, hydraulic conductivity values for the $\mathrm{RGA}$ range from $1.1 \times 10^{-4}$ to $1 \mathrm{~cm} / \mathrm{s}$. These values are presented to give a rough estimate of the magnitudes and ranges of values for the RGA. Results from an aquifer test performed in the RGA near the C-404 area in late 1989 indicated values ranging from $1.0 \times 10^{-2}$ to 4.0 $\times 10^{-2} \mathrm{~cm} / \mathrm{s}$. Slug tests performed in RGA monitoring wells by $\mathrm{CH} 2 \mathrm{M}$ Hill in 1990 resulted in values ranging from $2.1 \times 10^{-4}$ to $6.4 \times 10^{-2} \mathrm{~cm} / \mathrm{s}$. Data available from the TVA at the Shawnee Steam Plant indicate values that fall between $3.0 \times 10^{-4}$ and $1.0 \times$ $10^{-1} \mathrm{~cm} / \mathrm{s}$ or even greater values. This wide range in conductivity values suggests that the RGA is heterogeneous. Considering the depositional history of the gravel, this is to be expected.

It is possible to take available estimates of hydraulic conductivity data for the gravel aquifer and estimate possible ranges of groundwater flow velocity that might be encountered. This calculation uses Darcy's flow equation:

$$
\text { average linear velocity }=(K / n)(d h / d l) \text {, }
$$

where

$$
\begin{aligned}
K & =\text { hydraulic conductivity } \\
n & =\text { porosity } \\
d h / d l & =\text { head gradient. }
\end{aligned}
$$

Assuming that $K$ for the gravel lies within the range of $10^{-4}$ to $10^{-1} \mathrm{~cm} / \mathrm{s}$, that $n$ is -0.3 (i.e., $30 \%$ voids), and that $d h / d l$ is approximately $10^{-3}$ [i.e., $1 \mathrm{~m} / 1000 \mathrm{~m}(5.3 \mathrm{ft} / \mathrm{mile})]$, then the following results are obtained:

$$
\begin{aligned}
\text { velocity }= & <1 \mathrm{ft} / \text { year (low K) to }>300 \mathrm{ft} / \text { year } \\
& (\text { high } \mathrm{K}) .
\end{aligned}
$$

The above results agree generally with estimates provided by CH2M Hill (PGDP 1990). Earlier estimates of groundwater flow velocity within the gravel aquifer at the C-404 facility (based on hydraulic conductivity values derived from slug tests and measured head gradients) were in the range of $1.52 \mathrm{~m} /$ year (5 ft/year) (D'Appolonia 1983). Apparently, this and other low estimates of flow velocities for this region suggested that contaminant migration would be a very slow process. It is now recognized that $K$ is highly variable and site-specific flow velocity estimates must be interpreted cautiously. In addition, head gradients have been observed to vary considerably during the year. The possibility that groundwater velocities as high as 90 $\mathrm{m} /$ year ( $300 \mathrm{ft} / \mathrm{year}$ ) might be possible illustrates the importance of detailed site characterization work.

In contrast to the large production capability of the gravel aquifer, sand lenses interbedded in the clay facies of the Continental Deposits are observed to have extremely low yields. In 1990, CH2M Hill performed slug tests on several monitoring wells completed in the upper Continental Deposits and obtained hydraulic conductivity values ranging from approximately $2.0 \times 10^{-7}$ to $5.0 \times 10^{-3} \mathrm{~cm} / \mathrm{s}$. Furthermore, earlier investigations at PGDP indicated that sand and gravel lenses within the upper Continental Deposits are fairly discontinuous. Ambiguities in observed hydraulic head data support interpretations that these lenses may not constitute a continuous aquifer.

Several activities were undertaken in 1990 to address geologic and hydrogeologic uncertainties. High-resolution seismic data have been collected, and their interpretation should provide additional subsurface information to resolve further the configuration of the RGA. Also, GeoTrans, Inc., has developed a numerical computer model. This three-dimensional groundwater flow model was designed to provide a quantitative integration of all available hydrogeologic data, evaluate hydrogeologic controls on groundwater flow beneath the site, and identify data inadequacies or areas of uncertainty. 
Groundwater is used for drinking water and other domestic uses, irrigation of gardens, and watering livestock. No industrial groundwater users exist north of PGDP. About 15 private residences north of the plant use groundwater.

\subsection{REGIONAL DEMOGRAPHY}

The WKWMA and lightly populated farmland are in the immediate environs of PGDP. The population within the $80-\mathrm{km}(50-$ mile) radius (see Fig. 1.10$)$ is about 535,000 persons. Of these, about 36,500 live within $16.1 \mathrm{~km}$ ( 10 miles) of the plant; about 104,000 live within $32.2 \mathrm{~km}$ (20 miles). The unincorporated communities of Grahamviile and Heath are located 2 to $3 \mathrm{~km}$ (1.24 to 1.86 miles) east of the plant. Portions of 28 counties, 11 of which are in Kentucky, 4 in Missouri, 10 in Illinois, and 3 in Tennessee, are included within an $80-\mathrm{km}(50-\mathrm{mile})$ radius of the plant. The largest cities in the region are Paducah, Kentucky, located approximately 16 air km (10 miles) east of the plant, and Cape Girardeau, Missouri, located approximately 64 air $\mathrm{km}$ (40 miles) to the west.

\subsection{CLIMATE}

Paducah is located in the humid continental zone. Summers are generally dry; precipitation occurs mainly in the spring and fall. Winters are characterized by moderately cold days; the average temperature during the coldest month, January, averages about $1.7^{\circ} \mathrm{C}\left(35^{\circ} \mathrm{F}\right)$. Summers are warm and humid; the average temperature in July is about $26^{\circ} \mathrm{C}$ $\left(79^{\circ} \mathrm{F}\right)$. Yearly precipitation averages about $112 \mathrm{~cm}$ (44 in.). The prevailing wind direction is south to southwest.

\subsection{APPLICABLE ENVIRONMENTAL REQUIREMENTS}

It is PGDP policy to minimize or eliminate waste generation and to protect people and the environment. Internal procedures have been established and implemented to accomplish these tasks. Under the authority of the Atomic Energy Act, DOE has issued a multitude of orders covering waste minimization, pollution control, effluent and environmental monitoring, and periodic reporting. Federal
Environmental Protection Agency (EPA) regulations that are designed to implement various federal laws and that apply to PGDP include the Clean Air Act (CAA), the Clean Water Act (CWA), the Toxic Substances Control Act (TSCA), the National Emissions Standards for Hazardous Air Pollutants (NESHAP), the Resource Conservation and Recovery Act (RCRA), the Safe Drinking Water Act (SDWA), the Superfund Amendments and Reauthorization Act (SARA), the National Environmental Policy Act (NEPA), and the Comprehensive Environmental Response, Compensation, and Liability Act (CERCLA). Kentucky environmental laws are implemented by regulations of the Cabinet for Natural Resources and Environmental Protection. PGDP air pollution sources; wastewater discharges; hazardous waste treatment, storage, and disposal; and waste management facilities are all permitted by the Natural Resources and Environmental Protection Cabinet.

\subsection{ENVIRONMENTAL PROGRAM INFORMATION}

During May 1990, PGDP performed a self assessment of environmental program activities that identified specific findings and corrective actions. The action plans developed for each of the findings have been prioritized and are now being implemented.

The major finding was that environmental programs lack formality and control. This finding has required PGDP to provide additional emphasis in its training and procedures programs. PGDP's environmental program development also has been hindered by a lack of technical expertise. This issue is being resolved by recruiting and hiring of experienced environmental professionals in the expanding Environmental Compliance Department.

In 1990, the Environmental Management Division was directed to provide environmental training on several issues. In May 1990, an overview of Hazardous Waste Regulations and Contingency Plan and Spill Reporting procedures was given to employees involved in elements of the RCRA Part B application implementation. In June and July 1990 , PGDP hosted a DOE Tiger Team Assessment. This effort was sponsored by DOE to provide an independent oversight of PGDP's management of environmental, safety, health, and management 
programs. The scope of this effort included the following:

- Address PGDP status with federal, Kentucky, and local environmental regulations.

- Consider impacts on all environmental media.

- Identify noteworthy practices that warrant communication throughout the DOE system.

- Assess potential root causes of any noted environmental weaknesses to aid in developing corrective actions.

- Provide PGDP with information to improve environmental programs and compliance status.

Sixty-three compliance and best management practice findings were identified during the assessment. Four noteworthy practices were also identified. None of the findings identified were serious enough to discontinue operation of any facility. Action plans have been developed and are being implemented to resolve the tindings. In November 1990, all PGDP supervisors received a four-hour environmental checklist training course that required each supervisor to "walk-your-space" and identify potential environmental problems. In December 1990, PGDP supervisors received 8 hours of environmental laws and regulations training that included an overview of RCRA, CERCLA, CWA, SDWA, CAA, TSCA, and NEPA.

The Pollution Prevention Awareness Program (PPAP) Committee was formed in CY 1990 to comply with DOE Order 5400.1, "General Environmental Protection Program" and other regulations (i.e., EPA, KDEP, and Energy Systems policies). This group is responsible for managing the program and increasing pollution awareness throughout PGDP. The scope of the PPAP includes education and public relations activities associated with pollution prevention. Its objectives will be accomplished by environmental pollution recognition and prevention, training, special awareness campaigns, and awards and incentives programs. The committee will meet quarterly to evaluate the effectiveness of the PPAP and provide ideas for improvement.

During the year, the committee has developed waste minimization suggestion forms, issued pollution prevention bulletins, and contacted EPA for waste reduction information. These programs have been implemented by the Waste Minimization Program Manager.

The PGDP Waste Minimization Program is a continual review and evaluation of production, production support, operation, maintenance, and administrative activities that generate waste. This review process has led to several modifications in activities performed at PGDP, including substituting nonhazardous products for hazardous ones, modifying operations, and performing feasibility studies in areas to reduce generation of hazardous waste.

Feasibility studies were performed in CY 1990 on reducing paint waste, recovering solvents for recycling, eliminating chlorinated solvents, recycling spent lead from bullets used at the target range, and monitoring chemical and regulated substances inventory. A statement on the progress of the waste minimization program was included in the Annual Hazardous Waste Report submitted to the Kentucky Division of Waste Management. 


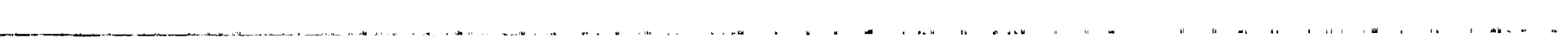




\section{AIRBORNE DISCHARGES, AMBIENT AIR MONITORING, METEOROLOGICAL MONITORING, AND EXTERNAL GAMMA RADIATION}

Environmental monitoring is an integral part of the PGDP air pollution control program. The federal Clean Air Act (CAA), Kentucky Division for Air Quality (KDAQ) regulations, and DOE orders require the identification of potential and actual sources of air pollution, controls to abate pollution to within specified limits, and measurements to demonstrate the results. The identification, controls, and emission or throughput limits are included in the regulatory agency's permit. PGDP has 27 sources listed on the operating permit; however, not all sources were operated in 1990. Table 2.1 lists the permitted sources and the types of control equipment used for air pollution prevention.

PGDP maintains an ongoing program to identify and evaluate air contaminant emission sources not listed on the operating permit. When the emission sources are evaluated and air contaminant emissions are determined, application addendums are forwarded to KDAQ for evaluation of permit applicability. (PGDP has not received an updated operating permit since January 1986 due to lack of resources and manpower at KDAQ. Even so, PGDP continues to submit applicatiun addendums to KDAQ to ensure compliance with KDAQ regulations.) This effort was initiated in April 1987 with the submission of an application to add five sources to the existing operating permit. After promulgation of the KDAQ Air Toxics Regulations in November 1986, PGDP submitted an additional comprehensive Air Toxics Review application to KDAQ in May 1988. This application increased the number of emission points that have been evaluated by PGDP to 70 , and each evaluation has indicated compliance with the Air Toxics Regulations in terms of emission limits and ambient air impact. Extensive corporate and DOE audits and surveys by frontline supervisors have identified additional sources that have been evaluated and submitted to KDAQ for permit evaluation.

Although a number of the sources are not operating or no longer exist, PGDP has identified 104 potential air contaminant sources for evaluation of permit

Table 2.1. 1990 PGDP stack emissions summary

\begin{tabular}{|c|c|c|c|c|}
\hline \multirow{2}{*}{ Stack ${ }^{a}$} & \multirow{2}{*}{ Control equipment } & \multicolumn{3}{|c|}{ Emission } \\
\hline & & Effluent & $\mathrm{kg} /$ year & Curies $^{b}$ \\
\hline $\begin{array}{l}\text { C-310 } \\
\text { cascade vent }\end{array}$ & Chemical traps & $\begin{array}{l}{ }^{234} \mathrm{U} \\
{ }^{235} \mathrm{U} \\
{ }^{238} \mathrm{U} \\
{ }^{99} \mathrm{Tc}\end{array}$ & $\begin{array}{l}3.6 \times 10^{-6} \\
4.8 \times 10^{-4} \\
3.1 \times 10^{-2} \\
2.3 \times 10^{-5}\end{array}$ & $\begin{array}{l}2.22 \times 10^{-5} \\
1.03 \times 10^{-6} \\
1.05 \times 10^{-5} \\
3.9 \times 10^{-4}\end{array}$ \\
\hline $\begin{array}{l}\text { C- } 600 \\
\text { steam plant }\end{array}$ & $\begin{array}{l}\text { Use of low-sulfur coal, } \\
\text { control of excess air, } \\
\text { electrostatic } \\
\text { precipitators }\end{array}$ & $\begin{array}{l}\mathrm{SO}_{2} \\
\mathrm{NO}_{x} \\
\text { Particulates } \\
\mathrm{CO}\end{array}$ & $\begin{array}{l}276,380 \\
278,613 \\
11,284 \\
9,091\end{array}$ & \\
\hline
\end{tabular}

${ }^{a}$ See Fig. 2.1.

${ }^{b}$ Based on a product assay of $1.5 \%{ }^{235} \mathrm{U}$. 
applicability, and expects to increase that number in CY 1991. Not all of the potential emission points require permitting, and information documenting this is forwarded to KDAQ. The primary goal of the air compliance program is to identify each air contaminant emission point at PGDP, quantify the emissions from the source, document compliance with the applicable regulation, and submit this information to KDAQ for permit evaluation.

PGDP submitted one construction permit application to KDAQ in 1990, which was for upgrading the C-637-2B cooling tower. The KDAQ Permit Review Branch subsequently determined that the work to be performed on the C-637-2B tower and the work performed on other towers did not require construction permits.

PGDP was issued a construction permit on January 23,1990 , to install a cartridge filter on the C-726 blasting farility to control particulate emissions. A successful compliance demonstration was performed for KDAQ in March 1991. PGDP will submit an addendum to the pending operating application to include the blasting facility and the new cartridge filter in the operating permit.

The release of contamination into the atmosphert is minimized by avoiding any unnecessary waste generation and by applying effective control technology to meet (1) all permit conditions and (2) the DOE requirement to maintain radionuclide emissions as low as reasonably achievable (ALARA). This control program to reduce emissions is evaluated continually. Table 2.4 of Part 2 compares selected actual emissions with linits or standards set by regulations or permits. The primary basis for evaluating the control achieved is by emissions sampling and ambient air monitoring. Performance of control devices also may be checked by state or federal inspections. The data generated by stack emissions sampling were used to calculate radiation doses to the nearest neighbors and the surrounding population (see Sect. 7).

\subsection{AIRBORNE DISCHARGES}

The CAA of 1977 requires EPA to administer through the states a program that requires air contaminant sources to obtain permits to construct and operate. After receiving and reviewing an application for a plant-wide operating permit, KDAQ issued permit No. 0-85-110 to PGDP on
September 30,1985 , granting operation of an air contaminant source. The permit lists 27 emission points and has no expiration date. Not all of the emission points were active in 1990; the major sources in operation (see Fig. 2.1) were

- two coal- and oil-fired boilers and one gas- and oil-fired boiler in the C-600 steam plant,

- the cascade purge vent stack at C-310, and

- two vapor degreasers in C-400.

Other air emissions reported include those resulting from asbestos removal, boiler startup and shutdown, fire-training exercises, chemical spills, process leaks, or emissions above normal levels.

The pollution parameters that must be quantified to demonstrate compliance with permits or the DOE ALARA policy are particulates, opacity, sulfur dioxide, volatile organic compounds (VOCs), radionuclides, and fluorides. Certain processes also are regulated by throughput limits and usage rates. The 1990 cumulative radiological emissions and steam plant emissions are tabulated by source in Table 2.1. The C-600 steam plant emissions routinely reported are sulfur dioxide $\left(\mathrm{SO}_{2}\right)$, nitrogen oxides $\left(\mathrm{NO}_{\mathrm{x}}\right)$, particulates, carbon monoxide (CO), non-methane VOCs, and methane. The $\mathrm{SO}_{2}$ is continuously monitored in the stack in terms of pounds of $\mathrm{SO}_{2}$ per million $\mathrm{BTU}$ input to the boiler. Data from the continuous $\mathrm{SO}_{2}$ monitor and fuel usage data are combined to determine monthly and annual emissions. Emissions other than $\mathrm{SO}_{2}$ are calculated from fuel usage using emission factors from EPA guidance document AP-42. The excess combustion air averages about $20 \%$ and is minimized to control $\mathrm{NO}_{x}$ in the flue gases and to optimize boiler efficiency. Monitoring is not required for total suspended particulates. The KDAQ permit limit of $20 \%$ opacity is achieved by use of electrostatic precipitators (ESPs) operating at $99 \%$ efficiency for particulate removal. Performance tests and emission factor calculations have shown emission levels of less than $0.1 \mathrm{lb}$ of total suspended particulates per million BTU boiler input. A PGDP procedure requires monthly visible emission evaluations of boiler stack effluent by EPA method 9 for documentation of the $20 \%$ opacity limit.

The ESPs provide minimal stack particulate emissions while the boilers are operating, but visible 


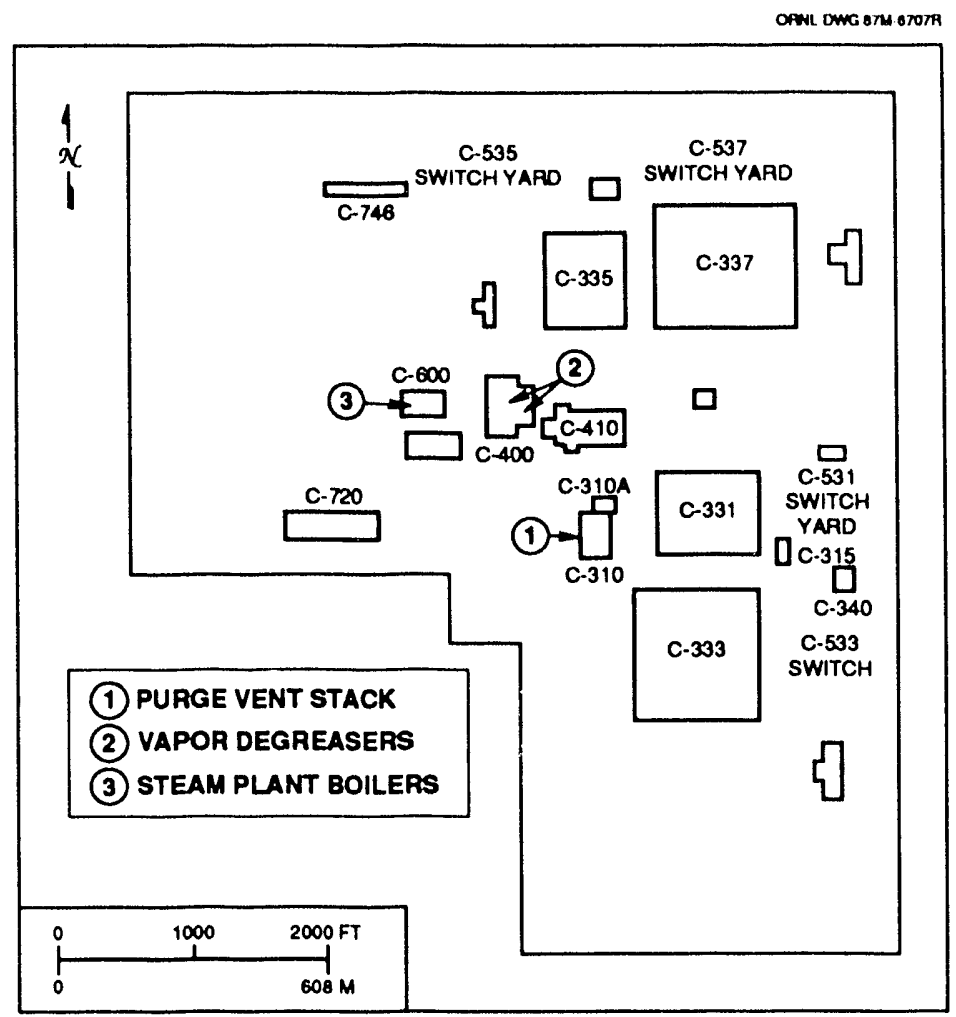

Fig. 2.1. Location of major air emissions sources at PGDP.

emissions occur during malfunctions, startups, shutdowns, and some maintenance activities. These periods are brief and infrequent and are reported to KDAQ prior to the activities if possible. Table 2.1 shows the total steam plant emissions. Tables 2.2 and 2.3 of Part 2 present monthly emissions and historical data.

The C-310 stack is used as the vent for the cascade system. Low-molecular-weight gases travel up the cascade to be released via the C-310 stack. Gaseous fluorides and traces of uranium and technetium are released in small quantities. High-speed centrifugal separation and chemical traps are used to control stack emissions. The stack gases are continuously sampled, and samples are analyzed daily. Tables 2.2 and 2.3 of Part 2 lists monthly and annual emission rates.

Stack-sampling trend analysis performed on the C-310 stack indicates a dramatic decrease in uranium emissions since 1983. In 1983 the average monthly uranium emission was 336 grams. Discounting anomalous averages due to system upsets, this monthly average decreased each year to an average monthly emission of 2.6 grams in 1990 . This monthly emission rate is slightly higher than in the previous two years (discounting above average emissions due to system upsets) due to the development of a statistical lower limit of detection. Prior to September 1990 , daily uranium emissions could be reported as low as $<0.01 \mathrm{gram}$. The results of a statistical study in September 1990 indicated that the lower limit of detection for daily uranium emissions was 0.07 grams. The development of this new lower limit of detection raised the minimum monthly emission rate from 0.3 grams to 2.1 grams. It should be stressed that this is not an actual increase in emissions; it is merely the establishment of a level of confidence that is higher than that previously used.

PGDP operates two vapor degreasers in the $\mathrm{C}-400$ cleaning building. One of the degreasers is large enough $[1.5 \times 6.9 \times 5.4 \mathrm{~m}(5 \times 23 \times 18 \mathrm{ft})]$ to accommodate the largest components of gaseous diffusion process equipment. This degreaser uses trichloroethylene (TCE) as a cleansing agent. The TCE is contained in troughs at the north and south ends of the degreaser. The troughs also contain steam coils that vaporize the TCE. The TCE vapor then migrates to the center of the degreaser (between the 
troughs) where the equipment to be cleaned is situated. Condensing coils are located near the top of the degreaser to condense and to recycle the vaporized TCE after it has been used to degrease the equipment.

The smaller degreaser $[1.5 \times 1.8 \times 1.5 \mathrm{~m}(5 \times$ $6 \times 5 \mathrm{ft}$ )] uses 1,1,1-trichloroethane as the degreasing agent. Steam coils that vaporize the 1,1,1-trichlorethane are located in the bottom of the degreaser. Cundensing coils are used to condense and to recycle the vaporized $1,1,1$-trichloroethane after use.

Both degreasers have movable covers that minimize the degreasing agent losses except during equipment insertion or removal. However, losses of the degreasing agents are inevitable because of the large area exposed and the high volatility of the agents. These losses are calculated and reported as plant emissions. The Air Toxics Operating Application (submitted to KDAQ in 1988) assumed that $90 \% \mathrm{c} f$ the agents are lost to the atmosphere, and the rest are contained in the degreaser sludge. A project is in process to identify a less volatile alternative for TCE and 1,1,1-trichloroethane. A less volatile aqueous degreaser is being tested at various locations in the plant as an alternative.

In November 1986, KDAQ promulgated two Air Toxics Regulations. These regulations established emission limits for specific substances considered toxic. The first regulation applies to facilities constructed before November 11, 1986, and lists 92 regulated substances. The second regulation applies to facilities constructed after November 11, 1986, and lists more than 730 regulated substances. In conjunction with an environmental subcontractor, PGDP submitted an Operating Permit Application with Air Toxics Review to KDAQ on April 27, 1988. This application contained calculations stating that PGDP's toxic emissions are either (1) below the Significant Emission Level and thus exempt from the regulations or (2) below the Threshold Ambient Limit as shown by computer modeling and in compliance with the regulations. The KDAQ Permit Review Branch has this application for review; however, it is far behind in reviewing operating permit applications because of a backlog. PGDP pianis to develop a formal tracking system to ensure compliance with the Air Toxics regulations.

\subsection{AMBIENT AIR}

PGDP maintains and operates an ambient air system to assess the impact on the ambient air of various air contaminates emitted by PGDP. The results of the data generated by the ambient air system are also used to demonstrate compliance with the ambient air quality standards for gaseous fluorides established by KDAQ.

Ambient air is sampled continuously for gaseous fluorides and radioactive particulates at the following locations:

- Plant North (PN), Plant South (PS), Plant East (PE), and Plant West (PW) within the plant fence;

- Boundary North (BN) and Boundary East (BE) at the plant boundary;

- One North (1N), One South (1S), One West (1W), One East (1E), and One Southeast (1SE) at 1 mile from the fence; and

- Grahamville (GR), the nearest community.

Figure 2.2 shows these locations. The sample collectors (consisting of filters treated with sodium carbonate for ambient collection of fluorides) are exchanged and analyzed each week for alpha and beta activity and fluoride concentrations. To ensure data accuracy, samples are discarded without analysis if final sample flow decreases more than $40 \%$ from the initial flow rate, if the sampler is found not to be running, or if, upon opening the filter holder, the analyst finds the filter cracked (Coker 1988).

After the sample filters have been collected from the ambient-air-monitoring stations, they are stored at least $168 \mathrm{~h}$ to permit decay of the short-lived daughters of naturally occurring radon. They then are analyzed for alpha and beta activity by an automatic low-background alpha/beta proportional counter (PGDP 1990). After the radioactivity measurements have been made, the filters are leached with water, and fluoride content is measured by specific ion electrode analysis (PGDP 1979). The results of the analyses are logged onto a computer data base and used to demonstrate compliance with KDAQ gaseous fluoride ambient air quality standards. In response to the Ambient Environmental Monitoring Assessment performed by CH2M Hill in 1988, PGDP has proposed some improvements in the ambient-air-monitoring program. An 


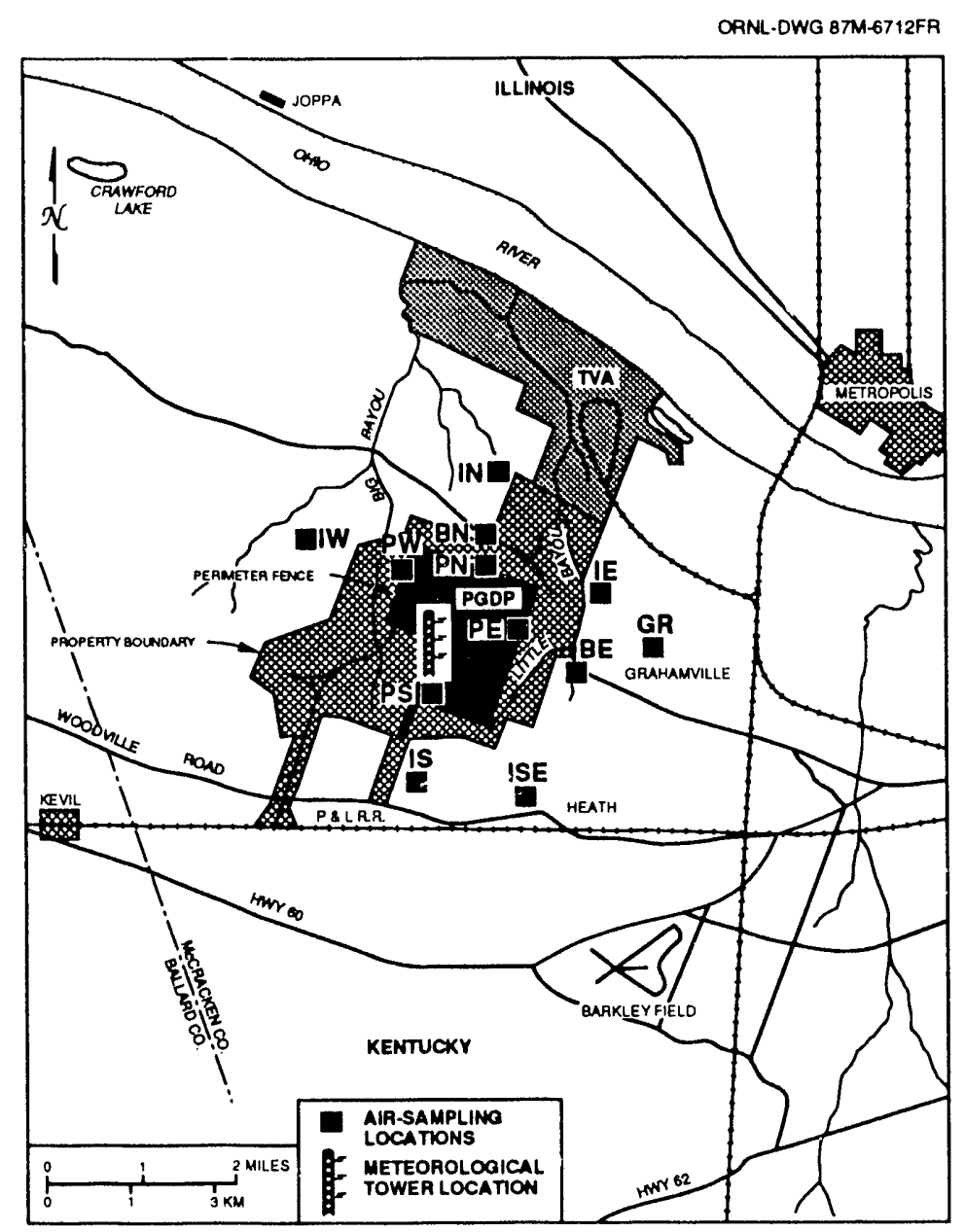

Fig. 2.2. Location of air-sampling and meteorological monitoring stations at PGDP.

ambient-air-monitoring plan is being developed to implement these improvements to the monitoring system. Tables 2.2 and 2.3 provide a summary of 1990 ambient air measurements. All fluoride samples were well below the Kentucky ambient air standards for fluorides. The highest annual average for fluorides was $0.159 \mathrm{ppb}$ at the plant north (PN) site. This concentration was well below the annual arithmetic mean standard of $500 \mathrm{ppb}$ for fluorides. The maximum weekly concentration of fluorides of $0.333 \mathrm{ppb}$ at the Plant North location was only $17 \%$ of the Kentucky secondary fluoride maximum weekly standard of $2 \mathrm{ppb}$.

\subsection{METEOROLOGICAL MONITORING}

Representative meteorological data are required at DOE facilities by DOE Order 5400.1 to support environmental-monitoring activities. This information is essential to characterize atmospheric transport and diffusion conditions in the vicinity of PGDP and to represent other meteorological conditions (e.g., precipitation, temperature, and atmospheric moisture) that are important to environmental surveillance activities such as air quality and radiation monitoring.

At PGDP on-site meteorological data are used in calculating radiation doses to the public (see Sect. 7). In addition, on-site meteorological data are used by various groups within the plant, for example, by Environmental Restoration to correlate precipitation with groundwater flow and by Power Operations to investigate electrical equipment failures.

A $60-\mathrm{m}$ tower located south of the Administration Building (C-100) contains instrumentation at 10- and 60-m (32.8- and 196.9-ft) heights. Appropriate meteorological parameters such as wind speed and direction, temperature, barometric 
Table 2.2. 1990 PGDP environmental air sampling for fluorides

\begin{tabular}{|c|c|c|c|c|}
\hline \multirow{2}{*}{ Point $^{a}$} & \multirow{2}{*}{$\begin{array}{c}\text { No. of } \\
\text { samples }\end{array}$} & \multicolumn{3}{|c|}{ Concentration (ppb) } \\
\hline & & Min & $\operatorname{Max}^{b}$ & $A v^{c}$ \\
\hline $1(\mathrm{PN})$ & 51 & 0.061 & 0.333 & 0.159 \\
\hline 2 (PE) & 49 & 0.056 & 0.199 & 0.107 \\
\hline 3 (PS) & 49 & 0.037 & 0.149 & 0.085 \\
\hline 4 (PW) & 49 & 0.060 & 0.248 & 0.098 \\
\hline $5(\mathrm{BN})$ & 49 & 0.057 & 0.224 & 0.107 \\
\hline $6(\mathrm{BE})$ & 49 & 0.056 & 0.106 & 0.073 \\
\hline $7(\mathrm{IN})$ & 51 & 0.059 & 0.143 & 0.079 \\
\hline 8 (IE) & 49 & 0.055 & 0.121 & 0.074 \\
\hline 9 (ISE) & 49 & 0.055 & 0.103 & 0.070 \\
\hline 10 (IS) & 50 & 0.049 & 0.134 & 0.068 \\
\hline 11 (niv) & 49 & 0.052 & 0.133 & 0.067 \\
\hline 12 (GR) & 51 & 0.057 & 0.135 & 0.074 \\
\hline
\end{tabular}

${ }^{a}$ See Fig. 2.2.

${ }^{b}$ Kentucky Secondary Air Quality Standard (401 KAR. 53:010) for maximum 1-week average is $2.0 \mathrm{ppb}$ as HF.

'Kentucky Primary Air Quality Standard (401 KAR 53:010) for annual arithmetic mean is $500 \mathrm{ppm}$.

Table 2.3. 1990 PGDP environmental air sampling for radioactivity

\begin{tabular}{|c|c|c|c|c|c|c|c|}
\hline \multirow[t]{2}{*}{ Point $^{a}$} & \multicolumn{3}{|c|}{$\begin{array}{c}\text { Gross alpha } \\
\left(\mu \mathrm{Ci} / \mathrm{mL} \times 10^{-14}\right)\end{array}$} & \multicolumn{3}{|c|}{$\begin{array}{c}\text { Gross beta } \\
\left(\mu \mathrm{Ci} / \mathrm{mL} \times 10^{-13}\right)\end{array}$} & \multirow{2}{*}{$\begin{array}{l}\text { No. of } \\
\text { samples }\end{array}$} \\
\hline & Min & Max & Av & Min & Max & Av & \\
\hline$!(\mathrm{FN})$ & 0.00 & 1.34 & 0.39 & 0.00 & 0.78 & 0.33 & 51 \\
\hline 2 (PE) & $-\hat{u} .10^{b}$ & 1.62 & 0.30 & 0.09 & 0.92 & 0.32 & 49 \\
\hline 3 (PS) & 0.00 & 1.36 & 0.27 & 0.00 & 0.53 & 0.31 & 49 \\
\hline 4 (PW) & $-0.3 \prime$ & 0.96 & 0.28 & 0.00 & 0.96 & 0.31 & 49 \\
\hline $5(\mathrm{BN})$ & -0.11 & 0.74 & 0.26 & 0.10 & 0.60 & 0.31 & 49 \\
\hline $6(\mathrm{BE})$ & -0.09 & 0.19 & 0.30 & 0.10 & 0.77 & 0.31 & 49 \\
\hline $7(\mathrm{IN})$ & -0.22 & 0.98 & 0.32 & 0.11 & 0.87 & 0.31 & 51 \\
\hline 8 (IE) & 0.00 & 0.91 & 0.26 & 0.10 & 0.82 & 0.33 & 49 \\
\hline 9 (ISE) & -0.11 & 1.96 & 0.33 & 0.05 & 1.01 & 0.31 & 49 \\
\hline 10 (IS) & -0.12 & 1.38 & 0.32 & 0.00 & 0.59 & 0.29 & 50 \\
\hline 11 (16' & -0.21 & 0.97 & 0.30 & 0.10 & 0.76 & 0.30 & 49 \\
\hline 12 (GR) & -0.10 & 1.19 & 0.25 & 0.10 & 1.00 & 0.32 & 51 \\
\hline
\end{tabular}

${ }^{a}$ See Fig. 2.2.

${ }^{b}$ Because of fluctuation in the instrument used to analyz: for radioactivity, the background count is higher than that for the sample; this accounts for the negative counts. 
pressure, relative humidity, and rainfall, are monitored to provide valuable data on atmospheric stability and other data essential to reliable atmospheric dispersion modeling.

Computer-aided atmospheric dispersion modeling is a valuable tool that uses emission and meteorological data. Modeling is used to determine the impacts of operations with regard to the transport of air contaminants and to predict air quality impacts from a source due to abnormal airborne emissions. In addition, PGDP can postulate a multitude of emergency scenarios and estimate effects of unplanned releases on employees and population centers downwind of the source. PGDP uses the Hazardous Atmospheric Release Model Meteorological Computer Program. This is an atmospheric dispersion model that uses emission and meteorological data to simulate unplanned releases or events causing environmental concern.

\subsection{EXTERNAL GAMMA RADIATION MONITORING}

One of th notential pathways of exposure for population groups living within the vicinity of DOE facilities is exposure to external radiation. Dose rates from penetrating radiation (gamma rays) were measured at a number of locations in the PGDP environs during 1990. Long-term measurements were made using thermoluminescent dosimeters (TLDs). Instantaneous dose rates were also measured with hand-held meters during radiation surveys conducted at numerous locations on and around the PGDP Site.

\subsubsection{Thermoluminescent Dosimeter Sampling Program}

During 1990, TLDs were placed in the environment to obtain data on external gamma radiation. These TLDs react to gamma and neutron radiation and, to some extent, to cosmic radiation. Fifteen monitoring dosimeters were in use during three quarters of 1990. Measurements for the first quarter of 1990 were not available due to a change made in the sampling program. Figure 2.3 provides the locations of the monitoring dosimeters. Ten quality control TLDs were in use during each quarter; Fig. 2.4 shows their locations.

The external gamma radiation program is conducted using guidance from ANSI Standard
N545-1975. The TLDs are identified, annealed, calibrated, packaged, and shipped by Oak Ridge National Laboratory (ORNL). When they arrive at PGDP, they are promptly positioned in the PGDP

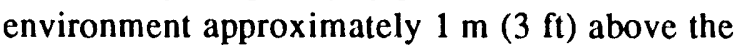
ground. The TLD packages are placed in four types of locations: along the plant perimeter fence, at the reservation boundary, at nearby residences or communities, and at two background locations more distant from the site. After the quarterly exposure period, the TLDs are collected and returned to ORNL for exposure determination.

Although the TLD exposures were measured in microroentgens per hour $(\mu \mathrm{R} / \mathrm{h})$, measured doses are also reported in dose equivalent units (mrem) to allow comparison with dose standards and dose equivalents reported elsewhere in this document. To convert to $\mathrm{mrem} /$ year, some exposure period must be assumed. To allov: for comparison, continuous exposure has been assumed at all locations. In reality, exposure will vary depending on public access to that location. Table 2.4 shows the average exposure rates for each TLD location. Table 2.5 lists quality control data for the TLDs. The mean exposure rate for indicator locations as measured by the TLDs (excluding perimeter fence data) is approximately $7.49 \mu \mathrm{R} / \mathrm{h}$. When that rate is compared with the mean background exposure rates, there is no significant difference at the $95 \%$ confidence level. Assuming continuous exposure at this level, the external whole-body dose would be approximately 67 $\mathrm{mrem} /$ year. This corresponds to the average external whole-body dose estimated to be received by people throughout Kentucky and Tennessee, which is between 60 and $70 \mathrm{mrem} /$ year (Klement 1972). Dose rates at the plant perimeter were somewhat higher than the background rates. The higher exposure rates at locations near the perimeter fence were attributed to direct radiation from the uranium cylinder storage and handling areas. Although the rates are elevated, these areas have only limited access and actually allow for very low exposure periods.

Because of the extremely small amounts of gamma radiation emitted by PGDP compared with natural background radiation, accurate measurements using TLDs :e difficult to obtain. The exposure rates measured by the TLD system during 1990 have a high level of uncertainty because of the lack of agreement of the quality control measurements with ANSI 


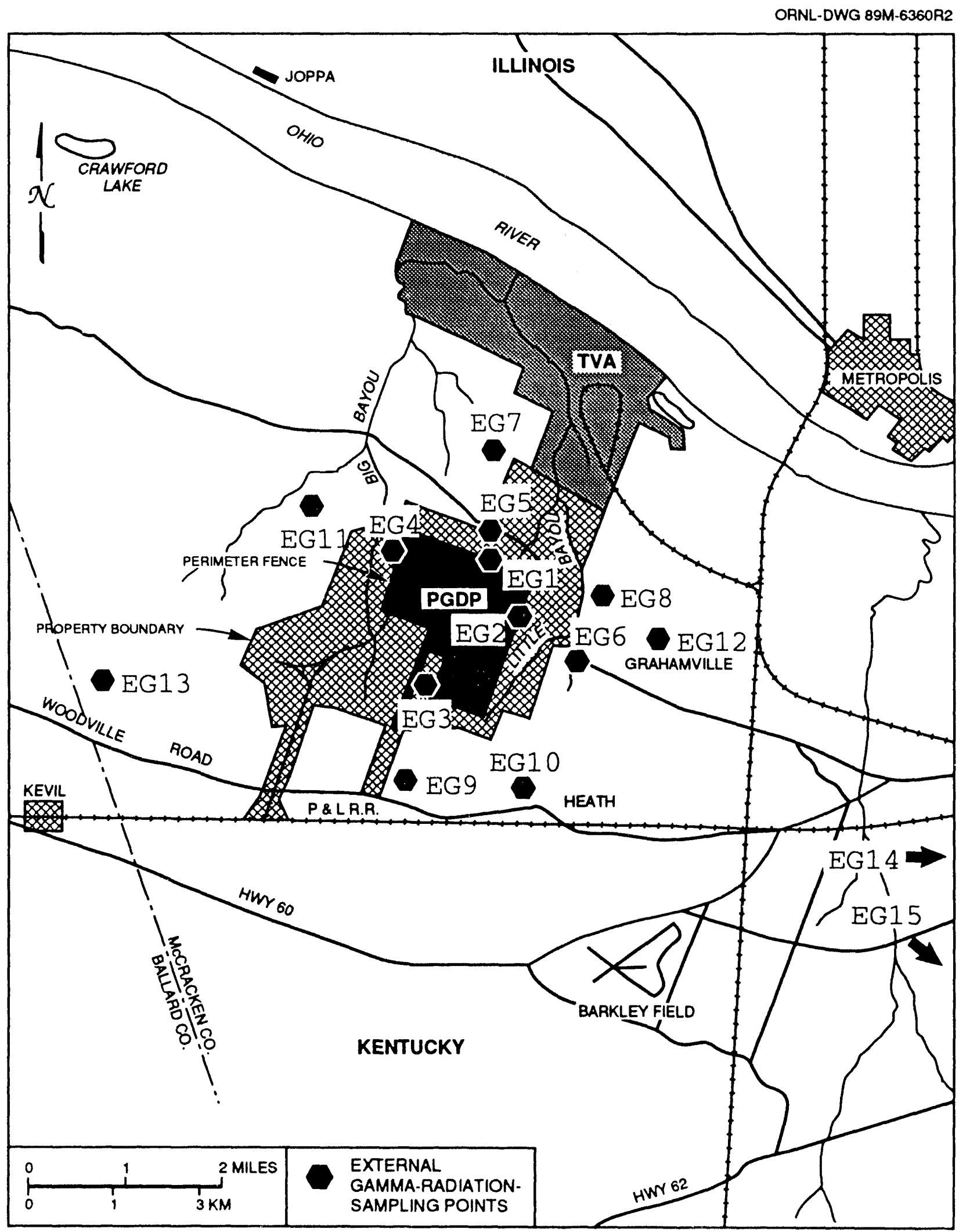

Fig. 2.3. Thermoluminescent dosimeter locations at PGDP. 


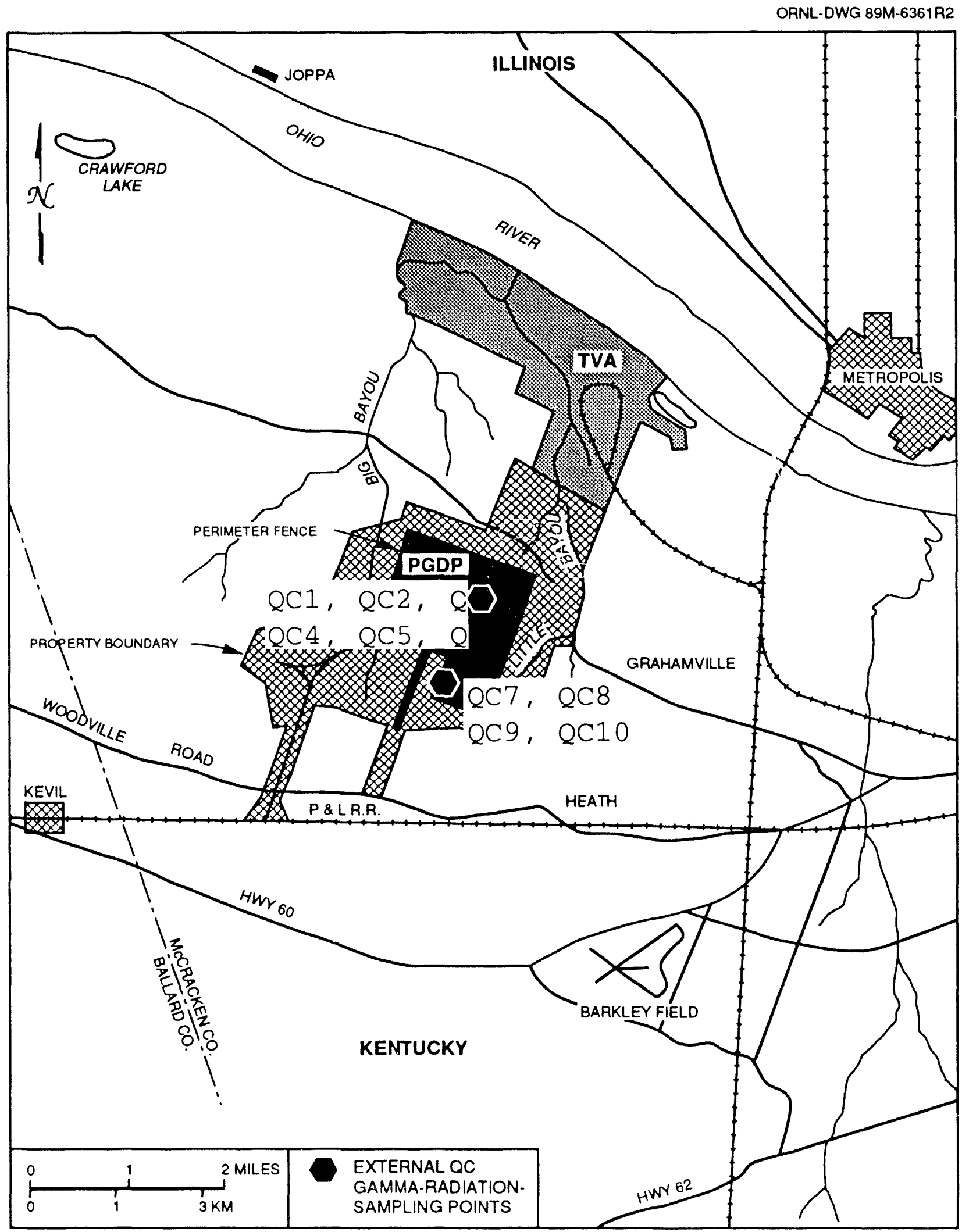

Fig. 2.4. Quality control thermoluminescent dosimeter locations at PriDP. 
Table 2.4. Maximum potential 1990 PGDP external gamma exposure rates

\begin{tabular}{|c|c|c|c|}
\hline \multirow{2}{*}{$\mathrm{ID}^{a}$} & \multirow{2}{*}{ Location } & \multicolumn{2}{|c|}{ Average } \\
\hline & & $\mu \mathrm{R} / \mathrm{hr}$ & (mrem/year) \\
\hline EG1 & Air sampler perimeter north (PN) & 6.68 & 58.5 \\
\hline EG2 & Air sampler perimeter east (PE) & 7.25 & 63.5 \\
\hline EG3 & Air sampler perimeter south (PS) & 47.01 & 411.8 \\
\hline EG4 & Air sampler perimeter west (PW) & 16.92 & 148.2 \\
\hline EG5 & Air sampler boundary north (BN) & 6.44 & 56.4 \\
\hline EG6 & Air sampler boundary east (BE) & 8.79 & 77.0 \\
\hline EG7 & Air sampler 1 mile north (1N) & 6.95 & 60.9 \\
\hline EG8 & Air sampler 1 mile east (1E) & 8.04 & 70.4 \\
\hline EG9 & Air sampler 1 mile south (1S) & 7.85 & 68.8 \\
\hline EG10 & Air sampler 1 mile southeast (1SE) & 8.68 & 76.0 \\
\hline EG11 & Air sampler 1 mile west (1W) & 7.68 & 67.3 \\
\hline EG12 & Air sampler in Grahamville & 6.27 & 54.9 \\
\hline EG13 & House in McGruder Village & 6.71 & 58.8 \\
\hline EG14 & House in Paducah near Noble Park & 8.02 & 70.2 \\
\hline EG15 & House south of Paducah on Oaks Road & 8.78 & 76.9 \\
\hline
\end{tabular}

${ }^{a}$ See Fig. 2.3.

Table 2.5. 1990 QC data for PGDP external gamma exposure

\begin{tabular}{|c|c|c|c|c|c|}
\hline $\mathrm{ID}^{a}$ & Location and description & $\begin{array}{l}\text { Second quarter } \\
(\mu \mathrm{R} / \mathrm{hr})\end{array}$ & $\begin{array}{c}\text { Third quarter } \\
(\mu \mathrm{R} / \mathrm{hr})\end{array}$ & $\begin{array}{c}\text { Fourth quarte } \\
(\mu \mathrm{R} / \mathrm{hr})\end{array}$ & $\begin{array}{c}\text { Average } \\
(\mu \mathrm{R} / \mathrm{h})\end{array}$ \\
\hline QC1 & Office cycle, C-710 & 3.15 & 2.98 & 2.13 & 2.75 \\
\hline QC2 & $1 / 2$ office cycle, C-710 & 3.39 & 3.02 & 3.70 & $\begin{array}{l}3.37 \\
81.6 \% \text { agreement }\end{array}$ \\
\hline QC3 & Freezer cycle, C-710 & 3.15 & 2.06 & 2.13 & 2.45 \\
\hline QC4 & $1 / 2$ freezer cycle, C-710 & 2.42 & 3.70 & 2.78 & $\begin{array}{l}2.97 \\
82.5 \% \text { agreement }\end{array}$ \\
\hline QC5 & Oven cycle, C-710 & 0.63 & -0.69 & 0.43 & 0.12 \\
\hline QC6 & $1 / 2$ oven cycle, $C-710$ & 0.48 & -1.0 & 0.92 & $\begin{array}{l}0.13 \\
92.3 \% \text { agreement }\end{array}$ \\
\hline QC7 & Light dependence, unwrapped, EG3 & 38.93 & 57.46 & 44.64 & 47.01 \\
\hline QC8 & Light dependence, wrapped, EG3 & 49.45 & 50.59 & 52.72 & $\begin{array}{l}50.92 \\
92.3 \% \text { agreement }\end{array}$ \\
\hline QC9 & $\begin{array}{l}\text { Light dependence, unwrapped, } \\
\text { spiked } 100 \text { mrem, EG3 }\end{array}$ & & 46.93 & 54.42 & 50.67 \\
\hline QC10 & $\begin{array}{l}\text { Light dependence, wrapped, } \\
\text { spiked } 100 \text { mrem, EG3 }\end{array}$ & 83.96 & 51.97 & 54.0 & $\begin{array}{l}63.31 \\
80.0 \% \text { agreement }\end{array}$ \\
\hline
\end{tabular}

${ }^{a}$ See Fig. 2.4. 
Standard N545-1975. However, the data indicate that levels of gamma radiation both at and beyond the plant perimeter have not increased significantly over time. Figure 2.5 compares the trend over a 3-year period at each location. The radiation fields surrounding the cylinder storage yard are also somewhat static.

\subsubsection{Environmental Radiation Surveys}

Results of an aerial radiological survey performed in May 1990 compared with a similar survey performed in August 1976 show that, over the past 15 years, only subtle changes have occurred in the spatial distribution of man-made radionuclides at PGDP. No significant gamma activity attributable to PGDP was detected outside the reservation boundary. The anomalous radiation levels detected by the survey were attributed to the known location of uranium cylinder storage areas.

Roadways, creeks, and random locations within WKWMA were surveyed during 1990 with BICRON microR-meters to detect levels of radioactivity. Measurements were taken along the perimeter fence and at distances up to 30 feet perpendicular to the fence to identify "hot spots." Measurements then were taken at 24 locations on the reservation to which the public has limited access. A subsequent survey was performed using the grid system over the Wildlife Management Area surrounding the reservation boundary. The banks and creek beds of both Little and Big Bayou creeks also were surveyed.

All measurements taken at or beyond the reservation boundary were within the background range. Elevated radiation levels were observed on the plant entrance road, adjacent to the plant fence around the $C-745$ cylinder storage areas, and within the Little Bayou Creek bed. Because each of these areas is within the reservation boundaries, public access is administratively controlled and limited. Radiation measurements made in the Little Bayou Creek bed on DOE property were consistently above background levels. The highest dose rate observed along the creek banks during 1990 was $0.039 \mathrm{mrem} / \mathrm{h}$, or about 4 times the background dose rate normally observed. Measurements taken along the plant entrance road directly across from the C-745 cylinder storage areas were also above background levels. Dose rates ranged from 0.035 to $0.040 \mathrm{mrem} / \mathrm{h}$. Based on appropriate exposure periods and administrative

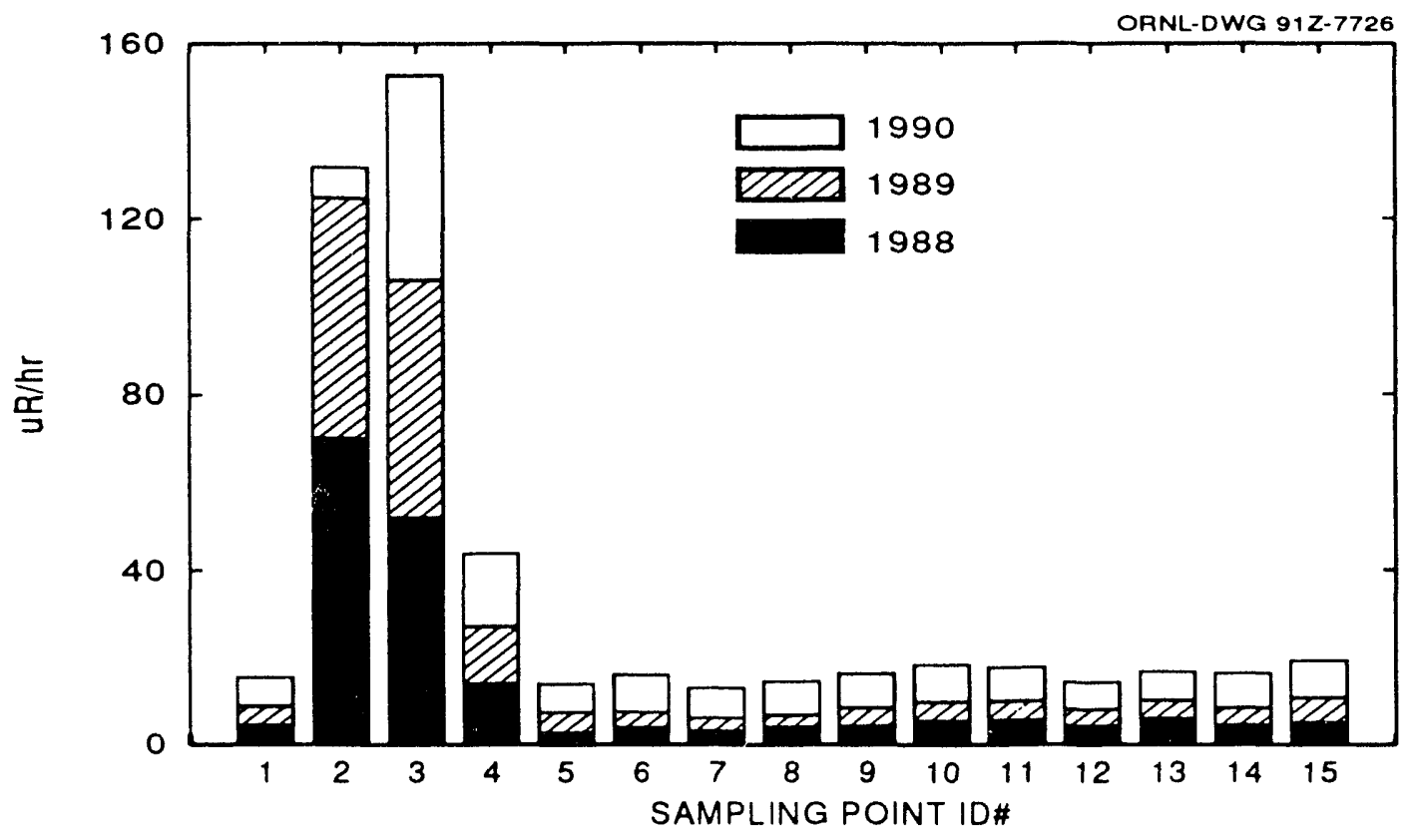

Fig. 2.5. PGDP external gamma radiation, 1988-1990. 
controls, none of these locations should result in a dose to a member of the public that would exceed the public dose limit of $100 \mathrm{mrem} / \mathrm{year}$.

\subsection{CONCLUSIONS}

During $1990,0.03 \mathrm{mCi}(31.8 \mathrm{~g})$ of uranium was released to the atmosphere from the C-310 stack. This number is considerably lower than the $0.29 \mathrm{mCi}$ $(205 \mathrm{~g})$ of uranium released in 1989 . The relatively high emissions of 1989 were due to an upset in the cylinder burping station in October 1989 in which the uranium effluent detector (space recorder) failed to detect an increase in uranium effluent concentrations from the chemical traps. Corrective actions implemented as a result of the 1989 upset have been successful in maintaining the lowest possible emissions in accordance with the ALARA concept. An interesting comparison can be drawn between PGDP's actual uranium emissions from the C-310 stack, and the new limit (standard) for DOE-owned facilities established by EPA under the National Emission Standards for Hazardous Air Pollutants (NESHAP) regulation. In December 1989, EP 1 established a standard of 10 mrem effective dose equivalent to the most affected off-site person. This means that PGDP must not expose the most affected off-site person to radionuclides from atmospheric releases that would result in an annual effective dose equivalent of 10 mrem or more. Air dispersion modeling performed for PGDP by ORNL indicates that an annual effective dose equivalent of $10 \mathrm{mrem}$ to the most affected off-site person would require an emission rate of 10,685 grams ( 23.5 pounds) per day for an entire year. This rate is considerably more than the total 1990 emissions of 31.8 grams, indicating that uranium emissions from the C-310 stack are well below those that would cause undue health effects.

Also during $1990,0.4 \mathrm{mCi}(23 \mathrm{mg})$ of technetium were released. This number is down from $3.6 \mathrm{mCi}$ released in 1989. There has been no new introduction of ${ }^{99} \mathrm{Tc}$ into the cascade and no increase of ${ }^{99} \mathrm{Tc}$ in product withdrawal. Air dispersion modeling also was performed to identify the technetium emissions that would result in an effective dose equivalent of 10 mrem to the most affected off-site person. Results indicate that it would require an emission rate of 68,500 milligrams ( 0.151 pounds) per day for an entire year to achieve the $10 \mathrm{mrem}$ standard. This rate is much greater than the total 1990 technetium emission of 23 milligrams.

The stack-monitoring data, their characteristics, and the joint frequency distribution of wind speed, stability, and wind direction are needed to calculate the amount of exposure of the surrounding population to plant emissions. The wind roses shown in Figs. 2.6 and 2.7 summarize the wind speed frequency distribution data for the 1990 dose model estimates (see Sect. 7). 


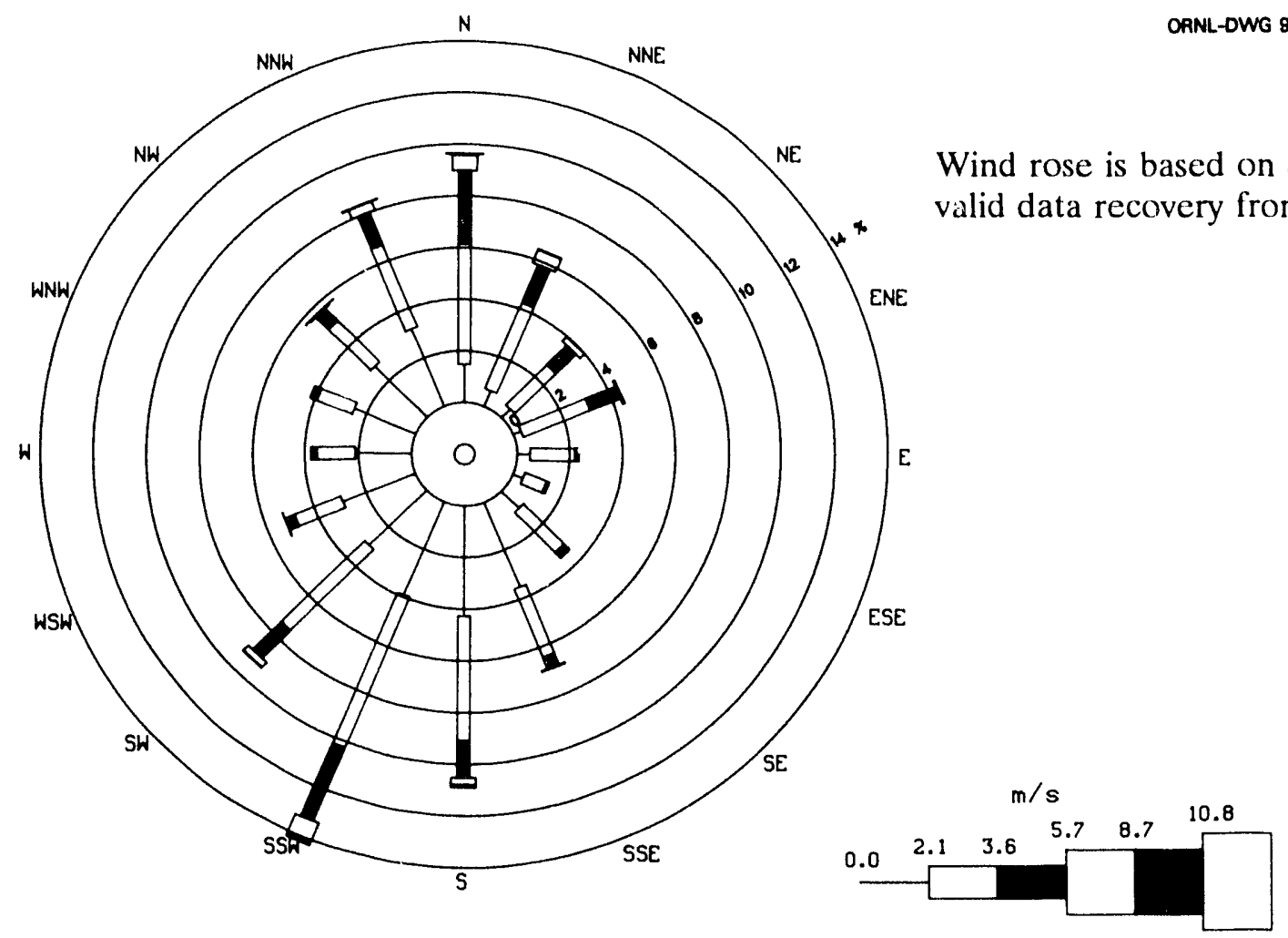

Fig. 2.6. Wind rose (10-m level) showing the wind speed frequency distribution data used for the 1990 estimates.

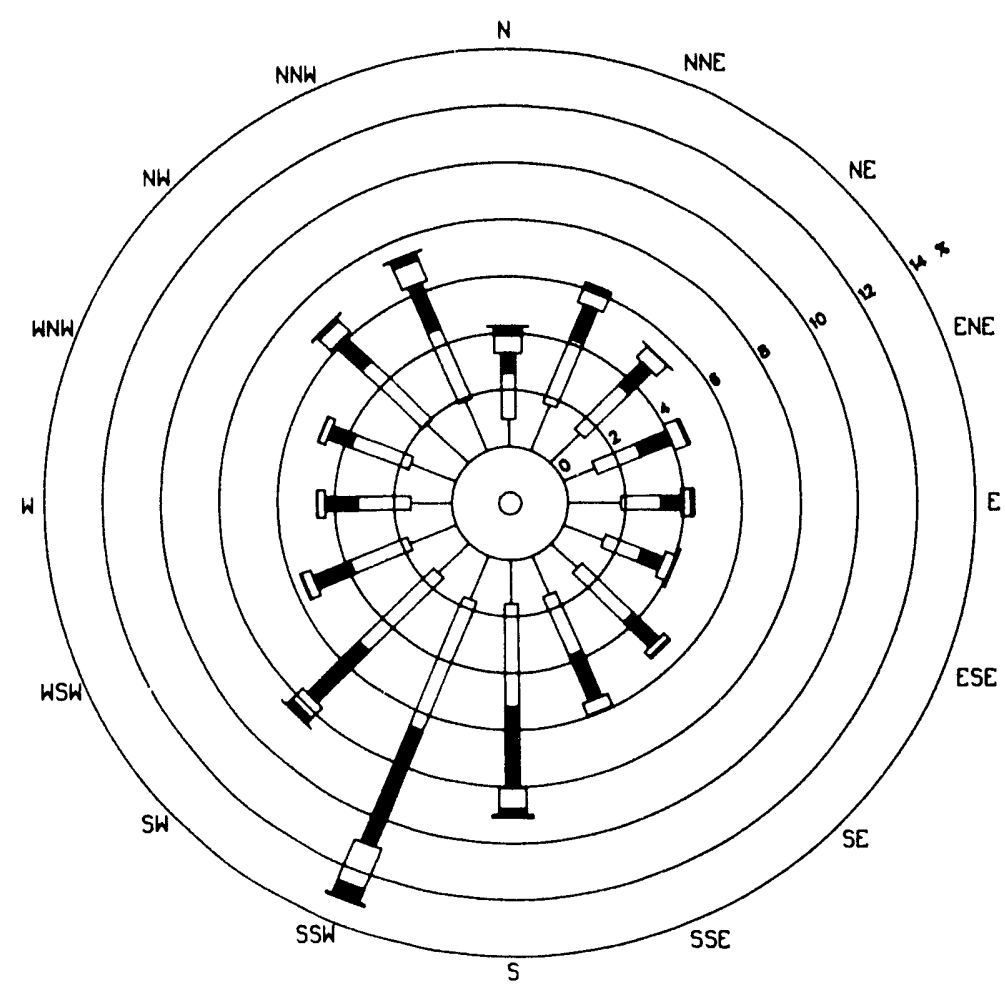

ORNL-OWG 80-10125

Wind rose is based on $99.6 \%$ valid data recovery from 1989 .

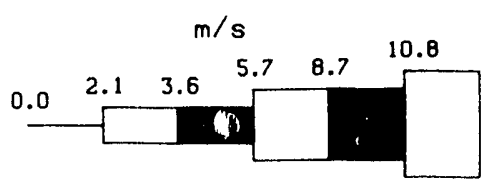

Fig. 2.7. Wind rose $(60-\mathrm{m}$ level) showing the wind speed frequency distribution data used for the 1990 estinates. 


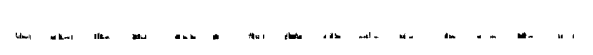

点
$=$
$=$ 


\section{SURFACE WATER}

PGDP is located in the western part of the Ohio River basin. Surface drainage from the site is to two small tributaries of the Ohio River: Big Bayou Creek on the west and Little Bayou Creek on the east (Fig. 3.1). These two streams join north of the site and discharge to the Ohio River at about river kilometer 1524 (river mile 945), which is about 56 miles upstream from the confluence of the Ohio and Mississippi rivers. These creeks exhibit widely fluctuating discharge characteristics that are closely tied to local precipitation. Natural runoff makes up a small portion of the flow in Big Bayou and Little Bayou creeks during the dry periods. The PGDP site is not located in the Ohio River 100-year floodplain

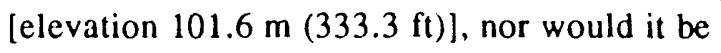
affected by the historical high-water elevation of

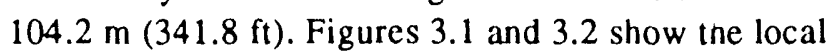
PGDP surface hydrology systems and the regional area primary surface hydrology.

The vast majority of liquid effluents at PGDP consist of once-through cooling water, although a variety of liquid effluents (uranium-contaminated as well as noncontaminated) result from activities associated with uranium precipitation and facility-cleaning operations. Conventional liquid discharges such as domestic sewage, steam plant wastewaters, and coal-pile runoff also exist. Routine monitoring activities provide data to quantify total discharges to surface water, demonstrate compliance with federal, state, and DOE requirements, and assist in evaluating the effectiveness of effluent treatment and control programs.

\subsection{SURFACE WATER MONITORING}

SW13 (see Fig. 3.3), the north-south diversion ditch, is monitored on a weekly basis. This ditch receives coal-pile runoff, the $\mathrm{C}-400$ decontamination solution filtrate, and hydrostatic test water. A continuous leak sampler is used for the 7-day composite. The 7-day composite sample and a grab sample are analyzed for weekly parameters listed in Table 3.1. Each week, a $100-\mathrm{mL}$ sample is poured into a yearly composite container. At the end of each year, the composite sample is analyzed for annual parameters listed in Table 3.1. Analysis of samples indicates elevated levels of uranium and alpha and beta activity. However, this ditch is on-site and flows into the C-616 lagoon before discharging through outfall 001 .

Monthly sampling is conducted at Big Bayou Creek upstream (SW1), Big Bayou downstream (SW5), Little Bayou downstream (SW10), Ohio River upstream (SW29), and Ohio River downstream (SW30). Tables 3.15 through 3.22 of Part 2 provide surface water monitoring data.

Comparisons of the radiological results from upstream and downstream locations on Big Bayou Creek indicate that there is no significant difference ( $95 \%$ confidence level) between the two data sets for either gross beta activity or technetium- 99 . The gross alpha results do indicate elevated levels of alpha activity in Big Bayou Creek downstream from PGDP. This activity most likely reflects the release of uranium in plant effluents.

Two locations on the Ohio River, L29 and L30, are monitored monthly for parameters listed in Table 3.1. The data are presented in Tables 3.19 and 3.20 of Part 2. Samples tested for 1,2-dichloroethane, discharged by Calvert City's industrial complex, were $<5 \mu \mathrm{g} / \mathrm{L}$.

The surface runoff from the C-746-S residential landfill and the C-746-T inert landfill is monitored quarterly. Sampling is performed to comply with Kentucky Division of Waste Management requirements for landfill operations. Background water quality is sampled at Big Bayou Creek location 1 (SW 1). Comparisons of the radiological results from Big Bayou Creek with each landfill location indicate that there is no significant different $(95 \%$ 
ORNL-DWG 87M-8429R

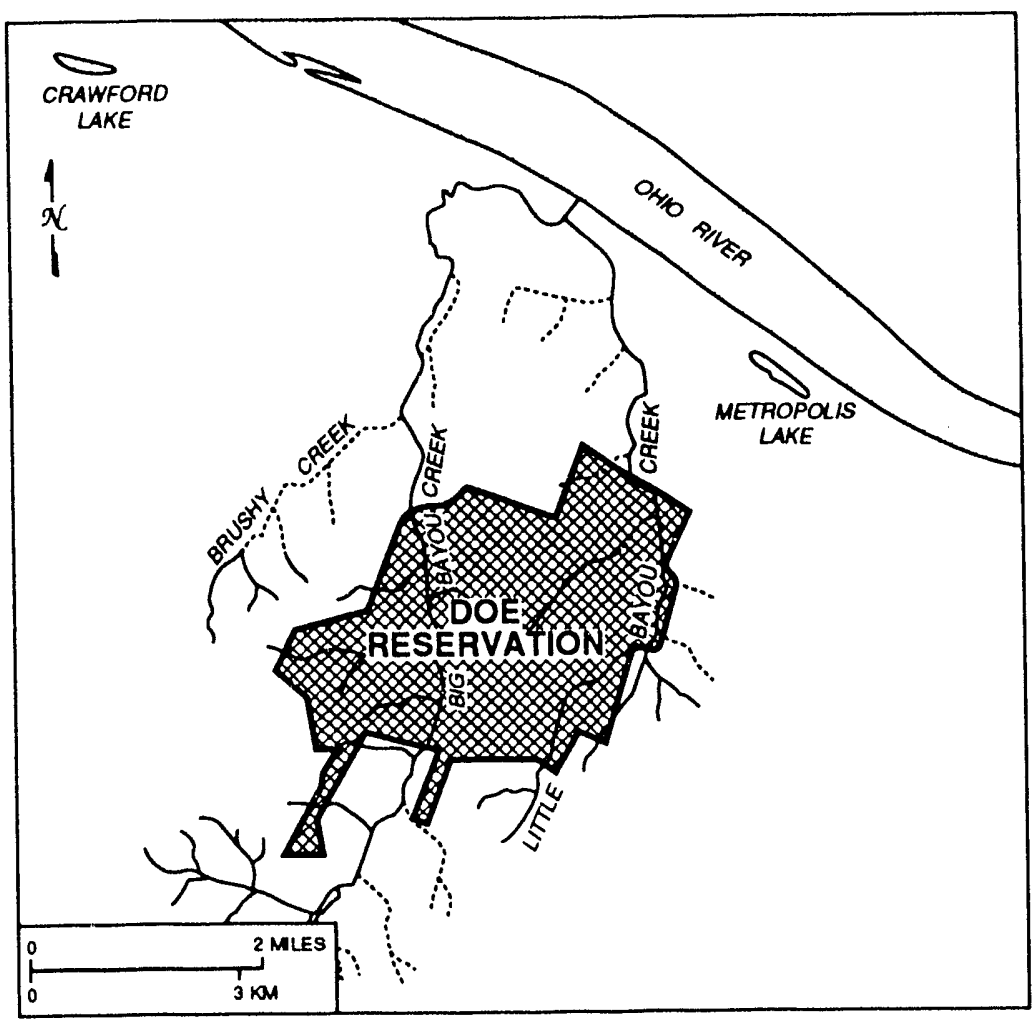

Fig. 3.1. PGDP site surface hydrology systems.

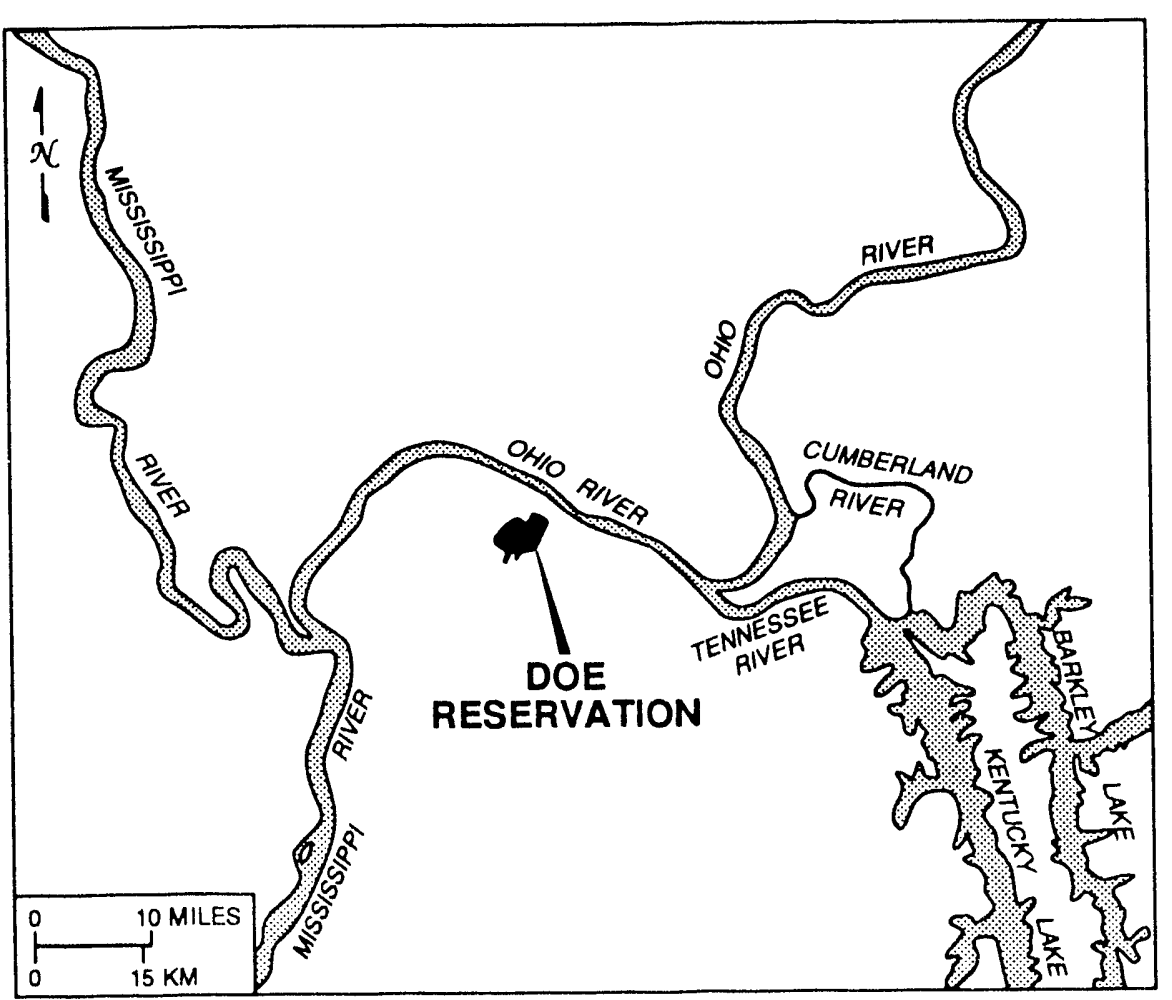

Fig. 3.2. Regional area primary surface hydrology. 


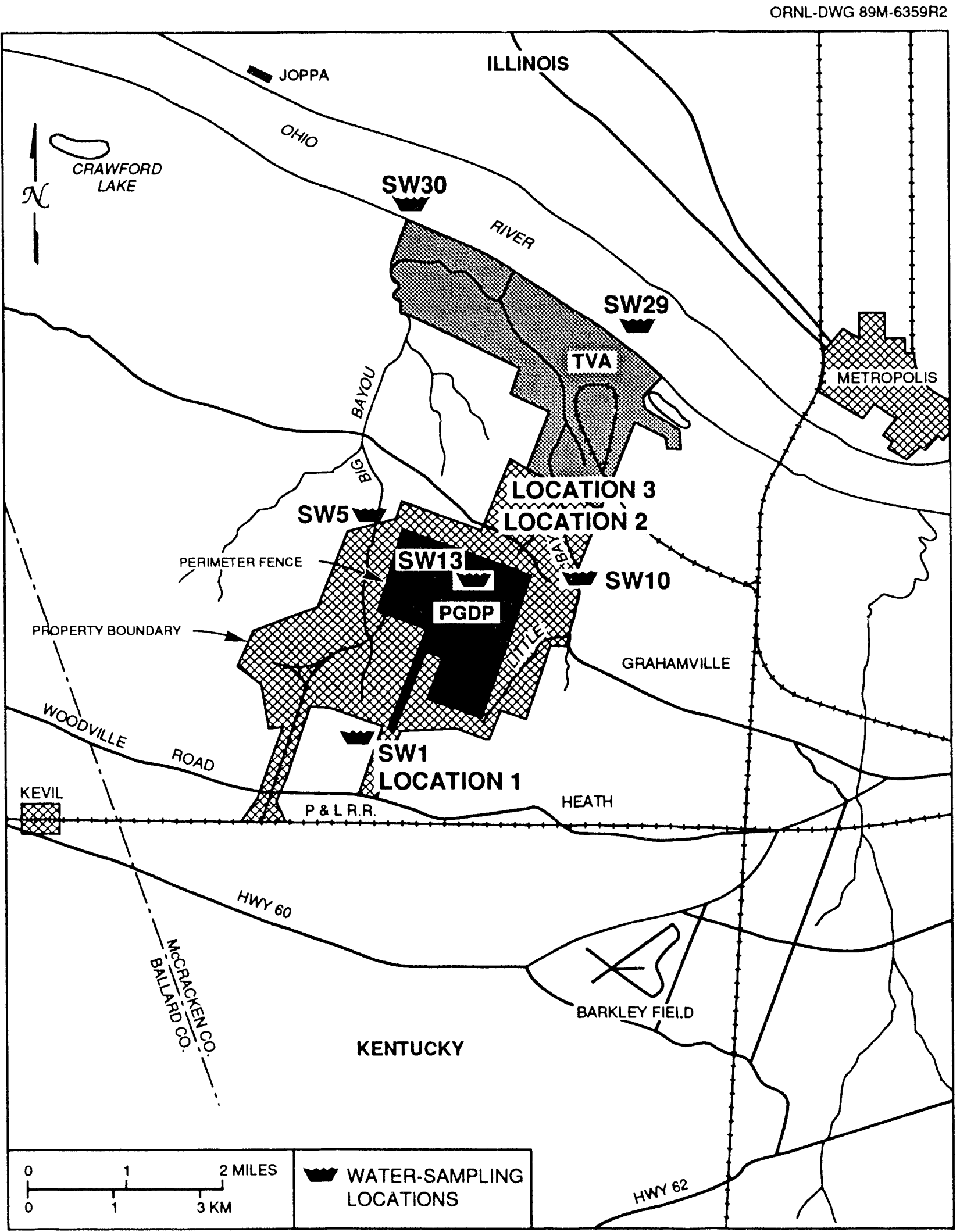

Fig. 3.3. Surface water monitoring locations at PGDP. 
Table 3.1. Summary of collection and analysis frequencies of surface water samples in 1989

\begin{tabular}{|c|c|c|c|c|}
\hline Station $^{a}$ & Parameter & Collection frequency & Sample type & Analysis frequency \\
\hline \multicolumn{5}{|c|}{$C-746-S$ and $C-746-T$ landfill runoff } \\
\hline $\begin{array}{l}\text { Location } 1 \\
\text { (SW1), } \\
\text { Location 2, } \\
\text { Location } 3\end{array}$ & $\begin{array}{l}\text { Chloride, sulfate, pH, } \mathrm{Na} \text {, } \\
\text { U, TOC, TSS, TDS, } \\
\text { total solids, specific } \\
\text { conductivity, gross } \\
\text { alpha, gross beta }\end{array}$ & Quarterly & Grab & Quarterly \\
\hline \multicolumn{5}{|c|}{ Surface water locations } \\
\hline SW29 & $\begin{array}{l}\mathrm{NO}_{3}-\mathrm{N}, \mathrm{SO}_{4}, \text { chloride, } \\
\mathrm{Cr}^{+6}, \mathrm{pH}, \mathrm{PO}_{4}, \mathrm{U}, \mathrm{F}, \\
\text { dissolved alpha and } \\
\text { beta, suspended } \\
\text { alpha and beta, } \\
\text { SW1-temperature } \\
\text { weekly }\end{array}$ & Monthly & Grab & Monthly \\
\hline sw30 & $\begin{array}{l}\mathrm{NO}_{3}-\mathrm{N}, \mathrm{SO}_{4}, \text { chloride, } \\
\mathrm{Cr}+6, \mathrm{pH}, \mathrm{PO}_{4}, \mathrm{U}, \mathrm{F} \\
\text { dissolved alpha and } \\
\text { beta, 1,2-dichloroethane }\end{array}$ & Monthly & Grab & Monthly \\
\hline SW13 & $\begin{array}{l}\mathrm{NO}_{3}-\mathrm{N}, \mathrm{PO}_{4}, \text { chloride, } \\
\mathrm{Cr}^{+6}, \mathrm{pH}, \mathrm{U}, \mathrm{F}^{-} \\
\text {dissolved alpha and } \\
\text { beta, suspended alpha } \\
\text { and beta, } \mathrm{SO}_{4}\end{array}$ & Weekly & $\begin{array}{l}\text { Grab and } \\
7 \text {-day } \\
\text { composite }\end{array}$ & Weekly \\
\hline SW13 & $\begin{array}{l}\mathrm{U}, \mathrm{Ni}, \mathrm{Hg}, \mathrm{Cd}, \mathrm{As}, \mathrm{Ba}, \mathrm{Cu}, \\
\mathrm{Pb}, \mathrm{Se}, \mathrm{Ag} \text {, dissolved } \\
\text { alpha and beta, suspended } \\
\text { alpha and beta, }{ }^{99} \mathrm{Tc} \text {, } \\
{ }^{237} \mathrm{~Np},{ }^{239} \mathrm{Pu},{ }^{230} \mathrm{Th}, \\
{ }^{2}{ }^{233} \mathrm{U}, \mathrm{Cr}, \mathrm{ICP} \\
\text { metals scan }\end{array}$ & Annually & $\begin{array}{l}\text { Annual } \\
\text { composite }\end{array}$ & Annually \\
\hline SW1 & $\begin{array}{l}\mathrm{NO}_{3}-\mathrm{N}, \mathrm{SO}_{4}, \text { chloride, } \\
\mathrm{Cr}^{+6}, \mathrm{pH}_{1} \mathrm{PO}_{4}, \mathrm{U}, \mathrm{F} \\
{ }^{99} \mathrm{Tc},{ }^{2}{ }^{235} \mathrm{U}, 237 \mathrm{~Np}, \\
{ }^{239} \mathrm{Pu}, \text { gross alpha and } \\
\text { beta, temperature } \\
\text { weekly }\end{array}$ & Monthly & Grab & Monthly \\
\hline SW5, SW 10 & $\begin{array}{l}\text { Gross alpha and beta, } \\
{ }^{99} \mathrm{Tc}, \%{ }^{235} \mathrm{U},{ }^{237} \mathrm{~Np} \\
{ }^{239} \mathrm{Pu}\end{array}$ & Monthly & Grab & Monthly \\
\hline
\end{tabular}

${ }^{a}$ See Fig. 3.3. 
confidence level) between each data set. However, comparisons of the iron, total suspended solids, dissolved solids, and total solids between the background and indicator locations indicate a significant difference (95\% confidence level) is present. Extra emphasis on erosion control at the landfill should lower the solids content in the runoff.

\subsection{KPDES MONITORING}

The CWA is currently administered for PGDP by the Kentucky Division of Water (KDOW) through the Kentucky Pollutant Discharge Elimination System (KPDES) wastewater-discharge-permitting program. The earlier National Pollutant Discharge Elimination System (NPDES) permit (KY0004049) was issued by Region IV EPA and became effective on February 15, 1975. It was revised on February 4, 1977, and was to expire in 1980. Although PGDP had applied for a new permit at the time the old one expired, no system was in place at KDOW to replace the old NPDES system, and a new permit could not be issued. PGDP operated under the original 1975 permit until October 22, 1986, when the state of Kentucky issued the KPDES permit (KY0004049). On November 5, 1986, the state permit was adjudicated because the permit limits were not achievable. Monitoring then resumed under the old NPDES permit. As a part of the negotiations associated with the adjudication process, an Agreed Order was proposed whereby interim limits were included in the KPDES permit while a biological-monitoring study (see Subsect. 3.4) was carried out at PGDP. Table 3.1 of Part 2 shows interim limits, sampling frequency, and the type of sample required by the Agreed Order. The Agreed Order became effective on October 12, 1987.

Monitoring then resumed under the KPDES permit with the Agreed Order modifications. The K?DES permit will expire in October 1991. Permit renewal applications are currently being prepared and are due to KDOW in May 1991.

Monitoring of 16 individual outfalls is conducted in accordance with the KPDES Agreed Order. Table 3.2 lists all outfalls and their contributing processes; Fig. 3.4 depicts the location of the outfalls. Table 3.1 in Part 2 cites the effluent limits set forth by the Agreed Order.

Tables 3.2 through 3.14 in Part 2 give the yearly minimum, maximum, and average for each outfall monitored. Since no flow occurred at outfall 003 in 1990, no monitoring data were obtained. Flow from

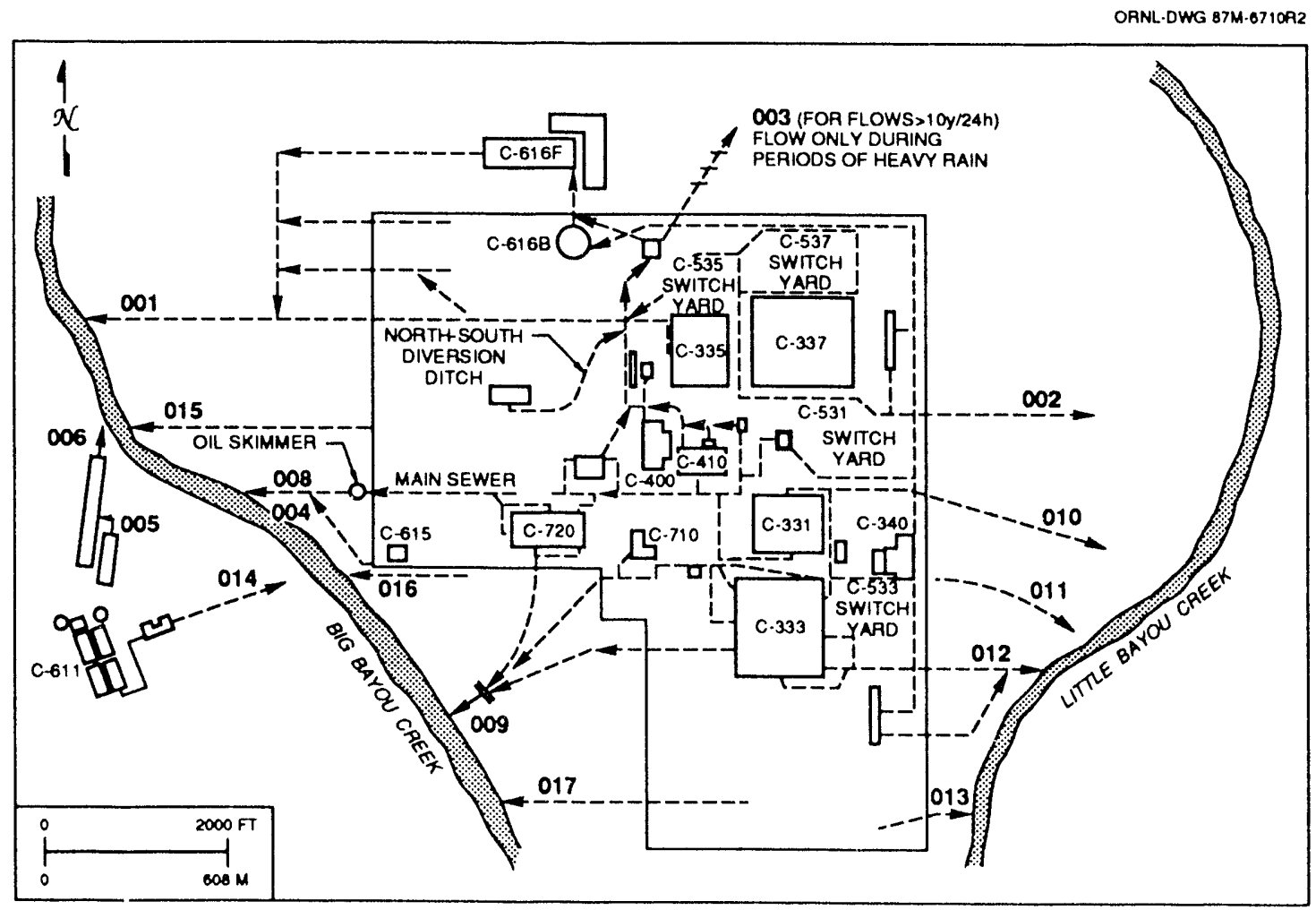

Fig. 3.4. KPDES outfall locations at PGDP. 
Table 3.2. Kentucky Pollutant Discharge Elimination System outfalls at PGDP

\begin{tabular}{|c|c|c|}
\hline Location ${ }^{a}$ & Drainage source & Contributing process \\
\hline 001 & $\begin{array}{l}\text { C-616, C-600, C-400, C-410 } \\
\text { C-635, C-335, C-337, C-55, } \\
\text { C-537, C-746-A, C-747-A } \\
\text { C-635-6 }\end{array}$ & $\begin{array}{l}\text { Recirculating cooling water blowdown } \\
\text { treatment effluent, coal pile runoff, } \\
\text { once-through cooling water, surface runoff, } \\
\text { roof and floor drains, treated } \\
\text { uranium solutions, sink drains }\end{array}$ \\
\hline$\infty 2$ & C-360, C-637, C-337-A & $\begin{array}{l}\text { Once-through cooling water, roof and } \\
\text { floor drains, sink drains, extended } \\
\text { geration sewage treatment system }\end{array}$ \\
\hline$o^{n}$ & North edge of plant & $\begin{array}{l}\text { Storm overflow of north-south diversion } \\
\text { ditch discharges }\end{array}$ \\
\hline 004 & $\begin{array}{l}\text { C-615 sewage treatment plant } \\
\text { C-710, C-728, C-750, C-100 } \\
\text { C- } 620, \text { C }-400\end{array}$ & $\begin{array}{l}\text { Domestic sewage, laboratory sink drains, } \\
\text { mo' or cleaning, garage drains, } \\
\text { laundry, X-ray processing and } \\
\text { silver recovery unit effluent, } \\
\text { machine coolant treatment } \\
\text { filtrate, condensate blowdown, } \\
\text { once-through cooling water, } \\
\text { spent pl.otographic solutions }\end{array}$ \\
\hline 005 & C-611 primary sludge lagoon & $\begin{array}{l}\text { Water treatrient plant sludge, sand filter } \\
\text { backwash, laboratory sink drains }\end{array}$ \\
\hline 006 & C-611 secondary lagoon & $\begin{array}{l}\text { Water treatment plant sludge, sand filter } \\
\text { backwash, laboratory sink drains } \\
\text { from outfall } 005\end{array}$ \\
\hline 007 & Outfall eliminated & \\
\hline 008 & $\begin{array}{l}\text { C-743, C-742, C-741, C-723 } \\
\text { C-721, C-728, C-729, C-400 } \\
\text { C-420, C-410, C-727, C-411 } \\
\text { C- }-331, \text { C }-310, \text { C-724, C-744 } \\
\text { C- } 600, \text { C }-405, \text { C }-409, \text { C- } 631 \\
\text { C-720 }\end{array}$ & $\begin{array}{l}\text { Surface drainage, roof and floor drains, } \\
\text { once-through cooling water, paint shop } \\
\text { discharge, condensate, instrument shop } \\
\text { cleaning area, metal cleaning rinse } \\
\text { water, sink drains }\end{array}$ \\
\hline 009 & $\begin{array}{l}\text { C-810, C-811, C-331, C-333, C-310 } \\
\text { C-100, C-102, C-101, C-212 } \\
\text { C-200, C-300, C-320, C-302 } \\
\text { C-750, C-710, C-720 }\end{array}$ & $\begin{array}{l}\text { Surface drainage, roof and floor drains, } \\
\text { condensate, once-through cooling water. } \\
\text { sink drains }\end{array}$ \\
\hline 010 & C-531, C-331 & $\begin{array}{l}\text { Switchyard runoff, roof and floor drains, } \\
\text { condensate, sink drains }\end{array}$ \\
\hline 011 & $\begin{array}{l}\text { C-340, C-533, C-532, C-315 } \\
\text { C-333, C-331 }\end{array}$ & $\begin{array}{l}\text { Once-through cooling water, roof and floor } \\
\text { drains, switchyand runoff, condensate. } \\
\text { sink drains }\end{array}$ \\
\hline 012 & C-633, C-533, C-333-A & $\begin{array}{l}\text { Roof, floor, and sink drains } \\
\text { runoff, condensate, surface runoff, } \\
\text { extended aeration sewage treatment } \\
\text { system }\end{array}$ \\
\hline 013 & Southeast corner of plant & Surface runoff \\
\hline 014 & C-611 U-shaped sludge lagoon & Sand filter backwash, sanitary water \\
\hline 015 & West centreal plant areas & Surface runoff \\
\hline 016 & Southwest comer of plant & Surface runoff \\
\hline 017 & Extreme south area of plant & Surface runoff \\
\hline
\end{tabular}

asee Fig. 3.4. 
the north-south diversion ditch is normally channeled through outfall 001 via a lift station that pumps the effluent through the C-616 full-flow lagoon; however, during a rainfall with flows greater than 10 year $/ 24 \mathrm{~h}$ (i.e., a maximum daily average flow over a 10 -year occurrence interval), the lift station overflows to 003 . This is the only time that 003 discharges and is monitored. Outfall 005 is not regularly monitored because its effluent flows into the C-611 secondary lagoon. Outfall 006, the C-611 secondary lagoon, is monitored for the same parameters as those required by outfall 005 . Outfall 007 is not allowed to experience any discharge. This outfall is a septic field for the C-611 water treatment plant. Outfall 014 was not monitored in 1990. This U-shaped lagoon experiences flow only when the C-611 sludge lagoon is dredged. Every 2 or 3 years the C-611 sludge lagoon is dredged, and the filter backwash is directed to outfall 014 . Monitoring of outfall 014 occurs at this time.

During 1990, PGDP experienced a compliance rate of $99.31 \%$ with the KPDES Agreed Order effluent limits. (The 1989 compliance rate was $98.27 \%$.) The number of noncompliances in 1990 was 33 , zompared with 82 in 1989. Table 3.3 indicates the noncompliances experienced under the Agreed Order. The noncompliances during 1990 were total residual chlorine, $\mathrm{pH}$, temperature, total suspended solids, and fecal coliform. Once-through cooling waker (sanitary water disinfected with chlorine for public consumption and usage) was a large portion of PGDP's effluent and accounted for most of the total residual chlorine noncompliances. The C-615 sewage treatment plant, which uses chlorine to disinfect its effluent, also contributed to total residual chlorine in effluent waters. Fecal coliform noncompliances were due to malfunctions of the flow-proportionate chlorinator. Temperature noncompliances were the result of the heat in once-through cooling water and steam condensate discharge. Total suspended solids noncompliances occurred because of dust and solids washed down the ditches by rainfa!l runoff.

Corrective measures have been taken to alleviate the number of KPDES noncompliances. Sodium thiosulfate feed stations exist at outfalls 008,009 , 010,011 , and 012 to reduce the total residual chlorinz in the effluent water. After installation of the sodium thiosulfate feed stations, the number of total residual chlorine noncompliances dropped from 64 in 1989 to
12 in 1990. The plant effluent chlorine and temperature control project, currently under construction, will provide facilities to lower the temperature in outfalls $001,002,010,011$, and 012 and reduce the total residual chlorine in outfalls 001 , $002,008,010,011$, and 012. Construction should be complete in June 1991.

Erosion control devices, such as silt fences, hay bales, and filter fabric, have been installed at construction sites. The use of such devices and improved overs: iht have caused the number of total suspended solids noncumpliances to drop from 5 in 1989 to 3 in 1990.

Biological-monitoring studies have indicated that slightly elevated pH in PGDP effluents is not causing elevation of $\mathrm{pH}$ in the receiving streams above water quality criteria. Therefore, a pH range of 6.0 to 10.0 will be pursued during the KPDES permit renewal process.

During 1990, two meetings were held with KDOW. The first meeting was on June 7, 1990. Items discussed included the potential issuance of a new Agreed Order for PGDP by KDOW. Some of the requirements in the Agreed Order would be monitoring of outfall 018 (landfill rainfall runoff point), completion of the plant effluent chlorine and temperature control project by June 1991, total suspended solids monitoring requirements for rainfall runoff outfalls, and PCB effluent limits. On August 31,1990 , a notice of violation (NOV) for discharges of PCBs above water quality criteria in Big and Lit!? Bayou Creeks was received. The NOV was the subject of the second meeting with KDOW. October 3, 1990, was the meeting date. PCB source investigation plans and the $P C B$ management program were discussed. A draft Agreed Order will be issued by KDOW in 1991. Compliance with the Agreed Order will resolve the NOV.

During 1990, installation of new flow measuring devices at KPDES outfalls was completed. Also, several refrigerated autosamplers were placed in service. The installation of the new flow measuring devices corrected a 1988 EPA Region IV compliance sampling inspection finding.

\subsection{RADIOLOGICAL MONITORING OF EFFLUENTS}

During 1990, the effluent outfalls were reevaluated based on their potential for release of 


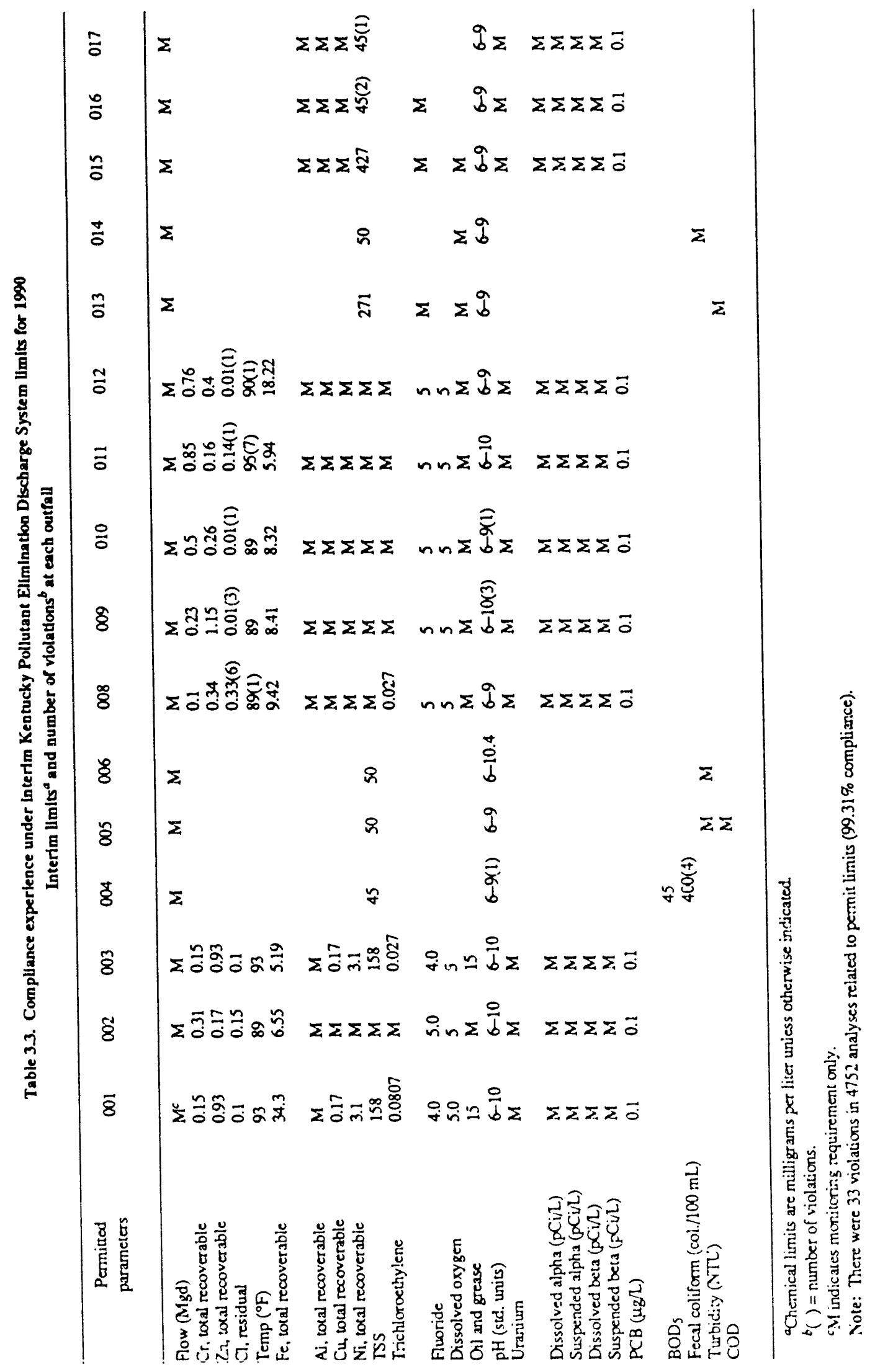


radioactive material and the results of historical radiological monitoring. Based on this evaluation, continuous monitoring was determined not to be required by DOE order. Radiological sampling was periodically conducted by random grab sampling. Although there are no specific effluent limits for radiological parameters in the KPDES permit, DOE Orders 5400.5 and Draft 5400.6 set guidelines for allowable concentrations of radiological species in various effluents and require radiological monitoring to protect the public health.

Beginning in 1991, in addition to sampling required by the KPDES permit, each sampling point with annual average radionuclide concentrations greater than $1 \%$ of the Derived Concentration Guide (DCG) for any radionuclide will be sampled on a weekly basis. Two locations currently monitored on a quarterly basis will be increased to weekly to generate a sufficient amount of data to characterize these discharges.

Tables 3.23 and 3.24 in Part 2 give the yearly minimum, maximum, and average concentrations of uranium and technetium at each effluent monitoring location. Each radionuclide is compared with the DCG and is presented as a percentage of that standard. The average concentrations were small percentages of the corresponding DCGs for both uranium and technetium at all locations.

Routine monitoring also provides data to estimate the total radionuclide discharge to surface waters. Because current monitoring provides only instantaneous measurements for both concentration of radionuclides and flow, there is a large uncertainty associated with this estimation. During 1990 , $180.7 \mathrm{~kg}$ of uranium was discharged to surface waters. Technetium releases to surface waters decreased from $8 \mathrm{~g}$ in 1989 to $5.2 \mathrm{~g}$ in 1990 . Table 3.25 in Part 2 shows monthly data for the major contributors to the total discharge during 1990.

\subsection{BIOLOGICAL MONITORING OF EFFLUENTS AND RECEIVING WATERS}

The Biological Monitoring Program (BMP) at PGDP is designed to evaluate the acceptability of PGDP effluents under KPDES regulations, to characterize the potential for health effects and environmental impacts of the effluents, and to make recommendations on the biological acceptability of planned effluent treatments. The BMP is performed by researchers at the University of Kentucky (UK) in consultation with staff from Oak Ridge National Laboratory (ORNL). The latter group work to make available their technical expertise gained from other biological-monitoring programs at DOE facilities.

The findings and recommendations of the BMP are presented in a draft report of the first 3 years' activities (Birge, Short, and Lauth December 1990). The ecological studies conducted for the BMP provide data not only for evaluation of the health and productivity of Big Bayou and Little Bayou creeks at present but also for retrospective and future analyses of the drainage system to detect changes. A reduction in the density and diversity of macroinvertebrate taxa and in the biomass of periphyton indicate an adverse impact of effluents in the region of Big Bayou Creek that receives continuous flow from four outfalls $(009$, 008,006 , and 001). The observed impact is localized in that no effect is evident in downstream macroinvertebrate communities. Furthermore, studies of the fish fauna show no adverse impact on species diversity or abundance. The ecological data further indicate that a substantial improvement has occurred in the quality of the streams compared with a site survey completed in 1978 (Eischen et al. 1978).

Bioaccumulation studies are in progress to detect toxicants that may be of importance to human health and to determine whether organisms received elevated exposures to specific compounds regulated by the KPDES program. Residue analyses of caddisfly larvae, mayfly nymphs, and fisi show a tendency for elevated body burdens of copper, cadmium, chromium, and iron in various locations of Big Bayou Creek. Aluminum, nickel, and zinc also accumulate in these organisms at various locations of Big Bayou Creek. These findings are consistent with the increased metal concentrations sometimes found in effluents as part of the chemical-monitoring activities.

Toxicity testing is an integral part of the BMP because it provides a mears to evaluate the acute and chronic effects of PGDP effluents to aquatic biota as well as to obtain information on temporal changes in toxicity of the plant discharges. None of the PGDP effluents was found to be consistently or highly toxic. However, moderate and statistically significant toxicity was detected occasionally in some of the effluents discharged in the Bayou drainage system. 


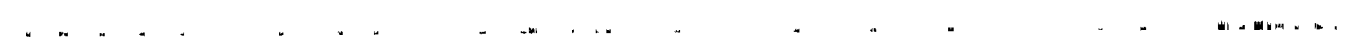




\section{GROUNDWATER}

Monitoring and protection of groundwater resources at PGDP is required by federal and state regulations and DOE orders; monitoring efforts have been initiated at PGDP to reflect these requirements. Additionally, characterization activities have been undertaken that will resolve the recognized deficiencies in understanding of the site geology and hydrogeology. These activities are intended to develop a clear, thorough understanding of the subsurface geology and hydrogeology to aid in developing technically effective monitoring strategies.

DOE Order 5400.1 outlines requirements for groundwater monitoring at all DOE facilities and specifies the development of three dociments relating to the groundwater monitoring: an Environmental Monitoring Plan, a Groundwater Protection Program Management Plan (GWPP MP), and a Groundwater Monitoring Plan (GMP). The GWPP MP for PGDP (KY/ER-2) and the GMP (Early et al. 1989) for PGDP have been completed.

The general objective of the GWPP MP is to formalize and to structure the PGDP GWPP by identifying specific responsibilities and assigning them to the various entities within the plant who are matrixed to the program. The GWPP management structure coordinates and manages all projects and initiatives relevant to groundwater protection so that the objectives defined in DOE 5400.1 can be reached. As much as possible, Environmental Restoration and Environmental Compliance initiatives are coordinated and integrated to be complementary.

The GMP ensures the development of an adequate understanding of the geologic and hydrogeologic characteristics of the entire reservation so that future activities will be technically valid and justifiable. The general objective of the GMP is to provide a comprehensive blueprint for DOE to follow at each specific facility that (1) targets the environmental protection of groundwater, (2) is consistent with DOE's commitment to operate its facilities in an environmentally safe manner, and (3) complies with all relevant environmental laws. The goal of the document is to fulfill these objectives for PGDP by providing a monitoring plan that accomplishes the following:

- develops an appropriate level of understanding of (1) site subsurface geology and groundwater hydrology, and (2) flow pathways and rates of contamination migration from existing waste disposal sites to underlying aquifers;

- provides the framework within which an integrated strategy for long-term monitoring of existing disposal sites can be developed to aid evaluation of remedial action alternatives; and

- creates a data base and fundamental geotechnical understanding of the site to facilitate future waste disposal decisions.

The third component of DOE Order 5400.1 relating to groundwater monitoring, a written environmental monitoring plan, is currently being developed to reflect the above-mentioned documents. This plan will contain the rationale and design criteria for the monitoring programs, the extent and frequency of monitoring and measurements, procedures for laboratory analyses, quality assurance requirements, program implementation procedures, and the directions for the preparation and disposition of reports.

This section discusses the objectives of the monitoring programs conducted at PGDP (Subsect. 4.1), current monitoring being conducted (Subsect. 4.2), and related activities (Subsect. 4.3). The 1990 groundwater monitoring results are presented in Sect. 4, Part 2). 


\subsection{TECHNICAL OBJECTIVES}

The primary objectives of groundwater monitoring are to detect as early as possible any contamination resulting from past and present land disposal of wastes and to provide the basis for developing groundwater quality assessments if contamination is detected. Additional objectives outlined in DOE Order 5400.1 require that groundwater monitoring at all DOE facilities "determine and document the effects of operations on groundwater quality and quantity." The order specifically requires groundwater monitoring to be conducted on-site and in the vicinity of DOE facilities to:

- obtain data to determine baseline conditions of groundwater quality and quantity;

- demonstrate compliance with, and implementation of, all applicable regulations and DOE orders;

- provide data to permit early detection of groundwater pollution or contamination;

- provide a reporting mechanism for detected groundwater pollution or contamination;

- identify existing and polential groundwater contamination sources and maintain surveillance of these sources; and

- provide data for making decisions about land disposal practices and the management and protection of groundwater resources.

\subsection{DESCRIPTION}

The monitoring and protection of groundwater at PGDP are required by federal and state regulations and DOE orders. Federal groundwater regulations generally are promulgated and enforced by EPA. PGDP lies within EPA Region IV jurisdiction, which encompasses the southeastern United States. The EPA regional headquarters is located in Atlanta, Georgia.

State groundwater regulations are promulgated and enforced by the Kentucky Division of Waste Management (KDWM), located in Frankfort, Kentucky. A KDWM field office for western Kentucky is located in Paducah, Kentucky, but most interactions between PGDP and KDWM concerning groundwater involve the Hazardous Waste Branch of KDWM in Frankfort.

Groundwater-monitoring activities at PGDP are described as "effluent monitoring" or "environmental surveillance monitoring." Effluent monitoring as applied to groundwater is monitoring to achieve compliance with one or more federal or state regulations, permit conditions, or environmental commitments made in Environmental Impact Statements, Environmental Assessments, or other official documents. Included under this heading is groundwater monitoring at either interim-status or permitted-status RCRA units, monitoring of 3004 $(u / v)$ RCRA facilities, monitoring in conjunction with CERCLA actions (e.g., RI/FSs), monitoring around landfills in compliance with permit regulations, and monitoring around underground storage tanks (USTs). In addition, greundwater monitoring in response to administrative orders or a memorandum of understanding (e.g., Agreed Order between the facility and EPA) is included as effluent monitoring.

Environmental surveillance monitoring is defined as perimeter exit pathway monitoring and off-site water well monitoring. Perimeter exit pathway monitoring is conducted to aid understanding of the effects of facility operations on the regional groundwater quality and quantity. In addition to verifying compliance with regulatory requirements at the reservation boundary, perimeter exit pathway monitoring provides a means of detecting previously unidentified on-site groundwater quality problems. Off-site water well monitoring is conducted to address public concerns about off-site groundwater contamination, especially of drinking water sources.

The general characteristics that differentiate groundwater effluent and surveillance monitoring are summarized in Table 4.1. Subsects. 4.2.1 and 4.2.2 describe the existing effluent and environmental surveillance monitoring conducted by PGDP. For a more detailed description of the groundwatermonitoring requirements prescribed by the applicable regulations and DOE orders, the reader is referred to the PGDP GWPP MP (KY/ER-2). Analytical results from the sampling described below are included in Tables 4.1-4.10 of Part 2. 
Table 4.1. Comparison of general characteristics of groundwater effluent and groundwater survelliance monitoring

\begin{tabular}{ll}
\hline \multicolumn{1}{c}{ Groundwater effluent monitoring } & \multicolumn{1}{c}{ Groundwater surveillance monitoring } \\
\hline $\begin{array}{l}\text { Regulation, permit, or investigation driven } \\
\begin{array}{l}\text { Monitors individual units, facilities, or } \\
\text { waste area groupings }\end{array}\end{array}$ & $\begin{array}{l}\text { DOE order driven } \\
\text { Monitors entire plant }\end{array}$ \\
$\begin{array}{l}\text { Monitoring locations are generally on-site } \\
\text { Short, intermediate, and/or long-term monitoring } \\
\begin{array}{l}\text { Constantly changes sites, adds wells, deletes wells, } \\
\text { changes parameters, changes frequencies }\end{array}\end{array}$ & $\begin{array}{l}\text { Permanent } \\
\text { Rarely changes after full implementation }\end{array}$ \\
\hline
\end{tabular}

\subsubsection{Emluent Monitoring}

\subsubsection{RCRA interim status and permit-monitoring programs}

RCRA groundwater monitoring is required under two separate sections of the regulations applying to units that are under interim status or are regulated (and therefore have a RCRA permit). Kentucky is an authorized state and maintains the permitting/ enforcement authority for the PGDP RCRA units.

Currently, the only RCRA facility at PGDP that requires groundwater monitoring is the $\mathrm{C}-404$ low-level radioactive waste burial ground, which is currently under interim status regulations awaiting a post-closure permit. The C-404 unit was a low-level waste burial ground until 1986, when routine testing programs indicated that the gold precipitate disposed of in early 1986 was hazardous due to the characteristics of extraction procedure toxicity. The unit was certified closed in 1987 as a hazardous waste landfill. A postclosure permit application was prepared and submitted to the state of Kentucky in June 1989. Twelve detection-monitoring wells were subsequently installed to monitor groundwater quality during the postclosure-care period (see Fig. 4.1 and Table 4.2). The detection wells were installed in the shallow ground system (SGS) and the underlying regional gravel aquifer (RGA), which is considered to be the uppermost aquifer. A statistical evaluation of the indicator parameters was conducted utilizing quarterly sample results from the initial year of monitoring. The evaluation indicated that well 88 had significantly greater levels of contamination for TCE, uranium, ${ }^{99} \mathrm{Tc}$, and arsenic than well 94 , which was assumed to be upgradient. As a result, the state of
Kentucky determined that additional information was needed to support the postclosure permit application.

The state of Kentucky was notified, and an assessment-monitoring plan was proposed to the state. The plan included further assessment of the plume, using the groundwater investigation currently being conducted at PGDP pursuant to a CERCLA Administrative Consent Order (ACO) between DOE and EPA. Additionally, Appendix IX sampling was to be performed at C-404. As a result of a meeting conducted on August 27, 1990, among Kentucky, DOE, and Martin Marietta Energy Systems, Inc., the state suggested entering into an Agreed Order outlining the proposed plan and schedules for assessment monitoring at C-404. The state indicated that a draft Agreed Order would be prepared and submitted to DOE for review. Until specific details relating to assessment monitoring are defined, monitoring continues at this unit on a quarterly basis for the constituents listed in Table 4.3. Table 4.1 in Part 2 contains the quarterly sampling results for this unit collected during 1990.

KDWM regulations governing hazardous waste management require that groundwater information for interim status units be reported in conjunction with the Annual Hazardous Waste Treatment, Storage and Disposal Report (401KAR 35:060). This report was submitted to DOE before March 1, 1991, and contained the following data collected at C-404 during 1990:

- quarterly sampling results,

- Appendix IX sampling results,

- water-level data, and

- results from an aquifer test performed at C-404. 


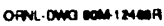

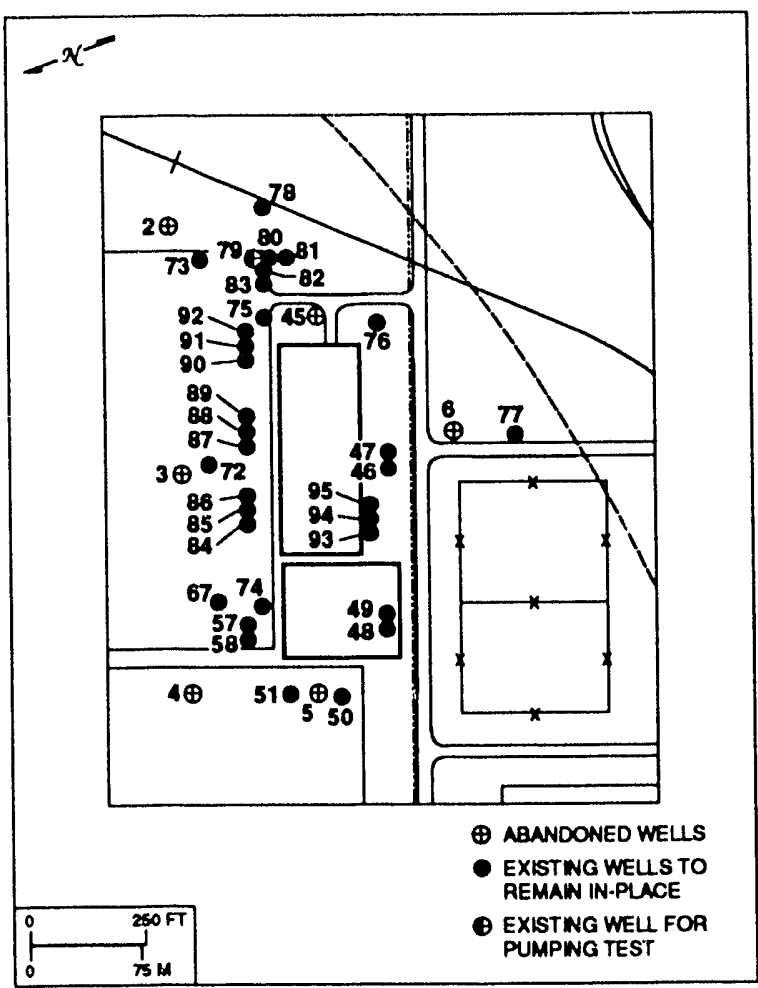

Fig. 4.1. Approximate locations of wells around the C-404 area.

Table 4.2. RCRA monitoring wells at C-404

\begin{tabular}{cc}
\hline Well No. & Monitored zone \\
\hline 84 & RGA \\
85 & SGS \\
86 & RGA \\
87 & RGA \\
88 & SGS \\
89 & RGA \\
90 & RGA \\
91 & SGS \\
92 & RGA \\
93 & RGA \\
94 & SGS \\
95 & RGA \\
\hline
\end{tabular}


Table 4.3. C-404 detection monitoring parameters

\begin{tabular}{ll}
\hline \multicolumn{1}{c}{ Analyte } & Method \\
\hline Selenium (total and dissolved) & EC-1040 \\
Cadmium (total and dissolved) & EC-1400 \\
Lead (total and dissolved) & EC-1400 \\
Uranium & EC-1910 \\
Arsenic (total and dissolved) & EC-1040 \\
Trichlorethylene & EC-1704 \\
Total organic halogens & \\
Total organic carbon & EC-1873 \\
pH & ES-14 \\
Temperature & ES-14 \\
Conductivity & EC-1240 \\
99Tc & EC-1860 \\
\hline
\end{tabular}

Additionally, the report presented a preliminary evaluation of contaminant migration based on an analysis of groundwater flow beneath C-404 and listed activities being conducted during the CERCLA investigation that are expected to impact assessment monitoring at C-404. For more information concerning this facility, the reader is referred to this report.

\subsubsection{Underground storage tank monitoring}

As with regulations governing solid waste management units (SWMUs) and CERCLA sites, few specific requirements for groundwater monitoring have been established for USTs. In general, the UST regulations require groundwater monitoring in only two instances: (1) as one of several acceptable leak detection alternatives and (2) during site characterization to determine the extent of a release of regulated substances from the UST.

During a scheduled well evaluation in July 1989 , evidence of combustible vapors was discovered in a plant well. Subsequent investigation of two underground tanks at the C-750 garage confirmed that they were leaking. These tanks were emptied of product, exploratory soil borings were conducted, and a monitoring well was installed. The current monitoring effort being conducted to target petroleum consists of sampling wells $47,52,68,69,70,71$, and 96 on a bimonthly basis for BTEX and total petroleum hydrocarbons. This sampling is in addition to the regular quarterly sampling that these wells undergo. The 1990 sampling results for these wells are presented in Table 4.2 in Part 2.

A general UST investigation also is scheduled during 1991 that will target two USTs at the C-750 garage and four additional USTs in the general vicinity. The intent of the investigation is to determine if any tanks not previously investigated have leaked, to identify possible pathways of contamination, and to suggest alternatives and recommended actions for the remediation of the site. A minimum of 12 wells are to be installed during this investigation (CDM 1991). Subsequent long-term monitoring requirements for these wells will be determined when the investigation is completed.

\subsubsection{CERCLA/Administrative Consent Order monitoring}

\section{Off-site well monitoring}

With the discovery of contamination in groundwater north of the plant in August 1988, DOE and EPA entered into an ACO under CERCLA Sects. 104 and 106 to determine the nature and extent of off-site contamination. The EPA ACO, Docket No. 88-35-c, Part V, Sect. J, 2 and 3, requires monthly sampling of potentially affected wells and plant well 66 for TCE, ${ }^{99} \mathrm{Tc}$, and gross alpha and beta. Any lcvels exceeding the national interim primary drinking water standards for alpha $(>15 \mathrm{pCi} / \mathrm{L})$ and beta $(>50 \mathrm{pCi} / \mathrm{L})$ must be analyzed further to determine the cause. 
Extensive groundwater monitoring of residential and plant wells was initiated. Over 280 plant and off-site wells have been sampled and analyzed for TCE and ${ }^{99} \mathrm{Tc}$. Action levels for the Environmental Restoration Program are $1 \mu \mathrm{g} / \mathrm{L}$ TCE and $25 \mathrm{pCi} / \mathrm{L}$ ${ }^{99} \mathrm{Tc}$. Wells showing levels above this are defined as contaminated.

Based on the results of this initial sampling, PGDP established a sampling program that exceeds the EPA ACO requirements. This program includes:

- Monthly sampling for the wells already showing contamination. These wells are monitored monthly for TCE, ${ }^{99} \mathrm{Tc}$, gross alpha, and gross beta to establish any changes in concentration that might indicate contaminant plume migration.

- Weekly sampling of wells with the highest potential for contamination. These wells are sampled weekly for TCE and ${ }^{99}$ Tc. Additionally, during the first week of the monthly sampling period, the wells are sampled for gross alpha and gross beta.

- Bimonthly sampling of wells with little chance of contamination. These wells are sampled on a bimonthly basis for only TCE and ${ }^{99} \mathrm{Tc}$.

- Quarterly sampling of Tennessee Valley Authority (TVA) wells by a TVA sampling team from Muscle Shoals, Alabama. PGDP obtains a portion of its water for its analysis of TCE and ${ }^{99} \mathrm{TC}$.

- Monthly sampling of noncontaminated wells and residential wells. These wells have not shown contamination, but they are sampled monthly for TCE,

${ }^{99} \mathrm{Tc}$, and gross alpha and beta because of their proximity to TVA wells showing contamination.

Table 4.4 lists the wells included within each category.

Figure 4.2 shows the location of any residential or TVA well having TCE or ${ }^{99} \mathrm{TC}$ contamination. An off-site drinking well is considered contaminated if any sample has levels above the DOE/PGDP action limits of $25 \mathrm{pCi} / \mathrm{L}$ for ${ }^{99} \mathrm{Tc}$ and $1 \mu \mathrm{g} / \mathrm{L}$ for TCE. Ongoing sampling of residential wells performs two functions: (1) detecting the spread of contamination to other wells and (2) gaining additional information about those wells already contaminated. Each sample is analyzed for TCE and ${ }^{99} \mathrm{Tc}$, and residents are notified of the results of each sample. The residences are also sampled regularly for gross alpha and beta. Action is taken to supply alternate water supplies if the action levels are exceeded. The $25 \mathrm{pCi} / \mathrm{L}$ action level is well below $900 \mathrm{pCi} / \mathrm{L}$ for ${ }^{99} \mathrm{Tc}$, which is approximately equivalent to the $4-\mathrm{mrem} /$ year exposure standard for manmade beta-emitting radionuclides. This exposure is based upon the consumption of $2 \mathrm{~L} / \mathrm{d}$ of water. Residential wells sampled weekly and monthly are shown in Fig. 4.3. TVA monitoring wells are sampled quarterly (Fig. 4.4).

Data generated by this sampling program (see Tables 4.3-4.5, Part 2) aid PGDP in protecting the health of affected residents by giving advance warning of increases in contaminant levels so appropriate actions can be taken. They also are being used by plant personnel and consultants to identify the sources and to quantify the extent of contamination.

\section{Site investigation for groundwater contamination}

The ACO also required a site investigation to determine the nature and extent of off-site contamination and to assess remedial alternatives for the possible on-site sources for this contamination. DOE/Energy Systems contracted with $\mathrm{CH} 2 \mathrm{M}$ Hill to develop and implement a work plan for the site investigation that would determine the nature and extent of contamination off-site to protect human health and the environment. Phase 1 of the two-part investigation has been completed. Thirty-five new monitoring wells were installed upgradient and downgradient of the plant (Table 4.5).

Each of these wells was sampled at least once for constituents listed in the Target Compound List (TCL) and for selected radionuclides. Additionally, 80 existing monitoring wells and nearby residential wells were inspected and evaluated, with 40 wells selected for water quality monitoring during the investigation. Each of the 40 wells was sampled up to four times during the investigation for constituents listed in the TCL and for selected radiounuclides. An additional 29 wells were sampled once for TCL and radionuclides. A complete discussion of the investigation and results is presented in the draft Results of the Site Investigation, Phase I (CH2M Hill 1990). 
Table 4.4. Wells included in the CERCLA/ACO well-monitoring program

\begin{tabular}{|c|c|c|c|c|}
\hline $\begin{array}{c}\text { Monthly } \\
\text { (contaminated) }\end{array}$ & Weekly & Bimonthly & Quarterly & $\begin{array}{c}\text { Monthly } \\
\text { (noncontaminated) }\end{array}$ \\
\hline $\begin{array}{l}\text { RA } 2^{a} \\
\text { RA } 4 \text { (MW 20) } \\
\text { RA } 5 \\
\text { RA 16 } \\
\text { RA } 17 \\
\text { RA 18 } \\
\text { RA } 113 \\
\text { RA 245 } \\
\text { MW } 38^{b} \\
\text { MW } 41 \\
\text { MW } 43 \\
\text { MW } 44 \\
\text { MW } 66\end{array}$ & $\begin{array}{l}\text { RA } 10 \\
\text { RA } 12 \\
\text { RA } 13 \\
\text { RA } 14 \\
\text { RA 19 } \\
\text { RA } 39 \\
\text { RA 40 } \\
\text { RA } 54 \\
\text { RA } 31 \\
\text { RA 294 }\end{array}$ & $\begin{array}{l}\text { RA 8 } \\
\text { RA 9 } \\
\text { RA 20 } \\
\text { RA 22 } \\
\text { RA 23 } \\
\text { RA 24 } \\
\text { RA 25 } \\
\text { RA 26 } \\
\text { RA 28 } \\
\text { RA 41 } \\
\text { RA 42 } \\
\text { RA 53 } \\
\text { RA 69 } \\
\text { RA 79 } \\
\text { RA 88 } \\
\text { RA 89 } \\
\text { RA 112 } \\
\text { RA 293 }\end{array}$ & $\begin{array}{l}\text { RA } 154 \\
\text { RA } 155 \\
\text { RA } 156 \\
\text { RA } 157 \\
\text { RA } 158 \\
\text { RA } 159 \\
\text { RA } 161 \\
\text { RA } 162 \\
\text { RA } 163 \\
\text { RA } 164 \\
\text { RA } 165 \\
\text { RA } 166 \\
\text { RA } 167 \\
\text { RA } 168 \\
\text { RA } 169 \\
\text { RA } 170 \\
\text { RA } 171 \\
\text { RA } 172 \\
\text { RA } 173 \\
\text { RA } 174 \\
\text { RA } 182 \\
\text { RA } 183 \\
\text { RA } 184 \\
\text { RA } 229 \\
\text { RA } 230 \\
\text { RA } 231 \\
\text { RA } 232\end{array}$ & $\begin{array}{l}\text { RA 21 } \\
\text { RA 43 } \\
\text { RA 72 } \\
\text { RA 82 } \\
\text { RA 83 } \\
\text { RA 84 } \\
\text { RA 6 }\end{array}$ \\
\hline
\end{tabular}

aff-site residential well or TVA monitoring well.

${ }^{b}$ PGDP monitoring well (located on-site, monitoring required by ACO).

The major findings of the $\mathrm{CH} 2 \mathrm{M}$ Hill Phase I Site Investigation include the following:

- The primary on-site contaminants in the shallow groundwater system are ${ }^{99} \mathrm{Tc}$ and TCE with occasional detectablc toluene.

- No off-site contaminants were detected in the SGS, although one off-site SGS well indicated the presence of ${ }^{99} \mathrm{Tc}$. However, this result was not substantiated by additional sampling and analysis.

- The primary off-site contaminants in the regional gravel aquifer are TCE and ${ }^{99} \mathrm{Tc}$, with

bis(2-ethylhexyl)phthalate seen occasionally; however, a source for bis(2-ethylhexyl)phthalate at PGDP has not been found.

- TCE and ${ }^{99} \mathrm{Tc}$ contamination was found on site.

- The following parameters were detected in one well each in the deep groundwater system: benzene, toluene, ethylbenzene, xylene, and ${ }^{99} \mathrm{Tc}$. However, it should be noted that the BTEX compounds were detected in only one well for one sampling event. Other sampling events of the same wells showed no BTEX contamination, suggesting that detections of BTEX compounds in the deep groundwater system were erroneous.

- The parameters ${ }^{234} \mathrm{U}$ and ${ }^{238} \mathrm{U}$ were detected in several wells in the deep groundwater system at the detection limit. However, the uranium results are questionable because no pathway is evident for the uranium to reach the deep gravel system. Additionally, no uranium was detected in the RGA or SGS of these same well clusters. The anomalous uranium results for the deep groundwater system appear to be related to analytical difficulties. 
ORNL-DWG 89M-8336R2

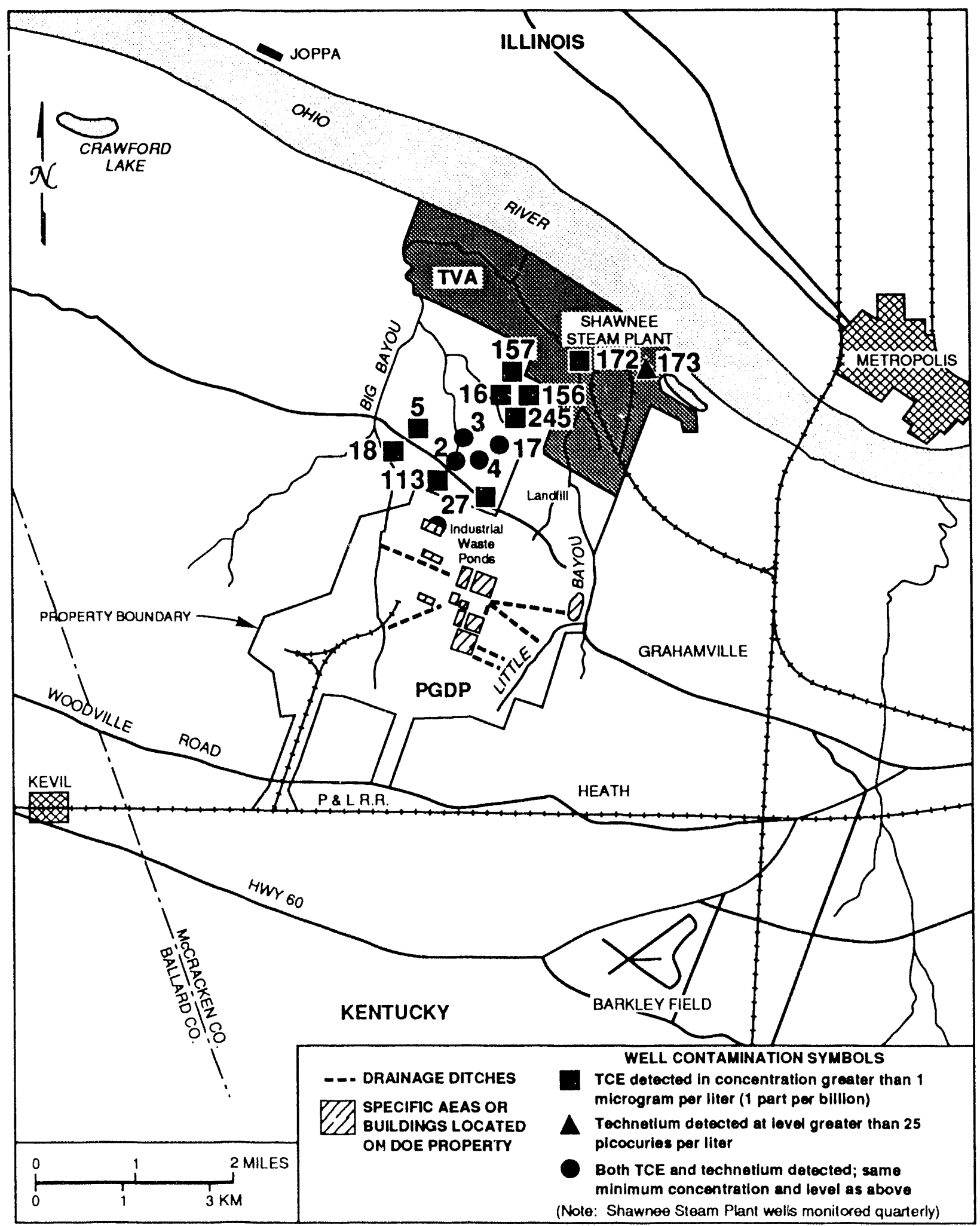

Fig. 4.2. Off-site groundwater-sampling locations where ${ }^{99} \mathrm{Tc}$ and TCE were detected. 
ORNL-DWG 89M-8335R2

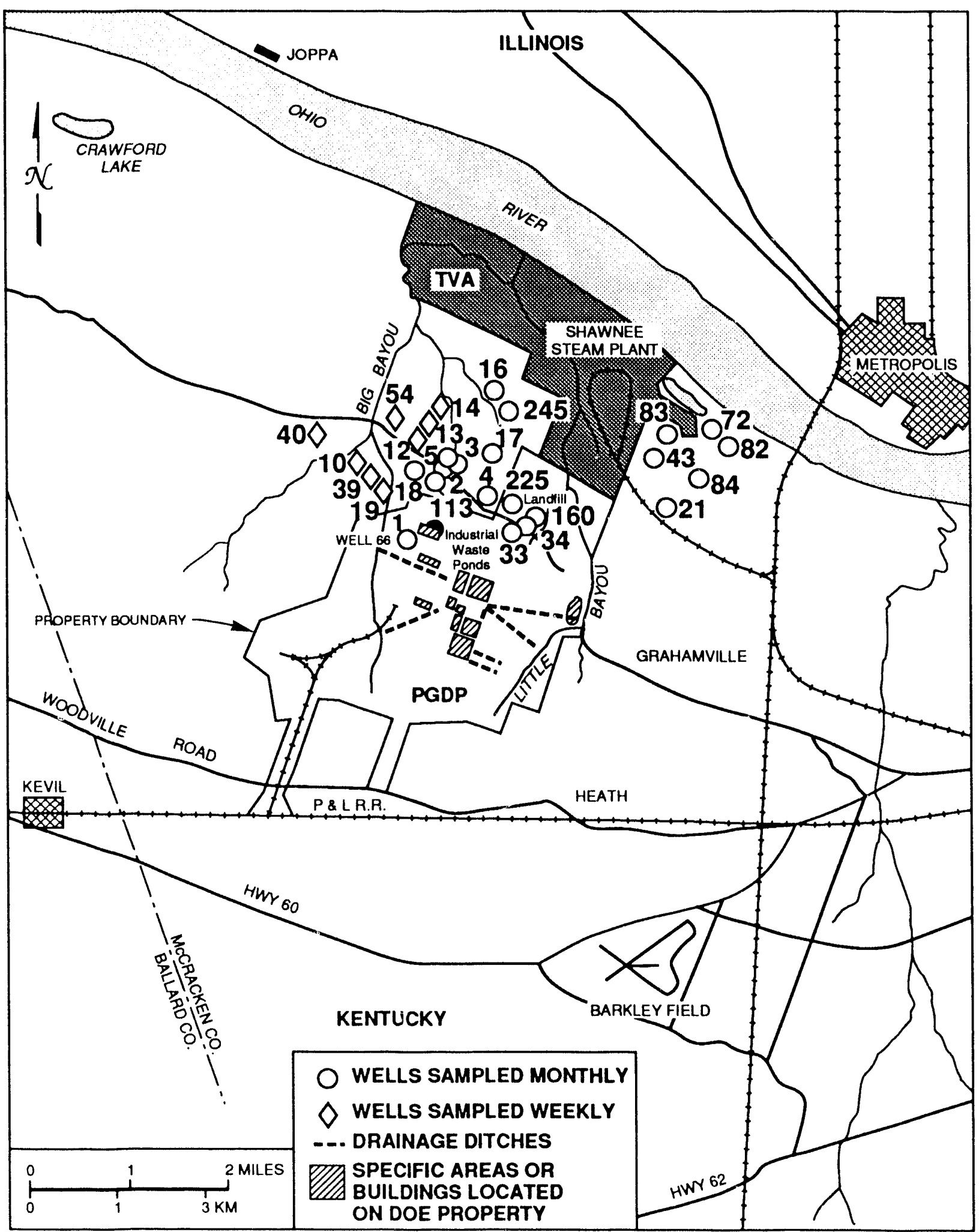

Fig. 4.3. Wells sampled weekly and monthly. 
ORNL-DWG 89M-8412R

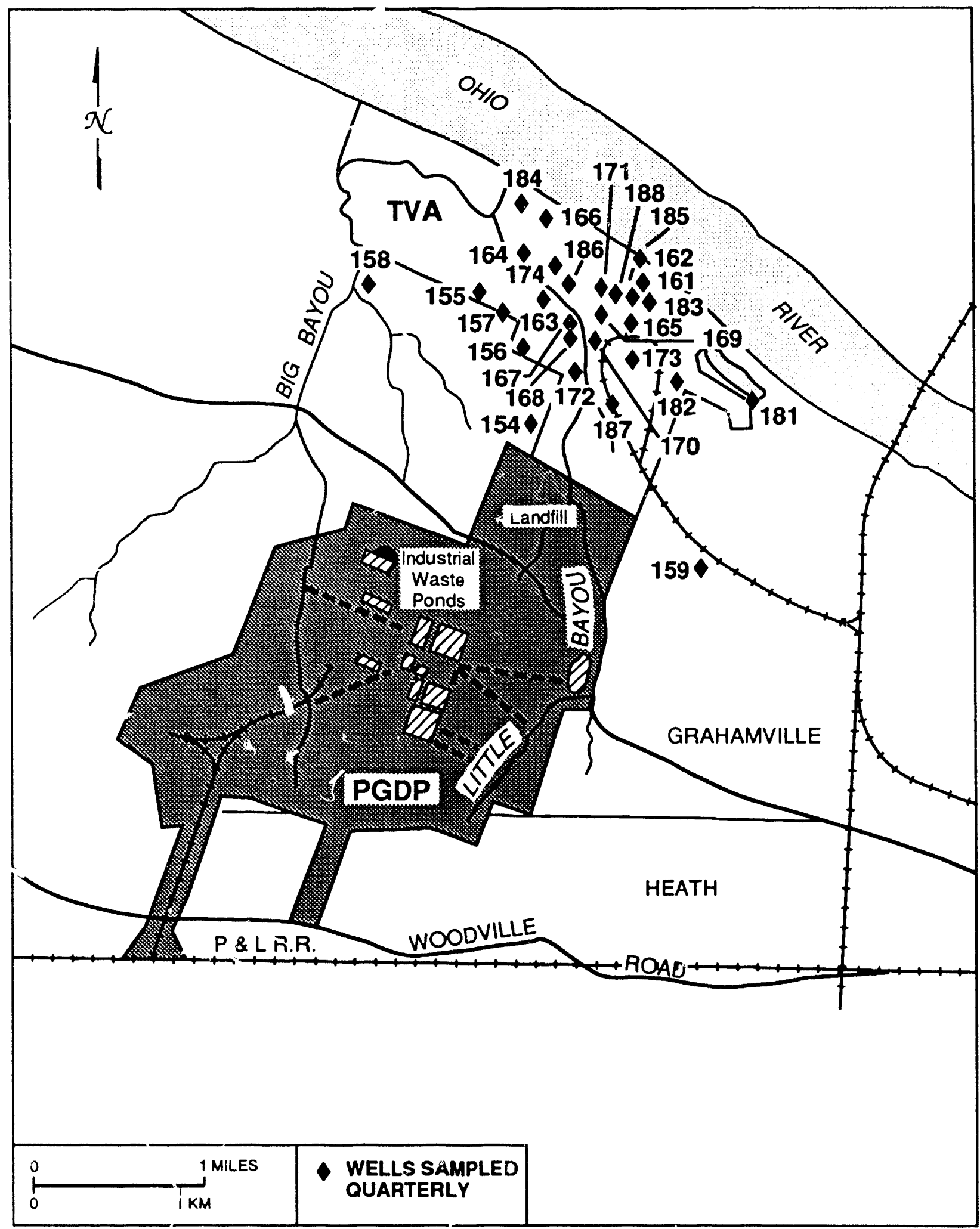

Fig. 4.4. TV A wells sampled quarterly. 
Table 4.5. Environmental restoration monitoring wells installed during 1990

\begin{tabular}{clll}
\hline Well & $\begin{array}{c}\text { Monitored } \\
\text { zone }\end{array}$ & Well & $\begin{array}{c}\text { Monitored } \\
\text { zone }\end{array}$ \\
\hline 120 & McN $^{a}$ & 137 & RGA \\
121 & McN & 138 & SGS \\
122 & McN & 139 & RGA \\
123 & RGA $^{b}$ & 140 & McN \\
124 & RGA $_{12}$ & 141 & RGA \\
125 & RGA & 142 & RGA \\
126 & RGA & 143 & SGS \\
127 & SGS & 144 & RGA \\
128 & SGS & 145 & RGA \\
129 & RGA & 146 & RGA \\
130 & RGA & 147 & RGA \\
131 & SGS & 148 & RGA \\
132 & RGA & 149 & SGS \\
133 & EoC & 150 & RGA \\
134 & RGA & 151 & RGA \\
135 & RGA & 152 & RGA \\
136 & RGA & 153 & SGS \\
& & 154 & SGS \\
\hline
\end{tabular}

${ }^{a}$ McNairy Formation.

${ }^{b}$ Regional gravel aquifer.

'Shallow ground water system.

${ }^{d}$ Undifferentiated Eocene sands.

\subsubsection{State solid waste disposal regulations}

Compliance-monitoring requirements exist at the KDWM-permitted facilities C-746-S and C-746-T. Sample frequency and analytes are dictated by the specific permit for each facility. Wells $16-19$ and 38-44 (see Fig, 4.5) serve as monitoring stations for these facilities. These wells are sampled quarterly for the constituents in Table 4.6 and annually for the additional constituents in Table 4.7. Additionally, the wells are analyzed for chloride during the first and third quarters of each year.

\subsubsection{RCRA 3004}

Additional groundwater monitoring to be performed by the ERP relates to RCRA 3004(u and v) and CERCLA requirements for characterizing contamination from all nonregulated sources (i.e., SWMUs not regulated under a RCRA permit or interim status) at a facility that has had releases that may contaminate groundwater. Results of this monitoring will be used to determine and implement remedial actions as necessary to protect human health and the environment. Prescriptive regulations, such as those governing RCRA interim status and regulated units, do not exist for remedial action groundwater monitoring at this time.

Sites at PGDP that are clearly SWMUs as defined by RCRA have been assessed in PGDP 1987a. This report contains a description of each unit, including its approximate location, size, and status; information on the types and amounts of waste (if known) associated with the unit; and a description of releases if available. Additionally, an initial determination has been made of the need for a RCRA Facility Investigation (RFI) for each unit. As a rule, all treatment, storage, or disposal units with known releases that were unmonitored, or for which the operating history was completely or partially unknown, were considered to need an RFI.

A second report under separate cover, PGDP $1987 \mathrm{~b}$, provides information on 24 known and potential spill sites on the PGDP plant site. While these sites are presented in a separate report from the SWMUs, they have been integrated into the PGDP 


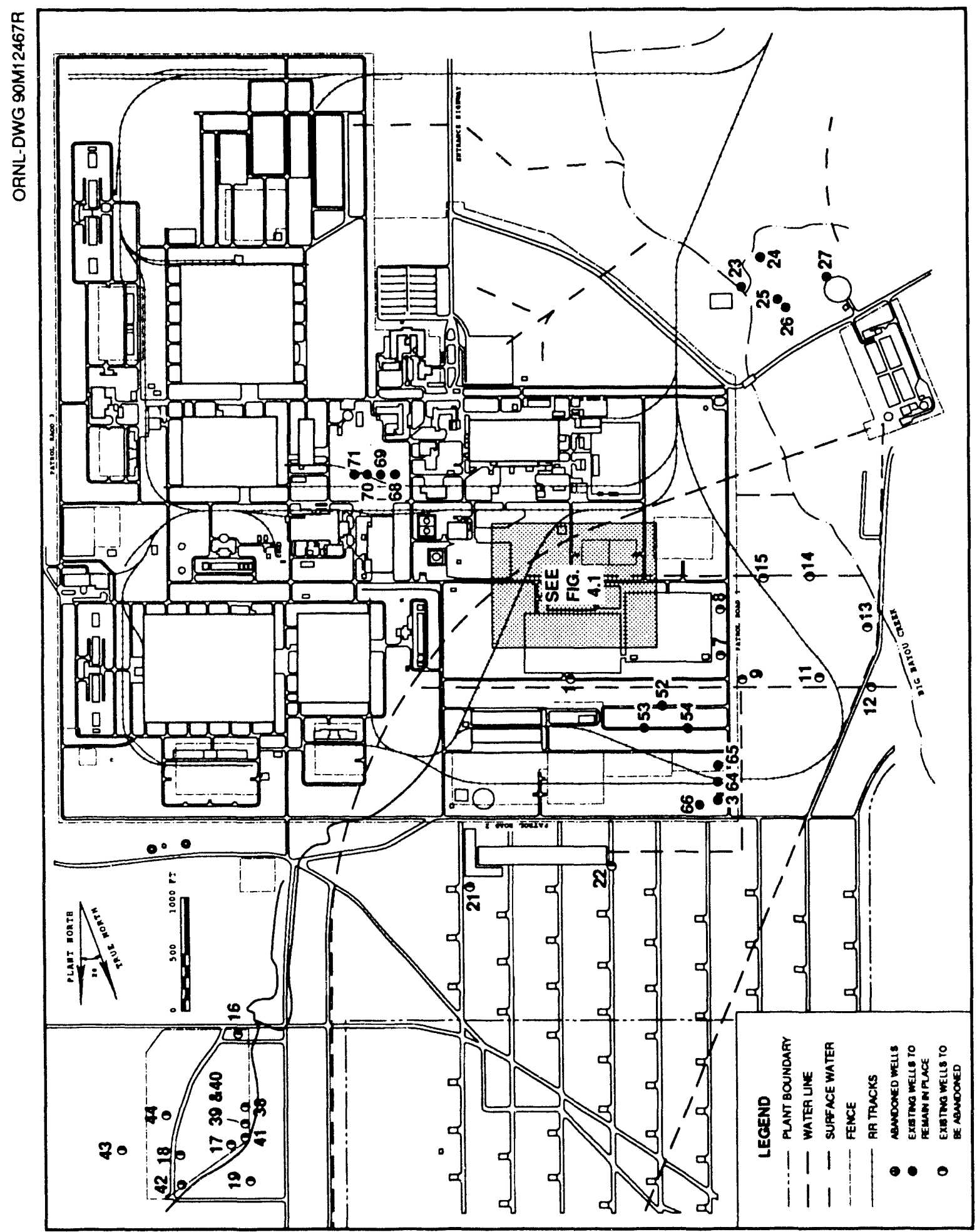


Table 4.6. Quarterly analytical parameters

\begin{tabular}{ll}
\hline \multicolumn{1}{c}{ Parameter } & Method \\
\hline Dissolved alpha & EC-1010 \\
Dissolved beta & EC-1010 \\
Suspended alpha & EC-1010 \\
Suspended beta & EC-1010 \\
Uranium & EC-1910 \\
Flouride & EC-1330 \\
Total organic halogens & \\
Total organic carbon & EC-1873 \\
Chromium & EC-1400 \\
Copper & EC-1400 \\
Nickel & EC-1400 \\
Iron & EC-1400 \\
Lead & EC-1400 \\
Zinc & EC-1400 \\
Nitrate & EC-1400 \\
Sulfate & EC-1500 \\
PCBs & EC-1130 \\
TCE & EC-1704 \\
99Tc & EC-1860 \\
pH & ES-14 \\
Temperature & ES-14 \\
Conductivity & EC-1240 \\
Depth & ES-2 \\
Color & EC-1220 \\
Turbidity & EC-1880 \\
\hline & \\
\hline & \\
\hline
\end{tabular}

Table 4.7. Annual analytical parameters

\begin{tabular}{ll}
\hline \multicolumn{1}{c}{ Parameter } & Method \\
\hline Americium & EC-1020 \\
Cobalt & \\
Cesium & \\
Radium & \\
Hexavalent chromium & EC-1180 \\
Dissolved solids & EC-1760 \\
Alkalinity & EC-1005 \\
Phosphate & EC-1610 \\
Chloride & EC-1130 \\
Calcium & EC-1400 \\
Cadmium & EC-1400 \\
Magnesium & EC-1400 \\
Manganese & EC-1400 \\
Sodium & EC-1400 \\
Selenium & EC-1040 \\
\hline
\end{tabular}


Table 4.8. Waste management units currently monitored at PGDP

\begin{tabular}{cl}
\hline $\begin{array}{c}\text { Unit No. } \\
\text { (from preliminary assessment) }\end{array}$ & \multicolumn{1}{c}{ Name } \\
\hline 5 & C-746-F classified burial ground \\
2 & C-749 uranium burial ground \\
3 & C-404 low-level radioactive waste burial ground \\
9 & C-746-S residential landfill \\
10 & C-746-T inert landfill \\
7 & C-747-A burial ground \\
30 & C-747-A burn area \\
13 & C-746-P clean scrap yard \\
12 & C-747-A UF 4 drum yard \\
14 & C-746-E contaminated scrap yard \\
15 & C-746-C scrap yard \\
8 & C-746-K inactive sanitary landfill \\
17 & C-616-E sludge lagoon \\
18 & C-616-F full-flow lagoon \\
\hline
\end{tabular}

ORNL.DWG 80M-8037R

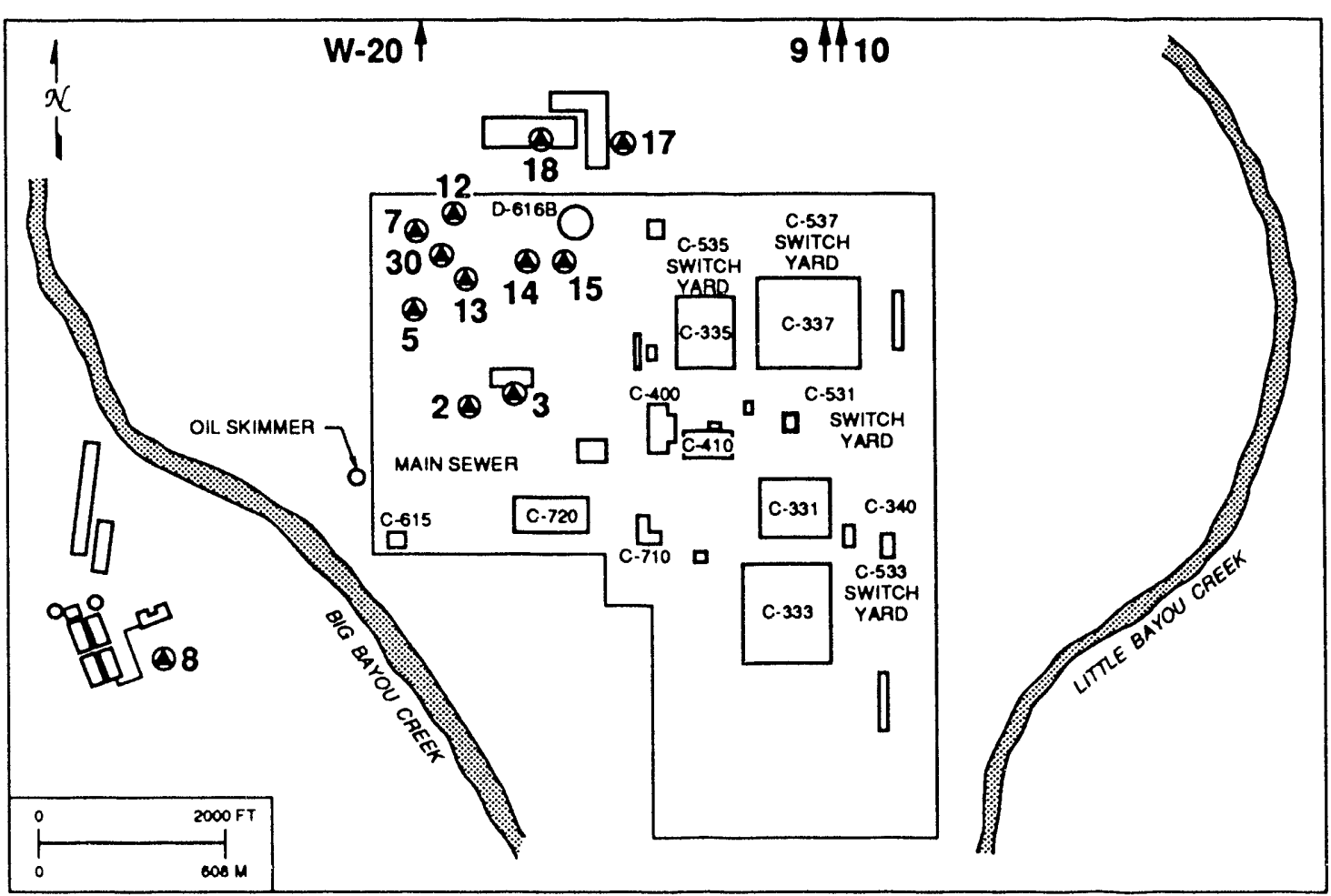

Fig. 4.6. Waste management units currently monitored at PGDP. 
Table 4.9. Wells monitored at SWMUs

\begin{tabular}{clcc}
\hline Well & Monitored zone & Well & Monitored zone \\
\hline 16 & SGS $^{a}$ & 46 & RGA \\
17 & RGA $^{b}$ & 47 & SGS \\
18 & SGS & 48 & RGA \\
19 & RGA & 50 & RGA \\
20 & RGA & 51 & RGA \\
21 & RGA & 52 & RGA \\
22 & RGA & 53 & SGS \\
23 & PCC & 57 & SGS \\
24 & PCC & 59 & \\
26 & RGA & 60 & \\
27 & PCC & 61 & \\
38 & RGA & 62 & \\
39 & RGA & 63 & RGA \\
40 & RGA & 64 & SGS \\
41 & RGA & 65 & RGA \\
42 & RGA & 66 & RGA \\
43 & PCCRGA & 67 & RGA \\
44 & RGA & 68 & RGA \\
54 & RGA & 71 & RGA \\
\hline
\end{tabular}

aShallow groundwater system.

${ }^{b}$ Regional gravel aquifer.

cPorters Creek Clay.

Note: Wells 59-62 are residential wells located off-site and are monitored for background purposes.

ERP without regard for their classification. All these sites likely will require further investigation.

To date, no ERP groundwater monitoring has been initiated at SWMUs pursuant to RCRA $3004 \mathrm{u}$ and $v$ and CERCLA requirements. PGDP is awaiting guidance from EPA about which units are to be investigated under the HSWA permit. The HSWA permit is expected to be issued to PGDP in 1991.

\subsubsection{Solid waste management unit monitoring}

Groundwater monitoring is conducted at several SWMUs at PGDP (see Table 4.8, Fig. 4.6). Well installation at selected units began in 1979 and continued through the mid-1980s. This monitoring effort was initially based in part on DOE orders that required monitoring at low-level radioactive waste sites. Currently, with the exception of wells 23-27, these wells are monitored quarterly for the constituents listed in Table 4.6 and annually for the additional constituents listed in Table 4.7. Wells 23-27 are sampled only annually for the constituents listed in Table 4.7. As indicated earlier, many of these units are targeted for investigation under the
ERP. As characterization continues during these projects, monitoring at these facilities will be changed accordingly. A total of 38 wells, including wells located at C-746-S and C-746-T, monitor SWMUs (Table 4.9).

The 1990 monitoring data are presented in Part 2 Tables 4.6-4.10. The following paragraphs give a brief discussion of the SWMUs currently monitored.

Unit 5, the C-746-F classified burial yard, is used for the disposal of cascade equipment, paper, and electronic media (such as computer disks) that are classified or may reveal classified information.

Unit 2, the C-749 uranium burial ground, was used from the late 1950s to the mid-1970s for the disposal of uranium scrap, some of which was pyrophoric (i.e., easily ignitable in air). To stabilize the uranium, it was submerged in waste oil. Unit 9, the C-746-S residential landfill, is used for the disposal of nonhazardous putrescible wastes such as paper, cardboard, and cafeteria wastes. C-746-S is permitted by KDWM. Unit 10, the C-746-T inert landfill, is used for the disposal of fly ash from the steam plant and nonputrescible construction wastes such as wood 
timbers and concrete. Unit 7, the C-747-A burial ground, was used for the disposal of all types of waste material from plant operations. Well 66 , the monitoring well with the highest level of TCE and ${ }^{99} \mathrm{Tc}$ contamination, is adjacent to this area. Unit 30 , the C-747-A burn area, was used for burning combustible wastes until approximately 1970 . This unit is located in the vicinity of the C-747-A burial ground.

Unit 13, the C-747-P clean scrap yard, is used to accumulate uncontaminated scrap metal for sale to reclaimers. Unit 12 , the C-747-A UF 4 drum yard, consists of a large waste pile of crushed $\mathrm{UF}_{4}$ drums. Unit 14, the C-746-E contaminated scrap yard, contains contaminated scrap metal generated during plant operations. Scrap material is separated by metal type. Most contamination is from depleted, natural, or slightly enriched uranium on the metal surfaces. Unit 15 , the C-746-C scrap yard, contains scrap metal of all types. The contamination is mostly from depleted, natural, or slightly enriched uranium.

Unit 8, the C-746-K inactive sanitary landfill, was used for the disposal of fly ash from 1951 to 1982. Sanitary trash was also placed in this landfill until 1982. A 15.24-cm (6-in.) clay cap was placed on this landfill in 1982. Unit 17, the C-616-E sludge lagoon, is an on-grade surface impoundment that receives the sludge from the C-616 chromium reduction facility. The chromium hydroxide sludge has been subjected to the extraction procedure toxicity tests and found to be nonhazardous under RCRA. Unit 18, the C-616-F full-flow lagoon, is an on-grade surface impoundment that receives the overflow from the C-616-E sludge lagoon and the liquid effluent from the clarifiers at the C-616 chromate reduction facility. In addition, effluents from the C-400 cleaning and decontamination building and coal pile runoff are piped to this impoundment.

\subsubsection{Environmental Surveillance Monitoring}

Implementation of groundwater surveillance monitoring, as prescribed by DOE Order 5400.1 and defined previously, is required during 1991. Formal definition of this new program as required by DOE 5400.1 is nearing completion, with implementation expected to begin when funding is approved.

Environmental surveillance monitoring will consist of two components. The first component will require monitoring at the plant perimeter via installation of new monitoring wells and the use of selected wells installed during the ongoing environmental restoration groundwater investigation. The second component will require the use of selected residential wells in the area. The Groundwater Surveillance Plan for PGDP (Forstrom et al. in press) describes in detail the rationale and criteria to be used to design the plant perimeter and off-site water well surveillance networks for PGDP.

The 1991 Environmental Monitoring Report will present the results of this monitoring program under two new sections entitled "Plant Perimeter Surveillance" and "Off-Site Water Well Surveillance."

\subsubsection{Groundwater Monitoring Results}

Technetium was detected in many plant and off-site wells and is being investigated as part of the ERP. While it was, in many cases, below regulatory concern $(<900 \mathrm{pCi} / \mathrm{L})$, its presence indicates a release into the groundwater regime because there are no natural sources of ${ }^{99} \mathrm{Tc}$.

Because of the close proximity of many units within the plant, contamination in wells associated with a particular unit may or may not be conclusive evidence that a release has occurred from that unit. Further study (to be conducted under the ERP) will be needed to provide this evidence. A summary of results for wells by SWMUs and monitoring programs is presented below. Table 4.10 presents the parameter analyzed, the recommended limit, and the wells exceeding this limit.

Wells 47,57 , and 58 , shallow groundwater system wells in the C-404 and C-749 areas, continue to yield samples with high TCE and/or ${ }^{99} \mathrm{Tc}$ concentrations. In addition, elevated levels of arsenic, chromium, and manganese were present in samples from one well each. Nearby wells $46,48,50,51$, and 67 , completed in the regional gravel aquifer, provided samples during 1990 without detectable TCE concentrations and with ${ }^{99} \mathrm{Tc}$ levels below the reference level. Manganese concentrations were elevated in one well.

Wells $16-19$ and 38-44 are used to monitor groundwater in the C-746-S and C-746-T areas. High levels of chromium, manganese, and TCE were present in samples from two wells each in the RGA. Three RGA wells produced ${ }^{99} \mathrm{Tc}$ concentrations above the reference level. The three shallow groundwater 
Table 4.10. Annual and semiannual effluent monitoring at SWMUs

\begin{tabular}{|c|c|c|c|}
\hline Parameter & $\begin{array}{l}\text { Applicable } \\
\text { value }\end{array}$ & Reference & $\begin{array}{c}\text { Wells exceeding reference } \\
\text { value at least once } \\
\text { during } 1990\end{array}$ \\
\hline $\mathrm{Cr}$ & $0.05 \mathrm{mg} / \mathrm{L}$ & 1 & $M W 17,47,71$ \\
\hline $\mathrm{Cu}$ & $1.0 \mathrm{mg} / \mathrm{L}$ & 2 & None \\
\hline $\mathrm{Fe}$ & $0.3 \mathrm{mg} / \mathrm{L}$ & 2 & $\begin{array}{l}\text { MW16, 17, 18, 19, 20, 21, 22, 23, } \\
24,26,27,39,41,42,43, \\
46,47,48,54,57,62,63\end{array}$ \\
\hline $\mathrm{Ni}$ & None & NA & NA \\
\hline $\mathrm{Pb}$ & $0.05 \mathrm{mg} / \mathrm{L}$ & 1 & (Detection limit of $0.2 \mathrm{mg} / \mathrm{L}$ ) \\
\hline $\operatorname{Zn}$ & $5.0 \mathrm{mg} / \mathrm{L}$ & 2 & MW23, 24, 26, 27 \\
\hline Total As & $0.05 \mathrm{mg} / \mathrm{L}$ & 1 & MW88 \\
\hline Total Cd & $0.01 \mathrm{mg} / \mathrm{L}$ & 1 & None \\
\hline Total Pb & $0.05 \mathrm{mg} / \mathrm{L}$ & 1 & None \\
\hline Total Se & $0.01 \mathrm{mg} / \mathrm{L}$ & 1 & None \\
\hline Dissolved As & None & NA & NA \\
\hline Dissolved Cd & None & NA & NA \\
\hline Dissolved $\mathrm{Pb}$ & None & NA & NA \\
\hline Dissolved Se & None & NA & NA \\
\hline $\mathrm{Ca}$ & None & NA & NA \\
\hline $\mathrm{Mg}$ & None & NA & NA \\
\hline $\mathrm{Mn}$ & $0.05 \mathrm{mg} / \mathrm{L}$ & 2 & MW18, 21, 22, 23, 27 \\
\hline $\mathrm{Na}$ & None & NA & NA \\
\hline $\mathrm{Cr}^{6+}$ & None & NA & NA \\
\hline $\mathrm{pH}$ & $6.5-8.5$ units & 2 & $\begin{array}{l}\text { MW16, 19, 20, 22, 27, 38, 39, 40, } \\
41,42,43,44,46,47,63,65, \\
66,67,68,71,84,86,87,88, \\
89,90\end{array}$ \\
\hline Temperature & None & NA & NA \\
\hline & $250 \mathrm{mg} / \mathrm{L}$ & 2 & None \\
\hline $\mathrm{NO}_{3}-\mathrm{N}$ & $10 \mathrm{mg} / \mathrm{L}$ & 1 & None \\
\hline $\mathrm{SO}_{4}$ & $250 \mathrm{mg} / \mathrm{L}$ & 2 & MW21 \\
\hline Turbidity & 5 NTU & 1 & $\begin{array}{l}\text { MW16, 17, 18, 19, 20, 21, 22, } 23 \text {, } \\
39,41,42,43,46,47,48,54, \\
57,62,63,64,66\end{array}$ \\
\hline Color & 15 units & 2 & MW22, 46, 57 \\
\hline $\mathrm{F}$ & $4.0 \mathrm{mg} / \mathrm{L}$ & 1 & None \\
\hline Conductivity & None & NA & NA \\
\hline TOC & None & NA & $\mathrm{NA}$ \\
\hline TDS & $500 \mathrm{mg} / \mathrm{L}$ & 2 & MW $16,17,18,21,23$ \\
\hline Alkalinity & None & NA & NA \\
\hline $\mathrm{PO}_{4}-\mathrm{P}$ & None & NA & NA \\
\hline TCE & $5 \mu \mathrm{g} / \mathrm{L}$ & 4 & $\begin{array}{l}\text { MW20, } 21,22,38,40,41,44,47, \\
57,66,68,71,88,91,94, R 2, \\
\text { R5, R17, R113, R157 }\end{array}$ \\
\hline PCB & None & NA & NA \\
\hline TOX & None & NA & NA \\
\hline & None & NA & NA \\
\hline${ }^{241} \mathrm{Am}$ & $1 \mathrm{pCi} / \mathrm{L}$ & 3 & $\begin{array}{l}\text { MW16, 22, 26, 27, 40, 42, 63, } 64 \text {, } \\
65,66\end{array}$ \\
\hline${ }^{60} \mathrm{Co}$ & $400 \mathrm{pCi} / \mathrm{L}$ & 1 & None \\
\hline${ }^{99} \mathrm{Tc}$ & $900 \mathrm{pCi} / \mathrm{L}$ & 1 & MW66, 88, R2 \\
\hline${ }^{222} \mathrm{Rn}$ & $2 \times 10^{7} \mathrm{pCi} / \mathrm{L}$ & 3 & None \\
\hline
\end{tabular}


Table 4.10 (continued)

\begin{tabular}{|c|c|c|c|}
\hline Parameter & $\begin{array}{l}\text { Applicable } \\
\text { value }\end{array}$ & Reference & $\begin{array}{c}\text { Wells exceeding reference } \\
\text { value at least once } \\
\text { during } 1990\end{array}$ \\
\hline Dissolved alpha & None & 1 & NA \\
\hline Suspended alpha & None & 1 & NA \\
\hline Dissolved beta & None & 1 & NA \\
\hline Suspended beta & None & 1 & NA \\
\hline Gross alpha & $15 \mathrm{pCi} / \mathrm{L}$ & 1 & MW66, R2, R17 \\
\hline Gross beta & $50 \mathrm{pCi} / \mathrm{L}$ & 1 & MW20, 66, R2, R17, R113 \\
\hline Benzene & $5 \mu \mathrm{g} / \mathrm{L}$ & 1 & MW 47, 68, 69, 96 \\
\hline Toluene & $2 \mathrm{mg} / \mathrm{L}$ & 5 & None \\
\hline Xylene & $10 \mathrm{mg} / \mathrm{L}$ & 5 & None \\
\hline Ethylbenzene & $700 \mu \mathrm{g} / \mathrm{L}$ & 5 & MW69,96 \\
\hline
\end{tabular}

$\mathrm{NA}=$ not applicable.

1. 40 CFR Pt. 141. Safe Drinking Water Act-National Primary Drinking Water Regulations, as amended.

2. 40 CFR Pt. 143. Safe Drinking Water Act-National Secondary Drinking Water Regulations, as amended.

3. Derived Concentration Guides (DCGs) for Air and Water. DOE Order 5400.5.

4. U.S Environmental Protection Agency. National Primary Drinking Water Regulations; Synthetic Organic Chemicals. Fed. Regist. 54(97) (May 22, 1989).

sys!em wells produced water with high manganese levels. Well 20 continues to show elevated levels of TCE and ${ }^{99}$ ГC. TCE and ${ }^{99} \mathrm{Tc}$ levels have increased over the 1989 levels reported. Iron and chromium concentrations exceeded the drinking water standards once each during 1990.

Wells 21 and 22 located at the C-616 lagoon indicate the presence of ${ }^{99} \mathrm{Tc}$. Technetium and TCE exceed the reference standards in well 22, but no TCE has been detected in well 21. Both wells 21 and 22 , based upon the one annual sample, show elevated manganese concentrations. Sulphate concentrations in well 21 are above the drinking water standard of $250 \mathrm{mg} / \mathrm{L}$.

Wells $47,52,68,69,70$, and 71 were monitored for petroleum products during 1990. No benzene, ethylbenzene, toluene, or xylene was detected in wells 52 and 70 during 1990 . Well 47 showed slightly elevated levels of benzene, toluene, and xylene, with no ethylbenzene present. Well 68 had elevated levels of benzene, toluene, and xylene from May through September, with ethylbenzene remaining elevated. Benzene was the only petroleum product present in well 71 . Wells 69 and 96 have elevated concentrations of benzene, ethylbenzene, toluene, and xylene. Wells $47,52,68$, and 71 show elevated concentrations of TCE and ${ }^{99} \mathrm{Tc}$.

Wells 84 through 95 are located at the C-404 low-level waste burial ground. TCE was not elevated in wells $84,85,86,89,92$, and 95 during 1990. All wells in this area indicate the presence of ${ }^{99} \mathrm{Tc}$, with wells $84,85,88,89,90$, and 94 having ${ }^{99} \mathrm{Tc}$ activities greater than $25 \mathrm{pCi} / \mathrm{L}$ during 1990.

Wells 52, 53, and 54 are located at the C-746-F burial area. Wells 52 and 53 were not sampled during 1990 because the pumps were inoperable. Iron concentrations in well 54 are extremely elevated.

Wells 68, 69, and 71 are located south of the C-400 decontamination building. No TCE or ${ }^{99} \mathrm{Tc}$ data are available for well 69. TCE and ${ }^{99} \mathrm{Tc}$ concentrations are elevated in wells 68 and 71 .

Wells 23, 24, 26, and 27 are located on the southwest side of the plant. All wells show concentrations of zinc above the drinking water standards. Wells 23 and 27 reported manganese concentrations above the drinking water limit in 1990, and chromium was elevated in well 23. 
Wells $63,64,65$, and 66 are associated with the C-746 scrap yard. The highest concentrations of ${ }^{99} \mathrm{Tc}$ and TCE during 1990 were reported from well 66 . An elevated ${ }^{99} \mathrm{Tc}$ level was also monitored in well 65 .

High chromium and manganese concentrations were reported also from single wells.

\subsection{PROJECT ACCOMPLISHMENTS}

As discussed in the introduction to Sect. 4, work continues under the auspices of the GWPP to address recognized deficiencies in the understanding of the site hydrogeology and geology (Early et al. 1989). Activities consist of specific projects performed and directed by the Environmental Restoration Department's Hydrogeologic Services Section (HSS) and the coordination of related activities conducted by other organizations. These activities are designed to complement existing compliance and restoration initiatives. Information from related activities is assimilated and analyzed with respect to addressing global deficiencies identified in the GMP.

The next two sections describe special projects that were conducted during 1991 and related projects that have served to augment progress toward characterization of the site.

\subsubsection{Hydrogeological Services Section}

The HSS has three main responsibilities: (1) oversee and maintain the PGDP GPP, (2) provide technical oversight and input on environmental restoration projects, and (3) provide technical services as requested to line organizations within the plant. Embodied within item 1 is implementation of the GMP, which identifies deficiencies in the understanding of the site flow system and prescribes activities to address these deficiencies. Toward this end, several activities designed to complement ongoing compliance and environmental restoration activities were conducted and/or completed during 1990.

\subsubsection{Modeling}

GeoTrans, Inc., was contracted to provide a calibrated three-dimensional numerical groundwater flow and transport model for the PGDP site. GeoTrans was chosen because it possesses relevant experience, having performed a similar study for the TVA Shawnee Steam Plant located just north of
PGDP. The project, performed under the direction of the HSS, consisted of a three-stage study completed with submission of the final report (GeoTrans, Inc. 1990), source code, and data files in Octobur 1990.

The first objective of the study was to assimilate available geologic and hydraulic data to support model development. A general approach for the modeling effort was then defined and agreed upon by the HSS. Initial modeling efforts consisted of two-dimensional numerical modeling to identify roughly the sensitivity of the flow system to various parameters and to identify boundary conditions. The last stage consisted of developing the threedimensional model and performing calibration and sensitivity runs. The model then was used to assess the current hydrogeologic conceptualization and to evaluate the effect of hypothesized paleochannels as preferential flow paths.

It was decided that insufficient data existed to support a far-fteld transport model. Particle tracking using the flow model was performed instead to assess possible advective transport pathways within the RGA.

The modeling effort and results from the study are discussed in great detail in the final report. Major conclusions resulting from the study are:

- The hypothesized paleochannels within the RGA, as modeled, do not appear to play a significant role in transport migration.

- The time to traverse the SGS to the RGA ranged from 6.5 to 29.3 years.

- Traverse time to the Ohio River, once contaminants entered the RGA, ranged from 7.1 to 20 years.

In addition, the analysis emphasized the following data needs in order of importance:

- additional water-level monitoring on the terrace face,

- expansion to a regional water-level monitoring program that is measured regularly and contemporaneously,

- delineation of transmissivity or gravel thickness near the Ohio River,

- continuous water-level measurements on the Ohio River and along a line of at least three wells,

- continued monitoring/construction of cluster wells,

- aquifer testing in typical areas, 
be considered. The final report discussing the study is expected by April 1991.

$\mathrm{CH} 2 \mathrm{M}$ Hill was asked to obtain monthly water-level measurements from up to 100 existing wells in and around the DOE Reservation. Additionally, as new wells are completed during Phase 2, they will be included in the monthly measurements. This project was initiated in October 1990 and will continue until the completion of Phase 2 of the Site Investigation, at which time HSS will assume responsibility for the water-level measurements.

Efforts to develop a sufficient level of understanding of the hydraulics and geochemistry of the flow system will continue through implementation of the GMP. Staff within HSS are assigned specific technical tasks related to areas of expertise that include geology, hydrogeology, and geochemistry. Every effort is made to gather and analyze all relevant data, with the overall goal of developing an adequate understanding of the site hydrogeology, geochemistry, and geology.

\subsubsection{Related Activities}

As indicated earlier, efforts are made to coordinate all related activities to ensure that maximum information is gained to augment the overall technical and programmatic goals of the GWPP. This is done by assigning a hydrogeologist within HSS to a particular related project. He or she tracks the project and provides technical input to ensure that the specific project objectives and the overall GWPP objectives are met to the extent possible. Specific projects are discussed below.

\subsubsection{Environmental Restoration Program (CERCLA Phase 1, UST, HSWA)}

Specific projects conducted by the ERP that will affect the GWPP are the Site Investigation, Phase 1 (completed, see Subsect. 4.2.1.3); Site Investigation, Phase 2 (ongoing during 1991); the C-750 UST investigation (ongoing during 1991); and investigations expected under HSWA (see Subsect. 4.2.1.3).

Input was provided during 1990 by HSS to ensure that the design of the planned ERP projects was technically justifiable based on the current understanding of the site. Additionally, where possible, recommendations were made to ensure that the various projects complement one another and minimize replication of effort. Information from these projects will be used by the subcontractor to fulfill the stated objectives of each project and by HSS, where applicable, to ensure that the overall objectives of the GWPP are achieved.

\subsubsection{Facility Safety Analysis Report}

Work continues on development of the Facility Safety Analysis Report. Of particular interest to the GWPP is work related to natural phenomena that involves characterizing the seismic hazard and site hydrology.

The Gaseous Diffusion Plant Upgrade Program and the PGDP GWPP have similar goals in the area of subsurface hydrogeologic investigations and analyses. A meeting was held in December 1990 involving members of both programs to gain a more nearly complete understanding of the purposes of the two programs and to examine potential areas of cooperation. As a result of this meeting, it was agreed that quarterly technical workshops would be conducted to discuss efforts involving the geology, hydrogeology, and computer modeling. Also, key PGDP HSS personnel will become closely involved in the groundwater modeling effort conducted by the Upgrade Program. The PGDP HSS will potentially provide a summary and evaluation of the local geology and hydrogeology to support the safety analysis report effort.

Specific data from the upgrade effort have already been made available to HSS, including lithologic and geophysical data, stream gage data, and technical input relating to ongoing ER activities. 


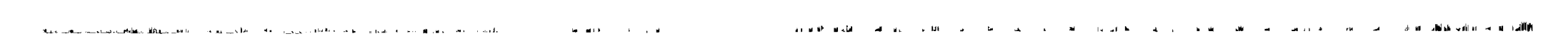




\section{BIOLOGICAL SAMPLING}

\subsection{FOOD CROP AND TISSUE SAMPLING}

The PGDP staff sampled food crops and animal tissue during 1990 from the vicinity of the Paducah plant. Animal tissue samples collected were deer, raccoon, squirrel, carp, bluegill, and a frog. Food crop samples collected were cucumbers, corn, squash, tomatoes, purple hull peas, peppers, cabbage, shelly beans, grapes, and persimmons. Figure 5.1 shows the locations where samples were obtained. Table 5.1 shows the concentration of various radionuclides analyzed (wet weight basis) in edible vegetation and animal tissue. Each was analyzed for ${ }^{239} \mathrm{Pu}$, ${ }^{230} \mathrm{Th},{ }^{235} \mathrm{U},{ }^{237} \mathrm{~Np},{ }^{234} \mathrm{U}$, and ${ }^{238} \mathrm{U}$. Only the radionuclides that were present above the detection limit ( $99 \%$ confidence level) were included.

Also displayed in Table 5.1 is the calculated worst-case dose from ingestion of each food crop over a 1-year period. The assumptions used in the calculations were that the individuals obtained one-third of their vegetables and one-fourth of their fruits from a garden in the vicinity of PGDP. The ingestion rates for each type of food were obtained from a national survey (95th percentile values). An individual was assumed to eat a portion of each food type every day of the year. The doses from each type of crop were significantly below $1 \mathrm{mrem} / \mathrm{year}$.

Assuming an individual eats produce from a garden containing all 10 types of crops represented by this sampling, the total dose is less than the DOE dose limit of $10 \mathrm{mrem} / \mathrm{year}$ from any one pathway.

All food crops sampled were obtair ${ }^{n}$ from areas in the vicinity of PGDP. Since no backgrou:d locations were sampled, no comparison can be made. However, all doses are within the DOE recommendations for acceptable dose.

\subsection{VEGETATION SAMPLING}

Vegetation (grass) samples are collected at 18 locations every 3 months. The samples are returned to the laboratory, dried, and analyzed for fluorides. The primary objective of vegetation sampling is to determine the total fluorides in foliage for comparison with the fluoride-in-foliage section of the Kentucky air pollution control regulations. Figure 5.2 shows the locations of the grass sampling points. These locations represent the perimeter fence, property boundary, and 1.6- and 8-km (1- and 5-mile) distances as related to the primary emission point. Samples are delivered to the laboratory, air-dried for 1 month, digested, and analyzed for fluoride.

Table 5.2 summarizes the analyses.

Samples collected outside the fence area are compared with the Kentucky Ambient Air Quality Standard of $60 \mu \mathrm{g} / \mathrm{g}$ for a 2-month average. All samples were well below the $60 \mu \mathrm{g} / \mathrm{g}$ standard. Samples taken outside the fence area range from less than $5 \%$ to less than $7 \%$ of the standard.

\subsection{DEER HARVEST}

In August 1990, eight deer were harvested in the West Kentucky Wildlife Management Area (WKWMA) to monitor the effects of PGDP on the ecology surrounding the plant. In addition, two deer were harvested in the Land Between the Lakes area for background comparison. Liver and muscle samples were analyzed for metals, radionuclides, and PCBs. Bone and thyroid samples were analyzed for radionuclides, fat samples for $\mathrm{PCBs}$, and hair samples for technetium. The results for muscle samples are shown in Table 5.3. 
ORNL-DWG 89M-6358R2

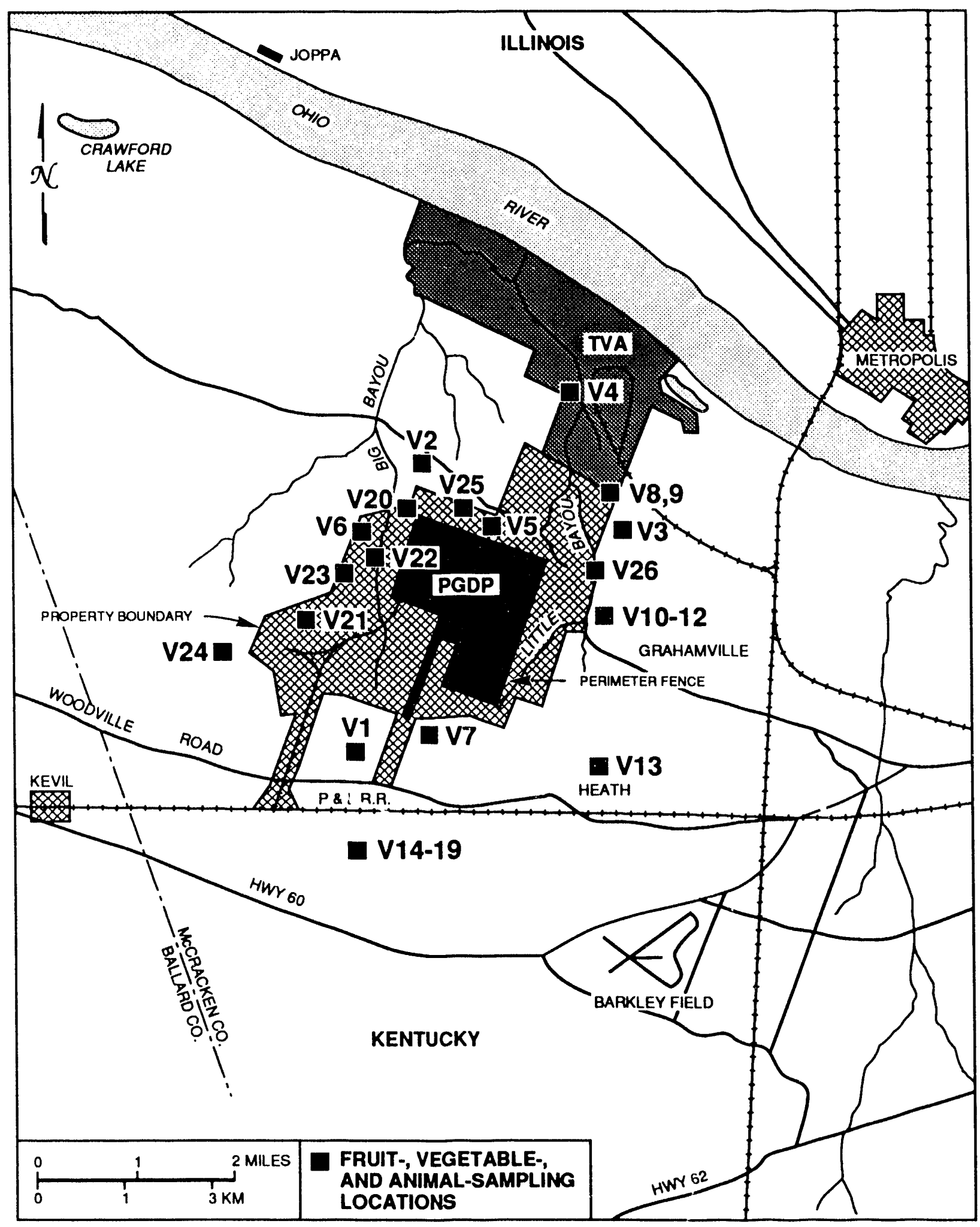

Fig. 5.1. Fruit, vegetable, and animal collection locations. 
Table 5.1. Annual food crop and tissue sampling

\begin{tabular}{|c|c|c|c|c|c|c|c|c|}
\hline $\begin{array}{l}\text { Location }^{a} \\
\text { (sample) }\end{array}$ & $\begin{array}{c}{ }^{237} \mathrm{~Np} \\
(\mathrm{pCi} / \mathrm{g})\end{array}$ & $\begin{array}{c}{ }^{239} \mathrm{Pu} \\
(\mathrm{pCi} / \mathrm{g})\end{array}$ & $\begin{array}{c}{ }^{99} \mathrm{Tc} \\
(\mathrm{pC} / \mathrm{g})\end{array}$ & $\begin{array}{c}{ }^{230} \mathrm{Th} \\
(\mathrm{pCi} / \mathrm{g})\end{array}$ & $\begin{array}{c}{ }^{234} \mathrm{U} \\
(\mathrm{pC} \mathrm{i} / \mathrm{g})\end{array}$ & $\begin{array}{c}{ }^{235} \mathrm{U} \\
(\mathrm{pC} / \mathrm{g})\end{array}$ & $\begin{array}{c}{ }^{238} \mathrm{U} \\
(\mathrm{pCi} / \mathrm{g})\end{array}$ & $\begin{array}{c}\text { Worst-case } \\
\text { dose } \\
\text { (mrem/year) }\end{array}$ \\
\hline 1 Raccoon & 0 & 0 & 0 & 0 & 0 & 0 & 0 & 0 \\
\hline 2 Squirrel & 0 & 0 & 0.410 & 0 & 0.014 & $\mathbf{0}$ & 0 & $b$ \\
\hline 3 Squirrel & 0 & 0 & 0 & 0 & 0.008 & $\mathbf{0}$ & 0 & $b$ \\
\hline 4 Carp & 0 & 0 & 0 & 0.011 & 0.017 & 0 & 0 & 0.097 \\
\hline 5 Bluegill & 0 & 0 & 0 & 0 & 0.020 & 0.007 & 0 & 0.028 \\
\hline 5 Frog & 0 & 0 & 0 & 0 & 0 & 0 & 0 & 0 \\
\hline 7 Deer & 0 & 0 & 0 & 0 & 0.008 & 0 & 0 & 0.089 \\
\hline 8 Cucumber & 0 & 0 & 0 & 0 & 0.020 & 0 & 0 & 0.080 \\
\hline 9 Grapes & 0 & 0 & 0 & 0 & 0.017 & 0 & 0 & 0.057 \\
\hline 10 Corn & 0 & 0 & 0 & 0 & 0 & 0 & 0 & 0 \\
\hline 11 Beans & 0 & 0 & 0 & 0 & 0.008 & 0 & 0 & 0.035 \\
\hline 12 Squash & 0 & 0 & 0.216 & 0 & 0.009 & 0 & 0 & 0.110 \\
\hline 13 Mix Veg & 0 & 0 & 0 & 0 & 0 & 0 & 0 & 0 \\
\hline 14 Peas & 0 & 0 & 0 & 0 & 0.030 & 0 & 0 & 0.085 \\
\hline is 5quash & 0 & 0 & 0 & 0 & 0.0 is & $\mathbf{0}$ & 0 & 0.054 \\
\hline ¿5 Peppers & 0 & 0 & 0 & 0 & 0.012 & $\mathbf{0}$ & 0 & 0.043 \\
\hline 17 Cucumber & 0 & 0 & 0 & 0 & 0.011 & $\mathbf{0}$ & 0 & 0.040 \\
\hline 18 Cabbage & 0 & 0 & 0 & 0 & 0.010 & 0 & 6 & 0.140 \\
\hline 19 Tomato & 0 & 0 & 0 & 0 & 0.030 & $0 . n_{16}$ & 0.011 & 0.259 \\
\hline 20 Corn & 0 & 0 & 0 & 0 & 0.024 & 0 & 0 & 0.194 \\
\hline 21 Corn & 0 & 0 & 0 & 0 & 0.007 & 0 & 0 & 0.055 \\
\hline 22 Corn & 0 & 0 & 0 & 0 & 0.032 & 0 & 0 & $0.26 \mathrm{~L}$ \\
\hline 23 Persimmon & 0 & 0 & 0 & 0 & 0.007 & 0 & 0 & 0.035 \\
\hline 24 Persimmon & 0 & 0 & 0 & 0 & 0.026 & 0 & 0 & 0.124 \\
\hline 25 Persimmon & 0 & 0 & 0 & 0 & 0.010 & 0 & 0 & 0.048 \\
\hline 26 Persimmon & 0 & 0 & 0 & 0 & 0.032 & 0 & 0 & 0.151 \\
\hline
\end{tabular}

${ }^{a}$ See Fig. 5.1.

${ }^{b}$ Not calculated.

The ${ }^{234} U$ values wee the only radionuclide results that were statistically different from zero. Also, one background deer showed detectable levels of ${ }^{235} \mathrm{U}$ in the muscle, and detectable levels of ${ }^{238} \mathrm{U}$ were observed in both background and reservaticn deer bone samples. The mean concentration of ${ }^{234} \mathrm{U}$ for the reservation deer is $0.0097 \mathrm{pCi} / \mathrm{g}$. The radiological data indicate no significant difference (95\% confidence) between the concentrations of ${ }^{234} \mathrm{U}$ in the reservation and background deer.

Potential health effects from ingestion of deer meat (muscle) were evaluated by ORNL. Analytical data on concentrations of $\mathrm{PCBs}$ and 27 metals were evaluated. Since all PCB concentrations were below the limits of detection, no evaluation was made of the potential PCB intake. Only seven metals were found at detectable leve!s, and these are al! essentia! elements for humans.
The potential health implications from consuming deer from the PGDP reservation were evaluated by comparing metal concentrations in the deer meat to those typically found in domestic beef and by comparing possible intakes to U.S. EPA intake criteria. The metal concentrations were also compared to the background locations. The data ( $\mathrm{T}:=1$ es 5.1 and 5.2 in Part 2) indicate no significant diffe.ence in metal concentrations found in the reservation and the background deer. There was also general agreement with concentrations found in comfosite saniples of edible portions of domestic beef. Therefure, any risks associated with eating the deer from the PGDP reservation area are sirnilar to risks from eating decr meat from the Land Between the Lakes area. Also, any risks would be similar to those associated with eating beef. 
ORNL-DWG $87 M-6712 E R$

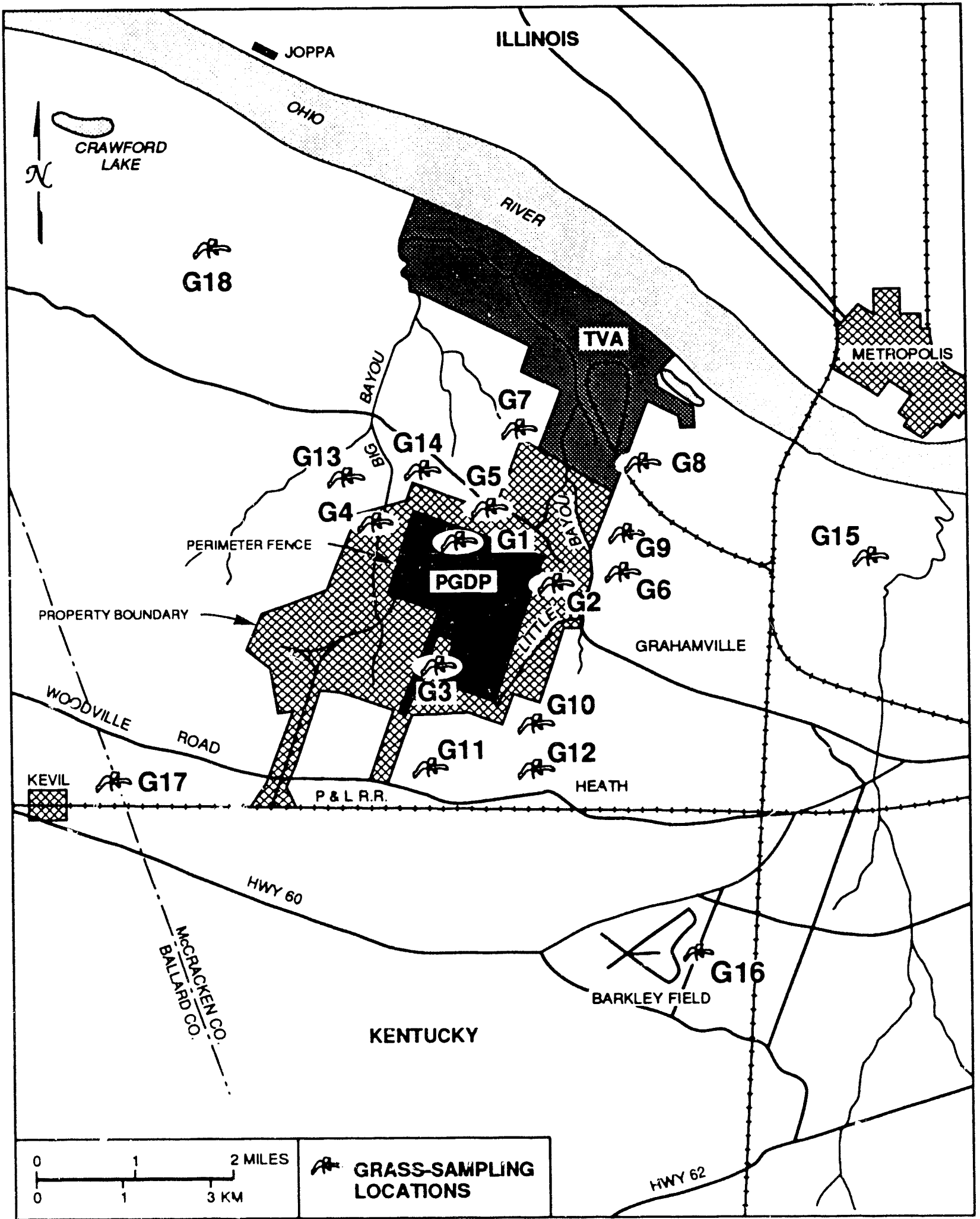

Fì. 5.2. Grass sumpiing ivations. 
Table 5.2. PGDP fluoride in grass, 1990 (dry weight)

Growing season is April through September

\begin{tabular}{lccccccc}
\hline Point & No. of & $\begin{array}{c}\text { Min } \\
\text { samples }\end{array}$ & $\begin{array}{c}\text { Max } \\
(\mu \mathrm{g} / \mathrm{g})\end{array}$ & $\begin{array}{c}\text { Annual Av } \\
(\mu \mathrm{g} / \mathrm{g})\end{array}$ & $\begin{array}{c}\text { Av during } \\
\text { growing } \\
\text { season } \\
(\mu \mathrm{g} / \mathrm{g})\end{array}$ & $\begin{array}{c}\text { Std }^{b} \\
(\mu \mathrm{g} / \mathrm{g})\end{array}$ & $\%$ Std \\
\hline G1 & 4 & 3.9 & 13 & 7.7 & 7 & $c$ & $c$ \\
G2 & 4 & $<3$ & 8.2 & 5.6 & 6.6 & $c$ & $c$ \\
G3 & 4 & $<3$ & 3 & $<3$ & $<3$ & $c$ & $c$ \\
G4 & 4 & $<3$ & 3 & $<3$ & $<3$ & $c$ & \\
G5 & 4 & 3.2 & 4 & 3.8 & $<4$ & 60 & 7 \\
G6 & 4 & $<3$ & 3 & $<3$ & $<3$ & 60 & $<5$ \\
G7 & 4 & $<3$ & 3 & $<3$ & $<3$ & 60 & $<5$ \\
G8 & 4 & $<3$ & 3 & $<3$ & $<3$ & 60 & $<5$ \\
G9 & 4 & $<3$ & $<3$ & $<3$ & $<3$ & 60 & $<5$ \\
G10 & 4 & $<3$ & $<3$ & $<3$ & $<3$ & 60 & $<5$ \\
G11 & 4 & $<3$ & $<3$ & $<3$ & $<3$ & 60 & $<5$ \\
G12 & 4 & $<3$ & 3.6 & $<3.2$ & $<3.3$ & 60 & $<6$ \\
G13 & 4 & $<3$ & 3.6 & $<3.2$ & $<3.3$ & 60 & $<6$ \\
G14 & 4 & $<3$ & $<3$ & $<3$ & $<3$ & 60 & $<5$ \\
Gi5 & 4 & $<3$ & 3.4 & $<3.1$ & $<3.2$ & 60 & $<5$ \\
G16 & 4 & $<3$ & $<3$ & $<3$ & $<3$ & 60 & $<5$ \\
G17 & 4 & $<3$ & $<3$ & $<3$ & $<3$ & 60 & $<5$ \\
G18 & 4 & $<3$ & 4 & $<3$ & $<3.5$ & 60 & $<6$ \\
\hline
\end{tabular}

${ }^{a}$ See Fig. 5.2.

${ }^{b}$ Kentucky Ambient Air Quality Standards (401 KAR 53:010): Fluoride measured on forage is not to exceed an average of $40 \mu \mathrm{g} / \mathrm{g}$ over the growing season, $60 \mu \mathrm{g} / \mathrm{g}$ for a 2 -month average, or $80 \mu \mathrm{g} / \mathrm{g}$ for a 1 -month average (dry weight).

Sampling locations are on government property inside the plant security fence.

Noce: Lower limit of detection is $3 \mu \mathrm{g} \mathrm{F} / \mathrm{g}$.

Table 5.3. Annual deer harvest, 1990

(Confidence that contaminants are present in samples is 99\%)

\begin{tabular}{cccccccccc}
\hline Dar & $\begin{array}{c}\mathrm{Ca} \\
(\mu \mathrm{g} / \mathrm{g})\end{array}$ & $\begin{array}{c}\mathrm{Cu} \\
(\mu \mathrm{g} / \mathrm{g})\end{array}$ & $\begin{array}{c}\mathrm{Fe} \\
(\mu \mathrm{g} / \mathrm{g})\end{array}$ & $\begin{array}{c}\mathrm{Mg} \\
(\mu \mathrm{g} / \mathrm{g})\end{array}$ & $\begin{array}{c}\mathrm{Na} \\
(\mu \mathrm{g} / \mathrm{g})\end{array}$ & $\begin{array}{c}\mathrm{P} \\
(\mu \mathrm{g} / \mathrm{g})\end{array}$ & $\begin{array}{c}\mathrm{Zn} \\
(\mu \mathrm{g} / \mathrm{g})\end{array}$ & $\begin{array}{c}{ }^{234} \mathrm{U} \\
(\mathrm{pCi} / \mathrm{g})\end{array}$ & $\begin{array}{c}235 \mathrm{U} \\
(\mathrm{pCi} / \mathrm{g})\end{array}$ \\
\hline 1 & 25 & 1.2 & 35 & 250 & 350 & 2,300 & 20 & 0.0046 & $a$ \\
2 & 22 & 1.2 & 27 & 270 & 310 & 2,500 & 18 & 0.0205 & $a$ \\
3 & 21 & 1.3 & 23 & 280 & 350 & 2,500 & 14 & 0.0105 & $a$ \\
4 & 23 & 1.3 & 24 & 280 & 290 & 2,500 & 17 & 0.0059 & $a$ \\
5 & 20 & 1.7 & 35 & 270 & 340 & 2,400 & 17 & 0.0062 & $a$ \\
6 & 19 & 1.4 & 44 & 250 & 230 & 2,300 & 16 & 0.0067 & $a$ \\
7 & 22 & 1.4 & 30 & 260 & 390 & 2,400 & 22 & 0.0057 & $a$ \\
8 & 17 & 1.5 & 35 & 240 & 280 & 2,300 & 12 & 0.0176 & $a$ \\
& & & & & & & & & \\
BG-1 & 25 & 1.0 & 34 & 250 & 300 & 2,300 & 24 & 0.0195 & 0.0068 \\
BG-2 & 20 & 1.3 & 32 & 250 & 270 & 2,300 & 19 & $a$ & $a$ \\
\hline
\end{tabular}

${ }^{a}$ Not detected. 


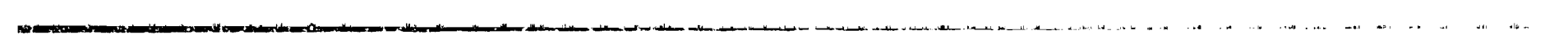




\section{SOIL AND SEDIMENT MONITORING}

Soil and sediment data are collected to show the accumulation (if any) of pollutants that may have been deposited from airborne or waterborne sources. Although sampling procedures are designed to minimize the well-known variability found in soils and sediments, the significance of individual data points is small. Data collected over a period of years may reveal trends if they exist.

\subsection{SOIL SAMPLING}

Soil samples are taken annually at ten locations: north, south, east, and west at the property boundary and at distances of $8 \mathrm{~km}$ ( 5 miles) beyond the property boundary (see Fig. 6.1). Remote (background) samples are taken at two locations 13 to $15 \mathrm{~km}$ (8.08 to 9.32 miles) from PGDP. Each sampling site was selected because the soil appeared (or was known) to have been undisturbed for a number of years. Two $1-\mathrm{m}^{2}\left(11-\mathrm{ft}^{2}\right)$ areas $3 \mathrm{~m}(10 \mathrm{ft})$ apart are measured out. The vegetation to a height of 10 to $20 \mathrm{~mm}$ ( 0.4 to $0.8 \mathrm{in}$.) above the soil is removed. Samples from the center and each corner of the $1-\mathrm{m}^{2}$ area are removed by pushing down and twisting the sampler into the soil to a depth of $5 \mathrm{~cm}$ ( 2 in.). The plugs of soil are composited into a labeled plastic bag. Table 6.1 lists samples analyzed for parameters.

Table 6.2 gives the concentrations of uranium in soil samples from 1985 through 1990 . The average uranium content of all property boundary samples is higher than the average for the 8-km (4.97-mile) samples and approximatel' two times the average for the background samples. The range of sample analyses during 1990 was from a low of $2.2 \mu \mathrm{g}$ of uranium per gram of soil at the background site west of PGDP to a high of $7.1 \mu \mathrm{g} / \mathrm{g}$ at the south boundary. The concentrations of uranium in soil (Table 6.2) are typical of soils in westem Kentucky.
Table 6.3 lists the concentrations for PCBs and radionuclides. No significant differences between property boundary locations and remote locations were noted. Analysis of each soil sample for 36 metals revealed no significant differences in concentration of any element among the locations. Concentrations of radionuclides in the soil showed a consistent increase over concentrations reported in 1989. Because the concentrations were higher in each group of samples, including background, the increases were probably due to laboratory variability.

\subsection{SEDIMENT SAMPLING}

The stream bottom is a very important constituent of the aquatic environment. If a pollutant is a suspended solid or attached to suspended sediment, it can settle to the bottom (hence the need for sediment sampling), be filtered by certain organisms, or become attached to plant surfaces. Pollutants in solution can adsorb on suspended organic and inorganic solids or be assimilated by plants and animals. The suspended solids, dead biota, or excreta settle to the bottom and become part of the organic substrate that supports the bottom-dwelling community of organisms. Figure 6.2 shows possible exposure routes (Jinks and Eisenbud 1972) of trace metals (including uranium) in an aquatic ecosystem.

Sediments play a dominant role in aquatic ecology by serving as a repository for radioactive or chemical substances that pass via the bottom-feeding biota to the higher trophic levels. Soluble pollutants introduced into a body of water reach the bottom sediment primarily by adsorption on suspended solids that later deposit on the bottom. The deposited remains of biota that have absorbed pollutants may also be an important source of radioactive and chemical pollutants that enter the food chain.

Sediment samples were taken from 26 locations. Figure 6.3 shows the location of each sampling point. 
ORNL-DWG 87M-6712BR

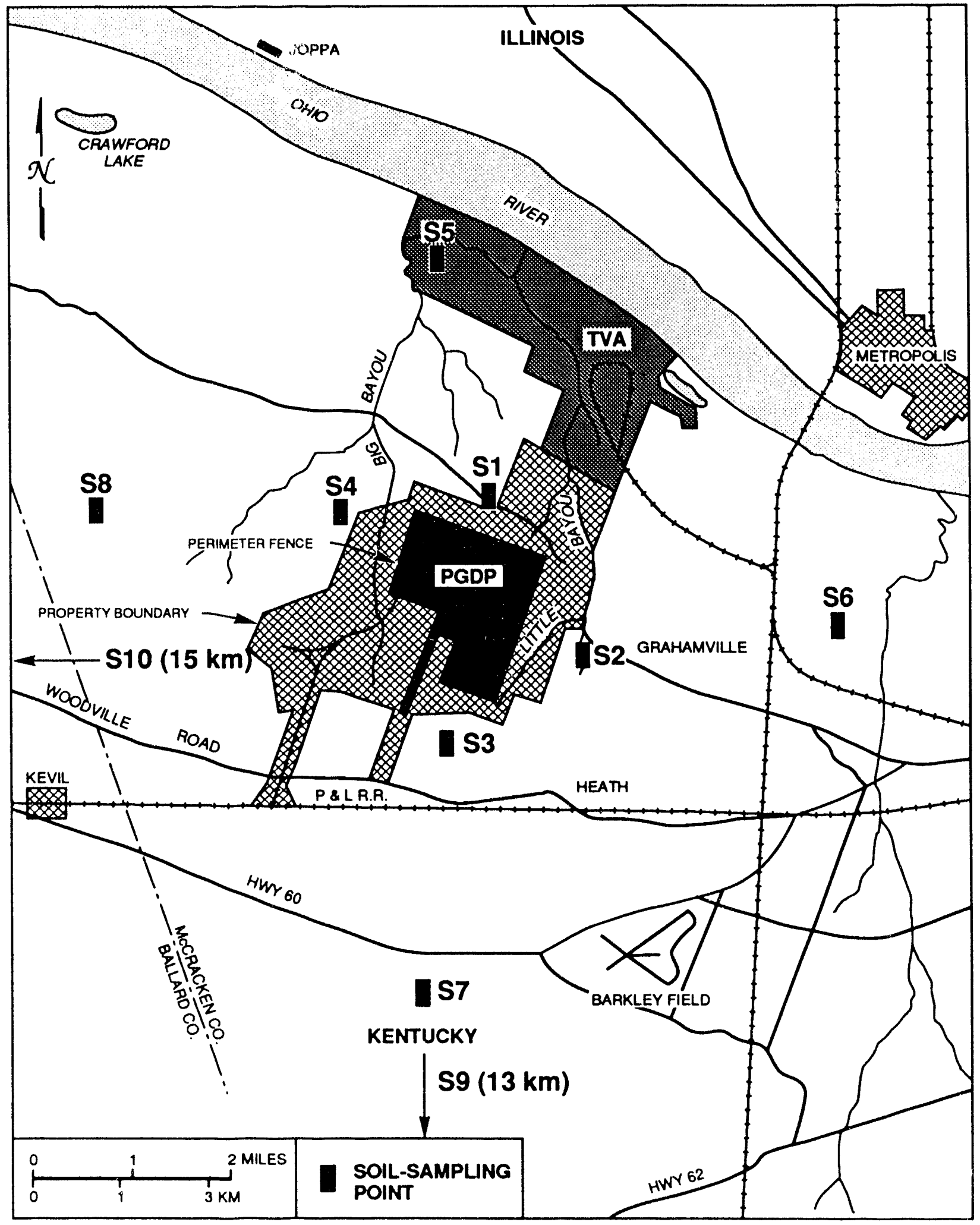

Flg. 6.1. PGDP soll-sampling locatons. 
Table 6.1. Summary of collection and analysis frequencies of soll and sediment samples in 1990

\begin{tabular}{|c|c|c|c|c|}
\hline Station & Parameter & $\begin{array}{l}\text { Collection } \\
\text { frequency }\end{array}$ & Sample type & $\begin{array}{l}\text { Analysis } \\
\text { frequency }\end{array}$ \\
\hline \multicolumn{5}{|c|}{ Soil } \\
\hline $\begin{array}{l}\text { S1, S2, S3, S4, S5, } \\
\text { S6, S7, S8, S9, } \\
\text { S10 }\end{array}$ & $\begin{array}{l}\mathrm{U},{ }^{239} \mathrm{Pu},{ }^{237} \mathrm{Ng},{ }^{137} \mathrm{Cs},{ }^{235} \mathrm{U},{ }^{230} \mathrm{Th}, \\
\mathrm{Tc},{ }^{40} \mathrm{~K}, \mathrm{PCB}, \mathrm{Ag}, \mathrm{Al}, \mathrm{Ba}, \\
\mathrm{Be}, \mathrm{Bi}, \mathrm{Ca}, \mathrm{Cd}, \mathrm{Co}, \mathrm{Cr}, \mathrm{Cu}, \mathrm{Fe} \\
\mathrm{K}, \mathrm{Li}, \mathrm{Mg}, \mathrm{Mn}, \mathrm{Mo}, \mathrm{Na}, \mathrm{Nb}, \mathrm{Ni} \text {, } \\
\mathrm{P}, \mathrm{Pb}, \mathrm{Ru}, \mathrm{Sb}, \mathrm{Si}, \mathrm{Sn}, \mathrm{Sr}, \mathrm{Ta} \\
\mathrm{Th}, \mathrm{Ti}, \mathrm{Tl}, \mathrm{V}, \mathrm{W}, \mathrm{Zn}, \mathrm{Zr}, \mathrm{As} \text {, } \\
\text { and } \mathrm{Hg} \text { on } \mathrm{S} 5-\mathrm{Si} 10\end{array}$ & Annually & Grab & Annually \\
\hline \multicolumn{5}{|c|}{ Sediment ${ }^{b}$} \\
\hline $\begin{array}{l}\text { SS1, SS2, SS3, SS4, SS5, } \\
\text { SS6, SS7, SS8, SS9, } \\
\text { SS10, SS11, SS12, SS13, } \\
\text { SS14, SS15, SS16, SS17, } \\
\text { SS18, SS19, SS20, SS21, } \\
\text { SS22, SS23, SS24, SS25, } \\
\text { SS26 }\end{array}$ & $\begin{array}{l}{ }^{137} \mathrm{Cs},{ }^{40} \mathrm{~K},{ }^{237} \mathrm{~Np},{ }^{239} \mathrm{Pu},{ }^{99} \mathrm{Tc},{ }^{230} \mathrm{Th},{ }^{234} \mathrm{U}, \\
{ }^{238} \mathrm{U},{ }^{235} \mathrm{U}, \mathrm{PCB}, \mathrm{Ag}, \mathrm{Al}, \mathrm{Ba}, \mathrm{Be}, \mathrm{Bi}, \\
\mathrm{Cd}, \mathrm{Ca}, \mathrm{Co}, \mathrm{Cr}, \mathrm{Cu}, \mathrm{Fe}, \mathrm{Hg}, \mathrm{K}, \\
\mathrm{Li}, \mathrm{Mg}, \mathrm{Mn}, \mathrm{Mo}, \mathrm{Na}, \mathrm{Nb}, \mathrm{Ni}, \mathrm{P}, \\
\mathrm{Pb}, \mathrm{Ru}, \mathrm{Sb}, \mathrm{Si}, \mathrm{Sn}, \mathrm{Sr}, \mathrm{Ta}, \mathrm{Th}, \\
\mathrm{Ti}, \mathrm{Tl}, \mathrm{V}, \mathrm{W}, \mathrm{Zn}, \mathrm{Zr}, \mathrm{As}\end{array}$ & Annually & Grab & Annually \\
\hline
\end{tabular}

${ }^{a}$ See Fig. 6.1.

Table 6.2. Concentrations of uranium in soil at PGDP, 1985-1990

$(\mu \mathrm{g} / \mathrm{g})$

\begin{tabular}{lllllll}
\hline Location & 1985 & 1986 & 1987 & 1988 & 1989 & 1990 \\
\hline
\end{tabular}

Property boundary

\begin{tabular}{|c|c|c|c|c|c|c|}
\hline S1 (north) & 5 & 6 & 4.8 & 4.9 & 2.2 & 5.0 \\
\hline S2 (east) & 3 & 5 & 3.4 & 4.6 & 2.4 & 3.9 \\
\hline S3 (south) & 2 & 6 & 5.5 & 4.3 & 5.6 & 7.1 \\
\hline S4 (west) & 3 & 3 & 2.5 & 2.2 & 1.4 & 3.3 \\
\hline \multicolumn{7}{|c|}{$8 \mathrm{~km}$ from plans } \\
\hline S5 (north) & 3 & 4 & 3.9 & 4.2 & 2.2 & 4.3 \\
\hline S6 (east) & 2 & 3 & 2.6 & 2.3 & 1.1 & 2.5 \\
\hline S7 (south) & 3 & 4 & 2.7 & 2.5 & 1.2 & 2.8 \\
\hline S8 (west) & 2 & 4 & 2.8 & 3.4 & 1.2 & 2.9 \\
\hline \multicolumn{7}{|c|}{13 to $15 \mathrm{~km}$ from plant } \\
\hline S9 (south) & 1 & 2 & 2.4 & 2.5 & 0.8 & 2.2 \\
\hline S10 (west) & 2 & 3 & 2.9 & 2.1 & 0.7 & 2.7 \\
\hline
\end{tabular}

${ }^{a}$ See Fig. 6.1. 
Table 6.3. Radionuclide and polychlorinated biphenyl concentrations in soil at PGDP in 1990

\begin{tabular}{|c|c|c|c|c|c|c|c|c|}
\hline Location $^{a}$ & $\begin{array}{c}{ }^{235} \mathrm{U} \\
\text { (wt } \% \text { ) }\end{array}$ & $\begin{array}{c}{ }^{137} \mathrm{Cs} \\
(\mathrm{pCi} / \mathrm{g})\end{array}$ & $\begin{array}{c}{ }^{40} \mathrm{~K} \\
(\mathrm{pCi} / \mathrm{g})\end{array}$ & $\begin{array}{c}{ }^{237} \mathrm{~Np} \\
(\mathrm{pCi} / \mathrm{g})\end{array}$ & $\begin{array}{c}{ }^{239} \mathrm{Pu} \\
(\mathrm{pCi} / \mathrm{g})\end{array}$ & $\begin{array}{l}{ }^{230} \mathrm{Th} \\
(\mathrm{pCi} / \mathrm{g})\end{array}$ & $\begin{array}{c}{ }^{99} \mathrm{Tc} \\
(\mathrm{pCi} / \mathrm{g})\end{array}$ & $\begin{array}{c}\text { РCB } \\
(\mu g / g)\end{array}$ \\
\hline \multicolumn{9}{|c|}{ Property boundary } \\
\hline $\begin{array}{l}\text { S1 (north) } \\
\text { S2 (east) } \\
\text { S3 (south) } \\
\text { S4 (west) }\end{array}$ & $\begin{array}{l}0.66 \\
0.56 \\
0.55 \\
0.61\end{array}$ & $\begin{array}{l}0.625 \\
0.840 \\
1.548 \\
1.910\end{array}$ & $\begin{array}{l}15.25 \\
14.70 \\
11.59 \\
13.40\end{array}$ & $\begin{array}{r}-0.014 \\
-0.003 \\
0.002 \\
-0.011\end{array}$ & $\begin{array}{l}0.030 \\
0.009 \\
0.038 \\
0.019\end{array}$ & $\begin{array}{l}0.940 \\
1.615 \\
1.640 \\
2.120\end{array}$ & $\begin{array}{l}0.090 \\
0.00 \\
0.00 \\
0.35\end{array}$ & $\begin{array}{l}<0.1 \\
<0.1 \\
<0.1 \\
<0.1\end{array}$ \\
\hline \multicolumn{9}{|c|}{$8 \mathrm{~km}$ from plant } \\
\hline $\begin{array}{l}\text { S5 (north) } \\
\text { S6 (east) } \\
\text { S7 (south) } \\
\text { S8 (west) }\end{array}$ & $\begin{array}{l}0.69 \\
0.69 \\
0.70 \\
0.69\end{array}$ & $\begin{array}{l}0.560 \\
2.450 \\
1.835 \\
1.210\end{array}$ & $\begin{array}{l}17.24 \\
13.20 \\
17.86 \\
16.10\end{array}$ & $\begin{array}{r}0.006 \\
-0.014 \\
-0.005 \\
0.006\end{array}$ & $\begin{array}{l}0.004 \\
0.014 \\
0.004 \\
0.012\end{array}$ & $\begin{array}{l}0.800 \\
0.580 \\
1.300 \\
2.650\end{array}$ & $\begin{array}{l}0.72 \\
0.00 \\
0.190 \\
0.042\end{array}$ & $\begin{array}{l}<0.1 \\
<0.1 \\
<0.1 \\
<0.1\end{array}$ \\
\hline \multicolumn{9}{|c|}{13 to $15 \mathrm{~km}$ from plant } \\
\hline $\begin{array}{l}\text { S9 (south) } \\
\text { S10 (west) }\end{array}$ & $\begin{array}{l}0.71 \\
0.71\end{array}$ & $\begin{array}{l}4.000 \\
0.233\end{array}$ & $\begin{array}{l}16.10 \\
18.56\end{array}$ & $\begin{array}{r}-0.007 \\
0.007\end{array}$ & $\begin{array}{r}-0.007 \\
0.006\end{array}$ & $\begin{array}{l}1.090 \\
2.295\end{array}$ & $\begin{array}{l}0.032 \\
0.040\end{array}$ & $\begin{array}{l}<0.1 \\
<0.1\end{array}$ \\
\hline
\end{tabular}

${ }^{a}$ See Fig. 6.1.

At each location a clean sampling scoop is used to obtain a sample (taking as few rocks as possible) from the bottom of the stream or lagoon. Approximately $2 \mathrm{~kg}(4.5 \mathrm{lb})$ of sediment is placed in a new plastic bag. The samples are dried and delivered to the analytical laboratory. Table 6.1 lists a summary of the collection and analyses frequencies.

Table 6.4 gives 1990 radionuclide and PCB data. Both radionuclides and PCBs are elevated at SS7, the C-615 sewage sludge. The sludge is drummed annually for storage. $\mathrm{S}$ siments in the $\mathrm{N} / \mathrm{S}$ diversion ditch, an on-site ditch, contain elevated levels of radionuclides and $\mathrm{PCBs}$. Effluents from this ditch flow into the C-616 full-flow lagoon before discharge through KPDES outfall 001. Big Bayou Creek sediments (SS1) show levels of radionuclides above those at the upstream Big Bayou Creek station (SS20). In addition, Little Bayou Creek sediments (SS2) indicate levels above those found at the upstream Little Bayou Creek station (SS21). During 1990, a public advisory was issued for the Little Bayou Creek area and signs were posted to make the public aware that prolonged exposure could result in a dose above background (see Subsect. 2.4.2, Environmental Radiation Survey). Many of the KPDES outfall sedinients contain levels of radionuclides and $\mathrm{PCBs}$ above background. Cesium was present in all sediment samples and is present throughout the world from weapons testing.

A variety of metals is analyzed in each sediment sample. Metals analyses in each 1990 sediment sample were distinctly elevated above the 1989 metals data. PGDP had analyzed the 1990 samples, but not the 1989 samples. PrDP reanalyzed archived 1989 samples and selected 1990 samples. The analytical results were in good agreement, indicating the difference in the ritial results was due to variability between the two laboratories. 


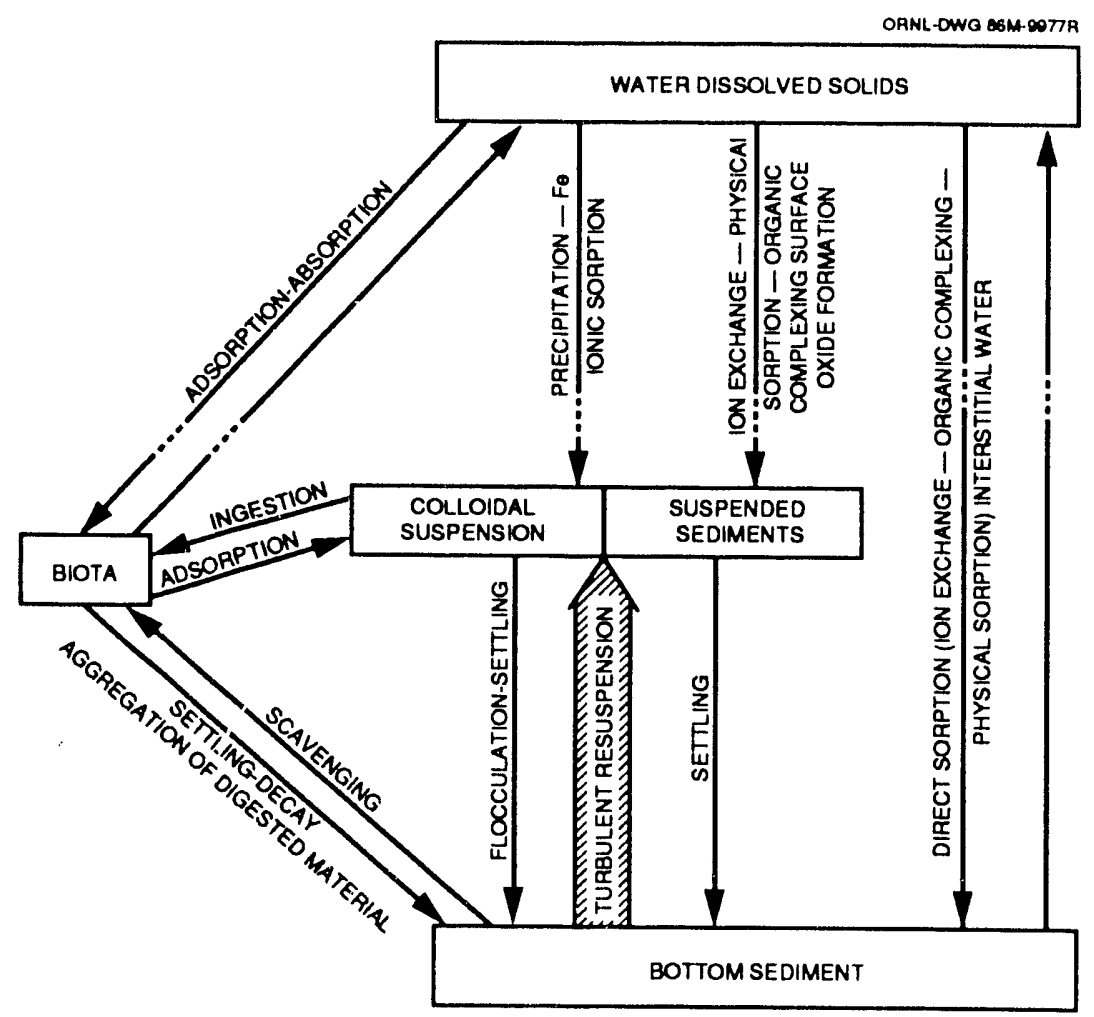

Fig. 6.2. Routes of trace metals in an aquatic ecosystem. Source: Jinks and Eisenbud 1972.

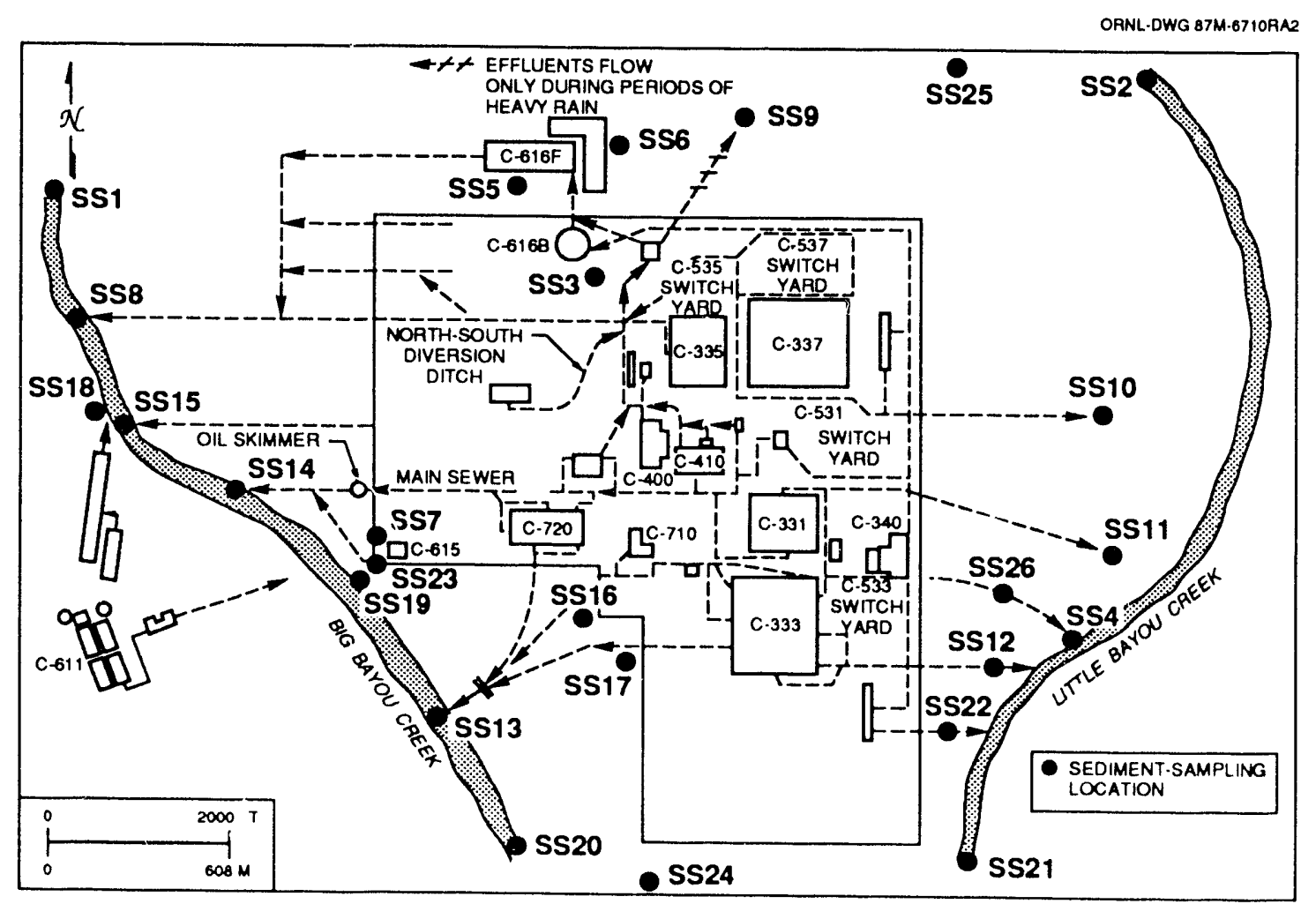

Fig. 6.3. PGDP sediment-sampling locations. 
Table 6.4. 1990 PGDP sediment data

\begin{tabular}{|c|c|c|c|c|c|c|c|c|c|}
\hline Location ${ }^{a}$ & $\begin{array}{l}{ }^{99} \mathrm{Tc} \\
(\mathrm{pCi} / \mathrm{g})\end{array}$ & $\begin{array}{l}{ }^{237} \mathrm{~Np}^{b} \\
(\mathrm{pCi} / \mathrm{g})\end{array}$ & $\begin{array}{l}{ }^{239} \mathrm{Pu}^{b} \\
(\mathrm{pCi} / \mathrm{g})\end{array}$ & $\begin{array}{l}{ }^{230} \mathrm{Th} \\
(\mathrm{pCi} / \mathrm{g})\end{array}$ & $\begin{array}{l}{ }^{137} \mathrm{Cs} \\
(\mathrm{pCi} / \mathrm{g})\end{array}$ & $\begin{array}{c}{ }^{40} \mathrm{~K} \\
(\mathrm{pC} \mathrm{C} / \mathrm{g})\end{array}$ & $\begin{array}{c}{ }^{235} \mathrm{U} \\
(w t \%)\end{array}$ & $\begin{array}{c}U \\
(\mu g / g)\end{array}$ & $\begin{array}{l}\text { PCB } \\
(\mu g / g)\end{array}$ \\
\hline SS1 Big Bayou & 9.37 & 0.075 & 0.021 & 1.90 & 0.31 & 7.90 & 0.48 & 24 & $<0.1$ \\
\hline SS2 Little Bayou & 1.35 & 0.012 & 0.009 & 0.49 & 0.05 & 3.50 & 0.19 & 39 & 0.2 \\
\hline $\begin{array}{l}\text { SS3 N/S diversion ditch } \\
\text { (L-13) }\end{array}$ & 176.80 & 4.13 & 2.653 & 18.00 & 0.39 & 24.00 & 0.59 & 123 & 0.2 \\
\hline SS4 C-340 ditch (K-011) & 0.16 & -0.02 & -0.004 & 2.400 & 0.01 & 11.70 & 0.19 & 48 & $<0.1$ \\
\hline SS5 C-616 full-flow lagoon & 10.09 & 0.069 & -0.009 & 1.80 & 0.27 & 12.30 & 0.59 & 9 & $<0.1$ \\
\hline SS6 C-616 sludge lagoon & 0.57 & 0.058 & -0.007 & 0.59 & 0.04 & 0.90 & 0.63 & 4 & $<1.0$ \\
\hline SS7 C-615 sewage sludge & 63.85 & 0.300 & 0.992 & 1.47 & 3.05 & 12.38 & 0.69 & 1850 & 41 \\
\hline SS8 C-335 ditch $(\mathrm{K}-001)$ & 21.40 & 0.150 & 0 & 2.04 & 0.11 & 10.40 & 0.48 & 22 & $<0.1$ \\
\hline $\begin{array}{l}\text { SS9 overflow diversion ditch } \\
\text { (K-003) }\end{array}$ & 60.18 & 0.700 & 1.590 & 43.60 & 0.80 & 15.50 & 0.53 & 26 & $<0.1$ \\
\hline $\begin{array}{l}\text { SS10 C-337 ditch east } \\
(\mathrm{K}-002)\end{array}$ & 0.33 & 0.006 & -0.004 & 1.80 & 0.10 & 9.95 & 0.62 & 3 & 0.2 \\
\hline $\begin{array}{l}\text { SSI1 C-331 ditch } \\
(\mathrm{K}-010)\end{array}$ & 0.64 & 0.003 & 0.072 & 1.01 & 0.05 & 8.13 & 0.47 & 4 & $<0.5$ \\
\hline $\begin{array}{l}\text { SS12 C-333 ditch } \\
(\mathrm{K}-012)\end{array}$ & 1.32 & 0.012 & -0.010 & 1.60 & 0.01 & 10.20 & 0.65 & 3 & $<0.5$ \\
\hline $\begin{array}{l}\text { SS } 13 \text { southwest ditch } \\
(\mathrm{K}-009)\end{array}$ & 1.30 & 0.027 & 0.010 & 0.65 & 0.07 & 7.00 & 0.64 & 2 & $<0.1$ \\
\hline $\begin{array}{l}\text { SS14 west ditch dam } 7 \\
(\mathrm{~K}-008)\end{array}$ & 19.20 & 0.045 & 0.068 & 1.70 & 0.10 & 5.12 & 0.55 & 14 & $<0.1$ \\
\hline $\begin{array}{l}\text { SSi } 15 \text { west ditch dam } 8 \\
(\mathrm{~K}-015)\end{array}$ & 3.15 & 0.260 & 0.14 & 2.90 & 2.64 & 13.08 & 0.42 & 17 & $<0.1$ \\
\hline $\begin{array}{l}\text { SS16 C-720 parking lot } \\
\text { into southwest ditch }\end{array}$ & 3.90 & 0.150 & 0.18 & 2.34 & 0.27 & 9.48 & 0.57 & 10 & 0.3 \\
\hline $\begin{array}{l}\text { SS17 C-333 ditch into } \\
\text { southwest ditch }\end{array}$ & 2.21 & -0.010 & -0.003 & 2.04 & 0.11 & 8.60 & 0.65 & 2 & $<0.1$ \\
\hline SS18 C-611 sludge & 0.74 & -0.011 & 0 & 16.09 & 0.08 & 5.04 & 0.71 & 3 & 0.3 \\
\hline $\begin{array}{l}\text { SS } 19 \text { upstream Big Bayou } \\
\text { wooden bridge }\end{array}$ & 0.04 & -0.014 & -0.010 & 1.23 & 0.07 & 5.00 & 0.70 & 1.4 & $<0.1$ \\
\hline $\begin{array}{l}\text { SS20 upstream Big Bayou } \\
\text { (L-1) }\end{array}$ & 0.10 & 0.012 & -0.003 & 1.73 & 0.06 & 5.9 & 0.70 & 1.1 & $<0.5$ \\
\hline SS21 upstream Little Bayou & 0 & -0.010 & -0.005 & 2.30 & 0.11 & 15.74 & 0.70 & 3 & $<0.6$ \\
\hline SS $22 \mathrm{~K}-013$ & 0.35 & 0.016 & 0 & 2.13 & 0.22 & 14.37 & 0.46 & 6 & $<1.0$ \\
\hline SS23 K -016 & 0 & 0.011 & -0.003 & 1.60 & 0.24 & 12.20 & 0.63 & 2 & $<0.1$ \\
\hline SS24 K-017 & 0.47 & 0.020 & 0.010 & 2.02 & 0.12 & 12.69 & 0.60 & 3 & $<0.5$ \\
\hline SS25 K-018 & 24.10 & 0.195 & 0.627 & 9.30 & 0.50 & 9.85 & 0.53 & 16 & 0.4 \\
\hline $\begin{array}{l}\text { SS26 upstream of C-340 } \\
\text { oil dam }\end{array}$ & 8.80 & 0.044 & 0.002 & 1.59 & 0.19 & 14.00 & 0.21 & 507 & 4.7 \\
\hline
\end{tabular}

${ }^{a}$ See Fig. 6.3.

${ }^{b}$ Negative numbers indic ate that analytical result minus backgr itnd is less than zero. 


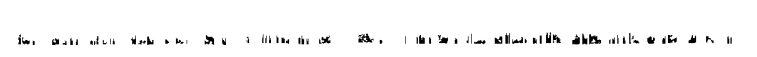




\section{POTENTIAL RADIATION DOSE TO THE PUBLIC}

PGDP emits effluents, some of which are radioactive and some of which are chemically or biologically reactive. Waste minimization and pollution abatement systems reduce these effluents, and emission and environmental monitoring is used to evaluate these controls, to determine compliance with regulations, and to allow estimates of the radiation and chemical doses received by members of the public.

DOE Order 5400.1 limits the dose to members of the public to less than $100 \mathrm{mrem} / \mathrm{year}$ effective dose equivalent from all pathways resulting from the operation of a DOE facility. Knowledge of the demography and land use of the area surrounding the plant and identification of on-site sources have indicated certain radionuclides and exposure pathways by which groups of people can be exposed to radiation. Figures 7.1 and 7.2 give a comprehensive view of the pathways between radioactive materials released to the environment and human beings. In practice, only a few pathways are the major sources of exposure in any given situation. A preliminary assessment of risk from PGDP contaminants to the health of the public living off-site was conducted by $\mathrm{CH} 2 \mathrm{M}$ Hill for the Phase I Site Investigation. This study identified four primary pathways that could potentially contribute greater than $1 \%$ to the total off-site dose: groundwater ingestion, sediment ingestion, ingestion of wildlife and food crops, and exposure to direct radiation. To assess fully the potential dose to the public, a hypothetical group of extreme characteristics is used to postulate an upper limit to the dose of any real group. The assumptions used to calculate the dose from those exposures are summarized in Tables 7.1-7.6 of Part 2. In addition, the dose from all pathways from atmosp'neric releases is also calculated as required for compliance with the National Emission Standard for Hazardous Air Pollutants (NESHAP) regulations.

\subsection{TERMINOLOGY}

- Committed effective dose equivalent (CEDE) is the total internal dose (measured in mrem/year) received over a 50-year period resulting from the intake of radionuclides in a 1-year period. The CEDE is the product of the annual intake (pCi) and the dose conversion factor for each radionuclide (mrem/pCi).

- Collective effective dose equivalent is a measure in person-rems of long-term radiation effects over a wide area. It is calculated by multiplying the average dose within defined areas by the number of persons living in that area.

- Effective dose equivalent includes the committed effective dose equivalent from internal deposition of radionuclides and the dose from penetrating radiation from sources external to the body. This is a risk-equivalent value and can be used to estimate the health-effects risk to the exposed individual.

\subsection{WATERBORNE RADIONUCLIDES}

Liquid effluents are monitored to determine the total quantity of waterborne radionuclides going to the environment. The concentrations of various radionuclides are measured in the creeks and in groundwater under the plant. A survey of surface water and groundwater users in the vicinity of PGDP was conducted in 1990 to determine the number of residents using water wells within a 4 -mile radius of PGDP and to determine the number of surface water intakes on the Ohio River within 15 miles downstream of the plant.

No residents or businesses that responded to the questionnaire reported using a private surface water intake on the Ohio River or on Little or Big Bayou Creeks for any part of their water supply. The nearest downstream water intake point on the Ohio River used for drinking purposes is at Cairo, Illinois, which 


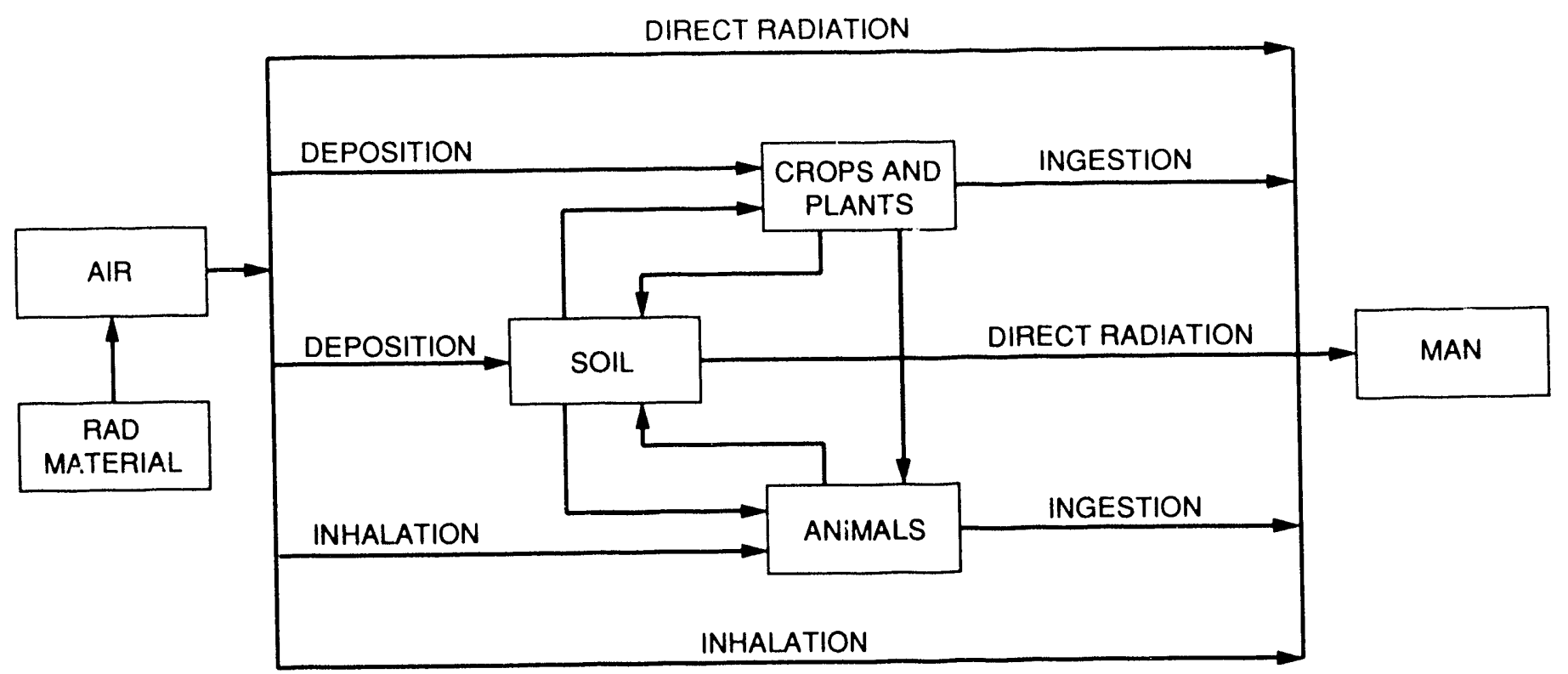

Fig. 7.1. Pathways between radioactive material released to the atmosphere and individuals.

ORNL.DWG 91M.8297

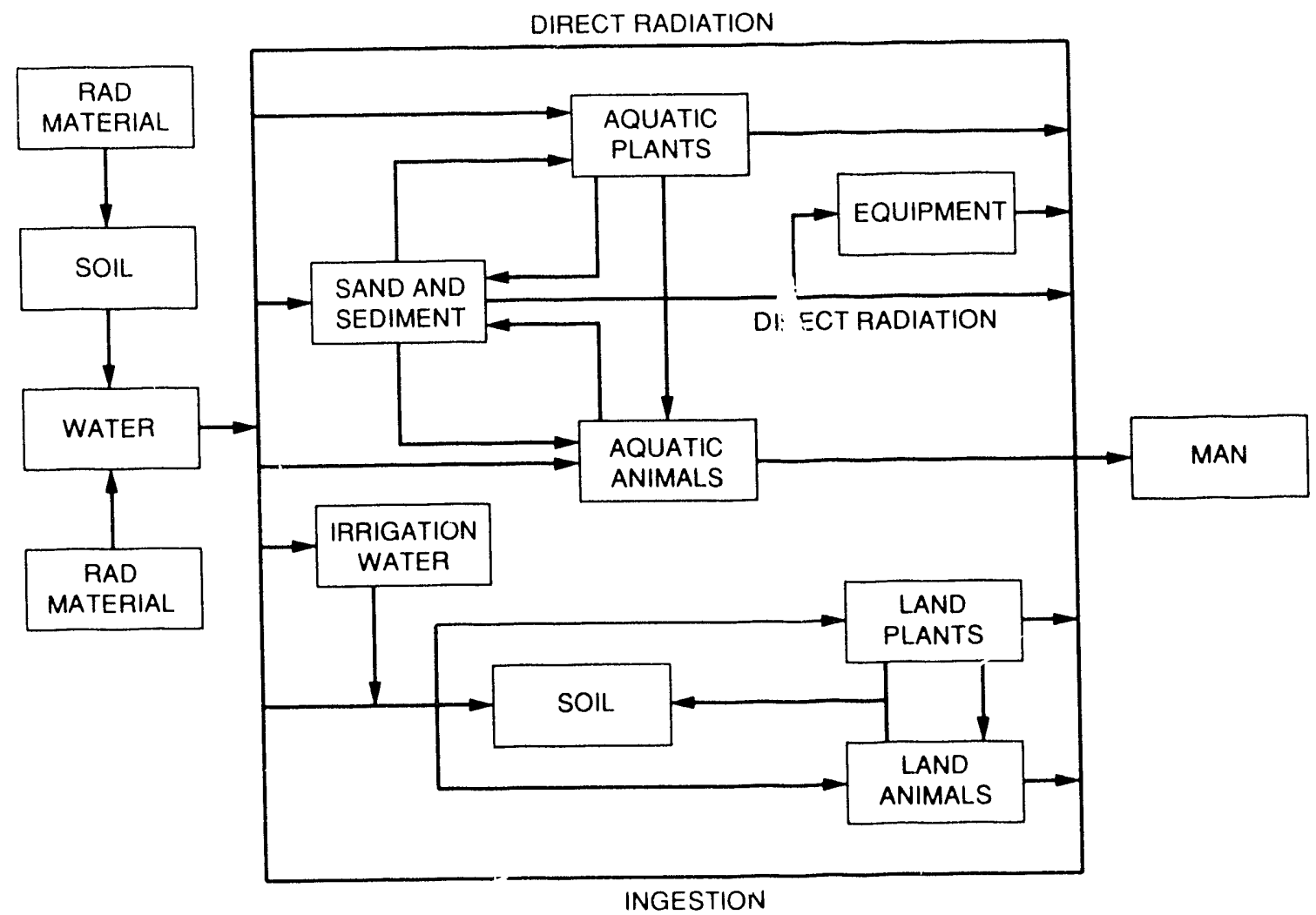

Fig. 7.2. Pathways between radioactive material released to the gr'sundwater and individuals. 
is beyond the scope of impact from PGDP. Private groundwater wells were the major water supply of residents surrounding the Paducah plant. Most residents reported using water from their residential wells for drinking, irrigation, and domestic uses.

A dose to the maximally exposed individual from consuming well water can be calculated using the assumptions outlined in Table 7.1 of Part 2. Under conditiuns of continuous exposure, members of the public are assumed to ingest $730 \mathrm{~L}$ of drinking water per year. Based on this criterion, the dose to the maximally exposed individual from drinking well water contaminated with technetium at the PGDP detection limit $(25 \mathrm{pCi} / \mathrm{L})$ would be $0.024 \mathrm{mrem} / \mathrm{year}$. This dose can be compared with the dose from ingestion of water contaminated at the Safe Drinking Water Act level of $900 \mathrm{pCi} / \mathrm{L}^{99} \mathrm{Tc}$. This dose would be $0.85 \mathrm{mrem} /$ year. A risk estimation was prepared for the Phase I Site Investigation to assess the potential risk to individuals who might have been previously exposed to contaminated groundwater.

\subsection{DIRECT RADIATION}

The exposed pathway for external gamma radiation was evaluated using the results of radiation surveys covering the banks of Litt'e and Big Bayou Creeks and areas on Hobbs road across from the cylinder storage area. These areas were determined to have elevated radioactive contamination or elevated count rates. The dose values are the product of the exposure rate $(\mathrm{mR} / \mathrm{h})$ from the radiological survey and the expusure time at a particular location.

Exposures on Hobbs road are limited to through traffic; therefore, the exposure time is minimal and a dose will not be calculated. To determine a realistic exposure time for the Little Bayou Creek area, several assumptions were used. During 1990, the WKWMA allowed hunting and dog trials in this area for a period ranging from September 1 to March 30 (213 days). For exposure in the creeks, an individual was assumed to hunt every day during this period and spend a total of one-half hour in the Little Bayou Creek bed. This exposure time is probably exaggerated because signs are posted in this area stating that prolonged exposure could result in a dose abuve background. Using the maximum exposure rate measured in the creek as worst-case, the dose to this maximally exposed individual would be $4.15 \mathrm{mrem} / \mathrm{year}$. These assumptions are summarized in Table 7.6 of Part 2. Even using these extreme assumptions, the dose is within the guideline value of less than $10 \mathrm{mrem} / \mathrm{year}$ from any one pathway.

\subsection{CONTAMINATED SEDIMENT IN LITTLE BAYOU CREEK}

Exposure to contaminated sediment in Little and Big Bayou Creeks could occur during fishing, hunting, or other recreational activities. Contact and exposure may occur primarily through incidental ingestion of contaminated sediment or inhalation of contaminated particles. According to the exposure assumptions in Tables 7.2 and 7.3, Part 2, and the maximum detected concentration of each radionuclide in the sediment samples, the worst-case dose would be received by an individual who was assumed to spend time in the WKWMA every day during the season as in Sect. 7.3. The estimated total dose would be $0.65 \mathrm{mrem} /$ year from this pathway.

\subsection{INGESTION OF TERRESTRIAL FOODSTUFFS}

Terrestrial wildlife, such as deer, can come into contact witn contaminated soil, ingest plants that have taken up contaminants or have become coated with contaminated dust, or ingest contaminated water. Hunting is permitted in the Wildlife Management Area surrounding PGDP, and the limit for deer harvest is two deer per person per season. Assuming that an individual kills two average-weight deer and consumes the edible portions of those deer during the year, the dose to this individual based on the maximum detected concentrations of each radionuclide in the deer muscle would be $0.22 \mathrm{mrem} / \mathrm{ycar}$. Uranium-234 was the only radionuclide present above the detection limits. Dose calculations are summarized in Table 7.4, Part 2.

Similarly, ingestion doses from homegrown fruits and vegetables were calculated using the assumptions summarized in Table 7.5 of Part 2. Using the maximum detected concentrations of each radionuclide in all ten food types, the worst-case individual dose is calculated to be $1.15 \mathrm{mrem} /$ year. This assumes that an individual ate a portion of each food crop every day of the year. Both ingestion doses include radionuclides that are naturally occurring in addition to any contribution from PGDP. 


\subsection{AIRBORNE RADIONUCLIDES}

In addition to the primary pathways, radioactive emissions to air are monitored to determine the extent to which the general public could be exposed and to demonstrate compliance with EPA regulations and DOE directives on radiation exposure to the public. The airborne radioactivity from PGDP operations is normally too low to be detected in the presence of natural background radiati $n$ in the environment. Therefore, potential doses to the public are calculated through the use of a dispersion model. This model calculates how measured quantities of released radionuclides mix with the atmosphere, where they travel, how they are diluted, and where they may deposit. Once the dispersion is calculated, population data and concentration/dose conversion factors are used to calculate individual and population doses. These doses include exposure from all pathways represented in Fig. 7.1.

The calculations were made using the AIRDOS-EPA suite of computer codes (Moore et al. 1979; Sjoreen and Miller 1984; Begovich et al. 1981). The computer codes used plant-specific radionuclide emission data for 1990 , meteorological data collected during 1990 at the $60-\mathrm{m}$ station at the Paducah site, and dose conversion factors based on the International Commission on Radiological Protection (ICRP). Organ weighting factors used in estimating effective dose equivalents are also based on ICRP recommendations (ICRP 1977).

EFA regulations for emissions of radionuclides from PGDP to the atmosphere are regulated under NESHAP. Beginning in 1990, the NESHAP limit is $10 \mathrm{mrem} / \mathrm{year}$ effective dose equivalent to any member of the public from all atmospheric pathways. Since use of the new limit is conservative with respect to the old limits and since it uses contemporary units, all dose estimates are presented as effective dose equivalents.

The calculated 50-year committed effective dose equivalent to the maximally exposed irdividual is estimated to be $1.8 \times 10^{-4}$ mrem (well below the 10-mrem limit). Table 7.4 of Part 2 shows ristorical data for doses to the maximally exposed irdividual, who, under most circumstances, is the person living closest to the plant in the predominant wind direction. The maximally exposed individual for 1990 is located $3050 \mathrm{~m}(10,000 \mathrm{ft})$ north-northeast of the plant site.

The primary pathway of exposure is inhalation. Neptunium-237 is the primary contributor to the inhalation dose, and ${ }^{90} \mathrm{Tc}$ plays an important role in the ingestion dose calculations.

The collective dose equivalent is a good measure of long-term radiation effects over a wide area. The collective effective dose equivalent in 1990 for the 535,211 persons residing within $80 \mathrm{~km}$ (50 miles) of the plant site was estimated to be $1.5 \times 10^{-3}$ person-rem from PGDP emissions. This can be compared with a collective dose for the same population of $2 \times 10^{5}$ person-rem/year from natural background.

\subsection{CONCLUSIONS}

Table 7.1 summarizes the annual dose from radiological contaminants that could potentially be received by a member of the public living near PGDP, assuming worst-case exposure from all major

Table 7.1. Summary of annual dose from radiological contaminants

Worst case combined exposure pathways

\begin{tabular}{lcc}
\hline \multicolumn{1}{c}{ Pathway } & Dose (mrem/year) & Percent of total \\
\hline Ingestion of groundwater & 0.024 & 0.4 \\
Ingestion of sediments & 0.65 & 10.5 \\
Ingestion of foodcrops & 1.15 & 18.5 \\
Ingestion of deer meat & 0.22 & 3.5 \\
Direct external gamma- & & \\
Litule Bayou Creek & 4.15 & 67.0 \\
Atmospheric releases & 0.00018 & $<0.1$ \\
Total annual dose & & 100.0 \\
all pathways & 6.20 & \\
\hline
\end{tabular}


pathways. The calculated maximum combined dose is $6.2 \mathrm{mrem} / \mathrm{year}$. This level is substantially in compliance with the DOE annual dose limit of $100 \mathrm{mrem} /$ year. The major contributor to the dose is direct external radiation that could be received by extended exposure to the Little Bayou Creek bed. This area has been posted to notify the public of that risk. 


\section{SOLID WASTE MANAGEMENT PROGRAM}

\subsection{DESCRIPTION}

\subsubsection{Purpose}

The Solid Waste Management Program at PGDP is designed to protect the environment, the public, and on-site personnel through the proper management of solid wastes generated by plant operations and eventually to dispose of the wastes in an environmentally acceptable manrer. A "cradle-to-grave" system provides management services for all types of waste from the point of generation through ultimate disposal. The system ensures that wastes are managed in accordance with state and federal regulations; DOE Orders 5480.3, $5400.3,5820.2 \mathrm{~A}$, and $5480.1 \mathrm{~B}$; and accepted industry practices. In addition to waste disposal, the program includes efforts to minimize the quantities of wastes generated and to treat wastes to reduce volume and toxicity.

In addition to the day-to-day waste management activities, the Solid Waste Management Program must anticipate future needs in both the technical and regulatory areas. Staff members provide technology development and regulatory review services to ensure that the program remains in compliance, that future waste management needs are anticipated, and that proper planning in response to these needs occurs. These efforts are coordinated with personnel at the other Oak Ridge Operations (ORO) sites to facilitate the consolidation of work and the enhancement of communications between sites.

\subsubsection{Regulatory Review}

RCRA regulates the generation, storage, transportation, treatment, and disposal of hazardous wastes and facilities involved in these activities. The state of Kentucky has been authorized by EPA to administer specific sections of RCRA in lieu of the federal program. This authorization has resulted in the promulgation of regulations in the Kentucky Administrative Regulations (KAR). The state also administers the disposal of sanitary and inert wastes through regulations published in the KAR. PGDP is subject to most of the requirements of these regulations. However, radioactive wastes such as source, special nuclear, and by-product materials are exempt from RCRA regulation by the Atomic Energy Act of 1954. The hazardous components of mixed waste (i.e., hazardous wastes containing radionuclides) are regulated by RCRA.

Wastes containing PCBs are regulated by TSCA. As in the case of mixed wastes, PCB wastes containing radionuclides are also managed under TSCA. PCB wastes containing hazardous wastes are managed in accordance with RCRA and TSCA by application of the more stringent regulation.

The CWA and the CAA do not directly affect solid waste management activities. However, the operation of waste management facilities must not adversely affect the ability of PGDP to comply with these regulations. Such compliance is also planned for in accordance with NEPA requirements, one of which is that the environmental impacts of plant projects be considered during the project planning process.

DOE has issued orders establishing policies in waste management areas: DCE Order 5632.1A prescribes requirements for the physical protection of classified wastes; DOE Order 5400.3 addresses the management of hazardous and mixed wastes at DOE facilities and directs that such wastes will be managed in an environmentally acceptable manner. Low-level radioactive wastes without hazardous or toxic constituents at DOE facilities are regulated under the federal Atomic Energy Act. These wastes are managed under DOE Order 5820.2A, which was issued in September 1988. This order establishes 
handling and disposal policies and a waste classification system to be implemented throughout DOE.

\subsubsection{Compliance Activities}

Hazardous waste facilities at PGDP currently are operated under interim status granted by the state of Kentucky (facility EPA ID KY8890008982). The Part $A$ application is updated as hazardous waste management needs dictate. Part B applications have been submitted for the eight storage and treatment units located on the plant site and the postclosure of the C-404 low-level radioactive waste burial ground. The Kentucky Division of Waste Management is evaluating the latest version of the permit application. Until a permit is issued, PGDP facilities will continue to operate according to the interim status provisions of 401 KAR Chap. 35.

\subsubsection{Program Strategy}

Proper identification, characterization, and classification of waste materials is essential in ensuring that waste management activities are performed safely, efficiently, and in compliance with regulations and policies. This is an ongoing process that must react to changes within the plant and to changes in regulations and policies beyond the control of plant management. A system of administrative controls assigns responsibilities for waste-handling activities and specifies criteria that must be met before a waste is accepted by the Waste Management Department. These controls include plant-wide Standard Practice Procedures; job-specific Standard Operating Procedures; waste sampling, analysis, and handling requirements of the facility Part B r ermit application; and other requirements. For wastes that are not handled through the Waste Management Department (such as process wastes discharged directly from a treatment unit), a system of administrative controls and, in some cases, physical controls (e.g., valve lock-outs, etc.) are used to ensure that the waste is properly characterized prior to discharge. The primary control in these instances is the Kentucky Pollutant Discharge Elimination System (KPDES) Permit under the CWA. RCRA characterizations are performed periodically on these wastes at the point of generation and, where necessary, following treatment.
To facilitate waste management activities, a new Generator Waste Management Program was developed. Implemented in 1990, the program focuses on the proper identification, segregation, and packaging of wastes at the point of generation. Following completion of a successful pilot program in the C-720 area, implementation in the rest of the plant is under way.

PGDP has in place a program to minimize the amount of waste being generated. Under the direction of the Plant Waste Minimization Program manager, a team of waste management, technical, operations, and maintenance personnel is charged with identifying opportunities and strategies for waste minimization and coordinating efforts to accomplish strategies. Where possible, avoiding or minimizing waste is to be accomplished through process changes that eliminate the waste stream or recycle it back into use. However, given the nature of the processes at PGDP, opportunities for waste elimination and recycling at the source are limited.

Other options include reducing waste stream toxicity and hazard through the use of less toxic or hazardous raw materials or limiting the use of toxic and hazardous materials. For example, limiting the use of TCE to large degreasing units and using less toxic solvents in the field has reduced the quantity of waste oil requiring disposal as a hazardous waste. Installing new treatment processes or modifying existing processes can also reduce waste stream toxicity and volume. Segregating waste materials to reduce the volume of hazardous or radionuclide-contaminated materials requiring special handling and disposal is a common practice.

Several options are available for waste disposal. Some wastes are treated and disposed of directly (e.g., the neutralization of waste acids). Sanitary and inert wastes are also disposed of on-site. Most hazardous and all PCB wastes are disposed of off-site, preferably by incineration. All off-site disposal facilities must meet RCRA and TSCA regulatory requirements. Some wastes (such as mixed and low-level radioactive wastes) must be placed in on-site long-term storage until treatment or disposal technology is developed and demonstrated.

PGDP has prepared a plan including projects and budget requirements for waste management activities needed to ensure regulatory compliance. As part of the overall DOE effort (PGDP Feb. 14, 1990), this 
plan (discussed in Subsect. 4.4.2) is to be used as a program strategy document. Projects for waste minimization and new storage, treatment, and disposal facilities are part of the plan. PGDP also currently generates, or has generated in the past, several wastes that cannot be treated or disposed of at this time. Beginning in 1990 and continuing for the next several years, PGDP will be identifying and evaluating technologies for the treatment and disposal of these wastes.

\subsection{WASTE GENERATION}

\subsubsection{Types of Waste Generated}

Residential. This waste category includes office, cafeteria, and similar wastes.

Inert (Industrial). Fly ash for coal-fired boilers and construction spoils make up the bulk of this category.

RCRA hazardous. This class of wastes is defined by RCRA regulations. Characteristic hazardous wastes at PGDP include waste acids such as sulfuric and nitric acids, solutions containing metals such as chromium, and ignitable wastes such as paint solvents. Listed hazardous wastes include TCE and various laboratory chemicals.

Mixed. These wastes consist of RCRA hazardous wastes contaminated with radionuclides. Uranium is the most common contaminant.

$P C B$ s. All wastes containing more than 50 parts per million (ppm) of PCBs by weight and wastes resulting from $\mathrm{PCB}$ spill cleanup operations are handled as PCB wastes. Waste containing detectable (i.e., $>1 \mathrm{ppm}$ in soil, $>0.5$ parts per billion (ppb) in water, and $>2 \mathrm{ppm}$ in oil) PCBs are disposed of as PCB wastes but are not classified as such.

$P C B$ /radioactive. This category consists of $\mathrm{PCB}$ wastes (as defined in the preceding) that are contaminated with $>50 \mathrm{ppm}$ depleted $U$, detectable $\mathrm{Np}, \mathrm{Pu}, \mathrm{Th}$, and/or Tc.

Transuranic. These wastes contain more than 100 $\mathrm{nCi} / \mathrm{g}$ of transuranic radionuclides. The most common radionuclides are ${ }^{239} \mathrm{Pu}$ and ${ }^{237} \mathrm{~Np}$. A small quantity of this type of waste is stored at PGDP. This waste is not currently produced at the plant.

Low-level radioactive. This category consists of any nonhazardous, non-PCB or PCB-contaminated, or nontransuranic waste containing uranium $\geq 17 \mathrm{pCi} / \mathrm{g}$ total uranium activity and/or containing uranium with a determinable assay $>0.711 \%$ and/or containing detectable quantities of $\mathrm{Tc}, \mathrm{Np}, \mathrm{Pu}, \mathrm{Am}$, or other reactor-produced or artifically created radionuclides.

Asbestos. This waste, classified as either "clean" or "contaminated" depending on the absence or presence of uranium, consists of friable asbestos generated by plant maintenance operations.

Scrap metal. This stream, also classified as either "clean" or "regulated," consists of scrap metal generated by maintenance operations and machine shop work.

Nonhazardous. This category consists of miscellaneous wastes not fitting into one of the preceding categories. An example of this would be nonhazardous liquids not suitable for on-site disposal.

Classified. Wastes considered to contain sensitive security information are accorded special handling. Wastes in any of the preceding categories may also be considered classified.

\subsubsection{Waste-Generating Activities}

Utilities operations. Wastes produced during the operation of plant auxiliary systems include fly ash produced by the generation of steam from coal-fired boilers, sludge produced by the treatment of sewage, and sludges produced by the lime-soda ash softening of water from the Ohio River for process use. Sewage treatment sludges contain PCBs and uranium. The sewage sludge is drummed and stored. Another plant waste stream is the blowdown from the recirculating cooling water system. The blowdown, which contains about $8 \mathrm{ppm}$ chromium, is hazardous and is treated to remove the chromium.

Chemical operations. The majority of the low-level radioactive waste produced at PGDP is produced by the Chemical Operations Department. The major contaminant is uranium; trace quantities of ${ }^{99} \mathrm{Tc},{ }^{237} \mathrm{~Np},{ }^{230} \mathrm{Th}$, and ${ }^{239} \mathrm{Pu}$ are also present. The largest low-level waste stream is the filter cake produced by the lime precipitation treatment of spent decontamination, cylinder wash, and laboratory waste solutions. Smaller amounts of other low-level wastes include contaminated floor sweep, articles of clothing, small parts, and supplies.

Some hazardous wastes are also produced by the Chemical Operations Department. These include spent TCE used in degreasing and waste from a small-parts nickel-deplating process. The lime 
precipitation process waste is occasionally a mixed waste.

Fabrication and maintenance. Maintenance activity is generally divided into two types-shop and field. Shop activities include major equipment repair, rebuilding and construction, metal machining, forming and welding, instrument repair, carpentry, and painting. Scrap metal, both clean and contaminated, is produced by shop activity. A variety of machining fluids (generally oils), lubricating oils, and cutting fluids are used. Most of the wastes produced from these materials are nonhazardous. Small amounts of spent chlorinated solvents including TCE and 1,1,1-trichloroethane are produced by degreasing operations. Other hazardous wastes include painting wastes, which are hazardous because of their ignitability. Most of the other wastes, such as scrap wood, boxes, and other containers, are classified as nonhazardous sanitary or industrial waste.

Waste lubricating oil forms a large-volume waste stream produced by field maintenance activities. The oil is classified as hazardous, nonhazardous, or contaminated depending on the chlorinated solvent or radionuclide content. Clean and contaminated asbestos wastes result from the repair of systems such as steam-heating systems that were insulated during plant construction. Clean and contaminated scrap metal, nonhazardous construction debris, PCBs and PCB-contaminated wastes, and waste oils also are produced at PGDP through maintenance activity.

Laboratory operations. Small quantities of hazardous, nonhazardous, low-level radioactive, and
PCB wastes are geinerated by laboratory operations. The bulk of the wastes are residues or leftovers from analytical work. Uranium salvage solutions are mixed waste. Waste oils, solvents, and other organic materials are also hazardous, as are discarded laboratory chemicals.

Environmental restoration activities. PGDP has begun an extensive Environmental Restoration Program (ERP) designed to investigate the current groundwater contamination problem and on-site waste management units and spill sites. Drill tailings, grout, equipment wash water, and water from sampling activities are being generated and are managed in accordance with regulations and plant procedures.

\subsubsection{Waste Generation Summary}

Table 8.1 summarizes the waste generated on-site during 1990. The types of waste are described in Sect. 8.2.1. The quantities are indicated in the table.

The most significant changes in waste generation rates between 1989 and 1990 occurred in the low-level radioactive waste (LLW), hazardous, and mixed waste areas. The increase in the hazardous and mixed waste categories was primarily due to the implementation of the toxicity characteristic leaching procedure test. This procedure resulted in reclassification of some previously nonhazardous wastes as hazardous or mixed in 1990. Uranium-contaminated waste oils represent the major type of waste that was reclassified as mixed.

Table 8.1. 1990 PGDP waste generation summary

\begin{tabular}{lcr}
\hline \multicolumn{1}{c}{ Waste type } & Volume $\left(\mathrm{m}^{3}\right)$ & Mass $(\mathrm{kg})$ \\
\hline Hazardous & 52.7 & 55,207 \\
Mixed & 53.4 & 49,309 \\
Residential & $4,746.0$ & $\mathrm{NA}^{a}$ \\
Inert & $2,144.0$ & $\mathrm{NA}$ \\
PCB & 150.0 & 77,318 \\
PCB/radioactive & 85.0 & 82,321 \\
Low-level & 685.0 & 536,167 \\
Asbestos & 48.0 & $\mathrm{NA}$ \\
Classified & 0.0 & 0 \\
Clean metal & 404.0 & $\mathrm{NA}$ \\
Contaminated metal & 264.0 & $\mathrm{NA}$ \\
Miscellaneous nonhazardous & 44.0 & 33,600 \\
\hline
\end{tabular}

Not applicable. 
The incriase in LLW was due to two factors. First, 86,300 kg of material previously classified as "Recoverable" was redesignated as LLW in 1990. The reclassification was due to the shutdown of off-site recovery processes. Second, approximately $367,750 \mathrm{~kg}$ of radioactivity contaminated soils were generated by KPDES compliance projects.

\subsection{WASTE MANAGEMENT ACTIVITIES}

\subsubsection{Waste Management System}

Containerized wastes and wastes requiring off-site disposal are managed by the Waste Management Department. All wastes are required to have a Request for Disposal form completed before they can be moved. This form functions as an internal manifest. Should the information on the form be insufficient, the waste is sampled and characterized before being disposed of or stored. Characterization is routinely performed on several waste streams in accordance with the Waste Analysis Plan in the facility Part B Permit Application, off-site disposal facility requirements, general RCRA, TSCA, and $C W A$ requirements, and other criteria set forth by DOE and internal procedures.

Once a waste has been properly identified and characterized, it is packaged for shipment and/or storage. U.S. Department of Transportation (DOT) criteria are used to select containers such as drums. Small quantities of chemicals are lab-packed by either PGDP personnel or off-site disposal facility personnel.

Wastes are managed at several on-site facilities. Residential and industrial waste, clean scrap metal, clean asbestos, and treated medical wastes are disposed of on-site. Some hazardous wastes are treated to render them nonhazardous prior to disposal. Some low-level radioactive wastes are treated to reduce their volume. Clean (i.e., without technetium, uranium, or transuranic contamination) PCB and hazardous wastes are disposed of off-site at inspected and permitted incinerators. Off-site landfills are used only under special circumstances. Some wastes, such as mixed and $\mathrm{PCB} /$ radioactive wastes, cannot currently be disposed of and are placed in indefinite storage. Medical wastes are treated by autoclaving. They are then packaged in containers appropriate for the type of waste and are disposed of in the residential landfill.

All waste management units are operated in accordance with appropriate regulations. Hazardous, mixed, PCB, PCB/uranium, and LLW are tracked and accounted for using a computerized inventory system. Each container is assigned a unique identification number that is entered into a computer data base. Bulk liquids are inventoried at the time they are placed in tanks. Quantities of other wastes are estimated.

Wastes not managed by the Waste Management Department are discharged directly from treatment units or activity areas. Such wastes are routinely characterized to ensure that they are being properly hanilled.

\subsubsection{Waste Management Facilities}

A number of waste management units are located on the PGDP site. Each unit handles a limited number of types of waste. Units are grouped according to three general types-storage, treatment, and disposal. Table 8.2 shows the 1990 waste treatment data; Table 8.3 shows the 1990 on-site disposal information. The PGDP waste management units are listed in the following subsection.

Table 8.2. 1990 PGDP waste disposal

\begin{tabular}{ccc}
\hline Waste type & Quantity $\left(\mathrm{m}^{3}\right)$ & Treatment \\
\hline $\begin{array}{c}\text { Uranium salvage } \\
\text { (mixed) }\end{array}$ & 3.6 & Neutralization/precipitation \\
$\begin{array}{c}\text { Machine coolant } \\
\text { (nonhazardous) }\end{array}$ & 11.4 & Coagulation/filtration \\
\hline
\end{tabular}


Table 8.3. 1990 PGDP on-site waste disposal

\begin{tabular}{llc}
\hline Waste type & $\begin{array}{c}\text { Disposal } \\
\text { method }\end{array}$ & Quantity $\left(\mathrm{m}^{3}\right)$ \\
\hline Residential & Landfill & 4,746 \\
Inert & Landfill & 2,144 \\
\hline
\end{tabular}

\subsubsection{RCRA hazardous and mixed waste facilities}

\section{RCRA-permitted units}

C-733 hazardous waste storage area. A diked, roofed storage area for container and tank storage. Capacity is approximately $190,890 \mathrm{~L}(50,500 \mathrm{gal})$.

$C-746-Q$ hazardous waste storage area. A diked, totally enclosed area for container storage. No ignitable wastes are to be stored in the area. Capacity is approximately $190,890 \mathrm{~L}(50,000 \mathrm{gal})$.

$C-746-R$ waste solvent storage area. A diked area used for the temporary storage of drummed waste oils during sampling activities. Some mixed, hazardous, and PCB wastes are also stored in tanks.

$C-400-B$ waste solution storage tank. An 18,900-L (5000-gal) stainless steel storage tank. The tank is contained in a concrete, stainless-steel-lined containment area.

C-400-C nickel stripper evaporation unit. A hazardous waste treatment unit. Hazardous wastes are evaporated in a 454-L (120-gal) stainless steel steam-heated tank.

C-400-D lime precipitation tank. A $16,254-\mathrm{L}$ (4300-gal) stainless-steel tank used for neutralization and metals precipitation.

C-409 hazardous waste pilot plant. Used for technology development work and the limited treatment and disposal of small quantities of hazardous wastes.

\section{Permit-by-rule facilities}

C-616 chromium reduction facility. A wastewater treatment unit used to remove chromium from the recirculating cooling water blowdown. This is a RCRA "permit-by-rule" facility.

C-403 neutralization tank. An in-ground tank used as a ho' 'ing tank for wastewater from the C-400 building. It has limited use as a "permit-by-rule" elementary neutralization unit.
C-410-C neutralization tank. An in-ground tank used for the neutralization of spent battery acids and fluorine cell electrolytes. This is a "permit-by-rule" elementary neutralization unit.

\subsubsection{PCBs and PCB/uranium waste facilities}

C-746-A storage area. A storage area located in the $\mathrm{C}-746-\mathrm{A}$ warehouse. The area is diked and has a capacity of approximately 3000 drums. PCB and $\mathrm{PCB} /$ uranium wastes are stored here.

$C-337$ and $C-333$ PCB waste storage areas. Container storage areas located in the $\mathrm{C}-337$ and C-333 process buildings. These areas are lined and diked with a synthetic material meeting EPA requirements. Approximately 2300 drums are stored in these areas.

\subsubsection{Nonhazardous waste management areas}

C-746-S residential landfill. Used for the disposal of sanitary trash. Currently one cell is being utilized.

C-746- $T$ industrial landfill. Used for the disposal of fly ash, clean asbestos, and construction debris.

$C-728$ waste oil storage. A diked area that includes two clean oil storage tanks with capacities of 15,120 and $30,240 \mathrm{~L}$ (4000 and $8000 \mathrm{gal}$ ). Waste oil is stored here until recycled off-site.

\subsubsection{Scrap metal facilities}

C-746-P1 west clean scrap metal yard. Used for the accumulation of clean scrap metal for resale.

$C$-746-P east regulated scrap yards. Areas used for the storage of scrap metal containing nontransferable radioactive contamination.

\subsubsection{Low-level radioactive waste facilities}

$C-746-Q$ low-level waste storage area. Located within the $C-746-Q$ building. The building is enclosed and diked. Approximately 1600 drums may be stored here. The area may be expanded as space becomes available.

$C-746-M$ storage building. A diked, totally enclosed drum storage area. The capacity of the area is approximately 60 drums. 


\subsubsection{Orf-Site Disposal Activities}

Incineration is the preferred method for off-site treatment/disposal of waste. Landfills and other types of disposal are used only on a limited basis under special circumstances. All commercial sites are visited and approved by Energy Systems personnel prior to use. These visits are used to inspect the facilities and to review management, permit, and insurance information. Site visits are repeated annually.

Off-site treatment/disposal is arranged for by the Waste Management and Purchasing Departments. Unless special circumstances warrant other arrangements, all such disposals are bid and awarded to the qualified contractor with the lowest bid. Commercial transporters or transportation provided by the waste management firm are used to move the waste from the PGDP site. Table 8.4 shows the off-site waste treatment/disposal quantities for 1990 .

All containers of waste must meet DOT shipping requirements. Packages are inspected and inventoried prior to shipment.

\subsubsection{Waste Placed in Storage}

In some cases wastes are accumulated to provide for cost-effective off-site disposal. These wastes are placed in interim storage. In some cases waste generated in 1990 will be retained on-site in storage until suitable disposal options are available. Several waste streams including mixed and $\mathrm{PCB} /$ radioactive wastes cannot be disposed of currently by any means. These wastes are placed in indefinite storage on-site (see Table 8.5). The quantities in the table represent the total amount of waste in inventory at the end of 1990.

\subsubsection{Special Activities}

\subsubsection{Waste generation program}

To improve regulatory compliance and reduce costs associated with waste management activities, a waste generation program was developed and implemented in the C-720 Maintenance Facility. The program established waste identification, segregation, packaging, and management standards for waste generators. The program has eliminated the presence of unidentified waste containers, improved waste segregation practices, and prevented the buildup of wastes in generation areas. Full implementation is scheduled for 1991.

\subsubsection{Waste treatment technologies demonstrations}

In conjunction with the Process and Long-range Technical Support (P\&LRTS) Program, requests for expressions of interest in treating two PGDP waste streams (cooling tower debris and $\mathrm{PCB} /$ radioactive wastes currently in storage) were distributed to commercial waste treatment and disposal firms. A number of firms responded positively, and a qualified bidders' list was established. Technology demonstration projects will be under way in 1991 .

\subsubsection{Off-site low-level waste disposal}

At the direction of DOE/ORO, PGDP began developing a program to dispose of LLW at other DOE facilities. PGDP personnel visited the Hanford Reservation in Washington state, and Hanford personnel conducted a preliminary audit of the PGDP waste management and certification program. Tentative plans are to initiate shipments in 1992.

Table 8.4. 1990 PGDP off-site waste disposal

\begin{tabular}{llrr}
\hline & & \multicolumn{2}{c}{ Quantity } \\
\cline { 3 - 4 } Waste type & Disposal method & $\left(\mathrm{m}^{3}\right)$ & $(\mathrm{kg})$ \\
\hline PCB & Incineration & 91.6 & 100,930 \\
PCB (solids) & Landfill & 41.5 & 48,879 \\
PCB & & 155.0 & 28,061 \\
transformers & Smelter & & \\
Hazardous & Incineration & 105.9 & 88,393 \\
Hazardous & Landfill & 1.5 & 35 \\
\hline
\end{tabular}




\section{SPECIAL STUDIES}

PGDP had a total of 536 spills or releases of various types of materials during CY 1990. A record of each incident is kept by the PGDP Shift

Superintendent's office. All cleanup debris generated was handled in accordance with PGDP standard operating procedures. The PGDP Shift

Superintendent's office reports all spills or releases to various levels of PGDP management and/or DOE officials as appropriate. Occurrences are categorized and notifications made in accordance with DOE Order 5000.3A "Occurrence Reporting and Processing of Operations Information."

Most of the spills during CY 1990 were from PCB gaskets (Fig. 9.1). A total of 261 incidents of leaking PCB gaskets was recorded during CY 1990. Troughs are installed beneath leaking ventilation gaskets immediately upon discovery of leaks. All gasket leaks were inside buildings. Highlights of the incidents are given in Sects. 9.1 through 9.1.11.

\subsection{UNUSUAL OCCURRENCES}

\subsubsection{Chromated Water Spill: C-335 Process Building}

On January 10, 1990, maintenance activities were being performed on the " $A$ " booster water strainer. Approximately $400 \mathrm{gal}$ of recirculating cooling water (RCW) containing 18 parts per million (ppm) sodium bichromate was released when a test valve broke due to corrosion. The water was contained inside the building. Composite sampling was initiated on outfall $\mathrm{K} 001$ and indicated chromium concentrations were below Kentucky Pollutant Discharge Elimination System (KPDES) Agreed Order limits. The water was drummed for disposal.

\subsubsection{PCB Capacitor Failure: C-533 Switchyard}

On April 26, 1990, two large high-voltage PCB capacitors in the "E" bank failed. The failure resulted in a release of approximately $4 \mathrm{oz}$. of 82 to $100 \%$ PCB onto the gravel below the capacitor bank. E-bank was taken out of service and the failed capacitors were removed for disposal. The spill site was cleaned up and closed out under the TSCA PCB spill cleanup policy.

\subsubsection{Diesel Fuel Spill: C-611 Diesel Generator}

On July 11, 1990, a fuel line fitting failed, releasing approximately $20 \mathrm{gal}$ of diesel fuel into the basement of C-611. The line, which fed the generator from an outside storage tank, was valved off. Area drains were isolated and the free liquid was cleaned up with absorbent materials. Some diesel did reach the plant drainage system, as evidenced by a sheen on the sludge and secondary lagoons into which the building effluents drain. Absorbent booms/pads were used to contain and clean up the release.

\subsubsection{Chromated Water Leak: C-337 Truck Alley}

On July 24,1990 , chromated water was noticed seeping up through cracks in the concrete of the C-337 truck alley. An RCW line had developed a leak due to corrosion. The RCW was flowing into a storm drain at approximately $5 \mathrm{gpm}$. It was estimated that 400 gal entered the storm drain system before the drain was plugged. Effluent at KPDES outfall $\mathrm{K} 002$ was contained with a sandbag dam and an inflatable plug. The water was pumped for transfer to the cooling tower basins and composite sampling was initiated to ensure that the release had been contained. The RCW line was taken out of service and repaired. No KPDES noncompliance occurred as a result of this leak.

\subsubsection{Sprinkler Water Spill: C-333 Filter Room 2}

On July 30, 1990, a leak developed in the A-6 sprinkler system inside filter room 2. Approximately 


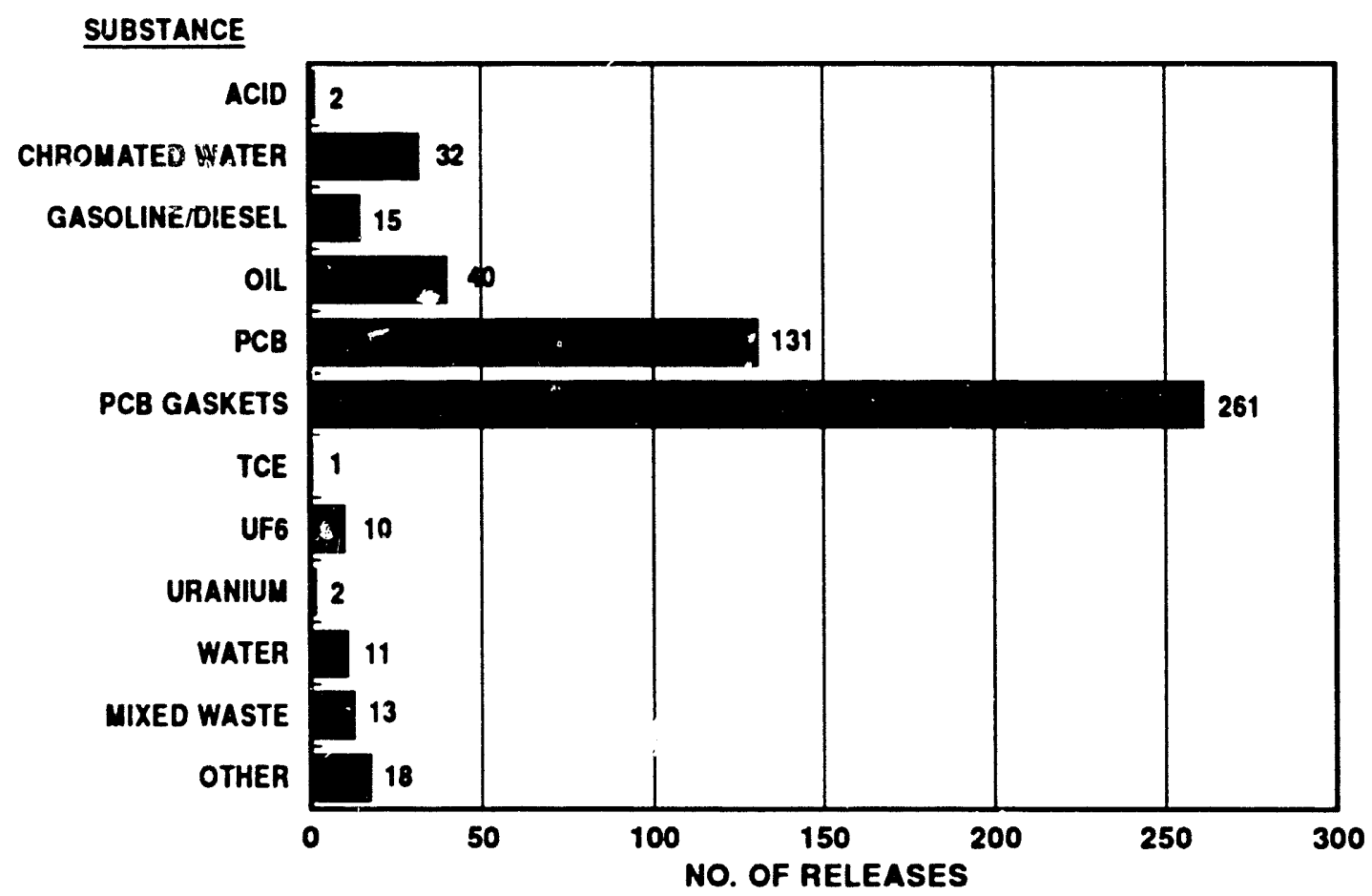

Fig. 9.1. Spills or releases at PGDP during 1990.

$4000 \mathrm{gal}$ of water leaked to the diked area inside the filter room. About $5 \mathrm{gal}$ overflowed to the ground outside of the building. The water was pumped into storage tanks for characterization and treatmen $/$ disposal. No water reached the plant drainage system.

\subsubsection{Chromated Water Spill: C-633 Cooling Tower}

On July 31,1990 , an elevated result in a routine hexavalent chromium grab sample prompted an investigation into possible sources. A concentration of $0.61 \mathrm{mg} / \mathrm{L} \mathrm{Cr}{ }^{+\epsilon}$ was indicated at KPDES outfall $\mathrm{K} 012$, while just upstream a pool containing a)proximately $2000 \mathrm{gal}$ of water was discovered to ha"e $7.6 \mathrm{mg} / \mathrm{Cr}^{+6}$. The flow at $\mathrm{K} 012$ was contained and the water pumped for transfer to the cooling tower basins. A 60 -in. RCW supply line was discovered to be leaking underground, allowing the chromated water to seep into the storm drain system. Pumping of the effluent to cooling tower basins continued until the leaking line was uncovered and repaired and sampling indicated acceptable discharge levels of chromium. No KPDES Agreed Order limits were violated as a result of the spill.

\subsubsection{PCB Capacitor Failure: C-331}

On August 4, 1990, a large high-voltage PCE capacitor failed, releasing approximately $0.5 \mathrm{gal}$ of 100\% PCBs. The oil was discovered puddled on the floor surrounding the capacitor cabinet. Power was shut off to the bank and absorbent materials were used to contain the spill. The capacitor was removed for disposal, and cleanup was initiated in accordance with the TSCA PCB spill cleanup policy. This cleanup included removal of free liquid and double wash/rinse of all affected surfaces, followed by statistical sampling for verification. Verification is pending.

\subsection{Potential Devices Leaking PCBs: Plant Switchyards}

On September 4, 1990, during a routine inspection of plant switchyards, approximately 60 potential devices (PDs) on the Oil Circuit Breakers (OCBs) were found to have PCB oil drips, weeps, and 
leaks. Only four had leaks that actually hit the ground, and the rest had drips or weeps forming on the cabinets. According to TSCA regulations, any PCBs on the external surface of equipment are a spill and must be treated accordingly. The PDs contain small PCB capacitors that apparently leak inside the $P D$ cabinet. Eventually the leaks inside migrate through seams onto the external surface. The OCBs were immediately flagged and labeled as ? ${ }^{2} \mathrm{CB}$ spill sites, and the external surfaces were decontaminated in accordance with TSCA PCB regulations. However, full compliance with the regulations will not be achieved until the leaking PDs are replaced. There is a replacement project currently under way; until it is completed, the PDs must be inspected on a daily basis and any new leaks cleaned immediately.

\subsubsection{Sludge Discharge: C-616-E Lagoon}

On September 12, 1990, during routine mowing activities at the C-616-E lagoon, a cleanout on the sludge discharge line from the C-616 clarifier was damaged. This caused the release of approximately $400 \mathrm{gal}$ of sludge-bearing water onto the ground. Shutting down the sludge discharge system then resulted in approximately $100 \mathrm{gal}$ of the water overflowing into a plant drainage ditch. The sludge discharge water contains chromium (III) hydroxide and residual iron (II) sulfate. The cleanout was repaired and spilled material was cleaned up and drummed for disposal. Sampling was conducted of KPDES outfall K001 as a precautionary measure. No KPDES noncompliances occurred.

\subsubsection{PCB Capacitor Failure: C-331}

On October 22, 1990, a capacitor failed in the C-331 building, spilling approximately $3 \mathrm{gal}(30 \mathrm{lb})$ of $100 \%$ PCB oil. The spill was immediately contained within the building, and the area was flagged and marked as a PCB spill site. Cleanup was initiated in accordance with TSCA PCB regulations. Sample results for verification of cleanup are pending.

\section{1.i1 Current Transformer Failure: C-533 Switchyard}

On December 27,1990 , approximately $345 \mathrm{gal}$ of non-PCB oil was released when the $Y$-line $A$ phase current transformer (CT) failed. The oil spread over a large area of the switchyard gravel. Due to water flow from the fire sprinkler system and heavy precipitation, the oil leached out of the switchyard and into KPDES outfall $\mathrm{K} 012$, forming a visible sheen on the ditch. On one $\alpha$ casion, the sheen broke through containment devices and reached Little Bayou Creek, prompting reports to Kentucky Division of Water and the National Response Center. Approximately 12055 -gal drums of gravel and soil have been excavated from the switchyard in an effort to remove as much of the free oil as possible. Efforts to contain and remove the oil from $\mathrm{K} 012$ are ongoing.

\subsection{SPECIAL STUDIES}

\subsubsection{Uranium Release Study}

Review of uranium quantities being discharged from KPDES Outfall 001 has shown an increasing trend in recent years. A contaminant-tracking sampling study was developed in early 1990 to address the potential problem. This study included monitoring of areas suspected of contributing to the total uranium discharge. Several locations were eliminated from the sampling plan, which indicated that they either were not major contributors or were contributing a known amount to the total uranium discharges.

Based on the data generated by this study through September, two areas were identified as major contributors to the total uranium discharge. Batch releases from the $\mathrm{C}-400$ uranium treatment system contribute to the total concentration. A Best A vailable Technology (BAT) treatment evaluation is currently being performed on this operation.

Recommendations for improvements to the system should allow further minimization of its contribution. The metals scrapyard has also been determined to be a major contributor of uranium to liquid effluents that flow from Outfall 001 during rainfall. The cause of the increase in uranium contributions from the area has not been directly determined. The extent of the contamination and possible remediation is being investigated as part of the Phase II Site Investigation Program.

The average concentration of uranium discharged from Outfall 001 for 1990 equals $4.52 \%$ of the discharge standard. This represents a $65 \%$ increase over 1989. Although this level is well below the limit, PGDP will continue environmental monitoring activities to track and trend the releases. 


\subsubsection{National Environmental Policy Act}

Implementing NEPA is a decision-making process that considers the need for a proposed action and an alternative action with emphasis on minimizing environmental impacts. It establishes policy, sets goals, and provides means for carrying out the policy. NEPA contains "action-forcing" provisions to ensure that federal agencies act according to the letter and spirit of the act.

Through the implementation of NEPA, the plant has a practicable means (consistent with the requirements of the act and other essential considerations of national policy) to restore and enhance the quality of the human environment and to avoid or minimize any possible effects of its actions upon the quality of the human environment.

During 1990 the NEPA section added two employees. Programs that have continued in 1990 include:

- field surveillance reports,

- heightened wetlands awareness,

- monthly NEPA status reports, and

- letters to engineering to confirm NEPA approval from DOE for specific projects.

During 1990 approximately 109 categorical exclusion determinations were submitted for approval, and 24 action description memorandums were issued to DOE for approval. Several field trips to construction sites have been documented. In addition, approximately 5500 work orders have been reviewed for environmental concerns; others have been sent to environmental, safety, and health departments for further review in their areas of expertise. Two environmental assessments were issued. No impact statements were issued during 1990.

\subsubsection{Environmental Advisory Committee}

The PGDP Environmental Advisory Committee is composed of five individuals who represent a cross section of scientists, educators, health professionals, and local businessmen. The committee was formed in 1986 and has been chartered with the following responsibilities:
- review the sources of environmental pollutants, the control systems, and the surveillance activities associated with operation of PGDP;

- evaluate plans for remedial activities and studies to correct, enlarge, or close waste management facilities, and provide recommendations for appropriate changes in strategy or direction;

- assess the long-term fate and health effects of trace quantities of uranium, other radionuclides, and other pollutants of concern in PGDP environs;

- advise on both scientific and community-concern aspects of environmental and health issues to the PGDP plant manager or the Director, Office of Environment, Safety, and Health, Martin Marietta Energy Systems, Inc., and

- advise on appropriate methods and forms of reporting environmental and health data to the general public.

The existence of the PGDP Environmental Advisory Committee is expected to continue until current needs are assessed and environmental problems are resolvəd.

During 1990, the PGDP Environmental Advisory Committee continued to participate in reviewing PGDP environmental programs. Two meetings were held in 1990 (May and November). The topics discussed at these meetings included the following:

- environmental nonconformance issues

- PGDP Tiger Team assessment (review process and findings)

- groundwater investigation update (Phase I)

- groundwater investigation (Phase II Work Plan)

- PCBs in Big and Little Bayou Creeks

- FSAR upgrade

- NESHAP air monitoring

- asbestos building survey results

- underground storage tank investigation/removal

- PCB gasket Federal Facility Compliance Agreement

The information exchange between PGDP and the Advisory Committee members continues to be utilized to impruve PGDP's environmental programs and its relations with local community members. 


\subsubsection{PCB-Contaminated Ventilation Duct Gaskets}

Buildings at PGDP contain ventilation duct systems for heating and cooling of both personnel space and process equipment. The gaskets in a number of these systems contain varying levels of PCBs. The gaskets therefore constitute non-totally enclosed PCB activities, which are prohibited by 40 CFR 761.20(a). Certain systems (notably the motor exhaust duct systems) have come in contact with leaching media (chiefly oil), resulting in migration or drips of PCBs to the floors of the process buildings. These drips of $\mathrm{PCB}$-contaminated oil are considered PCB spills.

Three mechanisms have been identified that cause PCB leaks from the ventilation duct gaskets. First, oil is drawn into the motor exhaust duct systems along with exhaust air from the motors. The oil comes from leaks in the process motor bearings. Once in the duct, the oil will contact and saturate the gaskets in the duct system. It leaches PCBs from the gaskets and then drips onto the process building floor below the duct. Second, some PCB-contaminated oil drips occur when oil from equipment leaks on the second floor of the process buildings migrates through penetrations in the floor and falls on top of the ducts. If the oils falls on a duct gasket, a PCB-contaminated oil drip can occur. Third, PCB drips from gaskets are possible without oil as a leaching medium during very high temperature excursions. Physical properties of the gasket components appear to be temperature dependent. The preceding two mechanisms can occur in either the motor exhaust or supply duct systems. However, installing spill containment/collection systems below the gaskets will contain PCB-contaminated drips resulting from these two mechanisms in the same manner as drips caused by oil within the motor exhaust duct systems.

Therefore, one of the ongoing actions that has been implemented is the installation of spill containment/collection systems below leaking gaskets. The systems consist of either polyvinyl chloride (PVC) or sheet metal troughs installed underneath the gaskets and PVC piping manifolds that connect large numbers of the troughs to common PCB oil collection points. Approximately 5000 of these trcughs have been installed through 1990. Also, a program for documenting and tracking newly identified PCB gasket drips is ongoing at PGDP to meet EPA PCB spill cleanup requirements. The major components of this program are documenting and identifying new spills, containing the spills by installing spill containment/collection systems, decontaminating the spill area, and verifying cleanup by post-cleanup sampling and analysis.

DOE and EPA are negotiating an agreement concerning compliance with TSCA and the PCB Regulations found at 40 CFR 761. The agreement will allow the use of PCB gaskets and spill containment/collection systems at PGDP. It will require installing containment/collection systems on all motor exhaust duct gaskets. A line item project is continuing to accomplish this task. Engineering design was initiated during March 1991. The most recent total estimated cost of this project at PGDP is approximately $\$ 20$ million dollars. 
" " 


\section{QUALITY ASSURANCE}

Quality assurance (QA) planning is integrated into every step of the environmental surveillance and monitoring effort. Each contributor is totally responsible for the quality of his or her contribution. Developed and evolved over many years of such activity and careful study of appropriate regulatory guidance, the surveillance and monitoring programs can be roughly divided into three major efforts: sampling of the environment, analysis of the samples, and treatment or interpretation of the results.

The Analytical Laboratory Department, the Environmental Services Department consisting of the Environmental Sampling Section, and the Quality Support Section are continuing to implement two laboratory internal programs to monitor the quality of analyses reported on surface water and groundwater samples. These programs use purchased certified standard materials prepared by Measurements Control that are submitted according to regulatory guidance to the groups performing the analyses. These results are used to assess lab performance and to provide more immediate feedback to analysts and customers involved in the programs.

The report for surface monitoring will be issued on a quarterly basis to inform lab supervisors and managers of data quality measurements in the Technical Services Division. The section has added a professional position to provide backup to the Measurement Control functions and to coordinate procedure preparation. This has resulted in a schedule and reminder system for writing and updating procedures, and development of a specific format for procedures that meets plant policy.

In the Environmental Sampling Section, the surface water/ambient group has started using the new flow-monitoring devices installed as part of an engineering project to upgrade the sampling locations. These devices were built to EPA specifications to monitor flows to be reported in the Discharge Monitoring Report. A new procedure was implemented to calibrate the field Total Residual Chlorine (TRC) analyzer. The procedure involves immediately comparing field instrument results to the referee amperometric titration method for determining TRC, eliminating the concern about volatile standard material.

The groundwater group has prepared a schedule for well-sampling activities to better utilize manpower and equipment and coordinate with laboratory and external contractor schedules. A monthly report was begun to update Environmental Restoration personnel in charge of these scheduled activities on the status of the activities and on problems encountered in carrying them out. A purge water collection procedure was written and implemented to separate water known to need treatment from water that could be discharged to surface drainage ditches. This procedure reduced the analytical workload and the amount of waste materials on the plant site. A professional position was created for supervising groundwater activities because of the increased workload and complexity in this area. Personnel in both groups in the Environmental Sampling Section have attended courses in groundwater sampling and Office of Safety and Health Administration hazardous worker training.

The Organic and Process Analysis Section of the Analytical Laboratory Department has procured analytical instruments and equipment to provide greater capacity for sample analyses and better quantification, or improved sample preparation. One gas chromatograph/mass spectrometer (GC/MS) and one gas chromatograph (GC) and autosampler were purchased to increase analytical capability. The new GC will allow the laboratory to lower further its lower reporting limit for PCBs. A purge and trap device for the GC/MS was obtained to improve sample quantification by rigidly controlling sample injection. A Lab Data System (LDS) also will enhance sample quantification by making more 
consistent recognition of chromatographic patterns possible and retaining these data for future use. Two liquid/liquid extractors and a concentrator were put into use to aid in sample preparation for PCB analysis.

The Spectroscopy and Microanalysis Section has added three staff members to meet the need for more metal analytical data. Several actions have been taken to reduce potential contamination in the analysis of metals. Glassware has been dedicated to Kentucky Pollutant Discharge Elimination System (KPDES) surface water analyses to eliminate the chance of cross contamination from high-level process or waste samples. Metal hoods have been lined with Teflon to prevent metal flakes from entering the digestion apparatus. Teflon tubing also has been applied to metal tips on dishwasher trays. These trays have metal rods over which glassware, such as volumetrics and breakers, are hung. The movement of the glassware was thought to cause metal particles to embed in the glass. The particles then might be extracted when acidified samples are left in the glassware for a significant time. Finally, a new digestion procedure from the EPA 600 Series for sediments and soils eliminates a concentration step, thus reducing the blank associated with the analysis and the sample turnaround time and freeing an analyst for other work. The new procedure also has eliminated a digestion step using $\mathrm{HCl}$ for silver, thallium, and lead. In past analyses, the recovery of these elements was poor due to their insolubility as chloride compounds or volatility.

A new staff member has been added to the Inorganic Analysis Section. The Chemical Analysis Lab has begun to use Analis control charting capabilities for producing control charts to monitor analytical results.

The Radiochemistry and Analytical Mass Spectroscopy Section has purchased new analytical equipment and computer software. A new liquid scintillation counter will increase analytical capability and result in lower background limits. Thirty-two alpha spectrometers were purchased and assembled for future use in transuranic analyses. Both types of instruments came with computer software, and a new set of software was purchased to handle quality assurance/quality control data and checks. A microwave sample preparation system was implemented to allow improved digestion and evaporation of sample material. All low-level environmental work was confined to a clean area containing dedicated equipment and glassware to prevent contamination. One professional and one technician were added to the section's staff.

\subsection{SAMPLING QUALITY ASSURANCE}

\subsubsection{Basic Concepts and Practices}

From the point of conception of any sampling program, QA plays an important role. Each monitoring or sampling organization plans a project, sets objectives, identifies responsibilities, and selects sampling methods and the appropriate sampling instruments or devices according to use and cleaning practices recommended by the American Society for Testing and Materials, the EPA, or other established authorities. The number of samples, location of sampling sites, sampling methods, sampling schedule, and coordination of sampling and analytical resources to meet critical completion times must all be decided. The rationale for these decisions and others is mainly the responsibility of the sampling organization with input from compliance and analytical organizations. Sampling plans and field documentation are prepared as appropriate. Chain-of-custody documentation is prepared from the point of sampling, and the samples are properly protected until they are placed into the custody of analytical laboratory control programs. In the laboratory, chain of custody continues until the sample is analyzed. For hazardous waste samples, chain of custody is maintained to the point of sample disposal. The performance of all field analytical procedures is documented using EPA-approved methods when available. Table 10.7 of Part 2 lists these procedures.

\subsubsection{Air Monitoring}

The design of the ambient air samplers is based on an internal study that determined the efficiency of potassium carbonate-impregnated filter paper for collecting gaseous fluorides. The procedure requires that flows be measured using a calibrated flow meter. If the flow drops more than $40 \%$ of the initial reading, the sample is not used; this helps to ensure that reported data accurately reflect plant emissions. Air-filter-sampling data are recorded in the field logs and the chain-of-custody logs, and they are entered into the computer system. Table 10.1 of Part 2 lists 
the analytical procedures. See Subsect. 10.2.2.4, Tables 10.21 and 10.22 (Part 2) for quality control (QC) data.

\subsubsection{Water Monitoring}

Water sampling is conducted both for PGDP's information and to meet regulatory requirements. Procedures have been written for surveillance samples and for KPDES permit sampling. Guidance for developing these procedures has been codified ( 40 CFR Pt. 136.3) and may also be found in other applicable sources. Records are kept in the field logs and the chain-of-custody logs and are entered into the computer system. The chain-of-custody logs also record the subsampling (i.e., procedure by which aliquots of a sample are divided for specific analysis) and preservation for each sample. The chain-of-custody logs are stored in the Environmental Sampling office. The analytical procedures for these samples are listed in Tables 10.2, 10.3, and 10.7 of Part 2. See Subsects. 10.2.2.1 through 10.2.2.3 and Tables 10.8 through 10.21 (Part 2) for QC data.

\subsubsection{Groundwater Monitoring}

Water samples from plant wells are collected according to written procedures based on published guidelines (U.S. EPA 1987). Field measurements used for reporting analytical data are taken using culibrated instruments to ensure accurate data. Records are kept in the ficld logbook and on the chain-of-custody logs for wells and are entered into the computer system. The chain-of-custody logs also record subsampling and preservation for each sample. The analytical procedures for these samples are listed in Tables 10.2, 10.3, 10.6, and 10.7 of Part 2. See Subsects. 10.2.2.1 through 10.2.2.4 and Tables 10.8 through 10.21 (Part 2) for QC data.

\subsubsection{Biological Monitoring}

Plant monitoring consists of a quarterly sampling of grass from the surrounding area to determine levels of fluoride concentrations and annual sampling of wildlife, vegetation, and garden materials for radioactive analytes. Analytical procedures for these samples are listed in Table 10.4 of Part 2.

\subsubsection{Soil and Sediment}

Samples of soil and sediment are collected according to published procedures (Watson 1989; Malis 1989). Included in both these types are background samples that are used to establish the baseline from which the plant's contribution can be calculated. No field measurements are taken in these sampling procedures. Potassium -40 in these samples is analyzed as a QC check on the accuracy of the data. Because the ${ }^{40} \mathrm{~K}$ levels are not affected by plant operations and are analyzed by the same method as the other analyses, any deviation from expected values indicates procedural problems. Records are kept in the field logs and the chain-of-custody logs and are entered into the computer system. The analytical procedures for these samples are listed in Table 10.5 of Part 2. Because of sample loads in the Paducah analytical laboratory, these samples were analyzed at Oak Ridge National Laboratory (ORNL) for PCBs and radionuclides. Some minor variance is expected between current and past data because of different analytical practices and capabilities between ORNL and PGDP.

\subsubsection{External Gamma}

Monitoring for gamma radiation is mandated by DOE Orders 5400.XY, 5400.1, and 5400.5. Guidance for procedures is found in ANSI Standard N545-1975. The calibration, preparation, and analysis of PGDP thermo-luminescent dosimeters is performed by ORNL.

\subsubsection{Solid Waste Monitoring}

Solid waste sampling and characterizations are conducted to ensure storage and disposal of solid waste in accordance with TSCA, RCRA, and DOE Order 5820.2A. Requests for both routine and special sampling and characterizations are issued by Environmental Compliance and Waste Management personnel. Guidance for sampling and characterization is obtained from EPA guidelines (U.S. EPA 1987) and other applicable regulations. Records are maintained in field logs, laboratory notebooks, and chain-of-custody books, and in the AnaLIS data management computer system. Results from RCRA evaluations of waste streams and special 
RCRA evaluations are summarized in quarterly, semi-annual, and/or annual reports.

\subsection{ANALYTICAL QUALITY ASSURANCE}

The analytical laboratories of the Energy Systems installations continue a long tradition of QA. Such terms as sound methodology, safe practices, analytical recovery, precision, accuracy, and QC are well established. Since the beginning of each installation's operation, the laboratories have been involved in the handling and analysis of hazardous materials, materials for which strict accountability is required, and materials of high purity. QA is, therefore, a daily responsibility.

Upon receiving the samples from the sampling group or the sample transporter, the laboratory custodian assumes responsibility for the proper protection and handling of the samples. Using guidance from EPA, the laboratories document the steps in handling, analysis, and approval of results. The performance of all analytical procedures is documented using EPA-approved methods when they are available. These procedures for air, water, soil, sediment, biota, and groundwater (with traceability to EPA methods), are listed in Tables 10.1 through 10.6 of Part 2.

A key feature in analytical QA is QC. PGDP participates in programs that are (1) internal to the laboratory, (2) internal to the Quality and Technical Services Division but external to the laboratory, and (3) external to the plant.

\subsubsection{Internal Quality Control}

All analytical activities are supported by the use of standard materials or reference materials. The compositions of these materials are well known and are used in calibration of instruments, method stand ardization, spike additions for recovery testing, and other practices. Certified standards from the National Institute for Standards and Technology, EPA, or other DOE laboratories are often used in such work.

These internal programs are the mainstay of analytical QC. They are the basis for ensuring reliable results on a daily basis and between batches. The total effort in these programs is at least $10 \%$ of the total laboratory effort (in accordance with EPA expectations) and probably reaches $20 \%$ in some activities.

The internal QC and QA programs have become a major factor in the environmental analysis procedures because of the low levels of pollutants measured and the relationships of these measured values to regulatory limits. These $\mathrm{QC}$ programs also provide for laboratory analyst training and qualification in the many procedures involved. The daily $\mathrm{QC}$ data are stored in a retrievable manner so they can be related to the analytical results they support. Tables 10.8 and 10.9 (Part 2) are examples of some of these programs.

\subsubsection{External Quality Coutrol}

All of the Energy Systems installations are directed by DOE and by the EPA regulators to participate in external quality control programs. PGDP also participates in voluntary external programs to provide for improved analytical QC. These programs generate data that are readily recognizable as objective measures that permit the participating laboratories and the government agencies a periodic review of performance. Although participation is mandated, the degree of participation is voluntary, so each laboratory can select parameters that are of particular interest to that plant. The sources of these programs are laboratories in EPA, DOE, and even the commercial sector. The PGDP laboratories participate in these external programs. Examples are given in Tables 10.10 through 10.21 (Part 2) for both radiological and nonradiological areas.

The analytical laboratory has an appointed measurements control coordinator who is functionally independent of the laboratory. In addition to monitoring the general quality of analytical data, the officer administers a program of generating QC samples of known composition (including some shown in Table 10.8 of Part 2) and periodically submitting these to the laboratory as known controls of unknown levels. This officer also coordinates and evaluates the results of the external QC programs discussed in the following subsections. 


\subsubsection{Environmental Protection Agency Discharge Monitoring Report (DMR) QA Program}

EPA conducts a national QA program in support of the National Pollutant Discharge Elimination System (NPDES) program. All holders of major NPDES permits are required to participate. EPA furnishes the QC samples annually and evaluates the results. The state of Kentucky follows PGDP's performance in this program. PGDP is required to analyze those parameters on its permit that are included in the DMR-QA Program. Other parameters may be analyzed on a voluntary basis for documentation or method checking. Table 10.10 (Part 2) shows all parameters within acceptable limits.

\subsubsection{Proficiency Environmental Testing Program}

The PGDP laboratory participates in the Proficiency Environmental Testing Program (PET), a voluntary external measurement control program, using samples purchased from the Analytical Products Group (APG), Inc., a commercial supplier. Samples at two concentration levels are analyzed bimonthly and reported to APG. An evaluation report is received in approximately 3 weeks. Most samples are evaluated by comparing (in standard deviations) the reported value to the mean of the reporting laboratories. Samples for dissolved and suspended solids are $r$ npared with average percent recovery in the same $w$. The performance evaluation in the tables is derived using the same criteria as those in the EPA DMR-QA program. The measurement control coordinator keeps control charts on these analyses. Tables 10.11 through 10.16 (Part 2) present the results of the 1990 PET testing. The data have been modified to reflect the number of significant figures that the laboratory methods are routinely reporting.

Measurements that have unacceptable recoveries of more than 2.58 standard deviations from the mean are investigated to determine the cause. Of 534 measurements, 2 were deemed not acceptable. Refer to Sect. 10.3 for information about investigations.

\subsubsection{Proficiency Analytical Testing Program}

The PGDP laboratory participates in the Proficiency Analytical Testing Program (PAT), an external measurement control program from the National Institute for Occupational Safety and Health
(NIOSH). This program targets industrial hygiene analyses but also has application to environmental factors because the concerns in both fields overlap. Of 64 measurements, 3 were outliers (Part 2 , Tables 10.17 through 10.20). The performance evaluations for these tables are provided by NIOSH. The laboratory maintained a "proficient" rating for all analyses through 1990. Refer to Subsect. 10.3 for information about the investigations.

\subsubsection{DOE Environmental Measurements Laboratory Quality Assessment Program}

The PGDP laboratory participated in the Environmental Measurements Laboratory (EML) measurements control program as required by DOE Order 5400.1. The results are given in Tables 10.21 and 10.22 of Part 2. The performance evaluation is determined by using the three ratio ranges given in the EML report to determine acceptable, marginal, or not acceptable categories. There were no "not acceptable" results out of the 25 results reported.

\subsection{QUALITY INCIDENTS}

\subsubsection{Proficiency Environmental Testing Program}

Standard practice for PET results is to investigate all results rated "not acceptable." Those results rated "marginal" are reported to the laboratories as warnings but do not have formal investigations. The November 1990 round had two results rated "not acceptable." Investigation showed that reported values for both high-level orthophosphate and nitrate-nitrogen were calculated incorrectly because of a nonroutine dilution. Both results are analyzed from the same solution on the same instrument; therefore, the error in both values resulted from the same analysis error. Recalculation of the raw data resulted in values within acceptable limits. The error did not affect routine analyses. All internal QC checks were in order. The results for the low-level samples were within acceptable limits for both analyses.

In addition to the external program from PET, an internal program was used in 1990 to monitor environmental results. Standard material from the PET Program is submitted along with routine environmental KPDES and well samples to provide quick feedback to the analytical labs. These data will 
be used to generate a KPDES QA report each month for the Environmental Compliance Department to assure the quality of the analytical results it is using in reports to regulatory agencies.

\subsubsection{Proficiency Analytical Testing Program}

The chromium and lead outliers in the October round of this program were due to a calculation error in the analytical laboratory. The value reported was a factor of 10 lower than it should have been. Supervision has instructed analysts on checking calculations.

The asbestos outlier in the October round of this program was investigated, but no specific cause was determined. All internal QC was within acceptable limits. It was noted that for the sample involved, 123 laboratories reported results that were outliers, with 94 being low outliers. This information leads the laboratory to question the homogeneity of the material used for that sample.

\subsubsection{Internal Quality Incidents}

Results from samples sent for analysis to laboratories outside DOE have been returned with significant quality problems. The results have shown instances of laboratory contamination, holding time exceedances, and problems with required $Q C$ data. Problems of this type may cause the data to be unusable or, at a minimum, require extensive investigation and justification before it is used. In many cases, a resample is required, causing delay in plant projects depending on the data.

Samples from the Sanitary and Inert Landfill wells did not include all the required analytical requests to satisfy the permit with the state of Kentucky. Samples were taken to supply data required by the Environmental Restoration Department and plant surveillance policies.

During the review of results from the soil and sediment sampling, many of the metal and radionuclide results were noted as not agreeing with past data. This trend was investigated by sampling and analytical personnel. The elevated metal results were traced to the procedural changes discussed in the opening of Sect. 10 that provided better quantification of materials present in the samples. The cause for changes in radiochemical results was less obvious. A reanalysis was performed on selected archived 1989 samples and the corresponding 1990 samples. The results of the reanalyses of 1990 samples agreed with the results first reported. The results on the 1989 samples originally analyzed by ORNL increased, agreeing with the 1990 PGDP data. It was assumed that the changes were caused by small but noticeable changes in analytical technique. The change was not attributed to changes in PGDP emissions, because the same increases also were noted in all the background samples that are not influenced by PGDP emissions.

Elevated beta radiation results were found in several monitoring wells northeast of the plant. Investigations into these problems determined that natural beta radiation from $K-40$ was the cause. These wells are located in agricultural areas of the West Kentucky Wildlife Management Area. Fertilizers used in the fields contain potassium that would leach into the groundwater.

Isopropyl alcohol, used to decontaminate sampling equipment, has caused both analytical and pollution problems for the plant. The use of these materials caused the KPDES monitoring requirements to change in the affected ditch. Requirements also were added for sampling and analysis of collected purge and cleaning water to quantify this contaminant. Some of the isopropyl alcohol will degrade into acetone upon exposure to sunlight, adding a second analytical monitoring requirement. The analytical technique used to measure these compounds is relatively difficult to perform due to the solubility of acetone and isopropyl alcohol. The compounds also were found in varying concentrations unexpected by the analytical laboratory. This caused contamination of the instrument, requiring downtime for cleaning.

Beta radiation levels due to ${ }^{99} \mathrm{Tc}$ have caused elevated results for alpha measurements due to a phenomenon called "cross talk." Cross talk is caused by some of the beta energy's being detected in the alpha energy channels, resulting in erroneous counts. The phenomenon was recognized by the laboratory and is corrected routinely in final reports. 


\section{INTRODUCTION}


All information for this section is presented in Part 1. 
2. AIRBORNE DISCHARGES, AMBIENT AIR MONITORING, METEOROLOGICAL MONITORING, AND EXTERNAL GAMMA RADIATION 
Table 2.1. Permitted alr sources at PGDPa

\begin{tabular}{|c|c|c|}
\hline Source No. & Location & Control equipment \\
\hline 1 & C- 600 No. 2 boiler & $\begin{array}{l}\text { Electrostatic precipitators } \\
\text { and low-sulfur coal }\end{array}$ \\
\hline 2 & C- 600 No. 3 boilet & $\begin{array}{l}\text { Electrostatic precipitators } \\
\text { and low-sulfur coal }\end{array}$ \\
\hline 4 & $C-405$ incinerator (north) ${ }^{b}$ & Venturi scrubber \\
\hline 5 & $C-405$ incinerator (south) ${ }^{b}$ & Venturi scrubber \\
\hline 7 & C-310 purge vent & $\begin{array}{l}\text { Chemical traps, high-speed } \\
\text { centrifuge }\end{array}$ \\
\hline 8 & C-410 fluorine production & Cold condensers ${ }^{c}$ \\
\hline 15 & $\mathrm{C}-400 \mathrm{UF}_{4}$ pulverizer & Filters \\
\hline 26 & C.746 reverberatory furnace ${ }^{b}$ & \\
\hline 27 & C-746 aluminum sweat furnace $b$ & \\
\hline 29 & C -400 gold recovery $b^{b}$ & \\
\hline 31 & C-724 paint spray booth & Water wash scrubber \\
\hline 32 & C. 725 paint spray booth & Water wash scrubber \\
\hline 33 & C. $746-A$ rotary calciner $b$ & $\mathrm{CaCO}_{3}$ traps \\
\hline 34 (a) & Smelter - central dust collector $b$ & Filters \\
\hline 35 & C- 600 No. 1 boiler & \\
\hline 36 & Smelter-induction furnace $b$ & Torit filters \\
\hline 37 & C- 600 coal handling equipment & Water sprays \\
\hline 38 & $\begin{array}{l}\text { C-400 Detrex open-top vapor } \\
\text { degreaser }\end{array}$ & $\begin{array}{l}\text { Covered systems and } \\
\text { condensing coils }\end{array}$ \\
\hline 39 & $\begin{array}{l}\text { C }-400 \text { Blakeslee open-top vapor } \\
\text { degreaser }\end{array}$ & $\begin{array}{l}\text { Covered systems and } \\
\text { condensing coils }\end{array}$ \\
\hline 40 & $\begin{array}{l}\text { C-720 Branson open-top vapor } \\
\text { degreaser [trichloroethylene] }\end{array}$ & \\
\hline 41 & C-720 cold cleaning degreaser & \\
\hline 42 & Chemical unloading & Wet cyclone scrubber \\
\hline 43 & $\begin{array}{l}\text { C-340 uranium alloy remelting } \\
\text { operation }^{b}\end{array}$ & Filters \\
\hline
\end{tabular}

aPermit No. 0-85-110 issued on Sept. 30, 1985.

bShut down with no plans to restart.

Not used due to low production. 


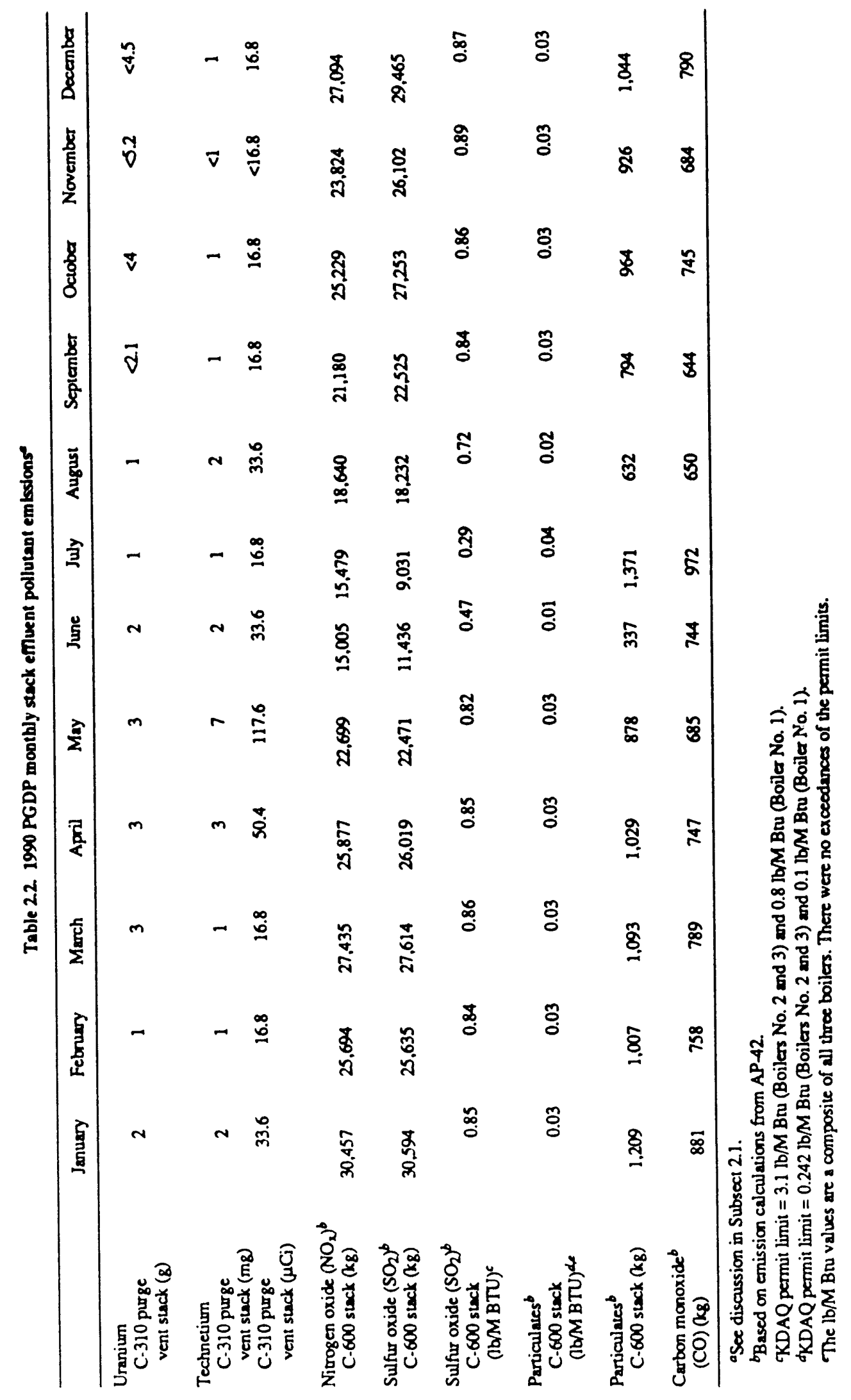


Table 23. 1990 PGDP annual stack effluent pollutant emissions

\begin{tabular}{|c|c|c|c|c|c|}
\hline & $\begin{array}{l}1990 \\
\text { Total }\end{array}$ & $\begin{array}{l}1989 \\
\text { Total }\end{array}$ & $\begin{array}{l}1988 \\
\text { Total }\end{array}$ & $\begin{array}{l}1987 \\
\text { Total }\end{array}$ & $\begin{array}{l}1986 \\
\text { Total }\end{array}$ \\
\hline \multicolumn{6}{|l|}{ Uranium } \\
\hline $\begin{array}{l}\text { C- } 310 \text { purge } \\
\text { vent stack }(g)\end{array}$ & 31.8 & 205 & 16 & 34 & 46 \\
\hline$C-400$ pulverizer $(\mathrm{g})^{b}$ & 0 & 0 & 119 & 529 & 636 \\
\hline \multicolumn{6}{|l|}{ Technetium } \\
\hline $\begin{array}{l}\text { C- } 310 \text { purge } \\
\text { vent stack }(\mathrm{mg})\end{array}$ & 23 & 211 & 221 & 56 & 520 \\
\hline $\begin{array}{l}\text { C-310 purge } \\
\text { vent stack }(\mu \mathrm{Ci})\end{array}$ & 386 & $3,565.9$ & 3,732 & 890 & 8,956 \\
\hline \multicolumn{6}{|l|}{ Nitrogen oxide $\left(\mathrm{NO}_{\mathbf{x}}\right)^{c}$} \\
\hline C. 600 stack $(\mathrm{kg})$ & 278,613 & 282,380 & 250,800 & 252,900 & 262,900 \\
\hline \multicolumn{6}{|l|}{ Sulfur dioxide $\left(\mathrm{SO}_{2}\right)^{c}$} \\
\hline C- 600 stack $(\mathrm{kg})$ & 276,380 & 292,309 & 188,000 & 178,700 & 176,400 , \\
\hline \multicolumn{6}{|l|}{ Particulates $^{c}$} \\
\hline C-600 stack (kg) & 11,284 & 11,272 & & & \\
\hline $\begin{array}{l}\text { Carbon monoxide } \\
\text { (CO) }(\mathrm{kg})\end{array}$ & 9,091 & 8,179 & & & \\
\hline
\end{tabular}

${ }^{a}$ See discussion in Subsect 2.1.

bIncludes data only for the period the process was in operation.

${ }^{\mathrm{C}} \mathrm{B}$ ased on emission calculations from AP-42.

Table 2.4. Comparison of selected actual emissions and limits/standards

\begin{tabular}{|c|c|c|c|}
\hline Source & Pollutant & Emission & Limiv/Standard \\
\hline C-310 stack & $\begin{array}{l}\text { Uranium } \\
{ }_{99} \mathrm{Tc} \\
\text { Fluorides }\end{array}$ & $\begin{array}{l}31.80 \mathrm{~g} / \text { year } \\
0.023 \mathrm{~g} / \text { year } \\
17.37 \mathrm{lb} / 12 \mathrm{~h}^{b}\end{array}$ & $\begin{array}{l}3.9 E 06 \mathrm{~g} / \text { year } \\
2.5 \mathrm{E} 04 \mathrm{~g} / \text { year } \\
50 \mathrm{lb} / 12 \mathrm{~h}\end{array}$ \\
\hline C -600 stack & $\begin{array}{l}\mathrm{SO}_{2} \\
\text { Particulates }\end{array}$ & $\begin{array}{l}0.76 \mathrm{lb} / \mathrm{m} \mathrm{Btu} \\
0.03 \mathrm{lb} / \mathrm{m} \mathrm{Btu}^{b}\end{array}$ & $\begin{array}{l}0.8 \mathrm{lb} / \mathrm{M} \mathrm{Btu} \\
3.1 \mathrm{lb} / \mathrm{M} \mathrm{Btu} \\
0.1 \mathrm{lb} / \mathrm{M} \mathrm{Btu} \\
0.24 \mathrm{lb} / \mathrm{M} \mathrm{Btu}\end{array}$ \\
\hline
\end{tabular}

${ }^{\circ}$ Based on emissions required to exceed the 10 mrem NESHAP limit.

${ }^{b}$ Annual average of all boilers combined.

${ }^{C}$ Boiler No. 1.

${ }^{\mathrm{B}}$ Boilers No. 2 and No. 3. 
3. SURFACE WATER 
Table 3.1. Interim limitations for Agreed Order-PGDP

\begin{tabular}{lccc}
\hline Monthly average & Daily maximum & $\begin{array}{c}\text { Sample } \\
\text { frequency }\end{array}$ & $\begin{array}{c}\text { Sample } \\
\text { type }\end{array}$ \\
\hline
\end{tabular}

Flow

$\mathrm{Cr}$, total recoverable

$\mathrm{Zn}$, total recoverable

Cl, total residual

Temperature

Fe, total recoverable

$\mathrm{Al}$, total recoverable

$\mathrm{Cu}$, total recoverable

$\mathrm{Ni}$, total recoverable

TSS

Trichloroethylene

Fluoride

Dissolved oxygen

Oil and grease

$\mathrm{pH}$

Uranium

Dissolved alpha

Suspended alpha

Dissolved beta

Suspended beta

PCB

Flow

$\mathrm{Cr}$, total recoverable

$\mathrm{Zn}$, total recoverable

Cl, total residual

Temperature

Fe, total recoverable

Al, wotal recoverable

$\mathrm{Cu}$, total recoverable

$\mathrm{Ni}$, total recoverable

TSS

Trichloroethylene

Fluoride

Dissolved oxygen

Oil and grease

$\mathrm{pH}$

Uranium

Dissolved alpha

Suspended alpha

Dissolved beta

Suspended beta

PCB

Flow

$\mathrm{Cr}$, wotal recoverable

$\mathrm{Zn}$, total recoverable

$\mathrm{Cl}$, total residual

Temperature

Fe, total recoverable
Ouffall 001

$\begin{array}{lll} & \text { 1/week } & \text { Instantaneous } \\ 0.15 \mathrm{mg} / \mathrm{L} & 1 / \text { week } & \text { Composite } \\ 0.93 \mathrm{mg} / \mathrm{L} & 1 / \text { week } & \text { Composite } \\ 0.1 \mathrm{mg} / \mathrm{L} & 1 / \text { week } & \text { Grab } \\ 93^{\circ} \mathrm{F} & 1 / \text { week } & \text { Grab } \\ 34.3 \mathrm{mg} / \mathrm{L} & 2 / \text { month } & \text { Composite } \\ & 2 / \text { month } & \text { Composite } \\ 0.17 \mathrm{mg} / \mathrm{L} & 2 / \text { month } & \text { Compo. } \\ 3.1 \mathrm{mg} / \mathrm{m} & 2 / \text { month } & \text { Composite } \\ 158 \mathrm{mg} / \mathrm{L} & 2 / \text { month } & \text { Composite } \\ 0.0807 \mathrm{mg} / \mathrm{L} & 2 / \text { month } & \text { Composite } \\ 4.0 \mathrm{mg} / \mathrm{L} & 2 / \text { month } & \text { Composite } \\ & \text { 2/month } & \text { Grab } \\ 15 \mathrm{mg} / \mathrm{L} & 2 / \text { month } & \text { Grab } \\ 10.0 & 1 / \text { week } & \text { Grab } \\ & 1 / \text { quarter } & \text { Grab } \\ & \text { 1/quarter } & \text { Grab } \\ & \text { 1/quarter } & \text { Grab } \\ & \text { 1/quarter } & \text { Grab } \\ & \text { 1/quarter } & \text { Grab } \\ 0.1 \mathrm{mg} / \mathrm{L} & \text { 1/quarter } & \text { Grab }\end{array}$

Ouffall 002

$\begin{array}{lll}0.31 \mathrm{mg} / \mathrm{L} & 1 / \text { week } & \text { Instantaneous } \\ 0.17 \mathrm{mg} / \mathrm{L} & 1 / \text { week } & \text { Composite } \\ 0.15 \mathrm{mg} / \mathrm{L} & 1 / \text { week } & \text { Composite } \\ 89^{\circ} \mathrm{F} & 1 / \text { week } & \text { Grab } \\ 6.55 \mathrm{mg} / \mathrm{L} & 1 / \text { week } & \text { Grab } \\ & 2 / \text { month } & \text { Composite } \\ & 1 / \text { month } & \text { Composite } \\ & 1 / \text { month } & \text { Composite } \\ & 1 / \text { month } & \text { Composite } \\ & 1 / \text { month } & \text { Composite } \\ & 1 / \text { month } & \text { Composite } \\ 5.0 \mathrm{mg} / \mathrm{L} & 2 / \text { month } & \text { Composite } \\ & 2 / \text { month } & \text { Grab } \\ & 1 / \text { month } & \text { Grab } \\ 10.0 & 1 / \text { week } & \text { Grab } \\ & 1 / \text { quarter } & \text { Grab } \\ & 1 / \text { quarter } & \text { Grab } \\ & 1 / \text { quarter } & \text { Grab } \\ & 1 / \text { quarter } & \text { Grab } \\ & 1 / \text { quarter } & \text { Grab } \\ & 1 / \text { quarter } & \text { Grab }\end{array}$

Ouffall 003

1/week

$0.93 \mathrm{mg} / \mathrm{L} \quad 1 /$ week

$0.1 \mathrm{mg} / \mathrm{L} \quad 1 /$ week

$93^{\circ} \mathrm{F}$

$1 /$ week

$5.19 \mathrm{mg} / \mathrm{L}$
Instantaneous

Composite

Composite

Grab

Grab

Composite 
Table 3.1 (continued)

\begin{tabular}{|c|c|c|c|c|}
\hline & Monthly average & Daily maximum & $\begin{array}{c}\text { Sample } \\
\text { frequency }\end{array}$ & $\begin{array}{c}\text { Sample } \\
\text { type }\end{array}$ \\
\hline $\begin{array}{l}\text { Al, total recoverable } \\
\text { Cu, total recoverable } \\
\text { Ni, total recoverable } \\
\text { TSS } \\
\text { Trichloroethylene } \\
\text { Fluoride } \\
\text { Dissolved oxygen } \\
\text { Oil and grease } \\
\text { pH } \\
\text { Uranium } \\
\text { Dissolved alpt:a } \\
\text { Suspended alpha } \\
\text { Dissolved beta } \\
\text { Suspended beta } \\
\text { PCB }\end{array}$ & $\begin{array}{l}0.26 \mathrm{mg} / \mathrm{L} \\
3.5 \mathrm{mg} / \mathrm{L} \\
5 \mathrm{mg} / \mathrm{L}(\mathrm{min}) \\
10 \mathrm{mg} / \mathrm{L} \\
6.0(\mathrm{~min})\end{array}$ & $\begin{array}{l}0.17 \mathrm{mg} / \mathrm{L} \\
3.1 \mathrm{mg} / \mathrm{L} \\
158 \mathrm{mg} / \mathrm{L} \\
0.027 \mathrm{mg} / \mathrm{L} \\
4.0 \mathrm{mg} / \mathrm{L} \\
\\
15 \mathrm{mg} / \mathrm{L} \\
10.0\end{array}$ & $\begin{array}{l}2 / \text { month } \\
2 / \text { month } \\
2 / \text { month } \\
2 / \text { month } \\
2 / \text { month } \\
2 / \text { month } \\
2 / \text { month } \\
2 / \text { month } \\
1 / \text { week } \\
1 / \text { quarter } \\
1 / \text { quarter } \\
1 / \text { quarter } \\
1 / \text { quarter } \\
1 / \text { quarter } \\
1 / \text { quarter }\end{array}$ & $\begin{array}{l}\text { Composite } \\
\text { Composite } \\
\text { Composite } \\
\text { Composite } \\
\text { Composite } \\
\text { Composite } \\
\text { Grab } \\
\text { Grab } \\
\text { Grab } \\
\text { Grab } \\
\text { Grab } \\
\text { Grab } \\
\text { Grab } \\
\text { Grab } \\
\text { Grab }\end{array}$ \\
\hline \multicolumn{5}{|c|}{ Outfall 004} \\
\hline $\begin{array}{l}\text { Flow } \\
\text { BODs } \\
\text { TSS } \\
\text { Fecal coliform } \\
\text { pH }\end{array}$ & $\begin{array}{l}30 \mathrm{mg} / \mathrm{L} \\
30 \mathrm{mg} / \mathrm{L} \\
200 \\
6.0(\mathrm{~min})\end{array}$ & $\begin{array}{l}45 \mathrm{mg} / \mathrm{L} \\
45 \mathrm{mg} / \mathrm{L} \\
400 \\
9.0\end{array}$ & $\begin{array}{l}2 / \text { month } \\
2 / \text { month } \\
2 / \text { month } \\
2 / \text { month } \\
2 / \text { month }\end{array}$ & $\begin{array}{l}\text { Instantaneous } \\
\text { Composite } \\
\text { Composite } \\
\text { Grab } \\
\text { Grab }\end{array}$ \\
\hline \multicolumn{5}{|c|}{ Ouffall 005} \\
\hline $\begin{array}{l}\text { Flow } \\
\text { TSS } \\
\text { COD } \\
\text { Turbidity } \\
\text { pH }\end{array}$ & $30 \mathrm{mg} / \mathrm{L}$ & $50 \mathrm{mg} / \mathrm{L}$ & $\begin{array}{l}\text { 1/week } \\
\text { 1/week } \\
\text { 1/week } \\
\text { 1/week } \\
\text { 1/week }\end{array}$ & $\begin{array}{l}\text { Instantaneous } \\
\text { Composite } \\
\text { Grab } \\
\text { Grab } \\
\text { Grab }\end{array}$ \\
\hline \multicolumn{5}{|c|}{ Ouffall 006} \\
\hline $\begin{array}{l}\text { Flow } \\
\text { TSS } \\
\text { COD } \\
\text { Turbidity } \\
\text { pH }\end{array}$ & $\begin{array}{l}30 \mathrm{mg} / \mathrm{L} \\
6.0(\mathrm{~min})\end{array}$ & $50 \mathrm{mg} / \mathrm{L}$ & $\begin{array}{l}\text { 1/week } \\
1 / \text { week } \\
1 / \text { week } \\
1 / \text { week } \\
1 / \text { week }\end{array}$ & $\begin{array}{l}\text { Instantaneous } \\
\text { Grab } \\
\text { Grab } \\
\text { Grab } \\
\text { Grab }\end{array}$ \\
\hline \multicolumn{5}{|c|}{ Outfall 008} \\
\hline $\begin{array}{l}\text { Flow } \\
\mathrm{Cr} \text {, total recoverable } \\
\mathrm{Zn} \text {, total recoverable } \\
\mathrm{Cl} \text {, total residual }\end{array}$ & & $\begin{array}{l}0.1 \mathrm{mg} / \mathrm{L} \\
0.34 \mathrm{mg} / \mathrm{L} \\
0.33 \mathrm{mg} / \mathrm{L}\end{array}$ & $\begin{array}{l}1 / \text { week } \\
1 / \text { week } \\
1 / \text { week } \\
1 / \text { week }\end{array}$ & $\begin{array}{l}\text { Instantaneous } \\
\text { Composite } \\
\text { Composite } \\
\text { Grab }\end{array}$ \\
\hline $\begin{array}{l}\text { Temperature } \\
\text { Fe, total recoverable } \\
\mathrm{Al} \text {, total recoverable } \\
\mathrm{Cu} \text {, total recoverable } \\
\mathrm{Ni} \text {, total recoverable } \\
\mathrm{TSS} \\
\text { Trichloroethylene } \\
\text { Fluoride } \\
\text { Dissolved oxygen } \\
\text { Oil and grease }\end{array}$ & $\begin{array}{l}3.5 \mathrm{mg} / \mathrm{L} \\
5 \mathrm{mg} / \mathrm{L}(\mathrm{min})\end{array}$ & $\begin{array}{l}0.027 \mathrm{mg} / \mathrm{L} \\
5.0 \mathrm{mg} / \mathrm{L}\end{array}$ & $\begin{array}{l}1 / \text { week } \\
2 / \text { month } \\
1 / \text { month } \\
1 / \text { month } \\
1 / \text { month } \\
1 / \text { month } \\
1 / \text { month } \\
2 / \text { month } \\
2 / \text { month } \\
1 / \text { month }\end{array}$ & $\begin{array}{l}\text { Grab } \\
\text { Composite } \\
\text { Composite } \\
\text { Composite } \\
\text { Composite } \\
\text { Composite } \\
\text { Composite } \\
\text { Composite } \\
\text { Grab } \\
\text { Grab }\end{array}$ \\
\hline
\end{tabular}


Table 3.1 (continued)

\begin{tabular}{|c|c|c|c|c|}
\hline & Monthly average & Daily maximum & $\begin{array}{c}\text { Sample } \\
\text { frequency }\end{array}$ & $\begin{array}{c}\text { Sample } \\
\text { type }^{a}\end{array}$ \\
\hline $\begin{array}{l}\mathrm{pH} \\
\text { Uranium } \\
\text { Dissolved alpha } \\
\text { Suspended alpha } \\
\text { Dissolved beta } \\
\text { Suspended beta } \\
\text { PCB }\end{array}$ & $6.0(\mathrm{~min})$ & $0.1 \mathrm{mg} / \mathrm{L}$ & $\begin{array}{l}\text { 1/week } \\
1 / \text { quarter } \\
1 / \text { quarter } \\
1 / \text { quarter } \\
1 / \text { quarter } \\
1 / \text { quarter } \\
1 / \text { quarter }\end{array}$ & $\begin{array}{l}\text { Grab } \\
\text { Grab } \\
\text { Grab } \\
\text { Grab } \\
\text { Grab } \\
\text { Grab } \\
\text { Grab }\end{array}$ \\
\hline
\end{tabular}

Flow

$\mathrm{Cr}$, total recoverable

$\mathrm{Zn}$, cotal recoverable

$\mathrm{Cl}$, total residual

Temperature

Fe, total recoverable

$\mathrm{Al}$, total recoverable

$\mathrm{Cu}$, total recoverable

$\mathrm{Ni}$, total recoverable

TSS

Trichloroethylene

Fluoride

Dissolved oxygen

Oil and grease

$\mathrm{pH}$

Uranium

Dissolved alpha

Suspended alpha

Dissolved beta

Suspended beta

PCB

Flow

$\mathrm{Cr}$, total recoverable

$\mathrm{Zn}$, total recoverable

$\mathrm{Cl}$, total residual

Temperature

Fe, total recoverable

Al, total recoverable

$\mathrm{Cu}$, total recoverable

$\mathrm{Ni}$, total recoverable

TSS

Trichloroethylene

Fluoride

Dissolved oxygen

Oil and grease

$\mathrm{pH}$

Uranium

Dissolved alpha

Suspended alpha

Dissolved beta

Suspended beta

PCB
Outfall 009

$3.5 \mathrm{mg} / \mathrm{L}$

$5.0 \mathrm{mg} / \mathrm{L}(\mathrm{min})$

$0.23 \mathrm{mg} / \mathrm{L}$
$1.15 \mathrm{mg} / \mathrm{L}$
$0.01 \mathrm{mg} / \mathrm{L}$
$89^{\circ} \mathrm{F}$
$8.41 \mathrm{mg} / \mathrm{L}$

$6.0(\mathrm{~min})$

$5.0 \mathrm{mg} / \mathrm{L}$

$0.1 \mathrm{mg} / \mathrm{L}$

$1 /$ week
$1 /$ week
$1 /$ week
$1 /$ week
$1 /$ week
$2 /$ month
$1 /$ month
$1 /$ month
$1 /$ month
$1 /$ month
$1 /$ month
$2 /$ month
$2 /$ month
$1 /$ month
$1 /$ week
$1 /$ quarter
$1 /$ quarter
$1 /$ quarter
$1 /$ quarter
1/quarter
1/quarter

Instantaneous

Composite

Composite

Grab

Grab

Composite

Composite

Composite

Composite

Composite

Composite

Composite

Grab

Grab

Grab

Grab

Grab

Grab

Grab

Grab

Grab

Outfall 010

$3.5 \mathrm{mg} / \mathrm{L}$
$5 \mathrm{mg} / \mathrm{Lin})$
6.0 (min)

$\begin{array}{lll}0.5 \mathrm{mg} / \mathrm{L} & 1 / \text { week } & \text { Instantaneous } \\ 0.26 \mathrm{mg} / \mathrm{L} & 1 / \text { week } & \text { Composite } \\ 0.01 \mathrm{mg} / \mathrm{L} & 1 / \text { week } & \text { Composite } \\ 89^{\circ} \mathrm{F} & 1 / \text { week } & \text { Grab } \\ 8.32 \mathrm{mg} / \mathrm{L} & 1 / \text { week } & \text { Grab } \\ & 2 / \text { month } & \text { Composite } \\ & 1 / \text { month } & \text { Composite } \\ & 1 / \text { month } & \text { Composite } \\ & 1 / \text { month } & \text { Composite } \\ & 1 / \text { month } & \text { Composite } \\ & 1 / \text { month } & \text { Composite } \\ 5.0 \mathrm{mg} / \mathrm{L} & 2 / \text { month } & \text { Composite } \\ & 2 / \text { month } & \text { Grab } \\ & 1 / \text { month } & \text { Grab } \\ 9.0 & 1 / \text { week } & \text { Grab } \\ & 1 / \text { quarter } & \text { Grab } \\ & 1 / \text { quarter } & \text { Grab } \\ & 1 / \text { quarter } & \text { Grab } \\ & 1 / \text { quarter } & \text { Grab } \\ & 1 / \text { quarter } & \text { Grab } \\ & 1 / \text { quarter } & \text { Grab }\end{array}$


Table 3.1 (continued)

\begin{tabular}{lccc} 
Monthly average & Daily maximum & $\begin{array}{c}\text { Sample } \\
\text { frequency }\end{array}$ & $\begin{array}{c}\text { Sample } \\
\text { type }\end{array}$ \\
\hline
\end{tabular}

Flow

Cr, total recoverable

$\mathrm{Zn}$, total recoverable

$\mathrm{Cl}$, total residual

Temperature

Fe, total recoverable

$\mathrm{Al}$, total recoverable

$\mathrm{Cu}$, total recoverable

$\mathrm{Ni}$, total recoverable

TSS

Trichloroethylene

Fluoride

Dissolved oxygen

Oil and grease

$\mathrm{pH}$

Uranium

Dissolved alpha

Suspended alpha

Dissolved beta

Suspended beta

PCB

Flow

Cr, total recoverable

$\mathrm{Zn}$, total recoverable

Cl, total residual

Temperature

$\mathrm{Fe}$, total recoverable

Al, total recoverable

$\mathrm{Cu}$, total recoverable

$\mathrm{Ni}$, total recoverable

TSS

Trichloroethylene

Fluoride

Dissolved oxygen

Oil and grease

$\mathrm{pH}$

Uranium

Dissolved alpha

Suspended alpha

Dissolved beta

Suspended beta

PCB

Flow

Fe, total recoverable

$\mathrm{Al}$, total recoverable

$\mathrm{Cu}$, total recoverable

$\mathrm{Ni}$, total recoverable

Ouffall 011

$3.5 \mathrm{mg} / \mathrm{L}$

$5 \mathrm{mg} / \mathrm{L}$ ( $\mathrm{min})$

$6.0(\mathrm{~min})$

10.0

$0.85 \mathrm{mg} / \mathrm{L}$
$0.16 \mathrm{mg} / \mathrm{L}$
$0.14 \mathrm{mg} / \mathrm{L}$
$95^{\circ} \mathrm{F}$
$5.94 \mathrm{mg} / \mathrm{L}$

$0.1 \mathrm{mg} / \mathrm{L}$

Ouffall 012

$0.76 \mathrm{mg} / \mathrm{L}$
$0.40 \mathrm{mg} / \mathrm{h}$
$0.01 \mathrm{mg} / \mathrm{L}$
$90^{\circ} \mathrm{F}$
$18.22 \mathrm{mg} / \mathrm{L}$

$5.0 \mathrm{mg} / \mathrm{L}$
9.0

$3.5 \mathrm{mg} / \mathrm{L}$

$5 \mathrm{mg} / \mathrm{L}$ (min)

$6.0(\mathrm{~min})$

$0.1 \mathrm{mg} / \mathrm{L}$

Outfall 013

\section{Instantaneous \\ Composite \\ Composite \\ Grab \\ Grab \\ Composite \\ Composite \\ Composite \\ Composite \\ Composite \\ Composite \\ Composite \\ Grab \\ Grab \\ Grab \\ Grab \\ Grab \\ Grab \\ Grab \\ Grab \\ Grab}

Instantaneous

Composite

Composite

Grab

Grab

Composite

Composite

Composite

Composite

Composite

Composite

Composite

Grab

Grab

Grab

Grab

Grab

Grab

Grab

Grab

Grab

$\begin{array}{ll}1 / \text { month } & \text { Instantaneous } \\ 1 / \text { month } & \text { Composite } \\ 1 / \text { month } & \text { Composite } \\ 1 / \text { month } & \text { Composite } \\ 1 / \text { month } & \text { Composite }\end{array}$


Table 3.1 (continued)

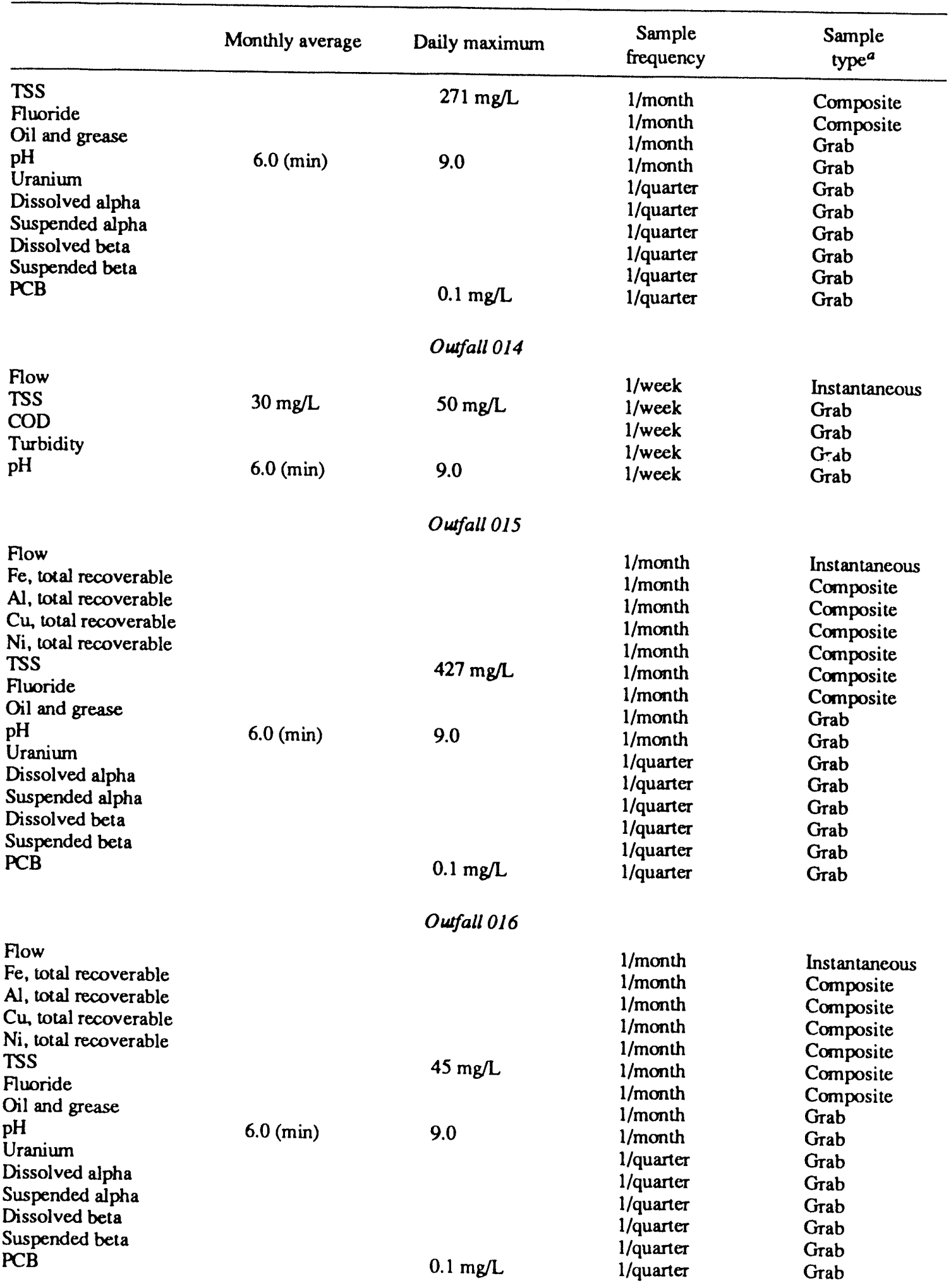


Table 3.1 (continued)

\begin{tabular}{|c|c|c|c|c|}
\hline & Monthly average & Daily maximum & $\begin{array}{l}\text { Sample } \\
\text { frequency }\end{array}$ & $\begin{array}{c}\text { Sample } \\
\text { type }^{a}\end{array}$ \\
\hline \multicolumn{5}{|c|}{ Outfall 017} \\
\hline $\begin{array}{l}\text { Flow } \\
\text { Fe, total recoverable } \\
\mathrm{Al} \text {, total recoverable } \\
\mathrm{Cu} \text {, total recoverable } \\
\mathrm{Ni} \text {, total recoverable } \\
\mathrm{TSS} \\
\text { Fluoride } \\
\text { Oil and grease } \\
\text { pH } \\
\text { Uranium } \\
\text { Dissolved alpha } \\
\text { Suspended alpha } \\
\text { Dissolved beta } \\
\text { Suspended beta } \\
\text { PCB }\end{array}$ & $6.0(\mathrm{~min})$ & $45 \mathrm{mg} / \mathrm{l}$ & $\begin{array}{l}1 / \text { month } \\
1 / \text { month } \\
1 / \text { month } \\
1 / \text { month } \\
1 / \text { month } \\
1 / \text { month } \\
1 / \text { month } \\
1 / \text { month } \\
1 / \text { month } \\
1 / \text { quarter } \\
1 / \text { quarter } \\
1 / \text { quarter } \\
1 / \text { quarter } \\
1 / \text { quarter } \\
1 / \text { quarter }\end{array}$ & $\begin{array}{l}\text { Instantaneous } \\
\text { Composite } \\
\text { Composite } \\
\text { Composite } \\
\text { Composite } \\
\text { Composite } \\
\text { Composite } \\
\text { Grab } \\
\text { Grab } \\
\text { Grab } \\
\text { Grab } \\
\text { Grab } \\
\text { Grab } \\
\text { Grab } \\
\text { Grab }\end{array}$ \\
\hline
\end{tabular}

9Jomposite samples are 24-h samples.

Table 3.2. 1990 annual data summary for discharge polnt $001^{*}$ KPDES Permit Number KY0004049

\begin{tabular}{|c|c|c|c|c|}
\hline Parameter & $\operatorname{Max}$ & Min & Av & $\begin{array}{c}\text { Number } \\
\text { of } \\
\text { samples }\end{array}$ \\
\hline Acetone $(\mu g / L)$ & $<10.0$ & $<10.0$ & $<10.0$ & 17 \\
\hline $\mathrm{Al}(\mathrm{mg} / \mathrm{L})$ & 1.52 & $<0.10$ & $<0.60$ & 24 \\
\hline $\mathrm{Cr}(\mathrm{mg} / \mathrm{L})$ & 0.07 & $<0.05$ & $<0.05$ & 56 \\
\hline $\mathrm{Cu}(\mathrm{mg} / \mathrm{L})$ & 0.01 & $<0.01$ & $<0.01$ & 24 \\
\hline Dissolved alpha (pCi/L) & 22.7 & 2.1 & 14.1 & 4 \\
\hline Dissolved beta (pCi/L) & 73.0 & 23.0 & 48.5 & 4 \\
\hline Dissolved oxygen (mg/L) & 14.0 & 5.5 & 8.7 & 24 \\
\hline $\mathrm{Fe}(\mathrm{mg} / \mathrm{L})$ & 1.75 & 0.12 & 0.51 & 24 \\
\hline Fluoride (mg/L) & 0.75 & 0.29 & 0.44 & 24 \\
\hline Isopropanol $(\mu \mathrm{g} / \mathrm{L})$ & $<50.0$ & $<25.0$ & $<27.9$ & 17 \\
\hline Oil and Grease (mg/L) & $<.0$ & $\delta .0$ & $<5.0$ & 24 \\
\hline $\mathrm{Ni}(\mathrm{mg} / \mathrm{L})$ & $<0.05$ & $<0.05$ & $<0.05$ & 24 \\
\hline PCB $(\mu g / L)$ & $<0.5$ & $<0.1$ & $<0.4$ & 9 \\
\hline Total residual $\mathrm{Cl}_{2}(\mathrm{mg} / \mathrm{L})$ & 0.05 & $<0.01$ & $<0.02$ & 52 \\
\hline Suspended alpha $(\mathrm{pCi} / \mathrm{L})$ & 3.8 & $-1.1^{b}$ & 1.4 & 4 \\
\hline Suspended beta $(p \mathrm{Ci} / \mathrm{L})$ & 12.0 & $-5.0^{b}$ & 1.8 & 4 \\
\hline Trichloroethylene $(\mu \mathrm{g} / \mathrm{L})$ & $<.0$ & $<1.0$ & $<1.2$ & 25 \\
\hline${ }^{99} \mathrm{Tc}(\mathrm{pCi} / \mathrm{L})$ & 107.0 & $-890.0^{b}$ & 4.2 & 53 \\
\hline Temperature $\left({ }^{\circ} \mathrm{F}\right)$ & 92.0 & 48.0 & 69.6 & 52 \\
\hline Total suspended solids (mg/L) & 33.0 & $<4.0$ & $<10.7$ & 23 \\
\hline Uranium $(\mathrm{mg} / \mathrm{L})$ & 0.240 & $<0.001$ & $<0.042$ & 53 \\
\hline Water flow (Mgd) & 16.600 & 0.546 & 1.677 & 51 \\
\hline $\mathrm{Zn}(\mathrm{mg} / \mathrm{L})$ & 0.180 & $<0.005$ & $<0.015$ & 52 \\
\hline $\mathrm{pH}$ (units) & 9.4 & 6.8 & & 52 \\
\hline
\end{tabular}

${ }^{a}$ See Fig. 3.4.

${ }^{b}$ Negative numbers indicate that analytical result minus background was less than zero. 
Table 3.3. 1990 annual data summary for discharge point $\mathbf{0 0 2}^{\alpha}$ KPDES Permit Number KY0004049

\begin{tabular}{|c|c|c|c|c|}
\hline Parameter & Max & Min & Av & $\begin{array}{c}\text { Number } \\
\text { of } \\
\text { samples }\end{array}$ \\
\hline $\mathrm{Al}(\mathrm{mg} / \mathrm{L})$ & 0.52 & $<0.10$ & $<0.30$ & 12 \\
\hline $\mathrm{Cr}(\mathrm{mg} / \mathrm{L})$ & 0.19 & $<0.05$ & $<0.09$ & 54 \\
\hline $\mathrm{Cu}(\mathrm{mg} / \mathrm{L})$ & $<0.01$ & $<0.01$ & $<0.01$ & 12 \\
\hline Dissolved alpha (pCi/L) & 6.0 & 0.5 & 3.4 & 4 \\
\hline Dissolved beta (pCi/L) & 20.0 & $-2.0^{b}$ & 5.5 & 4 \\
\hline Dissolved oxygen (mg/L) & 15.2 & 5.5 & 9.1 & 24 \\
\hline $\mathrm{Fe}(\mathrm{mg} / \mathrm{L})$ & 3.50 & 0.04 & 0.45 & 24 \\
\hline Fluoride (mg/L) & 0.23 & 0.10 & 0.16 & 24 \\
\hline Oil and grease (mg/L) & $<5.0$ & $<5.0$ & $\diamond .0$ & 12 \\
\hline $\mathrm{Ni}(\mathrm{mg} / \mathrm{L})$ & $<0.05$ & $<0.05$ & $<0.05$ & 12 \\
\hline PCB $(\mu g / L)$ & $<0.5$ & $<0.1$ & $<0.4$ & 5 \\
\hline Total residual $\mathrm{Cl}_{2}(\mathrm{mg} / \mathrm{L})$ & 0.15 & $<0.01$ & $<0.03$ & 52 \\
\hline Suspended alpha (pCi/L) & 1.8 & $-4.3^{\tilde{b}}$ & $-0.3^{b}$ & 4 \\
\hline Suspended beta $(p C i / L)$ & 10.0 & $-8.0^{b}$ & $-1.8^{b}$ & 4 \\
\hline Trichloroethylene $(\mu \mathrm{g} / \mathrm{L})$ & $<5.0$ & $<1.0$ & $<1.3$ & 13 \\
\hline Temperature $\left({ }^{\circ} \mathrm{F}\right)$ & 86.0 & 45.0 & 66.1 & 52 \\
\hline Total suspended solids (mg/L) & 12.0 & $<4.0$ & $<.7$ & 12 \\
\hline Uranium (mg/L) & 0.012 & $<0.001$ & $<0.005$ & 5 \\
\hline Water flow (Mgd) & 1.640 & 0.033 & 0.156 & 52 \\
\hline $\mathrm{Zn}(\mathrm{mg} / \mathrm{L})$ & 0.065 & $<0.005$ & $<0.024$ & 52 \\
\hline pH (units) & 9.1 & 7.0 & & 52 \\
\hline
\end{tabular}

${ }^{a}$ See Fig. 3.4.

${ }^{b}$ Negative numbers indicate that analytical result minus background was less than zero.

Table 3.4. 1990 annual data summary for dischar ge point $004^{a}$ KPDES Permit Number KY0004049

\begin{tabular}{lcccc}
\hline \multicolumn{1}{c}{ Parameter } & Max & Min & Av & $\begin{array}{c}\text { Number } \\
\text { of } \\
\text { samples }\end{array}$ \\
\hline Ammonia (mg/L) & 1.1 & $<0.2$ & $<0.6$ & 9 \\
BOD $(\mathrm{mg} / \mathrm{L})$ & 20.0 & $<5.0$ & $<8.5$ & 24 \\
Fecal coli (col./100 mL) & 600 & $<1.0$ & $<103.3$ & 24 \\
Total suspended solids (mg/L) & 12.0 & $<4.0$ & $<5.3$ & 24 \\
Water flow (Mgd) & 0.416 & 0.264 & 0.346 & 24 \\
pH (units) & 9.2 & 6.9 & & 24 \\
\hline
\end{tabular}

${ }^{a}$ See Fig. 3.4. 
Table 3.5. 1990 annual data summary for discharge polnt $006^{*}$ KPDES Permit Number KY0004049

\begin{tabular}{lcccc}
\hline \multicolumn{1}{c}{ Parameter } & Max & Min & Av & $\begin{array}{c}\text { Number } \\
\text { of } \\
\text { samples }\end{array}$ \\
\hline COD (mg/L) & 34.0 & $<5.0$ & $<14.6$ & 54 \\
Total suspended solids (mg/L) & 43.0 & 4.0 & 17.3 & 52 \\
Turbidity (NTU) & 21.0 & 3.0 & 9.4 & 52 \\
Water flow (Mgd) & 3.880 & 0.390 & 0.942 & 52 \\
pH (units) & 10.3 & 6.2 & & 53 \\
Total residual Cl 2 (mg/L) & 0.01 & $<0.01$ & $<0.01$ & 18 \\
PCB ( $\mu g / L)$ & $<1.0$ & $<0.1$ & $<0.4$ & 4 \\
\hline
\end{tabular}

${ }^{a}$ See Fig. 3.4.

Table 3.6. 1990 annual data summary for discharge point $008^{\circ}$ KPDES Permit Number KY0004049

\begin{tabular}{|c|c|c|c|c|}
\hline Parameter & $\operatorname{Max}$ & Min & Av & $\begin{array}{c}\text { Number } \\
\text { of } \\
\text { samples }\end{array}$ \\
\hline $\mathrm{Al}(\mathrm{mg} / \mathrm{L})$ & 0.61 & $<0.10$ & $<0.16$ & 12 \\
\hline $\mathrm{Cr}(\mathrm{mg} / \mathrm{L})$ & 0.09 & $<0.05$ & $<0.05$ & 53 \\
\hline $\mathrm{Cu}(\mathrm{mg} / \mathrm{L})$ & $<0.01$ & $<0.01$ & $<0.01$ & 12 \\
\hline Dissolved alpha (pCi/L) & 11.4 & 3.2 & 6.8 & 4 \\
\hline Dissolved beta (pCi/L) & 31.0 & $-20.0^{b}$ & 8.8 & 4 \\
\hline Dissolved oxygen $(\mathrm{mg} / \mathrm{L})$ & 14.4 & 5.4 & 8.1 & 24 \\
\hline $\mathrm{Fe}(\mathrm{mg} / \mathrm{L})$ & 0.70 & 0.07 & 0.28 & 24 \\
\hline Fluoride (mg/L) & 1.00 & 0.15 & 0.42 & 24 \\
\hline Oil and grease (mg/L) & $<5.0$ & $<5.0$ & $<5.0$ & 13 \\
\hline $\mathrm{Ni}(\mathrm{mg} / \mathrm{L})$ & $<0.05$ & $<0.05$ & $<0.05$ & 12 \\
\hline PCB $(\mu g / L)$ & $<1.0$ & $<0.1$ & $<0.4$ & 7 \\
\hline Total residual $\mathrm{Cl}_{2}(\mathrm{mg} / \mathrm{L})$ & 0.61 & $<0.01$ & $<0.13$ & 54 \\
\hline Suspended alpha (pCi/L) & 8.0 & 1.1 & 3.3 & 4 \\
\hline Suspended beta ( $\mathrm{pCi} / \mathrm{L})$ & 2.0 & $-6.0^{b}$ & $-0.5^{b}$ & 4 \\
\hline Trichloroethylene $(\mu \mathrm{g} / \mathrm{L})$ & 1.0 & $<1.0$ & $<1.0$ & 13 \\
\hline${ }^{99} \mathrm{Tc}(\mathrm{pCi} / \mathrm{L})$ & 960.0 & 0 & 27.5 & 53 \\
\hline Temperature $\left({ }^{\circ} \mathrm{F}\right)$ & 91.0 & 50.0 & 68.9 & 52 \\
\hline Total suspended solids (mg/L) & 26.0 & $<4.0$ & $<6.1$ & 12 \\
\hline Uranium ( $\mathrm{mg} / \mathrm{L})$ & 0.039 & $<0.001$ & $<0.007$ & 53 \\
\hline Water flow (Mgd) & 3.830 & 0.497 & 1.046 & 51 \\
\hline $\ln (\mathrm{mg} /)$ & 0.13 & $<0.005$ & $<0.03$ & 52 \\
\hline pH (units) & 8.6 & 6.1 & & 52 \\
\hline
\end{tabular}

aSee Fig. 3.4.

${ }^{b}$ Negative numbers indicate that analytical result minus background was less than zero. 
Table 3.7. 1990 annual data summary for discharge point $009^{\circ}$ KPDES Permit Number KY0004049

\begin{tabular}{|c|c|c|c|c|}
\hline Parameter & $\operatorname{Max}$ & Min & Av & $\begin{array}{c}\text { Number } \\
\text { of } \\
\text { samples }\end{array}$ \\
\hline $\mathrm{Al}(\mathrm{mg} / \mathrm{L})$ & 1.67 & 0.36 & 0.91 & 12 \\
\hline $\mathrm{Cr}(\mathrm{mg} / \mathrm{L})$ & 0.05 & $<0.05$ & $<0.05$ & 52 \\
\hline $\mathrm{Cu}(\mathrm{mg} / \mathrm{L})$ & 0.01 & $<0.01$ & $<0.01$ & 12 \\
\hline Dissolved alpha (pCi/L) & 4.2 & 0.5 & 2.0 & 4 \\
\hline Dissolved beta (pCi/L) & 19.0 & 6.0 & 12.8 & 4 \\
\hline Dissolved oxygen (mg/L) & 15.8 & 5.8 & 9.6 & 24 \\
\hline $\mathrm{Fe}(\mathrm{mg} / \mathrm{L})$ & 1.35 & 0.42 & 0.78 & 24 \\
\hline Fluoride $(\mathrm{mg} / \mathrm{L})$ & 0.26 & 0.11 & 0.17 & 24 \\
\hline Oil and grease $(\mathrm{mg} / \mathrm{L})$ & 5.6 & $<5.0$ & $<5.0$ & 14 \\
\hline $\mathrm{Ni}(\mathrm{mg} / \mathrm{L})$ & 0.05 & $<0.02$ & $<0.05$ & 12 \\
\hline $\mathrm{PCB}(\mu \mathrm{g} / \mathrm{L})$ & $<1.0$ & $<0.1$ & $<0.4$ & 8 \\
\hline Total residual $\mathrm{Cl}_{2}(\mathrm{mg} / \mathrm{L})$ & 0.05 & $<0.01$ & $<0.01$ & 54 \\
\hline Suspended alpha (pCi/L) & 4.3 & $-1.1^{b}$ & 1.3 & 4 \\
\hline Suspended beta (pCi/L) & 2.0 & $-10.0^{b}$ & $-3.5^{b}$ & 4 \\
\hline Trichloroethylene $(\mu \mathrm{g} / \mathrm{L})$ & $<5.0$ & $<1.0$ & $<1.3$ & 13 \\
\hline Temperature $\left({ }^{\circ} \mathrm{F}\right)$ & 89.0 & 43.0 & 63.9 & 52 \\
\hline Total suspended solids (mg/L) & 32.0 & $<4.0$ & $<16.3$ & 12 \\
\hline Uranium (mg/L) & 0.006 & 0.002 & 0.004 & 5 \\
\hline Water flow (Mgd) & 6.480 & 0.035 & 0.283 & 51 \\
\hline $\mathrm{Zn}(\mathrm{mg} / \mathrm{L})$ & 0.04 & $<0.005$ & $<0.02$ & 52 \\
\hline $\mathrm{pH}$ (units) & 10.1 & 5.7 & & 52 \\
\hline
\end{tabular}

${ }^{a}$ See Fig. 3.4.

begative numbers indicate that analytical result minus background was less than zero.

Table 3.8. 1990 annual data summary for discharge point $010^{\circ}$ KPDES Permit Number KY0004049

\begin{tabular}{|c|c|c|c|c|}
\hline Parameter & $\operatorname{Max}$ & Min & Av & $\begin{array}{c}\text { Number } \\
\text { of } \\
\text { samples }\end{array}$ \\
\hline $\mathrm{Al}(\mathrm{mg} / \mathrm{L})$ & 2.36 & 0.41 & 1.18 & 12 \\
\hline $\mathrm{Cr}(\mathrm{mg} / \mathrm{L})$ & 0.34 & $<0.005$ & $<0.06$ & 53 \\
\hline $\mathrm{Cu}(\mathrm{mg} \Omega)$ & $<0.01$ & $<0.01$ & $<0.01$ & 12 \\
\hline Dissolved alpha (pCi/L) & 26.3 & 5.9 & 15.1 & 4 \\
\hline Dissolved beta (pCi/L) & 69.0 & 9.0 & 29.0 & 4 \\
\hline Dissolved oxygen $(\mathrm{mg} / \mathrm{L})$ & 15.7 & 4.6 & 9.0 & 24 \\
\hline $\mathrm{Fe}(\mathrm{mg} / \mathrm{L})$ & 2.63 & 0.35 & 1.15 & 24 \\
\hline Fluoride (mg/L) & 0.39 & 0.15 & 0.25 & 24 \\
\hline Oil and grease (mg/L) & $<5.0$ & $<5.0$ & $<5.0$ & 12 \\
\hline $\mathrm{Ni}(\mathrm{mg} / \mathrm{L})$ & $<0.05$ & $<0.05$ & $<0.05$ & 12 \\
\hline $\operatorname{PCB}(\mu \mathrm{g} / \mathrm{L})$ & $<1.0$ & $<0.1$ & $<0.5$ & 5 \\
\hline Total residual $\mathrm{Cl}_{2}(\mathrm{mg} / \mathrm{L})$ & 0.02 & $<0.01$ & $<0.01$ & 52 \\
\hline Suspended alpha $(\mathrm{pCi} / \mathrm{L})$ & 1.8 & $-3.6^{b}$ & $-0.3^{b}$ & 4 \\
\hline Suspended beta $(\mathrm{pCi} / \mathrm{L})$ & 14.0 & $-3.0^{b}$ & 3.3 & 4 \\
\hline Trichloroethylene $(\mu \mathrm{g} / \mathrm{L})$ & $<5.0$ & $<1.0$ & $<1.3$ & 13 \\
\hline Temperature $\left({ }^{\circ} \mathrm{F}\right)$ & 89.0 & 40.0 & 62.6 & 52 \\
\hline Total suspended solids ( $\mathrm{mg} / \mathrm{L}$ ) & 48.0 & $<4.0$ & $<16.3$ & 12 \\
\hline Uranium $(\mathrm{mg} / \mathrm{L})$ & 0.074 & 0.002 & 0.040 & 5 \\
\hline Water flow (Mgd) & 1.090 & 0.012 & 0.097 & 52 \\
\hline $\mathrm{Zn}(\mathrm{mg} / \mathrm{L})$ & 0.07 & $<0.005$ & $<0.018$ & 52 \\
\hline $\mathrm{pH}$ (units) & 9.3 & 7.0 & & 52 \\
\hline
\end{tabular}

${ }^{a}$ See Fig. 3.4.

${ }^{b}$ Negative numbers indicate that analytical result minus background was less than zero. 
Table 3.9. 1990 annual data summary for discharge polnt $011^{\star}$ KPDES Permit Number KY0004049

\begin{tabular}{|c|c|c|c|c|}
\hline Parameter & Max & Min & Av & $\begin{array}{c}\text { Number } \\
\text { of } \\
\text { samples }\end{array}$ \\
\hline $\mathrm{Al}(\mathrm{mg} / \mathrm{L})$ & 1.89 & $<0.10$ & $<0.29$ & 12 \\
\hline $\mathrm{Cr}(\mathrm{mg} / \mathrm{L})$ & 0.05 & $<0.05$ & $<0.05$ & 53 \\
\hline $\mathrm{Cu}(\mathrm{mg} / \mathrm{L})$ & 0.02 & $<0.01$ & $<0.01$ & 12 \\
\hline Dissolved alpha ( $\mathrm{pCi} / \mathrm{L})$ & 32.2 & 1.1 & 17.6 & 4 \\
\hline Dissolved beta (pCi/L) & 36.0 & 6.0 & 17.3 & 4 \\
\hline Dissolved oxygen (mi/l) & 10.9 & 4.4 & 7.2 & 24 \\
\hline $\mathrm{Fe}(\mathrm{mg} / \mathrm{L})$ & 1.87 & $<0.01$ & $<0.24$ & 24 \\
\hline Fluoride (mg/L) & 0.21 & 0.10 & 0.15 & 24 \\
\hline Oil and grease (mg/L) & $\delta .0$ & $<5.0$ & $<5.0$ & 12 \\
\hline $\mathrm{Ni}(\mathrm{mg} / \mathrm{L})$ & $<0.05$ & $<0.05$ & $<0.05$ & 12 \\
\hline $\mathrm{FCB}\left(\mu_{8} \pi\right)$ & $<1.0$ & $<0.1$ & $<0.4$ & 7 \\
\hline Total resicual $\mathrm{Cl}_{2}$ (mg/L) & 0.22 & $<0.01$ & $<0.04$ & 52 \\
\hline Suspended alpha (pCi/L) & 0.8 & $-0.7^{6}$ & 0.3 & 4 \\
\hline Suspended beta ( $(\mathrm{Ci} / \mathrm{L})$ & 29.0 & $-5.0^{b}$ & 5.8 & 4 \\
\hline Trichloroethylene $(\mu g / L)$ & 19.0 & $<1.0$ & $<5.5$ & 13 \\
\hline $99 \mathrm{Tc}(p \mathrm{Ci} / \mathrm{L})$ & 25.0 & $-940.0^{b}$ & $-10.9^{b}$ & 53 \\
\hline Temperanure ( $\left.{ }^{\circ}:\right)$ & 100.0 & 56.0 & 80.6 & 52 \\
\hline Totai suspended solids (mg/L) & 50.0 & $<4.0$ & $<8.9$ & 12 \\
\hline Uranium (mg/L) & 0.220 & 0.004 & 0.059 & 54 \\
\hline Waler flow (Mgd) & 1.070 & 0.051 & 0.138 & 52 \\
\hline $\mathrm{Zn}(\mathrm{mg} / \mathrm{L})$ & 0.069 & $<0.005$ & $<0.013$ & 52 \\
\hline $\mathrm{pH}$ (units) & 8.5 & 6.9 & & 52 \\
\hline
\end{tabular}

aSee Fig. 3.4.

${ }^{b}$ Negative numbers indicate that analytical result minus background was less than zero.

Taible 3.10. 1990 annual data summary for discharge pcint $012^{\star}$ KPDES Peimit Number KY0004049

\begin{tabular}{|c|c|c|c|c|}
\hline Parameter & Max & Min & Av & $\begin{array}{c}\text { Number } \\
\text { of } \\
\text { samples }\end{array}$ \\
\hline $\mathrm{Al}(\mathrm{mg} / \mathrm{l})$ & 4.25 & 0.22 & 0.76 & 12 \\
\hline $\operatorname{Cr}(\pi, 2)$ & 0.52 & $<0.05$ & $<0.07$ & 52 \\
\hline $\mathrm{Cu}(\mathrm{mg} / \mathrm{L})$ & $<0.01$ & $<0.01$ & $<0.01$ & 12 \\
\hline Dissolved alpha $(x \mathrm{Ci} / \mathrm{L})$ & 4.5 & $-6.2^{b}$ & 0.7 & 4 \\
\hline Dissolved beta ( $\mu \mathrm{i} / \mathrm{L})$ & 110.0 & 0 & 31.5 & 4 \\
\hline Dissolved oxygen (mg/l.) & 13.7 & 5.2 & 8.6 & 24 \\
\hline$F-(m g / l)$ & 3.51 & 0.13 & 0.56 & 24 \\
\hline Fluoride (mg/L) & 0.38 & 0.15 & 0.25 & 24 \\
\hline Oil and grease (mg/L) & 5.4 & $\delta .0$ & $<5.0$ & 14 \\
\hline Ni (mgL) & 0.11 & $<0.05$ & $<0.05$ & 12 \\
\hline $\operatorname{PCB}(\mu \mathrm{g} / \mathrm{L})$ & $<1.0$ & $<0.1$ & $<0.5$ & 6 \\
\hline Total rwidual $\mathrm{Cl}_{2}(\mathrm{mg} / \mathrm{L})$ & 0.04 & $<0.01$ & $<0.01$ & 53 \\
\hline Suspended ajpha (pCi/L) & 124 & 1.6 & 5.6 & 4 \\
\hline Suspended beta $(p \mathrm{Ci} / \mathrm{L})$ & 11.0 & 1.0 & 4.5 & 4 \\
\hline Trichloroethylene $(\mu \mathrm{g} / \mathrm{L})$ & $<5.0$ & $<1.0$ & $<1.3$ & 13 \\
\hline${ }^{99} \mathrm{Tc}(\mathrm{pCi} / \mathrm{L})$ & 490.0 & 0 & 35.2 & 41 \\
\hline Temperature $\left({ }^{\circ} \mathrm{F}\right)$ & 91.0 & 47.0 & 67.7 & 52 \\
\hline Total suspended solids ( $\mathrm{mg} / \mathrm{L})$ & 50.0 & $<4.0$ & $<9.3$ & 12 \\
\hline Uranium ( $\mathrm{mg} / \mathrm{L})$ & 0.08 & 0.002 & 0.02 & 7 \\
\hline Water fow (Mgd) & 2.390 & 0.025 & 0.187 & 52 \\
\hline $\mathrm{Zn}(\mathrm{mg} / \mathrm{L})$ & 0.14 & $<0.005$ & $<0.03$ & 52 \\
\hline $\mathrm{pH}$ (units) & 8.8 & 6.3 & & 52 \\
\hline
\end{tabular}

"Soe Fig. 3.4.

${ }^{b}$ Negative numbers indicate that analytical result minus background was less than zero. 
Table 3.11. 1990 annual data summary for discharge point $013^{a}$ KPDES Permit Number KY0004049

\begin{tabular}{lcccc}
\hline \multicolumn{1}{c}{ Parameter } & Max & Min & Av & $\begin{array}{c}\text { Number } \\
\text { of } \\
\text { samples }\end{array}$ \\
\hline Al (mg/L) & 13.25 & 0.18 & 3.38 & 12 \\
Cu (mg/L) & $<0.01$ & $<0.01$ & $<0.01$ & 12 \\
Dissolved alpha (pCi/L) & 6.3 & $-16.7^{b}$ & $-1.1^{b}$ & 4 \\
Dissolved beta (pCi/L) & 43.0 & $-9.0^{b}$ & 14.5 & 4 \\
Fe (mg/L) & 10.60 & 0.15 & 2.74 & 12 \\
Fluoride (mg/L) & 1.10 & 0.19 & 0.66 & 12 \\
Oil and grease (mg/L) & 6.4 & 5.0 & $<5.1$ & 12 \\
Ni (mg/L) & $<0.05$ & $<0.05$ & $<0.05$ & 12 \\
PCB ( $\mu$ g/L) & $<0.5$ & $<0.1$ & $<0.4$ & 4 \\
Suspended alpha (pCi/L) & 2.9 & $-3.8^{b}$ & $-0.08^{b}$ & 4 \\
Suspended beta (pCi/L) & 4.0 & $-7.0^{b}$ & $-1.5^{b}$ & 4 \\
Total suspended solids (mg/L) & 265.0 & $<4.0$ & $<63.9$ & 12 \\
Uranium (mg/L) & 0.007 & 0.003 & 0.005 & 4 \\
Water flow (Mgd) & 8.350 & 0.134 & 1.530 & 12 \\
pH (units) & 8.4 & 7.4 & & 12 \\
\hline
\end{tabular}

${ }^{a}$ See Fig. 3.4.

${ }^{b}$ Negative numbers indicate that analytical result minus background was less than zero.

Table 3.12. 1990 annual data summary for discharge point $015^{\circ}$ KPDES Permit Number KY0004049

\begin{tabular}{lcccc}
\hline \multicolumn{1}{c}{ Parameter } & Max & Min & Av & $\begin{array}{c}\text { Number } \\
\text { of } \\
\text { samples }\end{array}$ \\
\hline Al (mg/L) & 6.85 & 0.63 & 2.54 & 12 \\
Cu (mg/L) & $<0.01$ & $<0.01$ & $<0.01$ & 12 \\
Dissolved alpha (pCi/L) & 49.0 & 7.5 & 28.4 & 4 \\
Dissolved beta (pCi/L) & 89.0 & 19.0 & 45.3 & 4 \\
Fe (mg/L) & 4.59 & 0.51 & 1.91 & 12 \\
Fluoride (mg/L) & 2.70 & 0.28 & 0.66 & 12 \\
Oil and grease (mg/L) & 6.6 & $<5.0$ & $<5.2$ & 12 \\
Ni (mg/L) & 0.16 & $<0.05$ & $<0.06$ & 12 \\
PCB ( $\mu$ g/L) & $<0.5$ & $<0.1$ & $<0.4$ & 4 \\
Suspended alpha (pCi/L) & 2.8 & $-4.1^{b}$ & 0.4 & 4 \\
Suspended beta (pCi/L) & 17.0 & $-7.0^{b}$ & 1.8 & 4 \\
Total suspended solids (mg/L) & 219.0 & 7.0 & 56.4 & 12 \\
Uranium (mg/L) & 0.130 & $0.0 \mathrm{i} 5$ & 0.065 & 4 \\
Water flow (Mgd) & 3.850 & 0.001 & 0.383 & 12 \\
pH (units) & 8.8 & 7.6 & & 12 \\
\hline
\end{tabular}

${ }^{a}$ See Fig. 3.4.

${ }^{b}$ Negative numbers indicate that analytical result minus background was less than zero. 
Table 3.13. 1990 annual data summary for discharge point $016^{\star}$ KPDES Permit Number KY0004049

\begin{tabular}{|c|c|c|c|c|}
\hline Parameter & $\operatorname{Max}$ & Min & Av & $\begin{array}{c}\text { Number } \\
\text { of } \\
\text { samples }\end{array}$ \\
\hline $\mathrm{Al}(\mathrm{mg} / \mathrm{L})$ & 7.81 & $<0.10$ & 2.03 & 10 \\
\hline $\mathrm{Cu}(\mathrm{mg} / \mathrm{L})$ & 0.02 & $<0.01$ & $<0.01$ & 10 \\
\hline Dissolved alpha (pCi/L) & 6.1 & $-3.8^{\bar{b}}$ & 1.3 & 4 \\
\hline Dissolved beta ( $\mathrm{pCi} / \mathrm{L})$ & 65.0 & $-2.0^{b}$ & 23.8 & 4 \\
\hline $\mathrm{Fe}(\mathrm{mg} / \mathrm{L})$ & 7.07 & 0.36 & 1.84 & 10 \\
\hline Fluoride (mg/L) & 0.32 & 0.17 & 0.25 & 10 \\
\hline Oil and grease (mg/L) & 5.7 & $<5.0$ & $<.1$ & 10 \\
\hline $\mathrm{Ni}(\mathrm{mg} / \mathrm{L})$ & $<0.05$ & $<0.05$ & $<0.05$ & 10 \\
\hline PCB $(\mu \mathrm{g} / \mathrm{L})$ & $<0.5$ & $<0.1$ & $<0.4$ & 4 \\
\hline Suspended alpha $(\mathrm{pCi} / \mathrm{L})$ & 5.2 & $-1.1^{b}$ & 2.2 & 4 \\
\hline Suspended beta (pCi/L) & 24.0 & $-14.0^{b}$ & $-0.8^{b}$ & 4 \\
\hline Total suspended solids (mg/L) & 557.0 & 6.0 & 75.6 & 10 \\
\hline Uranium (mg/L) & 0.006 & $<0.001$ & $<0.003$ & 4 \\
\hline Water flow (Mgd) & 6.1 & 0.001 & 1.035 & 9 \\
\hline $\mathrm{pH}$ (units) & 8.9 & 7.3 & & 10 \\
\hline
\end{tabular}

asee Fig. 3.4.

${ }^{b}$ Negative numbers indicate that analytical result minus background was less than zero.

Table 3.14. 1990 annual data summary for discharge point $017^{*}$ KPDES Permit Number KY0004049

\begin{tabular}{lcccc}
\hline \multicolumn{1}{c}{ Parameter } & Max & Min & Av & $\begin{array}{c}\text { Number } \\
\text { of } \\
\text { samples }\end{array}$ \\
\hline Al (mg/L) & 2.18 & 0.17 & 0.82 & 12 \\
Cu (mg/) & $<0.01$ & $<0.01$ & $<0.01$ & 12 \\
Dissolved alpha (pCi/L) & 9.3 & $-9.0^{b}$ & 2.3 & 4 \\
Dissolved beta (pCi/L) & 74.0 & $-6.0^{b}$ & 20.0 & 4 \\
Fe (mg/L) & 2.39 & 0.18 & 0.80 & 12 \\
Fluoride (mg/L) & 0.66 & 0.28 & 0.49 & 12 \\
Oil and grease (mg/L) & 5.1 & $<5.0$ & $<5.0$ & 12 \\
Ni (mg/L) & $<0.05$ & $<0.05$ & $<0.05$ & 12 \\
PCB ( $\mu / \mathrm{l} / \mathrm{L})$ & $<0.5$ & $<0.1$ & $<0.4$ & 4 \\
Suspended alpha (pCi/L) & 8.0 & $-4.5^{b}$ & 2.3 & 4 \\
Suspended beta (pCi/L) & 33.0 & $-9.0^{b}$ & 4.0 & 4 \\
Total suspended solids (mg/L) & 73.0 & 4.0 & 21.7 & 12 \\
Uranium (mg/L) & 0.009 & 0.003 & 0.005 & 4 \\
Water flow (Mgd) & 1.960 & 0.001 & 0.315 & 12 \\
pH (units) & 8.3 & 7.7 & & 12 \\
\hline
\end{tabular}

asee Fig. 3.4.

${ }^{b}$ Negative numbers indicate that analytical result minus background was less than zero. 
Table 3.15. 1990 annual data summary for upstream Big Bayou Creek Location SW1

\begin{tabular}{|c|c|c|c|c|}
\hline Parameter & Max & Min & Av & $\begin{array}{c}\text { Number } \\
\text { of } \\
\text { samples }\end{array}$ \\
\hline$\% 0^{235} \mathrm{U}(\% \mathrm{wt})$ & 0.874 & 0 & 0.522 & 3 \\
\hline Chloride (mg/L) & 132.0 & 5.0 & 21.4 & 16 \\
\hline Conductivity ( $\mu \mathrm{mhos} / \mathrm{cm})$ & 254 & 151 & 214 & 4 \\
\hline $\mathrm{Cr}^{6}(\mathrm{mg} / \mathrm{L})$ & 0.01 & $<0.01$ & $<0.01$ & 12 \\
\hline Dissolved alpha (pCi/L) & 6.4 & $-6.8^{\bar{b}}$ & $-0.3^{b}$ & 12 \\
\hline Dissolved beta $(p \mathrm{C} / / \mathrm{L})$ & 27.0 & $-15.0^{b}$ & 8.7 & 12 \\
\hline Dissolved Solids (mg/L) & 153.0 & 118.0 & 137.5 & 4 \\
\hline Fluoride $(\mathrm{mg} / \mathrm{L})$ & 0.18 & $<0.10$ & $<0.14$ & 12 \\
\hline $\mathrm{Fe}(\mathrm{mg} / \mathrm{L})$ & 2.25 & 0.55 & 1.46 & 4 \\
\hline $\mathrm{Na}(\mathrm{mg} / \mathrm{L})$ & 24.2 & 7.5 & 15.9 & 2 \\
\hline $\mathrm{NO}_{3}-\mathrm{N}(\mathrm{mg} / \mathrm{L})$ & 1.7 & $<1.0$ & $<1.1$ & 12 \\
\hline${ }^{237} \mathrm{~Np}(\mathrm{pCi} / \mathrm{L})$ & $<5.0$ & $<5.0$ & $<5.0$ & 3 \\
\hline${ }^{239} \mathrm{Pu}(\mathrm{pCi} / \mathrm{L})$ & $<5.0$ & $<5.0$ & $<5.0$ & 3 \\
\hline Suspended alpha $(\mathrm{pCi} / \mathrm{L})$ & 8.9 & $-2.7^{b}$ & 0.7 & 12 \\
\hline Suspended beta (pCi/L) & 7.0 & $-17.0^{b}$ & $-0.9^{b}$ & 12 \\
\hline Total suspended solids ( $\mathrm{mg} / \mathrm{L}$ ) & 48.0 & 12.0 & 26.3 & 4 \\
\hline${ }^{99} \mathrm{Tc}(\mathrm{pCi} / \mathrm{L})$ & 18.0 & 3.0 & 10.7 & 3 \\
\hline Temperature $\left({ }^{\circ} \mathrm{F}\right)$ & 86.0 & 37.0 & 58.2 & 63 \\
\hline Uranium (mg/L) & 0.003 & $<0.001$ & $<0.001$ & 19 \\
\hline pH (units) & 8.7 & 7.3 & & 14 \\
\hline Gross alpha $(\mathrm{pCi} / \mathrm{L})$ & 5.5 & $-1.6^{b}$ & 1.19 & 7 \\
\hline Gross beta (pCi/L) & 66.0 & $-1.0^{b}$ & 14.6 & 7 \\
\hline $\mathrm{PO}_{4}-\mathrm{P}(\mathrm{mg} / \mathrm{L})$ & 5.9 & $<2.0$ & $<2.5$ & 12 \\
\hline $\mathrm{SO}_{4}(\mathrm{mg} / \mathrm{L})$ & 123.0 & 16.0 & 31.1 & 16 \\
\hline Total solids (mg/L) & 201 & 145.0 & 163.5 & 4 \\
\hline $\mathrm{TOC}(\mathrm{mg} / \mathrm{L})$ & 5.0 & 1.0 & 3.5 & 4 \\
\hline
\end{tabular}

See Fig. 3.3.

${ }^{b}$ Negative numbers indicate that analytical result minus background was less than zero.

Table 3.16. 1990 annual data summary for downstream Blg Bayou Creek Location SW5

\begin{tabular}{lcccc}
\hline \multicolumn{1}{c}{ Parameter } & Max & Min & Av & $\begin{array}{c}\text { Number } \\
\text { of } \\
\text { samples }\end{array}$ \\
\hline${ }^{2235} \mathrm{U}(\% \mathrm{wt})$ & 0.47 & 0 & 0.31 & 3 \\
${ }^{237} \mathrm{~Np}(\mathrm{pCi} / \mathrm{L})$ & $<.0$ & $<5.0$ & $<5.0$ & 3 \\
${ }^{239} \mathrm{Pu}(\mathrm{pC} / \mathrm{L})$ & $<.0$ & $<5.0$ & $<5.0$ & 3 \\
${ }^{99} \mathrm{ic}(\overline{\mathrm{p}} \mathrm{Ci} / \mathrm{L})$ & 27.0 & 5.0 & 17.0 & 3 \\
Uranium $(\mathrm{mg} / \mathrm{L})$ & 0.032 & 0.006 & 0.018 & 3 \\
Gross alpha $(\mathrm{pCi} / \mathrm{L})$ & 13.9 & 7.1 & 10.3 & 3 \\
Gross beta $(\mathrm{pCi} / \mathrm{L})$ & 34.0 & 15.0 & 21.7 & 3 \\
\hline
\end{tabular}

'See Fig. 3.3. 
Table 3.17. 1990 annual data summary for downstream Little Bayou Creek Location SW10

\begin{tabular}{|c|c|c|c|c|}
\hline Parameter & Max & Min & Av & $\begin{array}{c}\text { Number } \\
\text { of } \\
\text { samples }\end{array}$ \\
\hline$\%{ }^{235} \mathrm{U}(\% \mathrm{wt})$ & 0.281 & 0.238 & 0.267 & 3 \\
\hline $\mathrm{Cr}^{6+}(\mathrm{mg} / \mathrm{L})$ & 0.06 & 0.06 & 0.06 & 1 \\
\hline${ }^{237} \mathrm{~Np}(\mathrm{pCi} / \mathrm{L})$ & $<.0$ & $<5.0$ & $<5.0$ & 2 \\
\hline${ }^{239} \mathrm{Pu}(\mathrm{pCi} / \mathrm{L})$ & $\delta .0$ & $<5.0$ & $<5.0$ & 2 \\
\hline${ }^{99} \mathrm{Tc}(\mathrm{pCi} / \mathrm{L})$ & 13.0 & 6.0 & 10.3 & 3 \\
\hline Uranium (mg/L) & 0.047 & 0.009 & 0.025 & 3 \\
\hline Gross alpha (pCi/L) & 17.6 & 4.3 & 9.0 & 3 \\
\hline Gross beta (pCi/L) & 25.0 & 13.0 & 17.3 & 3 \\
\hline
\end{tabular}

'See Fig. 3.3.

Table 3.18. 1990 annual data summary for north-south diverslon ditch Location SW13

\begin{tabular}{|c|c|c|c|c|}
\hline Parameter & $\operatorname{Max}$ & Min & Av & $\begin{array}{c}\text { Number } \\
\text { of } \\
\text { samples }\end{array}$ \\
\hline Chloride (mg/L) & 1440.0 & 10.0 & 209.9 & 52 \\
\hline $\mathrm{Cr}^{6+}(\mathrm{mg} / \mathrm{L})$ & 0.05 & $<0.01$ & $<0.01$ & 52 \\
\hline Dissolved alpha (pCi/L) & 959.0 & $-13.0^{b}$ & 59.2 & 51 \\
\hline Dissolved beta $(p \mathrm{C} / \Omega)$ & 1113.0 & $-12.0^{b}$ & 101.6 & 51 \\
\hline Fluoride $(\mathrm{mg} / \mathrm{L})$ & 6.8 & 0.4 & 1.1 & 52 \\
\hline $\mathrm{NO}_{3}-\mathrm{N}(\mathrm{mg} / \mathrm{L})$ & 9.9 & $<1.0$ & $<2.6$ & 52 \\
\hline Suspended al pha $(\mathrm{pCi} / \mathrm{L})$ & 8.8 & $-13.3^{b}$ & 1.8 & 51 \\
\hline Suspended beta (pCi/L) & 44.? & $-13.0^{b}$ & 6.3 & 51 \\
\hline Temperature $\left({ }^{\circ} \mathrm{F}\right)$ & 95.0 & 39.0 & 67.1 & 53 \\
\hline Water flow (Mgd) & 0.795 & 0.059 & 0.217 & 52 \\
\hline $\mathrm{pH}$ (units) & 10.7 & 6.9 & & 52 \\
\hline $\mathrm{PO}_{4}-\mathrm{P}(\mathrm{mg} / \mathrm{L})$ & 2.3 & $<1.2$ & $<2.0$ & 52 \\
\hline $\mathrm{SO}_{4}(\mathrm{mg} / \mathrm{L})$ & 196.0 & 19.0 & 120.6 & 52 \\
\hline Uranium (mg/L) & 2.000 & 0.002 & 0.110 & 52 \\
\hline
\end{tabular}

'See Fig. 3.3.

${ }^{b}$ Negative numbers indicate that analytical result minus background was less than zero. 
Table 3.19. 1990 annual data summary for Ohlo River upstream of PGDP Location SW29

\begin{tabular}{|c|c|c|c|c|}
\hline Parameter & $\operatorname{Max}$ & Min & Av & $\begin{array}{c}\text { Number } \\
\text { of } \\
\text { samples }\end{array}$ \\
\hline Chloride (mg/L) & 23.0 & 4.0 & 10.3 & 12 \\
\hline $\mathrm{Cr}^{6+}(\mathrm{mg} / \mathrm{L})$ & 0.01 & $<0.01$ & $<0.01$ & 12 \\
\hline Dissolved alpha (pCi/L) & 6.4 & $-10.9^{b}$ & 0.1 & 12 \\
\hline Dissolved beta $(\mathrm{pCi} / \mathrm{L})$ & 24.0 & $-9.0^{b}$ & 6.1 & 12 \\
\hline Fluoride $(\mathrm{mg} / \mathrm{L})$ & 0.19 & $<0.10$ & $<0.13$ & 12 \\
\hline $\mathrm{NO}_{3}-\mathrm{N}(\mathrm{mg} / \mathrm{L})$ & 1.5 & $<1.0$ & $<1.1$ & 12 \\
\hline PCB $(\mu \mathrm{g} / \mathrm{L})$ & $<0.5$ & $<0.5$ & $<0.5$ & 3 \\
\hline Suspended alpha $(\mathrm{pCi} / \mathrm{L})$ & 5.2 & $-3.2^{b}$ & 0.7 & 12 \\
\hline Suspended beta $(\mathrm{pCi} / \mathrm{L})$ & 28.0 & $-18.0^{b}$ & 1.3 & 12 \\
\hline $\mathrm{pH}$ (units) & 8.8 & 7.4 & & 12 \\
\hline $\mathrm{SO}_{4}(\mathrm{mg} / \mathrm{L})$ & 62.0 & 10.0 & 29.0 & 12 \\
\hline Uranium (mg/L) & $<0.001$ & $<0.001$ & $<0.001$ & 12 \\
\hline
\end{tabular}

${ }^{a}$ See Fig. 3.3.

${ }^{b}$ Negative numbers indicate that analytical result minus background was less than zero.

Table 3.20. 1990 annual data summary for Ohio River downstream of PGDP Location SW30"

\begin{tabular}{lcccc}
\hline \multicolumn{1}{c}{ Parameter } & Max & Min & Av & $\begin{array}{c}\text { Number } \\
\text { of } \\
\text { samples }\end{array}$ \\
\hline Chloride (mg/L) & 22.0 & 5.0 & 11.0 & 11 \\
$\mathrm{Cr}^{6+}(\mathrm{mg} / \mathrm{L})$ & 0.01 & $<0.01$ & $<0.01$ & 11 \\
Dissolved alpha (pCi/L) & 12.1 & $-7.6^{b}$ & 2.9 & 11 \\
Dissolved beta (pCi/L) & 21.0 & $-12.0^{b}$ & 6.5 & 11 \\
Fluoride (mg/L) & 0.26 & $<0.10$ & $<0.15$ & 11 \\
$\mathrm{NO}_{3}-\mathrm{N}(\mathrm{mg} / \mathrm{L})$ & 1.4 & $<1.0$ & $<1.1$ & 11 \\
$\mathrm{PO}_{4}-\mathrm{P}(\mathrm{mg} / \mathrm{L})$ & $<2.0$ & $<2.0$ & $<2.0$ & 11 \\
Suspended alpha (pCi/L) & 7.9 & $-1.8^{b}$ & 1.9 & 11 \\
Suspended beta (pCi/L) & 42.0 & $-18.0^{b}$ & 3.7 & 11 \\
$99 \mathrm{Tc}(\mathrm{pCi} / \mathrm{L})$ & 0 & 0 & 0 & 11 \\
Uranium (mg/L) & 0.002 & $<0.001$ & $<0.001$ & 11 \\
pH (units) & 8.9 & 7.4 & & 11 \\
$1,2-$ dichloroethane $(\mu \mathrm{g} / \mathrm{L})$ & $<5.0$ & $<5.0$ & $<5.0$ & 11 \\
SO (mg/L) & 66.0 & 14.0 & 31.9 & \\
\hline
\end{tabular}

${ }^{a}$ See Fig. 3.3.

${ }^{b}$ Negative numbers indicate that analytical result minus background was less than zero. 
Table 3.21. C-746-S and C-746-T sanitary and inert landfills Sampling point $2^{\star}$

\begin{tabular}{|c|c|c|c|c|}
\hline Parameter & $\operatorname{Max}$ & Min & Av & $\begin{array}{c}\text { Number } \\
\text { of } \\
\text { samples }\end{array}$ \\
\hline Chloride (mg/L) & 11.0 & 2.0 & 7.75 & 4 \\
\hline Conductivity ( $\mu \mathrm{mhos} / \mathrm{cm})$ & 370 & 119.0 & 232.75 & 4 \\
\hline Dissolved Solids (mg/L) & 322.0 & 224.0 & 270.5 & 4 \\
\hline $\mathrm{Fe}(\mathrm{mg} / \mathrm{L})$ & 82.0 & 3.5 & 29.6 & 4 \\
\hline Gross alpha (pCi/L) & 71.7 & 6.9 & 37.8 & 4 \\
\hline Gross beta $(p \mathrm{Ci} / \mathrm{L})$ & 58.0 & 10.0 & 32.3 & 4 \\
\hline $\mathrm{Na}(\mathrm{mg} / \mathrm{L})$ & 13.2 & 4.7 & 7.7 & 4 \\
\hline pH (units) & 8.2 & 7.9 & & 4 \\
\hline $\mathrm{SO}_{4}(\mathrm{mg} / \mathrm{L})$ & 78.0 & 16.0 & 35.3 & 4 \\
\hline Total suspended solids (mg/L) & 6069.0 & 724.0 & 3709.8 & 4 \\
\hline Total solids $(\mathrm{mg} / \mathrm{L})$ & 6370.0 & 948.0 & 3980.3 & 4 \\
\hline TOC (mg/L) & 29.0 & 1.0 & 9.5 & 4 \\
\hline Uranium (mg/L) & 0.009 & 0.002 & 0.006 & 4 \\
\hline
\end{tabular}

asee Fig. 3.3.

Table 3.22. C-746-S and C-746-T sanitary and inert landfills Sampling point $3^{*}$

\begin{tabular}{lcccc}
\hline \multicolumn{1}{c}{ Parameter } & Max & Min & Av & $\begin{array}{c}\text { Number } \\
\text { of } \\
\text { samples }\end{array}$ \\
\hline Chloride (mg/L) & 18.0 & $<$ & 8.5 & 4 \\
Conductivity $(\mu \mathrm{mhos} / \mathrm{cm})$ & 446.0 & 214.0 & 356.3 & 4 \\
Dissolved Solids (mg/L) & 346.0 & 213.0 & 279.3 & 4 \\
Fe (mg/L) & 113.9 & 1.2 & 33.7 & 4 \\
Gross alpha (pCi/L) & 30.4 & 1.6 & 11.8 & 4 \\
Gross beta (pCi/L) & 53.0 & 8.0 & 28.3 & 4 \\
Na (mg/L) & 14.6 & 5.8 & 10.3 & 4 \\
pH (units) & 8.4 & 7.9 & & 4 \\
SO 4 (mg/L) & 129.0 & $<5$ & 81.5 & 4 \\
Total suspended solids (mg/L) & 2996.0 & 161.0 & 1031.3 & 4 \\
Total solids (mg/L) & 3270.0 & 374.0 & 1310.5 & 4 \\
TOC (mg/L) & 9.0 & 1.0 & 6.0 & 4 \\
Uranium (mg/L) & 0.010 & 0.004 & 0.007 & 4 \\
\hline
\end{tabular}

${ }^{a}$ See Fig. 3.3. 
Table 3.23. 1990 radionuclide concentrations in effluents Uranlum

\begin{tabular}{|c|c|c|c|c|c|}
\hline \multirow[t]{2}{*}{ Location $^{a}$} & \multirow{2}{*}{$\begin{array}{l}\text { Number of } \\
\text { samples }\end{array}$} & \multicolumn{3}{|c|}{$\begin{array}{l}\text { Concentration } \\
(\mathrm{pCi} / \mathrm{L})\end{array}$} & \multirow{2}{*}{$\begin{array}{l}\text { Percent of derived } \\
\text { concentration guide } b\end{array}$} \\
\hline & & $\operatorname{Max}$ & Min & Av & \\
\hline 001 & 53 & 162.0 & 0.68 & 26.8 & 4.52 \\
\hline 002 & 5 & 8.1 & 0.68 & 3.38 & 0.56 \\
\hline 008 & 53 & 26.3 & 0.68 & 4.39 & 0.74 \\
\hline 009 & 5 & 4.0 & 1.35 & 2.43 & 0.40 \\
\hline 010 & 5 & 50.0 & 1.35 & 27.0 & 4.56 \\
\hline 011 & 54 & 148.5 & 2.7 & 39.5 & 6.67 \\
\hline 012 & 6 & 52.6 & 1.35 & 17.7 & 2.99 \\
\hline 013 & 4 & 4.72 & 2.02 & 3.04 & 0.50 \\
\hline 015 & 4 & 87.8 & 10.12 & 43.74 & 7.29 \\
\hline 016 & 4 & 4.0 & 0.68 & 2.02 & 0.34 \\
\hline 017 & 4 & 6.1 & 2.02 & 3.58 & 0.60 \\
\hline 018 & 2 & 60.8 & 18.90 & 39.82 & 6.64 \\
\hline SW13 & 52 & 1350.0 & 1.35 & 74.25 & 12.38 \\
\hline
\end{tabular}

${ }^{a}$ See Figs. 3.3 and 3.4.

${ }^{b}$ Derived Concentration Guide for uranium total is $600 \mathrm{pCi} / \mathrm{L}$.

Table 3.24. 1990 radionuclide concentrations in water KPDES Permit Number KY0004049

Technetium-99

\begin{tabular}{|c|c|c|c|c|c|}
\hline \multirow[t]{2}{*}{ Location $^{a}$} & \multirow{2}{*}{$\begin{array}{c}\text { Number } \\
\text { of } \\
\text { samples }\end{array}$} & \multicolumn{3}{|c|}{$\begin{array}{l}\text { Concentration } \\
(\mathrm{pCi} / \mathrm{L})\end{array}$} & \multirow{2}{*}{$\begin{array}{l}\text { Percent of derived } \\
\text { concentration guide }\end{array}$} \\
\hline & & Max & Min & Av & \\
\hline 001 & 52 & 107 & 0.0 & 21.44 & $2.14 \times 10^{-2}$ \\
\hline 008 & 52 & 56 & 0.0 & 9.62 & $9.62 \times 10^{-3}$ \\
\hline 011 & 52 & 25 & 0.0 & 17.87 & $1.78 \times 10^{-2}$ \\
\hline 012 & 40 & 306 & 0.0 & 23.85 & $2.38 \times 10^{-2}$ \\
\hline
\end{tabular}

${ }^{a}$ See Fig. 3.4.

${ }^{b}$ Derived Concentration Guide for ${ }^{99} \mathrm{Tc}$ is $1 \times 10^{5} \mathrm{pCi} / \mathrm{L}$. 
Table 3.25. 1990 PGDP major discharges to surface water

\begin{tabular}{|c|c|c|c|c|c|c|}
\hline \multirow{2}{*}{ Month } & \multicolumn{3}{|c|}{$\begin{array}{l}\text { Uranium } \\
(\mathbf{k g})\end{array}$} & \multicolumn{3}{|c|}{$\begin{array}{l}\text { Technetium } \\
\text { (mCi) }\end{array}$} \\
\hline & $\begin{array}{c}\text { KPDES } \\
001\end{array}$ & $\begin{array}{c}\text { KPDES } \\
008\end{array}$ & $\begin{array}{c}\text { KPDES } \\
011\end{array}$ & $\begin{array}{c}\text { KPDES } \\
001\end{array}$ & $\begin{array}{c}\text { KPDES } \\
008\end{array}$ & $\begin{array}{c}\text { KPDES } \\
011\end{array}$ \\
\hline January & 12.0 & 0.74 & 0.50 & 3.71 & 1.80 & 0.16 \\
\hline February & 10.4 & 0.70 & 0.53 & 5.93 & 1.49 & 0.08 \\
\hline March & 5.7 & 0.71 & 0.66 & 5.44 & 1.45 & 0.11 \\
\hline April & 36.7 & 6.47 & 2.57 & 3.81 & 1.22 & 0.02 \\
\hline May & 19.9 & 2.38 & 0.80 & 5.00 & 2.50 & 0.08 \\
\hline June & 0.6 & 0.59 & 0.50 & 1.68 & 0.23 & 0.07 \\
\hline July & 1.9 & 0.33 & 0.14 & 2.45 & 0.67 & 0.06 \\
\hline August & 0.9 & 0.20 & 0.12 & 1.16 & 0.46 & 0.02 \\
\hline September & 0.6 & 0.28 & 0.08 & 1.61 & 0.28 & $0 . C 1$ \\
\hline October & 13.9 & 0.45 & 1.76 & 16.76 & 1.49 & 0.15 \\
\hline November & 1.4 & 0.18 & 1.34 & 1.34 & 0.10 & 0.10 \\
\hline December & 42.1 & 1.82 & 6.49 & 17.42 & 2.26 & 0.42 \\
\hline Total & 146.1 & 14.85 & 15.49 & 66.31 & 13.95 & 1.28 \\
\hline
\end{tabular}

${ }^{a}$ See Fig. 3.4. 


\section{GROUNDWATER}




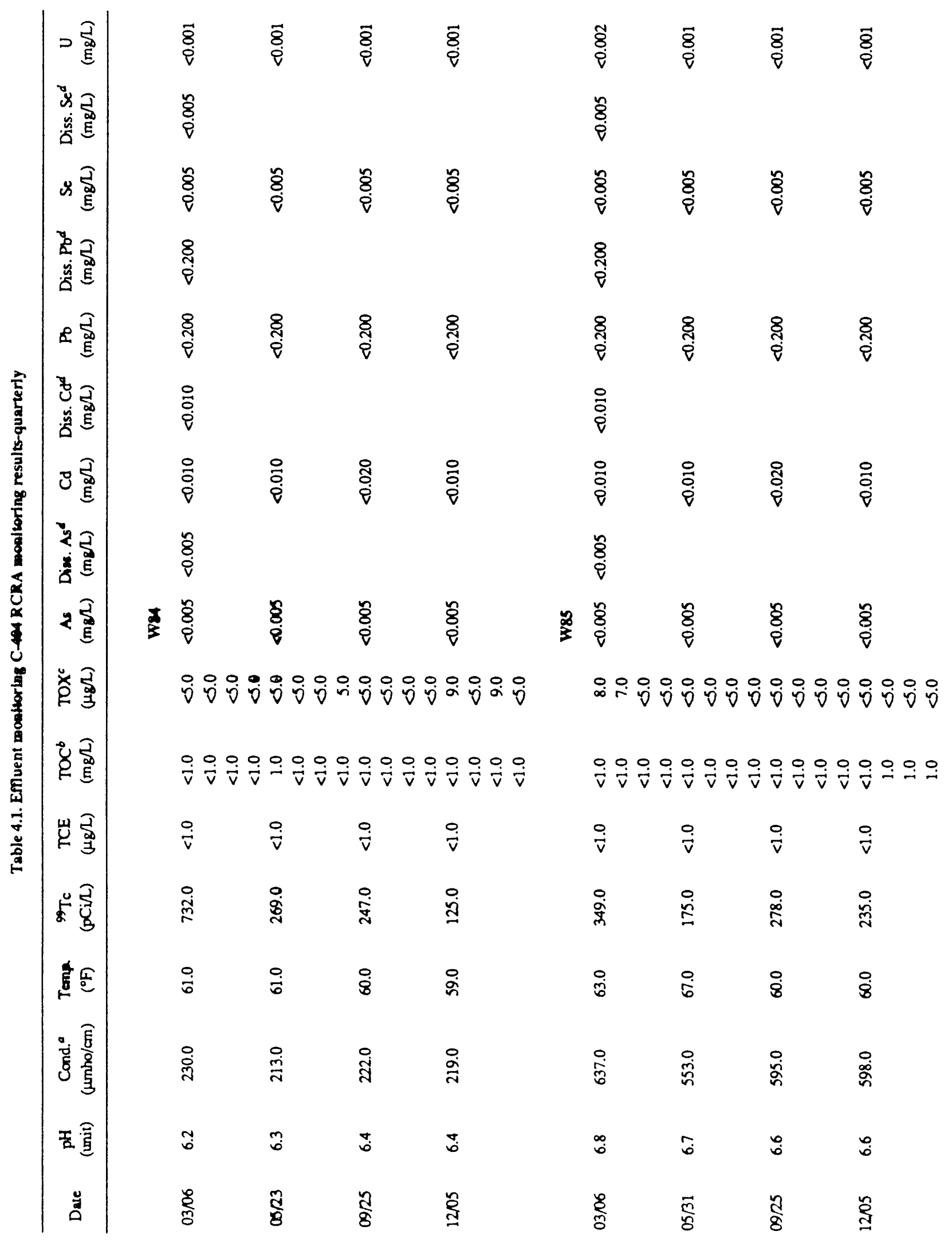




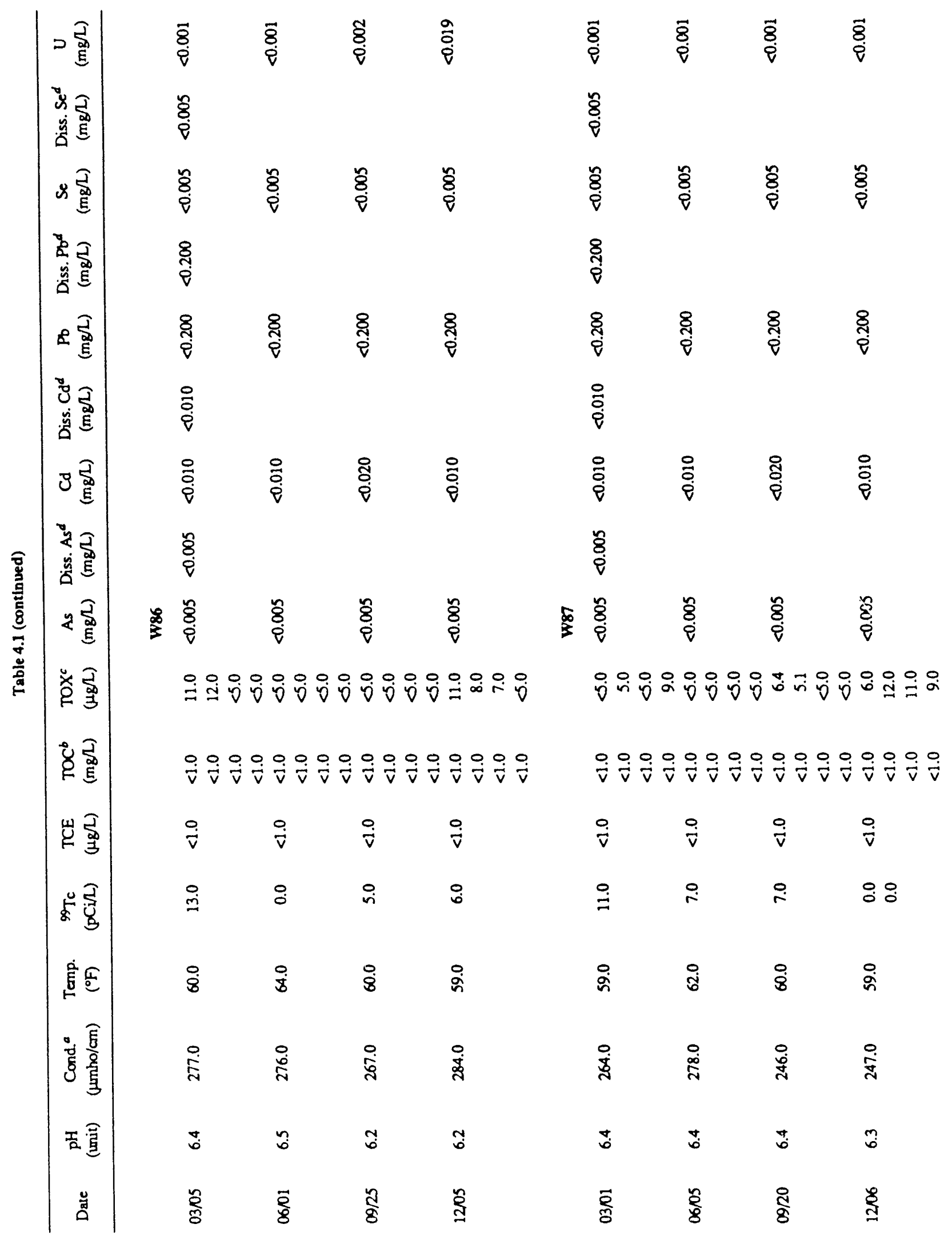




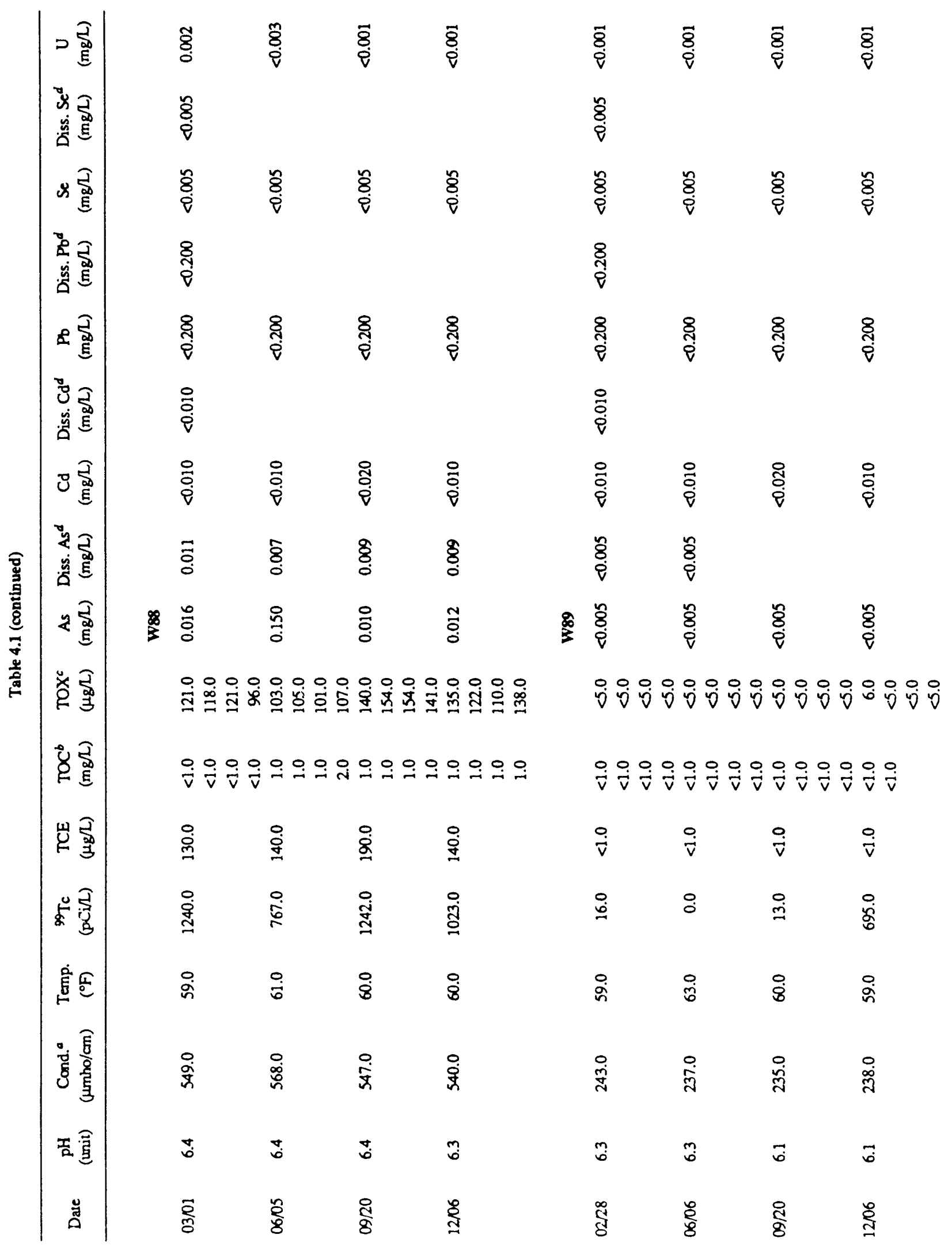




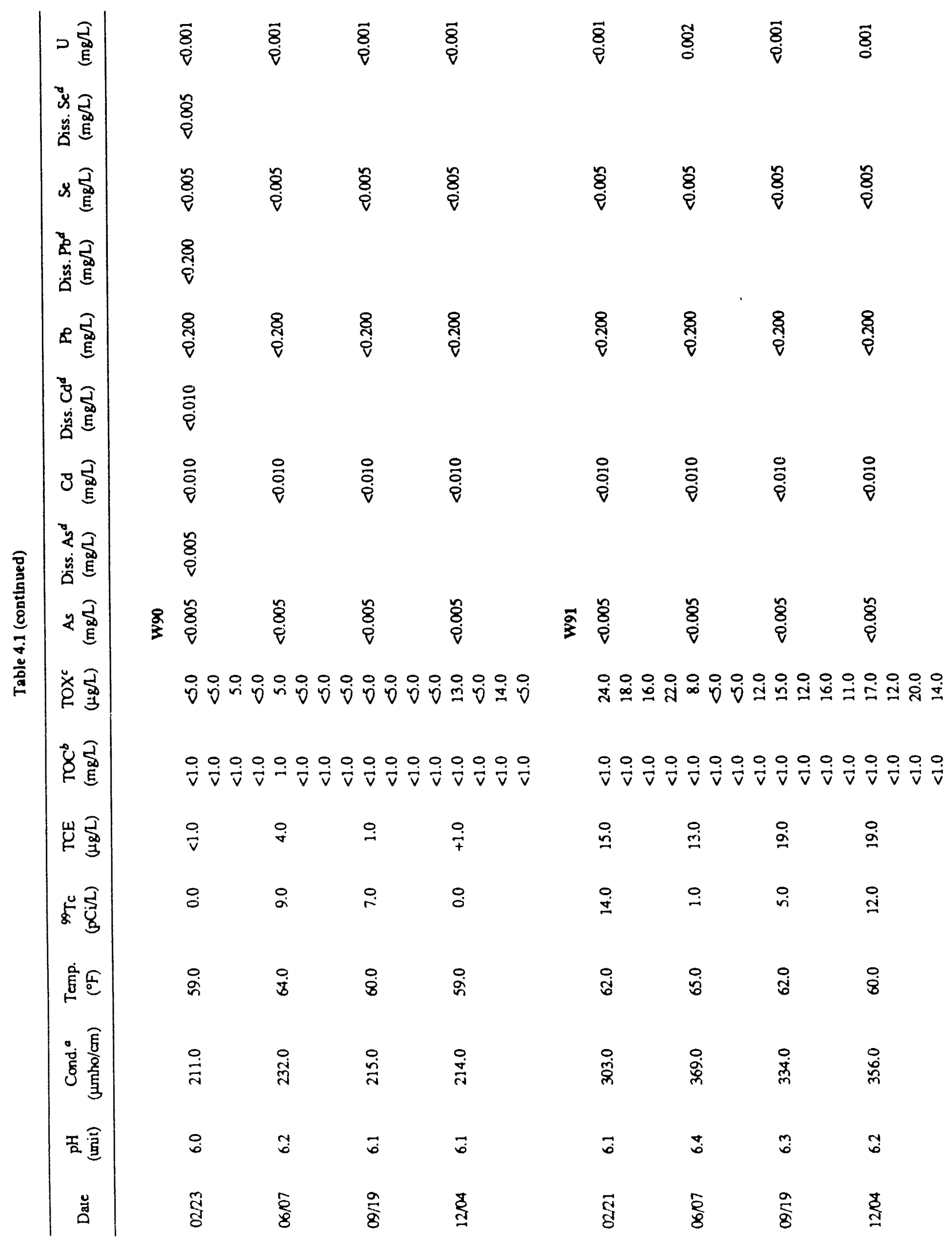




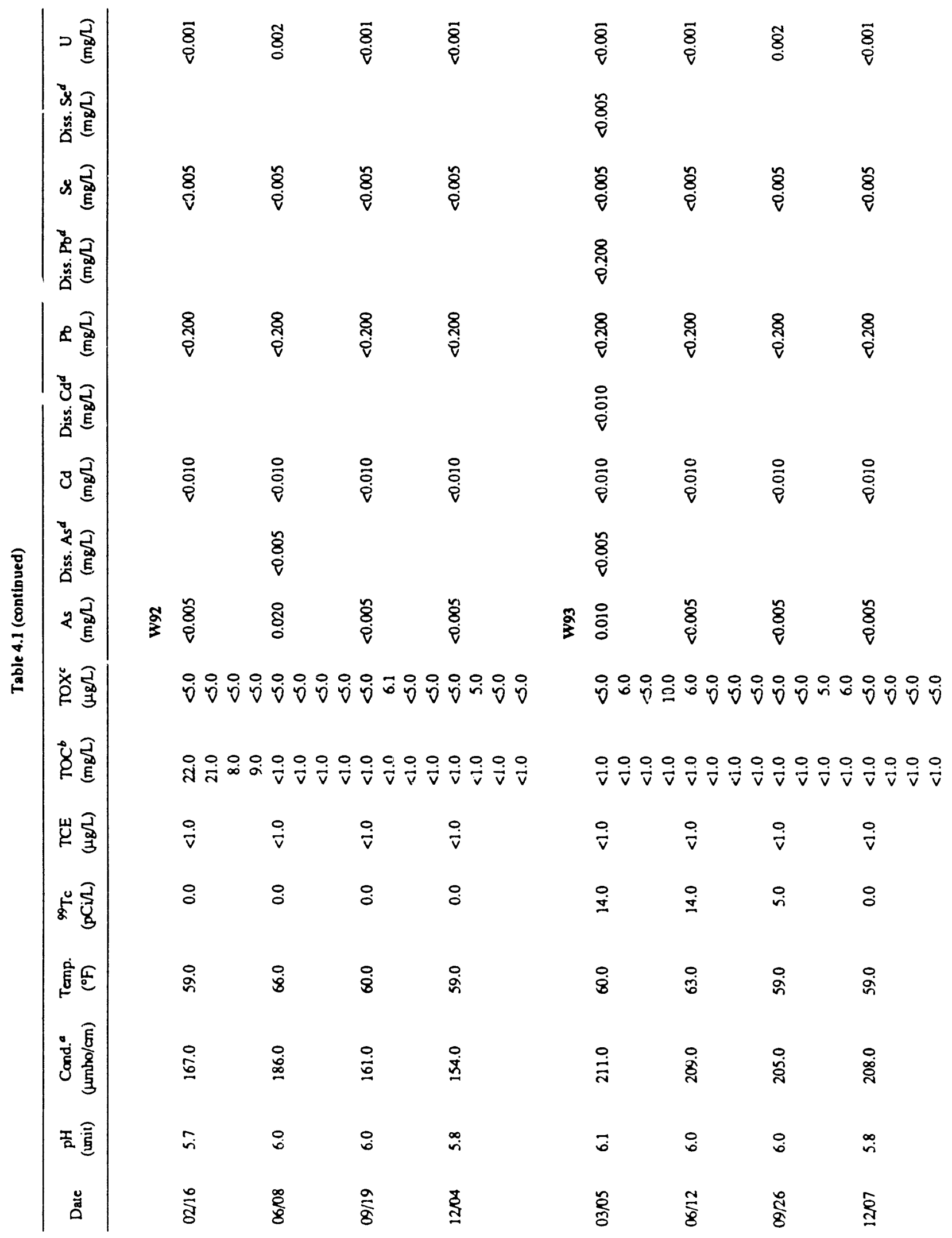




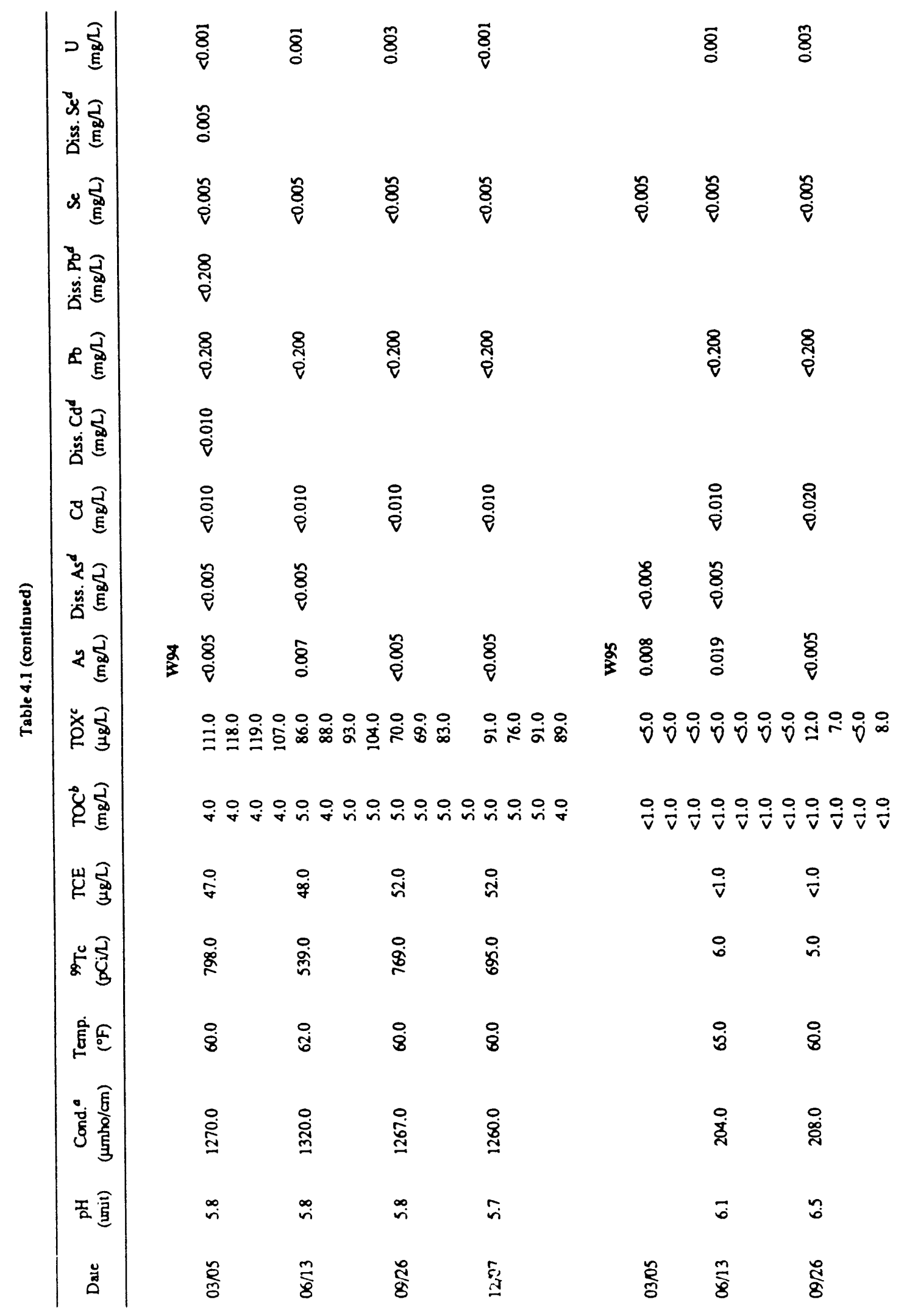




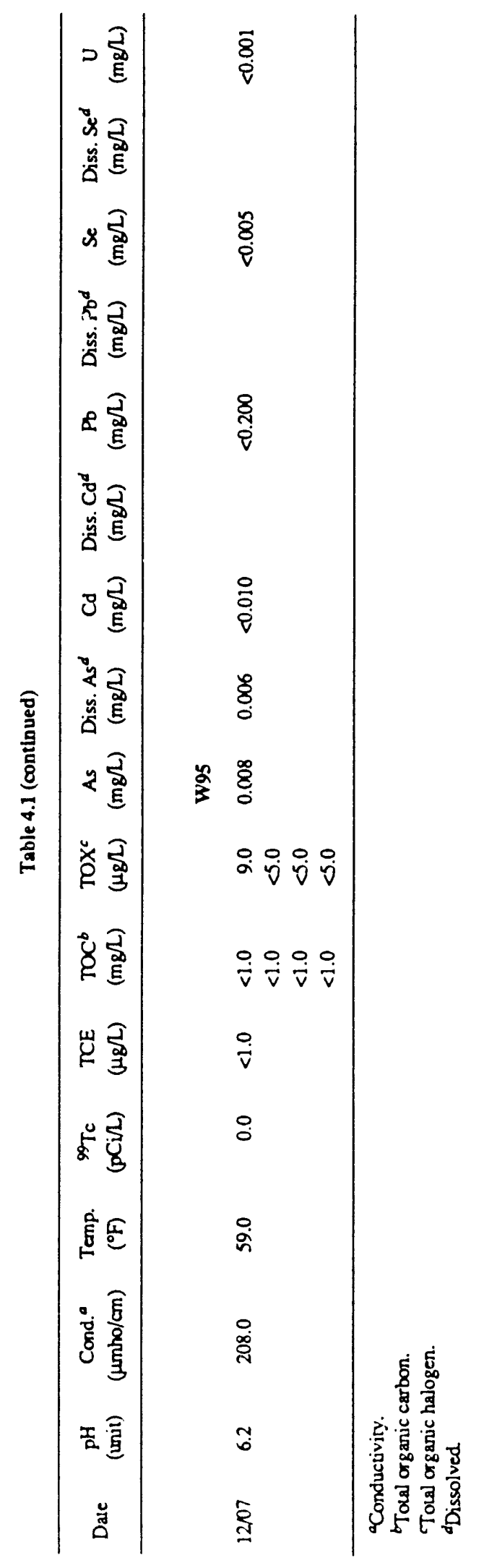


Table 4.2. Emluent monitoring at underground storage tanks

\begin{tabular}{|c|c|c|c|c|c|}
\hline Date & $\begin{array}{c}\text { Benzene } \\
(\mu g / L)\end{array}$ & $\begin{array}{l}\text { Ethylbenzene } \\
\qquad(\mu \mathrm{g} / \mathrm{L})\end{array}$ & $\begin{array}{l}\text { Tolvene } \\
(\mu g / L)\end{array}$ & $\begin{array}{c}\text { Petro } \\
\text { hydrocarbon } \\
(\mathrm{mg} / \mathrm{L})\end{array}$ & $\begin{array}{l}\text { Xylene } \\
(\mu g / L)\end{array}$ \\
\hline \multicolumn{6}{|c|}{ W47 } \\
\hline $01 / 12$ & $<$ & $<5$ & $<5$ & 0.20 & $<5$ \\
\hline $03 / 22$ & $\delta$ & $<5$ & $<5$ & & $<5$ \\
\hline $03 / 23$ & & & & 0.10 & \\
\hline $05 / 18$ & $<$ & $<5$ & $<5$ & 1.70 & $<5$ \\
\hline $08 / 01$ & 7 & $<5$ & 10 & & 8 \\
\hline $10 / 24$ & & & & $<0.10$ & \\
\hline $12 / 20$ & $\delta$ & $<5$ & $<5$ & $<0.10$ & $<5$ \\
\hline \multicolumn{6}{|c|}{ W52 } \\
\hline $01 / 11$ & $\delta$ & $<5$ & $<5$ & $<0.10$ & $<5$ \\
\hline $03 / 16$ & $<5$ & $<5$ & $<5$ & 0.80 & $<5$ \\
\hline $05 / 11$ & 0 & $<5$ & $<5$ & 0.20 & $<5$ \\
\hline $07 / 10$ & $\delta$ & $<5$ & $<5$ & $<0.10$ & $<5$ \\
\hline $10 / 12$ & $\infty$ & $<5$ & $<5$ & $<0.10$ & $<5$ \\
\hline \multicolumn{6}{|c|}{ W68 } \\
\hline $01 / 12$ & $<$ & $<5$ & $<5$ & $<0.10$ & $<5$ \\
\hline $03 / 23$ & $<$ & $<5$ & $<5$ & $<0.10$ & $<5$ \\
\hline $05 / 11$ & $<$ & $<5$ & 6 & $<0.10$ & 6 \\
\hline $07 / 11$ & 15 & $<5$ & 18 & $<0.10$ & 11 \\
\hline $09 / 28$ & $\delta$ & $<5$ & $<5$ & $<0.10$ & $<5$ \\
\hline $11 / 06$ & $<5$ & $<5$ & +5 & $<0.10$ & +5 \\
\hline \multicolumn{6}{|c|}{ W69 } \\
\hline $01 / 05$ & 55 & 930 & $<20$ & 1.50 & 1200 \\
\hline $03 / 16$ & 53 & 960 & $<20$ & 1.80 & 920 \\
\hline $05 / 11$ & 59 & 930 & 12 & 1.80 & 900 \\
\hline $07 / 13$ & $<100$ & 1000 & $<100$ & 2.11 & 700 \\
\hline $09 / 28$ & $<100$ & 690 & $<100$ & 2.30 & 460 \\
\hline $11 / 06$ & -40 & 850 & $<100$ & 0.81 & 540 \\
\hline \multicolumn{6}{|c|}{ W70 } \\
\hline $01 / 05$ & $\infty$ & $<5$ & $<5$ & 0.10 & $<5$ \\
\hline $03 / 16$ & 5 & $<5$ & $<5$ & $<0.10$ & $<5$ \\
\hline $05 / 11$ & $\delta$ & $<5$ & $<5$ & 0.30 & $<5$ \\
\hline $07 / 10$ & $\delta$ & $<5$ & $<5$ & 0.10 & $<5$ \\
\hline $09 / 28$ & $\infty$ & $<5$ & $<5$ & $<0.10$ & $<5$ \\
\hline $11 / 06$ & $<$ & $<5$ & $<5$ & $<0.10$ & $<5$ \\
\hline
\end{tabular}


Table 4.2 (continued)

\begin{tabular}{|c|c|c|c|c|c|}
\hline Date & $\begin{array}{c}\text { Benzene } \\
(\mu \mathrm{g} / \mathrm{L})\end{array}$ & $\begin{array}{c}\text { Ethylbenzene } \\
(\mu g / L)\end{array}$ & $\begin{array}{c}\text { Toluene } \\
(\mu g / L)\end{array}$ & $\begin{array}{c}\text { Petro } \\
\text { hydrocarbon } \\
(\mathrm{mg} / \mathrm{L})\end{array}$ & $\begin{array}{l}\text { Xylene } \\
(\mu \mathrm{g} / \mathrm{L})\end{array}$ \\
\hline \multicolumn{6}{|c|}{ W71 } \\
\hline $01 / 12$ & $\delta$ & $<5$ & $<5$ & $<0.10$ & $<5$ \\
\hline $03 / 23$ & $\delta$ & $<5$ & $<5$ & $<0.10$ & $<5$ \\
\hline $05 / 11$ & $\delta$ & $<5$ & $<5$ & $<0.10$ & $<5$ \\
\hline $07 / 11$ & $<$ & $<5$ & $<5$ & $<0.10$ & $<5$ \\
\hline $09 / 28$ & $\delta$ & $<5$ & $<5$ & $<0.10$ & $<5$ \\
\hline $11 / 06$ & $\delta$ & $<5$ & $<5$ & $<0.10$ & $<5$ \\
\hline \multicolumn{6}{|c|}{ W96 } \\
\hline $01 / 04$ & $<100$ & 750 & 760 & 264.00 & 4200 \\
\hline $03 / 16$ & 100 & 900 & 900 & 283.00 & 6300 \\
\hline $05 / 11$ & $<500$ & 1300 & 1100 & 160.00 & 6700 \\
\hline $07 / 10$ & -100 & 1500 & 1300 & 34.40 & 7300 \\
\hline $09 / 28$ & -100 & 1500 & 1100 & 32.30 & 7400 \\
\hline $11 / 06$ & $\sim 100$ & 1600 & 1100 & 7.15 & 8000 \\
\hline
\end{tabular}


Table 4.3. ACO/CERCLA off-site quarterly monitoring results for TCE and ${ }^{99} \mathrm{TC}$

\begin{tabular}{|c|c|c|}
\hline Date & $\begin{array}{c}\text { TCE } \\
(\mu \mathrm{g} / \mathrm{L})\end{array}$ & $\begin{array}{c}{ }^{99} \mathrm{Tc} \\
(\mathrm{pC} \mathrm{i} / \mathrm{L})\end{array}$ \\
\hline \multicolumn{3}{|c|}{ R154 } \\
\hline $\begin{array}{l}04 / 11 \\
06 / 20 \\
09 / 18 \\
12 / 12\end{array}$ & $\begin{array}{l}<1.0 \\
<1.0 \\
<1.0 \\
<1.0\end{array}$ & $\begin{array}{l}25.0 \\
25.0 \\
25.0 \\
25.0\end{array}$ \\
\hline \multicolumn{3}{|c|}{ R155 } \\
\hline $\begin{array}{l}04 / 11 \\
06 / 19 \\
09 / 18 \\
12 / 11\end{array}$ & $\begin{array}{l}<1.0 \\
<1.0 \\
<1.0\end{array}$ & $\begin{array}{l}<5.0 \\
<25.0 \\
<25.0 \\
<25.0\end{array}$ \\
\hline \multicolumn{3}{|c|}{ R156 } \\
\hline $\begin{array}{l}04 / 10 \\
06 / 19 \\
09 / 18 \\
12 / 12\end{array}$ & $\begin{array}{r}<1.0 \\
1.0 \\
+1.0\end{array}$ & $\begin{array}{l}25.0 \\
25.0 \\
25.0 \\
25.0\end{array}$ \\
\hline \multicolumn{3}{|c|}{ R157 } \\
\hline $\begin{array}{l}04 / 11 \\
06 / 19 \\
09 / 18 \\
12 / 11\end{array}$ & $\begin{array}{l}3.0 \\
2.0 \\
2.0\end{array}$ & $\begin{array}{l}25.0 \\
25.0 \\
25.0 \\
25.0\end{array}$ \\
\hline \multicolumn{3}{|c|}{ R158 } \\
\hline $\begin{array}{l}09 / 18 \\
12 / 11\end{array}$ & $\begin{array}{l}<1.0 \\
<1.0\end{array}$ & $\begin{array}{l}25.0 \\
<5.0\end{array}$ \\
\hline \multicolumn{3}{|c|}{ R159 } \\
\hline $\begin{array}{l}04 / 11 \\
06 / 19 \\
09 / 18 \\
12 / 12\end{array}$ & $\begin{array}{l}<1.0 \\
<1.0 \\
<1.0\end{array}$ & $\begin{array}{l}<5.0 \\
<25.0 \\
<25.0 \\
<25.0\end{array}$ \\
\hline \multicolumn{3}{|c|}{ R161 } \\
\hline $\begin{array}{l}04 / 10 \\
06 / 18 \\
09 / 17\end{array}$ & $\begin{array}{l}<1.0 \\
<1.0 \\
<1.0\end{array}$ & $\begin{array}{r}25.0 \\
<5.0 \\
2.0\end{array}$ \\
\hline \multicolumn{3}{|c|}{ R162 } \\
\hline $\begin{array}{l}04 / 09 \\
06 / 18 \\
09 / 17\end{array}$ & $\begin{array}{l}<1.0 \\
<1.0 \\
<1.0\end{array}$ & $\begin{array}{r}25.0 \\
25.0 \\
2.0\end{array}$ \\
\hline
\end{tabular}


Table 4.3 (continued)

\begin{tabular}{|c|c|c|}
\hline Date & $\begin{array}{c}\text { TCE } \\
(\mu \mathrm{g} / \mathrm{L})\end{array}$ & $\begin{array}{c}{ }^{99} \mathrm{Tc} \\
(\mathrm{pCi} / \mathrm{L})\end{array}$ \\
\hline & R163 & \\
\hline \multirow[t]{2}{*}{$\begin{array}{l}06 / 18 \\
09 / 17\end{array}$} & $\begin{array}{l}<1.0 \\
<1.0 \\
<1.0\end{array}$ & $\begin{array}{r}<5.0 \\
<5.0 \\
5.0\end{array}$ \\
\hline & R164 & \\
\hline & $\begin{array}{l}<1.0 \\
<1.0 \\
<1.0 \\
<1.0\end{array}$ & $\begin{array}{r}<5.0 \\
<5.0 \\
1.0 \\
8.0\end{array}$ \\
\hline & R165 & \\
\hline \multirow[t]{2}{*}{$\begin{array}{l}04 / 09 \\
06 / 18\end{array}$} & $\begin{array}{l}<1.0 \\
<1.0\end{array}$ & $<25.0$ \\
\hline & R166 & \\
\hline $\begin{array}{l}04 / 09 \\
06 / 18 \\
09 / 17\end{array}$ & $\begin{array}{l}<1.0 \\
<1.0 \\
<1.0\end{array}$ & $\begin{array}{r}25.0 \\
<5.0 \\
0.0\end{array}$ \\
\hline $09 / 17$ & R167 & \\
\hline $\begin{array}{l}04 / 09 \\
06 / 18 \\
09 / 17\end{array}$ & $\begin{array}{l}<1.0 \\
<1.0 \\
<1.0\end{array}$ & $\begin{array}{r}25.0 \\
25.0 \\
9.0\end{array}$ \\
\hline $09 / 17$ & R168 & \\
\hline $\begin{array}{l}04 / 09 \\
06 / 18 \\
09 / 17 \\
12 / 10\end{array}$ & $\begin{array}{l}<1.0 \\
<1.0 \\
<1.0 \\
<1.0\end{array}$ & $\begin{array}{r}25.0 \\
<5.0 \\
1.0\end{array}$ \\
\hline $\begin{array}{l}12 / 10 \\
12 / 17\end{array}$ & R169 & \\
\hline $\begin{array}{l}04 / 10 \\
06 / 18 \\
09 / 17 \\
12 / 11\end{array}$ & $\begin{array}{l}<1.0 \\
<1.0 \\
<1.0 \\
<1.0\end{array}$ & $\begin{array}{r}25.0 \\
<5.0 \\
4.0 \\
<5.0\end{array}$ \\
\hline $12 / 11$ & R170 & \\
\hline $\begin{array}{l}04 / 11 \\
06 / 20 \\
09 / 18 \\
12 / 12\end{array}$ & $\begin{array}{l}<1.0 \\
<1.0 \\
<1.0 \\
<1.0\end{array}$ & $\begin{array}{l}<5.0 \\
25.0 \\
<5.0 \\
<5.0\end{array}$ \\
\hline
\end{tabular}


164 Paducah Environmental Report, Vol. 3-1990

Table 4.3 (continued)

\begin{tabular}{|c|c|c|}
\hline Date & $\begin{array}{c}\text { TCE } \\
(\mu g / L)\end{array}$ & $\begin{array}{c}{ }^{99} \mathrm{Tc} \\
(\mathrm{pCi} / \mathrm{L})\end{array}$ \\
\hline & R171 & \\
\hline $\begin{array}{l}04 / 10 \\
06 / 19 \\
09 / 17 \\
12 / 11\end{array}$ & $\begin{array}{l}<1.0 \\
<1.0 \\
<1.0\end{array}$ & $\begin{array}{r}<5.0 \\
<25.0 \\
1.0 \\
<25.0\end{array}$ \\
\hline $12 / 11$ & R172 & \\
\hline $\begin{array}{l}04 / 09 \\
06 / 18 \\
09 / 17\end{array}$ & $\begin{array}{r}<1.0 \\
<1.0 \\
1.0\end{array}$ & $\begin{array}{r}<25.0 \\
<25.0 \\
4.0\end{array}$ \\
\hline $09 / 17$ & $\mathbf{R 1 7 3}$ & \\
\hline $\begin{array}{l}04 / 11 \\
06 / 20 \\
09 / 18 \\
12 / 12\end{array}$ & $\begin{array}{l}<1.0 \\
<1.0 \\
<1.0 \\
<1.0\end{array}$ & $\begin{array}{r}89.0 \\
44.0 \\
92.0 \\
126.0\end{array}$ \\
\hline $12 / 12$ & R174 & \\
\hline $\begin{array}{l}04 / 11 \\
06 / 20 \\
09 / 18 \\
12 / 12\end{array}$ & $\begin{array}{l}<1.0 \\
<1.0 \\
<1.0 \\
<1.0\end{array}$ & $\begin{array}{l}<25.0 \\
<25.0 \\
<25.0 \\
<25.0\end{array}$ \\
\hline $12 / 12$ & R182 & \\
\hline \multirow[t]{2}{*}{$\begin{array}{l}09 / 18 \\
12 / 12\end{array}$} & $\begin{array}{l}<1.0 \\
<1.0\end{array}$ & $\begin{array}{l}<5.0 \\
<5.0\end{array}$ \\
\hline & $\mathbf{R 1 8 3}$ & \\
\hline $\begin{array}{l}04 / 11 \\
06 / 20 \\
09 / 18 \\
12 / 12\end{array}$ & $\begin{array}{l}<1.0 \\
<1.0 \\
<1.0 \\
<1.0\end{array}$ & $\begin{array}{l}<5.0 \\
<25.0 \\
<25.0 \\
<25.0\end{array}$ \\
\hline $12 / 12$ & R184 & \\
\hline \multirow[t]{2}{*}{$\begin{array}{l}09 / 18 \\
12 / 12\end{array}$} & $\begin{array}{l}<1.0 \\
<1.0\end{array}$ & $\begin{array}{l}<5.0 \\
<5.0\end{array}$ \\
\hline & W20 & \\
\hline $\begin{array}{l}01 / 18 \\
04 / 19 \\
10 / 10 \\
11 / 01 \\
12 / 13\end{array}$ & $\begin{array}{r}77.0 \\
110.0 \\
210.0 \\
220.0 \\
160.0\end{array}$ & $\begin{array}{r}57.0 \\
54.0 \\
129.0 \\
112.0 \\
37.0\end{array}$ \\
\hline
\end{tabular}


Table 4.3 (continued)

\begin{tabular}{|c|c|c|}
\hline Date & $\begin{array}{c}\text { TCE } \\
(\mu g / L)\end{array}$ & $\begin{array}{c}{ }^{99} \mathrm{Tc} \\
(\mathrm{pCi} / \mathrm{L})\end{array}$ \\
\hline & W38 & \\
\hline $\begin{array}{l}02 / 08 \\
03 / 07 \\
04 / 11 \\
05 / 15 \\
06 / 08 \\
07 / 24 \\
08 / 01 \\
09 / 21 \\
10 / 11 \\
11 / 08 \\
12 / 27\end{array}$ & $\begin{array}{l}3.0 \\
2.0 \\
2.0 \\
2.0 \\
2.0 \\
3.0 \\
3.0 \\
3.0 \\
3.0 \\
3.0 \\
4.0\end{array}$ & $\begin{array}{r}16.0 \\
16.0 \\
14.0 \\
5.0 \\
9.0 \\
15.0 \\
3.0 \\
26.0 \\
28.0 \\
39.0 \\
29.0\end{array}$ \\
\hline $12 / 27$ & W41 & \\
\hline $\begin{array}{l}02 / 22 \\
03 / 07 \\
04 / 19 \\
05 / 24 \\
06 / 18 \\
07 / 19 \\
08 / 02 \\
09 / 21 \\
10 / 11 \\
10 / 31 \\
11 / 09 \\
12 / 19\end{array}$ & $\begin{array}{l}12.0 \\
14.0 \\
17.0 \\
15.0 \\
14.0 \\
17.0 \\
12.0 \\
17.0 \\
15.0 \\
19.0 \\
15.0 \\
16.0\end{array}$ & $\begin{array}{r}2.0 \\
23.0 \\
0.0 \\
4.0 \\
9.0 \\
12.0 \\
0.0 \\
6.0 \\
7.0 \\
11.0 \\
27.0 \\
1.0\end{array}$ \\
\hline $12 / 19$ & W43 & \\
\hline $\begin{array}{l}02 / 28 \\
03 / 07 \\
04 / 18 \\
05 / 22 \\
06 / 18 \\
07 / 20 \\
08 / 08 \\
09 / 26 \\
10 / 04 \\
11 / 20 \\
12 / 11\end{array}$ & $\begin{array}{l}<1.0 \\
<1.0 \\
<1.0 \\
<1.0 \\
<1.0 \\
<1.0 \\
<1.0 \\
<1.0 \\
<1.0 \\
<1.0 \\
<1.0\end{array}$ & $\begin{array}{r}12.0 \\
11.0 \\
0.0 \\
0.0 \\
13.0 \\
11.0 \\
1.0 \\
8.0 \\
2.0 \\
0.0 \\
8.0\end{array}$ \\
\hline
\end{tabular}


166 Paducah Environmental Report, Vol. 3-1990

Table 4.3 (continued)

\begin{tabular}{|c|c|c|}
\hline Date & $\begin{array}{c}\text { TCE } \\
(\mu g / L)\end{array}$ & $\begin{array}{c}{ }^{99} \mathrm{Tc} \\
(\mathrm{pCi} / \mathrm{L})\end{array}$ \\
\hline & W44 & \\
\hline $\begin{array}{l}01 / 09 \\
02 / 13 \\
03 / 07 \\
04 / 24 \\
05 / 30 \\
06 / 19 \\
07 / 19 \\
08 / 07 \\
09 / 21 \\
10 / 16 \\
11 / 19 \\
12 / 11\end{array}$ & $\begin{array}{l}18.0 \\
15.0 \\
21.0 \\
18.0 \\
14.0 \\
14.0 \\
18.0 \\
18.0 \\
21.0 \\
22.0 \\
22.0 \\
21.0\end{array}$ & $\begin{array}{r}19.0 \\
0.0 \\
9.0 \\
0.0 \\
0.0 \\
8.0 \\
1.0 \\
5.0 \\
0.0 \\
7.0 \\
0.0 \\
2.0\end{array}$ \\
\hline $12 / 11$ & W58 & \\
\hline \multirow[t]{2}{*}{$\begin{array}{l}04 / 17 \\
05 / 30\end{array}$} & $<20.0$ & 12.0 \\
\hline & W66 & \\
\hline $\begin{array}{l}01 / 18 \\
02 / 22 \\
03 / 14 \\
04 / 10 \\
05 / 17 \\
06 / 22 \\
07 / 25 \\
08 / 22 \\
09 / 20 \\
10 / 17 \\
11 / 09 \\
11 / 12\end{array}$ & $\begin{array}{r}5000.0 \\
2900.0 \\
4900.0 \\
5900.0 \\
4100.0 \\
4200.0 \\
3500.0 \\
4700.0 \\
1600.0 \\
3900.0 \\
<1.0 \\
<1.0 \\
<1.0 \\
<1.0 \\
<1.0 \\
2000.0 \\
2200.0\end{array}$ & $\begin{array}{r}2558.0 \\
2378.0 \\
2318.0 \\
2212.0 \\
2091.0 \\
2128.0 \\
1658.0 \\
2235.0 \\
1184.0 \\
1982.0 \\
25.0 \\
25.0 \\
25.0 \\
25.0 \\
25.0 \\
1289.0 \\
1691.0\end{array}$ \\
\hline
\end{tabular}


Table 4.4. ACO/CERCLA off-site quarterly monitoring results for gross alpha and gross beta

\begin{tabular}{|c|c|c|}
\hline Date & $\begin{array}{c}\text { Gross alpha } \\
(\mathrm{pCi} / \mathrm{L})\end{array}$ & $\begin{array}{c}\text { Gross beta } \\
\text { (pCi/L) }\end{array}$ \\
\hline \multicolumn{3}{|c|}{ W20 } \\
\hline $\begin{array}{l}10 / 10 \\
12 / 13\end{array}$ & $\begin{array}{l}2.3 \\
2.5\end{array}$ & $\begin{array}{l}93.0 \\
58.0\end{array}$ \\
\hline \multicolumn{3}{|c|}{ W38 } \\
\hline $\begin{array}{l}02 / 08 \\
03 / 07 \\
05 / 15 \\
06 / 08 \\
07 / 24 \\
09 / 21 \\
10 / 11 \\
12 / 27\end{array}$ & $\begin{array}{l}5.8 \\
2.0 \\
2.4 \\
5.4 \\
6.0 \\
1.0 \\
3.8 \\
4.2\end{array}$ & $\begin{array}{r}16.0 \\
10.0 \\
16.0 \\
16.0 \\
5.0 \\
10.0 \\
13.0 \\
32.0\end{array}$ \\
\hline \multicolumn{3}{|c|}{ W41 } \\
\hline $\begin{array}{l}02 / 22 \\
03 / 07 \\
05 / 24 \\
06 / 18 \\
07 / 19 \\
09 / 21 \\
10 / 11 \\
11 / 09 \\
12 / 19\end{array}$ & $\begin{array}{l}4.9 \\
2.7 \\
5.0 \\
0.2 \\
0.4 \\
2.5 \\
0.7 \\
8.4 \\
5.2\end{array}$ & $\begin{array}{r}1.0 \\
6.0 \\
8.0 \\
0.0 \\
9.0 \\
3.0 \\
2.0 \\
24.0 \\
4.0\end{array}$ \\
\hline \multicolumn{3}{|c|}{ W43 } \\
\hline $\begin{array}{l}03 / 07 \\
05 / 22 \\
06 / 18 \\
07 / 20 \\
09 / 26 \\
10 / 04 \\
11 / 20\end{array}$ & $\begin{array}{r}3.8 \\
15.6 \\
1.1 \\
0.4 \\
1.0 \\
1.2 \\
0.1\end{array}$ & $\begin{array}{r}7.0 \\
24.0 \\
1.0 \\
6.0 \\
2.0 \\
2.0 \\
3.0\end{array}$ \\
\hline
\end{tabular}


168 Paducah Environmental Report, Vol. 3-1990

Table 4.4 (continued)

\begin{tabular}{|c|c|c|}
\hline Date & $\begin{array}{c}\text { Gross alpha } \\
(p C i / L)\end{array}$ & $\begin{array}{c}\text { Gross beta } \\
(\mathrm{pCi} / \mathrm{L})\end{array}$ \\
\hline \multicolumn{3}{|c|}{ W44 } \\
\hline $\begin{array}{l}02 / 13 \\
03 / 07 \\
05 / 30 \\
06 / 19 \\
07 / 19 \\
09 / 21 \\
10 / 16 \\
11 / 19\end{array}$ & $\begin{array}{l}2.0 \\
0.2 \\
6.1 \\
1.0 \\
2.3 \\
7.7 \\
1.6 \\
7.9\end{array}$ & $\begin{array}{l}4.0 \\
2.0 \\
2.0 \\
2.0 \\
5.0 \\
2.0 \\
3.0 \\
6.0\end{array}$ \\
\hline \multicolumn{3}{|c|}{ W58 } \\
\hline $04 / 17$ & 2703.2 & 2884.0 \\
\hline \multicolumn{3}{|c|}{ W66 } \\
\hline $\begin{array}{l}02 / 22 \\
03 / 14 \\
05 / 17 \\
06 / 22 \\
09 / 20 \\
11 / 09 \\
11 / 13 \\
12 / 26\end{array}$ & $\begin{array}{r}7.2 \\
118.4 \\
2.4 \\
8.8 \\
10.5 \\
6.9 \\
4.1 \\
2.3\end{array}$ & $\begin{array}{r}728.0 \\
1632.0 \\
3106.0 \\
1895.0 \\
907.0 \\
14.0 \\
1001.0 \\
1638.0\end{array}$ \\
\hline
\end{tabular}


Table 4.5. ACO/CERCLA off-site effluent monitoring-weekly, monthly, and bimonthly

\begin{tabular}{|c|c|c|c|c|c|}
\hline Date & $\begin{array}{c}\text { TCE } \\
(\mu \mathrm{g} / \mathrm{L})\end{array}$ & $\begin{array}{c}{ }^{99} \mathrm{Tc} \\
(\mathrm{pCi} / \mathrm{L})\end{array}$ & $\begin{array}{l}\text { Gross alpha } \\
(p \mathrm{Ci} / \mathrm{L})\end{array}$ & $\begin{array}{c}\text { Gross beta } \\
(\mathrm{pCi} / \mathrm{L})\end{array}$ & $\begin{array}{l}\text { Radon } \\
(\mathrm{pCi} / \mathrm{L})\end{array}$ \\
\hline \multicolumn{6}{|c|}{$\mathbf{R 2}$} \\
\hline $02 / 07$ & 1300.0 & 1088.0 & 17.6 & 633.0 & \\
\hline $03 / 09$ & 560.0 & 1192.0 & 33.1 & 976.0 & \\
\hline \multirow[t]{2}{*}{$03 / 14$} & & & 1.1 & 2.0 & \\
\hline & & & 5.0 & 1814.0 & \\
\hline $04 / 05$ & 1300.0 & 941.0 & 44.5 & 1460.0 & \\
\hline $04 / 08$ & 1600.0 & 867.0 & 23.6 & 1313.0 & \\
\hline $05 / 10$ & 1600.0 & 491.0 & 3.2 & 575.0 & \\
\hline $06 / 06$ & 1300.0 & 897.0 & 0.2 & 718.0 & \\
\hline $07 / 03$ & 1700.0 & 658.0 & 4.4 & 451.0 & \\
\hline $08 / 07$ & 1700.0 & 1232.0 & 10.9 & 1818.0 & \\
\hline $09 / 18$ & 2000.0 & 1352.0 & 5.0 & 1126.0 & \\
\hline $10 / 10$ & 1400.0 & 1216.0 & 3.8 & 1597.0 & \\
\hline $11 / 19$ & 1800.0 & 1290.0 & 0.1 & 1326.0 & \\
\hline $11 / 28$ & 1700.0 & 1163.0 & 1.8 & 2256.0 & \\
\hline $12 / 12$ & 1500.0 & 1039.0 & 2.3 & 1169.0 & \\
\hline \multicolumn{6}{|c|}{$\mathbf{R 5}$} \\
\hline $03 / 23$ & 2.0 & $<25.0$ & 0.4 & 1.0 & \\
\hline $04 / 17$ & 1.0 & $<25.0$ & 0.5 & 19.0 & \\
\hline $05 / 10$ & $<1.0$ & $<25.0$ & 1.5 & 3.0 & \\
\hline $06 / 06$ & 4.0 & $<25.0$ & 0.3 & 1.0 & \\
\hline $07 / 06$ & 2.0 & $<25.0$ & 3.2 & 0.0 & \\
\hline $08 / 07$ & 1.0 & $<25.0$ & 1.5 & 3.0 & \\
\hline $09 / 18$ & 4.0 & $<25.0$ & 1.6 & 1.0 & \\
\hline $10 / 05$ & 1.0 & $<25.0$ & 2.9 & 0.0 & \\
\hline $11 / 28$ & 4.0 & $<25.0$ & 1.0 & 7.0 & \\
\hline $12 / 13$ & 2.0 & $<25.0$ & 3.4 & 6.0 & \\
\hline \multicolumn{6}{|c|}{ R6 } \\
\hline $03 / 07$ & $<1.0$ & $<25.0$ & 3.9 & 24.0 & \\
\hline $03 / 14$ & $<1.0$ & $<25.0$ & 0.2 & 2.0 & \\
\hline $04 / 19$ & $<1.0$ & $<25.0$ & 2.7 & 6.0 & \\
\hline $05 / 09$ & $<1.0$ & $<25.0$ & 4.1 & 3.0 & \\
\hline $06 / 06$ & & $<25.0$ & 1.1 & 1.0 & \\
\hline $06 / 11$ & $<1.0$ & & & & \\
\hline $07 / 02$ & $<1.0$ & $<25.0$ & 1.9 & 12.0 & \\
\hline $08 / 20$ & $<1.0$ & $<25.0$ & 1.4 & 3.0 & \\
\hline $09 / 18$ & $<1.0$ & $<25.0$ & 1.8 & 5.0 & \\
\hline $10 / 16$ & $<1.0$ & $<25.0$ & 2.9 & 3.0 & \\
\hline $11 / 06$ & $<1.0$ & $<25.0$ & 10.1 & 24.0 & \\
\hline $11 / 28$ & $<1.0$ & $<25.0$ & 0.4 & 6.0 & \\
\hline $12 / 17$ & $<1.0$ & $<25.0$ & 6.6 & 7.0 & \\
\hline \multicolumn{6}{|c|}{ R8 } \\
\hline $01 / 05$ & $<1.0$ & $<25.0$ & & & \\
\hline $03 / 07$ & $<1.0$ & $<25.0$ & & & \\
\hline $05 / 09$ & $<1.0$ & $<25.0$ & & & \\
\hline $07 / 17$ & $<1.0$ & $<25.0$ & & & \\
\hline $09 / 17$ & $<1.0$ & $<25.0$ & & & \\
\hline $11 / 19$ & $<1.0$ & $<25.0$ & & & \\
\hline
\end{tabular}


Table 4.5 (continued)

\begin{tabular}{|c|c|c|c|c|c|}
\hline Date & $\begin{array}{c}\text { TCE } \\
(\mu g / L)\end{array}$ & $\begin{array}{c}{ }^{99} \mathrm{Tc} \\
(\mathrm{pCi} / \mathrm{L})\end{array}$ & $\begin{array}{l}\text { Gross alpha } \\
(p \mathrm{Ci} / \mathrm{L})\end{array}$ & $\begin{array}{c}\text { Gross beta } \\
(\mathrm{pCi} / \mathrm{L})\end{array}$ & $\begin{array}{l}\text { Radon } \\
(p C i / L)\end{array}$ \\
\hline \multicolumn{6}{|c|}{ R9 } \\
\hline $\begin{array}{l}02 / 22 \\
04 / 24 \\
06 / 27 \\
08 / 28 \\
10 / 24 \\
12 / 28\end{array}$ & $\begin{array}{l}<1.0 \\
<1.0 \\
<1.0 \\
<1.0 \\
<1.0 \\
<1.0\end{array}$ & $\begin{array}{l}<25.0 \\
<25.0 \\
<25.0 \\
<25.0 \\
<25.0 \\
<25.0\end{array}$ & & & \\
\hline \multicolumn{6}{|c|}{ R10 } \\
\hline $\begin{array}{l}01 / 04 \\
01 / 08 \\
01 / 25 \\
01 / 22 \\
01 / 31\end{array}$ & $\begin{array}{l}<1.0 \\
<1.0 \\
<1.0 \\
<1.0 \\
<1.0\end{array}$ & $\begin{array}{l}<25.0 \\
<25.0 \\
<25.0 \\
<25.0 \\
<25.0\end{array}$ & 4.3 & 4.0 & 768.0 \\
\hline $02 / 05$ & $<1.0$ & $<25.0$ & 4.5 & 16.0 & 832.0 \\
\hline $02 / 13$ & $<1.0$ & $<25.0$ & & & \\
\hline $02 / 20$ & $<1.0$ & $<25.0$ & & & \\
\hline $02 / 26$ & $<1.0$ & $<25.0$ & & & \\
\hline $03 / 05$ & $<1.0$ & $<25.0$ & 1.8 & 0.3 & 800.0 \\
\hline $03 / 14$ & $<1.0$ & $<25.0$ & 0.0 & 1.0 & \\
\hline $03 / 19$ & $<1.0$ & $<25.0$ & & & \\
\hline $03 / 26$ & $<1.0$ & $<25.0$ & & & \\
\hline $04 / 02$ & $<1.0$ & $<25.0$ & 1.2 & 1.0 & 656.0 \\
\hline $04 / 09$ & $<1.0$ & $<25.0$ & & & \\
\hline $04 / 16$ & $<1.0$ & $<25.0$ & & & \\
\hline $04 / 23$ & $<1.0$ & $<25.0$ & & & \\
\hline $04 / 30$ & $<1.0$ & $<25.0$ & 8.2 & 4.0 & 895.0 \\
\hline $05 / 08$ & $<1.0$ & $<25.0$ & & & \\
\hline $05 / 14$ & $<1.0$ & $<25.0$ & & & \\
\hline $05 / 21$ & $<1.0$ & $<25.0$ & & & \\
\hline $05 / 30$ & $<1.0$ & $<25.0$ & & & \\
\hline $06 / 06$ & $<1.0$ & $<25.0$ & 1.7 & 4.0 & 1064.0 \\
\hline $06 / 11$ & $<1.0$ & $<25.0$ & & & \\
\hline $06 / 18$ & $<1.0$ & $<25.0$ & 0.5 & 4.0 & \\
\hline $06 / 26$ & $<1.0$ & $<25.0$ & & & \\
\hline $07 / 02$ & $<1.0$ & $<25.0$ & 4.0 & 8.0 & \\
\hline $07 / 09$ & $<1.0$ & $<25.0$ & & & 799.0 \\
\hline $07 / 16$ & $<1.0$ & $<25.0$ & & & \\
\hline $07 / 23$ & $<1.0$ & $<25.0$ & & & \\
\hline $07 / 30$ & $<1.0$ & $<25.0$ & & & \\
\hline $08 / 06$ & $<1.0$ & $<25.0$ & 5.4 & 19.0 & \\
\hline $08 / 13$ & $<1.0$ & $<25.0$ & & & 745.0 \\
\hline $08 / 20$ & $<1.0$ & $<25.0$ & & & \\
\hline $08 / 27$ & $<1.0$ & $<25.0$ & & & \\
\hline $09 / 04$ & $<1.0$ & $<25.0$ & 6.1 & 5.0 & 665.0 \\
\hline $09 / 10$ & $<1.0$ & $<25.0$ & & & \\
\hline $09 / 18$ & $<1.0$ & $<25.0$ & 2.5 & 8.0 & \\
\hline $09 / 24$ & $<1.0$ & $<25.0$ & & & \\
\hline $10 / 01$ & $<1.0$ & $<25.0$ & 3.0 & 6.0 & 802.0 \\
\hline $10 / 08$ & $<1.0$ & $<25.0$ & & & \\
\hline $10 / 15$ & $<1.0$ & $<25.0$ & & & \\
\hline $10 / 22$ & $<1.0$ & $<25.0$ & & & \\
\hline $10 / 29$ & $<1.0$ & $<25.0$ & & & \\
\hline
\end{tabular}


Table 4.5 (continued)

\begin{tabular}{|c|c|c|c|c|c|}
\hline Date & $\begin{array}{c}\text { TCE } \\
(\mu g / L)\end{array}$ & $\begin{array}{c}99 \mathrm{Tc} \\
(\mathrm{pCi} / \mathrm{L})\end{array}$ & $\begin{array}{c}\text { Gross alpha } \\
\text { (pCi/L) }\end{array}$ & $\begin{array}{c}\text { Gross beta } \\
(\mathrm{pCi} / \mathrm{L})\end{array}$ & $\begin{array}{l}\text { Radon } \\
\text { (pCi/L) }\end{array}$ \\
\hline \multicolumn{6}{|c|}{ R10 } \\
\hline $\begin{array}{l}11 / 05 \\
11 / 28 \\
12 / 03 \\
12 / 10 \\
12 / 17 \\
12 / 26 \\
12 / 31\end{array}$ & $\begin{array}{l}<1.0 \\
<1.0 \\
<1.0 \\
<1.0 \\
<1.0 \\
<1.0 \\
<1.0\end{array}$ & $\begin{array}{l}<25.0 \\
<25.0 \\
<25.0 \\
<25.0 \\
<25.0 \\
<25.0 \\
<25.0\end{array}$ & $\begin{array}{l}0.6 \\
3.6 \\
1.9\end{array}$ & $\begin{array}{r}5.0 \\
21.0 \\
10.0\end{array}$ & $\begin{array}{l}383.0 \\
780.0\end{array}$ \\
\hline \multicolumn{6}{|c|}{$\mathbf{R} 12$} \\
\hline $\begin{array}{l}01 / 04 \\
01 / 08 \\
01 / 15 \\
01 / 22 \\
01 / 31\end{array}$ & $\begin{array}{l}<1.0 \\
<1.0 \\
<1.0 \\
<1.0 \\
<1.0\end{array}$ & $\begin{array}{l}<25.0 \\
<25.0 \\
<25.0 \\
<25.0 \\
<25.0\end{array}$ & 0.9 & 3.0 & 373.0 \\
\hline $\begin{array}{l}02 / 05 \\
(12 / 13\end{array}$ & $\begin{array}{l}<1.0 \\
<1.0\end{array}$ & $\begin{array}{l}<25.0 \\
<25.0\end{array}$ & 0.6 & 7.0 & 401.0 \\
\hline $12 / 20$ & $<1.0$ & $<25.0$ & & & \\
\hline $02 / 26$ & $<1.0$ & $<25.0$ & & & \\
\hline $03 / 05$ & $<1.0$ & $<25.0$ & 2.0 & 6.0 & 330.0 \\
\hline $03 / 12$ & $<1.0$ & $<25.0$ & & & \\
\hline $03 / 19$ & $<1.0$ & $<25.0$ & & & \\
\hline $03 / 26$ & $<1.0$ & $<25.0$ & & & \\
\hline $04 / 02$ & $<1.0$ & $<25.0$ & 1.4 & 2.0 & 342.0 \\
\hline $04 / 09$ & $<1.0$ & $<25.0$ & & & \\
\hline $04 / 16$ & $<1.0$ & $<25.0$ & & & \\
\hline $04 / 23$ & $<1.0$ & $<25.0$ & & & \\
\hline $04 / 30$ & $<1.0$ & $<25.0$ & 4.3 & 17.0 & 426.0 \\
\hline $05 / 08$ & $<1.0$ & $<25.0$ & & & \\
\hline 0 S/14 & $<1.0$ & $<25.0$ & & & \\
\hline $05 / 21$ & $<1.0$ & $<25.0$ & & & \\
\hline $05 / 30$ & $<1.0$ & $<25.0$ & & & \\
\hline $06 / 04$ & $<1.0$ & $<25.0$ & 4.3 & 6.0 & 352.0 \\
\hline $06 / 11$ & $<1.0$ & $<25.0$ & & & \\
\hline $06 / 18$ & $<1.0$ & $<25.0$ & 0.7 & 0.0 & \\
\hline $06 / 26$ & & $<25.0$ & & & \\
\hline $07 / 02$ & $<1.0$ & $<25.0$ & 3.5 & 4.0 & \\
\hline $07 / 09$ & $<1.0$ & $<25.0$ & & & 457.0 \\
\hline $57 / 10^{\circ}$ & $<1.0$ & $<25.0$ & & & \\
\hline $.7 / 23$ & $<1.0$ & $<25.0$ & & & \\
\hline 0 iß30 & $<1.0$ & $<25.0$ & & & \\
\hline $08: 06$ & $<1.0$ & $<25.0$ & 7.2 & 5.0 & \\
\hline $0^{\circ} / 13$ & $<1.0$ & $<25.0$ & & & 391.0 \\
\hline $08 / 20$ & $<1.0$ & $<25.0$ & & & \\
\hline $08 / 27$ & $<1.0$ & 25.0 & & & \\
\hline $09 / 04$ & $<1.0$ & $<25.0$ & 3.4 & 1.0 & 428.0 \\
\hline $09 / 10$ & $<1.0$ & $<25.0$ & & & \\
\hline $09 / 17$ & $<1.0$ & $<5.0$ & & & \\
\hline $09 / 24$ & $<1.0$ & $<25.0$ & & & \\
\hline $10 / 01$ & $<1.0$ & $<25.0$ & 2.5 & 4.0 & 424.0 \\
\hline $10 / 08$ & $<1.0$ & $<25.0$ & & & \\
\hline $10 / 15$ & $<1.0$ & .25 .0 & & & \\
\hline $10 / 22$ & $<1.0$ & $<25.0$ & & & \\
\hline $10 / 29$ & $<1.0$ & $<25.1$ & & & \\
\hline
\end{tabular}


Table 4.5 (continued)

\begin{tabular}{|c|c|c|c|c|c|}
\hline Date & $\begin{array}{c}\text { TCE } \\
(\mu g / L)\end{array}$ & $\begin{array}{c}{ }^{99} \mathrm{Tc} \\
(\mathrm{pCi} / \mathrm{L})\end{array}$ & $\begin{array}{c}\text { Gross alpha } \\
(\mathrm{pCi} / \mathrm{L})\end{array}$ & $\begin{array}{c}\text { Gross beta } \\
(\mathrm{pCi} / \mathrm{L})\end{array}$ & $\begin{array}{l}\text { Radon } \\
(\mathrm{pCi} / \mathrm{L})\end{array}$ \\
\hline \multicolumn{6}{|c|}{$\mathbf{R} 12$} \\
\hline $\begin{array}{l}11 / 05 \\
11 / 12 \\
11 / 19 \\
11 / 26 \\
12 / 03 \\
12 / 10 \\
12 / 17 \\
12 / 26 \\
12 / 31\end{array}$ & $\begin{array}{l}<1.0 \\
<1.0 \\
<1.0 \\
<1.0 \\
<1.0 \\
<1.0 \\
<1.0 \\
<1.0 \\
<1.0\end{array}$ & $\begin{array}{l}<25.0 \\
<25.0 \\
<25.0 \\
<25.0 \\
<25.0 \\
<25.0 \\
<25.0 \\
<25.0 \\
<25.0\end{array}$ & 3.0 & 8.0 & $\begin{array}{l}329.0 \\
459.0 \\
435.0\end{array}$ \\
\hline \multicolumn{6}{|c|}{$\mathbf{R} 13$} \\
\hline $\begin{array}{l}01 / 04 \\
01 / 08 \\
01 / 15 \\
01 / 22 \\
01 / 31\end{array}$ & $\begin{array}{l}<1.0 \\
<1.0 \\
<1.0 \\
<1.0 \\
<1.0\end{array}$ & $\begin{array}{l}<25.0 \\
<25.0 \\
<25.0 \\
<25.0 \\
<25.0\end{array}$ & 1.6 & 8.0 & 361.0 \\
\hline $02 / 05$ & $<1.0$ & $<25.0$ & 1.6 & 4.0 & 374.0 \\
\hline $02 / 13$ & $<1.0$ & $<25.0$ & & & \\
\hline $02 / 20$ & $<1.0$ & $<25.0$ & & & \\
\hline $\begin{array}{l}02 / 26 \\
03 / 05\end{array}$ & $\begin{array}{l}<1.0 \\
<1.0\end{array}$ & $\begin{array}{l}<25.0 \\
<25.0\end{array}$ & 1.0 & 1.0 & 344.0 \\
\hline $03 / 12$ & $<1.0$ & $<25.0$ & & & \\
\hline $03 / 19$ & $<1.0$ & $<25.0$ & & & \\
\hline $03 / 26$ & $<1.0$ & $<25.0$ & & & \\
\hline $04 / 02$ & $<1.0$ & $<25.0$ & 0.0 & 1.0 & \\
\hline $04 / 09$ & $<1.0$ & $<25.0$ & & & \\
\hline $04 / 16$ & $<1.0$ & $<25.0$ & & & \\
\hline $04 / 23$ & $<1.0$ & $<25.0$ & & & \\
\hline $04 / 30$ & $<1.0$ & $<25.0$ & 0.0 & 4.0 & 434.0 \\
\hline $05 / 08$ & $<1.0$ & $<25.0$ & & & \\
\hline $05 / 14$ & $<1.0$ & $<25.0$ & & & \\
\hline $05 / 21$ & $<1.0$ & $<25.0$ & & & \\
\hline $05 / 30$ & $<1.0$ & $<25.0$ & & & \\
\hline $06 / 04$ & $<1.0$ & $<25.0$ & 5.0 & 12.0 & 371.0 \\
\hline $06 / 11$ & $<1.0$ & $<25.0$ & & & \\
\hline $06 / 18$ & $<1.0$ & $<25.0$ & 0.9 & 2.0 & \\
\hline $06 / 26$ & $<1.0$ & $<25.0$ & & & \\
\hline $07 / 02$ & $<1.0$ & $<25.0$ & 4.1 & 10.0 & \\
\hline $07 / 09$ & $<1.0$ & $<25.0$ & & & 427.0 \\
\hline $07 / 16$ & $<1.0$ & $<25.0$ & & & \\
\hline $07 / 23$ & $<1.0$ & $<25.0$ & & & \\
\hline $07 / 30$ & $<1.0$ & $<25.0$ & & & \\
\hline $08 / 06$ & $<1.0$ & $<25.0$ & 7.5 & 1.0 & \\
\hline $08 / 13$ & $<1.0$ & $<25.0$ & & & 319.0 \\
\hline $08 / 20$ & $<1.0$ & $<25.0$ & & & \\
\hline $08 / 27$ & $<1.0$ & $<25.0$ & & & \\
\hline $09 / 04$ & $<1.0$ & $<25.0$ & 9.0 & 23.0 & 417.0 \\
\hline $09 / 10$ & $<1.0$ & $<25.0$ & & & \\
\hline $09 / 17$ & $<1.0$ & $<25.0$ & & & \\
\hline $09 / 24$ & $<1.0$ & $<25.0$ & & & \\
\hline
\end{tabular}


Table 4.5 (continued)

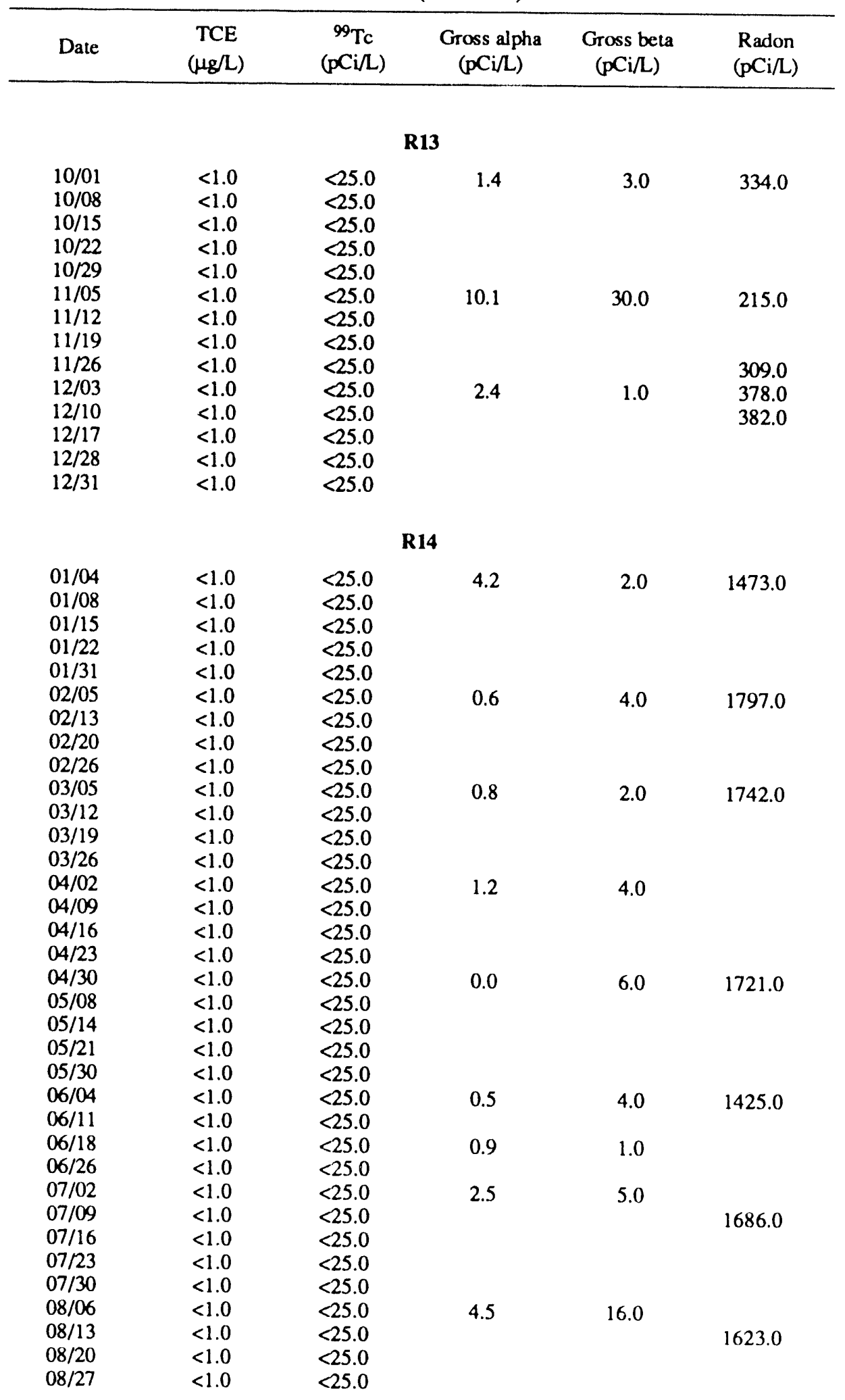


Table 4.5 (continued)

\begin{tabular}{|c|c|c|c|c|c|}
\hline Date & $\begin{array}{c}\text { TCE } \\
(\mu \& / L)\end{array}$ & $\begin{array}{c}{ }^{99} \mathrm{Tc} \\
(\mathrm{pCi} / \mathrm{L})\end{array}$ & $\begin{array}{c}\text { Gross alpha } \\
(\mathrm{pCi} / \mathrm{L})\end{array}$ & $\begin{array}{c}\text { Gross beta } \\
(\mathrm{pCi} / \mathrm{L})\end{array}$ & $\begin{array}{l}\text { Radon } \\
(\mathrm{pCi} / \mathrm{L})\end{array}$ \\
\hline \multicolumn{6}{|c|}{ R14 } \\
\hline $09 / 04$ & $<1.0$ & $<25.0$ & 3.0 & 3.0 & 1603.0 \\
\hline $09 / 10$ & $<1.0$ & $<25.0$ & & & \\
\hline $09 / 17$ & $<1.0$ & $<25.0$ & & & \\
\hline $09 / 24$ & $<1.0$ & $<25.0$ & & & \\
\hline $10 / 01$ & $<1.0$ & $<25.0$ & 1.2 & 0.0 & 1684.0 \\
\hline $10 / 08$ & $<1.0$ & $<25.0$ & & & \\
\hline $10 / 15$ & $<1.0$ & $<25.0$ & & & \\
\hline $10 / 22$ & $<1.0$ & $<25.0$ & & & \\
\hline $10 / 29$ & $<1.0$ & $<25.0$ & & & \\
\hline $11 / 05$ & $<1.0$ & $<25.0$ & 3.4 & 15.0 & 315.0 \\
\hline $11 / 12$ & $<1.0$ & $<25.0$ & & & \\
\hline $11 / 19$ & $<1.0$ & $<25.0$ & & & \\
\hline $11 / 26$ & $<1.0$ & $<25.0$ & & & 1234.0 \\
\hline $12 / 03$ & $<1.0$ & $<25.0$ & 3.8 & 2.0 & 1585.0 \\
\hline $12 / 10$ & $<1.0$ & $<25.0$ & & & 1641.0 \\
\hline $12 / 17$ & $<1.0$ & $<25.0$ & & & \\
\hline $12 / 26$ & $<1.0$ & $<25.0$ & & & \\
\hline $12 / 31$ & $<1.0$ & $<25.0$ & & & \\
\hline \multicolumn{6}{|c|}{ R16 } \\
\hline $01 / 17$ & $<1.0$ & $<25.0$ & 0.9 & 3.0 & \\
\hline $02 / 06$ & $<1.0$ & $<25.0$ & 3.8 & 13.0 & \\
\hline $03 / 02$ & $<1.0$ & $<25.0$ & 2.3 & 7.0 & 289.0 \\
\hline $03 / 14$ & & & 2.6 & 1.0 & \\
\hline $04 / 18$ & $<1.0$ & $<25.0$ & 3.0 & 12.0 & \\
\hline $05 / 18$ & $<1.0$ & $<25.0$ & 2.0 & 17.0 & \\
\hline $06 / 06$ & 6.0 & $<25.0$ & 0.5 & 5.0 & \\
\hline $07 / 25$ & $<1.0$ & $<25.0$ & 1.5 & 2.0 & 503.0 \\
\hline $08 / 15$ & 3.0 & $<25.0$ & 8.5 & 8.0 & \\
\hline $09 / 18$ & 5.0 & $<25.0$ & 2.5 & 4.0 & \\
\hline $10 / 22$ & $<1.0$ & $<25.0$ & 0.6 & 2.0 & \\
\hline $11 / 28$ & 4.0 & $<25.0$ & 2.3 & 40.0 & \\
\hline $12 / 18$ & +1.0 & $<25.0$ & 2.7 & 12.0 & \\
\hline \multicolumn{6}{|c|}{ R17 } \\
\hline $01 / 18$ & 100.0 & 81.0 & 1.5 & 91.0 & \\
\hline $02 / 21$ & 65.0 & 89.0 & 2.3 & 68.0 & \\
\hline $03 / 14$ & 100.0 & 111.0 & 6.4 & 67.0 & \\
\hline $04 / 27$ & 220.0 & 163.0 & 18.9 & 176.0 & \\
\hline $05 / 24$ & 200.0 & 167.0 & 5.3 & 141.0 & \\
\hline $06 / 06$ & 240.0 & 175.0 & 2.6 & 191.0 & \\
\hline $07 / 26$ & 220.0 & 161.0 & 9.6 & 179.0 & \\
\hline $08 / 15$ & 180.0 & 190.0 & 10.0 & 150.0 & \\
\hline $09 / 18$ & 180.0 & 155.0 & 5.5 & 177.0 & \\
\hline $10 / 24$ & 140.0 & 95.0 & 1.1 & 140.0 & \\
\hline $11 / 28$ & 120.0 & 95.0 & 1.1 & 123.0 & \\
\hline $12 / 20$ & 76.0 & 112.0 & 2.3 & 105.0 & \\
\hline
\end{tabular}


Table 4.5 (contlnued)

\begin{tabular}{|c|c|c|c|c|c|}
\hline Date & $\begin{array}{c}\text { TCE } \\
(\mu g / L)\end{array}$ & $\begin{array}{c}{ }^{99} \mathrm{Tc} \\
(\mathrm{pCi} / \mathrm{L})\end{array}$ & $\begin{array}{c}\text { Gross alpha } \\
(p \mathrm{Ci} / \mathrm{L})\end{array}$ & $\begin{array}{c}\text { Gross beta } \\
(\mathrm{pCi} / \mathrm{L})\end{array}$ & $\begin{array}{l}\text { Radon } \\
(\mathrm{pCi} / \mathrm{L})\end{array}$ \\
\hline \multicolumn{6}{|c|}{ R18 } \\
\hline $01 / 16$ & $<1.0$ & $<25.0$ & 2.1 & 9.0 & \\
\hline $02 / 02$ & $<1.0$ & $<25.0$ & 2.4 & 4.0 & \\
\hline $03 / 02$ & $<1.0$ & $<25.0$ & 2.7 & 4.0 & \\
\hline $04 / 05$ & $<1.0$ & $<25.0$ & 2.5 & 0.0 & \\
\hline $05 / 10$ & $<1.0$ & $<25.0$ & 2.7 & 5.0 & \\
\hline $06 / 07$ & $<1.0$ & $<25.0$ & 1.3 & 3.0 & \\
\hline $07 / 03$ & $<1.0$ & $<25.0$ & 2.3 & 4.0 & \\
\hline $08 / 03$ & $<1.0$ & $<25.0$ & 1.9 & 5.0 & \\
\hline $09 / 06$ & $<1.0$ & $<25.0$ & 6.1 & 19.0 & \\
\hline $10 / 05$ & $<1.0$ & $<25.0$ & 1.7 & 2.0 & \\
\hline $11 / 09$ & $<1.0$ & $<25.0$ & 6.9 & 14.0 & \\
\hline $12 / 18$ & $<1.0$ & $<25.0$ & 8.0 & 11.0 & \\
\hline \multicolumn{6}{|c|}{ R19 } \\
\hline $01 / 04$ & $<1.0$ & $<25.0$ & 4.5 & 4.0 & 531.0 \\
\hline $01 / 08$ & $<1.0$ & $<25.0$ & & & \\
\hline $01 / 15$ & $<1.0$ & $<25.0$ & & & \\
\hline $01 / 22$ & $<1.0$ & $<25.0$ & & & \\
\hline $01 / 31$ & $<1.0$ & $<25.0$ & & & \\
\hline $02 / 05$ & $<1.0$ & $<25.0$ & 0.1 & 10.0 & 572.0 \\
\hline $02 / 13$ & $<1.0$ & $<25.0$ & & & \\
\hline $02 / 20$ & $<1.0$ & $<25.0$ & & & \\
\hline $02 / 26$ & $<1.0$ & $<25.0$ & & & \\
\hline $03 / 05$ & $<1.0$ & $<25.0$ & 1.1 & 0.0 & 558.0 \\
\hline $03 / 12$ & $<1.0$ & $<25.0$ & & & \\
\hline $03 / 19$ & $<1.0$ & $<25.0$ & & & \\
\hline $03 / 26$ & $<1.0$ & $<25.0$ & & & \\
\hline $04 / 02$ & $<1.0$ & $<25.0$ & 6.0 & 4.0 & \\
\hline $04 / 09$ & $<1.0$ & $<25.0$ & & & \\
\hline $04 / 16$ & $<1.0$ & $<25.0$ & & & \\
\hline $04 / 23$ & $<1.0$ & $<25.0$ & & & \\
\hline $04 / 30$ & $<1.0$ & $<25.0$ & 0.0 & 2.0 & 699.0 \\
\hline $05 / 08$ & $<1.0$ & $<25.0$ & & & \\
\hline $05 / 14$ & $<1.0$ & $<25.0$ & & & \\
\hline $05 / 21$ & $<1.0$ & $<25.0$ & & & \\
\hline $05 / 30$ & $<1.0$ & $<25.0$ & & & \\
\hline $06 / 04$ & $<1.0$ & $<25.0$ & 8.3 & 3.0 & 491.0 \\
\hline $06 / 11$ & $<1.0$ & $<25.0$ & & & \\
\hline $06 / 18$ & $<1.0$ & $<25.0$ & 1.2 & 2.0 & \\
\hline $06 / 26$ & $<1.0$ & $<25.0$ & & & \\
\hline $07 / 02$ & $<1.0$ & $<25.0$ & 2.5 & 6.0 & \\
\hline $07 / 09$ & $<1.0$ & $<25.0$ & & & 579.0 \\
\hline $07 / 16$ & $<1.0$ & $<25.0$ & & & \\
\hline $07 / 23$ & $<1.0$ & $<25.0$ & & & \\
\hline $07 / 30$ & $<1.0$ & $<25.0$ & & & \\
\hline $08 / 06$ & $<1.0$ & $<25.0$ & 6.4 & 7.0 & \\
\hline $08 / 13$ & $<1.0$ & $<25.0$ & & & 527.0 \\
\hline $08 / 20$ & $<1.0$ & $<25.0$ & & & \\
\hline $08 / 27$ & $<1.0$ & $<25.0$ & & & \\
\hline $09 / 04$ & $<1.0$ & $<25.0$ & 4.3 & 2.0 & 585.0 \\
\hline $09 / 10$ & $<1.0$ & $<25.0$ & & & \\
\hline $09 / 17$ & $<1.0$ & $<25.0$ & & & \\
\hline $09 / 24$ & $<1.0$ & $<25.0$ & & & \\
\hline
\end{tabular}


Table 4.5 (continued)

\begin{tabular}{|c|c|c|c|c|c|}
\hline Date & $\begin{array}{c}\text { TCE } \\
(\mu g / L)\end{array}$ & $\begin{array}{c}{ }^{99} \mathrm{Tc} \\
(\mathrm{pCi} / \mathrm{L})\end{array}$ & $\begin{array}{l}\text { Gross alpha } \\
(\mathrm{pCi} / \mathrm{L})\end{array}$ & $\begin{array}{c}\text { Gross beta } \\
(\mathrm{pCi} / L)\end{array}$ & $\begin{array}{c}\text { Radon } \\
(\mathrm{pCi} / L)\end{array}$ \\
\hline \multicolumn{6}{|c|}{ R19 } \\
\hline $10 / 01$ & $<1.0$ & $<25.0$ & 0.5 & 0.0 & 595.0 \\
\hline $10 / 08$ & $<1.0$ & $<25.0$ & & & \\
\hline $10 / 15$ & $<1.0$ & $<25.0$ & & & \\
\hline $10 / 22$ & $<1.0$ & $<25.0$ & & & \\
\hline $10 / 29$ & $<1.0$ & $<25.0$ & & & \\
\hline $11 / 05$ & $<1.0$ & $<25.0$ & 9.4 & 28.0 & 313.0 \\
\hline $11 / 12$ & $<1.0$ & $<25.0$ & & & \\
\hline $11 / 19$ & $<1.0$ & $<25.0$ & & & \\
\hline $11 / 26$ & $<1.0$ & $<25.0$ & & & 457.0 \\
\hline $12 / 03$ & $<1.0$ & $<25.0$ & 3.8 & 0.0 & 616.0 \\
\hline $12 / 10$ & $<1.0$ & $<25.0$ & & & 482.0 \\
\hline $12 / 17$ & $<1.0$ & $<5.0$ & & & \\
\hline $12 / 26$ & $<1.0$ & $<25.0$ & & & \\
\hline $12 / 31$ & $<1.0$ & $<25.0$ & & & \\
\hline \multicolumn{6}{|c|}{$\mathbf{R} 20$} \\
\hline $09 / 10$ & $<1.0$ & $<25.0$ & & & \\
\hline $10 / 24$ & $<1.0$ & $<25.0$ & & & \\
\hline \multicolumn{6}{|c|}{ R21 } \\
\hline $01 / 10$ & $<1.0$ & $<25.0$ & 0.4 & 2.0 & \\
\hline $02 / 15$ & $<1.0$ & $<25.0$ & 3.4 & 2.0 & \\
\hline $03 / 14$ & $<1.0$ & $<25.0$ & 1.1 & 1.0 & \\
\hline $04 / 05$ & $<1.0$ & $<25.0$ & 1.3 & 2.0 & \\
\hline $05 / 17$ & $<1.0$ & $<25.0$ & 0.7 & 8.0 & \\
\hline $06 / 14$ & $<1.0$ & $<25.0$ & 1.2 & 1.0 & \\
\hline $07 / 10$ & $<1.0$ & $<25.0$ & 2.3 & 2.0 & \\
\hline $08 / 13$ & $<1.0$ & $<25.0$ & 2.0 & 6.0 & \\
\hline $09 / 12$ & $<1.0$ & $<25.0$ & 0.8 & 4.0 & \\
\hline $10 / 08$ & $<1.0$ & $<25.0$ & 1.8 & 0.0 & \\
\hline $11 / 13$ & $<1.0$ & $<25.0$ & 2.0 & 3.0 & \\
\hline $12 / 13$ & $<1.0$ & $<25.0$ & 5.7 & 11.0 & \\
\hline \multicolumn{6}{|c|}{$\mathbf{R 2 2}$} \\
\hline $02 / 26$ & $<1.0$ & $<25.0$ & & & \\
\hline $04 / 19$ & $<1.0$ & $<25.0$ & & & \\
\hline $06 / 21$ & $<1.0$ & $<25.0$ & & & \\
\hline $08 / 20$ & $<1.0$ & $<25.0$ & & & \\
\hline $10 / 16$ & $<1.0$ & $<25.0$ & & & \\
\hline $12 / 17$ & $<1.0$ & $<25.0$ & & & \\
\hline \multicolumn{6}{|c|}{ R23 } \\
\hline $01 / 10$ & $<1.0$ & $<25.0$ & & & \\
\hline $03 / 02$ & $<1.0$ & $<25.0$ & & & \\
\hline $05 / 17$ & $<1.0$ & $<25.0$ & & & \\
\hline $07 / 17$ & $<1.0$ & $<25.0$ & & & \\
\hline $09 / 17$ & $<1.0$ & $<25.0$ & & & \\
\hline $11 / 19$ & $<1.0$ & $<25.0$ & & & \\
\hline
\end{tabular}


Table 4.5 (continued)

\begin{tabular}{|c|c|c|c|c|c|}
\hline Date & $\begin{array}{c}\text { TCE } \\
(\mu g / L)\end{array}$ & $\begin{array}{c}{ }^{99} \mathrm{Tc} \\
(\mathrm{pCi} / \mathrm{L})\end{array}$ & $\begin{array}{c}\text { Gross alpha } \\
(\mathrm{pCi} / \mathrm{L})\end{array}$ & $\begin{array}{c}\text { Gross beta } \\
(\mathrm{pCi} / \mathrm{L})\end{array}$ & $\begin{array}{l}\text { Radon } \\
(\mathrm{pCi} / \mathrm{L})\end{array}$ \\
\hline \multicolumn{6}{|c|}{ R24 } \\
\hline $02 / 22$ & $<1.0$ & $<25.0$ & & & \\
\hline $04 / 19$ & $<1.0$ & $<25.0$ & & & \\
\hline $06 / 21$ & $<1.0$ & $<25.0$ & & & \\
\hline $08 / 20$ & $<1.0$ & $<25.0$ & & & \\
\hline $10 / 16$ & $<1.0$ & $<25.0$ & & & \\
\hline $12 / 17$ & $<1.0$ & $<25.0$ & & & \\
\hline \multicolumn{6}{|c|}{ R25 } \\
\hline $01 / 05$ & $<1.0$ & $<25.0$ & & & \\
\hline $03 / 07$ & $<1.0$ & $<25.0$ & & & \\
\hline $05 / 09$ & $<1.0$ & $<25.0$ & & & \\
\hline $07 / 02$ & $<1.0$ & $<25.0$ & & & \\
\hline $09 / 06$ & $<1.0$ & $<25.0$ & & & \\
\hline $11 / 06$ & $<1.0$ & $<25.0$ & & & \\
\hline \multicolumn{6}{|c|}{$\mathbf{R 2 6}$} \\
\hline $02 / 22$ & $<1.0$ & $<25.0$ & & & \\
\hline $04 / 19$ & $<1.0$ & $<25.0$ & & & \\
\hline $06 / 06$ & $<1.0$ & $<25.0$ & 0.6 & 2.0 & \\
\hline $08 / 20$ & $<1.0$ & $<25.0$ & & & \\
\hline $09 / 18$ & $<1.0$ & $<25.0$ & 1.0 & 4.0 & \\
\hline $10 / 16$ & $<1.0$ & $<25.0$ & & & \\
\hline $12 / 17$ & $<1.0$ & $<25.0$ & & & \\
\hline \multicolumn{6}{|c|}{ R28 } \\
\hline $01 / 05$ & $<1.0$ & $<25.0$ & & & \\
\hline $03 / 07$ & $<1.0$ & $<25.0$ & & & \\
\hline $05 / 09$ & $<1.0$ & $<25.0$ & & & \\
\hline $07 / 02$ & $<1.0$ & $<25.0$ & & & \\
\hline $09 / 06$ & $<1.0$ & $<25.0$ & & & \\
\hline $11 / 06$ & $<1.0$ & $<25.0$ & & & \\
\hline \multicolumn{6}{|c|}{$\mathbf{R 3 1}$} \\
\hline $01 / 04$ & $<1.0$ & $<25.0$ & & & \\
\hline $03 / 02$ & $<1.0$ & $<25.0$ & & & \\
\hline $06 / 21$ & $<1.0$ & $<25.0$ & & & \\
\hline $07 / 17$ & $<1.0$ & $<25.0$ & & & \\
\hline $09 / 06$ & $<1.0$ & $<25.0$ & & & \\
\hline $09 / 19$ & $<1.0$ & & & & \\
\hline $09 / 24$ & $<1.0$ & $<25.0$ & & & \\
\hline $10 / 01$ & $<1.0$ & $<25.0$ & 4.5 & 0.0 & 208.0 \\
\hline $10 / 08$ & $<1.0$ & $<25.0$ & & & \\
\hline $10 / 15$ & $<1.0$ & $<25.0$ & & & \\
\hline $10 / 22$ & $<1.0$ & $<25.0$ & & & \\
\hline $10 / 29$ & $<1.0$ & $<25.0$ & & & \\
\hline $11 / 05$ & $<1.0$ & $<25.0$ & 11.9 & 25.0 & 788.0 \\
\hline $11 / 12$ & $<1.0$ & $<25.0$ & & & \\
\hline $11 / 19$ & $<1.0$ & $<25.0$ & & & \\
\hline $11 / 26$ & $<1.0$ & $<25.0$ & & & 178.0 \\
\hline $12 / 03$ & $<1.0$ & $<25.0$ & 4.5 & 3.0 & 195.0 \\
\hline $12 / 10$ & $<1.0$ & $<25.0$ & & & 2600 \\
\hline $12 / 17$ & $<1.0$ & $<25.0$ & & & \\
\hline $12 / 26$ & $<1.0$ & $<25.0$ & & & \\
\hline $12 / 31$ & $<1.0$ & $<25.0$ & & & \\
\hline
\end{tabular}


Table 4.5 (continued)

\begin{tabular}{|c|c|c|c|c|c|}
\hline Date & $\begin{array}{c}\text { TCE } \\
(\mu \mathrm{g} / \mathrm{L})\end{array}$ & $\begin{array}{c}{ }^{99} \mathrm{Tc} \\
(\mathrm{pCi} / \mathrm{L})\end{array}$ & $\begin{array}{l}\text { Gross alpha } \\
(\mathrm{pCi} / \mathrm{L})\end{array}$ & $\begin{array}{c}\text { Gross beta } \\
\text { (pCi/L) }\end{array}$ & $\begin{array}{l}\text { Radon } \\
(\mathrm{pCi} / \mathrm{L})\end{array}$ \\
\hline \multicolumn{6}{|c|}{ R39 } \\
\hline $01 / 04$ & $<1.0$ & $<25.0$ & 3.9 & 6.0 & 501.0 \\
\hline $01 / 08$ & $<1.0$ & $<25.0$ & & & \\
\hline $01 / 15$ & $<1.0$ & $<25.0$ & & & \\
\hline $01 / 22$ & $<1.0$ & $<25.0$ & & & \\
\hline $01 / 31$ & $<1.0$ & $<25.0$ & & & \\
\hline $02 / 05$ & $<1.0$ & $<25.0$ & 1.7 & 14.0 & 863.0 \\
\hline $02 / 13$ & $<1.0$ & $<25.0$ & & & \\
\hline $02 / 20$ & $<1.0$ & $<25.0$ & & & \\
\hline $02 / 26$ & $<1.0$ & $<25.0$ & & & \\
\hline $03 / 05$ & $<1.0$ & $<25.0$ & 1.7 & 3.0 & 871.0 \\
\hline $03 / 12$ & $<1.0$ & $<25.0$ & & & \\
\hline $03 / 19$ & $<1.0$ & $<25.0$ & & & \\
\hline $03 / 26$ & $<1.0$ & $<25.0$ & & & \\
\hline $04 / 02$ & $<1.0$ & $<25.0$ & 0.5 & 1.0 & 690.0 \\
\hline $04 / 09$ & $<1.0$ & $<25.0$ & & & \\
\hline $04 / 16$ & $<1.0$ & $<25.0$ & & & \\
\hline $04 / 23$ & $<1.0$ & $<25.0$ & & & \\
\hline $04 / 30$ & $<1.0$ & $<25.0$ & 4.1 & 1.0 & 937.0 \\
\hline $05 / 08$ & $<1.0$ & $<25.0$ & & & \\
\hline $05 / 14$ & $<1.0$ & $<25.0$ & & & \\
\hline $05 / 21$ & $<1.0$ & $<25.0$ & & & \\
\hline $05 / 30$ & $<1.0$ & $<25.0$ & & & \\
\hline $06 / 04$ & $<1.0$ & $<25.0$ & 12.8 & 5.0 & 818.0 \\
\hline $06 / 11$ & $<1.0$ & $<25.0$ & & & \\
\hline $06 / 18$ & $<1.0$ & $<25.0$ & 0.3 & 1.9 & \\
\hline $06 / 26$ & $<1.0$ & $<25.0$ & & & \\
\hline $07 / 02$ & $<1.0$ & $<25.0$ & 2.1 & 4.0 & \\
\hline $07 / 09$ & $<1.0$ & $<25.0$ & & & 856.0 \\
\hline $07 / 16$ & $<1.0$ & $<25.0$ & & & \\
\hline $07 / 23$ & $<1.0$ & $<25.0$ & & & \\
\hline $07 / 30$ & $<1.0$ & $<25.0$ & & & \\
\hline $08 / 06$ & $<1.0$ & $<25.0$ & 9.0 & 9.0 & \\
\hline $08 / 13$ & $<1.0$ & $<25.0$ & & & 731.0 \\
\hline $08 / 20$ & $<1.0$ & $<25.0$ & & & \\
\hline $08 / 27$ & $<1.0$ & $<25.0$ & & & \\
\hline $09 / 04$ & $<1.0$ & $<25.0$ & 3.9 & 8.0 & 689.0 \\
\hline $09 / 10$ & $<1.0$ & $<25.0$ & & & \\
\hline $09 / 17$ & $<1.0$ & $<25.0$ & & & \\
\hline $09 / 24$ & $<1.0$ & $<25.0$ & & & \\
\hline $10 / 01$ & $<1.0$ & $<25.0$ & 2.3 & 1.0 & 691.0 \\
\hline $10 / 08$ & $<1.0$ & $<25.0$ & & & \\
\hline $10 / 15$ & $<1.0$ & $<25.0$ & & & \\
\hline $10 / 22$ & $<1.0$ & $<25.0$ & & & \\
\hline $10 / 29$ & $<1.0$ & $<25.0$ & & & \\
\hline $11 / 05$ & $<1.0$ & $<25.0$ & 4.3 & 16.0 & 237.0 \\
\hline $11 / 12$ & $<1.0$ & $<25.0$ & & & \\
\hline $11 / 19$ & $<1.0$ & $<25.0$ & & & \\
\hline $11 / 26$ & $<1.0$ & $<25.0$ & & & 500.0 \\
\hline $12 / 03$ & $<1.0$ & $<25.0$ & 0.6 & 10.0 & 682.0 \\
\hline $12 / 10$ & $<1.0$ & $<25.0$ & & & 553.0 \\
\hline $12 / 17$ & $<1.0$ & $<25.0$ & & & \\
\hline $12 / 26$ & $<1.0$ & $<25.0$ & & & \\
\hline $12 / 31$ & $<1.0$ & $<25.0$ & & & \\
\hline
\end{tabular}


Table 4.5 (continued)

\begin{tabular}{|c|c|c|c|c|c|}
\hline Date & $\begin{array}{c}\text { TCE } \\
(\mu g / L)\end{array}$ & $\begin{array}{c}{ }^{99} \mathrm{Tc} \\
(\mathrm{pCi} / \mathrm{L})\end{array}$ & $\begin{array}{c}\text { Gross alpha } \\
(p \mathrm{Ci} / \mathrm{L})\end{array}$ & $\begin{array}{l}\text { Gross beta } \\
(\mathrm{pCi} / \mathrm{L})\end{array}$ & $\begin{array}{l}\text { Radon } \\
\text { (pCi/L) }\end{array}$ \\
\hline \multicolumn{6}{|c|}{$\mathbf{R 4 0}$} \\
\hline $01 / 04$ & $<1.0$ & $<25.0$ & 1.3 & 2.0 & 316.0 \\
\hline $01 / 08$ & $<1.0$ & $<25.0$ & & & \\
\hline $01 / 15$ & $<1.0$ & $<25.0$ & & & \\
\hline $01 / 22$ & $<1.0$ & $<25.0$ & & & \\
\hline $01 / 31$ & $<1.0$ & $<25.0$ & & & \\
\hline $02 / 05$ & $<1.0$ & $<25.0$ & 3.1 & 9.0 & 358.0 \\
\hline $02 / 13$ & $<1.0$ & $<25.0$ & & & \\
\hline $02 / 20$ & $<1.0$ & $<25.0$ & & & \\
\hline $02 / 26$ & $<1.0$ & $<25.0$ & & & \\
\hline $03 / 05$ & $<1.0$ & $<25.0$ & 1.3 & 1.0 & 355.0 \\
\hline $03 / 14$ & $<1.0$ & $<25.0$ & 0.0 & 7.0 & \\
\hline $03 / 19$ & $<1.0$ & $<25.0$ & & & \\
\hline $03 / 26$ & $<1.0$ & $<25.0$ & & & \\
\hline $04 / 02$ & $<1.0$ & $<25.0$ & 0.7 & 1.0 & 325.0 \\
\hline $04 / 09$ & $<1.0$ & $<25.0$ & & & \\
\hline $04 / 16$ & $<1.0$ & $<25.0$ & & & \\
\hline $04 / 23$ & $<1.0$ & $<25.0$ & & & \\
\hline $04 / 30$ & $<1.0$ & $<25.0$ & 3.3 & 4.0 & 341.0 \\
\hline $05 / 08$ & $<1.0$ & $<25.0$ & & & \\
\hline $05 / 14$ & $<1.0$ & $<25.0$ & & & \\
\hline $05 / 21$ & $<1.0$ & $<25.0$ & & & \\
\hline $05 / 30$ & $<1.0$ & $<25.0$ & & & \\
\hline $06 / 06$ & $<1.0$ & $<25.0$ & 2.0 & 3.0 & 453.0 \\
\hline $06 / 11$ & $<1.0$ & $<25.0$ & & & 453.0 \\
\hline $06 / 18$ & $<1.0$ & $<25.0$ & 2.9 & 3.0 & \\
\hline $06 / 26$ & $<1.0$ & $<25.0$ & & & \\
\hline $07 / 02$ & $<1.0$ & $<25.0$ & 0.3 & 7.0 & \\
\hline $07 / 09$ & $<1.0$ & $<25.0$ & & & 378.0 \\
\hline $07 / 16$ & $<1.0$ & $<25.0$ & & & \\
\hline $07 / 23$ & $<1.0$ & $<25.0$ & & & \\
\hline $07 / 30$ & $<1.0$ & $<25.0$ & & & \\
\hline $08 / 06$ & $<1.0$ & $<25.0$ & 5.6 & 8.0 & \\
\hline $08 / 13$ & $<1.0$ & $<25.0$ & & & 369.0 \\
\hline $08 / 20$ & $<1.0$ & $<25.0$ & & & \\
\hline $08 / 27$ & $<1.0$ & $<25.0$ & & & \\
\hline $09 / 04$ & $<1.0$ & $<25.0$ & 3.8 & 4.0 & 375.0 \\
\hline $09 / 10$ & $<1.0$ & $<25.0$ & & & \\
\hline $09 / 18$ & $<1.0$ & $<25.0$ & 2.3 & 10.0 & \\
\hline $09 / 24$ & $<1.0$ & $<25.0$ & & & \\
\hline $10 / 01$ & $<1.0$ & $<25.0$ & 0.9 & 1.0 & 353.0 \\
\hline $10 / 08$ & $<1.0$ & $<25.0$ & & & \\
\hline $10 / 15$ & $<1.0$ & $<25.0$ & & & \\
\hline $10 / 22$ & $<1.0$ & $<25.0$ & & & \\
\hline $10 / 29$ & $<1.0$ & $<25.0$ & & & \\
\hline $11 / 05$ & $<1.0$ & $<25.0$ & 1.5 & 3.0 & 176.0 \\
\hline $11 / 28$ & $<1.0$ & $<25.0$ & 0.2 & 19.0 & \\
\hline $12 / 03$ & $<1.0$ & $<25.0$ & 0.9 & 8.0 & 776.0 \\
\hline $12 / 10$ & $<1.0$ & $<25.0$ & & & 327.0 \\
\hline $12 / 17$ & $<1.0$ & $<25.0$ & & & \\
\hline $12 / 26$ & $<1.0$ & $<25.0$ & & & \\
\hline $12 / 31$ & $<1.0$ & $<25.0$ & & & \\
\hline
\end{tabular}


Table 4.5 (continued)

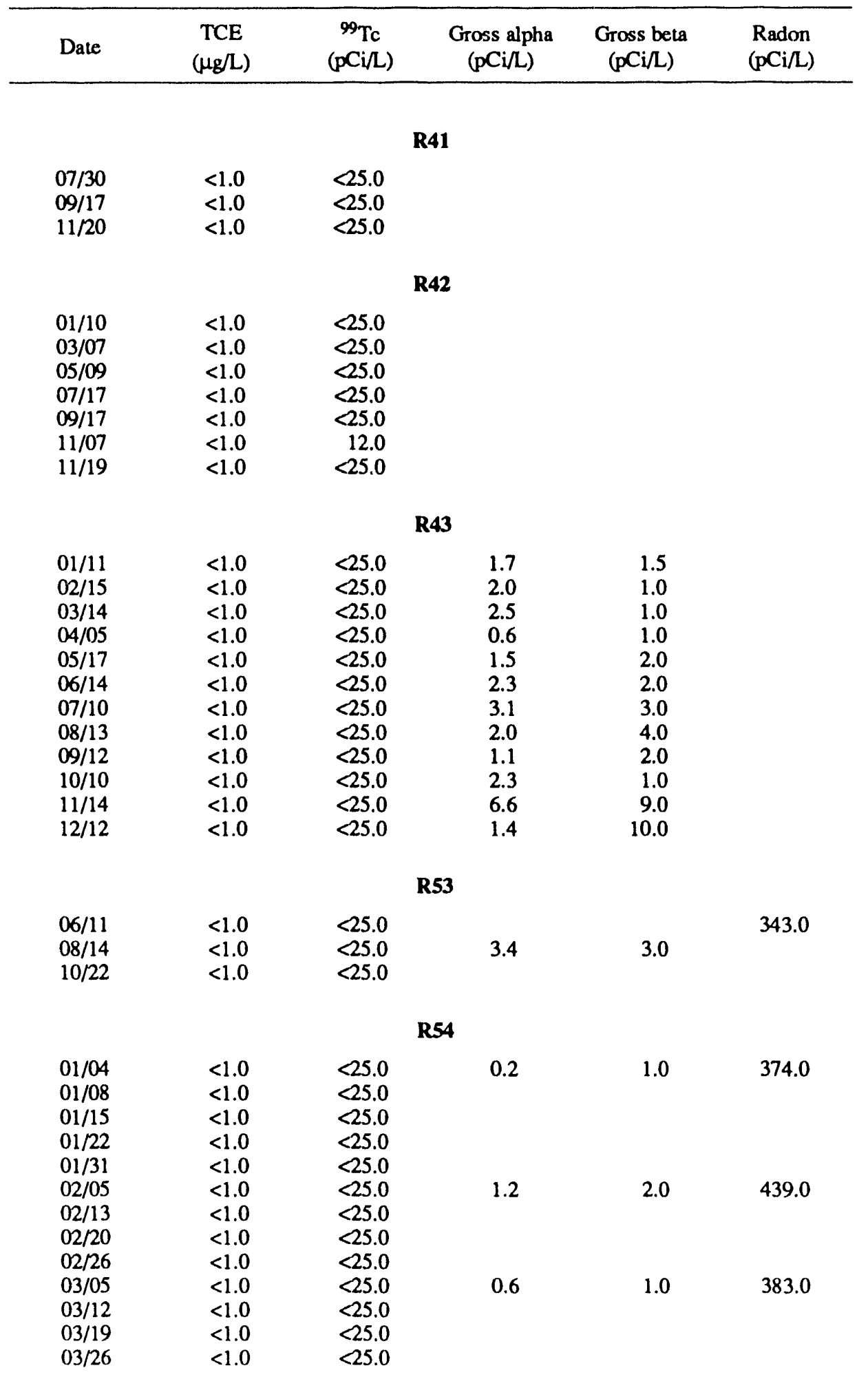


Table 4.5 (continued)

\begin{tabular}{|c|c|c|c|c|c|}
\hline Date & $\begin{array}{c}\text { TCE } \\
(\mu \mathrm{g} / \mathrm{L})\end{array}$ & $\begin{array}{c}{ }^{99} \mathrm{Tc} \\
(\mathrm{pCi} / \mathrm{L})\end{array}$ & $\begin{array}{c}\text { Gross alpha } \\
(\mathrm{pCi} / \mathrm{L})\end{array}$ & $\begin{array}{l}\text { Gross beta } \\
(\mathrm{pCi} / \mathrm{L})\end{array}$ & $\begin{array}{l}\text { Radon } \\
(\mathrm{pCi} / \mathrm{L})\end{array}$ \\
\hline \multicolumn{6}{|c|}{ R54 } \\
\hline $04 / 02$ & $<1.0$ & $<25.0$ & 0.2 & 1.0 & 391.0 \\
\hline $04 / 09$ & $<1.0$ & $<25.0$ & & & \\
\hline $04 / 16$ & $<1.0$ & $<25.0$ & & & \\
\hline $04 / 23$ & $<1.0$ & $<25.0$ & & & \\
\hline $04 / 30$ & $<1.0$ & $<25.0$ & 3.1 & 7.0 & 474.0 \\
\hline $05 / 08$ & $<1.0$ & $<25.0$ & & & \\
\hline $05 / 14$ & $<1.0$ & $<25.0$ & & & \\
\hline $05 / 21$ & $<1.0$ & $<25.0$ & & & \\
\hline $05 / 30$ & $<1.0$ & $<25.0$ & & & \\
\hline $06 / 04$ & $<1.0$ & $<25.0$ & 4.6 & 6.0 & 365.0 \\
\hline $06 / 11$ & $<1.0$ & $<25.0$ & & & \\
\hline $06 / 18$ & $<1.0$ & $<25.0$ & 0.4 & 0.0 & \\
\hline $06 / 26$ & $<1.0$ & $<25.0$ & & & \\
\hline $07 / 02$ & $<1.0$ & $<25.0$ & 2.4 & 9.0 & \\
\hline $07 / 09$ & $<1.0$ & $<25.0$ & & & 396.0 \\
\hline $07 / 16$ & $<1.0$ & $<25.0$ & & & \\
\hline $07 / 23$ & $<1.0$ & $<25.0$ & & & \\
\hline $07 / 30$ & $<1.0$ & $<25.0$ & & & \\
\hline 08/06 & $<1.0$ & $<25.0$ & 9.0 & 4.0 & \\
\hline $08 / 13$ & $<1.0$ & $<25.0$ & & & 452.0 \\
\hline $08 / 20$ & $<1.0$ & $<25.0$ & & & \\
\hline $08 / 27$ & $<1.0$ & $<25.0$ & & & \\
\hline $09 / 04$ & $<1.0$ & $<25.0$ & 1.7 & 4.0 & 423.0 \\
\hline $09 / 10$ & $<1.0$ & $<25.0$ & & & \\
\hline $09 / 17$ & $<1.0$ & $<25.0$ & & & \\
\hline $09 / 24$ & $<1.0$ & $<25.0$ & & & \\
\hline $10 / 01$ & $<1.0$ & $<25.0$ & 2.9 & 0.0 & 449.0 \\
\hline $10 / 08$ & $<1.0$ & $<25.0$ & & & \\
\hline $10 / 15$ & $<1.0$ & $<25.0$ & & & \\
\hline $10 / 22$ & $<1.0$ & $<25.0$ & & & \\
\hline $10 / 29$ & $<1.0$ & $<25.0$ & & & \\
\hline $11 / 05$ & $<1.0$ & $<25.0$ & 2.3 & 7.0 & 335.0 \\
\hline $11 / 12$ & $<1.0$ & $<25.0$ & & & \\
\hline $11 / 19$ & $<1.0$ & $<25.0$ & & & \\
\hline $11 / 26$ & $<1.0$ & $<25.0$ & & & 319.0 \\
\hline $12 / 03$ & $<1.0$ & $<25.0$ & 1.8 & 8.0 & 332.0 \\
\hline $12 / 10$ & $<1.0$ & $<25.0$ & & & 373.0 \\
\hline $12 / 17$ & $<1.0$ & $<25.0$ & & & \\
\hline $12 / 26$ & $<1.0$ & $<25.0$ & & & \\
\hline $12 / 31$ & $<1.0$ & $<25.0$ & & & \\
\hline \multicolumn{6}{|c|}{ R69 } \\
\hline $01 / 05$ & $<1.0$ & $<25.0$ & & & \\
\hline $03 / 07$ & $<1.0$ & $<25.0$ & & & \\
\hline $05 / 09$ & $<1.0$ & $<25.0$ & & & \\
\hline $07 / 02$ & $<1.0$ & $<25.0$ & & & \\
\hline $09 / 12$ & $<1.0$ & $<25.0$ & & & \\
\hline $11 / 06$ & $<1.0$ & $<25.0$ & & & \\
\hline
\end{tabular}


Table 4.5 (continued)

\begin{tabular}{cccccc}
\hline \multirow{2}{*}{ Date } & TCE & ${ }^{99} \mathrm{Tc}$ & Gross alpha & Gross beta & Radon \\
& $(\mu \mathrm{g} / \mathrm{L})$ & $(\mathrm{pCi} / \mathrm{L})$ & $(\mathrm{pCi} / \mathrm{L})$ & $(\mathrm{pCi} / \mathrm{L})$ & $(\mathrm{pCi} / \mathrm{L})$ \\
\hline
\end{tabular}

$\mathbf{R 7 2}$

$\begin{array}{lllll}01 / 11 & <1.0 & <5.0 & 0.5 & 2.0 \\ 02 / 15 & <1.0 & <25.0 & 2.5 & 4.0 \\ 03 / 14 & <1.0 & <25.0 & 1.2 & 1.0 \\ 04 / 05 & <1.0 & <25.0 & 1.0 & 1.0 \\ 05 / 17 & <1.0 & <25.0 & 0.6 & 8.0 \\ 06 / 14 & <1.0 & <25.0 & 4.1 & 6.0 \\ 07 / 11 & <1.0 & <25.0 & 3.2 & 1.0 \\ 08 / 13 & <1.0 & <25.0 & 2.5 & 6.0 \\ 09 / 17 & <1.0 & <25.0 & 2.3 & 3.0 \\ 10 / 10 & <1.0 & <25.0 & 1.0 & 0.0 \\ 11 / 14 & <1.0 & <25.0 & 3.2 & 14.0 \\ 12 / 13 & <1.0 & <25.0 & 0.6 & 3.0\end{array}$

R79

$\begin{array}{lll}02 / 22 & <1.0 & <25.0 \\ 04 / 24 & <1.0 & <25.0 \\ 06 / 27 & <1.0 & <25.0 \\ 08 / 28 & <1.0 & <25.0 \\ 10 / 29 & <1.0 & <25.0 \\ 12 / 28 & <1.0 & <25.0\end{array}$

R82

$\begin{array}{lllll}01 / 10 & <1.0 & <25.0 & 0.7 & 3.0 \\ 02 / 15 & <1.0 & <25.0 & 2.5 & 1.0 \\ 03 / 14 & <1.0 & <25.0 & 2.0 & 2.0 \\ 04 / 05 & <1.0 & <25.0 & 0.3 & 2.0 \\ 05 / 17 & <1.0 & <25.0 & 7.3 & 8.0 \\ 06 / 14 & <1.0 & <25.0 & 2.1 & 3.0 \\ 07 / 10 & <1.0 & <25.0 & 4.5 & 1.0 \\ 08 / 13 & <1.0 & <25.0 & 1.6 & 6.0 \\ 09 / 12 & <1.0 & <25.0 & 1.6 & 5.0 \\ 10 / 08 & <1.0 & <25.0 & 2.8 & 2.0 \\ 11 / 13 & <1.0 & <25.0 & 1.0 & 8.0 \\ 12 / 13 & <5.0 & <25.0 & 1.0 & 5.0\end{array}$

$\mathbf{R} 83$

$\begin{array}{lllll}01 / 10 & <1.0 & <25.0 & 1.1 & 5.0 \\ 02 / 15 & <1.0 & <25.0 & 0.2 & 1.0 \\ 03 / 14 & <1.0 & <25.0 & 0.0 & 1.0 \\ 04 / 05 & <1.0 & <25.0 & 0.7 & 5.0 \\ 05 / 23 & <1.0 & <25.0 & 2.4 & 5.0 \\ 06 / 14 & <1.0 & <25.0 & 0.1 & 0.0 \\ 07 / 10 & <1.0 & <25.0 & 3.1 & 0.0 \\ 08 / 13 & <1.0 & <25.0 & 0.9 & 7.0 \\ 09 / 12 & <1.0 & <25.0 & 0.2 & 5.0 \\ 10 / 08 & <1.0 & <25.0 & 2.0 & 2.0 \\ 11 / 14 & <1.0 & <25.0 & 3.6 & 14.0 \\ 12 / 13 & <1.0 & <25.0 & 2.3 & 7.0\end{array}$


Table 4.5 (continued)

\begin{tabular}{|c|c|c|c|c|c|}
\hline Date & $\begin{array}{c}\text { TCE } \\
(\mu g / L)\end{array}$ & $\begin{array}{c}{ }^{99} \mathrm{Tc} \\
(\mathrm{pCi} / \mathrm{L})\end{array}$ & $\begin{array}{c}\text { Gross alpha } \\
(p \mathrm{Ci} / \mathrm{L})\end{array}$ & $\begin{array}{c}\text { Gross beta } \\
(\mathrm{pCi} / \mathrm{L})\end{array}$ & $\begin{array}{l}\text { Radon } \\
(\mathrm{pCi} / \mathrm{L})\end{array}$ \\
\hline \multicolumn{6}{|c|}{ R84 } \\
\hline $01 / 10$ & $<1.0$ & $<25.0$ & 0.6 & 3.0 & \\
\hline $02 / 15$ & $<1.0$ & $<25.0$ & 0.8 & 2.0 & \\
\hline $03 / 14$ & $<1.0$ & $<25.0$ & 2.0 & 1.0 & \\
\hline $04 / 05$ & $<1.0$ & $<25.0$ & 5.2 & 2.0 & \\
\hline $05 / 17$ & $<1.0$ & $<25.0$ & 1.1 & 3.0 & \\
\hline $06 / 14$ & $<1.0$ & $<25.0$ & 1.1 & 0.0 & \\
\hline $07 / 10$ & $<1.0$ & $<25.0$ & 3.8 & 3.0 & \\
\hline $08 / 13$ & $<1.0$ & $<25.0$ & 6.0 & 1.0 & \\
\hline $09 / 12$ & $<1.0$ & $<25.0$ & 0.8 & 7.0 & \\
\hline $10 / 08$ & $<1.0$ & $<25.0$ & 5.1 & 1.0 & \\
\hline $11 / 13$ & $<1.0$ & $<25.0$ & 7.5 & 6.0 & \\
\hline $12 / 13$ & $<1.0$ & $<25.0$ & 6.1 & 8.0 & \\
\hline \multicolumn{6}{|c|}{$\mathbf{R 8 8}$} \\
\hline $02 / 22$ & $<1.0$ & $<25.0$ & & & \\
\hline $04 / 24$ & $<1.0$ & $<25.0$ & & & \\
\hline $06 / 21$ & $<1.0$ & $<25.0$ & & & \\
\hline $10 / 24$ & $<1.0$ & $<25.0$ & & & \\
\hline $12 / 28$ & $<1.0$ & $<25.0$ & & & \\
\hline \multicolumn{6}{|c|}{ R89 } \\
\hline $06 / 27$ & $<1.0$ & $<25.0$ & & & \\
\hline $08 / 28$ & $<1.0$ & $<25.0$ & & & \\
\hline $10 / 29$ & $<1.0$ & $<25.0$ & & & \\
\hline \multicolumn{6}{|c|}{ R112 } \\
\hline $02 / 22$ & $<1.0$ & $<25.0$ & & & \\
\hline $04 / 24$ & $<1.0$ & $<25.0$ & & & \\
\hline $06 / 27$ & $<1.0$ & $<25.0$ & & & \\
\hline $08 / 28$ & $<1.0$ & $<25.0$ & & & \\
\hline $10 / 24$ & $<1.0$ & $<25.0$ & & & \\
\hline $12 / 28$ & $<1.0$ & $<25.0$ & & & \\
\hline \multicolumn{6}{|c|}{ R113 } \\
\hline $01 / 24$ & 14.0 & 58.0 & 0.9 & 21.0 & \\
\hline $02 / 07$ & 340.0 & 222.0 & 8.0 & 176.0 & \\
\hline $03 / 09$ & 520.0 & 402.0 & 11.5 & 230.0 & \\
\hline $04 / 20$ & 720.0 & 319.0 & 0.2 & 245.0 & \\
\hline $05 / 18$ & 520.0 & 266.0 & 1.6 & 177.0 & \\
\hline $06 / 18$ & 850.0 & 440.0 & 0.3 & 542.0 & \\
\hline $07 / 24$ & 860.0 & 376.0 & 2.0 & 296.0 & \\
\hline $09 / 25$ & 1400.0 & 655.0 & 9.2 & 546.0 & \\
\hline $10 / 30$ & 1600.0 & 286.0 & 7.4 & 116.0 & \\
\hline $11 / 16$ & 1000.0 & 404.0 & 0.4 & 225.0 & \\
\hline $12 / 12$ & 1000.0 & 486.0 & 2.3 & 226.0 & \\
\hline
\end{tabular}


Table 4.5 (continued)

\begin{tabular}{|c|c|c|c|c|c|}
\hline Date & $\begin{array}{c}\text { TCE } \\
(\mu g / L)\end{array}$ & $\begin{array}{c}{ }^{99} \mathrm{Tc} \\
(\mathrm{pCi} / \mathrm{L})\end{array}$ & $\begin{array}{l}\text { Gross alpha } \\
(\mathrm{pCi} / \mathrm{L})\end{array}$ & $\begin{array}{c}\text { Gross beta } \\
(\mathrm{pCi} / \mathrm{L})\end{array}$ & $\begin{array}{l}\text { Radon } \\
(\mathrm{pCi} / \mathrm{L})\end{array}$ \\
\hline \multicolumn{6}{|c|}{ R157 } \\
\hline $12 / 26$ & 2200.0 & 1691.0 & 2.3 & 1638.0 & \\
\hline \multicolumn{6}{|c|}{ R219 } \\
\hline $11 / 05$ & $<1.0$ & $<25.0$ & 9.5 & 27.0 & 212.0 \\
\hline \multicolumn{6}{|c|}{$\mathbf{R 2 9 3}$} \\
\hline $\begin{array}{l}03 / 02 \\
05 / 08 \\
07 / 17 \\
09 / 06 \\
11 / 19\end{array}$ & $\begin{array}{l}<1.0 \\
<1.0 \\
<1.0 \\
<1.0 \\
<1.0\end{array}$ & $\begin{array}{l}<5.0 \\
<25.0 \\
<25.0 \\
<25.0 \\
<25.0\end{array}$ & & & \\
\hline \multicolumn{6}{|c|}{ W20 } \\
\hline $\begin{array}{l}01 / 17 \\
02 / 02 \\
03,09 \\
04 / 07 \\
05 / 15 \\
06 / 13 \\
07 / 06\end{array}$ & $\begin{array}{r}69.0 \\
112.0 \\
<1.0 \\
89.0 \\
110.0 \\
210.0\end{array}$ & $\begin{array}{r}40.0 \\
30.0 \\
86.0 \\
<25.0 \\
79.0 \\
94.0 \\
124.0\end{array}$ & $\begin{array}{l}1.5 \\
2.3 \\
3.8 \\
1.8 \\
3.8 \\
8.6 \\
5.8\end{array}$ & $\begin{array}{r}20.0 \\
2.0 \\
48.0 \\
5.0 \\
44.0 \\
55.0 \\
65.0\end{array}$ & \\
\hline \multicolumn{6}{|c|}{ W41 } \\
\hline $01 / 17$ & $<1.0$ & $<25.0$ & 0.8 & 6.0 & \\
\hline $02 / 06$ & $<1.0$ & $<25.0$ & 3.4 & 7.0 & \\
\hline $03 / 02$ & $<1.0$ & $<25.0$ & 0.6 & 1.0 & 104.0 \\
\hline $03 / 14$ & & & 1.1 & 1.0 & \\
\hline $04 / 18$ & $<1.0$ & $<25.0$ & 1.7 & 6.0 & \\
\hline $05 / 18$ & $<1.0$ & $<25.0$ & 1.2 & 5.0 & \\
\hline $06 / 06$ & 4.0 & $<25.0$ & 1.2 & 2.0 & \\
\hline $07 / 25$ & $<1.0$ & $<25.0$ & 6.8 & 0.0 & 41.0 \\
\hline $08 / 15$ & 2.0 & $<25.0$ & 1.1 & 2.0 & \\
\hline $09 / 18$ & 4.0 & $<25.0$ & 0.7 & 3.0 & \\
\hline $10 / 22$ & $<1.0$ & $<25.0$ & 0.8 & 4.0 & \\
\hline $11 / 28$ & 3.0 & $<25.0$ & 0.8 & 1.0 & \\
\hline $12 / 18$ & $<1.0$ & $<25.0$ & 4.3 & 12.0 & \\
\hline
\end{tabular}


Table 4.6. Quarterly results of effluent monitoring at solid waste management units-fleld measurements and physical parameters

\begin{tabular}{|c|c|c|c|c|c|c|}
\hline Date & $\underset{\text { (units) }}{\mathrm{pH}}$ & $\begin{array}{l}\text { Conductivity } \\
(\mu \mathrm{mho} / \mathrm{cm})\end{array}$ & $\begin{array}{l}\text { Temp. } \\
\left({ }^{\circ} \mathrm{F}\right)\end{array}$ & $\begin{array}{l}\text { Turbidity } \\
\text { (NTU) }\end{array}$ & $\begin{array}{l}\text { Color } \\
\text { (units) }\end{array}$ & $\begin{array}{c}\text { Depth } \\
(\mathrm{ft})\end{array}$ \\
\hline \multicolumn{7}{|c|}{ W16 } \\
\hline $01 / 10$ & $\begin{array}{l}6.60 \\
6.60 \\
6.60 \\
6.70\end{array}$ & $\begin{array}{l}498.00 \\
494.00 \\
497.00 \\
496.00\end{array}$ & 60.00 & 10.00 & 5.00 & \\
\hline $05 / 22$ & $\begin{array}{l}7.20 \\
7.30 \\
7.30 \\
6.9\end{array}$ & $\begin{array}{l}502.00 \\
501.00 \\
504.00 \\
501.00\end{array}$ & 62.00 & 6.00 & 7.00 & \\
\hline $\begin{array}{l}08 / 09 \\
11 / 14\end{array}$ & $\begin{array}{l}6.10 \\
6.30 \\
6.40 \\
6.40 \\
6.50\end{array}$ & $\begin{array}{l}499.00 \\
496.00 \\
486.00 \\
493.00 \\
492.00\end{array}$ & $\begin{array}{l}72.00 \\
63.00\end{array}$ & $\begin{array}{l}5.00 \\
5.00\end{array}$ & $\begin{array}{l}8.00 \\
3.00\end{array}$ & $\begin{array}{l}18.44 \\
20.45\end{array}$ \\
\hline \multicolumn{7}{|c|}{ W17 } \\
\hline $\begin{array}{l}01 / 04 \\
05 / 22 \\
08 / 29 \\
11 / 29 \\
12 / 14\end{array}$ & $\begin{array}{l}6.50 \\
7.30\end{array}$ & 1370.00 & $\begin{array}{l}58.00 \\
59.00\end{array}$ & 10.00 & $\begin{array}{l}7.00 \\
\\
7.00 \\
7.00 \\
3.00\end{array}$ & $\begin{array}{l}44.99 \\
47.58 \\
51.22 \\
51.46\end{array}$ \\
\hline \multicolumn{7}{|c|}{ W18 } \\
\hline $01 / 09$ & $\begin{array}{l}7.00 \\
7.00 \\
7.00 \\
7.10\end{array}$ & $\begin{array}{l}1430.00 \\
1430.00 \\
1440.00 \\
1430.00\end{array}$ & 61.00 & 80.00 & 10.00 & 34.99 \\
\hline $05 / 16$ & $\begin{array}{l}7.40 \\
7.40 \\
7.40 \\
7.40\end{array}$ & $\begin{array}{l}1390.00 \\
1400.00 \\
1410.00 \\
1410.00\end{array}$ & 61.00 & 7000 & 8.00 & 32.51 \\
\hline $88 / 21$ & $\begin{array}{l}6.90 \\
6.90 \\
6.90 \\
6.90\end{array}$ & $\begin{array}{l}1390.00 \\
1390.00 \\
1400.00 \\
1390.00\end{array}$ & 61.00 & 70.00 & 12.00 & 33.60 \\
\hline $11 / 14$ & $\begin{array}{l}6.80 \\
6.80 \\
6.80 \\
6.80\end{array}$ & $\begin{array}{l}1390.00 \\
1350.00 \\
1410.00 \\
1390.00\end{array}$ & 61.00 & 60.00 & 9.00 & 34.34 \\
\hline \multicolumn{7}{|c|}{ W19 } \\
\hline $\begin{array}{l}01 / 11 \\
08 / 23\end{array}$ & 6.30 & 235.00 & 53.00 & & & $\begin{array}{l}4099 \\
36.64\end{array}$ \\
\hline $10 / 04$ & $\begin{array}{l}6.60 \\
6.50 \\
6.40 \\
6.10\end{array}$ & $\begin{array}{l}218.00 \\
219.00 \\
218.00 \\
218.00\end{array}$ & 74.00 & 16.00 & 8.00 & 35.30 \\
\hline
\end{tabular}


Table 4.6 (continued)

\begin{tabular}{|c|c|c|c|c|c|c|}
\hline Date & $\underset{\text { (units) }}{\mathrm{pH}}$ & $\begin{array}{l}\text { Conductivity } \\
\text { ( } \mu \mathrm{mho} / \mathrm{cm})\end{array}$ & $\begin{array}{l}\text { Temp. } \\
\left({ }^{\circ} \mathrm{F}\right)\end{array}$ & $\begin{array}{l}\text { Turbidity } \\
\text { (NTU) }\end{array}$ & $\begin{array}{l}\text { Color } \\
\text { (units) }\end{array}$ & $\begin{array}{c}\text { Depth } \\
(\mathrm{ft})\end{array}$ \\
\hline \multicolumn{7}{|c|}{ W20 } \\
\hline $01 / 18$ & $\begin{array}{l}6.30 \\
5.30 \\
6.30 \\
6.30\end{array}$ & $\begin{array}{l}325.00 \\
327.00 \\
326.00 \\
327.00\end{array}$ & 57.00 & 76.00 & 4.00 & \\
\hline $04 / 19$ & $\begin{array}{l}6.20 \\
6.20 \\
6.20 \\
6.20\end{array}$ & $\begin{array}{l}320.00 \\
314.00 \\
319.00 \\
319.00\end{array}$ & 58.00 & 40.00 & 4.00 & \\
\hline $11 / 01$ & $\begin{array}{l}6.50 \\
6.50 \\
6.50 \\
6.50\end{array}$ & $\begin{array}{l}321.00 \\
324.00 \\
323.00 \\
323.00\end{array}$ & 58.00 & 50.00 & 4.00 & \\
\hline \multicolumn{7}{|c|}{ W21 } \\
\hline $01 / 24$ & $\begin{array}{l}7.50 \\
7.50 \\
7.50 \\
7.50\end{array}$ & $\begin{array}{l}1500.00 \\
1510.00 \\
1520.00 \\
1520.00\end{array}$ & 60.00 & 7.00 & 8.00 & 47.50 \\
\hline $06 / 14$ & $\begin{array}{l}6.50 \\
6.50 \\
6.50 \\
6.50\end{array}$ & $\begin{array}{l}1480.00 \\
1480.00 \\
1490.00 \\
1500.00\end{array}$ & 69.00 & 2.00 & 7.00 & 41.62 \\
\hline $68 / 30$ & $\begin{array}{l}6.50 \\
6.50 \\
6.50 \\
6.50\end{array}$ & $\begin{array}{l}1560.00 \\
1560.00 \\
1560.00 \\
1560.00\end{array}$ & 66.00 & 0.55 & 7.00 & 43.10 \\
\hline $10 / 23$ & $\begin{array}{l}6.60 \\
6.60 \\
6.60 \\
6.60\end{array}$ & $\begin{array}{l}1560.00 \\
1560.00 \\
1560.00 \\
1560.00\end{array}$ & 61.00 & 2.00 & 23.00 & 45.23 \\
\hline \multicolumn{7}{|c|}{ W22 } \\
\hline $01 / 23$ & $\begin{array}{l}6.60 \\
6.60 \\
6.70 \\
6.70\end{array}$ & $\begin{array}{l}302.00 \\
304.00 \\
305.00 \\
301.00\end{array}$ & 57.00 & 200.00 & 13.00 & 45.74 \\
\hline $06 / 21$ & $\begin{array}{l}6.10 \\
6.10 \\
6.19 \\
6.10\end{array}$ & $\begin{array}{l}321.00 \\
323.00 \\
323.00 \\
324.00\end{array}$ & 67.00 & 4.00 & 17.00 & 39.25 \\
\hline $08 / 21$ & $\begin{array}{l}6.20 \\
6.20 \\
6.20 \\
6.20\end{array}$ & $\begin{array}{l}332.00 \\
333.00 \\
332.00 \\
332.00\end{array}$ & 68.00 & 1.50 & 27.00 & 40.82 \\
\hline $10 / 31$ & $\begin{array}{l}6.10 \\
6.10 \\
6.10 \\
6.10\end{array}$ & $\begin{array}{l}329.00 \\
334.00 \\
332.00 \\
334.00\end{array}$ & 64.00 & 5.00 & 7.00 & 43.5 \\
\hline & & & W23 & & & \\
\hline$x / 04$ & & & & & & 16.73 \\
\hline
\end{tabular}


Table 4.6 (continued)

\begin{tabular}{|c|c|c|c|c|c|c|}
\hline Date & $\underset{\text { (units) }}{\mathrm{pH}}$ & $\begin{array}{l}\text { Conductivity } \\
(\mu \mathrm{mho} / \mathrm{cm})\end{array}$ & $\begin{array}{l}\text { Temp. } \\
\left({ }^{\circ} \mathrm{F}\right)\end{array}$ & $\begin{array}{l}\text { Turbidity } \\
\text { (NTU) }\end{array}$ & $\begin{array}{l}\text { Color } \\
\text { (units) }\end{array}$ & $\begin{array}{c}\text { Depth } \\
(\mathrm{ft})\end{array}$ \\
\hline \multicolumn{7}{|c|}{ W24 } \\
\hline $09 / 05$ & & & & & & 11.45 \\
\hline \multicolumn{7}{|c|}{ W26 } \\
\hline $09 / 04$ & & & & & & 32.27 \\
\hline \multicolumn{7}{|c|}{ W27 } \\
\hline $09 / 05$ & 6.20 & 438.00 & 73.00 & 60.00 & 10.00 & 18.00 \\
\hline \multicolumn{7}{|c|}{ W38 } \\
\hline $04 / 11$ & $\begin{array}{l}6.30 \\
6.30 \\
6.30 \\
6.30\end{array}$ & $\begin{array}{l}439.00 \\
444.00 \\
443.00 \\
443.00\end{array}$ & 59.00 & 3.00 & 12.00 & 57.34 \\
\hline $08 / 0$ & $\begin{array}{l}6.60 \\
6.60 \\
6.60 \\
6.60\end{array}$ & $\begin{array}{l}446.00 \\
440.00 \\
441.00 \\
445.00\end{array}$ & 59.00 & 0.20 & 4.00 & 55.47 \\
\hline $11 / 08$ & $\begin{array}{l}6.30 \\
6.30 \\
6.30 \\
6.30\end{array}$ & $\begin{array}{l}439.00 \\
439.00 \\
439.00 \\
438.00\end{array}$ & 58.00 & 1.50 & 4.00 & 59.00 \\
\hline \multicolumn{7}{|c|}{ W39 } \\
\hline $01 / 11$ & $\begin{array}{l}6.50 \\
6.50 \\
6.50 \\
6.50\end{array}$ & $\begin{array}{l}762.00 \\
763.00 \\
764.00 \\
764.00\end{array}$ & 59.00 & 12.00 & 2.00 & 57.65 \\
\hline $04 / 11$ & $\begin{array}{l}6.50 \\
6.50 \\
6.50 \\
6.50\end{array}$ & $\begin{array}{l}716.00 \\
719.00 \\
716.00 \\
713.00\end{array}$ & 59.00 & 7.00 & 3.00 & 54.39 \\
\hline $08 / 01$ & $\begin{array}{l}6.40 \\
6.40 \\
6.41 \\
6.40\end{array}$ & $\begin{array}{l}715.00 \\
719.00 \\
720.00 \\
719.00\end{array}$ & 60.00 & 5.00 & 3.00 & 52.55 \\
\hline $11 / 08$ & $\begin{array}{l}6.20 \\
6.20 \\
6.20 \\
6.20\end{array}$ & $\begin{array}{l}745.00 \\
749.00 \\
749.00 \\
750.00\end{array}$ & 58.00 & 8.00 & 6.00 & 56.20 \\
\hline \multicolumn{7}{|c|}{ W40 } \\
\hline $01 / 11$ & $\begin{array}{l}6.20 \\
6.20 \\
6.20 \\
6.20\end{array}$ & $\begin{array}{l}345.00 \\
345.00 \\
344.00 \\
344.00\end{array}$ & 59.00 & 2.00 & 6.00 & 57.98 \\
\hline $04 / 2.3$ & $\begin{array}{l}6.30 \\
6.30 \\
6.30 \\
6.30\end{array}$ & $\begin{array}{l}343.00 \\
343.00 \\
344.00 \\
343.00\end{array}$ & 60.00 & 2.00 & 7.00 & 54.00 \\
\hline
\end{tabular}


Table 4.6 (continued)

\begin{tabular}{|c|c|c|c|c|c|c|}
\hline Date & $\underset{\text { (units) }}{\mathrm{pH}}$ & $\begin{array}{l}\text { Conductivity } \\
(\mu \mathrm{mho} / \mathrm{cm})\end{array}$ & $\begin{array}{l}\text { Temp. } \\
\left({ }^{\circ} \mathrm{F}\right)\end{array}$ & $\begin{array}{l}\text { Turbidity } \\
\text { (NTU) }\end{array}$ & $\begin{array}{l}\text { Color } \\
\text { (units) }\end{array}$ & $\begin{array}{l}\text { Depth } \\
\text { (ft) }\end{array}$ \\
\hline \multicolumn{7}{|c|}{ W40 } \\
\hline $08 / 02$ & $\begin{array}{l}6.10 \\
6.10 \\
6.10 \\
6.10\end{array}$ & $\begin{array}{l}340.00 \\
344.00 \\
345.00 \\
344.00\end{array}$ & 59.00 & 1.50 & 3.00 & 53.00 \\
\hline $11 / 07$ & $\begin{array}{l}6.30 \\
6.30 \\
6.30 \\
6.30\end{array}$ & $\begin{array}{l}353.00 \\
352.00 \\
352.00 \\
351.00\end{array}$ & 59.00 & 1.50 & 3.00 & 56.62 \\
\hline \multicolumn{7}{|c|}{ W41 } \\
\hline $04 / 19$ & $\begin{array}{l}6.20 \\
6.20 \\
6.20 \\
6.20\end{array}$ & $\begin{array}{l}358.00 \\
361.00 \\
360.00 \\
361.00\end{array}$ & 59.00 & 16.00 & 7.00 & 51.25 \\
\hline $08 / 02$ & $\begin{array}{l}6.00 \\
6.00 \\
6.00 \\
6.00\end{array}$ & $\begin{array}{l}352.00 \\
360.00 \\
360.00 \\
359.00\end{array}$ & 61.00 & 5.00 & 6.00 & 55.50 \\
\hline $10 / 31$ & $\begin{array}{l}6.10 \\
6.10 \\
6.10 \\
6.10\end{array}$ & $\begin{array}{l}359.00 \\
361.00 \\
359.00 \\
358.00\end{array}$ & 59.00 & 7.00 & 5.00 & 53.15 \\
\hline \multicolumn{7}{|c|}{ W42 } \\
\hline $02 / 27$ & $\begin{array}{l}6.30 \\
6.30 \\
6.30 \\
6.30\end{array}$ & $\begin{array}{l}677.00 \\
682.00 \\
682.00 \\
683.00\end{array}$ & 60.00 & 50.00 & 5.00 & 38.00 \\
\hline $04 / 24$ & $\begin{array}{l}6.50 \\
6.50 \\
6.50 \\
6.50\end{array}$ & $\begin{array}{l}696.00 \\
698.00 \\
700.00 \\
700.00\end{array}$ & 60.00 & 6.00 & 7.00 & 35.00 \\
\hline $08 / 08$ & $\begin{array}{l}6.50 \\
6.50 \\
6.50 \\
6.50\end{array}$ & $\begin{array}{l}689.00 \\
690.00 \\
691.00 \\
692.00\end{array}$ & 60.00 & 6.00 & 8.00 & 34.35 \\
\hline $11 / 07$ & $\begin{array}{l}6.10 \\
6.10 \\
6.10\end{array}$ & $\begin{array}{l}688.00 \\
689.00 \\
687.00\end{array}$ & & 15.00 & & \\
\hline \multicolumn{7}{|c|}{ W43 } \\
\hline $02 / 28$ & $\begin{array}{l}6.40 \\
6.40 \\
6.40 \\
6.40\end{array}$ & $\begin{array}{l}311.00 \\
313.00 \\
313.00 \\
314.00\end{array}$ & 58.00 & 12.00 & 7.00 & 48.74 \\
\hline
\end{tabular}


Table 4.6 (continued)

\begin{tabular}{|c|c|c|c|c|c|c|}
\hline Date & $\underset{\text { (units) }}{\mathrm{pH}}$ & $\begin{array}{l}\text { Conductivity } \\
(\mu \mathrm{mho} / \mathrm{cm})\end{array}$ & $\begin{array}{l}\text { Temp. } \\
\left({ }^{\circ} \mathrm{F}\right)\end{array}$ & $\begin{array}{l}\text { Turbidity } \\
\text { (NTU) }\end{array}$ & $\begin{array}{l}\text { Color } \\
\text { (units) }\end{array}$ & $\begin{array}{l}\text { Depth } \\
\text { (ft) }\end{array}$ \\
\hline \multicolumn{7}{|c|}{ W43 } \\
\hline $03 / 07$ & $\begin{array}{l}6.20 \\
6.20 \\
6.20 \\
6.20\end{array}$ & $\begin{array}{l}316.00 \\
316.00 \\
315.00 \\
316.00\end{array}$ & 58.00 & 15.00 & 4.00 & 46.62 \\
\hline $08 / 08$ & $\begin{array}{l}6.20 \\
6.20 \\
6.20 \\
6.20\end{array}$ & $\begin{array}{l}313.00 \\
316.00 \\
316.00 \\
316.00\end{array}$ & 58.00 & 2.50 & 8.00 & 45.00 \\
\hline $12 / 11$ & $\begin{array}{l}6.40 \\
6.40 \\
6.40 \\
6.40\end{array}$ & $\begin{array}{l}311.00 \\
313.00 \\
313.00 \\
313.00\end{array}$ & 58.00 & 1.50 & 2.00 & 48.77 \\
\hline \multicolumn{7}{|c|}{ W44 } \\
\hline $01 / 09$ & $\begin{array}{l}6.20 \\
6.20 \\
6.20 \\
6.20\end{array}$ & $\begin{array}{l}370.00 \\
372.00 \\
371.00 \\
372.00\end{array}$ & 59.00 & 2.00 & 5.00 & 78.93 \\
\hline $04 / 24$ & $\begin{array}{l}6.40 \\
6.40 \\
6.40 \\
6.40\end{array}$ & $\begin{array}{l}352.00 \\
353.00 \\
353.00 \\
354.00\end{array}$ & 59.00 & 2.00 & 5.00 & 75.16 \\
\hline $08 / 07$ & $\begin{array}{l}6.40 \\
6.40 \\
6.40 \\
6.40\end{array}$ & $\begin{array}{l}363.00 \\
365.00 \\
365.00 \\
366.00\end{array}$ & 59.00 & 1.50 & 7.00 & 74.27 \\
\hline $12 / 11$ & $\begin{array}{l}6.10 \\
6.10 \\
6.10 \\
6.10\end{array}$ & $\begin{array}{l}378.00 \\
378.00 \\
379.00 \\
381.00\end{array}$ & 59.00 & 0.98 & 3.00 & 78.17 \\
\hline & & & W46 & & & \\
\hline $03 / 06$ & $\begin{array}{l}6.30 \\
6.30 \\
6.30 \\
6.30\end{array}$ & $\begin{array}{l}218.00 \\
220.00 \\
220.00 \\
217.00\end{array}$ & 61.00 & 20.00 & 33.00 & 51.50 \\
\hline $05 / 16$ & $\begin{array}{l}6.80 \\
6.80 \\
6.80 \\
6.80\end{array}$ & $\begin{array}{l}213.00 \\
215.00 \\
216.00 \\
216.00\end{array}$ & 61.00 & 21.00 & 7.00 & 47.47 \\
\hline $08 / 16$ & $\begin{array}{l}6.20 \\
6.20 \\
6.20 \\
6.20\end{array}$ & $\begin{array}{l}230.00 \\
231.00 \\
231.00 \\
230.00\end{array}$ & 60.00 & 7.00 & 7.00 & 47.16 \\
\hline $10 / 17$ & $\begin{array}{l}6.40 \\
6.40 \\
6.40 \\
6.40\end{array}$ & $\begin{array}{l}241.00 \\
240.00 \\
241.00 \\
241.00\end{array}$ & 60.00 & 5.00 & 19.00 & 48.90 \\
\hline
\end{tabular}


Table 4.6 (continued)

\begin{tabular}{|c|c|c|c|c|c|c|}
\hline Date & $\begin{array}{c}\mathrm{pH} \\
\text { (units) }\end{array}$ & $\begin{array}{l}\text { Conductivity } \\
(\mu \mathrm{mho} / \mathrm{cm})\end{array}$ & $\begin{array}{l}\text { Temp. } \\
\left({ }^{\circ} \mathrm{F}\right)\end{array}$ & $\begin{array}{l}\text { Turbidity } \\
\text { (NTU) }\end{array}$ & $\begin{array}{l}\text { Color } \\
\text { (units) }\end{array}$ & $\begin{array}{c}\text { Depth } \\
\text { (ft) }\end{array}$ \\
\hline \multicolumn{7}{|c|}{ W47 } \\
\hline $\begin{array}{l}03 / 22 \\
10 / 25\end{array}$ & 8.90 & & 59.00 & 2500.00 & & $\begin{array}{l}19.31 \\
26.54\end{array}$ \\
\hline \multicolumn{7}{|c|}{ W48 } \\
\hline $05 / 16$ & $\begin{array}{l}6.90 \\
6.90 \\
6.90 \\
6.90\end{array}$ & $\begin{array}{l}195.00 \\
199.00 \\
199.00 \\
198.00\end{array}$ & 60.00 & 14.00 & 7.00 & 48.49 \\
\hline \multicolumn{7}{|c|}{ W54 } \\
\hline $05 / 31$ & $\begin{array}{l}6.40 \\
6.40 \\
6.40 \\
6.40 \\
6.70\end{array}$ & $\begin{array}{l}263.00 \\
262.00 \\
265.00 \\
246.00 \\
273.00\end{array}$ & 62.00 & 170.00 & 12.00 & 44.44 \\
\hline $\begin{array}{l}08 / 16 \\
08 / 17\end{array}$ & $\begin{array}{l}6.70 \\
6.70 \\
6.70 \\
6.60\end{array}$ & $\begin{array}{l}273.00 \\
268.00 \\
272.00 \\
260.00\end{array}$ & 71.00 & 31.00 & 11.00 & 44.85 \\
\hline $10 / 16$ & $\begin{array}{l}6.50 \\
6.50 \\
6.60 \\
6.60\end{array}$ & $\begin{array}{l}266.00 \\
282.00 \\
279.00 \\
278.00\end{array}$ & 72.00 & 28.00 & 13.00 & 47.10 \\
\hline \multicolumn{7}{|c|}{ W57 } \\
\hline $03 / 06$ & $\begin{array}{l}6.80 \\
6.80 \\
6.30 \\
6.60\end{array}$ & $\begin{array}{l}376.00 \\
374.00 \\
375.00 \\
378.00\end{array}$ & 65.00 & 230.00 & 20.00 & 23.45 \\
\hline $05 / 30$ & $\begin{array}{l}6.60 \\
6.80 \\
6.80 \\
6.90\end{array}$ & $\begin{array}{l}361.00 \\
365.00 \\
367.00 \\
366.00\end{array}$ & 64.00 & 160.00 & 10.00 & 22.78 \\
\hline $08 / 30$ & $\begin{array}{l}6.00 \\
6.30 \\
6.40 \\
6.50\end{array}$ & $\begin{array}{l}383.00 \\
375.00 \\
374.00 \\
372.00\end{array}$ & 63.00 & 100.00 & 18.00 & 21.97 \\
\hline $10 / 30$ & $\begin{array}{l}6.40 \\
6.40 \\
6.40 \\
6.40\end{array}$ & $\begin{array}{l}379.00 \\
377.00 \\
378.00 \\
374.00\end{array}$ & 65.00 & 80.00 & 6.00 & 22.00 \\
\hline \multicolumn{7}{|c|}{ W58 (well abandoned 9/13/90) } \\
\hline $08 / 16$ & 6.70 & 478.00 & 73.00 & 40.00 & 11.00 & 11.78 \\
\hline
\end{tabular}


Table 4.6 (continued)

\begin{tabular}{|c|c|c|c|c|c|c|}
\hline Date & $\underset{\text { (units) }}{\mathrm{pH}}$ & $\begin{array}{l}\text { Conductivity } \\
(\mu \mathrm{mho} / \mathrm{cm})\end{array}$ & $\begin{array}{l}\text { Temp. } \\
\left({ }^{\circ} \mathrm{F}\right)\end{array}$ & $\begin{array}{l}\text { Turbidity } \\
\text { (NTU) }\end{array}$ & $\begin{array}{l}\text { Color } \\
\text { (units) }\end{array}$ & $\begin{array}{l}\text { Depth } \\
\text { (ft) }\end{array}$ \\
\hline \multicolumn{7}{|c|}{ W62 } \\
\hline $11 / 13$ & $\begin{array}{l}6.90 \\
6.90 \\
6.90 \\
6.90\end{array}$ & $\begin{array}{l}307.00 \\
306.00 \\
307.00 \\
306.00\end{array}$ & 58.00 & 70.00 & 8.00 & \\
\hline \multicolumn{7}{|c|}{ W63 } \\
\hline $01 / 23$ & $\begin{array}{l}6.30 \\
6.30 \\
6.30 \\
6.30\end{array}$ & $\begin{array}{l}275.00 \\
274.00 \\
272.00 \\
273.00\end{array}$ & 60.00 & 20.00 & 7.00 & 48.24 \\
\hline $04 / 03$ & $\begin{array}{l}6.40 \\
6.40 \\
6.40 \\
6.40\end{array}$ & $\begin{array}{l}262.00 \\
264.00 \\
264.00 \\
265.00\end{array}$ & 60.00 & 9.00 & 6.00 & 45.70 \\
\hline $07 / 12$ & $\begin{array}{l}6.20 \\
6.20 \\
6.20 \\
6.20\end{array}$ & $\begin{array}{l}297.00 \\
298.00 \\
297.00 \\
297.00\end{array}$ & 60.00 & 29.00 & 12.00 & 42.63 \\
\hline $10 / 02$ & $\begin{array}{l}6.30 \\
6.30 \\
6.30 \\
6.30\end{array}$ & $\begin{array}{l}285.00 \\
287.00 \\
285.00 \\
284.00\end{array}$ & 60.00 & 10.00 & 7.00 & 45.67 \\
\hline \multicolumn{7}{|c|}{ W64 } \\
\hline $\begin{array}{l}01 / 25 \\
04 / 05\end{array}$ & $\begin{array}{l}6.80 \\
7.00\end{array}$ & 743.00 & $\begin{array}{l}59.00 \\
64.00\end{array}$ & 110.00 & & $\begin{array}{r}9.68 \\
21.15\end{array}$ \\
\hline $07 / 18$ & $\begin{array}{l}6.80 \\
6.80\end{array}$ & $\begin{array}{l}661.00 \\
689.00\end{array}$ & 71.00 & 6.00 & 6.00 & 19.76 \\
\hline $07 / 18$ & & $\begin{array}{l}679.00 \\
673.00\end{array}$ & & & & \\
\hline $10 / 03$ & $\begin{array}{l}6.80 \\
6.90 \\
6.80 \\
6.80\end{array}$ & $\begin{array}{l}592.00 \\
613.00 \\
587.00 \\
702.00\end{array}$ & 69.00 & 7.00 & 3.00 & 9.45 \\
\hline \multicolumn{7}{|c|}{ W65 } \\
\hline $02 / 02$ & & $\begin{array}{l}193.00 \\
196.00 \\
196.00 \\
194.00\end{array}$ & 59.00 & 2.00 & 3.00 & 48.61 \\
\hline$m / 13$ & $\begin{array}{l}6.50 \\
6.40 \\
6.40 \\
6.40\end{array}$ & & 61.00 & & & 48.10 \\
\hline $04 / 03$ & $\begin{array}{l}6.20 \\
6.20 \\
6.20 \\
6.20\end{array}$ & $\begin{array}{l}205.00 \\
204.00 \\
203.00 \\
203.00\end{array}$ & 60.00 & 2.00 & 5.00 & 45.67 \\
\hline
\end{tabular}


Table 4.6 (continued)

\begin{tabular}{|c|c|c|c|c|c|c|}
\hline Date & $\underset{\text { (units) }}{\mathrm{pH}}$ & $\begin{array}{l}\text { Conductivity } \\
(\mu \mathrm{mho} / \mathrm{cm})\end{array}$ & $\begin{array}{l}\text { Temp. } \\
\left({ }^{\circ} \mathrm{F}\right)\end{array}$ & $\begin{array}{l}\text { Turbidity } \\
\text { (NTU) }\end{array}$ & $\begin{array}{l}\text { Color } \\
\text { (units) }\end{array}$ & $\begin{array}{l}\text { Depth } \\
\text { (ft) }\end{array}$ \\
\hline \multicolumn{7}{|c|}{ W65 } \\
\hline $07 / 17$ & $\begin{array}{l}6.10 \\
6.10 \\
6.10 \\
6.10\end{array}$ & $\begin{array}{l}196.00 \\
198.00 \\
198.00 \\
198.00\end{array}$ & 60.00 & 2.00 & & 42.88 \\
\hline \multirow[t]{2}{*}{$10 / 02$} & $\begin{array}{l}6.10 \\
6.10 \\
6.10 \\
6.10\end{array}$ & $\begin{array}{l}194.00 \\
196.00 \\
196.00 \\
195.00\end{array}$ & 60.00 & 0.60 & 4.00 & 45.67 \\
\hline & & & W66 & & & \\
\hline $01 / 18$ & $\begin{array}{l}6.10 \\
6.10 \\
6.10 \\
6.10\end{array}$ & $\begin{array}{l}371.00 \\
370.00 \\
369.00 \\
370.00\end{array}$ & 58.00 & 5.00 & 3.00 & 47.32 \\
\hline $04 / 10$ & $\begin{array}{l}6.40 \\
6.40 \\
6.40 \\
6.40\end{array}$ & $\begin{array}{l}429.00 \\
427.00 \\
425.00 \\
435.00\end{array}$ & 59.00 & 7.00 & 4.00 & 43.61 \\
\hline $07 / 25$ & $\begin{array}{l}6.50 \\
6.50 \\
6.50 \\
6.50\end{array}$ & $\begin{array}{l}356.00 \\
357.00 \\
359.00 \\
359.00\end{array}$ & 60.00 & 0.20 & 7.00 & 41.48 \\
\hline $08 / 22$ & $\begin{array}{l}6.30 \\
6.30 \\
6.30 \\
6.30\end{array}$ & $\begin{array}{l}338.00 \\
339.00 \\
343.00 \\
343.00\end{array}$ & 60.00 & 2.00 & & 42.22 \\
\hline \multirow[t]{2}{*}{$10 / 17$} & $\begin{array}{l}6.30 \\
6.30 \\
6.30 \\
6.30\end{array}$ & $\begin{array}{l}329.00 \\
333.00 \\
333.00 \\
335.00\end{array}$ & 59.00 & 3.00 & 7.00 & 43.21 \\
\hline & & & W67 & & & \\
\hline $02 / 01$ & $\begin{array}{l}6.00 \\
6.00 \\
6.00 \\
6.00\end{array}$ & $\begin{array}{l}177.00 \\
179.00 \\
179.00 \\
179.00\end{array}$ & 59.00 & 3.00 & 2.00 & 50.45 \\
\hline $04 / 02$ & $\begin{array}{l}6.30 \\
6.30 \\
6.30 \\
6.30\end{array}$ & $\begin{array}{l}181.00 \\
181.00 \\
182.00 \\
176.00\end{array}$ & 60.00 & 3.00 & 5.00 & 48.00 \\
\hline $07 / 19$ & $\begin{array}{l}6.00 \\
6.00 \\
6.00 \\
6.00\end{array}$ & $\begin{array}{l}180.00 \\
180.00 \\
179.00 \\
179.00\end{array}$ & 61.00 & 2.00 & 6.00 & 44.70 \\
\hline $10 / 02$ & $\begin{array}{l}6.10 \\
6.10 \\
6.10 \\
6.10\end{array}$ & $\begin{array}{l}179.00 \\
178.00 \\
178.00 \\
178.00\end{array}$ & 60.00 & 1.30 & 6.00 & 47.12 \\
\hline
\end{tabular}


Table 4.6 (continued)

\begin{tabular}{|c|c|c|c|c|c|c|}
\hline Date & $\underset{\text { (units) }}{\mathrm{pH}}$ & $\begin{array}{l}\text { Conductivity } \\
(\mu \mathrm{mho} / \mathrm{cm})\end{array}$ & $\begin{array}{l}\text { Temp. } \\
\left({ }^{\circ} \mathrm{F}\right)\end{array}$ & $\begin{array}{l}\text { Turbidity } \\
\text { (NTU) }\end{array}$ & $\begin{array}{l}\text { Color } \\
\text { (units) }\end{array}$ & $\begin{array}{l}\text { Depth } \\
\text { (ft) }\end{array}$ \\
\hline \multicolumn{7}{|c|}{ W68 } \\
\hline $03 / 13$ & $\begin{array}{l}6.40 \\
6.40 \\
6.40 \\
6.40\end{array}$ & $\begin{array}{l}416.00 \\
415.00 \\
416.00 \\
416.00\end{array}$ & 63.00 & 4.00 & 3.00 & 53.48 \\
\hline $04 / 03$ & $\begin{array}{l}6.30 \\
6.30 \\
6.30 \\
6.30\end{array}$ & $\begin{array}{l}412.00 \\
413.00 \\
413.00 \\
411.00\end{array}$ & 60.00 & 3.00 & 4.00 & 52.75 \\
\hline $07 / 11$ & $\begin{array}{l}6.40 \\
6.40 \\
6.40 \\
6.40\end{array}$ & $\begin{array}{l}408.00 \\
408.00 \\
409.00 \\
409.00\end{array}$ & 63.00 & 2.00 & 6.00 & 48.11 \\
\hline $10 / 03$ & $\begin{array}{l}6.50 \\
6.50 \\
6.50 \\
6.50\end{array}$ & $\begin{array}{l}411.00 \\
412.00 \\
410.00 \\
411.00\end{array}$ & 60.00 & 0.70 & 3.00 & 51.45 \\
\hline \multirow[b]{2}{*}{$03 / 13$} & & & W71 & & & \\
\hline & $\begin{array}{l}5.90 \\
5.90 \\
5.90 \\
5.90\end{array}$ & $\begin{array}{l}538.00 \\
538.00 \\
538.00 \\
537.00\end{array}$ & 62.00 & 5.00 & 3.00 & 53.60 \\
\hline $04 / 04$ & $\begin{array}{l}6.00 \\
6.00 \\
6.00 \\
6.00\end{array}$ & $\begin{array}{l}549.00 \\
551.00 \\
546.00 \\
549.00\end{array}$ & 62.00 & 4.00 & 5.00 & 52.46 \\
\hline $07 / 11$ & $\begin{array}{l}6.10 \\
6.10 \\
6.10 \\
6.10\end{array}$ & $\begin{array}{l}567.00 \\
568.00 \\
571.00 \\
564.00\end{array}$ & 65.00 & 3.00 & 7.00 & 48.10 \\
\hline $10 / 03$ & $\begin{array}{l}5.80 \\
5.80 \\
5.80 \\
5.80\end{array}$ & $\begin{array}{l}567.00 \\
568.00 \\
567.00 \\
568.00\end{array}$ & 62.00 & 35.00 & 6.00 & 51.43 \\
\hline
\end{tabular}


Table 4.7. Quarterly effluent monitoring of organic and Inorganic parameters at solld waste management units

\begin{tabular}{|c|c|c|c|c|c|c|c|c|c|}
\hline Date & $\begin{array}{c}\mathrm{Cl}^{-} \\
(\mathrm{mg} / \mathrm{L})\end{array}$ & $\begin{array}{c}\mathrm{SO}_{4} \\
(\mathrm{mg} / \mathrm{L})\end{array}$ & $\begin{array}{c}\mathrm{NO}_{3} \\
(\mathrm{mg} / \mathrm{L})\end{array}$ & $\begin{array}{c}F \\
(\mathrm{mg} / \mathrm{L})\end{array}$ & $\begin{array}{c}\text { TOCa } \\
(\mathrm{mg} / \mathrm{L})\end{array}$ & $\begin{array}{l}\text { TOX } \\
(\mu g / L)\end{array}$ & $\begin{array}{c}\text { TCE } \\
(\mu g / L)\end{array}$ & $\begin{array}{c}{ }^{99} \mathrm{TC} \\
(\mathrm{pCi} / \mathrm{L})\end{array}$ & $\begin{array}{c}\text { PCB } \\
(\mu g / L)\end{array}$ \\
\hline \multicolumn{10}{|c|}{ W16 } \\
\hline $01 / 10$ & 15.00 & 128.00 & $<1.00$ & 0.40 & $\begin{array}{l}<1.00 \\
<1.00 \\
<1.00 \\
<1.00\end{array}$ & $\begin{array}{r}9.00 \\
<5.00 \\
<5.00 \\
6.00\end{array}$ & $<1.00$ & 8.00 & $<0.50$ \\
\hline $05 / 22$ & & 32.00 & 3.00 & 0.35 & $\begin{array}{r}2.00 \\
1.00 \\
<1.00 \\
<1.00\end{array}$ & $\begin{array}{r}<.00 \\
17.00 \\
12.00 \\
8.00\end{array}$ & $<1.00$ & 5.00 & $<0.50$ \\
\hline $08 / 09$ & $\begin{array}{r}8.00 \\
12.00\end{array}$ & $\begin{array}{l}32.00 \\
30.00\end{array}$ & $\begin{array}{l}2.70 \\
2.80\end{array}$ & $\begin{array}{l}0.35 \\
0.37\end{array}$ & $\begin{array}{l}1.00 \\
1.00\end{array}$ & $\begin{array}{l}6.00 \\
8.00\end{array}$ & $\begin{array}{l}<1.00 \\
<1.00\end{array}$ & $\begin{array}{l}18.00 \\
20.00\end{array}$ & $\begin{array}{l}<0.50 \\
<0.10\end{array}$ \\
\hline & & & & & $\begin{array}{l}1.00 \\
1.00 \\
1.00 \\
1.00\end{array}$ & $\begin{array}{r}8.00 \\
<5.00 \\
10.00 \\
28.00\end{array}$ & & & \\
\hline \multicolumn{10}{|c|}{ W17 } \\
\hline $01 / 04$ & 22.00 & 157.00 & $<1.00$ & 0.54 & 4.00 & 41.00 & $<1.00$ & 7.00 & $<0.50$ \\
\hline $05 / 22$ & & & & & & 53.00 & $<1.00$ & 3.00 & $<0.50$ \\
\hline $08 / 29$ & & & & & 3.00 & 46.00 & $<1.00$ & 9.00 & $<0.50$ \\
\hline $11 / 29$ & & & & & & 46.00 & $<1.00$ & 10.00 & $<0.10$ \\
\hline $12 / 14$ & 21.00 & 188.00 & $<1.00$ & 0.53 & 3.00 & & & & \\
\hline \multicolumn{10}{|c|}{ W18 } \\
\hline $01 / 09$ & 15.00 & 127.00 & $<1.00$ & 0.94 & $\begin{array}{l}7.00 \\
8.00 \\
7.00 \\
7.00\end{array}$ & $\begin{array}{l}27.00 \\
27.00 \\
32.00 \\
43.00\end{array}$ & $<1.00$ & 8.00 & $<0.50$ \\
\hline $05 / 16$ & & 116.00 & $<1.00$ & 0.82 & $\begin{array}{l}5.00 \\
6.00 \\
6.00 \\
6.00\end{array}$ & $\begin{array}{l}27.00 \\
24.00 \\
26.00 \\
26.00\end{array}$ & $<1.00$ & 1.00 & $<0.50$ \\
\hline $08 / 21$ & 15.00 & 124.00 & $<1.00$ & 0.84 & $\begin{array}{l}7.00 \\
7.00 \\
7.00 \\
7.00\end{array}$ & $\begin{array}{l}13.00 \\
<5.00 \\
14.00 \\
13.00\end{array}$ & $<1.00$ & 3.00 & $<0.50$ \\
\hline $11 / 14$ & 15.00 & 134.00 & $<1.00$ & 0.88 & $\begin{array}{l}7.00 \\
7.00 \\
7.00 \\
7.00\end{array}$ & $\begin{array}{l}18.00 \\
24.00 \\
25.00 \\
13.00\end{array}$ & $<1.00$ & 18.00 & $<0.10$ \\
\hline \multicolumn{10}{|c|}{ W19 } \\
\hline $\begin{array}{l}01 / 11 \\
05 / 24\end{array}$ & & & & 0.34 & $\begin{array}{l}7.00 \\
1.00\end{array}$ & $\begin{array}{r}<5.00 \\
6.00\end{array}$ & $\begin{array}{l}<1.00 \\
<1.00\end{array}$ & 4.00 & $<0.50$ \\
\hline $08 / 23$ & & & & & 1.00 & $<5.00$ & $<1.00$ & 0.00 & $<0.50$ \\
\hline $10 / 04$ & 6.00 & 12.00 & 1.00 & 0.27 & $\begin{array}{r}<1.00 \\
<1.00 \\
1.00 \\
<1.00\end{array}$ & $\begin{array}{r}<5.00 \\
6.00 \\
<5.00 \\
6.00\end{array}$ & $<1.00$ & 0.00 & 1.90 \\
\hline
\end{tabular}


Table 4.7 (continued)

\begin{tabular}{|c|c|c|c|c|c|c|c|c|c|}
\hline Date & $\begin{array}{c}\mathrm{Cl}^{-} \\
(\mathrm{mg} / \mathrm{L})\end{array}$ & $\begin{array}{c}\mathrm{SO}_{4} \\
(\mathrm{mg} / \mathrm{L})\end{array}$ & $\begin{array}{c}\mathrm{NO}_{3} \\
(\mathrm{mg} / \mathrm{L})\end{array}$ & $\begin{array}{c}\mathrm{F}^{-} \\
(\mathrm{mg} / \mathrm{L})\end{array}$ & $\begin{array}{l}\text { TOC }^{a} \\
(\mathrm{mg} / \mathrm{L})\end{array}$ & $\begin{array}{l}\mathrm{TOX}^{b} \\
(\mu \mathrm{g} / \mathrm{L})\end{array}$ & $\begin{array}{c}\text { TCE } \\
(\mu \mathrm{g} / \mathrm{L})\end{array}$ & $\begin{array}{c}{ }_{99}^{9} \mathrm{TC} \\
(\mathrm{pCi} / \mathrm{L})\end{array}$ & $\begin{array}{c}\text { PCB } \\
(\mu \mathrm{g} / \mathrm{L})\end{array}$ \\
\hline \multicolumn{10}{|c|}{ W20 } \\
\hline $01 / 18$ & 41.00 & 12.50 & $<1.00$ & 0.15 & $\begin{array}{l}<1.00 \\
<1.00 \\
<1.00 \\
<1.00\end{array}$ & $\begin{array}{l}55.00 \\
48.00 \\
42.00\end{array}$ & 77.00 & 57.00 & $<0.50$ \\
\hline $04 / 19$ & & 12.00 & $<1.00$ & 0.13 & $\begin{array}{r}<1.00 \\
1.00 \\
<1.00 \\
2.00\end{array}$ & $\begin{array}{l}75.00 \\
87.00 \\
85.00 \\
93.00\end{array}$ & 110.00 & 54.00 & $<0.50$ \\
\hline $11 / 01$ & & 11.00 & 1.40 & 0.13 & $\begin{array}{l}<1.00 \\
<1.00 \\
<1.00 \\
<1.00\end{array}$ & $\begin{array}{l}153.00 \\
157.00 \\
154.00 \\
150.00\end{array}$ & $\begin{array}{l}210.00 \\
220.00\end{array}$ & $\begin{array}{l}129.00 \\
112.00\end{array}$ & $<0.10$ \\
\hline $12 / 13$ & & & & & & & 160.00 & 37.00 & \\
\hline \multicolumn{10}{|c|}{ W21 } \\
\hline $01 / 24$ & 180.00 & 372.00 & $<1.00$ & 0.24 & $\begin{array}{l}1.00 \\
1.00 \\
1.00 \\
1.00\end{array}$ & $\begin{array}{l}38.00 \\
44.00 \\
55.00 \\
41.00\end{array}$ & $<1.00$ & 22.00 & $<0.50$ \\
\hline $06 / 14$ & & 330.00 & $<1.00$ & 0.27 & $\begin{array}{l}2.00 \\
2.00 \\
2.00 \\
2.00\end{array}$ & $\begin{array}{l}57.00 \\
37.00 \\
48.00 \\
42.00\end{array}$ & $<1.00$ & 20.00 & $<0.50$ \\
\hline $08 / 30$ & & 401.00 & $<1.00$ & 0.24 & $\begin{array}{l}2.00 \\
2.00 \\
2.00 \\
2.00\end{array}$ & $\begin{array}{l}45.00 \\
52.00 \\
38.00 \\
45.00\end{array}$ & $<1.00$ & 9.00 & $<0.50$ \\
\hline $10 / 23$ & & 399.00 & $<1.00$ & 0.24 & $\begin{array}{l}1.00 \\
1.00 \\
1.00 \\
1.00\end{array}$ & $\begin{array}{l}31.00 \\
43.00 \\
50.00 \\
58.00\end{array}$ & $<1.00$ & 5.00 & $<0.10$ \\
\hline \multicolumn{10}{|c|}{ W22 } \\
\hline $01 / 23$ & 41.00 & 13.00 & $<1.00$ & 0.13 & $\begin{array}{l}<1.00 \\
<1.00 \\
<1.00 \\
<1.00\end{array}$ & $\begin{array}{l}17.00 \\
23.00 \\
22.00 \\
11.00\end{array}$ & 10.00 & 6.00 & $<0.50$ \\
\hline $0, / 21$ & & 13.00 & $<1.00$ & 0.13 & $\begin{array}{l}<1.00 \\
<1.00 \\
<1.00 \\
<1.00\end{array}$ & $\begin{array}{l}38.00 \\
45.00 \\
45.00 \\
43.00\end{array}$ & 46.00 & 11.00 & $<0.50$ \\
\hline $08 / 21$ & 41.00 & 13.00 & $<1.00$ & 0.12 & $\begin{array}{r}<1.00 \\
<1.00 \\
<1.00 \\
<1.00 \\
1.00\end{array}$ & $\begin{array}{l}45.00 \\
49.00 \\
49.00 \\
50.00 \\
53.00\end{array}$ & 54.00 & $26.0 \mathrm{C}$ & $<0.50$ \\
\hline $10 / 31$ & & 13.00 & $<1.00$ & 0.11 & $\begin{array}{r}<1.00 \\
1.00 \\
<1.00 \\
<1.00\end{array}$ & $\begin{array}{l}65.00 \\
-4.00 \\
69.00 \\
58.00\end{array}$ & 59.00 & 30.00 & $<0.10$ \\
\hline
\end{tabular}


Table 4.7 (continued)

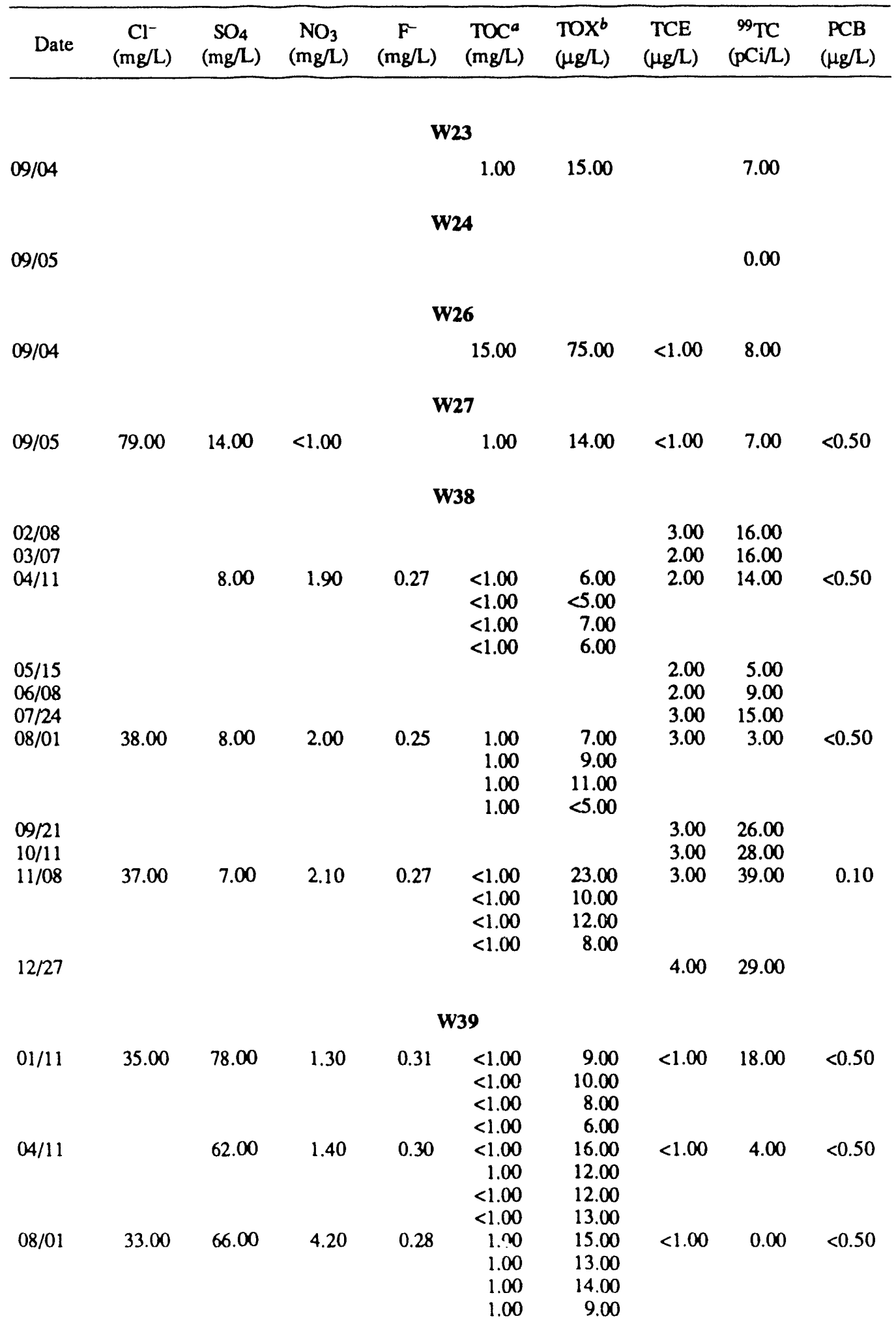


Table 4.7 (continued)

\begin{tabular}{|c|c|c|c|c|c|c|c|c|c|}
\hline Date & $\begin{array}{c}\mathrm{Cl}^{-} \\
(\mathrm{mg} / \mathrm{L})\end{array}$ & $\begin{array}{c}\mathrm{SO}_{4} \\
(\mathrm{mg} / \mathrm{L})\end{array}$ & $\begin{array}{c}\mathrm{NO}_{3} \\
(\mathrm{mg} / \mathrm{L})\end{array}$ & $\begin{array}{c}F \\
(\mathrm{mg} / \mathrm{L})\end{array}$ & $\begin{array}{c}\mathrm{TOC}^{a} \\
(\mathrm{mg} / \mathrm{L})\end{array}$ & $\begin{array}{l}\text { TOX }^{b} \\
(\mu g / L)\end{array}$ & $\begin{array}{c}\text { TCE } \\
(\mu \mathrm{g} / \mathrm{L})\end{array}$ & $\begin{array}{c}{ }^{99} \mathrm{TC} \\
(\mathrm{pCi} / \mathrm{L})\end{array}$ & $\begin{array}{c}\text { PCB } \\
(\mu \mathrm{g} / \mathrm{L})\end{array}$ \\
\hline \multicolumn{10}{|c|}{ W39 } \\
\hline $11 / 08$ & 36.00 & 70.00 & 1.40 & 0.29 & $\begin{array}{l}1.00 \\
1.00 \\
1.00 \\
1.00\end{array}$ & $\begin{array}{r}16.00 \\
17.00 \\
8.00 \\
18.00\end{array}$ & $<1.00$ & 10.00 & $<0.10$ \\
\hline \multicolumn{10}{|c|}{ W40 } \\
\hline $01 / 11$ & 30.00 & 12.00 & 1.50 & 0.18 & $\begin{array}{r}1.00 \\
<1.00 \\
2.00 \\
1.00\end{array}$ & $\begin{array}{r}<5.00 \\
5.00 \\
<5.00 \\
<5.00\end{array}$ & $<1.00$ & 0.00 & $<0.50$ \\
\hline $02 / 08$ & & & & & & & $<1.00$ & 5.00 & \\
\hline $04 / 23$ & & 13.00 & 1.60 & 0.16 & $\begin{array}{l}<1.00 \\
<1.00 \\
<1.00 \\
<1.00\end{array}$ & $\begin{array}{r}5.00 \\
8.00 \\
5.00 \\
10.00\end{array}$ & 4.00 & 6.00 & $<0.50$ \\
\hline $08 / 02$ & 18.00 & 13.00 & 1.60 & 0.15 & $\begin{array}{l}1.00 \\
1.00 \\
1.00\end{array}$ & $\begin{array}{l}<5.00 \\
<5.00 \\
<5.00\end{array}$ & $<1.00$ & 7.00 & $<0.50$ \\
\hline $11 / 07$ & 33.00 & 12.00 & 1.60 & 0.17 & $\begin{array}{l}<1.00 \\
<1.00 \\
<1.00 \\
<1.00\end{array}$ & $\begin{array}{r}1.00 \\
<5.00 \\
<5.00 \\
<5.00 \\
<5.00\end{array}$ & $\begin{array}{l}<5.00 \\
+1.00\end{array}$ & 2.00 & $<0.10$ \\
\hline \multicolumn{10}{|c|}{ W41 } \\
\hline $\begin{array}{l}02 / 22 \\
03 / 07\end{array}$ & & & & & & & $\begin{array}{l}12.00 \\
14.00\end{array}$ & $\begin{array}{r}2.00 \\
23.00\end{array}$ & \\
\hline $04 / 19$ & & 10.00 & 1.60 & 0.16 & $\begin{array}{r}<1.00 \\
1.00 \\
<1.00 \\
<1.00\end{array}$ & $\begin{array}{r}5.00 \\
9.00 \\
9.00 \\
11.00\end{array}$ & 17.00 & 0.00 & $<0.50$ \\
\hline $\begin{array}{l}05 / 24 \\
06 / 18 \\
07 / 19\end{array}$ & & & & & & & $\begin{array}{l}15.00 \\
14.00 \\
17.00\end{array}$ & $\begin{array}{r}4.00 \\
9.00 \\
12.00\end{array}$ & \\
\hline $08 / 02$ & 22.00 & 11.00 & 1.20 & 0.16 & $\begin{array}{l}1.00 \\
1.00 \\
1.00 \\
1.00\end{array}$ & $\begin{array}{l}19.00 \\
16.00 \\
17.00 \\
20.00\end{array}$ & 12.00 & 0.00 & $<0.50$ \\
\hline $\begin{array}{l}09 / 21 \\
10 / 11\end{array}$ & & & & & & & $\begin{array}{l}17.00 \\
15.00\end{array}$ & $\begin{array}{l}6.00 \\
7.00\end{array}$ & \\
\hline $10 / 31$ & 39.00 & 11.00 & 1.30 & 0.16 & $\begin{array}{l}<1.00 \\
<1.00 \\
<1.00 \\
<1.00\end{array}$ & $\begin{array}{l}19.00 \\
11.00 \\
22.00 \\
18.00\end{array}$ & 19.00 & 11.00 & $<0.10$ \\
\hline $\begin{array}{l}11 / 09 \\
12 / 19\end{array}$ & & & & & & & $\begin{array}{l}15.00 \\
16.00\end{array}$ & $\begin{array}{r}27.00 \\
1.00\end{array}$ & \\
\hline \multicolumn{10}{|c|}{ W42 } \\
\hline $02 / 27$ & 38.00 & 168.00 & $<1.00$ & 0.17 & $\begin{array}{r}2.00 \\
1.00 \\
<1.00 \\
<1.00\end{array}$ & $\begin{array}{r}11.00 \\
7.00 \\
9.00 \\
10.00\end{array}$ & $<1.00$ & 27.00 & $<0.50$ \\
\hline
\end{tabular}


Table 4.7 (continued)

\begin{tabular}{|c|c|c|c|c|c|c|c|c|c|}
\hline Date & $\begin{array}{c}\mathrm{Cl}^{-} \\
(\mathrm{mg} / \mathrm{L})\end{array}$ & $\begin{array}{c}\mathrm{SO}_{4} \\
(\mathrm{mg} / \mathrm{L})\end{array}$ & $\begin{array}{c}\mathrm{NO}_{3} \\
(\mathrm{mg} / \mathrm{L})\end{array}$ & $\begin{array}{c}F \\
(m g / L)\end{array}$ & $\begin{array}{l}\mathrm{TOC}^{a} \\
(\mathrm{mg} / \mathrm{L})\end{array}$ & $\begin{array}{l}\text { TOX } \\
(\mu g / L)\end{array}$ & $\begin{array}{c}\text { TCE } \\
(\mu g / L)\end{array}$ & $\begin{array}{c}{ }^{99} \mathrm{TC} \\
(\mathrm{pCi} / \mathrm{L})\end{array}$ & $\begin{array}{c}\text { PCB } \\
(\mu \mathrm{g} / \mathrm{L})\end{array}$ \\
\hline \multicolumn{10}{|c|}{ W42 } \\
\hline $04 / 24$ & & 187.00 & $<1.00$ & 0.17 & $\begin{array}{l}1.00 \\
1.00 \\
1.00 \\
1.00\end{array}$ & $\begin{array}{r}<.00 \\
7.00 \\
6.00 \\
10.00\end{array}$ & $<1.00$ & 12.00 & $<0.50$ \\
\hline $08 / 08$ & 23.00 & 186.00 & $<1.00$ & 0.16 & $\begin{array}{r}1.00 \\
1.00 \\
<1.00 \\
<1.00\end{array}$ & $\begin{array}{r}8.00 \\
<5.00 \\
6.00 \\
6.00\end{array}$ & $<1.00$ & 17.00 & $<0.50$ \\
\hline $11 / 07$ & 29.00 & 175.00 & $<1.00$ & & $\begin{array}{l}<1.00 \\
<1.00 \\
<1.00 \\
<1.00\end{array}$ & $\begin{array}{r}<.00 \\
8.00 \\
6.00\end{array}$ & & & \\
\hline \multicolumn{10}{|c|}{$\mathbf{W} 43$} \\
\hline $02 / 28$ & 29.00 & 8.00 & $<1.00$ & 0.15 & $\begin{array}{l}<1.00 \\
<1.00 \\
<1.00 \\
<1.00\end{array}$ & $\begin{array}{r}10.00 \\
6.00 \\
8.00 \\
<5.00\end{array}$ & $<1.00$ & 12.00 & $<0.50$ \\
\hline 03/07 & & & & & & & $<1.00$ & 11.00 & \\
\hline $03 / 07$ & & 9.00 & $<1.00$ & 0.16 & $\begin{array}{r}1.00 \\
1.00 \\
<1.00 \\
1.00\end{array}$ & $\begin{array}{r}8.00 \\
10.00 \\
7.00 \\
9.00\end{array}$ & $<1.00$ & 0.00 & $<0.50$ \\
\hline $05 / 22$ & & & & & & & $<1.00$ & 0.00 & \\
\hline $06 / 18$ & & & & & & & $<1.00$ & 13.00 & \\
\hline$(17 ! 20$ & & & & & & & $<1.00$ & 11.00 & \\
\hline $08 / 08$ & 18.00 & 9.00 & $<1.00$ & 0.15 & $\begin{array}{l}<1.00 \\
<1.00 \\
<1.00 \\
<1.00\end{array}$ & $\begin{array}{r}5.00 \\
<5.00 \\
<5.00 \\
<5.00\end{array}$ & $<1.00$ & 1.00 & $<0.50$ \\
\hline $09 / 26$ & & & & & & & $<1.00$ & 8.00 & \\
\hline $10 / 04$ & & & & & & & $<1.00$ & 2.00 & \\
\hline $11 / 20$ & & & & & & & $<1.00$ & 0.00 & \\
\hline $12 / 11$ & 29.00 & 8.00 & 1.10 & 0.15 & $\begin{array}{l}<1.00 \\
<1.00 \\
<1.00 \\
<1.00\end{array}$ & $\begin{array}{r}12.00 \\
10.00 \\
9.00 \\
5.00\end{array}$ & $<1.00$ & 8.00 & $<0.10$ \\
\hline \multicolumn{10}{|c|}{ W44 } \\
\hline $01 / 09$ & 37.00 & 15.00 & $<1.00$ & 0.21 & $\begin{array}{r}3.00 \\
<1.00 \\
<1.00 \\
<1.00\end{array}$ & $\begin{array}{l}22.00 \\
16.00 \\
17.00 \\
15.00\end{array}$ & 18.00 & 19.00 & $<0.50$ \\
\hline $\begin{array}{l}02 / 13 \\
03 / 07\end{array}$ & & & & & & & $\begin{array}{l}15.00 \\
21.00\end{array}$ & $\begin{array}{l}0.00 \\
9.00\end{array}$ & \\
\hline $04 / 24$ & & 16.00 & $<1.00$ & 0.19 & $\begin{array}{l}<1.00 \\
<1.00 \\
<1.00 \\
<1.00\end{array}$ & $\begin{array}{l}14.00 \\
15.00 \\
17.00 \\
14.00\end{array}$ & 18.00 & 0.00 & $<0.50$ \\
\hline $\begin{array}{l}05 / 30 \\
06 / 19 \\
07 / 19\end{array}$ & & & & & & & $\begin{array}{l}14.00 \\
14.00 \\
18.00\end{array}$ & $\begin{array}{l}0.00 \\
8.00 \\
1.00\end{array}$ & \\
\hline
\end{tabular}


Table 4.7 (continued)

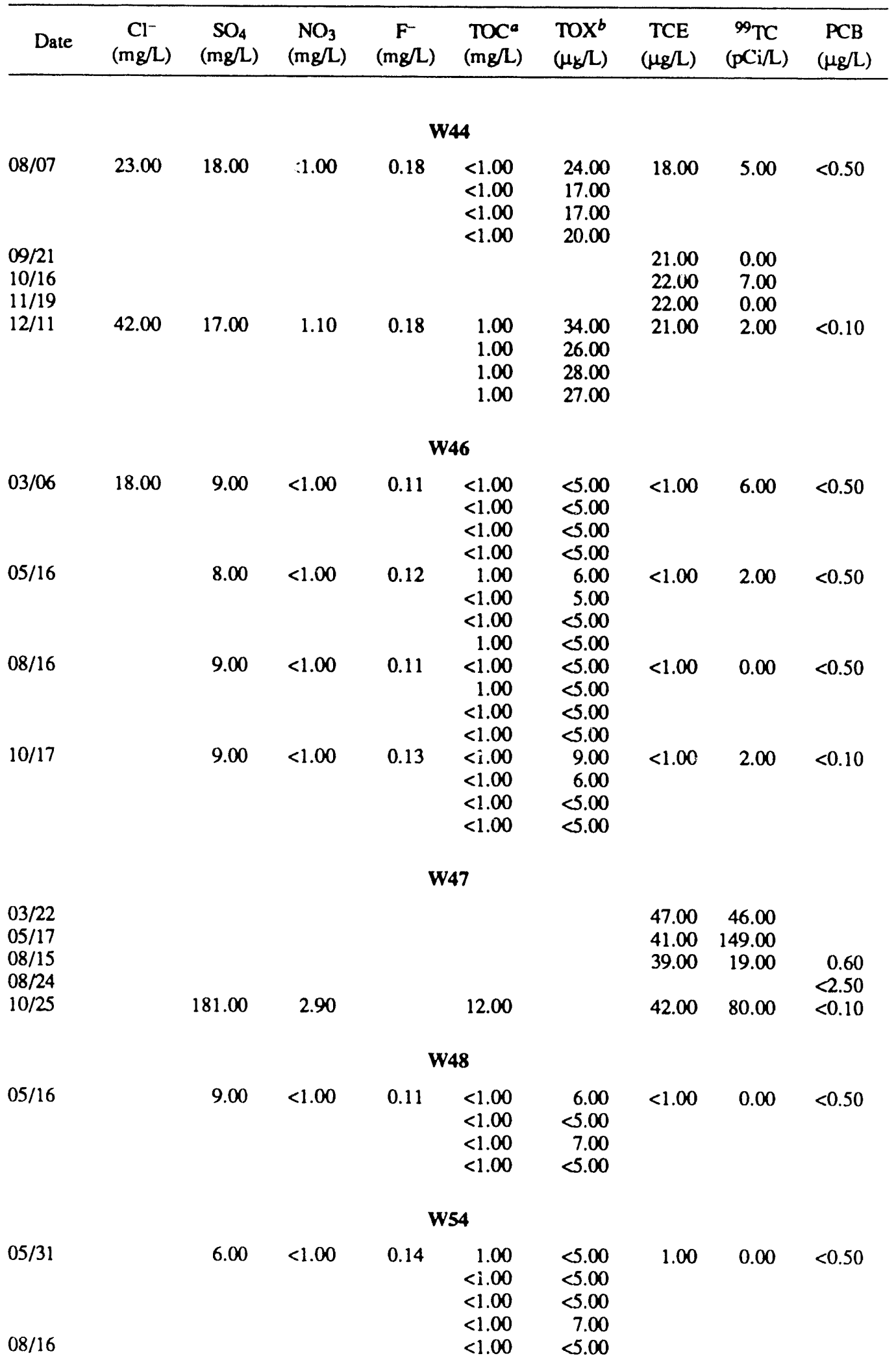


Table 4.7 (continued)

\begin{tabular}{|c|c|c|c|c|c|c|c|c|c|}
\hline Date & $\begin{array}{c}\mathrm{Cl}^{-} \\
(\mathrm{mg} / \mathrm{L})\end{array}$ & $\begin{array}{c}\mathrm{SO}_{4} \\
(\mathrm{mg} / \mathrm{L})\end{array}$ & $\begin{array}{c}\mathrm{NO}_{3} \\
(\mathrm{mg} / \mathrm{L})\end{array}$ & $\begin{array}{c}\mathrm{F}^{-} \\
(\mathrm{mg} / \mathrm{L})\end{array}$ & $\begin{array}{l}\text { TOCa } \\
(\mathrm{mg} / \mathrm{L})\end{array}$ & $\begin{array}{l}\operatorname{TOX}^{b} \\
(\mu g / L)\end{array}$ & $\begin{array}{c}\text { TCE } \\
(\mu \& / L)\end{array}$ & $\begin{array}{c}{ }^{99} \mathrm{TC} \\
(\mathrm{pCi} / \mathrm{L})\end{array}$ & $\begin{array}{c}\text { PCB } \\
(\mu g / L)\end{array}$ \\
\hline \multicolumn{10}{|c|}{ W54 } \\
\hline $08 / 17$ & & 7.00 & $<1.00$ & 0.16 & $\begin{array}{l}<1.00 \\
<1.00 \\
<1.00\end{array}$ & $\begin{array}{l}<.00 \\
<5.00 \\
<5.00\end{array}$ & 1.00 & 1.00 & $<0.50$ \\
\hline $10 / 16$ & & 5.00 & $<1.00$ & 0.11 & $\begin{array}{l}<1.00 \\
<1.00 \\
<1.00 \\
<1.00\end{array}$ & $\begin{array}{l}<.00 \\
<5.00 \\
<5.00 \\
<5.00\end{array}$ & $<1.00$ & 3.00 & $<5.00$ \\
\hline \multicolumn{10}{|c|}{ W57 } \\
\hline $03 / 06$ & 12.00 & 31.00 & $<1.00$ & 0.15 & $\begin{array}{l}1.00 \\
1.00 \\
1.00 \\
1.00\end{array}$ & $\begin{array}{l}35.00 \\
35.00 \\
38.00\end{array}$ & 8.00 & 355.00 & $<0.50$ \\
\hline $05 / 30$ & & 20.00 & $<1.00$ & 0.13 & $\begin{array}{r}<1.00 \\
<1.00 \\
<1.00 \\
1.00\end{array}$ & $\begin{array}{l}15.00 \\
16.00 \\
17.00 \\
16.00\end{array}$ & 8.00 & 66.00 & $<0.50$ \\
\hline $08 / 30$ & & 24.00 & $<1.00$ & 0.19 & $\begin{array}{r}1.00 \\
1.00 \\
<1.00 \\
1.00\end{array}$ & $\begin{array}{r}10.00 \\
9.00 \\
9.00 \\
9.00\end{array}$ & 4.00 & 316.00 & $<0.50$ \\
\hline $10 / 30$ & & 14.00 & $<1.00$ & 0.14 & $\begin{array}{l}3.00 \\
2.00 \\
2.00 \\
2.00\end{array}$ & $\begin{array}{l}16.00 \\
19.00 \\
18.00 \\
18.00\end{array}$ & 4.00 & 154.00 & $<0.10$ \\
\hline \multicolumn{10}{|c|}{ W58 } \\
\hline $08 / 16$ & & 91.00 & $<1.00$ & 2.10 & 1.00 & $<5.00$ & $<1.00$ & 109.00 & $<0.50$ \\
\hline \multicolumn{10}{|c|}{ W62 } \\
\hline $11 / 13$ & 3.00 & $<5.00$ & $<1.00$ & 0.21 & $\begin{array}{l}<1.00 \\
<1.00 \\
<1.00 \\
<1.00\end{array}$ & $\begin{array}{l}<5.00 \\
<5.00 \\
<5.00\end{array}$ & $<1.00$ & $<25.00$ & $<0.10$ \\
\hline \multicolumn{10}{|c|}{ W63 } \\
\hline $01 / 23$ & 16.00 & 12.00 & $<1.00$ & 0.14 & $\begin{array}{l}<1.00 \\
<1.00 \\
<1.00 \\
<1.00\end{array}$ & $\begin{array}{l}<5.00 \\
<5.00 \\
34.00 \\
31.00\end{array}$ & $<1.00$ & 1.00 & $<0.50$ \\
\hline $04 / 03$ & & 6.00 & $<1.00$ & 0.12 & $\begin{array}{l}<1.00 \\
<1.00 \\
<1.00 \\
<1.00\end{array}$ & $\begin{array}{r}<.00 \\
7.00 \\
<5.00 \\
10.00\end{array}$ & $<1.00$ & 0.00 & $<0.50$ \\
\hline $07 / 12$ & & 11.00 & $<1.00$ & 0.13 & $\begin{array}{l}<1.00 \\
<1.00 \\
<1.00 \\
<1.00\end{array}$ & $\begin{array}{r}13.00 \\
<5.00 \\
6.00 \\
<5.00\end{array}$ & $<1.00$ & 0.00 & $<0.50$ \\
\hline
\end{tabular}


Table 4.7 (continued)

\begin{tabular}{|c|c|c|c|c|c|c|c|c|c|}
\hline Date & $\begin{array}{c}\mathrm{Cl}^{-} \\
(\mathrm{mg} / \mathrm{L})\end{array}$ & $\begin{array}{c}\mathrm{SO}_{4} \\
(\mathrm{mg} / \mathrm{L})\end{array}$ & $\begin{array}{c}\mathrm{NO}_{3} \\
(\mathrm{mg} / \mathrm{l})\end{array}$ & $\begin{array}{c}\mathrm{F}^{-} \\
(\mathrm{mg} / \mathrm{L})\end{array}$ & $\begin{array}{c}\mathrm{TOC}^{a} \\
(\mathrm{mg} / \mathrm{L})\end{array}$ & $\begin{array}{l}\text { TOX }^{b} \\
(\mu g / L)\end{array}$ & $\begin{array}{c}\text { TCE } \\
(\mu \mathrm{g} / \mathrm{L})\end{array}$ & $\begin{array}{c}{ }^{99} \mathrm{TC} \\
(\mathrm{pCi} / \mathrm{L})\end{array}$ & $\begin{array}{c}\text { PCB } \\
(\mu \mathrm{g} / \mathrm{L})\end{array}$ \\
\hline \multicolumn{10}{|c|}{ W63 } \\
\hline $10 / 02$ & & 13.00 & $<1.00$ & 0.13 & $\begin{array}{l}<1.00 \\
<1.00 \\
<1.00 \\
<1.00\end{array}$ & & $<1.00$ & 0.00 & $<0.10$ \\
\hline \multicolumn{10}{|c|}{ W64 } \\
\hline $\begin{array}{l}01 / 25 \\
04 / 05\end{array}$ & 22.00 & 32.00 & 1.70 & 0.30 & & $<5.00$ & $\begin{array}{l}<1.00 \\
<1.00\end{array}$ & $\begin{array}{r}11.00 \\
0.00\end{array}$ & $<0.50$ \\
\hline $07 / 18$ & & 16.00 & 2.10 & 0.31 & $\begin{array}{l}1.00 \\
2.00 \\
1.00 \\
1.00\end{array}$ & $\begin{array}{r}7.00 \\
<5.00 \\
5.00 \\
<5.00\end{array}$ & $<1.00$ & 15.00 & $<0.50$ \\
\hline $10 / 03$ & & 17.00 & 2.00 & 0.30 & $\begin{array}{r}1.00 \\
<1.00 \\
<1.00 \\
<1.00\end{array}$ & & $<1.00$ & 3.00 & $<0.10$ \\
\hline \multicolumn{10}{|c|}{ W65 } \\
\hline $02 / 02$ & 11.00 & 10.00 & $<1.00$ & 0.11 & $\begin{array}{r}2.00 \\
<1.00 \\
<1.00 \\
<1.00\end{array}$ & $\begin{array}{l}<5.00 \\
<5.00 \\
<5.00 \\
<5.00\end{array}$ & $<1.00$ & 28.00 & $<0.50$ \\
\hline $04 / 03$ & & 10.00 & $<1.00$ & 0.12 & $\begin{array}{l}<1.00 \\
<1.00 \\
<1.00 \\
<1.00\end{array}$ & $\begin{array}{r}5.00 \\
5.00 \\
<5.00 \\
9.00\end{array}$ & $<1.00$ & 1.00 & $<0.50$ \\
\hline $07 / 17$ & & 9.00 & $<1.00$ & 0.11 & $\begin{array}{l}<1.00 \\
<1.00 \\
<1.00 \\
<1.00\end{array}$ & $\begin{array}{l}<5.00 \\
<5.00 \\
<5.00 \\
<5.00\end{array}$ & $<1.00$ & 0.00 & $<0.50$ \\
\hline $10 / 02$ & & 9.00 & $<1.00$ & 0.11 & $\begin{array}{l}<1.00 \\
<1.00 \\
<1.00 \\
<1.00\end{array}$ & & $<1.00$ & 0.00 & $<0.10$ \\
\hline \multicolumn{10}{|c|}{ W66 } \\
\hline $01 / 18$ & 27.00 & 25.00 & 7.90 & 0.11 & $\begin{array}{r}<1.00 \\
5.00 \\
<1.00 \\
<1.00\end{array}$ & $\begin{array}{l}2132.00 \\
2716.00 \\
2805.00 \\
2790.00\end{array}$ & $\sin 0.00$ & 2558.00 & $<0.50$ \\
\hline $\begin{array}{l}02 / 22 \\
03 / 14\end{array}$ & & & & & & & $\begin{array}{l}2900.00 \\
4900.00\end{array}$ & $\begin{array}{l}2378.00 \\
2318.00\end{array}$ & \\
\hline $04 / 10$ & & 10.00 & 7.50 & 0.11 & $\begin{array}{r}<1.00 \\
1.00 \\
1.00 \\
1.00\end{array}$ & $\begin{array}{l}2404.00 \\
2805.00 \\
2629.00 \\
2535.00\end{array}$ & 5900.00 & 2212.00 & $<0.50$ \\
\hline $\begin{array}{l}05 / 17 \\
06 / 22\end{array}$ & & & & & & & $\begin{array}{l}4100.00 \\
4200.00\end{array}$ & $\begin{array}{l}2091.00 \\
2128.00\end{array}$ & \\
\hline
\end{tabular}


Table 4.7 (continued)

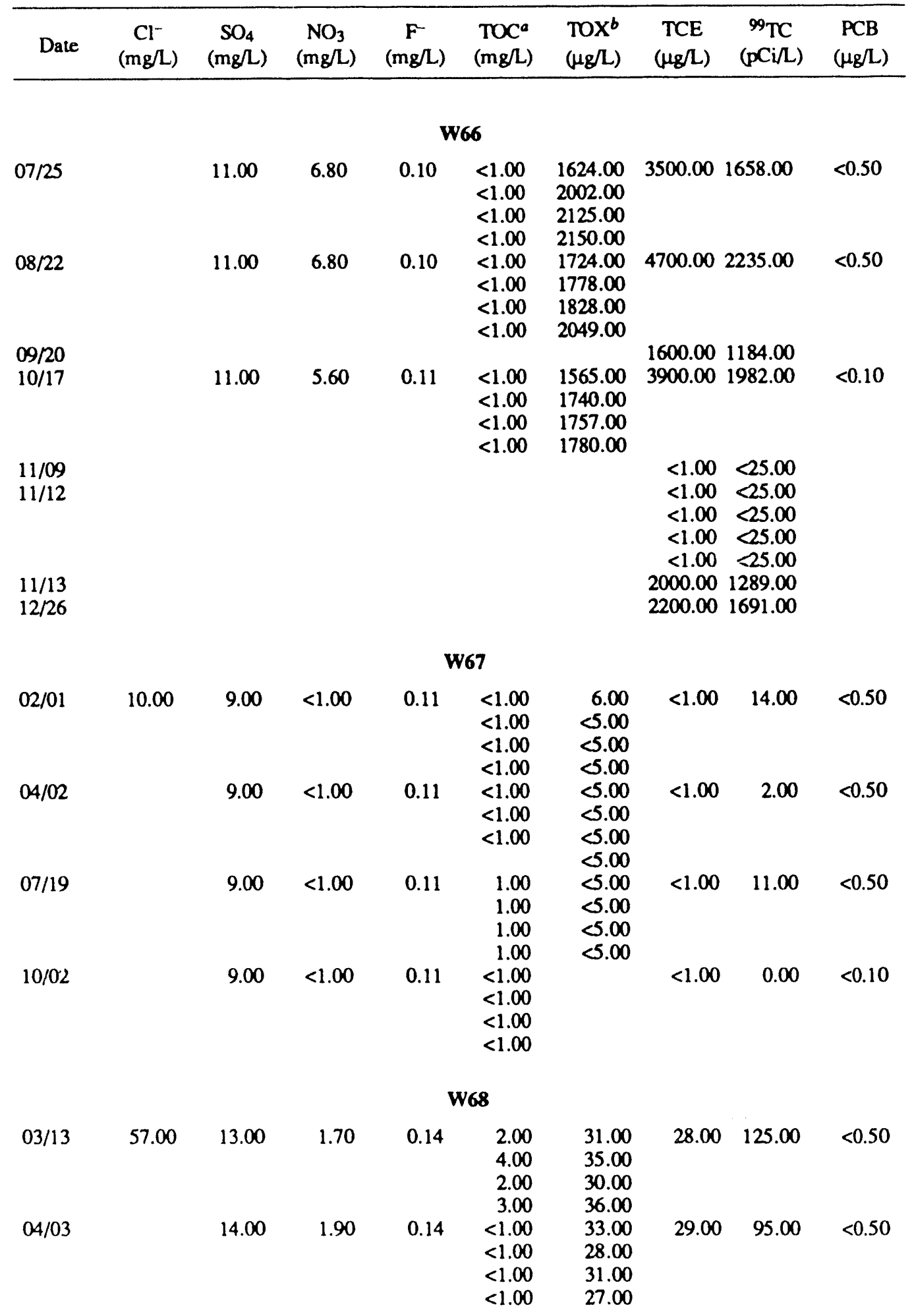


Table 4.7 (continued)

\begin{tabular}{|c|c|c|c|c|c|c|c|c|c|}
\hline Date & $\begin{array}{c}\mathrm{Cl}^{-} \\
(\mathrm{mg} / \mathrm{L})\end{array}$ & $\begin{array}{c}\mathrm{SO}_{4} \\
(\mathrm{mg} / \mathrm{L})\end{array}$ & $\begin{array}{c}\mathrm{NO}_{3} \\
(\mathrm{mg} / \mathrm{L})\end{array}$ & $\begin{array}{c}F^{-} \\
(m g / L)\end{array}$ & $\begin{array}{c}\text { TOC }^{a} \\
(\mathrm{mg} / \mathrm{L})\end{array}$ & $\begin{array}{l}\text { TOX }^{b} \\
(\mu g / L)\end{array}$ & $\begin{array}{c}\text { TCE } \\
(\mu g / L)\end{array}$ & $\begin{array}{c}{ }^{99} \mathrm{TC} \\
(\mathrm{pCi} / \mathrm{L})\end{array}$ & $\begin{array}{c}\text { РCB } \\
(\mu \mathrm{g} / \mathrm{L})\end{array}$ \\
\hline \multicolumn{10}{|c|}{ W68 } \\
\hline $07 / 11$ & & 13.00 & 1.40 & 0.16 & $\begin{array}{l}<1.00 \\
<1.00 \\
<1.00 \\
<1.00\end{array}$ & $\begin{array}{r}13.00 \\
8.00 \\
15.00 \\
14.00\end{array}$ & 12.00 & 102.00 & $<0.50$ \\
\hline $10 / 03$ & & 12.00 & 1.40 & 0.12 & $\begin{array}{l}<1.00 \\
<1.00 \\
<1.00 \\
<1.00\end{array}$ & & 30.00 & 107.00 & $<0.10$ \\
\hline \multicolumn{10}{|c|}{ W71 } \\
\hline $03 / 13$ & 97.00 & 8.00 & $<1.00$ & 0.11 & $\begin{array}{r}<1.00 \\
1.00 \\
2.00 \\
5.00\end{array}$ & $\begin{array}{l}28.00 \\
37.00 \\
26.00 \\
36.00\end{array}$ & 6.00 & 20.00 & $<0.50$ \\
\hline $04 / 04$ & & 11.00 & $<1.00$ & 0.12 & $\begin{array}{r}1.20 \\
1.20 \\
1.00 \\
<1.00\end{array}$ & $\begin{array}{l}31.00 \\
31.00 \\
37.00 \\
35.00\end{array}$ & 7.00 & 18.00 & $<0.50$ \\
\hline $07 / 11$ & & 8.00 & 1.20 & 0.11 & $\begin{array}{l}2.00 \\
2.00 \\
2.00 \\
1.00\end{array}$ & $\begin{array}{l}21.00 \\
36.00 \\
25.00 \\
30.00\end{array}$ & 3.00 & 2.00 & $<0.50$ \\
\hline $10 / 03$ & & 6.00 & $<1.00$ & 0.10 & $\begin{array}{l}1.00 \\
1.00 \\
1.00 \\
1.00\end{array}$ & & 3.00 & 1.00 & $<0.10$ \\
\hline
\end{tabular}

'Total organic carbon.

bTotal organic haolgen. 
Table 4.8. Quarterly effluent monitoring of metals at solid waste management units

\begin{tabular}{|c|c|c|c|c|c|c|}
\hline Date & $\begin{array}{c}\text { Chromium } \\
(\mathrm{mg} / \mathrm{L})\end{array}$ & $\begin{array}{l}\text { Copper } \\
(\mathrm{mg} / \mathrm{L})\end{array}$ & $\begin{array}{c}\text { Iron } \\
(\mathrm{mg} / \mathrm{L})\end{array}$ & $\begin{array}{c}\text { Lead } \\
(\mathrm{mg} / \mathrm{L})\end{array}$ & $\begin{array}{l}\text { Nickel } \\
(\mathrm{mg} / \mathrm{L})\end{array}$ & $\begin{array}{c}\text { Zinc } \\
(\mathrm{mg} / \mathrm{L})\end{array}$ \\
\hline \multicolumn{7}{|c|}{ W16 } \\
\hline $\begin{array}{l}01 / 10 \\
05 / 22 \\
08 / 09 \\
11 / 14\end{array}$ & $\begin{array}{l}<0.050 \\
<0.050 \\
<0.050 \\
<0.050\end{array}$ & $\begin{array}{l}0.380 \\
0.172 \\
0.301 \\
0.095\end{array}$ & $\begin{array}{r}0.870 \\
0.500 \\
0.965 \\
<0.010\end{array}$ & $\begin{array}{l}<0.200 \\
<0.200 \\
<0.200 \\
<0.200\end{array}$ & $\begin{array}{r}<0.050 \\
<0.050 \\
0.050 \\
<0.050\end{array}$ & $\begin{array}{l}0.400 \\
0.125 \\
0.258 \\
0.087\end{array}$ \\
\hline \multicolumn{7}{|c|}{ W17 } \\
\hline $\begin{array}{l}01 / 04 \\
05 / 22\end{array}$ & $<0.050$ & 0.640 & 0.140 & $<0.200$ & 0.260 & 1.500 \\
\hline $\begin{array}{l}08 / 29 \\
11 / 29\end{array}$ & $\begin{array}{r}0.148 \\
<0.050\end{array}$ & $\begin{array}{l}0.316 \\
0.639\end{array}$ & $\begin{array}{l}1.900 \\
0.326\end{array}$ & $\begin{array}{l}<0.200 \\
<0.200\end{array}$ & $\begin{array}{l}0.090 \\
0.073\end{array}$ & $\begin{array}{l}0.240 \\
0.627\end{array}$ \\
\hline \multicolumn{7}{|c|}{ W18 } \\
\hline $\begin{array}{l}01 / 09 \\
05 / 16 \\
08 / 21 \\
11 / 14\end{array}$ & $\begin{array}{l}<0.050 \\
<0.050 \\
<0.050 \\
<0.050\end{array}$ & $\begin{array}{r}0.140 \\
<0.010 \\
<0.010 \\
<0.010\end{array}$ & $\begin{array}{l}7.540 \\
7.700 \\
7.540 \\
7.450\end{array}$ & $\begin{array}{l}<0.200 \\
<0.200 \\
<0.200 \\
<0.200\end{array}$ & $\begin{array}{l}<0.050 \\
<0.050 \\
<0.050 \\
<0.050\end{array}$ & $\begin{array}{r}0.060 \\
0.009 \\
<0.005 \\
0.005\end{array}$ \\
\hline \multicolumn{7}{|c|}{ W19 } \\
\hline $\begin{array}{l}01 / 11 \\
05 / 24\end{array}$ & $<0.050$ & 0.800 & 0.220 & $<0.200$ & 0.120 & 1.950 \\
\hline $\begin{array}{l}08 / 23 \\
10 / 04\end{array}$ & $\begin{array}{l}<0.050 \\
<0.050\end{array}$ & $\begin{array}{l}0.702 \\
0.469\end{array}$ & $\begin{array}{l}1.310 \\
0.291\end{array}$ & $\begin{array}{l}<0.200 \\
<0.200\end{array}$ & $\begin{array}{r}0.066 \\
<0.050\end{array}$ & $\begin{array}{l}0.898 \\
0.550\end{array}$ \\
\hline \multicolumn{7}{|c|}{ W20 } \\
\hline $\begin{array}{l}01 / 18 \\
04 / 19 \\
11 / 01\end{array}$ & $\begin{array}{r}<0.050 \\
0.077 \\
<0.050\end{array}$ & $\begin{array}{l}0.100 \\
0.092 \\
0.093\end{array}$ & $\begin{array}{l}18.950 \\
10.560 \\
15.540\end{array}$ & $\begin{array}{l}<0.200 \\
<0.200 \\
<0.200\end{array}$ & $\begin{array}{l}<0.050 \\
<0.050 \\
<0.050\end{array}$ & $\begin{array}{l}0.080 \\
0.065\end{array}$ \\
\hline \multicolumn{7}{|c|}{ W21 } \\
\hline $\begin{array}{l}01 / 24 \\
06 / 14 \\
08 / 30 \\
10 / 23\end{array}$ & $\begin{array}{l}<0.050 \\
<0.050 \\
<0.050 \\
<0.050\end{array}$ & $\begin{array}{r}<0.010 \\
<0.010 \\
0.012 \\
<0.010\end{array}$ & $\begin{array}{l}0.770 \\
0.920 \\
0.780 \\
1.160\end{array}$ & $\begin{array}{l}<0.200 \\
<0.200 \\
<0.200 \\
<0.200\end{array}$ & $\begin{array}{l}0.100 \\
0.080 \\
0.060 \\
0.052\end{array}$ & $\begin{array}{l}0.070 \\
0.049 \\
0.072 \\
0.047\end{array}$ \\
\hline \multicolumn{7}{|c|}{ W22 } \\
\hline $\begin{array}{l}01 / 23 \\
06 / 21 \\
08 / 21 \\
10 / 31\end{array}$ & $\begin{array}{r}<0.050 \\
0.032 \\
<0.050 \\
<0.050\end{array}$ & $\begin{array}{l}<0.010 \\
<0.010 \\
<0.010 \\
<0.010\end{array}$ & $\begin{array}{r}12.550 \\
10.350 \\
10.000 \\
7.400\end{array}$ & $\begin{array}{l}<0.200 \\
<0.200 \\
<0.200 \\
<0.200\end{array}$ & $\begin{array}{l}<0.050 \\
<0.050 \\
<0.050 \\
<0.050\end{array}$ & $\begin{array}{r}0.005 \\
0.010 \\
<0.004 \\
0.013\end{array}$ \\
\hline \multicolumn{7}{|c|}{ W23 } \\
\hline $09 / 04$ & 0.064 & $<0.010$ & 5.700 & $<0.200$ & $<0.050$ & 68.350 \\
\hline \multicolumn{7}{|c|}{ W24 } \\
\hline $09 / 05$ & $<0.050$ & $<0.010$ & 1.142 & $<0.200$ & $<0.050$ & 20.480 \\
\hline
\end{tabular}


Table 4.8 (continued)

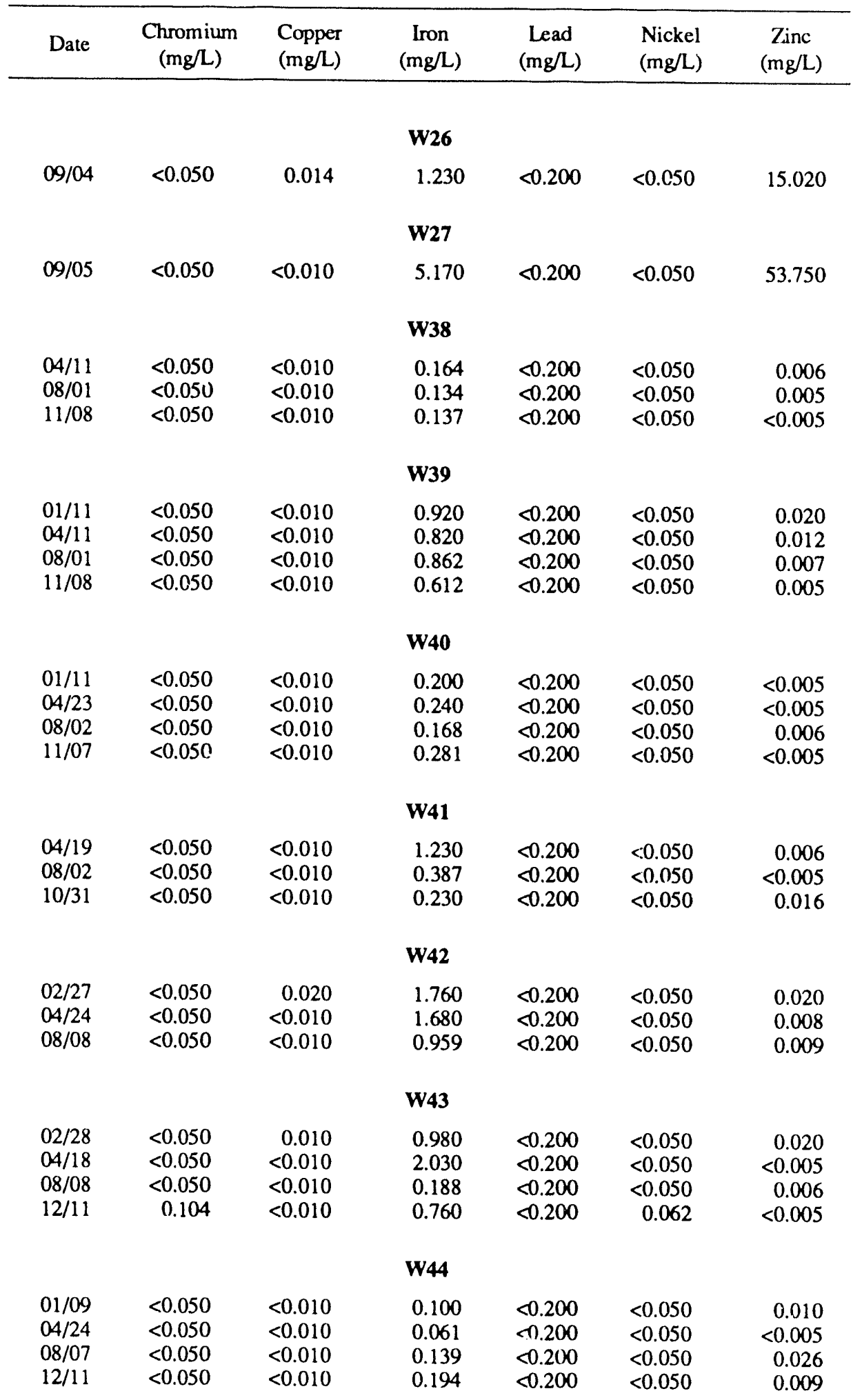


Table 4.8 (continued)

\begin{tabular}{|c|c|c|c|c|c|c|}
\hline Date & $\begin{array}{c}\text { Chromium } \\
(\mathrm{mg} / \mathrm{L})\end{array}$ & $\begin{array}{l}\text { Copper } \\
(\mathrm{mg} / \mathrm{L})\end{array}$ & $\begin{array}{c}\text { Iron } \\
(\mathrm{mg} / \mathrm{L})\end{array}$ & $\begin{array}{l}\text { Lead } \\
(\mathrm{mg} / \mathrm{L})\end{array}$ & $\begin{array}{l}\text { Nickel } \\
(\mathrm{mg} / \mathrm{l})\end{array}$ & $\begin{array}{c}\text { Zinc } \\
(\mathrm{mg} / \mathrm{L})\end{array}$ \\
\hline \multicolumn{7}{|c|}{ W46 } \\
\hline $\begin{array}{l}03 / 06 \\
05 / 16 \\
08 / 16 \\
10 / 17\end{array}$ & $\begin{array}{l}<0.050 \\
<0.050 \\
<0.050 \\
<0.050\end{array}$ & $\begin{array}{l}<0.010 \\
<0.010 \\
<0.010 \\
<0.010\end{array}$ & $\begin{array}{l}5.500 \\
7.600 \\
8.110 \\
9.310\end{array}$ & $\begin{array}{l}<0.200 \\
<0.200 \\
<0.200 \\
<0.200\end{array}$ & $\begin{array}{l}<0.050 \\
<0.050 \\
<0.050 \\
<0.050\end{array}$ & $\begin{array}{l}0.010 \\
0.026 \\
0.006 \\
0.011\end{array}$ \\
\hline \multicolumn{7}{|c|}{ W47 } \\
\hline $\begin{array}{l}03 / 22 \\
08 / 15 \\
08 / 24 \\
10 / 25\end{array}$ & 0.121 & 0.055 & 285.000 & $<0.200$ & 0.078 & 0.393 \\
\hline \multicolumn{7}{|c|}{ W48 } \\
\hline $05 / 16$ & $<0.050$ & $<0.010$ & 8.550 & $<0.200$ & $<0.050$ & 0.023 \\
\hline \multicolumn{7}{|c|}{ W54 } \\
\hline $\begin{array}{l}05 / 31 \\
08 / 17 \\
10 / 16\end{array}$ & $\begin{array}{r}<0.050 \\
<0.050 \\
0.016\end{array}$ & $\begin{array}{r}0.014 \\
<0.010 \\
<0.010\end{array}$ & $\begin{array}{r}17.230 \\
3.976 \\
4.553\end{array}$ & $\begin{array}{l}<0.200 \\
<0.200 \\
<0.200\end{array}$ & $\begin{array}{l}<0.050 \\
<0.050 \\
<0.050\end{array}$ & $\begin{array}{l}0.040 \\
0.012 \\
0.006\end{array}$ \\
\hline \multicolumn{7}{|c|}{ W57 } \\
\hline $\begin{array}{l}03 / 06 \\
05 / 30 \\
08 / 30 \\
10 / 30\end{array}$ & $\begin{array}{l}<0.050 \\
<0.050 \\
<0.050 \\
<0.050\end{array}$ & $\begin{array}{l}<0.010 \\
<0.010 \\
<0.010 \\
<0.010\end{array}$ & $\begin{array}{l}35.650 \\
20.060 \\
21.780 \\
11.100\end{array}$ & $\begin{array}{l}<0.200 \\
<0.200 \\
<0.200 \\
<0.200\end{array}$ & $\begin{array}{l}<0.050 \\
<0.050 \\
<0.050 \\
<0.050\end{array}$ & $\begin{array}{l}0.060 \\
0.014 \\
0.046 \\
0.031\end{array}$ \\
\hline \multicolumn{7}{|c|}{ W58 } \\
\hline $08 / 16$ & $<0.050$ & $<0.010$ & 4.386 & $<0.200$ & $<0.050$ & 0.013 \\
\hline \multicolumn{7}{|c|}{ W62 } \\
\hline $11 / 13$ & $<0.050$ & $<0.010$ & 5.950 & $<0.200$ & $<0.050$ & 0.006 \\
\hline \multicolumn{7}{|c|}{ W63 } \\
\hline $\begin{array}{l}01 / 23 \\
04 / 03 \\
07 / 12 \\
10 / 02\end{array}$ & $\begin{array}{r}0.070 \\
<0.050 \\
0.095 \\
<0.050\end{array}$ & $\begin{array}{l}<0.010 \\
<0.010 \\
<0.010 \\
<0.010\end{array}$ & $\begin{array}{l}1.670 \\
0.560 \\
2.870 \\
0.348\end{array}$ & $\begin{array}{l}<0.200 \\
<0.200 \\
<0.200 \\
<0.200\end{array}$ & $\begin{array}{l}0.110 \\
0.104 \\
0.138 \\
0.109\end{array}$ & $\begin{array}{r}<0.005 \\
0.005 \\
0.016 \\
<0.005\end{array}$ \\
\hline \multicolumn{7}{|c|}{ W64 } \\
\hline $\begin{array}{l}01 / 25 \\
07 / 18 \\
10 / 03\end{array}$ & $\begin{array}{r}0.050 \\
<0.050 \\
<0.050\end{array}$ & $\begin{array}{l}<0.010 \\
<0.010 \\
<0.010\end{array}$ & $\begin{array}{l}3.700 \\
0.602 \\
0.540\end{array}$ & $\begin{array}{l}<0.200 \\
<0.200 \\
<0.200\end{array}$ & $\begin{array}{l}0.130 \\
0.236 \\
0.110\end{array}$ & $\begin{array}{r}0.020 \\
0.010 \\
<0.005\end{array}$ \\
\hline
\end{tabular}


Table 4.8 (continued)

\begin{tabular}{|c|c|c|c|c|c|c|}
\hline Date & $\begin{array}{l}\text { Chromium } \\
(\mathrm{mg} / \mathrm{L})\end{array}$ & $\begin{array}{l}\text { Copper } \\
(\mathrm{mg} / \mathrm{L})\end{array}$ & $\begin{array}{c}\text { Iron } \\
(\mathrm{mg} / \mathrm{L})\end{array}$ & $\begin{array}{c}\text { Lead } \\
(\mathrm{mg} / \mathrm{L})\end{array}$ & $\begin{array}{l}\text { Nickel } \\
(\mathrm{mg} / \mathrm{L})\end{array}$ & $\begin{array}{c}\text { Zinc } \\
(\mathrm{mg} / \mathrm{L})\end{array}$ \\
\hline \multicolumn{7}{|c|}{ W65 } \\
\hline $\begin{array}{l}02 / 02 \\
04 / 03 \\
07 / 17 \\
10 / 02\end{array}$ & $\begin{array}{l}<0.050 \\
<0.050 \\
<0.050 \\
<0.050\end{array}$ & $\begin{array}{l}<0.010 \\
<0.010 \\
<0.010 \\
<0.010\end{array}$ & $\begin{array}{l}0.040 \\
0.048 \\
0.156 \\
0.033\end{array}$ & $\begin{array}{l}<0.200 \\
<0.200 \\
<0.200 \\
<0.200\end{array}$ & $\begin{array}{l}<0.050 \\
<0.050 \\
<0.050 \\
<0.050\end{array}$ & $\begin{array}{l}0.020 \\
0.021 \\
0.008 \\
0.050\end{array}$ \\
\hline \multicolumn{7}{|c|}{ W66 } \\
\hline $\begin{array}{l}01 / 18 \\
04 / 10 \\
07 / 25 \\
08 / 22 \\
10 / 17\end{array}$ & $\begin{array}{l}<0.050 \\
<0.050 \\
<0.050 \\
<0.050 \\
<0.050\end{array}$ & $\begin{array}{l}<0.010 \\
<0.010 \\
<0.010 \\
<0.010 \\
<0.010\end{array}$ & $\begin{array}{l}0.020 \\
0.360 \\
0.043 \\
1.437 \\
0.093\end{array}$ & $\begin{array}{l}<0.200 \\
<0.200 \\
<0.200 \\
<0.200 \\
<0.200\end{array}$ & $\begin{array}{r}<0.050 \\
<0.050 \\
<0.050 \\
0.185 \\
<0.050\end{array}$ & $\begin{array}{r}0.005 \\
0.060 \\
<0.005 \\
<0.001 \\
0.005\end{array}$ \\
\hline \multicolumn{7}{|c|}{ W67 } \\
\hline $\begin{array}{l}02 / 01 \\
04 / 02 \\
07 / 19 \\
10 / 02\end{array}$ & $\begin{array}{l}<0.050 \\
<0.050 \\
<0.050 \\
<0.050\end{array}$ & $\begin{array}{l}<0.010 \\
<0.010 \\
<0.010 \\
<0.010\end{array}$ & $\begin{array}{r}0.200 \\
0.112 \\
0.126 \\
<0.010\end{array}$ & $\begin{array}{l}<0.200 \\
<0.200 \\
<0.200 \\
<0.200\end{array}$ & $\begin{array}{l}0.060 \\
0.060 \\
0.082 \\
0.052\end{array}$ & $\begin{array}{r}<0.005 \\
0.005 \\
0.006 \\
<0.005\end{array}$ \\
\hline \multicolumn{7}{|c|}{ W68 } \\
\hline $\begin{array}{l}03 / 13 \\
04 / 03 \\
07 / 11 \\
10 / 03\end{array}$ & $\begin{array}{l}<0.050 \\
<0.050 \\
<0.050 \\
<0.050\end{array}$ & $\begin{array}{l}<0.010 \\
<0.010 \\
<0.010 \\
<0.010\end{array}$ & $\begin{array}{l}0.185 \\
0.081 \\
0.166 \\
0.020\end{array}$ & $\begin{array}{l}<0.200 \\
<0.200 \\
<0.200 \\
<0.200\end{array}$ & $\begin{array}{l}<0.050 \\
<0.050 \\
<0.050 \\
<0.050\end{array}$ & $\begin{array}{l}0.030 \\
0.032 \\
0.042 \\
0.027\end{array}$ \\
\hline \multicolumn{7}{|c|}{ W71 } \\
\hline $\begin{array}{l}03 / 13 \\
04 / 04 \\
07 / 11 \\
10 / 03\end{array}$ & $\begin{array}{r}0.115 \\
<0.050 \\
0.162 \\
0.108\end{array}$ & $\begin{array}{r}<0.010 \\
<0.010 \\
0.010 \\
<0.010\end{array}$ & $\begin{array}{l}0.995 \\
0.325 \\
1.230 \\
1.260\end{array}$ & $\begin{array}{l}<0.200 \\
<0.200 \\
<0.200 \\
<0.200\end{array}$ & $\begin{array}{l}0.094 \\
0.104 \\
0.195 \\
0.112\end{array}$ & $\begin{array}{l}0.011 \\
0.024 \\
0.033 \\
0.014\end{array}$ \\
\hline
\end{tabular}


Table 4.9. Quarterly effluent monitoring of radionuclide parameters at solid waste management units

\begin{tabular}{|c|c|c|c|c|c|}
\hline Date & $\begin{array}{l}\text { Uranium } \\
\text { (mg/L) }\end{array}$ & $\begin{array}{l}\text { Dissuived } \\
\text { alpha } \\
(p C i / L)\end{array}$ & $\begin{array}{c}\text { Suspended } \\
\text { alpha } \\
\text { (pCi/L) }\end{array}$ & $\begin{array}{c}\text { Dissolved } \\
\text { beta } \\
(p C i / L)\end{array}$ & $\begin{array}{c}\text { Suspended } \\
\text { beta } \\
(\mathrm{pCi} / \mathrm{L})\end{array}$ \\
\hline \multicolumn{6}{|c|}{ W16 } \\
\hline $\begin{array}{l}01 / 10 \\
05 / 22 \\
08 / 09 \\
11 / 14\end{array}$ & $\begin{array}{l}<0.001 \\
<0.001 \\
<0.001 \\
<0.001\end{array}$ & $\begin{array}{r}4.0 \\
22.4 \\
0.9 \\
5.3\end{array}$ & $\begin{array}{r}0.9 \\
15.3 \\
0.9 \\
0.2\end{array}$ & $\begin{array}{l}28.0 \\
24.0 \\
13.0 \\
28.0\end{array}$ & $\begin{array}{r}6.0 \\
24.0 \\
6.0 \\
3.0\end{array}$ \\
\hline \multicolumn{6}{|c|}{ W17 } \\
\hline $\begin{array}{l}01 / 04 \\
05 / 22 \\
08 / 29 \\
11 / 29\end{array}$ & $\begin{array}{l}0.014 \\
0.010 \\
0.011 \\
0.011\end{array}$ & $\begin{array}{r}9.0 \\
\\
2.3 \\
16.9\end{array}$ & $\begin{array}{l}2.3 \\
0.9\end{array}$ & $\begin{array}{l}15.0 \\
17.0\end{array}$ & $\begin{array}{r}15.0 \\
6.0\end{array}$ \\
\hline \multicolumn{6}{|c|}{ W18 } \\
\hline $\begin{array}{l}01 / 09 \\
05 / 16 \\
08 / 21 \\
11 / 14\end{array}$ & $\begin{array}{l}0.003 \\
0.002 \\
0.003 \\
0.003\end{array}$ & $\begin{array}{r}1.8 \\
13.9 \\
11.8 \\
10.5\end{array}$ & $\begin{array}{l}0.8 \\
1.9 \\
1.4 \\
1.4\end{array}$ & $\begin{array}{r}12.0 \\
4.0 \\
3.0 \\
8.0\end{array}$ & $\begin{array}{l}1.0 \\
2.0 \\
8.0 \\
8.0\end{array}$ \\
\hline \multicolumn{6}{|c|}{ W19 } \\
\hline $\begin{array}{l}01 / 11 \\
05 / 24 \\
08 / 23 \\
10 / 04\end{array}$ & $\begin{array}{r}0.001 \\
0.001 \\
<0.001 \\
<0.001\end{array}$ & $\begin{array}{r}2.3 \\
2.8 \\
10.0 \\
12.8\end{array}$ & $\begin{array}{l}2.0 \\
1.8 \\
1.1 \\
2.9\end{array}$ & $\begin{array}{r}20.0 \\
28.0 \\
9.0 \\
13.0\end{array}$ & $\begin{array}{l}1.0 \\
6.0 \\
4.0 \\
7.0\end{array}$ \\
\hline \multicolumn{6}{|c|}{$\mathbf{W} 20$} \\
\hline $\begin{array}{l}01 / 18 \\
04 / 19 \\
11 / 01\end{array}$ & $\begin{array}{l}<0.001 \\
<0.001 \\
<0.001\end{array}$ & $\begin{array}{l}5.3 \\
0.0 \\
0.0\end{array}$ & $\begin{array}{l}0.7 \\
0.0 \\
1.1\end{array}$ & $\begin{array}{r}29.0 \\
48.0 \\
101.0\end{array}$ & $\begin{array}{l}7.0 \\
0.0 \\
5.0\end{array}$ \\
\hline \multicolumn{6}{|c|}{$\mathbf{W} 21$} \\
\hline $\begin{array}{l}01 / 24 \\
06 / 14 \\
08 / 30 \\
10 / 23\end{array}$ & $\begin{array}{l}<0.001 \\
<0.001 \\
<0.001 \\
<0.001\end{array}$ & $\begin{array}{r}6.8 \\
21.7 \\
0.3 \\
8.1\end{array}$ & $\begin{array}{l}2.6 \\
1.1 \\
1.4 \\
1.6\end{array}$ & $\begin{array}{r}16.0 \\
8.6 \\
1.0 \\
5.0\end{array}$ & $\begin{array}{l}5.0 \\
5.0 \\
8.0 \\
5.0\end{array}$ \\
\hline \multicolumn{6}{|c|}{ W22 } \\
\hline $\begin{array}{l}01 / 23 \\
06 / 21 \\
08 / 21 \\
10 / 31\end{array}$ & $\begin{array}{l}<0.001 \\
<0.001 \\
<0.001 \\
<0.001\end{array}$ & $\begin{array}{l}2.5 \\
2.5 \\
5.5 \\
1.1\end{array}$ & $\begin{array}{l}2.3 \\
3.3 \\
2.1 \\
6.3\end{array}$ & $\begin{array}{l}25.0 \\
37.0 \\
21.0 \\
50.0\end{array}$ & $\begin{array}{l}3.0 \\
4.0 \\
4.0 \\
4.0\end{array}$ \\
\hline \multicolumn{6}{|c|}{ W23 } \\
\hline $09 / 04$ & 0.001 & 0.6 & 3.4 & 1.0 & 14.0 \\
\hline \multicolumn{6}{|c|}{ W24 } \\
\hline $09 / 05$ & & 1.0 & 4.4 & 1.0 & 13.0 \\
\hline
\end{tabular}


Table 4.9 (continued)

\begin{tabular}{|c|c|c|c|c|c|}
\hline Date & $\begin{array}{l}\text { Uranium } \\
(\mathrm{mg} / \mathrm{L})\end{array}$ & $\begin{array}{c}\text { Dissolved } \\
\text { alpha } \\
(\mathrm{pCi} / \mathrm{L})\end{array}$ & $\begin{array}{l}\text { Suspended } \\
\text { alpha } \\
(\text { pCi/L) }\end{array}$ & $\begin{array}{c}\text { Dissolved } \\
\text { beta } \\
(\mathrm{pCi} / \mathrm{L})\end{array}$ & $\begin{array}{c}\text { Suspended } \\
\text { beta } \\
(\mathrm{pCi} / \mathrm{L})\end{array}$ \\
\hline \multicolumn{6}{|c|}{ W26 } \\
\hline $09 / 04$ & 0.019 & 0.6 & 2.7 & 1.0 & 9.0 \\
\hline \multicolumn{6}{|c|}{ W27 } \\
\hline $09 / 05$ & $<0.001$ & 0.8 & 0.2 & 1.6 & 13.0 \\
\hline \multicolumn{6}{|c|}{ W38 } \\
\hline $04 / 11$ & $<0.001$ & 1.3 & 1.6 & 15.0 & 4.0 \\
\hline $08 / 01$ & $<0.001$ & 3.2 & 0.0 & 9.0 & 3.0 \\
\hline $11 / 08$ & $<0.001$ & 2.1 & 0.0 & 29.0 & 9.0 \\
\hline \multicolumn{6}{|c|}{ W39 } \\
\hline $01 / 11$ & $<0.001$ & 2.0 & 1.6 & 7.0 & 5.0 \\
\hline $04 / 11$ & $<0.001$ & 3.5 & 1.1 & 10.0 & 1.0 \\
\hline $08 / 01$ & $<0.001$ & 28.2 & 7.0 & 24.0 & 11.0 \\
\hline $11 / 08$ & $<0.001$ & 8.6 & 0.7 & 1.0 & 6.0 \\
\hline \multicolumn{6}{|c|}{ W40 } \\
\hline $01 / 11$ & $<0.001$ & 2.9 & 2.0 & 12.0 & 9.0 \\
\hline $04 / 23$ & $<0.001$ & 0.9 & 0.0 & 4.0 & 1.0 \\
\hline $08 / 02$ & $<0.001$ & 11.6 & 3.6 & 18.0 & 35.0 \\
\hline $11 / 07$ & $<0.001$ & 1.9 & 5.6 & 20.0 & 3.0 \\
\hline \multicolumn{6}{|c|}{ W41 } \\
\hline $04 / 19$ & $<0.001$ & 1.4 & 0.0 & 1.0 & 0.0 \\
\hline $08 / 02$ & $<0.001$ & 12.2 & 3.6 & 24.0 & 6.0 \\
\hline $10 / 31$ & $<0.001$ & 3.2 & 0.8 & 9.0 & 1.5 \\
\hline \multicolumn{6}{|c|}{ W42 } \\
\hline $02 / 27$ & $<0.001$ & 0.9 & 1.8 & 18.0 & 3.0 \\
\hline $04 / 24$ & $<0.001$ & 3.2 & 0.8 & 10.0 & 0.0 \\
\hline $08 / 08$ & $<0.001$ & 2.4 & 0.6 & 4.0 & 9.0 \\
\hline \multicolumn{6}{|c|}{ W43 } \\
\hline $02 / 28$ & $<0.001$ & 6.1 & 7.4 & 7.0 & 8.0 \\
\hline $04 / 18$ & $<0.001$ & 0.0 & 0.0 & 10.0 & 1.0 \\
\hline $08 / 08$ & $<0.001$ & 13.0 & 4.7 & 9.0 & 9.0 \\
\hline $12 / 11$ & $<0.001$ & 3.4 & 0.1 & 5.0 & 4.0 \\
\hline \multicolumn{6}{|c|}{ W44 } \\
\hline $01 / 09$ & $<0.001$ & 0.9 & 0.0 & 21.0 & 12.0 \\
\hline $04 / 24$ & $<0.001$ & 0.1 & 0.8 & 11.0 & 0.0 \\
\hline $08 / 07$ & $<0.001$ & 2.6 & 1.9 & 5.0 & 1.0 \\
\hline $12 / 11$ & $<0.001$ & 8.2 & 0.2 & 1.0 & 0.0 \\
\hline
\end{tabular}


Table 4.9 (continued)

\begin{tabular}{|c|c|c|c|c|c|}
\hline Date & $\begin{array}{l}\text { Uranium } \\
(\mathrm{mg} / \mathrm{L})\end{array}$ & $\begin{array}{l}\text { Dissolved } \\
\text { alpha } \\
\text { (pCi } / L)\end{array}$ & $\begin{array}{l}\text { Suspended } \\
\text { alpha } \\
\text { (pCi/L) }\end{array}$ & $\begin{array}{l}\text { Dissolved } \\
\text { beta } \\
\text { (pCi/L) }\end{array}$ & $\begin{array}{c}\text { Suspended } \\
\text { beta } \\
\text { (pCi/L) }\end{array}$ \\
\hline \multicolumn{6}{|c|}{ W46 } \\
\hline $\begin{array}{l}03 / 06 \\
05 / 16 \\
08 / 16 \\
10 / 17\end{array}$ & $\begin{array}{r}<0.001 \\
<0.001 \\
0.006 \\
0.001\end{array}$ & $\begin{array}{l}1.5 \\
2.9 \\
2.1 \\
5.2\end{array}$ & $\begin{array}{l}0.3 \\
1.9 \\
4.7 \\
1.1\end{array}$ & $\begin{array}{l}7.0 \\
2.0 \\
3.0 \\
2.0\end{array}$ & $\begin{array}{r}10.0 \\
0.0 \\
12.0 \\
9.0\end{array}$ \\
\hline \multicolumn{6}{|c|}{ W47 } \\
\hline $10 / 25$ & 0.067 & & & & \\
\hline \multicolumn{6}{|c|}{ W48 } \\
\hline $05 / 16$ & $<0.001$ & 2.2 & 7.2 & 4.0 & 14.0 \\
\hline \multicolumn{6}{|c|}{ W54 } \\
\hline $\begin{array}{l}05 / 31 \\
08 / 17 \\
10 / 16\end{array}$ & $\begin{array}{r}<0.001 \\
<0.001 \\
0.001\end{array}$ & $\begin{array}{l}4.1 \\
1.1 \\
8.5\end{array}$ & $\begin{array}{l}2.8 \\
1.7 \\
2.3\end{array}$ & $\begin{array}{r}42.0 \\
3.0 \\
6.0\end{array}$ & $\begin{array}{l}3.0 \\
5.0 \\
2.0\end{array}$ \\
\hline \multicolumn{6}{|c|}{ W57 } \\
\hline $\begin{array}{l}03 / 06 \\
05 / 30 \\
08 / 30 \\
10 / 30\end{array}$ & $\begin{array}{l}0.053 \\
0.020 \\
0.027 \\
0.021\end{array}$ & $\begin{array}{r}11.8 \\
10.5 \\
0.9 \\
0.4\end{array}$ & $\begin{array}{l}0.5 \\
0.1 \\
0.0 \\
5.6\end{array}$ & $\begin{array}{r}110.0 \\
154.0 \\
2.0 \\
113.0\end{array}$ & $\begin{array}{r}55.0 \\
1.0 \\
5.0 \\
15.0\end{array}$ \\
\hline \multicolumn{6}{|c|}{ W58 } \\
\hline $08 / 16$ & 12.000 & 1749.1 & 4.5 & 1265.0 & 25.0 \\
\hline \multicolumn{6}{|c|}{ W62 } \\
\hline $11 / 13$ & $<0.001$ & 4.5 & 1.8 & 8.0 & 6.0 \\
\hline \multicolumn{6}{|c|}{ W63 } \\
\hline $\begin{array}{l}01 / 23 \\
04 / 03 \\
07 / 12 \\
10 / 02\end{array}$ & $\begin{array}{r}<0.001 \\
<0.001 \\
<0.001 \\
0.002\end{array}$ & $\begin{array}{l}1.9 \\
4.2 \\
2.4 \\
1.8\end{array}$ & $\begin{array}{l}2.3 \\
2.7 \\
0.9 \\
1.6\end{array}$ & $\begin{array}{r}19.0 \\
12.0 \\
10.9 \\
8.0\end{array}$ & $\begin{array}{r}11.0 \\
4.9 \\
9.0 \\
6.0\end{array}$ \\
\hline \multicolumn{6}{|c|}{ W64 } \\
\hline $\begin{array}{l}01 / 25 \\
07 / 18 \\
10 / 03\end{array}$ & $\begin{array}{l}0.006 \\
0.002 \\
0.002\end{array}$ & $\begin{array}{l}2.0 \\
4.5\end{array}$ & $\begin{array}{l}0.6 \\
5.0\end{array}$ & $\begin{array}{r}12.0 \\
3.0\end{array}$ & $\begin{array}{r}11.0 \\
8.0\end{array}$ \\
\hline
\end{tabular}


Table 4.9 (continued)

\begin{tabular}{|c|c|c|c|c|c|}
\hline Date & $\begin{array}{l}\text { Uranium } \\
(\mathrm{mg} / \mathrm{L})\end{array}$ & $\begin{array}{l}\text { Dissolved } \\
\text { alpha } \\
(\mathrm{pCi} / \mathrm{L})\end{array}$ & $\begin{array}{l}\text { Suspended } \\
\text { alpha } \\
(\mathrm{pCi} / L)\end{array}$ & $\begin{array}{l}\text { Dissolved } \\
\text { beta } \\
\text { (pCi/L) }\end{array}$ & $\begin{array}{c}\text { Suspended } \\
\text { beta } \\
(\mathrm{pCi} / \mathrm{L})\end{array}$ \\
\hline \multicolumn{6}{|c|}{ W65 } \\
\hline $02 / 02$ & $<0.001$ & 2.6 & 0.5 & 14.0 & 5.0 \\
\hline $04 / 03$ & $<0.001$ & 0.8 & 1.1 & 1.0 & 1.0 \\
\hline $07 / 17$ & $<0.001$ & 10.0 & 6.2 & 14.0 & 3.0 \\
\hline $10 / 02$ & $<0.001$ & 5.0 & 2.9 & 10.0 & 12.0 \\
\hline \multicolumn{6}{|c|}{ W66 } \\
\hline $01 / 18$ & $<0.001$ & 1.5 & 4.1 & 1882.0 & 10.0 \\
\hline $04 / 10$ & 0.001 & 3.7 & 2.0 & 1484.0 & 10.0 \\
\hline $07 / 25$ & $<0.001$ & 2.8 & 3.2 & 1389.0 & 1.0 \\
\hline $08 / 22$ & $<0.001$ & 17.3 & 0.2 & 2037.0 & 0.0 \\
\hline $10 / 17$ & 0.001 & 31.8 & 16.0 & 1655.0 & 19.0 \\
\hline \multicolumn{6}{|c|}{ W67 } \\
\hline $02 / 01$ & $<0.001$ & 1.2 & 2.3 & 6.0 & 17.0 \\
\hline $04 / 02$ & $<0.001$ & 5.0 & 1.8 & 1.0 & 3.0 \\
\hline $07 / 19$ & $<0.001$ & 1.3 & 1.1 & 5.4 & 7.0 \\
\hline $10 / 02$ & $<0.001$ & 5.0 & 1.1 & 9.0 & 0.0 \\
\hline \multicolumn{6}{|c|}{ W68 } \\
\hline $03 / 13$ & $<0.001$ & 1.3 & 0.9 & 85.0 & 2.0 \\
\hline $04 / 03$ & $<0.001$ & 3.1 & 1.6 & 89.0 & 4.0 \\
\hline $07 / 11$ & $<0.001$ & 2.8 & 0.7 & 28.0 & 8.0 \\
\hline $10 / 03$ & $<0.001$ & 0.0 & 2.0 & 95.0 & 4.0 \\
\hline \multicolumn{6}{|c|}{ W71 } \\
\hline $03 / 13$ & $<0.001$ & 3.7 & 2.5 & 1.0 & 11.7 \\
\hline $04 / 04$ & $<0.001$ & 8.1 & 1.8 & 12.0 & 3.0 \\
\hline $07 / 11$ & $<0.001$ & 1.6 & 1.7 & 1.0 & 5.0 \\
\hline $10 / 03$ & $<0.001$ & 9.5 & 3.2 & 5.0 & 4.0 \\
\hline
\end{tabular}




\begin{tabular}{|c|c|c|c|c|c|c|c|c|c|}
\hline 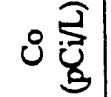 & \multicolumn{2}{|l|}{$\stackrel{8}{4}$} & \multicolumn{5}{|c|}{ ᄋ్లి } & g & స్రి \\
\hline 是炰 & 品 & & & & ?̊ & & & 8 & $\stackrel{8}{-}$ \\
\hline ¿ & $\stackrel{8}{i}$ & & $\underset{\mathrm{V}}{\mathbb{V}}$ & & $\stackrel{8}{\nabla}$ & & & $\underset{\sim}{8}$ & $\underset{8}{8}$ \\
\hline i & $\begin{array}{l}\text { oे } \\
\dot{\theta}\end{array}$ & & 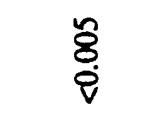 & & $\stackrel{\text { oे }}{0}$ & & $\begin{array}{l}\tilde{8} \\
\stackrel{\leftrightarrow}{\nabla}\end{array}$ & $\begin{array}{l}\text { ờ } \\
\text { ơ }\end{array}$ & 荢 \\
\hline 零总 & : & & त్రి & & ه্ & & $\stackrel{0}{0}$ & : & 兽 \\
\hline $0 \stackrel{\hat{D}}{\hat{E}}$ & ర్ & $\overline{0}$ & $\overline{\dot{\theta}}$ & & ฮั & & & $\ddot{\dot{\theta}}$ & $\ddot{\theta}$ \\
\hline 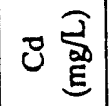 & $\overrightarrow{\dot{v}}$ & & i̊ & & $\ddot{0}$ & & $\dot{0}$ & $\dot{0}$ & $\overline{\dot{\theta}}$ \\
\hline 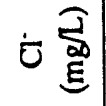 & 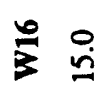 & 邑 & $\hat{z}$ & $\stackrel{\circ}{i}$ & $\stackrel{\infty}{\dot{m}}$ & घ요 & $\hat{B}$ & 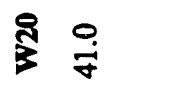 & సี \\
\hline Zू & $\frac{8}{6}$ & $\begin{array}{l}\tilde{a} \\
\ddot{3}\end{array}$ & 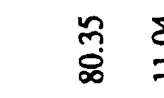 & تِ & \& & 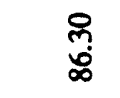 & $\begin{array}{l}\text { Fै } \\
\text { ते } \\
\text { : }\end{array}$ & 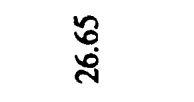 & $\stackrel{\text { s. }}{m}$ \\
\hline$\sum$ 事 & $\stackrel{\overbrace{}}{\varrho}$ & & ్ֶֻ & & స్ః & & $\stackrel{\infty}{\substack{n \\
n}}$ & $\underset{\infty}{q}$ & $\stackrel{n}{\vec{\oplus}}$ \\
\hline Uึ & $\stackrel{\check{n}}{\bar{n}}$ & & 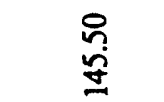 & & 兽 & & $\underset{\tilde{\Xi}}{\tilde{\Xi}}$ & $\stackrel{8}{9}$ & $\begin{array}{l}a \\
\stackrel{8}{8}\end{array}$ \\
\hline 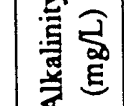 & 足 & & 芯 & & $\stackrel{\circ}{a}$ & & & $\frac{0}{n}$ & $\vec{\oplus}$ \\
\hline 㿝高 & $\begin{array}{l}8 \\
\vdots \\
\vdots\end{array}$ & & $\ddot{\tilde{j}}$ & & 品 & & & : & 过 \\
\hline 좀을 & & 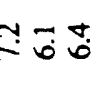 & ?ะ? & oे & & 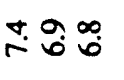 & के & ตู่ธู่ & $\because 208$ \\
\hline 今ّ & & స్ㅇㅇㅇㅎㅇ & 홓중 & 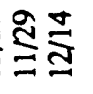 & & 옹 $\overline{\frac{8}{8}}$ & 홓응 & 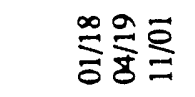 & 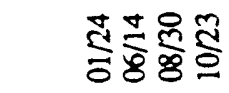 \\
\hline
\end{tabular}




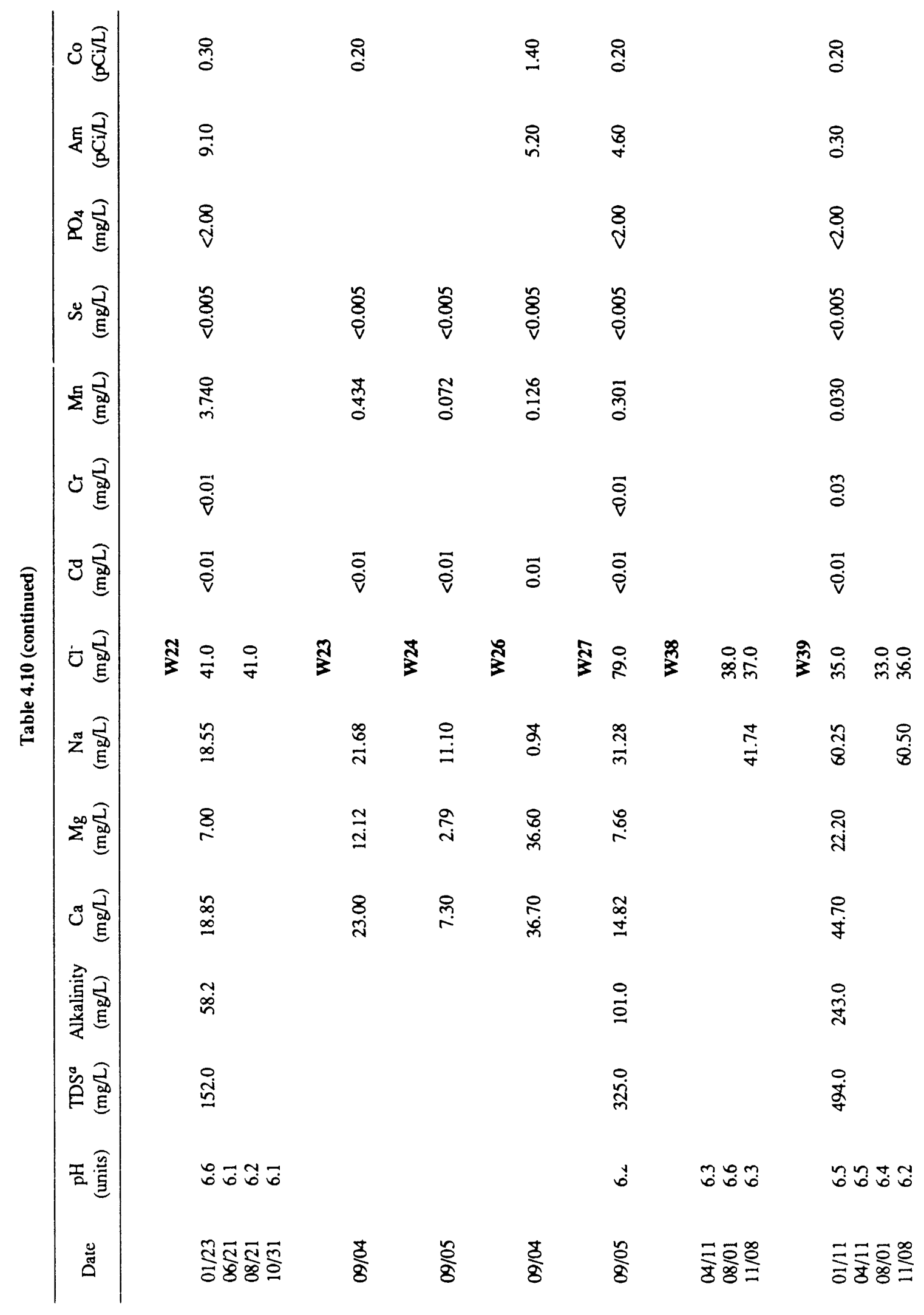




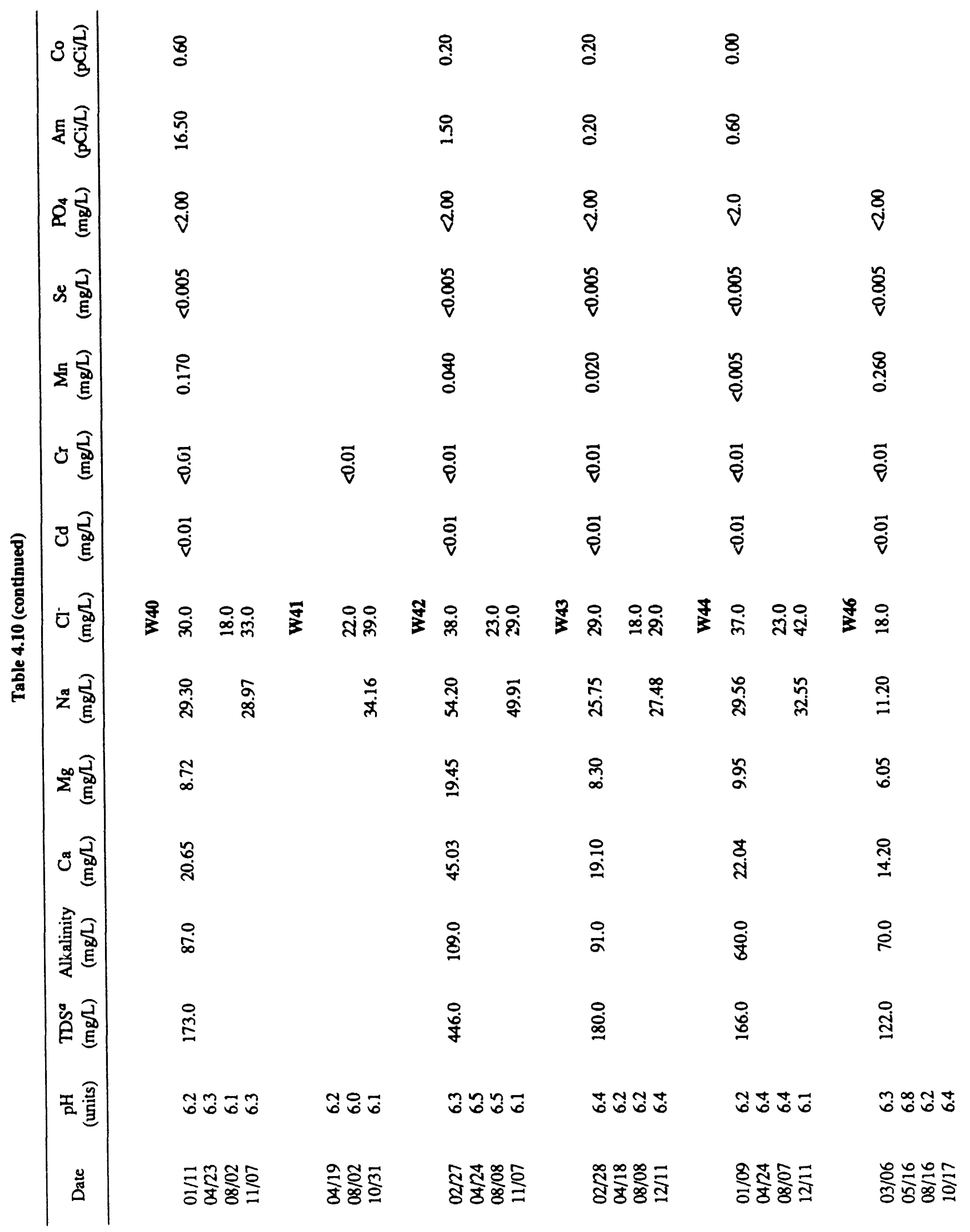




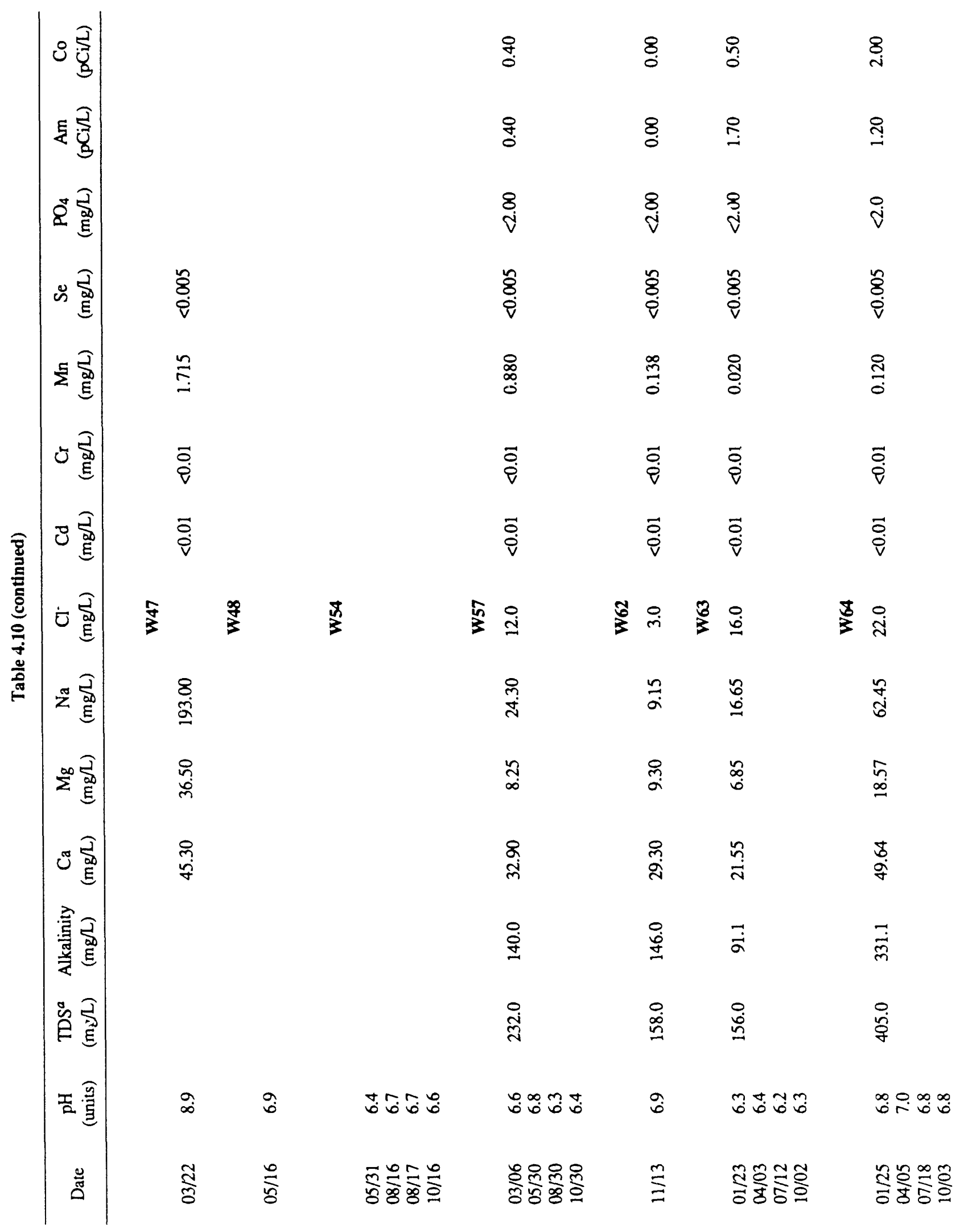




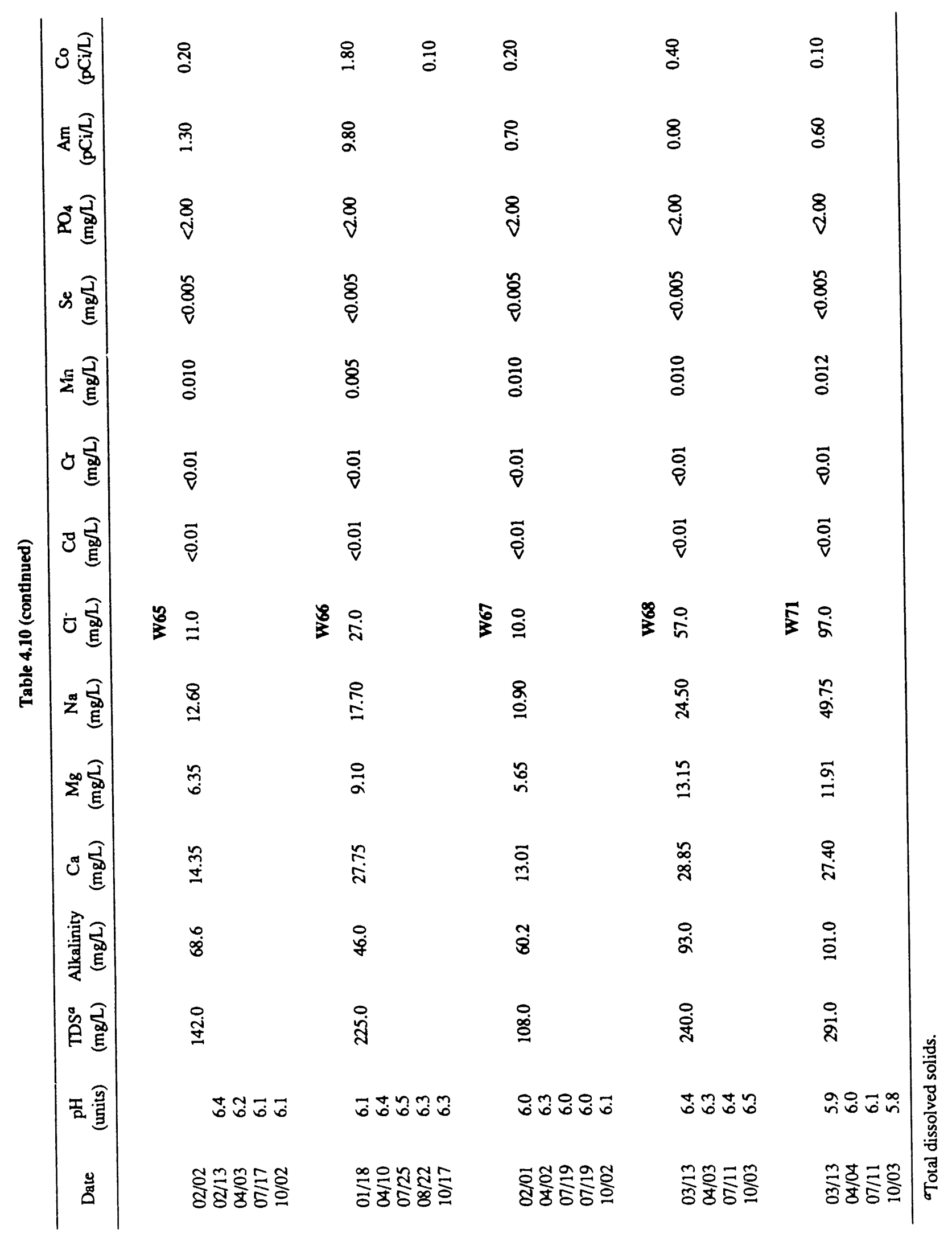




\section{BIOLOGICAL SAMPLING}


Table 5.1. Metal concentrations ( $\mathrm{mg} / \mathrm{kg}$ ) in deer meat and domestic beef

\begin{tabular}{lccc}
\hline Metal & $\begin{array}{c}\text { Reservation deer } \\
\text { average (range) }\end{array}$ & $\begin{array}{c}\text { Reference deer } \\
\text { average (range) }\end{array}$ & $\begin{array}{c}\text { Beef composite } \\
\text { typical }\end{array}$ \\
\hline $\mathrm{Ca}$ & $21(17-25)$ & $23(20-25)$ & 80 \\
$\mathrm{Cu}$ & $1.4(1.2-1.7)$ & $1.2(1.0-1.3)$ & 0.69 \\
$\mathrm{Fe}$ & $32(23-44)$ & $33(32-34)$ & 18.4 \\
$\mathrm{Mg}$ & $260(240-280)$ & $250(250-250)$ & 180 \\
$\mathrm{Na}$ & $320(230-390)$ & $290(270-300)$ & 580 \\
$\mathrm{P}$ & $2,400(2,300-2,500)$ & $2,300(2,300-2,300)$ & 1,610 \\
$\mathrm{Zn}$ & $17(12-22)$ & $22(19-24)$ & 35.7 \\
\hline
\end{tabular}

Table 5.2. Reference doses and metal intakes from ingesting one deer

\begin{tabular}{lcccc}
\hline & $\begin{array}{c}\text { Reference } \\
\text { dose, RfD } \\
(\mathrm{mg} / \text { day })\end{array}$ & $\begin{array}{c}\text { Annualized } \\
\text { reference } \\
\text { dose, RfD } \\
\text { (mg/year) }\end{array}$ & $\begin{array}{c}\text { Estimated } \\
\text { annual intake, } \\
\text { PGDP deer } \\
\text { (mg/year) }\end{array}$ & $\begin{array}{c}\text { Estimated } \\
\text { annual intake, } \\
\text { reference } \\
\text { (mg/year) }\end{array}$ \\
\hline $\mathrm{Ca}$ & & & $420(337-522)$ & $520(470-570)$ \\
$\mathrm{Cu}$ & 2.6 & 949 & $28(20-39)$ & $27(23-31)$ \\
$\mathrm{Fe}$ & & & $640(354-864)$ & $770(760-780)$ \\
$\mathrm{Mg}$ & & & $5,300(4,309-6,161)$ & $5,800(5,700-5,900)$ \\
$\mathrm{Na}$ & & $5,400(4,516-7,759)$ & $6,600(6,400-6,800)$ \\
$\mathrm{P}$ & 14 & $48,000(45,000-55,000)$ & $54,000(52,000-55,000)$ \\
$\mathrm{Zn}$ & & $340(210-440)$ & $500(450-550)$ \\
\hline
\end{tabular}


6. SOIL AND SEDIMENT MONITORING 
All information for this section is presented in Part 1. 


\section{POTENTIAL RADIATION DOSE TO THE PUBLIC}


Table 7.1. 1990 annual dose sstimation—worst case irgestion of groundwater

\begin{tabular}{|c|c|c|c|c|c|c|}
\hline \multirow[b]{2}{*}{ Radionuclide } & \multicolumn{4}{|c|}{ Intake (exposure) values ${ }^{a}$} & \multicolumn{2}{|c|}{ Dose values ${ }^{b}$} \\
\hline & $\begin{array}{l}\text { Concentration } \\
(\mathrm{pCC} / \mathrm{L})\end{array}$ & $\begin{array}{l}\text { Ingestion } \\
\text { rate } \\
\text { (L/day) }\end{array}$ & $\begin{array}{l}\text { Exposure } \\
\text { frequency } \\
\text { (days/year) }\end{array}$ & $\begin{array}{c}\text { Total } \\
\text { intake } \\
\text { (pCi/year) }\end{array}$ & $\begin{array}{l}\text { Ingestion dose } \\
\text { conversion } \\
\text { factor } \\
\text { (mrem/pCi) }\end{array}$ & $\begin{array}{c}\text { Annual } \\
\text { CEDE }^{c} \\
\text { (mrem/year) }\end{array}$ \\
\hline${ }^{99} \mathrm{Tc}$ & 25.000 & 2.0 & 365 & 18250.00 & $1.30 \mathrm{E}-06$ & 0.024 \\
\hline
\end{tabular}

${ }^{a}$ Exposure values from EPA 600/8-89-043, "Exposure Factors Handbook," July 1989.

${ }^{b}$ Dose factors from DOE/EH0071, "Internal Dose Conversion Factors for Calculation of Dose to the Public," July 1988.

${ }^{c}$ Committed effective dose equivalent as committed (50-year) dose due tc one year of exposure (mrem/year).

Table 7.2. 1990 annual dose estimation-ivorst case incidental ingestion of sediment in Little Bayou Creek

\begin{tabular}{|c|c|c|c|c|c|c|}
\hline \multirow[b]{2}{*}{ Radionuclide } & \multicolumn{4}{|c|}{ Intake (exposure) values ${ }^{a}$} & \multicolumn{2}{|c|}{ Dose values $^{b}$} \\
\hline & $\begin{array}{l}\text { Concentration } \\
(\mathrm{pCi} / \mathrm{g})\end{array}$ & $\begin{array}{l}\text { Ingestion } \\
\text { rate } \\
\text { (g/day) }\end{array}$ & $\begin{array}{c}\text { Exposure } \\
\text { frequency } \\
\text { (days/year) }\end{array}$ & $\begin{array}{c}\text { Total } \\
\text { intake } \\
\text { (pCi/year) }\end{array}$ & $\begin{array}{l}\text { Ingestion dose } \\
\text { conversion } \\
\text { factor } \\
\text { (mrem/pCi) }\end{array}$ & $\begin{array}{c}\text { Annual } \\
\text { CEDE }^{c} \\
\text { (mrem/year) }\end{array}$ \\
\hline${ }^{234} \mathrm{U}$ & 3.370 & 0.8 & 213 & 574.25 & $2.60 \mathrm{E}-24$ & 0.15 \\
\hline${ }^{235} \mathrm{U}$ & 0.150 & 0.8 & 213 & 25.56 & $2.50 \mathrm{E}-04$ & 0.01 \\
\hline${ }^{238} \mathrm{U}$ & 12.100 & 0.8 & 213 & 2061.84 & 2.3NE-04 & 0.47 \\
\hline${ }^{99} \mathrm{Tc}$ & 1.350 & 0.8 & 213 & 230.04 & $1.30 \mathrm{E}-06$ & 0.00 \\
\hline${ }^{237} \mathrm{~Np}$ & 0.022 & 0.8 & 213 & 3.75 & $3.90 \mathrm{E}-03$ & 0.01 \\
\hline${ }^{239} \mathrm{Pu}$ & 0.014 & 0.8 & 213 & 2.39 & $4.30 \mathrm{E}-03$ & 0.01 \\
\hline Total & & & & & & 0.65 \\
\hline
\end{tabular}

aExposure values from EPA 600/8-89-043, "Exposure Factors Handbook," July 1989.

bDose factors from DOE/EH0071, "Internal Dose Conversion Factors for Calculation of Dose to the Public," July 1988.

${ }^{c}$ Committed effective dose equivalent as committed (50-year) dose due to one year of exposure (mrem/year). 
Table 7.3. 1990 annual dose estimation-worst case incidental ingestion of sediment in 'uig Bayou Creek

\begin{tabular}{|c|c|c|c|c|c|c|}
\hline \multirow[b]{2}{*}{ Radionuclide } & \multicolumn{4}{|c|}{ Intake (exposure) values ${ }^{a}$} & \multicolumn{2}{|c|}{ Dose values $^{b}$} \\
\hline & $\begin{array}{l}\text { Concentration } \\
(\mathrm{pCi} / \mathrm{g})\end{array}$ & $\begin{array}{l}\text { Ingestion } \\
\text { rate } \\
\text { (g/day) }\end{array}$ & $\begin{array}{l}\text { Exposure } \\
\text { frequency } \\
\text { (days/year) }\end{array}$ & $\begin{array}{c}\text { Total } \\
\text { intake } \\
\text { (pCi/year) }\end{array}$ & $\begin{array}{l}\text { Ingestion dose } \\
\text { conversion } \\
\text { factor } \\
\text { (mrem/pCi) }\end{array}$ & $\begin{array}{c}\text { Annual } \\
\text { CEDE }^{c} \\
\text { (mrem/year) }\end{array}$ \\
\hline${ }^{234} \mathrm{U}$ & 5.290 & 0.8 & 213 & 901.42 & $2.60 \mathrm{E}-04$ & 0.23 \\
\hline${ }^{235} \mathrm{U}$ & 0.240 & 0.8 & 213 & 4.09 & $2.50 \mathrm{E}-04$ & 0.01 \\
\hline${ }^{238} \mathrm{U}$ & 7.660 & 0.8 & 213 & 1305.26 & $2.30 \mathrm{E}-04$ & 0.30 \\
\hline${ }^{99} \mathrm{Tc}$ & 9.270 & 0.8 & 213 & 1579.61 & $1.30 \mathrm{E}-06$ & 0.00 \\
\hline${ }^{237} \mathrm{~Np}$ & 0.063 & 0.8 & 213 & 10.35 & $3.90 \mathrm{E}-03$ & 0.04 \\
\hline${ }^{239} \mathrm{Pu}$ & 0.024 & 0.8 & 213 & 4.09 & $4.30 \mathrm{E}-03$ & 0.02 \\
\hline${ }^{230} \mathrm{Th}$ & 0.170 & 0.8 & 213 & 28.97 & $5.30 \mathrm{E}-04$ & 0.02 \\
\hline Total & & & & & & 0.62 \\
\hline
\end{tabular}

aExposure values from EPA 600/8-89-043, "Exposure Factors Handbook," July 1989.

${ }^{b}$ Dose factors from DOE/EH0071, "Internal Dose Conversion Factors for Calculation of Dose to the Public," July 1988.

${ }^{c}$ Committed effective dose equivalent as committed (50-year) dose due to one year of exposure (mrem/year).

Table 7.4. 1990 annual dose estimation-worst case ingestion of deer muscle

\begin{tabular}{|c|c|c|c|c|c|c|}
\hline \multirow[b]{2}{*}{ Radionuclide } & \multicolumn{4}{|c|}{ Intake (exposure) values ${ }^{a}$} & \multicolumn{2}{|c|}{ Dose values $^{b}$} \\
\hline & $\begin{array}{l}\text { Concentration } \\
(p C i / g)\end{array}$ & $\begin{array}{l}\text { Ingestion } \\
\text { rate } \\
\text { (g/day) }\end{array}$ & $\begin{array}{c}\text { Exposure } \\
\text { frequency } \\
\text { (days/year) }\end{array}$ & $\begin{array}{c}\text { Total } \\
\text { intake } \\
\text { (pCi/year) }\end{array}$ & $\begin{array}{l}\text { Ingestion dose } \\
\text { conversion } \\
\text { factor } \\
\text { (mrem/pCi) }\end{array}$ & $\begin{array}{c}\text { Annual } \\
\text { CEDE }^{c} \\
\text { (mrem/year) }\end{array}$ \\
\hline${ }^{234} U$ & 0.021 & 227.0 & 178 & 848.53 & $2.60 \mathrm{E}-04$ & 0.22 \\
\hline
\end{tabular}

${ }^{a}$ Exposure values per C. Logsdon. Personal communication with R. D. Smith, November 27, 1990.

'Dose factors from DOE/EH0071, "Internal Dose Conversion Factors for Calculation of Dose to the Public," July 1988.

${ }^{c}$ Committed effective dose equivalent as committed (50-year) dose due to one year of exposure (mrem/year). 
Table 7.5. 1990 annual dose estimation - worst case ingestion of foodcrops

\begin{tabular}{|c|c|c|c|c|c|c|c|c|}
\hline \multirow[b]{2}{*}{ Type } & \multirow[b]{2}{*}{ Nuclide } & \multicolumn{5}{|c|}{ Intake (exposure) values ${ }^{a}$} & \multicolumn{2}{|c|}{ Dose values ${ }^{b}$} \\
\hline & & $\begin{array}{l}\text { Concentration } \\
(p \mathrm{Ci} / g)\end{array}$ & $\begin{array}{l}\text { Ingestion } \\
\text { rate } \\
\text { (g/day) }\end{array}$ & $\begin{array}{c}\text { Exposure } \\
\text { frequency } \\
\text { (days/year) }\end{array}$ & $\begin{array}{c}\text { Fraction } \\
\text { ingested } \\
\text { homegrown }\end{array}$ & $\begin{array}{c}\text { Total } \\
\text { intake } \\
\text { (pCi/year) }\end{array}$ & $\begin{array}{l}\text { Ingestion } \\
\text { dose } \\
\text { conversion } \\
\text { factor } \\
\text { (mrem } / \mathrm{pCi} \text { ) }\end{array}$ & $\begin{array}{c}\text { Annual } \\
\text { CEDE }^{c} \\
\text { (mrem/year) }\end{array}$ \\
\hline Cucumber & ${ }^{234} \mathrm{U}$ & 0.020 & 105.0 & 365 & 0.4 & 306.60 & $2.60 \mathrm{E}-04$ & 0.080 \\
\hline Corn & ${ }^{234} \mathrm{U}$ & 0.032 & 213.0 & 365 & 0.4 & 1007.58 & $2.60 \mathrm{E}-04$ & 0.262 \\
\hline \multirow[t]{2}{*}{ Squash } & ${ }^{234} \mathrm{U}$ & 0.009 & 287.0 & 365 & 0.4 & 377.12 & $2.60 \mathrm{E}-04$ & 0.098 \\
\hline & ${ }^{99} \mathrm{Tc}$ & 0.216 & 287.0 & 365 & 0.4 & 9050.83 & $1.30 \bar{E}-06$ & 0.012 \\
\hline Peas & ${ }^{234} \mathrm{U}$ & 0.030 & 117.0 & 365 & 0.4 & 512.46 & $2.60 \mathrm{E}-04$ & 0.133 \\
\hline Peppers & ${ }^{234} \mathrm{U}$ & 0.012 & 123.0 & 365 & 0.4 & 208.31 & $2.60 \mathrm{E}-04$ & 0.054 \\
\hline Cabbage & ${ }^{234} \mathrm{U}$ & 0.010 & 102.0 & 365 & 0.4 & 153.39 & $2.60 \mathrm{E}-04$ & 0.040 \\
\hline \multirow[t]{3}{*}{ Tomatoes } & ${ }^{234} \mathrm{U}$ & 0.030 & 123.0 & 365 & 0.4 & 538.74 & $2.60 \mathrm{E}-04$ & 0.140 \\
\hline & ${ }^{235} \mathrm{U}$ & 0.017 & 123.0 & 365 & 0.4 & 296.31 & $2.50 \mathrm{E}-04$ & 0.074 \\
\hline & ${ }^{238} \mathrm{U}$ & 0.011 & 123.0 & 365 & 0.4 & 197.54 & $2.30 \mathrm{E}-04$ & 0.045 \\
\hline Beans & ${ }^{234} \mathrm{U}$ & 0.008 & 113.0 & 365 & 0.4 & 133.63 & $2.60 \mathrm{E}-04$ & 0.035 \\
\hline Grapes & ${ }^{234} \mathrm{U}$ & 0.017 & 120.0 & 365 & 0.3 & 220.75 & $2.60 \mathrm{E}-04$ & 0.057 \\
\hline Persimmons & ${ }^{234} \mathrm{U}$ & 0.032 & 164.0 & 365 & 0.3 & 581.84 & $2.60 \mathrm{E}-04$ & 0.151 \\
\hline Total & & & & & & & & 1.180 \\
\hline
\end{tabular}

aExposure values from EPA 600/8-89-043, "Exposure Factors Handbook," July 1989.

bLose factors from DOE/EH0071, "Internal Dose Conversion Factors for Calculation of Dose to the Public," July 1988.

${ }^{\circ}$ Committed effective dose equivalent as committed (50-year) dose due to one year of exposure (mrem/year).

Table 7.6. 1990 annual dose estimation-worst case direct radiation in Little Bayou Creek

\begin{tabular}{ccccc}
\hline $\begin{array}{c}\text { Dose } \\
\text { rate } \\
(\mathrm{mR} / \mathrm{h})\end{array}$ & $\begin{array}{c}\text { Quality } \\
\text { factor }^{a} \\
(\mathrm{mrem} / \mathrm{mR})\end{array}$ & $\begin{array}{c}\text { Exposure } \\
\text { rate } \\
\text { (h/trip) }\end{array}$ & $\begin{array}{c}\text { Frequency } \\
\text { (trip/year) }\end{array}$ & $\begin{array}{c}\text { Estimated } \\
\text { dose } \\
\text { (mrem/year) }\end{array}$ \\
\hline 0.039 & 1 & 0.5 & 213 & 4.15 \\
\hline
\end{tabular}

aQuality factor for converting gamma radiation from milliRoentgen to millirem.

${ }^{b}$ Exposure frequency per C. Logsdon. Personal communication with M. G. Guhy, May 10. 1991. 


\section{SOLID WASTE MANAGEMENT PROGRAM}


All information for this section is presented in Part 1. 
9. SPECIAL STUDIES 
All information for this section is presented in Part 1. 


\section{QUALITY ASSURANCE}


Table 10.1. PGDP environmental analysis procedures for air

\begin{tabular}{|c|c|c|c|}
\hline Parameter & Procedure & $\begin{array}{l}\text { NIOSH or } \\
\text { EPA method }\end{array}$ & $\begin{array}{l}\text { Lowest concentration } \\
\text { reported }\end{array}$ \\
\hline $\begin{array}{l}\text { Gross alpha, beta, air filters, } \\
\text { radiochemistry }\end{array}$ & EC-2100 & APHA $601,602^{a}$ & Result obtained \\
\hline Fluoride, air, SIE ( $\mu \mathrm{g} / \mathrm{sample})$ & SA-F-2 & & 5 \\
\hline Fluoride, stacks, SIE (mg/L) & SA-F-2 & & $\begin{array}{l}0.1 \text { sample } \\
\text { solution }\end{array}$ \\
\hline $\begin{array}{l}\text { Gamma-ray spectroscopy, } \\
\text { air filters }\end{array}$ & $R-26$ & & Result obtained \\
\hline $\begin{array}{l}\text { Metals in air particulates, } \\
\text { emission spectroscopy } \\
(\mu \mathrm{g} / \text { sample })\end{array}$ & SC-35-2 & NIOSH $7300^{b}$ & $\begin{array}{l}\text { For } 35 \text { metals, } \\
\text { mostly } 1-10 \\
\text { each }\end{array}$ \\
\hline Pu, air filters, radiochemistry & R-50 & EPA-680/4-75-001 & Result obtained \\
\hline${ }^{99} \mathrm{Tc}$, air filters, radiochemistry & $\mathrm{R}-46$ & & Result obtained \\
\hline $\begin{array}{l}\text { Th, alpha isotopes, } \\
\text { radiochemistry }\end{array}$ & R-17 & & Result obtained \\
\hline $\begin{array}{l}\text { U, air filters, fluorometric } \\
(\mu \mathrm{g} / \text { sample) }\end{array}$ & EC-285 & & 0.05 \\
\hline $\begin{array}{l}\mathrm{U} \text { isotopes, air filters, } \\
\text { radiochemistry }\end{array}$ & I-4 & EPA-680/4-75-001 & Result obtained \\
\hline U, stack gases, radiochemistry & I-4 & & Result obtained \\
\hline $\begin{array}{l}\mathrm{U} \text {, stack samples, fluorometric } \\
(\mathrm{mg} / \mathrm{L})\end{array}$ & SA-U-8 & & $\begin{array}{l}0.001 \\
\text { sample solution }\end{array}$ \\
\hline
\end{tabular}

${ }^{a}$ APHA Methods, American Public Health Assoc., 1977.

${ }^{b}$ NIOSH Manual of Analytical Methods, Third Ed., U.S. Dept. of Health, Education, and Welfare, 1989. 
Table 10.2. PGDP environmental analysis procedures for water

\begin{tabular}{|c|c|c|c|}
\hline Parameter & Procedure & EPA method & $\begin{array}{l}\text { Lowest concentration } \\
\text { reported }^{a}\end{array}$ \\
\hline Alkalinity $\left(\mathrm{CaCO}_{3}\right)(\mathrm{mg} / \mathrm{L})$ & $\mathrm{W}-10$ & 310.1 & 5 \\
\hline Gross alpha activity & $R-4$ & 900.0 & Result obtained \\
\hline Gross beta activity & $\mathrm{R}-4$ & 900.0 & Result obtained \\
\hline${ }^{241} \mathrm{Am}$ and ${ }^{244} \mathrm{Cm}$ & EC-1340 & & Result obtained \\
\hline \multicolumn{4}{|l|}{ As and Se, furnace-AA } \\
\hline $\begin{array}{l}\mathrm{As}(\mathrm{mg} / \mathrm{L}) \\
\mathrm{Se}(\mathrm{mg} / \mathrm{L})\end{array}$ & SC-ENV-1 & 206.2 & 0.005 \\
\hline $\mathrm{Se}(\mathrm{mg} / \mathrm{L})$ & SC-ENV-1 & 270.2 & 0.005 \\
\hline BOD (5-d) (mgl) & $\mathrm{W}-20$ & 405.1 & 5 \\
\hline $\begin{array}{l}\text { COD, spectrophotometric } \\
\text { method }(\mathrm{mg} / \mathrm{L})\end{array}$ & W-40 & Hach 8000 & 5 \\
\hline \multicolumn{4}{|l|}{ Anions, ion chr umatograph ${ }^{b}(\mathrm{mg} / \mathrm{L})$} \\
\hline $\begin{array}{l}\text { Chloride }(\mathrm{mg} / \mathrm{L}) \\
\text {. }\end{array}$ & W-50 & 300.0 & 2 \\
\hline Nitrate $(\mathrm{N})(\mathrm{mg} / \mathrm{L})$ & W-50 & 300.0 & 1 \\
\hline Sulfate $(\mathrm{mg} / \mathrm{L})$ & W-50 & 300.0 & 5 \\
\hline Phosphate (P) (mg/L) & W-50 & 300.0 & 2 \\
\hline $\begin{array}{l}\text { Chlorine (total residual), } \\
\text { amperometric }(\mathrm{mg} / \mathrm{L})\end{array}$ & W-160 & 330.1 & 0.01 \\
\hline $\begin{array}{l}\text { Chromium (V), } \\
\text { spectrophotometric (mg/L) }\end{array}$ & $W-100$ & USGS $^{c}$ & 0.01 \\
\hline $\begin{array}{l}\text { Coliform bacteria (fecal) } \\
(\text { col. } / 100 \mathrm{~mL})\end{array}$ & $W-80$ & $909 \mathrm{C} \mathrm{Std.} \mathrm{Mth.}{ }^{d}$ & 1 \\
\hline $\begin{array}{l}\text { Coliform bacteria (total) } \\
\quad(\text { col. } / 100 \mathrm{~mL})\end{array}$ & W-85 & 909A Std. Mth. & 1 \\
\hline Color (color units) & SA-CLR-1 & 110.2 & 1 \\
\hline $\begin{array}{l}\text { Conductance (specific) } \\
(\mu \mathrm{mho} / \mathrm{cm})\end{array}$ & SA-COND-1 & \\
\hline Cyanide (total) $(5-\mathrm{cm}$ cell) & EC-1270 & 335.2 & 0.004 \\
\hline Fluoride $(\mathrm{mg} / \mathrm{L})$ & SA-F-5 & 340.2 & 0.1 \\
\hline Gamma-ray emitters & EC-1340 & & Result obtained \\
\hline $\mathrm{Hg}($ total $)(\mathrm{mg} / \mathrm{L})$ & SC-ENV-2 & 245.1 & 0.0002 \\
\hline${ }^{239} \mathrm{~Np}$ & $\mathrm{R}-8$ & & Result obtained \\
\hline Nitrogen, ammonia, SIE (mg/L) & SA-NH3-2 & 350.3 & 0.2 \\
\hline Oil and grease, gravimetric $(\mathrm{mg} / \mathrm{L})$ & SA-O-G-1 & 413.1 & 5 \\
\hline Oil and grease, infrared $(\mathrm{mg} / \mathrm{L})$ & GA-9 & 413.2 & \\
\hline $\mathrm{pH}$, electrometric $(\mathrm{mg} / \mathrm{L})$ & W-110 & 150.1 & $\begin{array}{l}\text { Nearest } 0.1 \\
\text { pr? unit }\end{array}$ \\
\hline $\begin{array}{l}\text { Phosphorus (all forms) } \\
\text { spectrophotometric }(\mathrm{mg} / \mathrm{L})\end{array}$ & $W-120$ & 365.2 & 5.1 \\
\hline Pu isotopes & R-50 & & Result obtained \\
\hline $\operatorname{PCBs}(\mu \mathrm{g} / \mathrm{L})$ & OP-1 & 608 & 0.1 each Arochlor \\
\hline
\end{tabular}


Table 10.2 (continued)

\begin{tabular}{|c|c|c|c|}
\hline Parameter & Procedure & EPA method & $\begin{array}{l}\text { Lowest concentration } \\
\text { reported }^{a}\end{array}$ \\
\hline $\begin{array}{l}\text { Priority pollutants, organic } \\
\text { (volatile, purgeable) }\end{array}$ & OP-3 & 624 & \\
\hline Trichloroethylene $(\mu \mathrm{g} / \mathrm{L})$ & OP-3 & 624 & 1 \\
\hline Acetone $(\mu \mathrm{g} / \mathrm{L})$ & OP-3 & 624 & 10 \\
\hline Isopropanol $(\mu \mathrm{g} / \mathrm{L})$ & OP-3 & 624 & 25 \\
\hline Benzene $(\mu \mathrm{g} / \mathrm{L})$ & OP-3 & 624 & 5 \\
\hline Toluene $(\mu \mathrm{g} / \mathrm{L})$ & OP-3 & 624 & 5 \\
\hline Ethylbenzene $(\mu \mathrm{g} / \mathrm{L})$ & OP-3 & 624 & 5 \\
\hline Total xylene $(\mu \mathrm{g} / \mathrm{L})$ & OP-3 & 624 & 5 \\
\hline 1,2-Dichloroethane $(\mu \mathrm{g} / \mathrm{L})$ & OP-3 & 624 & 5 \\
\hline 1,1,1-Trichloroethane $(\mu \mathrm{g} / \mathrm{L})$ & OP-3 & 624 & 5 \\
\hline Tetrachloroethene $(\mu \mathrm{g} / \mathrm{L})$ & OP-3 & 624 & 5 \\
\hline Trihalomethanes $(\mu \mathrm{g} / \mathrm{L})$ & OP-3 & 624 & 5 \\
\hline 1,2-Dichloroethene $(\mu \mathrm{g} / \mathrm{L})$ & OP-3 & 624 & 5 \\
\hline Solids (dissolved) (mg $\mathrm{L})$ & W-140 & 160.1 & 10 \\
\hline Solids (total) $(\mathrm{mg} / \mathrm{L})$ & W-140 & 160.3 & 10 \\
\hline Solids (undissolved) $(\mathrm{mg} / \mathrm{L})$ & W-140 & 160.2 & 4 \\
\hline${ }^{99} \mathrm{Tc}$ & $R-46$ & & Result obtained \\
\hline Thorium isotopes & $R-17$ & & Result obtained \\
\hline $\begin{array}{l}\text { Total petroleum hydrocarbons } \\
(\mathrm{mg} / \mathrm{L})\end{array}$ & GA-28 & 418.1 & 0.1 \\
\hline $\begin{array}{l}\text { Total organic carbon, } \\
\text { combustion or oxidation }\end{array}$ & W- 150 & 415.1 & 1 \\
\hline Turbidity (NTU) & W-170 & 180.1 & 0.05 \\
\hline $\begin{array}{l}\text { Uranium (total), fluorometric } \\
(\mathrm{mg} / \mathrm{L})\end{array}$ & SA-U-8 & & $1 \times 10^{-3}$ \\
\hline Uranium isotopes & I-4 & & Result obtained \\
\hline Uranium isotopic abundances & I-4 & & Result obtained \\
\hline
\end{tabular}

aThe lowest concentration reported (LCR) may vary among specific samples, depending on interferences in the sample matrix. However, these LCRs have been assigned to accommodate most minor interferences. Some of the LCRs are higher than the method detection limits (MDLs) listed by EPA. This is consistent with guidance from EPA; however, any data reported below the MDLs must be supported by sound documentation. The LCRs applied meet the needs of the programs they support.

${ }^{b}$ Approved for drinking water only (reagent water).

cU.S. Geological Survey, "Methods for Analysis of Inorganic Substances in Water and Fluvial Sediment," Open-File Report 78-679; N. W. Skougstad et al., "Methods for Determination of Inorganic Substances in Water and Flavial Sediments," Chapter A1, in Techniques of Water-Resources Investigation, Book 5, U.S. Geological Survey, 1979.

${ }^{d}$ All references to Standard Methods for the 16th Edition, 1985. 
Table 10.3. PGDP atomic absorption and ICP environmental analysis procedures for water (lowest concentration reported)

\begin{tabular}{ccc}
\hline Element & $\begin{array}{c}\text { PGDP SC-ENV-1 } \\
\text { EPA 200 series } \\
\text { graphite furnace AA } \\
\text { (mg/L) }\end{array}$ & $\begin{array}{c}\text { PGDP SC-ENV-4 } b \text { and } \\
\text { SC-ICP-OPb } \\
\text { EPA 200.7 ICP } \\
(\mathrm{mg} / \mathrm{L})\end{array}$ \\
\hline $\mathrm{Ag}$ & & 0.03 \\
$\mathrm{Al}$ & & 0.1 \\
$\mathrm{As}$ & 0.005 & 0.1 \\
$\mathrm{Ba}$ & & 0.005 \\
$\mathrm{Ca}$ & & 0.01 \\
$\mathrm{Cd}$ & & 0.01 \\
$\mathrm{Cr}$ & & 0.05 \\
$\mathrm{Cu}$ & & 0.01 \\
$\mathrm{Fe}$ & & 0.01 \\
$\mathrm{~K}$ & & 2.0 \\
$\mathrm{~L}$ & & 0.02 \\
$\mathrm{Mg}$ & & 0.002 \\
$\mathrm{Mn}$ & & 0.005 \\
$\mathrm{Mo}$ & & 0.05 \\
$\mathrm{Na}$ & & 0.04 \\
$\mathrm{Ni}$ & & 0.05 \\
$\mathrm{~Pb}$ & & 0.2 \\
$\mathrm{Se}$ & 0.005 & 0.2 \\
$\mathrm{Zn}$ & & 0.005 \\
\hline
\end{tabular}

oThe lowest concentration reported (LCR) may vary among specific samples, depending on interferences in the sample matrix. However, these LCRs have been assigned to accommodate most minor interferences. Some of the LCRs are higher than the method detection limit (MDLs) listed by EPA. This is consistent with guidance from EPA; however, any data reported below the MDLs must be supported by sound documentation. The LCRs applied by Energy Systems laboratories meet the needs of the programs they support.

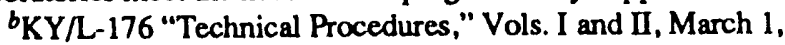
1991.

Table 10.4. PGDP environmental analysis procedures for biota

\begin{tabular}{|c|c|c|c|}
\hline Parameter & Procedure $^{a}$ & EPA method & $\begin{array}{l}\text { Lowest concentration } \\
\text { reported } \\
(\mathrm{mg} / \mathrm{kg})\end{array}$ \\
\hline Fluoride in vegetation & EC -4100 & & 3 \\
\hline $\begin{array}{l}\text { Gamma-ray spectrometry } \\
\text { of vegetation }\end{array}$ & EC-1340 & & Result obtained \\
\hline $\begin{array}{l}\mathrm{U} \text { (total and isotopic) in } \\
\text { vegetation }\end{array}$ & $1-4$ & & Result obtained \\
\hline
\end{tabular}

${ }^{a} \mathrm{KY} / \mathrm{L}-176$, "Technical Procedures," Vols. I and II, March 1, 1991. 
Table 10.5. PGDP environmental analysis procedures for soll and sediment

\begin{tabular}{|c|c|c|c|}
\hline Parameter & Procedure ${ }^{a, b}$ & EPA method ${ }^{c, d}$ & $\begin{array}{l}\text { Lowest concentration } \\
\text { reported } \\
(\mathrm{mg} / \mathrm{kg})\end{array}$ \\
\hline $\mathrm{Hg}$ (total), flameless AA & SC-ENV-2 & 245.5 & 0.2 \\
\hline $\mathrm{Np}$, direct gamma spectrum & R-15 EC-3300 & & Result obtained \\
\hline${ }^{23} \mathrm{~Np}$, radiochemical & R-17 EC-3305 & & Result obtained \\
\hline Pu, radiochemical & R-50 EC-3360 & & Result obtained \\
\hline PCBs, gas chromatographic & OP-2 & RCRA-8080 & 0.1 \\
\hline $\begin{array}{l}\text { Priority pollutants organic } \\
\text { (volatile purgeables) }\end{array}$ & OP-3 & RCRA- 8240 & \\
\hline Trichloroethene & OP-3 & RCRA-8240 & 1 \\
\hline Benzene & OP-3 & RCRA-8240 & 1 \\
\hline Toluene & OP-3 & RCRA-8240 & 1 \\
\hline Ethylbenzene & OP-3 & RCRA-8240 & 1 \\
\hline Xylenes (total) & OP-3 & RCRA-8240 & 1 \\
\hline 1,1,1-Trichloroethane & OP-3 & RCRA-8240 & 1 \\
\hline Tetrachloroethene & OP-3 & RCRA-8240 & 1 \\
\hline${ }^{99} \mathrm{Tc}$, radiochemical & $R-46$ & & Result obtained \\
\hline $\begin{array}{l}\text { Th (alpha-emitting) isotopes, } \\
\text { radiochemical }\end{array}$ & $\mathrm{R}-17$ & & Result obtained \\
\hline $\begin{array}{l}\text { Total petroleum } \\
\text { hydrocarbons }\end{array}$ & GA-28 & 418.1 & 0.1 \\
\hline 1,2,4-Trichlorobenzene & GA-28 & RCRA-8120 & 0.1 \\
\hline $\mathrm{U}$ (total), fluorometric & EC-3700 & & 0.5 \\
\hline $\begin{array}{l}\mathrm{U} \text { (total and isotopic), isotope } \\
\text { dilution mass spectrometric }\end{array}$ & $\mathrm{I}-4$ & & Result obtained \\
\hline $\mathrm{U}$ isotopes, radiochemical & $\mathrm{I}-4$ & & Result obtained \\
\hline Aluminum & SC-ENV-5 \& SC-ICP-OP & 200.7 & 6.0 \\
\hline Arsenic & SC-EN'J-5 & 200 series & 0.5 \\
\hline Barium & SC-ENV. 5 \& SC-ICP-OP & 200.7 & 0.04 \\
\hline Beryllium & SC-ENV-5 \& SC-ICP-OP & 200.7 & 0.1 \\
\hline Cadmium & SC-ENV-5 \& SC-ICP-OP & 200.7 & 0.6 \\
\hline Calcium & SC-ENV-5 \& SC-ICP-OP & 200.7 & 2.0 \\
\hline Chromium & SC-ENV-5 \& SC-ICP-OP & 200.7 & 0.4 \\
\hline Cobalt & SC-ENV-5 \& SC-ICP-OP & 200.7 & 0.4 \\
\hline Copper & SC-ENV-5 \& SC-ICP-OP & 200.7 & 0.2 \\
\hline Iron & SC-ENV-5 \& SC-ICP-OP & 200.7 & 1.0 \\
\hline Lead & SC-ENV-5 \& SC-ICP-OP & 200.7 & 4.0 \\
\hline Magnesium & SC-ENV-5 \& SC-ICP-OP & 200.7 & 0.1 \\
\hline Manganese & SC-ENV-5 \& SC-ICP-OP & 200.7 & 7.1 \\
\hline Molybdenum & SC-ENV-5 \& SC-ICP-OP & 200.7 & 1.6 \\
\hline Nickel & SC-ENV-5 \& SC-ICP-OP & 200.7 & 0.8 \\
\hline Potassium & SC-ENV-5 \& SC-ICP-OP & 200.7 & 10.0 \\
\hline Selenium & SC-ENV-1 & 200 series & 0.5 \\
\hline Silver & SC-ENV-5 \& SC-ICP-OP & 200.7 & 0.6 \\
\hline Sodium & SC-ENV-5 \& SC-ICP-OP & 200.7 & 1.0 \\
\hline Vanadium & SC-ENV-5 \& SC-ICP-OP & 200.7 & 0.6 \\
\hline Zinc & SC-ENV-5 \& SC-ICP-OP & 200.7 & 0.4 \\
\hline
\end{tabular}

${ }^{a}$ EC designation refers to procedures in "Environmental and Effluent Analysis Manual," Martin Marietta Energy Systems, September 19, 1989.

bOther designations in this column refer to "Technical Procedures," KY/L-176 Vols. I and II, Paducah Gaseous Diffusion Plant. cProcedures with RCRA designations refer to U.S. Environmental Protection Agency Dec. 1987, "Test Methoxds for Evaluating Solid Waste," SW-846.

${ }^{d}$ Remainder of procedures from U.S. Environmental Protection Agency March 1983, "Methods for Chemical Analysis of Water and Wastes," EPA-600/4-79-020. 
Table 10.6. PGDP analysis procedures for of

\begin{tabular}{|c|c|c|c|}
\hline Parameter & Procedure $e^{a, b}$ & EPA method ${ }^{c, d}$ & $\begin{array}{l}\text { Lowest concentration } \\
\text { reported }\end{array}$ \\
\hline $\begin{array}{l}\text { Gross alpha activity } \\
\text { Gross beta activity }\end{array}$ & $\begin{array}{l}\text { EC-1010 } \\
\text { EC-1010 }\end{array}$ & $\begin{array}{l}900.0 \\
900.0\end{array}$ & $\begin{array}{l}\text { Report result obtained } \\
\text { Report result obtained }\end{array}$ \\
\hline Benzene $(\mu g / L)$ & OP-3 & RCRA-8240 & 5 \\
\hline 1,2-Dichloroethane $(\mu \mathrm{g} / \mathrm{L})$ & OP-3 & RCRA-8240 & 5 \\
\hline Ethylbenzene $(\mu g / L)$ & OP-3 & RCRA-8240 & 5 \\
\hline PCBs $(\mu \mathrm{g} / \mathrm{L})$ & OP-1 & RCRA-8080 & 0.1 \\
\hline $\begin{array}{l}\text { Total petroleum } \\
\text { Hydrocarbons (mg/L) }\end{array}$ & GA-28 & 418.1 & 0.1 \\
\hline Toluene $(\mu g / L)$ & OP-3 & RCRA-8240 & 1 \\
\hline 1,1,1-Trichloroethane $(\mu \mathrm{g} / \mathrm{L})$ & OP-3 & RCRA-8240 & 5 \\
\hline $\begin{array}{l}\text { Trichloroethylene }(\mu \mathrm{g} / \mathrm{L}) \\
{ }_{99} \mathrm{Tc}(\mathrm{pCi} / \mathrm{L})\end{array}$ & $\begin{array}{l}\text { OP-3 } \\
R-46\end{array}$ & RCRA 8240 & $\begin{array}{l}1 \\
25\end{array}$ \\
\hline
\end{tabular}

${ }^{a} \mathrm{EC}$ designation refers to procedures in "Environmental and Effluent Analysis Manual," Martin Marietta Energy Systems, September 19, 1989.

bOher designations in this column refer to "Technical Procedures," KY/L-176 Vols. I and II, Paducah Gaseous Diffusion Plant.

cProcedures with RCRA designations refer to U.S. Environmental Protection Agency Dec. 1987. "Test Methods for Evaluating Solid Waste," SW-846.

${ }^{d}$ Remainder of procedures from U.S. Environmental Protection Agency March 1983, "Methods for Chemical Analysis of Water and Wastes," EPA-600/4-79-020.

Table 10.7. PGDP analysis procedures for field measurements

\begin{tabular}{llll}
\hline \multicolumn{1}{c}{ Parameter } & Procedure & EPA method & $\begin{array}{c}\text { Lowest } \\
\text { concentration } \\
\text { reported }\end{array}$ \\
\hline pH & ES-14 & 150.1 & $0.1^{a}$ \\
Dissolved oxygen (mg/L) & ES-14 & 360.1 & 0.1 \\
Temperature & ES-14 & 170.1 & $0.1^{b}$ \\
Total residual \\
chlorine (mg/L) & ES-16 & 330.5 & 0.01 \\
Depth (ft) & ES-2 & NA & 0.01 \\
\hline
\end{tabular}

aNearest pH unit.

${ }^{b}$ Nearest degree F. 
Table 10.8. PGDP internal measurement control program laboratory control data (inorganic)

\begin{tabular}{|c|c|c|c|c|c|}
\hline $\begin{array}{l}\text { Measurement } \\
\text { identification }\end{array}$ & Accepted mean ${ }^{a}$ & $\begin{array}{c}\text { Ratio of } \\
\text { observed mean } \\
\text { to } T^{a, b}\end{array}$ & $\begin{array}{l}\text { Percent } \\
\text { bias }\end{array}$ & $\begin{array}{l}\text { Number } \\
\text { of } \\
\text { analyses }\end{array}$ & $\begin{array}{l}\text { Percent } \\
\text { limit of } \\
\text { error per } \\
\text { analysis }\end{array}$ \\
\hline \multicolumn{6}{|c|}{ Fluorimetric analysis } \\
\hline Low-level uranium & $0.035 \mathrm{mg} / \mathrm{L}(\mathrm{T})$ & $1.03 \pm 0.01$ & $2.67 \pm 1.27$ & 220 & 18 \\
\hline \multicolumn{6}{|c|}{ Thermal ionization mass spectrometer } \\
\hline Uranium & $10-20 \mathrm{mg} / \mathrm{L}(\mathrm{T})$ & $1.206 \pm 0.165$ & $20.64 \pm 16.50$ & 17 & 56 \\
\hline Assay (wt $\%{ }^{235} \mathrm{U}$ ) & $0.0-1.00(\mathrm{~T})$ & $1.002 \pm 0.037$ & $0.17 \pm 3.71$ & 17 & 15 \\
\hline
\end{tabular}

aSamples sent at various theoretical levels. Statistics are reported on the ratio of reported result to the theoretical value with 1.000 indicating agreement.

${ }^{b} \mathrm{~T}=$ theoretical value.

${ }^{c}$ Limit of error of the $95 \%$ confidence level.

Table 10.9. PGDP internal measurement control program laboratory control data (organic)

\begin{tabular}{|c|c|c|c|c|c|}
\hline $\begin{array}{l}\text { Measurement } \\
\text { identification }\end{array}$ & $\begin{array}{l}\text { Accepted } \\
\text { mean }\end{array}$ & $\begin{array}{l}\text { Observed mean } \\
\pm \text { limit of error }\end{array}$ & $\begin{array}{l}\text { Number } \\
\text { of } \\
\text { analyses }\end{array}$ & $\begin{array}{l}\text { Percent limit } \\
\text { of error } \\
\text { per analysis }\end{array}$ & $\begin{array}{c}\% \\
\text { recovery }\end{array}$ \\
\hline \multicolumn{6}{|c|}{ Total organic halogens $(\mu g / L)$} \\
\hline $\begin{array}{l}\text { TOX, as trichlorophenol, } \\
\text { in water } \\
\text { (RCRA 9020) }\end{array}$ & $\begin{array}{l}100 \\
100\end{array}$ & $\begin{array}{l}100.9 \pm 2.19 \\
100.8 \pm 1.22\end{array}$ & $\begin{array}{r}29 \\
107\end{array}$ & $\begin{array}{l}12 \\
12\end{array}$ & $\begin{array}{l}100.9 \\
100.8\end{array}$ \\
\hline \multicolumn{6}{|c|}{ Polychlorinated biphenyls $(\mu g / L)$} \\
\hline $\begin{array}{l}\text { PCB, spike recovery, } \\
\text { in water } \\
\text { (EPA 608) }\end{array}$ & 40.0 & $34.7 \pm 30.9$ & 3 & 149 & 86.8 \\
\hline $\begin{array}{l}\text { PCB, spike recovery, } \\
\text { in groundwater } \\
\text { (RCRA 8080) }\end{array}$ & $\begin{array}{l}40.0 \\
50.0 \\
0.096\end{array}$ & $\begin{array}{l}38.2 \pm 5.44 \\
41.7 \pm 14.2 \\
0.081 \pm 0.013\end{array}$ & $\begin{array}{r}11 \\
4 \\
4\end{array}$ & $\begin{array}{l}47 \\
68 \\
32\end{array}$ & $\begin{array}{l}95.5 \\
83.4 \\
84.3\end{array}$ \\
\hline \multicolumn{6}{|c|}{ Trichloroethylene $(\mu g / L)$} \\
\hline $\begin{array}{l}\text { TCE, spike recovery, } \\
\text { in groundwater } \\
\text { (RCRA 8240) }\end{array}$ & 5.0 & $4.66 \pm 0.08$ & 150 & 21 & 93.2 \\
\hline $\begin{array}{l}\text { TCE, spike recovery, } \\
\text { in water } \\
\text { (EPA 624) }\end{array}$ & 5.0 & $4.62 \pm 0.28$ & 22 & 28 & 92.4 \\
\hline
\end{tabular}

${ }^{a}$ Limit of error of the $95 \%$ confidence level. 
Table 10.10. PGDP Environmental Protection Agency Performance Evaluation Report DMR-QA Study Number 010

\begin{tabular}{|c|c|c|c|c|c|}
\hline Parameter & $\begin{array}{l}\text { Reported } \\
\text { value }\end{array}$ & $\begin{array}{l}\text { True } \\
\text { value }\end{array}$ & $\begin{array}{l}\text { Acceptable } \\
\text { limits }\end{array}$ & $\begin{array}{l}\text { Warning } \\
\text { limits }\end{array}$ & $\begin{array}{c}\text { Performance }^{b} \\
\text { evaluation }\end{array}$ \\
\hline \multicolumn{6}{|c|}{ Trace metals $(\mu g / L)$} \\
\hline $\begin{array}{l}\text { Aluminum } \\
\text { Chromium } \\
\text { Copper } \\
\text { Iron } \\
\text { Nickel } \\
\text { Zinc }\end{array}$ & $\begin{array}{r}1190 \\
52.0 \\
80.0 \\
648.0 \\
209.0 \\
970.0\end{array}$ & $\begin{array}{c}1200 \\
50.0 \\
85.0 \\
650 \\
200 \\
900\end{array}$ & $\begin{array}{l}949-1440 \\
37.2-61.0 \\
72.9-94.5 \\
559-737 \\
172-227 \\
783-1000\end{array}$ & $\begin{array}{l}1010-1380 \\
40.2-58.0 \\
75.6-91.8 \\
581-715 \\
179-220 \\
810-976\end{array}$ & $\begin{array}{l}\text { Acceptable } \\
\text { Acceptable } \\
\text { Acceptable } \\
\text { Acceptable } \\
\text { Acceptable } \\
\text { Acceptable }\end{array}$ \\
\hline \multicolumn{6}{|c|}{ Miscellaneous parameters $(m g / L)^{c}$} \\
\hline $\begin{array}{l}\mathrm{pH} \text { (units) } \\
\text { Total suspended } \\
\quad \text { solids }\end{array}$ & $\begin{array}{r}5.9 \\
69.0\end{array}$ & $\begin{array}{l}6.00 \\
73.0\end{array}$ & $\begin{array}{l}5.86-6.12 \\
61.3-78.0\end{array}$ & $\begin{array}{l}5.89-6.09 \\
63.3-75.9\end{array}$ & $\begin{array}{l}\text { Acceptable } \\
\text { Acceptable }\end{array}$ \\
\hline Oil and grease & 17.8 & 18.0 & $10.6-23.2$ & $12.2-21.7$ & Acceptable \\
\hline $\begin{array}{l}\text { Total residual } \\
\text { chlorine }\end{array}$ & 1.50 & 1.50 & $0.896-1.82$ & $1.02-1.70$ & Acceptable \\
\hline \multicolumn{6}{|c|}{ Demand $(m g / L)$} \\
\hline $\begin{array}{l}\text { COD } \\
5 \text {-day BOD }\end{array}$ & $\begin{array}{l}75 \\
59\end{array}$ & $\begin{array}{l}76.2 \\
50.9\end{array}$ & $\begin{array}{l}58.3-93.6 \\
29.1-72.8\end{array}$ & $\begin{array}{l}62.7-89.2 \\
34.5-67.4\end{array}$ & $\begin{array}{l}\text { Acceptable } \\
\text { Acceptable }\end{array}$ \\
\hline
\end{tabular}

${ }^{a}$ Based on theoretical calculations or a reference value when necessary.

${ }^{b}$ Performance evaluation by EPA. 0-1.96 standard deviation for acceptable; $1.97-2.58$ standard deviation for check for error, outside 2.58 standard deviation for unacceptable.

${ }^{c}$ Units are in $\mathrm{mg} / \mathrm{L}$ except for $\mathrm{pH}$, which is reported in $\mathrm{pH}$ units. 
Table 10.11. January 1990 Analytical Products Group, Inc., Proficiency Environmental Testing Program

\begin{tabular}{|c|c|c|c|c|c|c|}
\hline Parameter & Level & $\begin{array}{l}\text { Reported } \\
\text { value }\end{array}$ & $\begin{array}{c}\text { Reference } \\
\text { value }\end{array}$ & $\begin{array}{c}\text { Mean of } \\
\text { reporting } \\
\text { labs }\end{array}$ & $\begin{array}{l}\text { No. of standard } \\
\text { deviations } \\
\text { from the } \\
\text { mean }\end{array}$ & $\begin{array}{c}\text { Performance } \\
\text { evaluation }\end{array}$ \\
\hline Alkalinity as & 1 & 50.4 & 54.18 & 53.04 & 0.638 & Acceptable \\
\hline $\begin{array}{l}\mathrm{CaCO}_{3} \\
(\mathrm{mg} / \mathrm{L})\end{array}$ & 2 & 78.6 & 80.51 & 78.67 & 0.016 & Acceptable \\
\hline Aluminum & 1 & 36 & 29.3 & 32.6 & 0.474 & Acceptable \\
\hline$(\mu \mathrm{g} / \mathrm{L})$ & 2 & 258 & 263.5 & 278.6 & 0.510 & Acceptable \\
\hline Ammonia as $\mathrm{N}$ & 1 & 0.78 & 0.86 & 0.83 & 0.412 & Acceptable \\
\hline$(\mathrm{mg} / \mathrm{L})$ & 2 & 2.4 & 2.46 & 2.37 & 0.036 & Acceptable \\
\hline Arsenic & 1 & 35 & 33.7 & 33.4 & 0.272 & Acceptable \\
\hline$(\mu \mathrm{g} / \mathrm{L})$ & 2 & 393 & 413.8 & 395.2 & 0.022 & Acceptable \\
\hline Barium & 1 & 342 & 362.3 & 363.0 & 0.972 & Acceptable \\
\hline$(\mu \mathrm{g} / \mathrm{L})$ & 2 & 1510 & 1564.8 & 1586.0 & 0.580 & Acceptable \\
\hline Beryllium & 1 & 46 & 47.8 & 47.2 & 0.366 & Acceptable \\
\hline$(\mu \mathrm{g} / \mathrm{L})$ & 2 & 149 & 138.3 & 138.5 & 0.888 & Acceptable \\
\hline BOD & 1 & 135 & 100.80 & 105.06 & 1.449 & Acceptable \\
\hline$(\mathrm{mg} / \mathrm{L})$ & 2 & 21 & 13.77 & 15.04 & 1.487 & Acceptable \\
\hline Cadmium & 1 & 97 & 92.1 & 92.5 & 0.793 & Acceptable \\
\hline$(\mu \mathrm{g} / \mathrm{L})$ & 2 & 198 & 186.2 & 187.0 & 0.945 & Acceptable \\
\hline Calcium & 1 & 9.0 & 9.57 & 9.37 & 0.729 & Acceptable \\
\hline (mg/L) & 2 & 4.55 & 4.87 & 4.85 & 0.749 & Acceptable \\
\hline Chloride & 1 & 75.8 & 75.88 & 76.04 & 0.081 & Acceptable \\
\hline (mg/L) & 2 & 97.1 & 97.17 & 98.14 & 0.215 & Acceptable \\
\hline Chromium & 1 & 28 & 29.2 & 29.9 & 0.372 & Acceptable \\
\hline$(\mu \mathrm{g} / \mathrm{L})$ & 2 & 244 & 250.0 & 252.7 & 0.374 & Acceptable \\
\hline COD & 1 & 145 & 162.30 & 158.54 & 1.047 & Acceptable \\
\hline (mg/L) & 2 & 25 & 22.17 & 23.08 & 0.268 & Acceptable \\
\hline Conductivity & 1 & 440 & 479.9 & 418.72 & 0.506 & Acceptable \\
\hline$(\mu \mathrm{mho} / \mathrm{cm})$ & 2 & 563 & 617.8 & 543.36 & 0.499 & Acceptable \\
\hline Copper & 1 & 25 & 28.4 & 29.0 & 0.859 & Acceptable \\
\hline$(\mu \mathrm{g} / \mathrm{L})$ & 2 & 132 & 141.2 & 143.1 & 1.113 & Acceptable \\
\hline Fluoride & 1 & 4.10 & 4.12 & 4.14 & 0.152 & Acceptable \\
\hline$(\mathrm{mg} / \mathrm{L})$ & 2 & 7.10 & 7.12 & 7.19 & 0.163 & Acceptable \\
\hline Hexavalent & 1 & 0.05 & 0.05 & 0.04 & 0.138 & Acceptable \\
\hline $\begin{array}{l}\text { chromium } \\
(\mathrm{mg} / \mathrm{L})\end{array}$ & 2 & 0.11 & 0.12 & 0.12 & 0.955 & Acceptable \\
\hline Iron & 1 & 34 & 36.5 & 39.4 & 0.544 & Acceptable \\
\hline$(\mu g / L)$ & 2 & 468 & 499.3 & 505.6 & 0.989 & Acceptable \\
\hline Lead & 1 & 118 & 122.7 & 122.3 & 0.211 & Acceptable \\
\hline$(\mu \mathrm{g} / \mathrm{L})$ & 2 & 285 & 284.6 & 285.4 & 0.015 & Acceptable \\
\hline Magnesium & 1 & 5.50 & 5.38 & 5.35 & 0.402 & Acceptable \\
\hline$(\mathrm{mg} / \mathrm{L})$ & 2 & 10.26 & 10.10 & 10.10 & 0.231 & Acceptable \\
\hline Manganese & 1 & 77 & 78.6 & 76.9 & 0.009 & Acceptable \\
\hline$(\mu \mathrm{g} / \mathrm{L})$ & 2 & 179 & 181.5 & 181.9 & 0.239 & Acceptable \\
\hline Mercury & 1 & 1.4 & 1.7 & 1.6 & 1.136 & Acceptable \\
\hline$(\mu \mathrm{g} / \mathrm{L})$ & 2 & 2.9 & 3.2 & 3.3 & 0.765 & Acceptable \\
\hline Nickel & 1 & 28 & 25.6 & 26.8 & 0.252 & Acceptable \\
\hline$(\mu \mathrm{g} / \mathrm{L})$ & 2 & 164 & 159.9 & 164.0 & 0.002 & Acceptable \\
\hline Nitrate as $\mathrm{N}$ & 1 & 0.72 & 0.69 & 0.66 & 0.545 & Acceptable \\
\hline$(\mathrm{mg} / \mathrm{L})$ & 2 & 1.7 & 1.61 & 1.40 & 0.571 & Acceptable \\
\hline Oil and grease & 1 & 9.6 & 10.03 & 9.10 & 0.140 & Acceptable \\
\hline$(\mathrm{mg} / \mathrm{L})$ & 2 & 38.6 & 40.13 & 33.04 & 0.579 & Acceptable \\
\hline
\end{tabular}


Table 10.11 (continued)

\begin{tabular}{|c|c|c|c|c|c|c|}
\hline Parameter & Level & $\begin{array}{l}\text { Reported } \\
\text { value }\end{array}$ & $\begin{array}{l}\text { Reference } \\
\text { value }\end{array}$ & $\begin{array}{l}\text { Mean of } \\
\text { reporting } \\
\text { labs }\end{array}$ & $\begin{array}{l}\text { No. of standard } \\
\text { deviations } \\
\text { from the } \\
\text { mean }\end{array}$ & $\begin{array}{c}\text { Performance } \\
\text { evaluation }\end{array}$ \\
\hline $\mathrm{pH}$ & 1 & 6.8 & 6.39 & 6.66 & 0.595 & Acceptable \\
\hline (units) & 2 & 6.6 & 6.19 & 6.44 & 0.653 & Acceptable \\
\hline Potassiumn & 1 & 16.08 & 17.16 & 16.56 & 0.303 & Acceptable \\
\hline (mg/L) & 2 & 11.51 & 12.74 & 12.11 & 0.271 & Acceptable \\
\hline Selenium & 1 & 14 & 15.8 & 17.4 & 0.890 & Acceptable \\
\hline$(\mu g / L)$ & 2 & 73 & 86.6 & 90.1 & 0.733 & Acceptable \\
\hline Silver & 1 & 56 & 58.8 & 57.6 & 0.280 & Acceptable \\
\hline$(\mu g / L)$ & 2 & 102 & 108.7 & 108.6 & 0.848 & Acceptable \\
\hline Sodium & 1 & 56.72 & 58.41 & 56.87 & 0.033 & Acceptabie \\
\hline (mg/l) & 2 & 83.12 & 85.12 & 82.69 & 0.054 & Acceptable \\
\hline Sulfate & 1 & 31.4 & 32.77 & 32.14 & 0.217 & Acceptable \\
\hline (mg/L) & 2 & 35.9 & 36.67 & 36.65 & 0.185 & Acceptable \\
\hline $\operatorname{TDS}^{b, c}$ & 1 & 134 & 107.5 & 104.61 & 0.769 & Acceptable \\
\hline (mg/l) & 2 & 291 & 274.1 & 102.32 & 0.446 & Acceptable \\
\hline TOC d & 1 & 76 & 61.09 & 61.47 & 2.097 & Waming \\
\hline$(\mathrm{mg} / \mathrm{L})$ & 2 & 9 & 8.35 & 8.64 & 0.211 & Acceptable \\
\hline Thallium & 1 & 18 & 24.3 & 23.5 & 1.696 & Acceptable \\
\hline$(\mu \mathrm{g} / \mathrm{L})$ & 2 & 200 & 250.0 & 249.1 & 1.518 & Acceptable \\
\hline Total hardness & 1 & 45.6 & 46.07 & 45.62 & 0.005 & Acceptable \\
\hline $\begin{array}{l}\text { as } \mathrm{CaCO}_{3} \\
(\mathrm{mg} / \mathrm{L})\end{array}$ & 2 & 55.5 & 53.74 & 53.99 & 0.391 & Acceptable \\
\hline Total organic & 1 & 29.0 & 33.8 & 47.4 & 0.469 & Acceptable \\
\hline $\begin{array}{l}\text { halides } \\
(! \because \tilde{\prime}))\end{array}$ & 2 & 183.0 & 152.9 & 133.6 & 0.698 & Acceptable \\
\hline Total residual & 1 & 0.59 & 0.60 & 0.58 & 0.134 & Acceptable \\
\hline $\begin{array}{l}\text { chlorine } \\
(\mathrm{mg} / \mathrm{L})\end{array}$ & 2 & 1.6 & 1.42 & 1.40 & 0.986 & Acceptable \\
\hline TSS $^{e, c}$ & 1 & 70 & 79.1 & $88.8^{c}$ & 0.041 & Acceptable \\
\hline$(\mathrm{mg} / \mathrm{L})$ & 2 & 189 & 221.7 & $91.8^{c}$ & 0.817 & Acceptable \\
\hline Trichloroethane & 1 & 16.0 & 19.0 & 18.4 & 0.988 & Acceptable \\
\hline$(\mu \mathrm{g} / \mathrm{L})$ & 2 & 54.0 & 65.0 & 60.0 & 0.841 & Acceptable \\
\hline Uranium & 1 & 156.0 & 160.2 & 167.6 & 1.060 & Acceptable \\
\hline$(\mu \mathrm{g} / \mathrm{L})$ & 2 & 1380 & 1401.4 & 1456.0 & 0.683 & Acceptable \\
\hline Vanadium & 1 & 109 & 130.0 & 130.4 & 1.662 & Acceptable \\
\hline$(\mu g / L)$ & 2 & 1240 & 1345.0 & 1365.5 & 1.292 & Acceptable \\
\hline Zinc & 1 & 56.0 & 53.9 & 55.1 & 0.092 & Acceptable \\
\hline$(\mu \mathrm{g} / \mathrm{L})$ & 2 & 149 & 148.1 & 146.4 & 0.164 & Acceptable \\
\hline
\end{tabular}

aPerformance evaluation made by using EPA criteria, 0-1.96 standard deviations for acceptable; $1.97-2.58$ standard for marginal; more than 2.58 standari deviations for not acceptable.

TDS = total dissolved solids.

${ }^{c}$ Average percent recovery for the participating laboratories.

TOC $=$ : tal organic carbon.

TSS = total suspended solids. 
Table 10.12. March 1990 Analytical Products Group, Inc, Proficiency Environmental Testing Program

\begin{tabular}{|c|c|c|c|c|c|c|}
\hline Parameter & Level & $\begin{array}{l}\text { Reported } \\
\text { value }\end{array}$ & $\begin{array}{c}\text { Reference } \\
\text { value }\end{array}$ & $\begin{array}{l}\text { Mean of } \\
\text { reporting } \\
\text { labs }\end{array}$ & $\begin{array}{l}\text { No. of standard } \\
\text { deviations } \\
\text { from the } \\
\text { mean }\end{array}$ & $\begin{array}{c}\text { Performance } \\
\text { evaluation }\end{array}$ \\
\hline Alkalinity as & 1 & 46.6 & 46.6 & 45.5 & 0.546 & Acceptable \\
\hline $\begin{array}{l}\mathrm{CaCO}_{3} \\
(\mathrm{mg} / \mathrm{L})\end{array}$ & 2 & 64.0 & 62.6 & 61.5 & 1.241 & Acceptable \\
\hline Aluminum & 1 & 54 & 52.7 & 55.4 & 0.099 & Acceptable \\
\hline$(\mu \mathrm{g} / \mathrm{L})$ & 2 & 193 & 193.2 & 205.9 & 0.397 & Acceptable \\
\hline Ammonia as $\mathrm{N}$ & 1 & 0.39 & 0.37 & 0.40 & 0.179 & Acceptable \\
\hline$(\mathrm{mg} / \mathrm{L})$ & 2 & 2.5 & 2.42 & 2.45 & 0.184 & Acceptable \\
\hline Arsenic & 1 & 88 & 79.4 & 78.5 & 1.412 & Acceptable \\
\hline$(\mu \mathrm{g} / \mathrm{L})$ & 2 & 160 & 179.6 & 181.1 & 1.442 & Acceptablc \\
\hline Barium & 1 & 359 & 362.3 & 350.7 & 0.293 & Acceptable \\
\hline$(\mu \mathrm{g} / \mathrm{L})$ & 2 & 2192 & 2235.5 & 2164.2 & 0.156 & Acceptable \\
\hline Beryllium & 1 & 39 & 42.8 & 40.6 & 0.247 & Acceptable \\
\hline$(\mu g / L)$ & 2 & 129 & 135.7 & 131.1 & 0.148 & Acceptable \\
\hline $\mathrm{BOD}$ & 1 & 234.0 & 214.0 & 193.4 & 1.024 & Acceptable \\
\hline$(\mathrm{mg} / \mathrm{L})$ & 2 & 43.0 & 40.2 & 36.0 & 0.730 & Acceptable \\
\hline Cadmium & 1 & 19 & 15.7 & 15.5 & 1.355 & Acceptable \\
\hline$(\mu \mathrm{g} / \mathrm{L})$ & 2 & 116 & 107.8 & 110.0 & 0.666 & Acceptable \\
\hline Calcium & 1 & 10.8 & 10.9 & 10.7 & 0.144 & Acceptable \\
\hline$(\mathrm{mg} / \mathrm{L})$ & 2 & 8.7 & 8.9 & 8.8 & 0.050 & Acceptable \\
\hline Chloride & 1 & 47.0 & 47.2 & 47.8 & 0.300 & Acceptable \\
\hline (mg/L) & 2 & 48.0 & 48.2 & 48.8 & 0.303 & Acceptable \\
\hline Chromium & 1 & 49 & 47.9 & 48.9 & 0.012 & Acceptable \\
\hline$(\mu \mathrm{g} / \mathrm{L})$ & 2 & 136 & 135.4 & 134.9 & 0.058 & Acceptable \\
\hline COD & 1 & 285.0 & 344.5 & 308.0 & 0.410 & Acceptable \\
\hline$(\mathrm{mg} / \mathrm{L})$ & 2 & 56.0 & 64.7 & 55.7 & 0.016 & Acceptable \\
\hline Conductivity & 1 & 283.0 & 307.7 & 282.2 & 0.054 & Acceptable \\
\hline$(\mu \mathrm{mho} / \mathrm{cm})$ & 2 & 321.0 & 352.8 & 316.3 & 0.293 & Acceptable \\
\hline Copper & 1 & 84 & 85.3 & 84.8 & 0.157 & Acceptable \\
\hline$(\mu \mathrm{g} / \mathrm{L})$ & 2 & 180 & 183.3 & 181.5 & 0.110 & Acceptable \\
\hline Fluoride & 1 & 1.8 & 1.79 & 1.78 & 0.186 & Acceptable \\
\hline$(\mathrm{mg} / \mathrm{L})$ & 2 & 6.1 & 6.06 & 6.02 & 0.270 & Acceptable \\
\hline Hexavalent & 1 & 0.03 & 0.033 & 0.031 & 0.126 & Acceptable \\
\hline $\begin{array}{l}\text { chromium } \\
(\mathrm{mg} / \mathrm{L})\end{array}$ & 2 & 0.13 & 0.125 & 0.125 & 0.722 & Acceptable \\
\hline Iron & 1 & 35 & 34.9 & 36.6 & 0.233 & Acceptable \\
\hline$(\mu \mathrm{g} / \mathrm{L})$ & 2 & 220 & 230.2 & 231.0 & 0.871 & Acceptable \\
\hline Lead & 1 & 27.0 & 24.5 & 25.3 & 0.458 & Acceptable \\
\hline$(\mu \mathrm{g} / \mathrm{L})$ & 2 & 428 & 402.4 & 389.2 & 0.667 & Acceptable \\
\hline Magnesium & 1 & 4.91 & 4.62 & $4.6^{?}$ & 0.965 & Acceptable \\
\hline$(\mathrm{mg} / \mathrm{L})$ & 2 & 7.14 & 6.81 & $6: 4$ & 0.675 & Acceptable \\
\hline Manganese & 1 & 63 & 60.5 & 58.4 & 0.944 & Acceptable \\
\hline$(\mu \mathrm{g} / \mathrm{L})$ & 2 & 166 & 163.3 & 161.7 & 0.506 & Acceptable \\
\hline Mercury & 1 & 1.8 & 1.80 & 1.75 & 0.133 & Acceptable \\
\hline$(\mu \mathrm{g} / \mathrm{L})$ & 2 & 2.3 & 2. & 2.47 & 0.224 & Acceptable \\
\hline Nickel & 1 & 57 & 57.3 & 55.6 & 0.153 & Acceptable \\
\hline$(\mu \mathrm{g} / \mathrm{L})$ & 2 & 186 & 188.7 & 187.0 & 0.054 & Acceptable \\
\hline Nitrate as $\mathrm{N}$ & 1 & 0.67 & 0.62 & 0.61 & 1.047 & Acceptable \\
\hline$(\mathrm{mg} / \mathrm{L})$ & 2 & 1.40 & 1.33 & 1.31 & 0.770 & Acceptable \\
\hline Oil and grease & 1 & 10.9 & 11.1 & 10.0 & 0.269 & Acceptable \\
\hline$(\mathrm{mg} / \mathrm{L})$ & 2 & 29.1 & 30.4 & 27.2 & 0.373 & Acceptable \\
\hline Orthophosphate & 1 & 0.36 & 0.36 & 0.36 & 0.090 & Acceptable \\
\hline as $\mathrm{P}(\mathrm{mg} / \mathrm{L})$ & 2 & 2.50 & 2.36 & 2.38 & 0.351 & Acceptable \\
\hline
\end{tabular}


Table 10.12 (continued)

\begin{tabular}{|c|c|c|c|c|c|c|}
\hline Parameter & Level & $\begin{array}{l}\text { Reported } \\
\text { value }\end{array}$ & $\begin{array}{l}\text { Reference } \\
\text { value }\end{array}$ & $\begin{array}{l}\text { Mean of } \\
\text { reporting } \\
\text { labs }\end{array}$ & $\begin{array}{l}\text { No. of standand } \\
\text { deviations } \\
\text { from the } \\
\text { mean }\end{array}$ & $\begin{array}{c}\text { Performance } \\
\text { evaluation }\end{array}$ \\
\hline $\mathrm{pH}$ & 1 & 7.9 & 7.84 & 7.91 & 0.020 & Acceptable \\
\hline (units) & 2 & 7.8 & 7.73 & 7.79 & 0.021 & Acceptable \\
\hline Poxassium & 1 & 14.45 & 13.19 & 12.88 & 1.239 & Acceptable \\
\hline$(\mathrm{mg} / \mathrm{L})$ & 2 & 7.589 & 6.78 & 6.74 & 1.333 & Acceptable \\
\hline Selenium & 1 & 17 & 14.7 & 15.2 & 0.938 & Acceptable \\
\hline$(\mu g / L)$ & 2 & 76 & 70.2 & 69.2 & 0.780 & Acceptable \\
\hline Silver & 1 & 38 & 34.3 & 34.2 & 0.660 & Acceptable \\
\hline$(\mu g / L)$ & 2 & 274 & 243.4 & 245.1 & 1.298 & Acceptable \\
\hline Sodium & 1 & 29.42 & 28.61 & 28.38 & 0.627 & Acceptable \\
\hline$(\mathrm{mg} / \mathrm{L})$ & 2 & 41.49 & 40.59 & 40.58 & 0.376 & Acceptable \\
\hline Sulfate & 1 & 12 & 12.3 & 12.1 & 0.069 & Acceptable \\
\hline (mg/L) & 2 & 16 & 16.6 & 16.5 & 0.313 & Acceptable \\
\hline $\operatorname{TDS}^{b x}$ & 1 & 204.0 & 189.3 & 0.45 & 0.415 & Acceptable \\
\hline (mg/L) & 2 & 504.0 & 507.1 & 0.59 & 0.138 & Acceptable \\
\hline $\mathrm{TOC}^{d}$ & 1 & 119.0 & 129.7 & 130.1 & 1.295 & Acceptable \\
\hline$(\mathrm{mg} / \mathrm{L})$ & 2 & 25.0 & 24.3 & 24.5 & 0.312 & Acceptable \\
\hline Thallium & 1 & 125 & 128.9 & 130.9 & 0.280 & Acceptable \\
\hline$(\mu g / L)$ & 2 & 350 & 386.2 & 379.5 & 0.552 & Acceptable \\
\hline Toluene & 1 & 46 & 47.2 & 42.9 & 0.34 & Acceptable \\
\hline$(\mu \mathrm{g} / \mathrm{L})$ & 2 & 82 & 83.9 & 84.6 & 0.29 & Acceptable \\
\hline Total hardness & 1 & 45.3 & 46.36 & 45.38 & 0.028 & Acceptable \\
\hline $\begin{array}{l}\text { as } \mathrm{CaCO}_{3} \\
(\mathrm{mg} / \mathrm{L})\end{array}$ & 2 & 48.7 & 50.37 & 49.29 & 0.129 & Acceptable \\
\hline Total organic & 1 & 24 & 18.1 & 19.4 & 1.157 & Acceptable \\
\hline $\begin{array}{l}\text { halides } \\
(\mu \mathrm{g} / \mathrm{L})\end{array}$ & 2 & 278 & 329.7 & 293.2 & 0.561 & Acceptable \\
\hline Total residual & 1 & 0.1 & 0.135 & 0.137 & 0.515 & Acceptable \\
\hline $\begin{array}{l}\text { chlorine } \\
\text { (mg/L) }\end{array}$ & 2 & 2.15 & 2.41 & 2.23 & 0.177 & Acceptable \\
\hline TSS $^{e x}$ & 1 & 29.0 & 31.0 & 7.79 & 0.177 & Acceptable \\
\hline$(\mathrm{mg} / \mathrm{L})$ & 2 & 278.0 & 331.7 & 4.98 & 1.523 & Acceptable \\
\hline 1,1,1-trichloroethane & 1 & 22 & 21.0 & 20.1 & 0.514 & Acceptable \\
\hline$(\mu \mathrm{g} / \mathrm{L})$ & 2 & 63 & 59.7 & 60.2 & 0.377 & Acceptable \\
\hline Uranium & 1 & 82 & 80.1 & 88.3 & 0.492 & Acceptable \\
\hline$(\mu \mathrm{g} / \mathrm{L})$ & 2 & 280 & 300.3 & 342.5 & 1.133 & Acceptable \\
\hline Vanadium & 1 & 76 & 90.0 & 88.2 & 0.786 & Acceptable \\
\hline$(\mu \mathrm{g} / \mathrm{L})$ & 2 & 1026 & 1087.9 & 1067.1 & 0.382 & Acceptable \\
\hline Zinc & 1 & 58 & 51.2 & 51.0 & 1.324 & Acceptable \\
\hline$(\mu g / L)$ & 2 & 140 & 135.0 & 134.7 & 0.622 & Acceptable \\
\hline
\end{tabular}

aperformance evaluation made by using EPA criteria, 0-1.96 standard deviations for acceptable; $1.97-2.58$ standard for marginal; more than 2.58 standard deviations for not acceptable.

bTDS = total dissolved solids.

${ }^{c}$ Average percent recovery for the participating laboratories.

TOC = total organic carbon.

TSS = total suspended solids. 
Table 10.13. May 1990 Analytical Products Group, Inc., Proficlency Environmental Testing Program

\begin{tabular}{|c|c|c|c|c|c|c|}
\hline Parameter & Level & $\begin{array}{l}\text { Reported } \\
\text { value }\end{array}$ & $\begin{array}{l}\text { Reference } \\
\text { value }\end{array}$ & $\begin{array}{l}\text { Mean of } \\
\text { reporting } \\
\text { labs }\end{array}$ & $\begin{array}{l}\text { No. of standard } \\
\text { deviations } \\
\text { from the } \\
\text { mean }\end{array}$ & $\begin{array}{l}\text { Performance } \\
\text { evaluation }\end{array}$ \\
\hline Alkalinity as & 1 & 47.5 & 51.7 & 51.3 & 1.143 & Acceptable \\
\hline $\begin{array}{l}\mathrm{CaCO}_{3} \\
(\mathrm{mg} / \mathrm{L})\end{array}$ & 2 & 38.3 & 36.3 & 36.7 & 0.480 & Acceptable \\
\hline Aluminum & 1 & 65 & 60.0 & 61.1 & 0.282 & Acceptable \\
\hline$(\mu \mathrm{g} / \mathrm{L})$ & 2 & 174 & 170.0 & 171.5 & 0.107 & Acceptable \\
\hline Ammonia as $\mathrm{N}$ & 1 & 0.27 & 0.262 & 0.253 & 0.298 & Acceptable \\
\hline$(\mathrm{mg} / \mathrm{L})$ & 2 & 1.9 & 1.92 & 1.96 & 0.299 & Acceptable \\
\hline Arsenic & 1 & 32 & 27.8 & 27.3 & 1.397 & Acceptable \\
\hline$(\mu \mathrm{g} / \mathrm{L})$ & 2 & 425 & 394.0 & 389.6 & 1.087 & Acceptable \\
\hline Barium & 1 & 345 & 333.3 & 331.8 & 0.884 & Acceptable \\
\hline$(\mu \mathrm{g} / \mathrm{L})$ & 2 & 1890 & 1810.7 & 1853.3 & 0.227 & Acceptable \\
\hline Beryllium & 1 & 21 & 20.1 & 19.8 & 0.718 & Acceptable \\
\hline$(\mu \mathrm{g} / \mathrm{L})$ & 2 & 129 & 120.6 & 117.7 & 1.735 & Acceptable \\
\hline $\mathrm{BOD}$ & 1 & 190 & 204.4 & 189.3 & 0.019 & Acceptable \\
\hline$(\mathrm{mg} / \mathrm{L})$ & 2 & 16 & 16.2 & 16.3 & 0.073 & Acceptable \\
\hline Cadmium & 1 & 47 & 42.1 & 42.2 & 1.24 & Acceptable \\
\hline$(\mu \mathrm{g} / \mathrm{L})$ & 2 & 239 & $2 ! 0.3$ & 215.0 & 2.225 & Warning \\
\hline Calcium & 1 & 9.35 & 9.33 & 9.32 & 0.059 & Acceptable \\
\hline$(\mathrm{mg} / \mathrm{L})$ & 2 & 27.84 & 29.39 & 28.59 & 0.405 & Acceptable \\
\hline Chloride & 1 & 49.8 & 50.0 & 50.1 & 0.152 & Acceptable \\
\hline$(\mathrm{mg} / \mathrm{L})$ & 2 & 101.3 & 104.7 & 101.5 & 0.033 & Acceptable \\
\hline Chromium & 1 & 40.0 & 37.0 & 37.6 & 0.440 & Acceptable \\
\hline$(\mu g / L)$ & 2 & 247 & 235.0 & 238.4 & 0.481 & Acceptable \\
\hline COD & 1 & 300 & 329.1 & 309.2 & 0.225 & Acceptable \\
\hline (mg/L) & 2 & 31 & 26.0 & 26.8 & 0.658 & Acceptable \\
\hline Conductivity & 1 & 302 & 327 & 302.9 & 0.047 & Acceptable \\
\hline$(\mu \mathrm{mho} / \mathrm{cm})$ & 2 & 505 & 550.6 & 501.2 & 0.147 & Acceptable \\
\hline Copper & 1 & 99 & 94.8 & 94.8 & 0.874 & Acceptable \\
\hline$(\mu \mathrm{g} / \mathrm{L})$ & 2 & 280 & 269.3 & 264.6 & 0.563 & Acceptable \\
\hline Fluoride & 1 & 1.2 & 1.20 & 1.19 & 0.109 & Acceptable \\
\hline$(\mathrm{mg} / \mathrm{L})$ & 2 & 6.1 & 6.02 & 6.08 & 0.065 & Acceptable \\
\hline Hexavalent & 1 & 0.02 & 0.022 & 0.022 & 0.339 & Acceptable \\
\hline $\begin{array}{l}\text { chromium } \\
(\mathrm{mg} / \mathrm{L})\end{array}$ & 2 & 0.43 & 0.435 & 0.421 & 0.271 & Acceptable \\
\hline Iron & 1 & 36 & 34.9 & 35.4 & 0.163 & Acceptable \\
\hline$(\mu \mathrm{g} / \mathrm{L})$ & 2 & 253 & 244.2 & 254.0 & 0.053 & Acceptable \\
\hline Lead & 1 & 73 & 70.5 & 70.7 & 0.256 & Acceptable \\
\hline$(\mu \mathrm{g} / \mathrm{L})$ & 2 & 288 & 265.0 & 263.6 & 0.935 & Acceptable \\
\hline Magnesium & 1 & 3.95 & 3.67 & 3.66 & 1.333 & Acceptable \\
\hline$(\mathrm{mg} / \mathrm{L})$ & 2 & 11.52 & 11.01 & 10.80 & 1.221 & Acceptable \\
\hline Manganese & 1 & 64 & 60.5 & 60.3 & 0.551 & Acceptable \\
\hline$(\mu \mathrm{g} / \mathrm{L})$ & 2 & 476 & 453.7 & 455.8 & 0.834 & Acceptable \\
\hline Mercury & 1 & 2 & 1.4 & 1.4 & 2.298 & Warning \\
\hline$(\mu \mathrm{g} / \mathrm{L})$ & 2 & 5 & 4.0 & 3.8 & 1.904 & Acceptable \\
\hline Nickel & 1 & 38 & 34.4 & 35.9 & 0.321 & Acceptable \\
\hline$(\mu \mathrm{g} / \mathrm{L})$ & 2 & 144 & 137.5 & 136.3 & 0.655 & Acceptable \\
\hline Nitrate as $\mathrm{N}$ & 1 & 0.24 & 0.20 & 0.19 & 1.078 & Acceptable \\
\hline$(\mathrm{mg} / \mathrm{L})$ & 2 & 1.9 & 1.80 & 1.80 & 1.023 & Acceptable \\
\hline Oil and grease & 1 & 16.8 & 17.9 & 14.0 & 0.575 & Acceptable \\
\hline$(\mathrm{mg} / \mathrm{L})$ & 2 & 29.8 & 31.8 & 29.3 & 0.083 & Acceptable \\
\hline Orthophosphate & 1 & 0.42 & 0.40 & 0.39 & 0.866 & Acceptable \\
\hline as $\mathrm{P}(\mathrm{mg} / \mathrm{L})$ & 2 & 3.5 & 3.61 & 3.56 & 0.194 & Acceptable \\
\hline
\end{tabular}


Table 10.13 (continued)

\begin{tabular}{|c|c|c|c|c|c|c|}
\hline Parameter & Level & $\begin{array}{l}\text { Reported } \\
\text { value }\end{array}$ & $\begin{array}{l}\text { Reference } \\
\text { value }\end{array}$ & $\begin{array}{l}\text { Mean of } \\
\text { reporting } \\
\text { labs }\end{array}$ & $\begin{array}{l}\text { No. of standard } \\
\text { deviations } \\
\text { from the } \\
\text { mean }\end{array}$ & $\begin{array}{c}\text { Performance } \\
\text { evaluation }\end{array}$ \\
\hline $\mathrm{pH}$ & 1 & 5.1 & 4.86 & 5.19 & 0.435 & Acceptable \\
\hline (units) & 2 & 5.9 & 5.45 & 5.78 & 0.704 & Acceptable \\
\hline Potassium & 1 & 18.09 & 18.27 & 18.22 & 0.087 & Acceptable \\
\hline$(\mathrm{mg} / \mathrm{L})$ & 2 & 5.26 & 5.43 & 5.46 & 0.389 & Acceptable \\
\hline Selenium & 1 & 39 & 36.7 & 36.3 & 0.414 & Acceptable \\
\hline$(\mu g / L)$ & 2 & 81 & 65.2 & 64.9 & 1.421 & Acceptable \\
\hline Silver & 1 & 24 & 22.0 & 22.2 & 0.506 & Acceptable \\
\hline$(\mu g / L)$ & 2 & 174 & 173.9 & 177.0 & 0.200 & Acceptable \\
\hline Sodium & 1 & 34.27 & 32.65 & 32.13 & 0.823 & Acceptable \\
\hline$(\mathrm{mg} / \mathrm{L})$ & 2 & 46.22 & 44.88 & 44.16 & 0.513 & Acceptable \\
\hline Sulfate & 1 & 10.1 & 10.3 & 10.2 & 0.064 & Acceptable \\
\hline$(\mathrm{mg} / \mathrm{L})$ & 2 & 37.0 & 37.9 & 35.7 & 0.184 & Acceptable \\
\hline Tetrachloroethane & 1 & 24 & 26.1 & 23.1 & 0.290 & Acceptable \\
\hline$(\mu \mathrm{g} / \mathrm{L})$ & 2 & 80 & 83.5 & 76.2 & 0.296 & Acceptable \\
\hline $\operatorname{TDS}^{b}$ & 1 & 154 & 151.8 & $101.4^{c}$ & 0.221 & Acceptable \\
\hline (mg/L) & 2 & 521 & 532.4 & $97.8^{c}$ & 0.006 & Acceptable \\
\hline TOC ${ }^{8}$ & 1 & 125.0 & 123.9 & 123.1 & 0.176 & Acceptable \\
\hline$(\mathrm{mg} / \mathrm{L})$ & 2 & 10.3 & 9.8 & 10.4 & 0.076 & Acceptable \\
\hline Thallium & 1 & 45 & 48.6 & 56.0 & 0.638 & Acceptable \\
\hline$(\mu g / L)$ & 2 & 645 & 648.7 & 589.9 & 0.566 & Acceptable \\
\hline Toluene & 1 & 18 & 19.0 & 17.5 & 0.175 & Acceptable \\
\hline$(\mu g / L)$ & 2 & 84 & 84.7 & 77.1 & 0.507 & Acceptable \\
\hline Total organic & 1 & 24 & 29.3 & 26.7 & 0.516 & Acceptable \\
\hline halides & 2 & 190 & 220.0 & 204.1 & 0.352 & Acceptable \\
\hline$(\mu \mathrm{g} / \mathrm{L})$ & & & & & & \\
\hline Total residual & 1 & 0.44 & 0.48 & 0.48 & 0.336 & Acceptable \\
\hline $\begin{array}{l}\text { chlorine } \\
(\mathrm{mg} / \mathrm{L})\end{array}$ & 2 & 2.6 & 2.60 & 2.47 & 0.576 & Acceptable \\
\hline TSS $^{e}$ & 1 & 47 & 59.3 & $92.2^{c}$ & 1.515 & Acceptable \\
\hline (mg/L) & 2 & 138 & 162.4 & $94.3^{c}$ & 1.340 & Acceptable \\
\hline Uranium & 1 & 59 & 60.1 & 62.5 & 0.856 & Acceptable \\
\hline$(\mu g / L)$ & 2 & 1010 & 1001.0 & 979.2 & 0.375 & Acceptable \\
\hline Vanadium & 1 & 41 & 50.0 & 49.6 & 1.920 & Acceptable \\
\hline$(\mu \mathrm{g} / \mathrm{L})$ & 2 & 1418 & 1348.8 & 1357.7 & 0.783 & Acceptable \\
\hline Zinc & 1 & 28 & 24.2 & 26.2 & 0.398 & Acceptable \\
\hline$(\mu \mathrm{g} / \mathrm{L})$ & 2 & 244 & 220.0 & 222.4 & 1.557 & Acceptable \\
\hline
\end{tabular}

aperformance evaluation made by using EPA criteria, 0-1.96 standard deviations for acceptable; $1.97-2.58$ standard for marginal; more than 2.58 standard deviations for not acceptable.

bTDS = intal dissolved solids.

${ }^{c}$ Average percent recovery for the participating laboratories.

dTOC = total organic carbon.

TSS = total suspended solids. 
Table 10.14. July 1990 Analytical Products Group, Inc., Proficiency Environmental Testing Program

\begin{tabular}{|c|c|c|c|c|c|c|}
\hline Parameter & Level & $\begin{array}{l}\text { Reported } \\
\text { value }\end{array}$ & $\begin{array}{l}\text { Reference } \\
\text { value }\end{array}$ & $\begin{array}{l}\text { Mean of } \\
\text { reporting } \\
\text { labs }\end{array}$ & $\begin{array}{l}\text { No. of standard } \\
\text { deviations } \\
\text { from the } \\
\text { mean }\end{array}$ & $\begin{array}{c}\text { Performance }^{a} \\
\text { evaluation }\end{array}$ \\
\hline Alkalinity as & 1 & 60.1 & 60.11 & 57.45 & 0.739 & Acceptable \\
\hline $\begin{array}{l}\mathrm{CaCO}_{3} \\
(\mathrm{mg} / \mathrm{L})\end{array}$ & 2 & 61.1 & 61.78 & 59.89 & 0.396 & Acceptable \\
\hline Aluminum & 1 & 36 & 40.0 & 46.1 & 0.721 & Acceptable \\
\hline$(\mu \mathrm{g} / \mathrm{L})$ & 2 & 274 & 280.1 & 281.0 & 0.250 & Acceptable \\
\hline Ammonia as $\mathrm{N}$ & 1 & 0.72 & 0.669 & 0.646 & 0.481 & Acceptable \\
\hline$(\mathrm{mg} / \mathrm{L})$ & 2 & 2.0 & 2.01 & 1.98 & 0.099 & Acceptable \\
\hline Arsenic & 1 & 36.7 & 43.68 & 42.40 & 0.924 & Acceptable \\
\hline$(\mu \mathrm{g} / \mathrm{L})$ & 2 & 207.5 & 236.40 & 230.36 & 0.719 & Acceptable \\
\hline Barium & 1 & 362 & 362.3 & 366.0 & 0.116 & Acceptable \\
\hline$(\mu \mathrm{g} / \mathrm{L})$ & 2 & 1140 & 1117.7 & 1133.6 & 0.071 & Acceptable \\
\hline Benzene & 1 & 15 & 17.6 & 17.5 & 1.130 & Acceptable \\
\hline$(\mu \mathrm{g} / \mathrm{L})$ & 2 & 60 & 65.0 & 66.3 & 0.878 & Acceptable \\
\hline Betyllium & 1 & 24 & 22.6 & 21.4 & 1.240 & Acceptable \\
\hline$(\mu \mathrm{g} / \mathrm{L})$ & 2 & 123 & 110.5 & 106.8 & 1.797 & Acceptable \\
\hline BOD & 1 & 143 & 130.5 & 127.1 & 0.657 & Acceptable \\
\hline$(\mathrm{mg} / \mathrm{L})$ & 2 & 42 & 40.1 & 37.5 & 0.584 & Acceptable \\
\hline Cadmium & 1 & 15 & 14.7 & 14.8 & 0.084 & Acceptable \\
\hline$(\mu \mathrm{g} / \mathrm{L})$ & 2 & 228 & 210.3 & 210.6 & 1.190 & Acceptable \\
\hline Calcium & 1 & 12.21 & 12.33 & 12.52 & 0.246 & Acceptable \\
\hline (mg/L) & 2 & 23.63 & 23.96 & 24.15 & 0.390 & Acceptable \\
\hline Chloride & 1 & 58 & 56.9 & 56.8 & 0.496 & Acceptable \\
\hline$(\mathrm{mg} / \mathrm{L})$ & 2 & 99 & 97.2 & 95.8 & 0.434 & Acceptable \\
\hline Chlorobenzene & 1 & 38 & 42.8 & 41.7 & 0.878 & Acceptable \\
\hline$(\mu g / L)$ & 2 & 58 & 64.5 & 63.9 & 1.008 & Acceptable \\
\hline Chromium & 1 & 32 & 32.6 & 33.6 & 0.257 & Acceptable \\
\hline$(\mu \mathrm{g} / \mathrm{L})$ & 2 & 121 & 119.6 & 119.5 & 0.177 & Acceptable \\
\hline COD & 1 & 210 & 210.1 & 204.3 & 0.323 & Acceptable \\
\hline$(\mathrm{mg} / \mathrm{L})$ & 2 & 62 & 64.6 & 59.2 & 0.344 & Acceptable \\
\hline Conductivity & 1 & 355 & 385.9 & 346.6 & 0.365 & Acceptable \\
\hline$(\mu \mathrm{mho} / \mathrm{cm})$ & 2 & 486 & 530.6 & 477.8 & 0.268 & Acceptable \\
\hline Copper & 1 & 90 & 94.8 & 92.2 & 0.390 & Acceptable \\
\hline$(\mu \mathrm{g} / \mathrm{L})$ & 2 & 152 & 154.7 & 154.5 & 0.242 & Acceptable \\
\hline Elhyl benzene & 1 & 6 & 7.1 & 6.7 & 0.724 & Acceptable \\
\hline$(\mu \mathrm{g} / \mathrm{L})$ & 2 & 87 & 95.1 & 93.2 & 0.727 & Acceptable \\
\hline Fluoride & 1 & 3.3 & 3.31 & 3.26 & 0.149 & Acceptable \\
\hline$(\mathrm{mg} / \mathrm{L})$ & 2 & 9.5 & 9.27 & 9.12 & 0.421 & Acceptable \\
\hline Hexavalent & 1 & 0.010 & 0.017 & 0.016 & 1.879 & Acceptable \\
\hline $\begin{array}{l}\text { chromium } \\
(\mathrm{mg} / \mathrm{L})\end{array}$ & 2 & 0.36 & 0.361 & 0.363 & 0.176 & Acceptable \\
\hline Iron & 1 & 47 & 55.8 & 55.8 & 0.910 & Acceptable \\
\hline$(\mu \mathrm{g} / \mathrm{L})$ & 2 & 533 & 523.2 & 523.0 & 0.274 & Acceptable \\
\hline Lead & 1 & 32 & 31.7 & 31.8 & 0.038 & Acceptable \\
\hline$(\mu \mathrm{g} / \mathrm{L})$ & 2 & 303 & 292.4 & 293.2 & 0.380 & Acceptable \\
\hline Magnesium & 1 & 3.8 & 3.56 & 3.62 & 0.889 & Acceptable \\
\hline$(\mathrm{mg} / \mathrm{L})$ & 2 & 11.5 & 10.73 & 10.78 & 0.766 & Acceptable \\
\hline Manganese & 1 & 63 & 60.5 & 59.7 & 0.753 & Acceptable \\
\hline$(\mu g / L)$ & 2 & 169 & 163.3 & 160.9 & 0.991 & Acceptable \\
\hline Metcury & 1 & 1.6 & 1.60 & 1.57 & 0.154 & Acceptable \\
\hline$(\mu \mathrm{g} / \mathrm{L})$ & 2 & 2.7 & 2.74 & 2.87 & 0.406 & Acceptable \\
\hline Nickel & 1 & 30 & 31.8 & 31.7 & 0.321 & Acceptable \\
\hline$(\mu \mathrm{g} / \mathrm{L})$ & 2 & 153 & 147.1 & 147.0 & 0.452 & Acceptable \\
\hline
\end{tabular}


Table 10.14 (continued)

\begin{tabular}{|c|c|c|c|c|c|c|}
\hline Parameter & Level & $\begin{array}{l}\text { Reported } \\
\text { value }\end{array}$ & $\begin{array}{l}\text { Reference } \\
\text { value }\end{array}$ & $\begin{array}{l}\text { Mean of } \\
\text { reporting } \\
\text { labs }\end{array}$ & $\begin{array}{l}\text { No. of standard } \\
\text { deviations } \\
\text { from the } \\
\text { mean }\end{array}$ & $\begin{array}{c}\text { Performance } \\
\text { evaluation }\end{array}$ \\
\hline Nitrate as $N$ & 1 & 1.1 & 0.86 & 0.85 & 2.097 & Warning \\
\hline$(\mathrm{mg} / \mathrm{L})$ & 2 & 1.6 & 1.32 & 1.34 & 1.739 & Acceptable \\
\hline Oil and grease & 1 & 5.3 & 5.32 & 6.04 & 0.330 & Acceptable \\
\hline$(\mathrm{mg} / \mathrm{L})$ & 2 & 44.2 & 47.9 & 40.6 & 0.436 & Acceptable \\
\hline Orthophosphate & 1 & \multicolumn{5}{|c|}{ Unreported } \\
\hline as $\mathrm{P}(\mathrm{mg} / \mathrm{L})$ & 2 & 1.2 & 1.12 & 1.09 & 1.226 & Acceptable \\
\hline $\mathrm{pH}$ & 1 & 8.9 & 8.92 & 8.70 & 0.590 & Acceptable \\
\hline (units) & 2 & 9.2 & 9.13 & 8.91 & 0.903 & Acceptable \\
\hline Potassium & 1 & 17.26 & 16.03 & 16.19 & 0.954 & Acceptable \\
\hline$(\mathrm{mg} / \mathrm{L})$ & 2 & 8.04 & 7.43 & 7.56 & 0.642 & Acceptable \\
\hline Selenium & 1 & 18.5 & 18.3 & 18.4 & 0.028 & Acceptable \\
\hline$(\mu \mathrm{g} / \mathrm{L})$ & 2 & 143.7 & 145.3 & 143.1 & 0.027 & Acceptable \\
\hline Silver & 1 & 13 & 17.2 & 17.6 & 1.892 & Acceptable \\
\hline$(\mu \mathrm{g} / \mathrm{L})$ & 2 & 171 & 173.9 & 174.4 & 0.376 & Acceptable \\
\hline Sodium & 1 & 44.84 & 42.07 & 43.00 & 0.781 & Acceptable \\
\hline$(\mathrm{mg} / \mathrm{L})$ & 2 & 50.72 & 47.87 & 48.25 & 1.137 & Acceptable \\
\hline Sulfate & 1 & 17 & 17.3 & 17.0 & 0.004 & Acceptable \\
\hline$(\mathrm{mg} / \mathrm{L})$ & 2 & 18 & 18.8 & 18.5 & 0.262 & Acceptable \\
\hline Tetrachloroethane & 1 & 7 & 8.2 & 7.6 & 0.480 & Acceptable \\
\hline$(\mu \mathrm{g} / \mathrm{L})$ & 2 & 92 & 108.8 & 103.0 & 0.057 & Acceptable \\
\hline $\operatorname{TDS}^{b, c}$ & 1 & 119 & 120.4 & 101.9 & 0.141 & Acceptable \\
\hline$(\mathrm{mg} / \mathrm{L})$ & 2 & 299 & 296.7 & 100.4 & 0.044 & Acceptable \\
\hline TOC & 1 & 84 & 79.1 & 78.5 & 0.879 & Acceptable \\
\hline$(\mathrm{mg} / \mathrm{L})$ & 2 & 27 & 24.3 & 24.5 & 0.987 & Acceptable \\
\hline Thallium & 1 & 47 & 48.6 & 48.6 & 0.184 & Acceptable \\
\hline$(\mu \mathrm{g} / \mathrm{L})$ & 2 & 385 & 386.2 & 368.0 & 0.425 & Acceptable \\
\hline Toluene & 1 & 10 & 11.4 & 10.9 & 0.627 & Acceptable \\
\hline$(\mu \mathrm{g} / \mathrm{L})$ & 2 & 54 & 61.2 & 60.0 & 0.991 & Acceptable \\
\hline Total hardness & 1 & 44 & 45.4 & 45.2 & 0.244 & Acceptable \\
\hline $\begin{array}{l}\text { as } \mathrm{CaCO}_{3} \\
(\mathrm{mg} / \mathrm{L})\end{array}$ & 2 & 102.6 & 104.0 & 102.8 & 0.064 & Acceptable \\
\hline Total organic & 1 & 40 & 40.7 & 39.2 & 0.194 & Acceptable \\
\hline $\begin{array}{l}\text { halides } \\
(\mu \mathrm{g} / \mathrm{L})\end{array}$ & 2 & 166 & 176.1 & 156.1 & 0.754 & Acceptable \\
\hline Total residual & 1 & 0.12 & 0.13 & 0.12 & 0.121 & Acceptable \\
\hline $\begin{array}{l}\text { chlorine } \\
(\mathrm{mg} / \mathrm{L})\end{array}$ & 2 & 2.3 & 2.27 & 2.11 & 0.557 & Acceptable \\
\hline $\mathrm{TSS}^{e x}$ & 1 & 66 & 71.0 & $92.9^{c}$ & 0.106 & Acceptable \\
\hline (mg/L) & 2 & 195 & 214.0 & $94.4^{c}$ & 0.501 & Acceptable \\
\hline Uranium & 1 & 128 & 120.1 & 121.4 & 0.927 & Acceptable \\
\hline$(\mu \mathrm{g} / \mathrm{L})$ & 2 & 1300 & 1301.3 & 1337.4 & 0.348 & Acceptable \\
\hline Vanadium & 1 & 265 & 287.5 & 279.9 & 0.545 & Acceptable \\
\hline$(\mu g / L)$ & 2 & 1040 & 1107.9 & 1107.8 & 0.792 & Acceptable \\
\hline Zinc & 1 & 47 & 48.5 & 48.9 & 0.371 & Acceptable \\
\hline$(\mu \mathrm{g} / \mathrm{L})$ & 2 & 233 & 225.0 & 225.6 & 0.459 & Acceptable \\
\hline
\end{tabular}

aPerformance evaluation made by using EPA criteria, $\Omega-1.96$ standard deviations for acceptable; $1.97-2.58$ standard for marginal; more than 2.58 standard deviations for not acceptable.

bTDS = total dissolved solids.

${ }^{c}$ Average percent recovery for the participating laboratories.

${ }^{\top}$ TOC = total organic carbon.

TSS = total suspended solids. 
Table 10.15. September 1990 Analytical Products Group, Inc., Proficiency Environmental Testing Program

\begin{tabular}{|c|c|c|c|c|c|c|}
\hline Parameter & Level & $\begin{array}{l}\text { Reported } \\
\text { value }\end{array}$ & $\begin{array}{l}\text { Reference } \\
\text { value }\end{array}$ & $\begin{array}{l}\text { Mean of } \\
\text { reporting } \\
\text { labs }\end{array}$ & $\begin{array}{l}\text { No. of standard } \\
\text { deviations } \\
\text { from the } \\
\text { mean }\end{array}$ & $\begin{array}{c}\text { Performance } \\
\text { evaluation }\end{array}$ \\
\hline Alkalinity as & 1 & 52.4 & 52.49 & 52.70 & 0.068 & Acceptable \\
\hline $\begin{array}{l}\mathrm{CaCO}_{3} \\
(\mathrm{mg} / \mathrm{L})\end{array}$ & 2 & 66.9 & 65.20 & 64.34 & 0.589 & Acceptable \\
\hline Aluminum & 1 & 79 & 60.0 & 66.5 & 0.597 & Acceptable \\
\hline$(\mu \mathrm{g} / \mathrm{L})$ & 2 & 387 & 400.1 & 354.8 & 0.268 & Acceptable \\
\hline Ammonia as $\mathrm{N}$ & 1 & 0.53 & 0.58 & 0.59 & 0.495 & Acceptable \\
\hline$(\mathrm{mg} / \mathrm{L})$ & 2 & 1.9 & 2.05 & 2.07 & 0.783 & Acceptable \\
\hline Arsenic & 1 & 46.5 & 39.71 & 40.32 & 0.783 & Acceptable \\
\hline$(\mu \mathrm{g} / \mathrm{L})$ & 2 & 232.5 & 183.9 & 185.9 & 1.848 & Acceptable \\
\hline Barium & 1 & 704 & 724.6 & 722.4 & 0.283 & Acceptable \\
\hline$(\mu \mathrm{g} / \mathrm{L})$ & 2 & 1251 & 1283.8 & 1271.5 & 0.265 & Acceptable \\
\hline Benzene & 1 & 28 & 26.6 & 27.4 & 0.104 & Acceptable \\
\hline$(\mu \mathrm{g} / \mathrm{L})$ & 2 & 58 & 52.6 & 57.5 & 0.046 & Acceptable \\
\hline Beryllium & 1 & 22 & 20.0 & 20.3 & 0.622 & Acceptable \\
\hline$(\mu \mathrm{g} / \mathrm{L})$ & 2 & 240 & 234.5 & 225.5 & 0.904 & Acceptable \\
\hline BOD & 1 & 229 & 221.4 & 200.7 & 0.482 & Acceptable \\
\hline (mg/L) & 2 & 41 & 41.1 & 37.7 & 0.372 & Acceptable \\
\hline Cadmium & 1 & 51 & 49.1 & 49.1 & 0.469 & Acceptable \\
\hline$(\mu \mathrm{g} / \mathrm{L})$ & 2 & 143 & 136.0 & 136.3 & 0.712 & Acceptable \\
\hline Calcium & 1 & 19.02 & 20.21 & 21.28 & 0.439 & Acceptable \\
\hline$(\mathrm{mg} / \mathrm{L})$ & 2 & 28.23 & 30.41 & 30.28 & 0.916 & Acceptable \\
\hline Carbon tetrachloride & 1 & 32 & 29.5 & 30.4 & 0.152 & Acceptable \\
\hline$(\mu \mathrm{g} / \mathrm{L})$ & 2 & 107 & 88.8 & 90.6 & 0.913 & Acceptable \\
\hline Chloride & 1 & 86 & 89.4 & 89.0 & 0.588 & Acceptable \\
\hline$(\mathrm{mg} / \mathrm{L})$ & 2 & 129 & 128.3 & 128.5 & 0.070 & Acceptable \\
\hline Chlorobenzene & 1 & 19 & 21.0 & 19.5 & 0.222 & Acceptable \\
\hline$(\mu g / L)$ & 2 & 60 & 62.4 & 62.6 & 0.257 & Acceptable \\
\hline Chloroform & 1 & 14 & 14.4 & 14.4 & 0.149 & Acceptable \\
\hline$(\mu \mathrm{g} / \mathrm{L})$ & 2 & 148 & 132.2 & 129.6 & 0.676 & Acceptable \\
\hline Chromium & 1 & 60 & 61.70 & 60.96 & 0.113 & Acceptable \\
\hline$(\mu g / L)$ & 2 & 118 & 122.0 & 119.0 & 0.072 & Acceptable \\
\hline COD & 1 & 333 & 356.5 & 338.3 & 0.240 & Acceptable \\
\hline$(\mathrm{mg} / \mathrm{L})$ & 2 & 60 & 66.1 & 62.4 & 0.197 & Acceptable \\
\hline Conductivity & 1 & 483 & 529.3 & 480.0 & 0.110 & Acceptable \\
\hline$(\mu \mathrm{mho} / \mathrm{cm})$ & 2 & 652 & 719.9 & 638.0 & 0.302 & Acceptable \\
\hline Copper & 1 & 40 & 31.6 & 32.1 & 1.557 & Acceptable \\
\hline$(\mu \mathrm{g} / \mathrm{L})$ & 2 & 140 & 133.7 & 132.7 & 0.585 & Acceptable \\
\hline Ethyl benzene & 1 & 12 & 13.6 & 13.3 & 0.431 & Acceptable \\
\hline$(\mu g / L)$ & 2 & 64 & 68.5 & 70.7 & 0.617 & Acceptable \\
\hline Fluoride & 1 & 2.2 & 2.26 & 2.20 & 0.025 & Acceptable \\
\hline$(\mathrm{mg} / \mathrm{L})$ & 2 & 6.0 & 6.07 & 6.06 & 0.177 & Acceptable \\
\hline Hexavalent & 1 & 0.07 & 0.058 & 0.058 & 2.476 & Waming \\
\hline $\begin{array}{l}\text { chromium } \\
(\mathrm{mg} / \mathrm{L})\end{array}$ & 2 & 0.30 & 0.30 & 0.30 & 0.004 & Acceptable \\
\hline Iron & 1 & 129 & 126.4 & 125.7 & 0.150 & Acceptable \\
\hline$(\mu \mathrm{g} / \mathrm{L})$ & 2 & 373 & 390.6 & 390.4 & 0.557 & Acceptable \\
\hline Lead & 1 & 34 & 37.6 & 37.1 & 0.588 & Acceptable \\
\hline$(\mu \mathrm{g} / \mathrm{L})$ & 2 & 263 & 293.6 & 266.0 & 0.131 & Acceptable \\
\hline Magnesium & 1 & 6.50 & 6.58 & 6.71 & 0.203 & Acceptable \\
\hline$(\mathrm{mg} / \mathrm{L})$ & 2 & 8.94 & 8.98 & 8.96 & 0.017 & Acceptable \\
\hline Manganese & 1 & 38 & 36.3 & 26.6 & 0.341 & Acceptable \\
\hline$(\mu \mathrm{g} / \mathrm{L})$ & 2 & 199 & 201.6 & 194.8 & 0.301 & Acceptable \\
\hline Mercury & 1 & 2 & 1.4 & 1.4 & 2.138 & Waming \\
\hline$(\mu g / L)$ & 2 & 5.2 & 4.49 & 4.04 & 1.261 & Acceptable \\
\hline
\end{tabular}


Table 10.15 (continued)

\begin{tabular}{|c|c|c|c|c|c|c|}
\hline Parameter & Level & $\begin{array}{l}\text { Reported } \\
\text { value }\end{array}$ & $\begin{array}{l}\text { Reference } \\
\text { value }\end{array}$ & $\begin{array}{l}\text { Mean of } \\
\text { reporting } \\
\text { labs }\end{array}$ & $\begin{array}{l}\text { No. of standard } \\
\text { deviations } \\
\text { from the } \\
\text { mean }\end{array}$ & $\begin{array}{c}\text { Performance }^{a} \\
\text { evaluation }\end{array}$ \\
\hline Nickel & 1 & 60 & 50.9 & 49.6 & 1.511 & Acceptable \\
\hline$(\mu \mathrm{g} / \mathrm{L})$ & 2 & \multirow{2}{*}{\multicolumn{5}{|c|}{ Unreported }} \\
\hline Nitrate as $\mathrm{N}$ & 1 & & & & & \\
\hline$(\mathrm{mg} / \mathrm{L})$ & 2 & 1.38 & 1.26 & 1.24 & 1.357 & Acceptable \\
\hline Oil and grease & 1 & 11.9 & 12.0 & 10.4 & 0.342 & Acceptable \\
\hline$(\mathrm{mg} / \mathrm{L})$ & 2 & 32.4 & 35.0 & 31.3 & 0.143 & Acceptable \\
\hline Orthophosphate & 1 & \multicolumn{5}{|c|}{ Unreported } \\
\hline as $\mathrm{P}(\mathrm{mg} / \mathrm{L})$ & 2 & 4.76 & 4.49 & 4.16 & 0.836 & Acceptable \\
\hline $\mathrm{pH}$ & 1 & 4.6 & 4.27 & 4.52 & 0.336 & Acceptable \\
\hline (units) & 2 & 7.9 & 7.50 & 7.62 & 0.714 & Acceptable \\
\hline Potassium & 1 & 12.94 & 13.15 & 13.45 & 0.340 & Acceptable \\
\hline$(\mathrm{mg} / \mathrm{L})$ & 2 & 14.63 & 15.01 & 14.98 & 0.315 & Acceptable \\
\hline Selenium & 1 & 21.5 & 20.37 & 19.53 & 0.577 & Acceptable \\
\hline$(\mu \mathrm{g} / \mathrm{L})$ & 2 & 162.5 & 150.35 & 145.09 & 0.709 & Acceptable \\
\hline Silver & 1 & 47 & 49.0 & 48.4 & 0.329 & Acceptable \\
\hline$(\mu \mathrm{g} / \mathrm{L})$ & 2 & 140 & 144.9 & 144.6 & 0.392 & Acceptable \\
\hline Sodium & 1 & 58.53 & 55.59 & 55.57 & 0.777 & Acceptable \\
\hline$(\mathrm{mg} / \mathrm{L})$ & 2 & 77.19 & 73.76 & 73.49 & 0.776 & Acceptable \\
\hline Sulfate & 1 & 34 & 35.2 & 34.2 & 0.054 & Acceptable \\
\hline$(\mathrm{mg} / \mathrm{L})$ & 2 & 46 & 44.4 & 43.1 & 0.679 & Acceptable \\
\hline Tetrachloroethane & 1 & 11 & 13.5 & 12.2 & 0.427 & Acceptable \\
\hline$(\mu \mathrm{g} / \mathrm{L})$ & 2 & 74 & 78.1 & 74.1 & 0.009 & Acceptable \\
\hline $\operatorname{TDS}^{b, c}$ & 1 & 126 & 150.2 & 102.9 & 1.072 & Acceptable \\
\hline$(\mathrm{mg} / \mathrm{L})$ & 2 & 267 & 276.1 & 101.0 & 0.648 & Acceptable \\
\hline TOC ${ }^{d}$ & 1 & 147 & 134.2 & 140.4 & 0.457 & Acceptable \\
\hline$(\mathrm{mg} / \mathrm{L})$ & 2 & 26 & 24.9 & 26.3 & 0.089 & Acceplable \\
\hline Thallium & 1 & 91 & 98.5 & 92.5 & 0.060 & Acceptable \\
\hline$(\mu \mathrm{g} / \mathrm{L})$ & 2 & 305 & 343.2 & 339.3 & 0.453 & Acceptable \\
\hline Total hardness & $\overline{1}$ & 77 & 77.6 & 76.5 & 0.115 & Acceptable \\
\hline $\begin{array}{l}\text { as } \mathrm{CaCO}_{3} \\
(\mathrm{mg} / \mathrm{L})\end{array}$ & 2 & 112 & 112.9 & 112.2 & 0.034 & Acceptable \\
\hline Total organic & 1 & 45 & 30.4 & 33.4 & 1.850 & Acceptable \\
\hline $\begin{array}{l}\text { halides } \\
(\mu \mathrm{g} / \mathrm{L})\end{array}$ & 2 & 164 & 150.1 & 137.5 & 1.667 & Acceptable \\
\hline Total residual & 1 & 0.45 & 0.529 & 0.492 & 0.416 & Acceptable \\
\hline $\begin{array}{l}\text { chlorine } \\
\text { (mg/L) }\end{array}$ & 2 & 1.97 & 2.115 & 1.982 & 0.064 & Acceptable \\
\hline TSSex & 1 & 63 & 70.9 & 90.6 & 0.168 & Acceptable \\
\hline$(\mathrm{mg} / \mathrm{L})$ & 2 & 193 & 219.5 & 93.2 & 0.729 & Acceptable \\
\hline 1,1,1-trichloroethane & 1 & 11 & 11.2 & 11.6 & 0.207 & Acceptable \\
\hline$(\mu \mathrm{g} / \mathrm{L})$ & 2 & 81 & 72.4 & 76.3 & 0.217 & Acceptable \\
\hline Uranium & 1 & 100 & 100.1 & 106.6 & 0.594 & Acceptable \\
\hline$(\mu \mathrm{g} / \mathrm{L})$ & 2 & 620 & 600.6 & 638.5 & 0.480 & Acceptable \\
\hline Vanadium & 1 & 246 & 261.9 & 268.9 & 0.437 & Acceptable \\
\hline$(\mu \mathrm{g} / \mathrm{L})$ & 2 & 1090 & 1066.2 & 1100.3 & 0.138 & Acceptable \\
\hline Zinc & 1 & 66 & 59.3 & 58.9 & 1.311 & Acceptable \\
\hline$(\mu g / L)$ & 2 & 166 & 163.3 & 164.3 & 0.133 & Acceptable \\
\hline
\end{tabular}

aperformance evaluation made by using EPA criteria, 0-1.96 standard deviations for acceptable; $1.97-2.58$ standard for marginal; more than 2.58 standard deviations for not acceptable.

bTDS = total dissolved solids.

${ }^{c}$ Average percent recovery for the participating laboratories.

${ }^{2} \mathrm{TOC}=$ total organic carbon.

TSS $=$ total suspended solids. 
Table 10.16. November 1990 Analytical Products Group, Inc., Proflciency Environmental Testing Program

\begin{tabular}{|c|c|c|c|c|c|c|}
\hline Parameter & Level & $\begin{array}{l}\text { Reported } \\
\text { value }\end{array}$ & $\begin{array}{c}\text { Reference } \\
\text { value }\end{array}$ & $\begin{array}{l}\text { Mean of } \\
\text { reporting } \\
\text { labs }\end{array}$ & $\begin{array}{l}\text { No. of standard } \\
\text { deviations } \\
\text { from the } \\
\text { mean }\end{array}$ & $\begin{array}{l}\text { Performance } \\
\text { evaluation }\end{array}$ \\
\hline Alkalinity as & 1 & 38.8 & 39.05 & 39.60 & 0.210 & Acceptable \\
\hline $\begin{array}{l}\mathrm{CaCO}_{3} \\
(\mathrm{mg} / \mathrm{L})\end{array}$ & 2 & 53.4 & 54.19 & 53.79 & 0.095 & Acceptable \\
\hline Aluminum & 1 & 70.7 & 66.87 & 70.15 & 0.033 & Acceptable \\
\hline$(\mu \mathrm{g} / \mathrm{L})$ & 2 & 320.4 & 315.25 & 326.41 & 0.168 & Acceptable \\
\hline Ammonia as $\mathrm{N}$ & 1 & 0.29 & 0.283 & 0.292 & 0.038 & Acceptable \\
\hline$(\mathrm{mg} / \mathrm{L})$ & 2 & 2.4 & 2.52 & 2.56 & 0.504 & Acceptable \\
\hline Antimony & 1 & 90.9 & 208.2 & 173.52 & 1.430 & Acceptable \\
\hline$(\mu \mathrm{g} / \mathrm{L})$ & 2 & 427.5 & 684.73 & 614.61 & 1.503 & Acceptable \\
\hline Arsenic & 1 & 33.5 & 31.76 & 30.47 & 0.662 & Acceptable \\
\hline$(\mu g / L)$ & 2 & 316 & 323.1 & 287.5 & 0.351 & Acceptable \\
\hline Barium & 1 & 428.5 & 434.7 & 423.4 & 0.177 & Acceptable \\
\hline$(\mu \mathrm{g} / \mathrm{L})$ & 2 & 1967.3 & 1999.1 & 1981.4 & 0.120 & Acceptable \\
\hline Beryllium & 1 & 38.7 & 37.69 & 36.21 & $0.8 \mathrm{M}$ & Acceptable \\
\hline$(\mu \mathrm{g} / \mathrm{L})$ & 2 & 220.4 & 208.54 & 203.37 & $1.1<$ & Acceptable \\
\hline BOD & 1 & 232 & 208.4 & 197.1 & 0.740 & Acceptable \\
\hline$(\mathrm{mg} / \mathrm{L})$ & 2 & 44 & 37.6 & 36.0 & 1.043 & Acceptable \\
\hline Cadmium & 1 & 31 & 28.6 & 29.8 & 0.181 & Acceptable \\
\hline$(\mu \mathrm{g} / \mathrm{L})$ & 2 & 122.4 & 119.28 & 120.96 & 0.122 & Acceptable \\
\hline Calcium & 1 & 7.33 & 7.554 & 7.682 & 0.536 & Acceptable \\
\hline$(\mathrm{mg} / \mathrm{L})$ & 2 & 24.2 & 25.51 & 25.17 & 0.594 & Acccptable \\
\hline Carbon tetrachloride & : & 10 & 10.8 & 10.4 & 0.328 & Acceptable \\
\hline$(\mu g / L)$ & 2 & 111 & 105.2 & 109.0 & 0.133 & Acceptable \\
\hline Chloride & 1 & 56 & 56.5 & 55.8 & 0.073 & Acceptable \\
\hline$(\mathrm{mg} / \mathrm{L})$ & 2 & 121 & 121.0 & 118.6 & 0.433 & Acceptable \\
\hline Chlorobenzene & 1 & 7 & 7.6 & 7.3 & 0.369 & Acceptable \\
\hline$(\mu \mathrm{g} / \mathrm{L})$ & 2 & 73 & 74.3 & 74.2 & 0.168 & Acceptable \\
\hline Chromium & 1 & 38.8 & 41.97 & 41.67 & 0.354 & Acceptable \\
\hline$(\mu \mathrm{g} / \mathrm{L})$ & 2 & 157.8 & 157.37 & 155.32 & 0.100 & Acceptable \\
\hline COD & 1 & 335 & 335.4 & 319.2 & 0.720 & Acceptable \\
\hline$(\mathrm{mg} / \mathrm{L})$ & 2 & 58 & 60.6 & 53.9 & 0.256 & Acceptable \\
\hline Cobalt & 1 & 139.3 & 142.78 & 142.12 & 0.397 & Acceptable \\
\hline$(\mu g / L)$ & 2 & 403.4 & 410.17 & 408.32 & 0.234 & Acceptable \\
\hline Conductivity & 1 & 313 & 338.5 & 315.0 & 0.114 & Acceptable \\
\hline$(\mu \mathrm{mho} / \mathrm{cm})$ & 2 & 576 & 633.2 & 567.4 & 0.198 & Acceptable \\
\hline Copper & 1 & 22 & 22.1 & 23.4 & 0.338 & Acceptable \\
\hline$(\mu \mathrm{g} / \mathrm{L})$ & 2 & 107.7 & 114.59 & 119.11 & 1.097 & Acceptable \\
\hline Fluoride & 1 & 2.3 & 2.34 & 2.37 & 0.287 & Acceptable \\
\hline (mg/L) & 2 & 5.7 & 5.72 & 5.78 & 0.198 & Acceptable \\
\hline Iron & 1 & 102.6 & 94.80 & 95.85 & 0.599 & Acceptable \\
\hline$(\mu \mathrm{g} / \mathrm{L})$ & 2 & 362.7 & 346.62 & 345.95 & 0.567 & Acceptable \\
\hline Lead & 1 & 74.5 & 88.08 & 87.78 & 1.069 & Acceptable \\
\hline$(\mu \mathrm{g} / \mathrm{L})$ & 2 & 233.5 & 233.31 & 233.53 & 0.001 & Acceptable \\
\hline Magnesium & 1 & 6.11 & 5.90 & 5.92 & 0.356 & Acceptable \\
\hline$(\mathrm{mg} / \mathrm{L})$ & 2 & 11.7 & 11.44 & 11.38 & 0.285 & Acceptable \\
\hline Manganese & 1 & 49.7 & 48.39 & 47.16 & 0.526 & Acceptable \\
\hline$(\mu g / L)$ & 2 & 111.8 & 108.88 & 110.40 & 0.168 & Acceptable \\
\hline Mercury & 1 & 1.85 & 1.90 & 1.73 & 0.347 & Acceptablc \\
\hline$(\mu \mathrm{g} / \mathrm{L})$ & 2 & 3.7 & 3.74 & 3.68 & 0.055 & Acceptable \\
\hline Molybdenum & 1 & 35.4 & 74.41 & 62.35 & 1.128 & Acceptable \\
\hline$(\mu \mathrm{g} / \mathrm{L})$ & 2 & 169.5 & 252.99 & 233.43 & 2.305 & Warning \\
\hline Nickel & 1 & 74.3 & 73.82 & 70.60 & 0.364 & Acceptable \\
\hline$(\mu \mathrm{g} / \mathrm{L})$ & 2 & 141.3 & 137.52 & 138.00 & 0.173 & Acceptable \\
\hline
\end{tabular}


Table 10.16 (continued)

\begin{tabular}{|c|c|c|c|c|c|c|}
\hline Parameter & Level & $\begin{array}{l}\text { Reported } \\
\text { value }\end{array}$ & $\begin{array}{l}\text { Reference } \\
\text { value }\end{array}$ & $\begin{array}{l}\text { Mean of } \\
\text { reporting } \\
\text { labs }\end{array}$ & $\begin{array}{l}\text { No. of standard } \\
\text { deviations } \\
\text { from the } \\
\text { mean }\end{array}$ & $\begin{array}{l}\text { Performance }^{a} \\
\text { evaluation }\end{array}$ \\
\hline Nitrate as $\mathrm{N}$ & 1 & \multicolumn{5}{|c|}{ Unreported } \\
\hline$(\mathrm{mg} / \mathrm{L})$ & 2 & 3.4 & 1.53 & 1.53 & 11.546 & Not acceptable \\
\hline Oil and grease & 1 & 6.9 & 7.44 & 7.55 & 0.183 & Acceptable \\
\hline$(\mathrm{mg} / \mathrm{L})$ & 2 & 29 & 31.0 & 27.5 & 0.202 & Acceptable \\
\hline Orthophosphate & 1 & \multicolumn{5}{|c|}{ Unreported } \\
\hline as $\mathrm{P}(\mathrm{mg} / \mathrm{L})$ & 2 & 9.6 & 4.66 & 4.56 & 6.758 & Not acceptable \\
\hline $\mathrm{pH}$ & 1 & 6.6 & 6.22 & 6.12 & 1.540 & Acceptable \\
\hline (units) & 2 & 7.9 & 7.98 & 7.72 & 0.739 & Acceptable \\
\hline Potassium & 1 & 11.3 & 11.9 & 11.6 & 0.344 & Acceptable \\
\hline$(\mathrm{mg} / \mathrm{L})$ & 2 & 16.5 & 17.3 & 16.9 & 0.344 & Acceptable \\
\hline Selenium & 1 & 15.6 & 12.22 & 12.57 & 1.623 & Acceptable \\
\hline$(\mu \mathrm{g} / \mathrm{L})$ & 2 & 165 & 155.4 & 146.8 & 0.703 & Acceptable \\
\hline Silver & 1 & 64.5 & 61.24 & 61.04 & 0.704 & Acceptable \\
\hline$(\mu g / L)$ & 2 & 389 & 382.2 & 380.6 & 0.273 & Acceptable \\
\hline Sodium & 1 & 38.2 & 36.50 & 36.34 & 0.579 & Acceptable \\
\hline$(\mathrm{mg} / \mathrm{L})$ & 2 & 58.3 & 56.57 & 55.05 & 0.789 & Acceptable \\
\hline Sulfate & 1 & 17 & 18.5 & 18.1 & 0.784 & Acceptable \\
\hline$(\mathrm{mg} / \mathrm{L})$ & 2 & 28 & 30.0 & 29.6 & 0.578 & Acceptable \\
\hline $\operatorname{TDS}^{b, c}$ & 1 & 187 & 195.2 & 102.27 & 0.319 & Acceptable \\
\hline (mg/L) & 2 & 217 & 225.8 & 100.76 & 0.860 & Acceptable \\
\hline TOC ${ }^{d}$ & 1 & 128 & 126.3 & 124.0 & 0.273 & Acceptable \\
\hline$(\mathrm{mg} / \mathrm{L})$ & 2 & 22 & 22.8 & 22.6 & 0.273 & Acceptable \\
\hline Thallium & 1 & 143.9 & 157.55 & 147.33 & 0.154 & Acceptable \\
\hline$(\mu \mathrm{g} / \mathrm{L})$ & 2 & 284.3 & 334.66 & 324.08 & 1.003 & Acceptable \\
\hline Total hardness & 1 & 43.6 & 43.17 & 43.44 & 0.047 & Acceptable \\
\hline $\begin{array}{l}\text { as } \mathrm{CaCO}_{3} \\
(\mathrm{mg} / \mathrm{L})\end{array}$ & 2 & 109.4 & 110.80 & 109.07 & 0.065 & Acceptable \\
\hline Total organic & 1 & 31 & 21.9 & 22.5 & 2.389 & Warning \\
\hline halides & 2 & 320 & 351.2 & 312.7 & 0.131 & Acceptable \\
\hline$(\mu \mathrm{g} / \mathrm{L})$ & & & & & & \\
\hline Total residual & 1 & 0.35 & 0.392 & 0.368 & 0.218 & Acceptable \\
\hline $\begin{array}{l}\text { chlorine } \\
\text { (mg/L) }\end{array}$ & 2 & 4.9 & 5.23 & 4.62 & 0.307 & Acceptable \\
\hline $\mathrm{TSS}^{e x}$ & 1 & 49 & 55.3 & 90.23 & 0.175 & Acceptable \\
\hline$(\mathrm{mg} / \mathrm{L})$ & 2 & 119 & 135.0 & 94.34 & 0.957 & Acceptable \\
\hline 1,1,1-trichlmoethane & 1 & 17 & 17.6 & 17.5 & 0.188 & Acceptable \\
\hline$(\mu \mathrm{g} / \mathrm{L})$ & 2 & 55 & 55.9 & 59.4 & 0.498 & Acceptable \\
\hline 1,1,2-trichloroethane & 1 & 31 & 32.9 & 33.2 & 0.558 & Acceptable \\
\hline$(\mu \mathrm{g} / \mathrm{L})$ & 2 & 87 & 85.7 & 89.2 & 0.193 & Acceptable \\
\hline Uranium & 1 & 110 & 120.1 & 115.7 & 0.483 & Acceptable \\
\hline$(\mu \mathrm{g} / \mathrm{L})$ & 2 & 900 & 1001.0 & 939.5 & 0.825 & Acceptable \\
\hline Vanadium & 1 & 75.6 & 110.21 & 106.17 & 1.746 & Acceptable \\
\hline$(\mu \mathrm{g} / \mathrm{L})$ & 2 & 1686.6 & 1691.6 & 1695.5 & 0.081 & Acceptable \\
\hline Zinc & 1 & 56.4 & 53.9 & 55.2 & 0.137 & Acceptable \\
\hline$(\mu \mathrm{g} / \mathrm{L})$ & 2 & 173.5 & 174.97 & 177.79 & 0.209 & Acceptable \\
\hline
\end{tabular}

aperformance evaluation made by using EPA criteria, 0-1.96 standard deviations for acceptable; $1.97-2.58$ standard for marginal; more than 2.58 standard deviations for not acceptable.

${ }^{b}$ TDS = total dissolved solids.

${ }^{c}$ Average percent recovery for the participating laboratories.

${ }^{d} \mathrm{TOC}=$ total organic carbon.

TSS = total suspended solids. 
Table 10.17. January 1990 National Institute for Occupational Safety and Health Froficlency Analytical Testing Program

\begin{tabular}{ccccccc}
\hline Parameter & $\begin{array}{c}\text { Control } \\
\text { number }\end{array}$ & $\begin{array}{c}\text { Reported } \\
\text { value }\end{array}$ & $\begin{array}{c}\text { Reference } \\
\text { value }^{a}\end{array}$ & $\begin{array}{c}\text { Performance } \\
\text { limits }\end{array}$ & $\begin{array}{c}\text { Performance } \\
\text { evaluation }\end{array}$ & $\begin{array}{c}\text { No. of } \\
\text { labs }\end{array}$ \\
\hline Lead & 1 & 0.0437 & 0.0443 & $0.0386-0.0501$ & Acceptable & 373 \\
(total mg) & 2 & 0.0617 & 0.0591 & $0.0519-0.0665$ & Acceptable & 373 \\
& 3 & 0.0200 & 0.0201 & $0.0169-0.0233$ & Acceptable & 373 \\
Cadmium & 4 & 0.0320 & 0.0328 & $0.0293-0.0364$ & Acceptable & 373 \\
(total mg) & 1 & 0.0084 & 0.0089 & $0.0078-0.0100$ & Acceptable & 372 \\
& 2 & 0.0121 & 0.0118 & $0.0106-0.0132$ & Acceptable & 372 \\
Zinc & 3 & 0.0157 & 0.0157 & $0.0142-0.0174$ & Acceptable & 372 \\
(total mg) & 4 & 0.0094 & 0.0099 & $0.0091-0.0109$ & Acceptable & 372 \\
& 1 & 0.1354 & 0.1457 & $0.1230-0.1685$ & Acceptable & 369 \\
Asbestos & 2 & 0.1052 & 0.1043 & $0.0897-0.1190$ & Acceptable & 369 \\
(fibers $/ \mathrm{mm}^{2}$ ) & 3 & 0.0828 & 0.0847 & $0.0733-0.0962$ & Acceptable & 369 \\
& 4 & 0.1593 & 0.1704 & $0.1478-0.1932$ & Acceptable & 369 \\
& 1 & 616.0 & 763.4 & $426.0-1198.5$ & Acceptable & 1237 \\
& 2 & 497.0 & 503.5 & $255.7-834.6$ & Acceptable & 1237 \\
\hline
\end{tabular}

${ }^{a}$ Reference value is calculated from transformed variables. See NIOSH PAT protocol for details.

${ }^{b}$ Performance limits set by NIOSH. Those within rarige are acceptable; those outside range are outliers.

Table 10.18. April 1990 National Institute for Occupational Safety and Heaith Proficiency Analytical Testing Program

\begin{tabular}{ccccccc}
\hline Parameter & $\begin{array}{c}\text { Control } \\
\text { number }\end{array}$ & $\begin{array}{c}\text { Reported } \\
\text { value }\end{array}$ & $\begin{array}{c}\text { Reference } \\
\text { value }^{a}\end{array}$ & $\begin{array}{c}\text { Performance } \\
\text { limits }\end{array}$ & $\begin{array}{c}\text { Performance } \\
\text { cvaluation }^{b}\end{array}$ & $\begin{array}{c}\text { No. of } \\
\text { labs }\end{array}$ \\
\hline Lead & 1 & 0.0236 & 0.0241 & $0.0206-0.0276$ & Acceptable & 384 \\
$\quad$ total mg) & 2 & 0.0422 & 0.0419 & $0.0370-0.0469$ & Acceptable & 384 \\
& 3 & 0.0588 & 0.0575 & $0.0508-0.0642$ & Acceptable & 384 \\
Cadmium & 4 & 0.0357 & 0.0361 & $0.0318-0.0403$ & Acceptable & 384 \\
(total mg) & 1 & 0.0149 & 0.0150 & $0.0135-0.0165$ & Acceptable & 381 \\
& 2 & 0.0082 & 0.0080 & $0.0073-0.0089$ & Acceptable & 381 \\
Zinc & 3 & 0.0123 & 0.0119 & $0.0107-0.0133$ & Acceptable & 381 \\
(total $\mathrm{mg}$ ) & 4 & 0.0100 & 0.0100 & $0.0089-0.0113$ & Acceptable & 381 \\
& 1 & 0.2161 & 0.2153 & $0.1917-0.2390$ & Acceptable & 377 \\
Asbestos & 2 & 0.1897 & 0.1842 & $0.1637-0.2049$ & Acceptable & 377 \\
(fibers $/ \mathrm{mm}^{2}$ ) & 3 & 0.1317 & 0.1275 & $0.1119-0.1432$ & Acceptable & 377 \\
& 4 & 0.1002 & 0.1009 & $0.0840-0.1179$ & Acceptable & 377 \\
& 1 & 193.0 & 217.8 & $37.1-548.9$ & Acceptable & 1273 \\
& 2 & 85.0 & 147.1 & $15.6-412.9$ & Acceptable & 1273 \\
& 3 & 213.0 & 246.8 & $42.3-612.0$ & Acceptable & 1273 \\
\hline
\end{tabular}

${ }^{a}$ Reference value is calculated from transformed variables. See NIOSH PAT protocol for details.

berformance limits set by NIOSH. Those within range are acceptable; those outside range are outliers. 
Table 10.19. July 1990 National Institute for Occupational Safety and Health Proficiency Analytical Testing Program

\begin{tabular}{|c|c|c|c|c|c|c|}
\hline Parameter & $\begin{array}{l}\text { Control } \\
\text { number }\end{array}$ & $\begin{array}{l}\text { Reported } \\
\text { value }\end{array}$ & $\begin{array}{c}\text { Reference } \\
\text { value }^{a}\end{array}$ & $\begin{array}{l}\text { Performance } \\
\text { limits }\end{array}$ & $\begin{array}{l}\text { Performance } \\
\text { evaluation }\end{array}$ & $\begin{array}{c}\text { No. of } \\
\text { labs }\end{array}$ \\
\hline \multirow{4}{*}{$\begin{array}{l}\text { Lead } \\
\qquad \text { (total mg) }\end{array}$} & 1 & 0.0668 & 0.0642 & $0.0543-0.0741$ & Acceptable & 390 \\
\hline & 2 & 0.0282 & 0.0268 & $0.0227-0.0310$ & Acceptable & 390 \\
\hline & 3 & 0.0892 & 0.0843 & $0.0731-0.0955$ & Acceptable & 390 \\
\hline & 4 & 0.0512 & 0.0483 & $0.0414-0.0552$ & Acceptable & 390 \\
\hline \multirow{4}{*}{$\begin{array}{l}\text { Cadmium } \\
\text { (total mg) }\end{array}$} & 1 & 0.0091 & 0.1071 & $0.0922-0.1220$ & Acceptable & 386 \\
\hline & 2 & 0.0119 & 0.1297 & $0.111^{-0}-0.1459$ & Acceptable & 386 \\
\hline & 3 & 0.0200 & 0.2185 & $0.1880-0.2491$ & Acceptable & 386 \\
\hline & 4 & 0.0128 & 0.1751 & $0.1512-0.1990$ & Acceptable & 386 \\
\hline \multirow{4}{*}{$\begin{array}{l}\text { Zinc } \\
\quad \text { (total mg) }\end{array}$} & 1 & 0.1066 & 0.1071 & $0.0922-0.1220$ & Acceptable & 382 \\
\hline & 2 & 0.1288 & 0.1297 & $0.1134-0.1459$ & Acceptable & 382 \\
\hline & 3 & 0.2224 & 0.2185 & $0.1880-0.2491$ & Acceptable & 382 \\
\hline & 4 & 0.1851 & 0.1751 & $0.1512-0.1990$ & Acceptable & 382 \\
\hline \multirow{4}{*}{$\begin{array}{l}\text { Asbestos } \\
\quad\left(\text { fibers } / \mathrm{mm}^{2}\right)\end{array}$} & 1 & 448 & 369.3 & $194.7-599.5$ & Acceptable & 1304 \\
\hline & 2 & 628 & 573.2 & $201.4-1135.2$ & Acceptable & 1304 \\
\hline & 3 & 1058 & 783.1 & $435.7-1231.5$ & Acceptable & 1304 \\
\hline & 4 & 318 & 224.8 & $104.8-390.1$ & Acceptable & 1304 \\
\hline
\end{tabular}

${ }^{a}$ Reference value is calculated from transformed variables. See NIOSH PAT protocol for details.

bPerformance limits set by NIOSH. Those within range are acceptable; those outside range are outliers.

Table 10.20. October 1990 National Institute for Occupational Safety and Health Proficiency Analytical Testing Program

\begin{tabular}{ccccccc}
\hline Parameter & $\begin{array}{c}\text { Control } \\
\text { number }\end{array}$ & $\begin{array}{c}\text { Reported } \\
\text { value }\end{array}$ & $\begin{array}{c}\text { Reference } \\
\text { value }\end{array}$ & $\begin{array}{c}\text { Performance } \\
\text { limits }\end{array}$ & $\begin{array}{c}\text { Performance } \\
\text { evaluation }^{b}\end{array}$ & $\begin{array}{c}\text { No. of } \\
\text { labs }\end{array}$ \\
\hline Cadmium & 1 & 0.0074 & 0.0072 & $0.0062-0.0082$ & Acceptable & 383 \\
(total mg) & 2 & 0.0100 & 0.0107 & $0.0090-0.0123$ & Acceptable & 383 \\
& 3 & 0.0120 & 0.0111 & $0.0094-0.0126$ & Acceptable & 383 \\
Chromium & 4 & 0.0196 & 0.0185 & $0.0157-0.0213$ & Acceptable & 383 \\
(total mg) & 1 & 0.0862 & 0.0894 & $0.0743-0.1046$ & Acceptable & 378 \\
& 2 & 0.0488 & 0.0528 & $0.0437-0.0618$ & Acceptable & 378 \\
Lead & 3 & 0.0100 & 0.1015 & $0.0828-0.1200$ & Outlier & 378 \\
(total mg) & 4 & 0.1922 & 0.1947 & $0.1578-0.2315$ & Acceptable & 378 \\
& 1 & 0.0528 & 0.0717 & $0.0639-0.0795$ & Outlicr & 355 \\
Asbestos & 2 & 0.0260 & 0.0265 & $0.0225-0.0304$ & Acceptable & 355 \\
(fibers $/ \mathrm{mm}^{2}$ ) & 3 & 0.0418 & 0.0392 & $0.0339-0.0445$ & Acceptable & 355 \\
& 1 & 0.0635 & 0.0598 & $0.0519-0.0676$ & Acceptable & 355 \\
& 2 & 79 & 173.3 & $55.9-355.4$ & Acceptable & 1321 \\
& 3 & 220 & 361.6 & $111.9-753.8$ & Acceptable & 1321 \\
& 4 & 329 & 521.3 & $221.3-948$ & Outlier & 1321 \\
\end{tabular}

${ }^{a}$ Reference value is calculated from transformed variables. See NIOSH PAT protocol for details.

${ }^{b}$ Performance limits set by NIOSH. Those within range are acceptable; those outside range are outlicrs. 
Table 10.21. March 1, 1990, Environmental Measurements Laboratory,

Semiannual Report of the DOE Operational Safety, Health, and Environment Division, Quality Assessment Program

\begin{tabular}{|c|c|c|c|c|}
\hline Isotope & EML value & $\begin{array}{l}\text { Reported value } \\
\text { (Rp) }\end{array}$ & $\begin{array}{c}\text { Ratio } \\
\text { (Rp/EML) }\end{array}$ & $\begin{array}{l}\text { Performance } \\
\text { evaluation }^{a}\end{array}$ \\
\hline \multicolumn{5}{|c|}{ Air ( $p$ Cilfilter $)$} \\
\hline $\begin{array}{l}{ }^{7} \mathrm{Be} \\
{ }^{144} \mathrm{Ce} \\
{ }^{57} \mathrm{Co} \\
{ }^{60} \mathrm{Co} \\
{ }^{137} \mathrm{Cs} \\
{ }^{144} \mathrm{Ce} \\
{ }^{134} \mathrm{Cs} \\
{ }^{54} \mathrm{Mn}\end{array}$ & $\begin{array}{l}0.514 E+02 \\
0.312 E+02 \\
0.650 E+01 \\
0.940 E+02 \\
0.204 E+02 \\
0.312 E+02 \\
0.182 E+02 \\
0.960 E+01\end{array}$ & $\begin{array}{l}0.558 E+02 \\
0.290 E+02 \\
0.638 E+01 \\
0.892 E+01 \\
0.188 E+02 \\
0.290 E+02 \\
0.132 E+02 \\
0.954 E+02\end{array}$ & $\begin{array}{l}1.09 \\
0.93 \\
0.98 \\
0.95 \\
0.92 \\
0.93 \\
0.73 \\
0.99\end{array}$ & $\begin{array}{l}\text { Acieptable } \\
\text { Acceptable } \\
\text { Acceptable } \\
\text { Acceptable } \\
\text { Acceptable } \\
\text { Acceptable } \\
\text { Marginal } \\
\text { Acceptable }\end{array}$ \\
\hline \multicolumn{5}{|c|}{ Soil ( $p C i / g)$} \\
\hline $\begin{array}{l}{ }^{40} \mathrm{~K} \\
{ }^{137} \mathrm{Cs}\end{array}$ & $\begin{array}{l}0.608 E+03 \\
0.175 E+05\end{array}$ & $\begin{array}{l}0.620 E+03 \\
0.202 E+05\end{array}$ & $\begin{array}{l}1.02 \\
1.15\end{array}$ & $\begin{array}{l}\text { Acceptable } \\
\text { Acceptable }\end{array}$ \\
\hline \multicolumn{5}{|c|}{ Water $(p C i / m L)$} \\
\hline $\begin{array}{l}{ }^{134} \mathrm{Cs} \\
{ }^{57} \mathrm{Co} \\
{ }^{54} \mathrm{Mn} \\
{ }^{60} \mathrm{Co} \\
{ }^{137} \mathrm{Cs} \\
{ }^{144} \mathrm{Ce} \\
\mathrm{U}(\mu \mathrm{g} / \mathrm{mL})\end{array}$ & $\begin{array}{l}0.462 E+03 \\
0.198 E+03 \\
0.103 E+03 \\
0.206 E+03 \\
0.198 E+03 \\
0.403 E+03 \\
0.788 E-01\end{array}$ & $\begin{array}{l}0.321 E+03 \\
0.176 E+03 \\
0.950 E+02 \\
0.163 E+03 \\
0.163 E+03 \\
0.355 E+03 \\
0.690 E-01\end{array}$ & $\begin{array}{l}0.69 \\
0.89 \\
0.92 \\
0.79 \\
0.82 \\
0.88 \\
0.88\end{array}$ & $\begin{array}{l}\text { Marginal } \\
\text { Acceptable } \\
\text { Acceptable } \\
\text { Marginal } \\
\text { Acceptable } \\
\text { Acceptable } \\
\text { Acceptable }\end{array}$ \\
\hline
\end{tabular}

${ }^{a}$ Performance evaluation determined by using the ratio of our value to EML. Acceptable range is 0.8-1.2; marginal range is $0.5-1.5$; not acceptable range is $<0.5$ or $>1.5$. 
Table 10.22. September 1990, Environmental Measurements Laboratory, Semiannual Report of the DOE Operational Safety, Health, and Environment Division, Quality Assessment Program

\begin{tabular}{lcccc}
\hline Isotope & EML value & $\begin{array}{c}\text { Reported value } \\
(\mathrm{Rp})\end{array}$ & $\begin{array}{c}\text { Ratio } \\
(\mathrm{Rp} / \mathrm{EML})\end{array}$ & $\begin{array}{c}\text { Performance } \\
\text { evaluation }^{a}\end{array}$ \\
\hline & & Air $(p$ Ci/filter $)$ & & \\
& & $0.332 \mathrm{E}+02$ & 1.00 & Acceptable \\
${ }^{54} \mathrm{Mn}$ & $0.333 \mathrm{E}+02$ & $0.118 \mathrm{E}+02$ & 1.04 & Acceptable \\
${ }^{57} \mathrm{Co}$ & $0.114 \mathrm{E}+02$ & $0.241 \mathrm{E}+02$ & 0.95 & Acceptable \\
${ }^{60} \mathrm{Co}$ & $0.254 \mathrm{E}+02$ & $0.164 \mathrm{E}+02$ & 1.04 & Acceptable \\
${ }^{137} \mathrm{Cs}$ & $0.157 \mathrm{E}+02$ & $0.450 \mathrm{E}-01$ & 0.88 & Acceptable \\
${ }^{239} \mathrm{Pu}$ & $0.510 \mathrm{E}-01$ & $0.170 \mathrm{E}+02$ & 1.04 & Acceptable \\
${ }^{134} \mathrm{Cs}$ & $0.163 \mathrm{E}+02$ & & & \\
& & Soil $(p C i / g)$ & & Acceptable \\
& & $0.454 \mathrm{E}+03$ & 0.88 & Acceptable \\
${ }^{40} \mathrm{~K}$ & $0.513 \mathrm{E}+03$ & $0.203 \mathrm{E}+03$ & 1.04 & \\
${ }^{137} \mathrm{Cs}$ & $0.196 \mathrm{E}+03$ & Water $(p C i / m L)$ & & Acceptable \\
\hline
\end{tabular}

aperformance evaluation of ermined by using the ratio of our value to EML. Acceptable range is 0.8-1.2; marginal range is $0.5-1.5$; $1 . x$ acceptable range is $<0.5$ or $>1.5$. 


\section{REFERENCES}

American Public Health Association (APHA) et al. 1985. Standard Methods for the Examination of Water and Wastewater, 16th ed., American Public Health Association, American Waterworks Association, Water Pollution Control Fed., Washington.

Begovich, C. L. et al. August 1981. DARTAB: A Program to Combine Airborne Radionuclide Environmental Exposure Data with Dosimetric and Health Effects Data To Generate Tabulations of Predicted Health Impacts, ORNL-5692, Union Carbide Corp. Nuclear Div., Oak Ridge Natl. Lab.

Birge, W. J., Lauth, J. R., and Short, T. M. December 1989. Biological Monitoring Program for the Paducah Gaseous Diffusion Plant, Three-Year Report (draft). University of Kentucky, Lexington.

CDM Federal Programs Cornoration 1991. Paducah Gaseous Diffusion Plant Remedial Investigation of the Underground Storage Tanks in the Vicinity of the C-750 Garage Facility, Draft Workplan and Sampling and Analysis Plan, Fairfax, Va.

40 CFR Pt. 60) Appendix A Method A, "Visual Determination of the Opacity of Emissions From Stationary Sources."

40 CFR 136.3 "Environmental Protection Agency Regulations on Test Procedures for the Analysis of Pollutants," 1987.

CH2M Hill 1990. Draft Results of the Site Investigation Phase I at the Paducah Gaseous Diffusion Plant, Paducah, Ky., KY/ER-4, Martin Marietta Energy Systems.

Coker, C. B. Mar. 9, 1988. "Environmental Air Sampling," ES-1.R0, Martin Marietta Energy
Systems, Paducah Gaseous Diffusion Plant, Kentucky.

D'Appolonia June 1983. Final Report, Groundwater Monitoring Program, PGDP, Paducah, Ky., Project 82-1397, ESO 15603, Paducah Gaseous Diffusion Plant, Paducah, Ky.

Douthitt, J. W. 1990. Paducah Gaseous Diffusion Plant Groundwater Protection Program Management Plan, KY/ER-2, Martin Marietta Energy Systems.

Early, T. O., Sigmon, C. F., and Williams, R. T. 1989. Groundwater Monitoring Plan for the Paducah Gaseous Diffusion Plant, Martin Marietta Energy Systems, Oak Ridge Natl. Lab.

Eischen, M. A. et al. 1978. Environmental Studies at the Paducah Gaseous Diffusion Plant. Paducah, Kentucky, Battelle Columbus Labs., Ohio.

ERC March 23, 1989. Groundwater Monitoring Phase 2, ESO 16749, ERC Environ. and Energy Serv., Nashville, Tenn.

Forstrom, J. M., Early, T. O., and Douthitt, J. W. 1991. Groundwater Surveillance Plan for the Paducah Gaseous Diffusion Plant, in press.

Geotrans, Inc. 1990. Numerical Modeling of Groundwater Flow at the Paducah Gaseous Diffusion Plant, Phase I and II.

Hoffman, F. O., et al., 1984. Preliminary Screening of Contaminants in Sediments, ORNL/TM-9370, Union Carbide Corp. Nuclear Div., Oak Ridge Natl. Lab. 
U.S. DOE July 9, 1985. DOE Manual, "Safety Requirements for the Packaging and Transportation of Hazardous Materials, Hazardous Substances, and Hazardous Waste," DOE Order 5480.3 .

U.S. DOE July 1988. Internal Dose Conversion Factors for Calculation of Dose to the Public, DOE/EH-0071.

U.S. DOE Sept. 26, 1988. DOE Manual, "Radioactive Waste Management," DOE Order 5820.2A.

U.S. DOE Nov. 9, 1988. DOE Manual, "General Environmental Protection Program," DOE Order 5400.1 .

U.S. DOE Feb. 22, 1989. DOE Manual, "Hazardous and Radioactive Mixed Waste Management Program," DOE Order 5400.3.

U.S. DOE Apr. 20, 1989. DOE Manual, "Environmental, Safety and Health Program for Department of Energy Operations," DOE Order $5480.1 \mathrm{~B}$.

U.S. DOE June 15, 1989. DOE Manual, "Radiological Effluent Monitoring and Environmental Surveillance," DOE Order 5400.XY.
U.S. DOE 1989. Environmental Restoration and Waste Management Five-Year Plan, DOE/S-0070.

U.S. DOE Feb. 8, 1990. DOE Manual, "Radiation Protection to the Public and the Environment," DOE Order 5400.5 .

U.S. Environmental Protection Agency (EPA) October 1986. Compilation of Air Pollutant Emission Factors, Vol. 1 (Suppl. A).

U.S. Environmental Protection Agency (EPA) December 1987. Test Methods for Evaluating Solid Waste, SW-846.

U.S. Environmental Protection Agency (EPA) 1988. Integrated Risk Information System (IRIS) Data Base.

U.S. Environmental Protection Agency (EPA) July 1989. Exposure Factors Handbook, EPA/600/8-89/043.

Watson, D. D. Mar. 23, 1989. Environmental Sediment Sampling, ES-7.R1, Martin Marietta Energy Systems, Paducah Gaseous Diffusion Plant, Kentucky. 


\section{Appendix}

\section{PADUCAH GASEOUS DIFFUSION PLANT CHEMICAL RELEASE DATA}

In addition to indicating the concentrations of various chemicals present in the environment near U.S. Department of Energy (DOE) facilities, in recent years the annual Environmental Reports have contained an estimate of the quantities of certain chemicals being emitted to the environment. This appendix contains an expanded list of chemicals with additional information regarding the types of releases, the estimated quantities released, the major processes contributing to the releases, and a brief description of the basis of estimates for CY 1990. Radiological chemical releases for CY 1990 are not included in this appendix; they are reported in the applicable sections in this report.

Three categories of chemical releases at cach DOE facility are reported in this appendix: (1) SARA 313, (2) Other Large Inventory Chemicals, and (3) Steam Plant Emissions. The SARA 313 chemicals are summarized from information currently being compiled for the SARA Title III, Section 313 report, required by the Superfund Amendments and Reauthorization Act of 1986 (SARA). This report is submitted on July 1 of each year for the previous calendar year and contains chemicals on EPA's toxic substance list. Currently, more than 300 specific chemicals and 20 chemical categories must be reviewed and possibly reported under SARA Sect. 313. If any of these chemicals was manufactured in excess of $25,000 \mathrm{lb}$, processed in excess of $25,000 \mathrm{lb}$, or "otherwise used" in excess of $10,000 \mathrm{lb}$ at a facility during CY 1990, the chemical must be reported. In many instances the estimate of quantities released was obtained via material balance calculations, monitoring data, or engineering calculations. In some cases no quantitative monitoring data, inventory estimates, or emission factors were readily available, and release estimates were based on "best engineering judgement." Information obtained from air permits, rate of operation, quantities used, and known treatment efficiencies were used to estimate quantities released into the environment. Typically, assumptions based on "best engineering judgement" were required in order to perform the calculations when all variables were not known. Considerable manpower was expended reviewing chemical inventory information and estimating the quantities released to the environment.

The second category of chemicals reported in this appendix is "Other large inventory chemicals." This listing is included to provide the reader with additional chemical information not reportable under SARA 313. Note that this is not a complete listing of all chemicals that may have been released at a site. This list was developed to better inform the reader of the additional chemicals (i.e., those that may be of interest to the general public) used and released at PGDP.

The third category, "Steam plant emissions," is release estimates of certain chemicals from the coaland/or gas-fired steam plants located at each site.

Information contained in this appendix may not coincide for all chemicals with the information to be reported under SARA. Title III, Sect. 313. The SARA 31.3 report must be submitted to EPA and the Kentucky Department of Environmental Protection no 
later than July 1, 1991. The information for this appendix was generated in March and April; additional refinements are under way. It is imperative that May and June be utilized to ensure compliance under SARA Title III, the community right-to-know law. The following table summarizes the chemical release information for PGDP.

Paducah Gaseous Diffusion Plant 1990 chemical release information

\begin{tabular}{|c|c|c|c|c|}
\hline $\begin{array}{l}\text { Chemical } \\
\text { name }\end{array}$ & $\begin{array}{l}\text { Type of } \\
\text { release }\end{array}$ & $\begin{array}{c}\text { Quantity released } \\
(\mathrm{lb} / \mathrm{kg})\end{array}$ & $\begin{array}{l}\text { Major release } \\
\text { source }\end{array}$ & $\begin{array}{l}\text { Basis of } \\
\text { estimate }\end{array}$ \\
\hline \multicolumn{5}{|c|}{ SARA 313} \\
\hline \multirow[t]{4}{*}{ Chromium $^{a}$} & $\begin{array}{l}\text { Air: fugitive } \\
\text { emissions }\end{array}$ & $3,750 / 1,700$ & $\begin{array}{l}\text { Cooling tower } \\
\text { system }\end{array}$ & $\begin{array}{l}\text { Material } \\
\text { balance }\end{array}$ \\
\hline & $\begin{array}{l}\text { Water: Big } \\
\text { Bayou Creek }\end{array}$ & $17 / 8$ & $\begin{array}{l}\text { C- } 616 \\
\text { chromium } \\
\text { reduction } \\
\text { facility }\end{array}$ & Monitoring \\
\hline & $\begin{array}{l}\text { Water: Little } \\
\text { Bayou Creek }\end{array}$ & $41 / 19$ & $\begin{array}{l}\text { Cooling tower } \\
\text { system, }\end{array}$ & Monitoring \\
\hline & $\begin{array}{l}\text { Land: to } \\
\text { C-616 sludge } \\
\text { lagoon }\end{array}$ & $10,600 / 4,800$ & $\begin{array}{l}\text { C- } 616 \\
\text { chromium } \\
\text { reduction } \\
\text { facility } \\
\text { sludge }\end{array}$ & Monitoring \\
\hline \multirow[t]{3}{*}{$\begin{array}{l}\text { Trichloro- } \\
\text { ethylene }\end{array}$} & $\begin{array}{l}\text { Air: point } \\
\text { source }\end{array}$ & $62,000 / 28,000$ & $\begin{array}{l}\text { C-400 } \\
\text { degreaser/ } \\
\text { storage tanks }\end{array}$ & $\begin{array}{l}\text { Material } \\
\text { balance }\end{array}$ \\
\hline & $\begin{array}{l}\text { Water: Big } \\
\text { Bayou Creek }\end{array}$ & $1 / 0.5$ & $\begin{array}{l}\text { C-400 } \\
\text { degreasing } \\
\text { operations }\end{array}$ & Monitoring \\
\hline & $\begin{array}{l}\text { Water: Little } \\
\text { Bayou Creek }\end{array}$ & $1 / 0.5$ & $\begin{array}{l}\text { Degreasing } \\
\text { operations }\end{array}$ & Monitoring \\
\hline Sulfuric acid & $\begin{array}{l}\text { Air: fugitive } \\
\text { emissions }\end{array}$ & $1,070 / 480$ & $\begin{array}{l}\text { Cooling } \\
\text { tower } \\
\text { system }\end{array}$ & $\begin{array}{l}\text { Engineering } \\
\text { calculations }\end{array}$ \\
\hline \multirow[t]{3}{*}{ Chlorine } & $\begin{array}{l}\text { Air: fugitive } \\
\text { emissions }\end{array}$ & $9,100 / 4,100$ & $\begin{array}{l}\text { Cooling tower } \\
\text { system }\end{array}$ & $\begin{array}{l}\text { Engineering } \\
\text { calculations }\end{array}$ \\
\hline & $\begin{array}{l}\text { Water: Big } \\
\text { Bayou Creek }\end{array}$ & $430 / 190$ & $\begin{array}{l}\text { C- } 615 \text { sewage } \\
\text { treatment } \\
\text { plant }\end{array}$ & Monitoring \\
\hline & $\begin{array}{l}\text { Water: Little } \\
\text { Bayou Creek }\end{array}$ & $28 / 13$ & $\begin{array}{l}\text { Once-through } \\
\text { cooling water }\end{array}$ & Monitoring \\
\hline Freon 114 & $\begin{array}{l}\text { Air: fugitive } \\
\text { emissions }\end{array}$ & $350,000 / 158,000$ & $\begin{array}{l}\text { Process } \\
\text { cooling }\end{array}$ & $\begin{array}{l}\text { Engineering } \\
\text { calculations }\end{array}$ \\
\hline
\end{tabular}


Paducah Gaseous Diffusion Plant 1990 chemical release information

\begin{tabular}{|c|c|c|c|c|}
\hline $\begin{array}{l}\text { Chemical } \\
\text { name }\end{array}$ & $\begin{array}{l}\text { Type of } \\
\text { release }\end{array}$ & $\begin{array}{l}\text { Quantity released } \\
(\mathrm{lb} / \mathrm{kg})\end{array}$ & $\begin{array}{l}\text { Major release } \\
\text { source }\end{array}$ & $\begin{array}{l}\text { Basis of } \\
\text { estimate }\end{array}$ \\
\hline \multicolumn{5}{|c|}{ Other large inventory chemicals } \\
\hline Fluorides & $\begin{array}{l}\text { Air: stack } \\
\text { emissions }\end{array}$ & $12,900 / 5,800$ & $\begin{array}{l}\text { C-310 stack } \\
\text { emissions }\end{array}$ & $\begin{array}{l}\text { Engineering } \\
\text { calculations/ } \\
\text { continuous } \\
\text { stack sampling }\end{array}$ \\
\hline Nitric acid & $\begin{array}{l}\text { Air: point } \\
\text { source }\end{array}$ & $2 / 1$ & $\begin{array}{l}\text { C-400 storage } \\
\text { tank }\end{array}$ & $\begin{array}{l}\text { Engineering } \\
\text { calculations }\end{array}$ \\
\hline Nitrogen & $\begin{array}{l}\text { Air: fugitive } \\
\text { emissions }\end{array}$ & $1,600,000 / 726,000$ & $\begin{array}{l}\text { General plant } \\
\text { cooling }\end{array}$ & $\begin{array}{l}\text { Material } \\
\text { balance }\end{array}$ \\
\hline Ammonia & $\begin{array}{l}\text { Air: fugitive } \\
\text { emissions }\end{array}$ & $525 / 240$ & $\begin{array}{l}\text { Blueprint } \\
\text { maclines }\end{array}$ & $\begin{array}{l}\text { Material } \\
\text { balance }\end{array}$ \\
\hline Freon 11 & $\begin{array}{l}\text { Air: fugitive } \\
\text { emissions }\end{array}$ & $2,400 / 1,080$ & $\begin{array}{l}\text { Air- } \\
\text { conditioning } \\
\text { systems }\end{array}$ & $\begin{array}{l}\text { Material } \\
\text { balance }\end{array}$ \\
\hline Freon 22 & $\begin{array}{l}\text { Air: fugitive } \\
\text { emissions }\end{array}$ & $1,100 / 500$ & $\begin{array}{l}\text { Air- } \\
\text { conditioning } \\
\text { systems }\end{array}$ & $\begin{array}{l}\text { Material } \\
\text { balance }\end{array}$ \\
\hline Freon 113 & $\begin{array}{l}\text { Air: fugitive } \\
\text { emissions }\end{array}$ & $3,000 / 1,400$ & $\begin{array}{l}\text { C-360 flush } \\
\text { solution for } \\
\text { sample cool- } \\
\text { down }\end{array}$ & $\begin{array}{l}\text { Material } \\
\text { balance }\end{array}$ \\
\hline \multicolumn{5}{|c|}{ Steam plant emissions } \\
\hline Sulfur dioxide ${ }^{b}$ & $\begin{array}{l}\text { Air: stack } \\
\text { emissions }\end{array}$ & $620,000 / 280,000$ & $\begin{array}{l}\text { Fossil fuels } \\
\text { combustion }\end{array}$ & $\begin{array}{l}\text { Emission } \\
\text { factors }\end{array}$ \\
\hline $\begin{array}{l}\text { Nitrogen } \\
\text { oxides }^{b}\end{array}$ & $\begin{array}{l}\text { Air: stack } \\
\text { emissions }\end{array}$ & $620,000 / 280,000$ & $\begin{array}{l}\text { Fossil fucls } \\
\text { combustion }\end{array}$ & $\begin{array}{l}\text { Emission } \\
\text { factors }\end{array}$ \\
\hline Particulates ${ }^{b}$ & $\begin{array}{l}\text { Air: stack } \\
\text { combustion }\end{array}$ & $25,000 / 11,000$ & $\begin{array}{l}\text { Fossil fuels } \\
\text { combustions }\end{array}$ & $\begin{array}{l}\text { Enission } \\
\text { factors }\end{array}$ \\
\hline $\begin{array}{l}\text { Carbon } \\
\text { monoxide } b\end{array}$ & $\begin{array}{l}\text { Air: stack } \\
\text { emissions }\end{array}$ & $20,000 / 9,000$ & $\begin{array}{l}\text { Fossil fuels } \\
\text { combustion }\end{array}$ & $\begin{array}{l}\text { Emission } \\
\text { factors }\end{array}$ \\
\hline
\end{tabular}

${ }^{a}$ Quantity calculated as chromium; chemical compound is sodium bichromate.

${ }^{b}$ U.S. Environmental Protection Agency October 1986. Compilation of Air Pollutant Emission Factors, Vol. 1 (Suppl. A). 


\section{INTERNAL DISTRIBUTION}

\author{
1. F. D. Adams \\ 2. D. Appino \\ 3. A. D. Arms \\ 4. D. L. Ashburn \\ 5. L. D. Bates \\ 6. B. A. Bell \\ 7. B. A. Berven \\ 8. A. K. Bracknell \\ 9. K. L. Brady \\ 10. T. R. Butz \\ 11. J. B. Cannon \\ 12-14. W. W. Chance \\ 15. R. B. Clapp \\ 16. R. B. Cloutier \\ 17. D. G. Cope \\ 18. T. K. Cothran \\ 19. D. M. Counce \\ 20. G. D. Del Cul \\ 21. R. J. Devol \\ 22. M. S. Dill \\ 23. J. W. Douthitt \\ 24. T. O. Early \\ 25. R. A. Evans \\ 26. J. D. Fletcher \\ 27. M. W. Francis \\ 28. C. G. Giltner \\ 29. S. T. Goodpasture \\ 30. G. A. Goslow \\ 31. M. G. Guhy \\ 32. L. E. Hall \\ 33. S. G. Hildebrand \\ 34. C. C. Hill \\ 35. F. O. Hoffman \\ 36. S. K. Holshauser \\ 37-87. T. G. Jett \\ 88. C. G. Jones \\ 89. D. W. Jones \\ 90. R. J. Keeling
}

91. W. A. Kelly

92. R. H. Ketelle

93. C. W. Kimbrough

94. F. C. Kornegay

95. E. H. Krieg

96. P. Y. Lu

97. A. P. Malinauskas

98. W. D. Malis

99. J. C. Massey

100. L. W. McMahon

101. L. J. Mezga

102. M. E. Mitchell

103-108. B. J. Montgomery

109. R. W. Morrow

110 . J. B. Murphy

111. T. J. Newsom

112. F. R. O' Donnell

113. G. V. Pierce

114. S. Polston

115. J. E. Powell

116. H. Pulicy

117-121. J. G. Rogers

122. R. T. Roseberry

123. R. H. Ross

124. G. W. Rymer

125. S. L. Shell

126. C. W. Sheward

127. J. E. Shoemaker

128. R. E. Simmons

129. S. P. N. Singh

130. E. L. Smith, Jr.

131. G. W. Snyder

132. A. J. Stewart

133. L. E. Stokes

134. A. J. Story

135. S. H. Stow

136. D. W. Swindle

137. M. F. Tardiff 


$\begin{aligned} \text { 138. } & \text { F. G. Taylor, Jr. } \\ \text { 139. } & \text { L. D. Taylor } \\ \text { 140. } & \text { T. Thomas } \\ \text { 141. } & \text { C. C. Travis } \\ \text { 142. } & \text { J. H. Turnery } \\ \text { 143. } & \text { J. W. Turner } \\ \text { 144. } & \text { L. D. Voorhees } \\ \text { 145. } & \text { B. T. Walton - RC } \\ \text { 146. } & \text { J. S. Wassom } \\ \text { 147. } & \text { D. A. Watersrary } \\ \text { 148. } & \text { D. S. Wattier } \\ \text { 149. } & \text { C. W. Weber } \\ 150-200 . & \text { D. C. West }\end{aligned}$

138. F. G. Taylor, Jr.

140. T. Thomas

141. C. C. Travis

142. J. H. Turnery

143. J. W. Turner

144. L. D. Voorhees

145. B. T. Walton - RC

146. J. S. Wassom

147. D. A. Watersrary

148. D. S. Wattier

150-200. D. C. West
201. B. Wilkes

202. J. K. Williams

203. W. R. Williams

204. A. R. Wilson

205. S. W. Wohlfort

206. Central Research Librar

207. ESD Library

208-209. ORNL Laboratory Records

210. ORNL Laboratory Records

211. ORNL Patent Section

212. ORNL Y-12 Technical Lib

213. PGDP Library

214. PORTS Library

215. ORGDP Library

\section{EXTERNAL DISTRIBUTION}

216. Assistant Manager for Energy Research and Development, U.S. Department of Energy/Oak Ridge Operations, P.O. Box E, Oak Ridge, TN 37831.

217-226. Office of Scientific and Technical Information.

227-400. This report is distributed widely by the Department of Energy's Oak Ridge Operations Office to local, state, and federal government agencies, the Congress, the public, and the news media. 

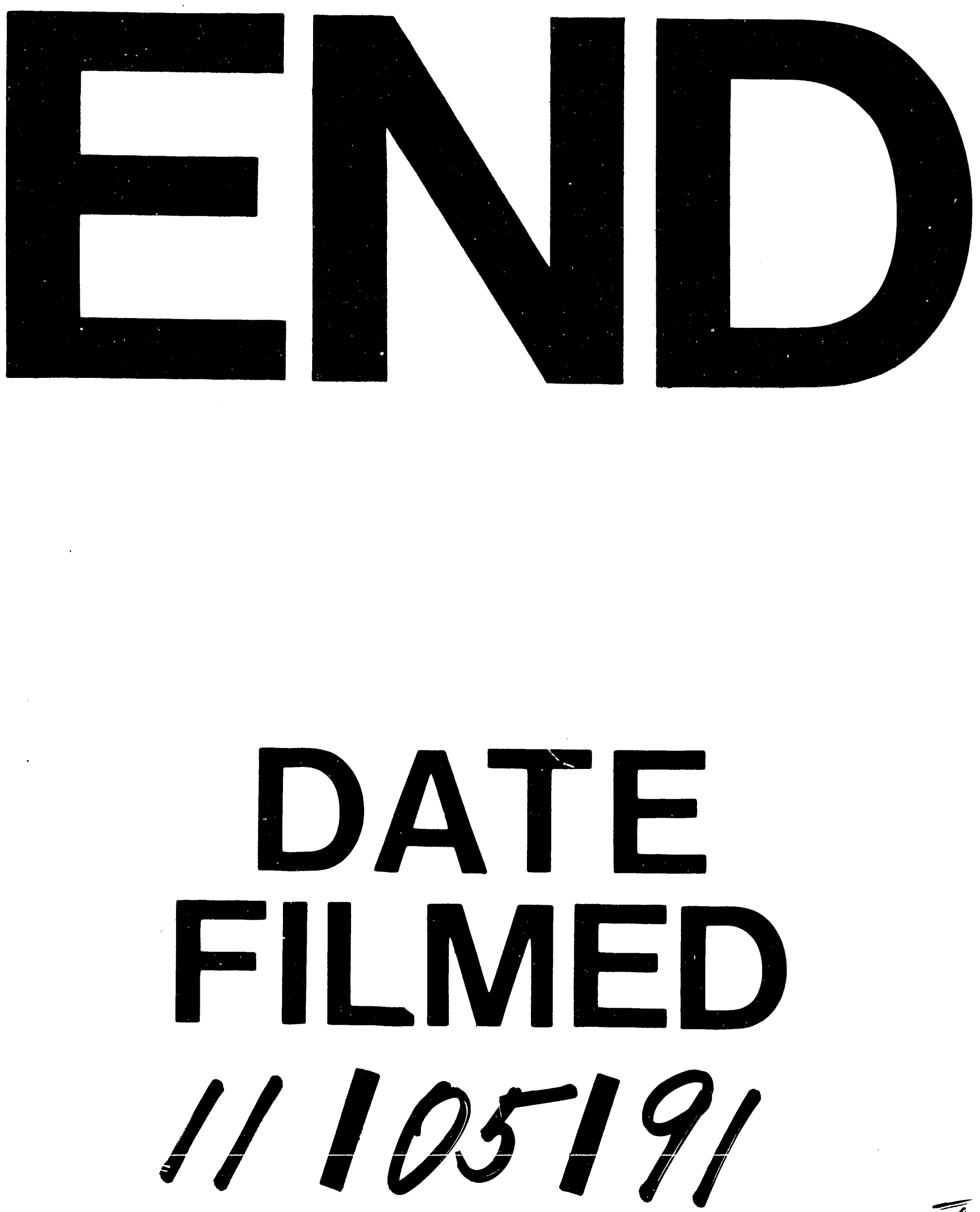
